\title{
Non refoulement en las fronteras marítimas del Sur de Europa Luis Gómez Anquela
}

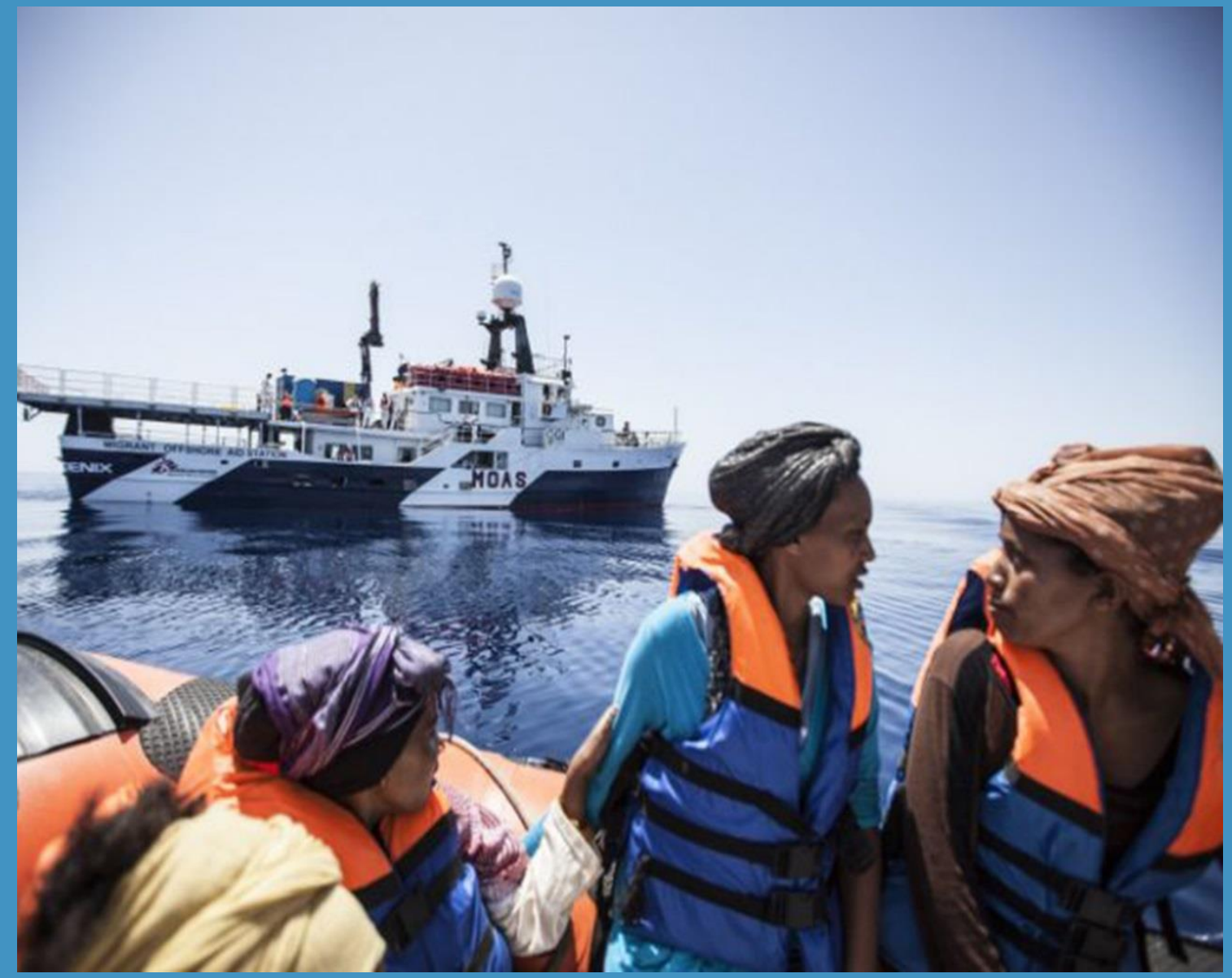

Abril de 2016

Maestría en Derechos Humanos

Universidad Nacional de La Plata
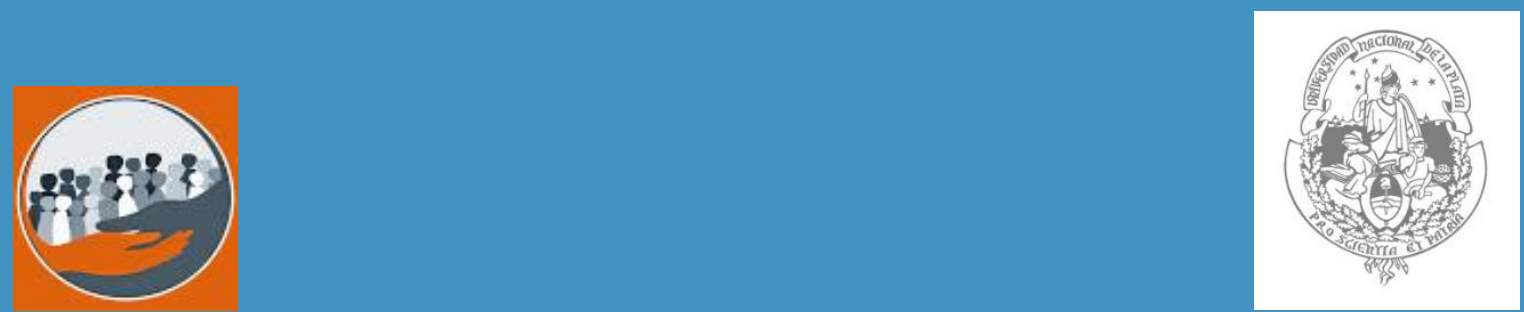

Universidad Nacional de La Plata

Facultad de Ciencias Jurídicas y Sociales

Instituto de Derechos Humanos

\section{NON REFOULEMENT EN LAS FRONTERAS MARÍTIMAS DEL SUR DE EUROPA}

Tesina presentada por Luis Gómez Anquela

Codirigida por Ma Carmen Pérez González y Javier Surasky

Madrid, abril de 2016

Foto de portada: C MOAS, 2015. 



\section{AGRADECIMIENTOS}

Escribir la presente tesis ha supuesto uno de los restos personales e intelectuales más apasionantes que he afrontado en mi vida. Aunque compuesto de numerosos momentos de trabajo solitario, una investigación de este tipo sería imposible sin la participación y ayuda de muchas personas y organizaciones, ya seae forma directa o indirecta.Valga estas palabras para reconocer, desde el cariño y agradecimiento, su contribución para que este trabajo llegue a feliz término.

En primer lugar, quiero agradecer a Carmen Pérez González y Javier Surasky, por aceptarme para realizar la presente tesis bajo su dirección. Para un investigador novato como yo, sus consejos y sugerencias me han guiado durante todo el proceso, ayudándome a enfocarme en el objeto que perseguía, despejando dudas y preocupaciones. Las ideas y textos que me aportaron han enriquecido y ampliado mi propia visión sobre la realidad estudiada. En la esfera personal, quiero reconocer su disponibilidad y comprensión ante mis irregulares ritmos de trabajo y el ánimo que me prestaron para superar los (inevitables) momentos de frustración.

De entre todas las personas a las que he tenido la oportunidad de consultar diversos aspectos de la investigación, quiero agradecer especilamente a tres de ellas: Lucia Carrara, por ayudarme desde mis primeros pasos, y por confrortarme continuamente para hacerme reflexionar y mejorar; Leandro Sugameli, por acercarme al trabajo concreto de las operaciones de Salvamento que realiza Médicos del Mundo; y Carmen Lorente, por introducirme en las procelosas aguas del Derecho del Mar y rescatarme del naufragio en más de una ocasión.

El texto aquí plasmado no procede únicamente de los resultados de la propia investigación, sino que se ha enriquecido por mi propia experiencia vital y profesional durante los últimos años. Por esta razón quiero recordar a los y las compañeras de Regionaal Open Jeugdcentrum Mechelen, Cáritas Española, Comisión Española de Ayuda al Refugiado y la Red Solidaria de Acogida, cuyos trabajos y luchas por los derechos de las personas migrantes y refugiadas ha inspirado el enfoque y los objetivos del presente trabajo.

La presente tesis se enmarca dentro de la realización de la Maestría de Derechos Humanos de la Universidad Nacional de La Plata. Esos dos años corresponden a una de las etapas más significativas de mi vida, un proceso de profundo aprendizaje a todos los niveles, y se la debe especialmente a los amigos que, entre charlas y chelas, hice entre compañeros y docentes de la misma. De forma especial quiero agradecerle todo lo que por mi hicieron a mi familia argentina: Taty, Cristian, Alicia y Tino. Me tratásteis como a un hijo y un hermano, vuestro amor y generosidad siempre estarán en mi recuerdo.

Finalmente, a mi familia, un apoyo y un ejemplo continuo, muchas gracias de todo corazón. Los valores que me inculcásteis desde pequeño son los mismos que guian mi vida y la base de este trabajo. Gracias también a todas aquellas personas que, aunque no os he podido nombrar aquí, habéis dejado huella en mi vida. 

A mis padres, Magda y Jaime 



\section{ÍNDICE}

1. INTRODUCCIÓN...............................................................................................1

1.1 LAS Migraciones en el MediterRÁNeo ................................................... 2

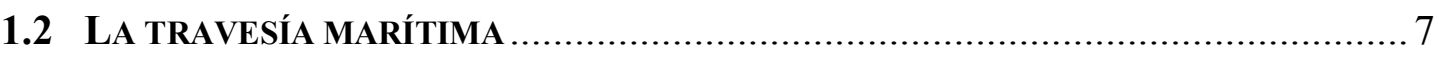

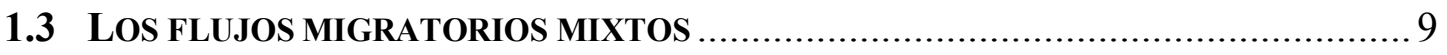

1.4 EL RÉGIMEN DE ASILO Y EL DERECHO DE LOS REFUGIADOS …....................... 13

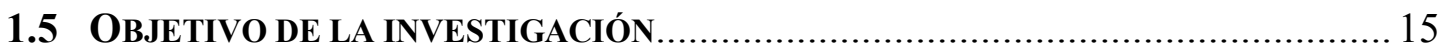

1.6 DELIMITACIÓN DEL CAMPO DE ANÁLISIS Y METODOLOGÍA ............................. 17

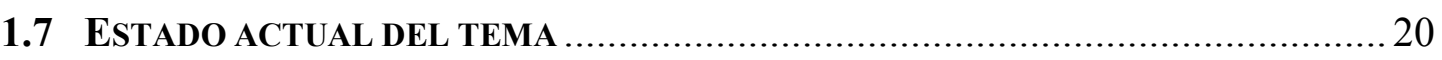

2. LA POLÍTICA MIGRATORIA Y DE ASILO DE LA UNIÓN EUROPEA .. 22

2.1 LA COMUNITARIZACIÓN DE LA POLÍTICA MIGRATORIA .................................2 24

2.1.1 Los antecedentes de la cooperación intergubernamental.......................24

2.1.2 El derecho originario y la Carta de Derechos Fundamentales ............... 26

2.1.3 Los programas de Tampere, La Haya y Estocolmo............................... 30

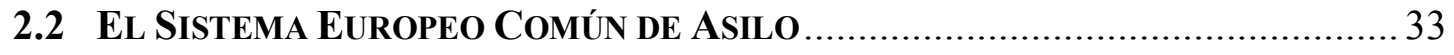

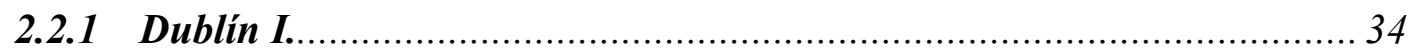

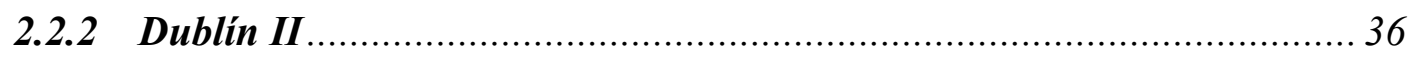

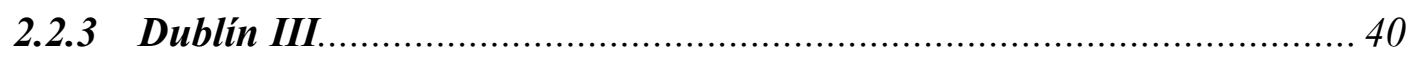

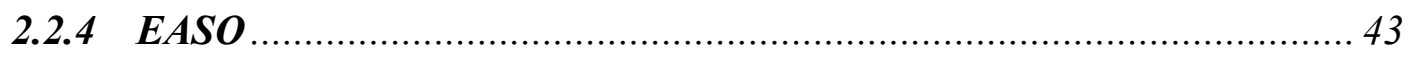

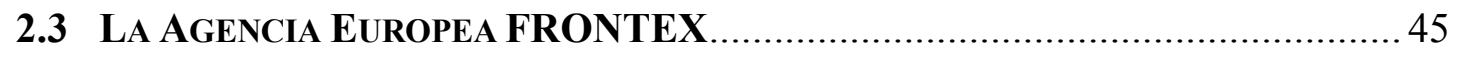

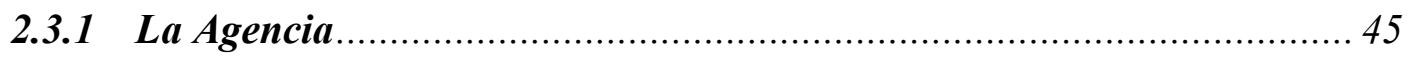

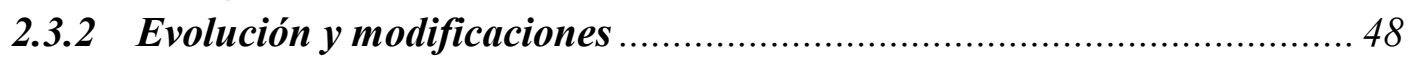

2.3.3 Rendición de cuentas y protección de los Derechos Humanos ...............52

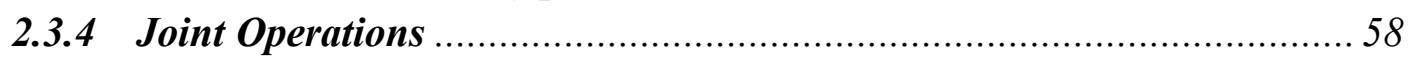

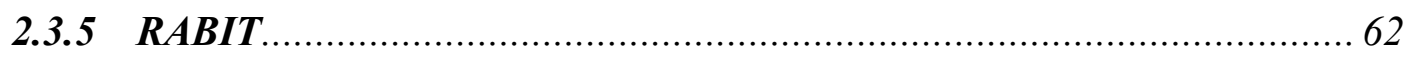

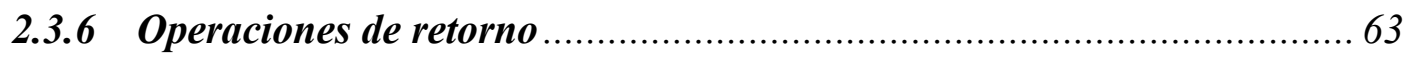

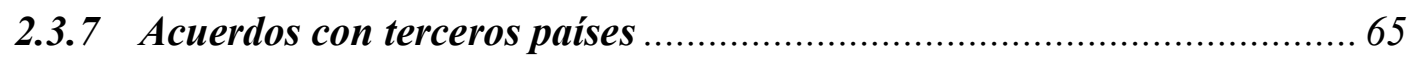

2.4 EL FUTURO DE LAS POLÍTICAS MIGRATORIAS EUROPEAS ................................6 68

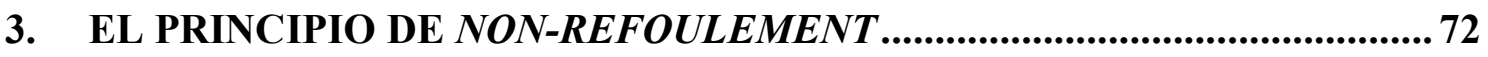

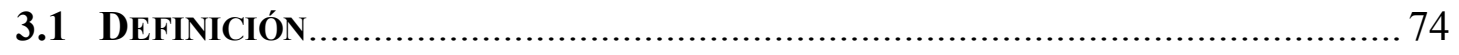

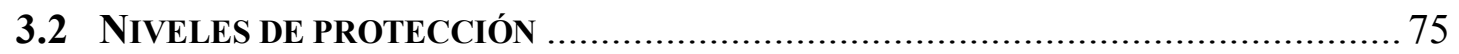

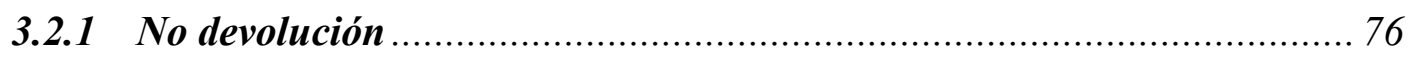

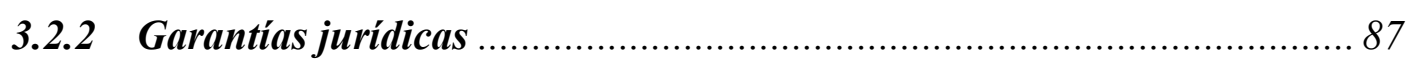

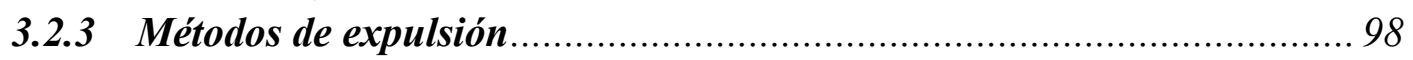

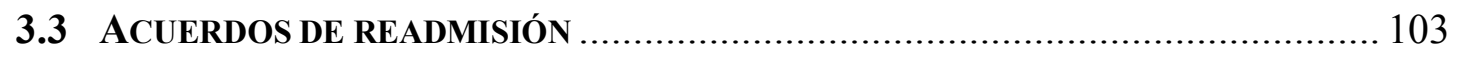

3.3.1 Acuerdos bilaterales.......................................................................... 104

3.3.2 Acuerdos a nivel europeo ........................................................... 108 


\section{TERRITORIALIDAD Y JURISDICCIÓN DE LOS DERECHOS}

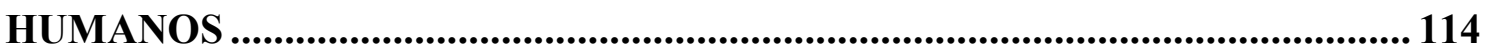

4.1 LA JURISDICCIÓN EN EL DERECHO INTERNACIONAL ……………................. 115

4.2 LA TERRITORIALIDAD EN EL DERECHO DE LOS REFUGIADOS......................... 123

4.3 JURISDICCIÓN Y TERRITORIALIDAD EN LA UNIÓN EUROPEA ……………........ 126

5. SALVAMENTO MARÍTIMO Y DERECHOS HUMANOS. .......................... 130

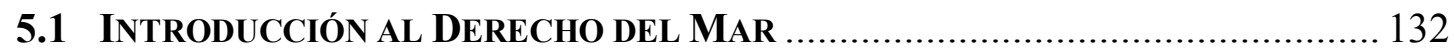

5.1.1 La politica marítima integrada (Integrated Maritime Policy) ............... 136

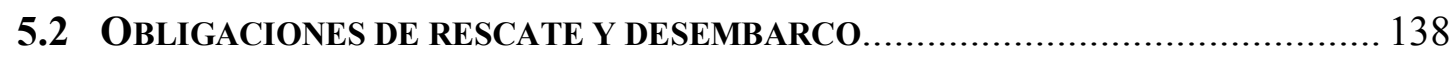

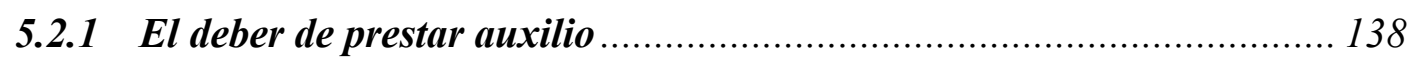

5.2.2 Los peligros de los viajes migratorios en el Mediterráneo ………......... 140

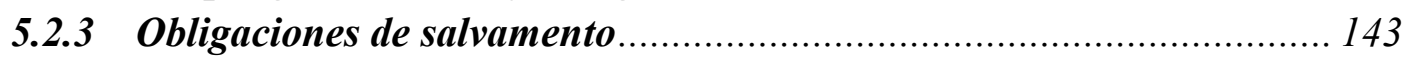

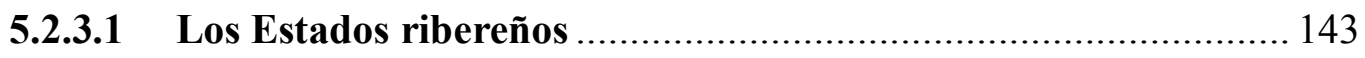

5.2.3.2 Buques y Estados de pabellón .................................................... 151

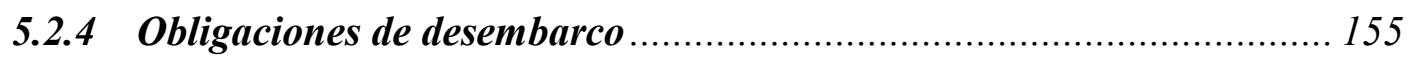

5.2.4.1 La evolución de las prácticas de desembarco marítimo ………... 155

5.2.4.2 La reforma de los Convenios SAR y SOLAS ……………......... 158

5.2.4.3 El desembarco en las fuentes auxiliares ........................................ 160

5.2.4.4 El concepto de lugar seguro ...................................................... 165

5.2.4.5 La entrada a puerto para navíos en peligro …………………..... 166

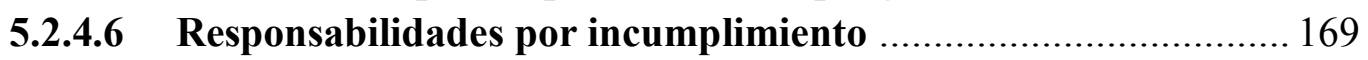

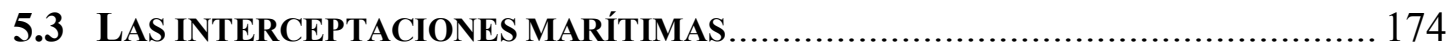

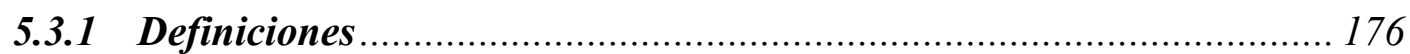

5.3.2 Servicios de salvamento y fronterizas................................................ 178

5.3.3 El principio de non-refoulement en la interceptación........................... 179

5.3.4 Las interceptaciones según las diferentes zonas marítimas ................... 182

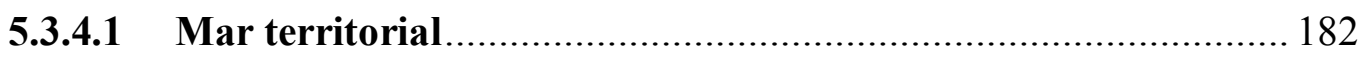

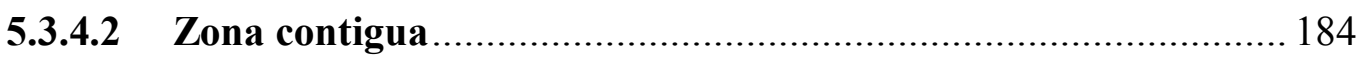

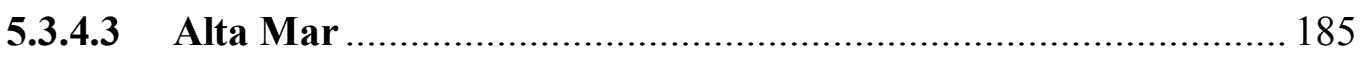

5.3.4.4 Zona marítima de un tercer estado ............................................ 189

5.4 LAS OPERACIONES DE INTERCEPTACIÓN DE FRONTEX Y LOS EEMM …….... 193

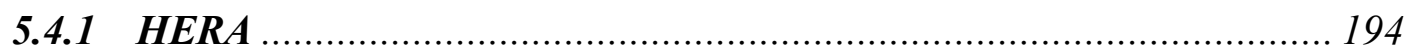

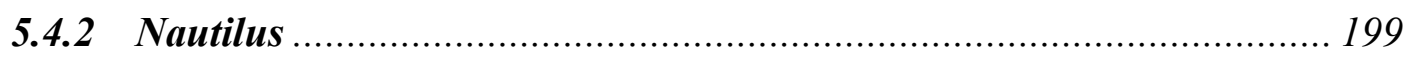

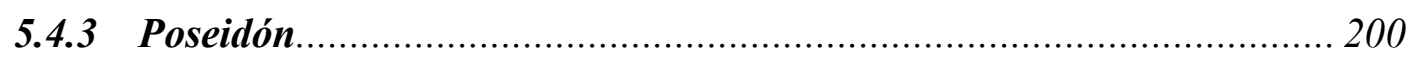

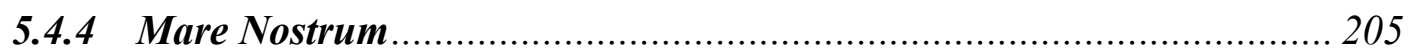

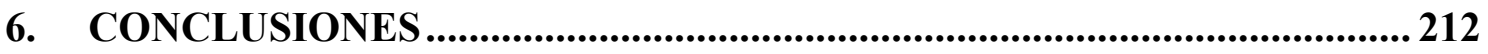


7. BIBLIOGRAFÍA Y DOCUMENTACIÓN 226

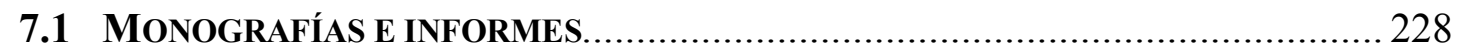

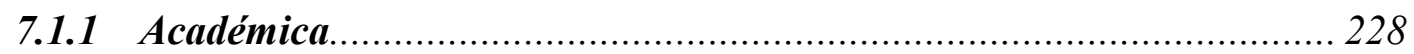

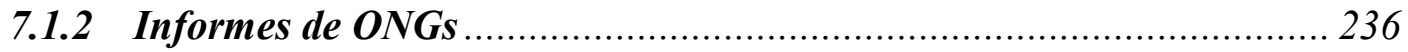

7.2 NORMATIVA, JURISPRUDENCIA Y OTRA DOCUMENTACIÓN INSTITUCIONAL.. 240

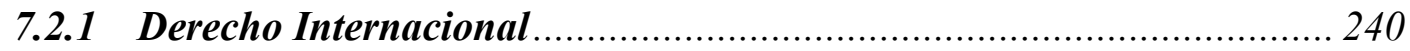

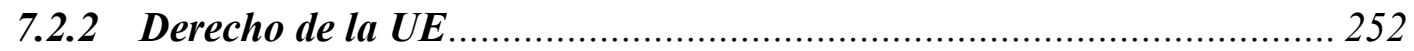

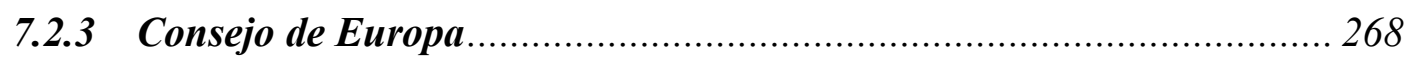

7.2.4 Otros instrumentos jurídicos nacionales e internacionales................... 274 



\section{Lista de abreviaturas}

ACNUR Alto Comisionado de las Naciones Unidas para los Refugiados

AGNU Asamblea General de las Naciones Unidas

AI Amnistía Internacional

CAT Convención Contra la Tortura y Otros Tratos o Penas Crueles, Inhumanos

o Degradantes

CDF Carta de los Derechos Fundamentales

CDH Comité de Derechos Humanos

CE Consejo Europeo

CEAR Comisión Española de Ayuda al Refugiado

CEDH Convenio Europeo de Derechos Humanos

CG51 Convención relacionada con el estatus de refugiados

CIJ Corte Internacional de Justicia

COM Comisión Europea

CSM Comité de Seguridad Marítima

EASO Agencia Europea de Apoyo al Asilo

ECRE European Council on Refugees and Exiles

ESLJ Espacio de Seguridad, Libertad y Justicia

FRA Agencia Europea de Derechos Fundamentales

FRONTEX Agencia Europea para la Cooperación Operativa en las Fronteras

Exteriores

HRW Human Rights Watch

IMP Política Marítima Integrada

JAI Consejo de Justicia y Asuntos de Interior

JRS Servicio Jesuita a Refugiados

MPC Migration Policy Institute

MSF Médicos Sin Fronteras

OIM Organización Internacional para las Migraciones

OMI Organización Marítima Internacional

ONU Organización de las Naciones Unidas

PE Parlamento Europeo

PIDCP Pacto Internacional de Derechos Civiles y Políticos

RABIT Equipos de intervención rápida en las fronteras

RCC Centro Coordinador de Salvamento

SALVAGE Convenio Internacional sobre Salvamento Marítimo

SAR Convenio internacional sobre búsqueda y salvamento marítimos

SBC Código de Fronteras de Schengen

SECA Sistema Europeo Común de Asilo

SIS Sistema de Información de Schengen

SOLAS Convenio Internacional para la Seguridad de la Vida Humana en el Mar

TEDH Tribunal Europeo de Derechos Humanos

TFUE Tratado de Funcionamiento de la Unión Europea

TJUE Tribunal de Justicia de la Unión Europea

TUE Tratado de la Unión Europea

UNCLOS Convención de las Naciones Unidas sobre el Derecho del Mar 

Cuéntales, que aún tengo, un corazón que late, que vuelve en versos los escombros, como quien iza banderas blancas. Cuéntales que al final del camino, alguien me abrió la puerta y me miró a los ojos. Que escuchó mi historia sin ponerla en duda. Que me ofreció un mapa, y me enseñó el rincón dónde no pega el viento.

Raquel Celis 

Capítulo 1

Introducción 



\section{Introducción}

La Declaración Universal de Derechos Humanos de 1948 establece en su artículo 14.1 que "en caso de persecución, toda persona tiene derecho a buscar asilo y a disfrutar de él, en cualquier país". Como varios autores han señalado ${ }^{1}$ el derecho que se proclama no es a "obtener asilo", sino simplemente a "buscarlo". Una redacción que coloca a este derecho en una posición bastante más débil que otros proclamados en la misma declaración, especialmente respecto de las obligaciones estatales que conllevaría.

Sin embargo, ni siquiera este endeble compromiso se cumple de forma plena. En los últimos años, cientos de miles de refugiados que intentaron llegar a Europa cruzando el Mediterráneo encuentran números obstáculos para ejercer ese derecho "a buscar asilo" debido a la acción de los Estados mediterráneos, tanto europeos como africanos, y de la Unión Europea. A los peligros del viaje marítimo, que han provocado la muerte de miles de personas, se suman las prácticas de devolución y push back que ejecutan los Estados europeos para impedir la llegada de estas embarcaciones a sus costas.

\subsection{Las Migraciones en el Mediterráneo}

El presente trabajo se centrará en las migraciones que se efectúan por vía marítima en el mar Mediterráneo, con origen en los países norteafricanos y en Turquía, y con destino los países del sur de Europa ${ }^{2}$. Los condicionantes políticos, sociales y económicos fracturan las dos orillas, cuyas fronteras marcan una de las fronteras con mayor desigualdad económica del planeta $^{3}$, y que en los últimos años ha visto como diversas guerras (Líbano, Libia, Siria) y conflictos políticos (Mauritania, Túnez, Egipto) han producido un incremento del número de refugiados que buscan alcanzar Europa. El

\footnotetext{
${ }^{1}$ Vid., Acosta Estévez, José B.: "La internacionalización de los derechos humanos y los mecanismos de protección de los refugiados". En: Camps Mirabet, Nuria (ed.): El Derecho Internacional ante las migraciones forzadas: refugiados, desplazados y otros migrantes involuntarios, Universitat de Lleida, 2005, pp. 15-58.

${ }^{2}$ Si bien no se encuentra dentro del ámbito geográfico mediterráneo, para la presente investigación tendremos en cuenta la ruta migratoria que se produce desde el noroeste africano hacia las Islas Canarias. Esta ruta adquirió una gran importancia en la última década tras el incremento de la vigilancia marítima en el Mediterráneo. Fue el escenario además de la primera operación conjunta de Frontex, HERA, como desarrollaremos más adelante.

${ }^{3}$ El PIB per cápita de España es 6 veces el de Marruecos (34.899 frente a 5.252). Por establecer una comparación entre otra frontera célebre, la diferencia entre el Estados Unidos y el de México es "solamente" de algo más del triple (56.421 frente a 15.931) Datos del Fondo Monetario Internacional: http://www.imf.org/external/pubs/ft/weo/2015/01/weodata/weoselgr.aspx (Consulta: 12 de diciembre de 2015)
} 


\section{CAPÍTULO 1}

agravamiento de la situación en los últimos años ha llevado a organizaciones como Amnistía Internacional a alertar de que Europa se enfrenta a la "mayor crisis de refugiados desde la II Guerra Mundial"4. Según datos de Frontex, ocho de cada diez personas que intentaron entrar en 2014 de forma irregular en la UE son potenciales solicitantes de asilo.

Existen cuatro rutas marítimas principales con destino a los países del sur de Europa. De oeste a este: desde las costas del Noroeste africano (Senegal, Mauritania, Cabo Verde, Marruecos) hasta las Islas Canarias; del norte de Marruecos al sur de España; de Túnez y Libia a Italia y Malta en el Mediterráneo Central; y desde Turquía a Grecia. Existen algunas rutas menos comunes, como las de Egipto a Creta e Italia, y de Argelia a Cerdeña y España.

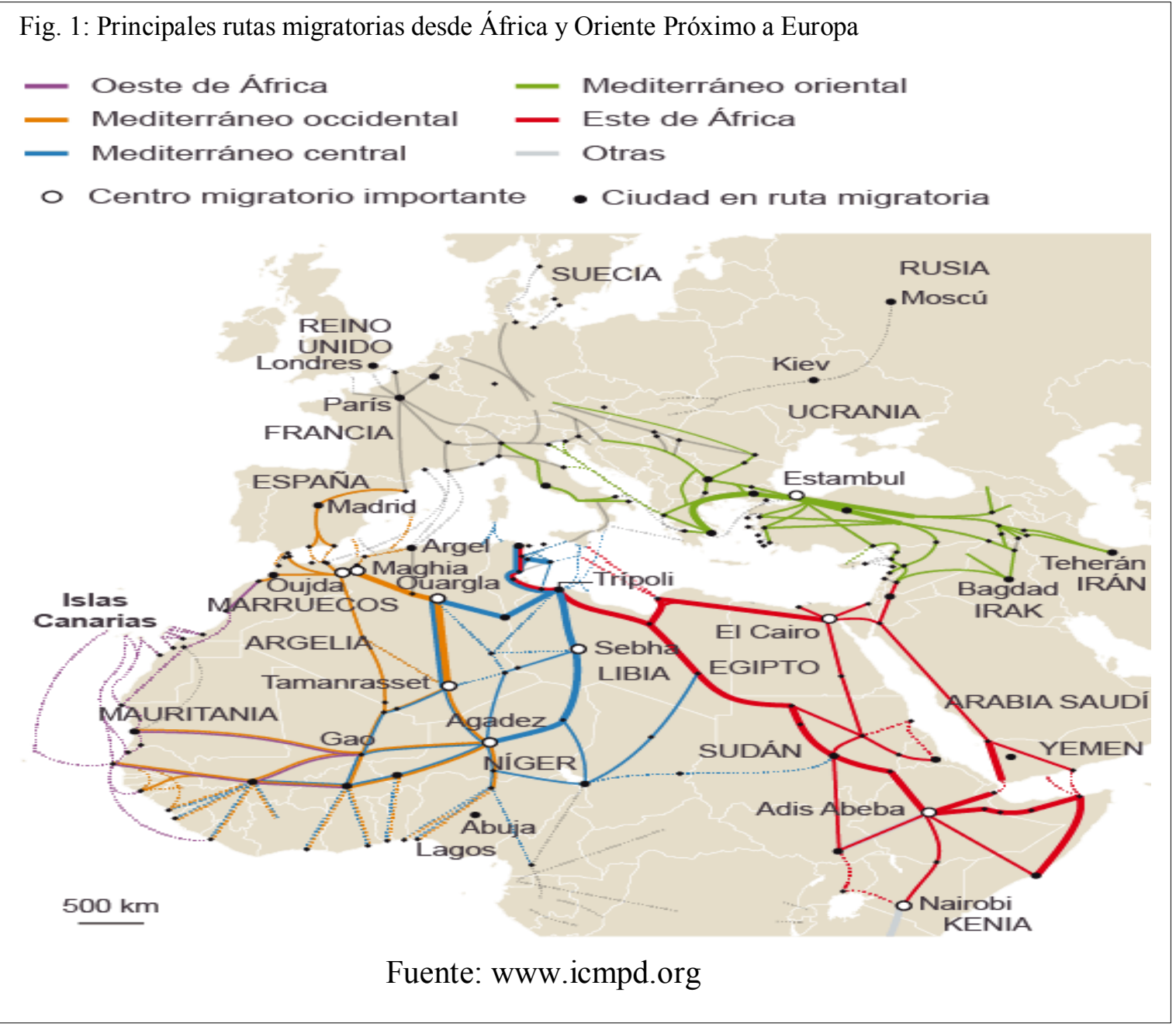

\footnotetext{
4 Amnistía Internacional: World leaders' neglect of refugees condemns millions to death and despair. Nota de prensa, 15 de junio de 2015. Disponible en: https://www.amnesty.org/en/latest/news/2015/06/world-leaders-neglect-of-refugees-condemns-millionsto-death-and-despair/ (Consulta: 12 de diciembre de 2015)
} 
En los últimos años, la cuestión de los refugiados se ha venido ligando cada vez más dentro de la temática más amplia de las migraciones, convertida a su vez en uno de los temas de debate más significativos a nivel político y social en el continente europeo. Hemos visto una creciente preocupación sobre este asunto, constatado en un gran número de publicaciones académicas, informes de organizaciones internacionales y no gubernamentales, obras de ficción y discursos políticos relativos a la migración. E1 número de extranjeros no europeos viviendo en el continente ha pasado de 14,4 millones (3,5\% de la población) en 1960 a 52,3 millones (10.3\%) en $2013^{5}$.

Los Estados europeos tratan de impedir esta llegada estableciendo políticas de interceptación de las embarcaciones en el mar, devolviendo a los migrantes a la costa de origen. En muchas otras ocasiones son las propias embarcaciones las que se encuentran en peligro y son rescatadas por las guardias costeras o buques pesqueros, o en los casos más trágicos, provocan la muerte de los tripulantes al ahogarse en el mar. Según cálculos del proyecto The Migrant Files, en las últimas décadas más de 30.000 personas han fallecido ahogados en el mar cuando trataban de alcanzar las costas europeas ${ }^{6}$. Aquellos que son llevados a puerto son retenidos en centros hasta que se procede a su identificación, que determina si pueden permanecer en el territorio al corresponderles algún tipo de protección o, por el contrario, son expulsados de vuelta a su país de origen.

Las aguas del mar Mediterráneo se han transformado en los últimos años en un espacio de frontera. Los Estados han reforzado sus medidas de control migratorio, y han señalado esta zona como una prioridad para sus políticas de seguridad, identificándola como la puerta de entrada de migrantes irregulares, mafias organizadas de tráfico y trata de personas, e incluso terroristas. Al aplicar estos dispositivos fronterizos fuera del área terrestre, han intentado esquivar sus responsabilidades jurídicas internacionales argumentando que estas no se aplican cuando los sucesos transcurren fuera de su territorio o zonas marítimas. Con estas políticas, los Estados intentan crear unas zonas donde quedan exentos de responsabilidad ante los derechos de los migrantes y refugiados, y donde además es difícil que ONG's o medios de comunicación vigilen sus actuaciones.

\footnotetext{
${ }^{5}$ De la Rica, Sara; Glitz, Albrecht y Ortega, Francesc: Immigraton in Europe: Trends, Policies and Empirical Evidence, Bonn, Forschungsinstitut zur Zikunft der Arbeit (IZA), Discussion Paper no. 7778, noviembre de 2013. Disponible en: http://ftp.iza.org/dp7778.pdf (Consulta: 12 de diciembre de 2015)

${ }^{6} \mathrm{El}$ proyecto está formado por varias agencias de noticias europeas, y tiene como objetivo medir el número de personas que mueren intentando alcanzar Europa (http://www.themigrantsfiles.com). En el capítulo 5.2.2 veremos más en detalle la mortalidad de la ruta migratoria.
} 


\section{CAPÍTULO 1}

El número de migrantes irregulares ${ }^{7}$ que intentan alcanzar Europa por vía marítima ha sufrido grandes vaivenes debido a la situación de los países de origen ${ }^{8}$. Las continuas imágenes de migrantes intentando alcanzar las costas europeas emitidas por los medios de comunicación han colocado el problema en el centro de la discusión pública, empujando a los gobiernos a adoptar medidas para intentar controlar la situación. Como señalan Van Selm y Cooper ${ }^{9}$, los migrantes que viajan por mar son a la vez los más visibles del mundo - en tanto se han convertido en el símbolo de la inmigración hacia los países ricos - y los más invisibles - miles de ellos han muerto ahogados, en tragedias que rara vez llegan a conocerse o son rápidamente olvidadas. Incluso si nos centramos en la migración africana a Europa por la ruta mediterránea, los migrantes irregulares suelen preferir vías menos peligrosas para llegar a su destino, como la falsificación de documentos, viajar escondidos en camiones o buques, o el salto a las vallas que rodean las ciudades españolas de Ceuta y Melilla o el río Evros que separa Grecia y Turquía.

La cuestión central siempre ha sido la conciliación entre las obligaciones de los Estados respecto de las necesidades humanitarias de refugiados y solicitantes de asilo con el derecho de los Estados de controlar sus fronteras, y sus preocupaciones (a menudo amplificadas por los medios de comunicación) sobre inmigración clandestina, llegadas masivas y los costes derivados de la acogida de refugiados. Las respuestas de estos han variado entre ambos extremos de la balanza, pero no podemos dejar de identificar una creciente tendencia hacia la criminalización de la inmigración ${ }^{10}$, y la adopción de una visión puramente policial y securitaria de la gestión fronteriza, que deja

\footnotetext{
${ }^{7}$ En el presente trabajo seguiré las recomendaciones de, entre otras organizaciones, OIT $(2004 ; 36)$ y AI (2006; 6) y emplearé preferentemente el término "migrantes irregulares" sobre otros que tienen connotaciones más negativas: ilegales, clandestinos, indocumentados, etc... No obstante mantendré las denominaciones cuando éstas aparezcan en otros documentos. Así, por ejemplo, la Conferencia Internacional sobre Población y Desarrollo de 1994 recomendó el término "indocumentado". En cambio, el simposio internacional sobre migración que se celebró en Bangkok en abril de 1999 recomendó el empleo de "irregular", dado que, en materia de migración, las irregularidades pueden manifestarse en diferentes momentos - la salida, el tránsito, la entrada y el regreso - y pueden se cometidas por el propio migrante o ir contra él o ella.

${ }^{8}$ En 2012 Frontex detectó 22.412 entradas ilegales al territorio europeo por vía marítima, un 30,9\% del total. Dos años después, con el conflicto sirio en marcha, las cifras se elevaron a 187.526 entradas, un $66,1 \%$ del total. La cifra supone un incremento del $836,7 \%$ en apenas dos años. En: Frontex: Annual Risk Analysis 2015. Varsovia, abril de 2015, Doc. 4613/2015, p. 16. Disponible en: http://frontex.europa.eu/assets/Publications/Risk Analysis/Annual Risk Analysis 2015.pdf (Consulta: 12 de diciembre de 2015)

9 -Van Selm, Joanne y Cooper, Betsy: The new "Boat People": Ensruing Safety and Determining Status. Migration Policy Institute Working Paper, enero de 2006, p. 1. Disponible en: http://www.migrationpolicy.org/research/new-boat-people-ensuring-safety-and-determining-status (Consulta: 12 de diciembre de 2015)

${ }^{10}$ Vid. Majcher, Izabella: "Crimmigration" in the European Union through the Lens of Immigration Detention. Global Detention Project Working Paper, no. 6, septiembre de 2013. Disponible en: http://www.globaldetentionproject.org/fileadmin/publications/Crimmigration_EU_final.pdf (Consulta: 12 de diciembre de 2015)
} 
postergadas las preocupaciones humanitarias y el respeto a los derechos de migrantes y refugiados ${ }^{11}$.

La incidencia estadística de estas migraciones marítimas es difícil de cuantificar. E1 carácter ilegal y oculto de estos viajes dificulta la recogida de estadísticas fiables. La organización Migration Policy Centre (MPC) elabora investigaciones sobre la llegada de migrantes a la UE, desagregados por ruta. El último informe ${ }^{12}$ mostraba los siguientes datos:

Fig. 2: Llegadas de migrantes irregulares por vía marítima a la UE, 1998-2015 (13/11)

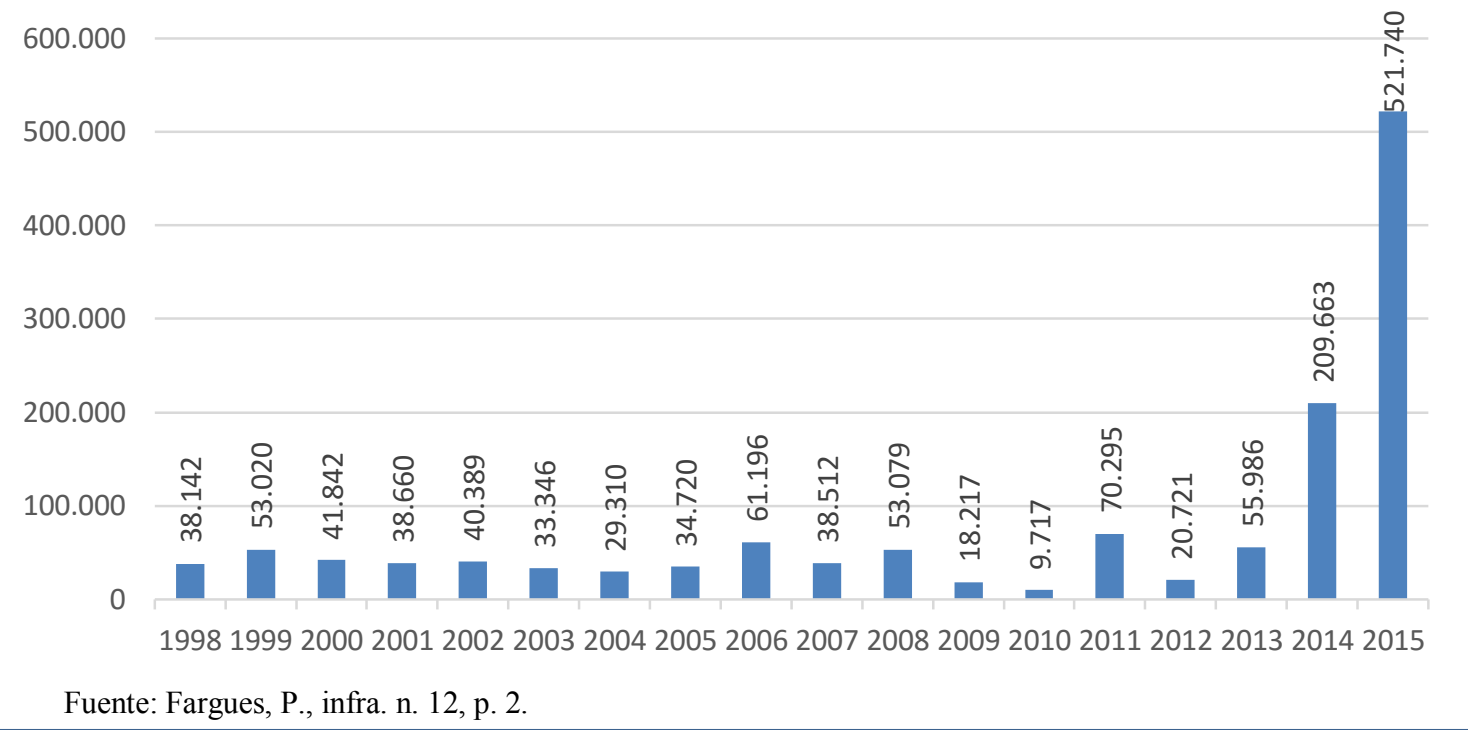

Durante el periodo de diecisiete años que cubre esta investigación, 1.368.55 migrantes han sido detectados al llegar a las costas europeas de manera irregular, lo que supone una media anual de 80.000 personas aproximadamente. No obstante, sigue tratándose de una cifra relativamente baja si la comparamos con el alrededor de millón y

${ }^{11}$ En su informe de 2013, el Relator Especial sobre los derechos humanos de los migrantes, François Crépeau, lamentó que las políticas europeas sobre migración y control fronterizo "se ha ido integrando cada vez más en los marcos de seguridad, que se centran en la vigilancia policial, la defensa y la lucha contra la delincuencia más que en un enfoque basado en los derechos." Consejo de Derechos Humanos, $29^{\circ}$ periodo de sesiones. Doc. A/HRC/23/46. Disponible en: http://daccess-ddsny.un.org/doc/UNDOC/GEN/G13/133/94/PDF/G1313394.pdf?OpenElement (Consulta: 12 de diciembre de 2015)

12 Fargues, Philippe: 2015: The year we mistook refugees for invaders. Florencia, European University Institute, Robert Schuman Centre for Advanced Studies, Migration Policy Centre, doc. 10.2870/093089, diciembre de 2015. 2 Disponible en: http://cadmus.eui.eu/bitstream/handle/1814/38307/Policy Brief 2015 12.pdf?sequence=1\&isAllowed=y (Consulta: 29 de enero de 2016) 


\section{CAPÍTULO 1}

medio de inmigrantes que recibe la UE cada año ${ }^{13}$. Se pueden observar varios fenómenos significativos que trataremos a lo largo del presente trabajo; como la reducción de las llegadas a partir de 2008 con el cierre de la ruta a las Islas Canarias ${ }^{14}$, el pico de 2011 tras de la revolución en Túnez ${ }^{15}$ o el fruto de la cooperación entre Italia y Libia antes de la caída de Gadafi. Precisamente el conflicto libio, junto al sirio, explican el ligero incremento de llegadas de 2013, que anticipa el notable cambio posterior: en 2014 se produjeron más de 200.000 entradas, y el último año los datos superan al millón de migrantes irregulares llegados por vía marítima. Estos dos últimos años concentran tantas llegadas como los quince anteriores, dato que permite comprender la gravedad de la crisis actual.

\subsection{La travesía marítima}

Los migrantes y refugiados que intentan acceder a Europa por vía marítima se encuentran en una situación de especial vulnerabilidad. En muchos casos este viaje marítimo es el último paso de un recorrido por el norte de África que puede durar años. A menudo deben ponerse en manos de mafias dedicadas al tráfico de migrantes clandestinos, y en ocasiones sufren el acoso de la policía o de delincuentes durante su estancia en los países de tránsito. Algunos colectivos tienen especial riesgo de sufrir violaciones de sus derechos durante el trayecto, como los menores no acompañados o las mujeres, víctimas a menudo de agresiones sexuales.

El viaje por mar en embarcaciones precarias conlleva una serie de riesgos para la vida de los migrantes, sometidos a las inclemencias del clima, la inestabilidad marítima y la difícil orientación. El transporte suele producirse en condiciones materiales penosas: embarcaciones en mal estado, atestadas, con escasas provisiones de alimento y agua, comandadas por patrones con poca o ninguna experiencia de navegación, etc... Además, los esfuerzos de los gobiernos desplegando patrullas fronterizas y sistemas de vigilancia han llevado a migrantes y traficantes de personas a elegir rutas y medios de

\footnotetext{
${ }^{13}$ De Bruycker, Philippe, Di Bartolomeo, Anna y Fargues, Philippe: Migrants smuggled by sea: facts, laws and policy options. Florencia, European University Institute, Robert Schuman Centre for Advanced Studies, Migration Policy Centre Research Report RR2013/09, 2013, p. 3. Disponible en: http://www.migrationpolicycentre.eu/docs/MPC-RR-2013-009.pdf (Consulta: 12 de diciembre de 2015)

${ }^{14}$ Ibíd, p. 4

15 Vid. Boubakri, Hassan: Revolution and International Migration in Tunisia, Florencia, European University Institute, Robert Schuman Centre for Advanced Studies, Migration Policy Center Research Report, RR2013/14, 2013. Disponible en: http://www.migrationpolicycentre.eu/docs/MPC-RR-201304.pdf (Consulta: 12 de diciembre de 2015)
} 
transporte más peligrosos, lo que incrementa las posibilidades de accidentes, poniendo en riesgo la vida de los migrantes ${ }^{16}$.

La obligación de socorrer a náufragos y personas en situación de peligro es uno de los principios básicos de la navegación. La costumbre dictaba que las personas rescatadas debían ser desembarcadas en el siguiente puerto de escala, donde se las prestaba la ayuda necesaria y podían regresar a su origen o continuar su ruta. Sin embargo, a partir de la crisis de refugiados vietnamitas de los años setenta, los gobiernos de todo el mundo se volvieron más reacios a permitir el desembarco de personas rescatadas en sus puertos, especialmente cuando se producían afluencias masivas de refugiados.

Durante las últimas décadas se han producido numerosas crisis de refugiados que llegaban por vía marítima a un país que rehusaba aceptarlos. En cada ocasión, tanto desde los órganos interestatales como de las organizaciones no gubernamentales de derechos humanos y de los refugiados han pedido soluciones para que se garanticen una adecuada protección de las personas que se ven envueltas en estas situaciones. Hasta el momento, no se ha conseguido una solución global, resolviéndose cada situación en virtud de la voluntad política de los diferentes actores implicados. Varias razones pueden explicar este fracaso: los distintos intereses entre los países involucrados (ya sean de origen, tránsito y destino, o que enarbolen el pabellón del buque), el temor de los Estados a perder soberanía, o a que junto a los refugiados en dichas embarcaciones viajen migrantes económicos que no se encuentran protegidos bajo la figura del refugiado.

Como veremos cuando analicemos los cambios normativos que se han producido en las últimas décadas, éstos siempre se producen como respuesta ante una crisis internacional de refugiados por vía marítima. El carácter ad hoc de estas reformas ha generado un corpus normativo falto de coherencia, con lagunas y contradicciones entre el respeto a la soberanía estatal y la protección de los derechos de migrantes y refugiados.

\footnotetext{
${ }^{16}$ El testimonio del periodista José Luis Manzanares es ilustrativo: "Los subsaharianos hacian el mismo trayecto en patera que los magrebies, unas doce horas, ero con la diferencia de que quizás, habian estado en el desierto tres meses. Venían desnutridos. Además, la travesía en patera la hacen más apiñados, entumecidos, con hipotermia, quemaduras por el sol y gasoil. Realmente están agotados. Por eso, cuando la patera se da la vuelta y caen al mar, se hunden como piedras" (En: Aldalur, Martín: Clandestinos. Barcelona, Ediciones B., 2010, p. 164)
} 


\section{CAPÍTULO 1}

En el ámbito europeo, el interés de los legisladores comunitarios y nacionales ha estado cada vez más influido por las preocupaciones en la seguridad interna y el control fronterizo ${ }^{17}$. Es preciso que se vuelva a situar en el centro del debate la vida y los derechos en peligro de las personas migrantes. Las medias de control y vigilancia de las fronteras marítimas deben cumplir los estándares internacionales del Derecho de los Refugiados y del Derecho Internacional de los Derechos Humanos. Las interceptaciones marítimas, cuando suponen el rechazo de la entrada de la embarcación y su retorno al lugar de partida, ponen en peligro la protección de los derechos fundamentales de los migrantes y refugiados.

Es preciso que se lleguen a acuerdos a nivel tanto a nivel de la Unión Europea como internacional para garantizar el salvamento en el mar y el desembarco a un lugar seguro, así como una adecuada acogida en tierra. Es necesaria además una adecuada identificación de las necesidades de las personas rescatadas, dado la naturaleza compleja de los flujos migratorios.

\subsection{Los flujos migratorios mixtos}

En estas rutas migratorias se produce lo que se conoce como un "flujo migratorio mixto", en tanto lo conforman no solamente refugiados, sino también migrantes de todo tipo: económicos, menores no acompañados, víctimas de redes de trata etc... En muchas ocasiones la propia distinción individual resulta compleja. Los Estados deben elaborar políticas de asilo para poder identificar individualmente la situación de cada persona, entre otras, para aquellas que puedan ser susceptibles de la protección internacional que conlleva el estatus de refugiado según la Convención de Ginebra de 1951 y su Protocolo de 1967 (en adelante, CG51), así como otras formas de protección subsidiaria. Desde un punto de vista más amplio, los Estados deben respetar los derechos humanos de todos los migrantes que se encuentran bajo su jurisdicción, ya sea territorial o de alguno de sus agentes ${ }^{18}$.

La naturaleza compleja de los flujos migratorios actuales dificulta la distinción precisa entre migrantes y refugiados. Lo que caracteriza a los llamados "flujos mixtos"

\footnotetext{
${ }^{17}$ Vid. Lutterbeck, Derek: Policing Migration in the Mediterranean. Mediterranean Politics Vol. 11, No. 1, 2006, pp. 59-82.

${ }^{18} \mathrm{Si}$ bien la migración también se produce dentro de las fronteras de un mismo país (por ejemplo, la que se produce del medio rural al urbano), aquí me centraré en la migración que comporta cruzar una frontera internacional.
} 
es que se componen de personas que migran empleando las mismas rutas y medios de transporte pero que lo hacen por diferentes razones, incluyendo tanto a personas que huyen de la persecución política o la violencia como por razones económicas ${ }^{19}$. La OIM ha definido los flujos mixtos como movimientos complejos de población que incluyen refugiados, solicitantes de asilo, migrantes económicos y de otro tipo ${ }^{20}$. La distinción entre refugiados "políticos" y migrantes "económicos" es en gran medida artificial ${ }^{21}$, en tanto razones de carácter político pueden pesar en la decisión de una persona de emigrar, y las personas que escapan de conflictos armados y regímenes opresivos también buscan trabajar y tener oportunidades económicas para desarrollar una vida digna $^{22}$. Además, existen también otras personas que no encajan en estas dos categorías, como las víctimas de trata, los menores no acompañados, o las personas apátridas. En ocasiones se utiliza el término "otros migrantes irregulares" para referirse a personas que abandonaron su país de origen debido a causas que no encajan en las normas nacionales e internacionales de asilo, como los desastres de origen natural o climático. El acceso a las solicitudes de asilo encuentra también barreras culturales o de género; por ejemplo, a pesar de que más del $50 \%$ de las personas refugiadas a nivel mundial son mujeres, el porcentaje entre las que presenta solicitudes de asilo es mucho menor ${ }^{23}$.

Si bien desde un punto de vista demográfico y sociológico ${ }^{24}$ la diferencia entre migrantes y refugiados aparece borrosa, en el ámbito del derecho internacional existe una intención clara de distinguir las obligaciones de los estados respecto a cada uno de estos grupos de personas. Tradicionalmente el Derecho Internacional Público ha tratado

19 Vid. ACNUR: La protección de los refugiados y la migración mixta: El Plan de los 10 puntos en acción, febrero de 2011. Disponible en: http://www.acnur.es/PDF/7526_20120511131557.pdf (Consulta: 12 de diciembre de 2015)

${ }^{20}$ OIM: Glossary on Migration, International Migration Law, $n^{\circ}$ 1, Doc. 71/04, Ginebra 2004, p. 42. Disponible en: http://unobserver.iom.int/sites/default/files/IML_1_EN.pdf (Consulta: 12 de diciembre de 2015)

${ }^{21}$ Como señalaba el ACNUR "En la actualidad carece de sentido trazar una línea estricta entre lo que son el desplazamiento voluntario y el desplazamiento forzado de personas, debido a que los motivos que provocan la migración son complejos e implican una mezcla de factores políticos, económicos y sociales. La naturaleza y complejidad de los desplazamientos actuales dificultan la determinación de una línea clara entre migrantes y refugiados". En: Corte Interamericana de Derechos Humanos: Opinión Consultiva $\mathrm{n}^{\mathrm{o}}$ 18: Condición jurídica y derechos de los migrantes indocumentados, 17 de septiembre de 2003, p. 85. Disponible en: http://www.corteidh.or.cr/docs/opiniones/seriea_18_esp.pdf (Consulta: 12 de diciembre de 2015)

${ }^{22}$ Así mismo, como señala Javier de Lucas (2006; p.30) dentro de la categoría de migrante existe un reduccionismo normativo que lo reduce al concepto de "trabajador inmigrante", excluyendo artificialmente a otros grupos "no deseados" por el país receptor como refugiados, sin trabajo o con un perfil no requerido, reagrupación familiar, etc...

${ }^{23}$ Por ejemplo, en el año 2014, de los 626.960 solicitantes de asilo en la Unión Europea sólo un 29,7\% (186.080) eran mujeres. Fuente: Eurostat: Asylum and first time asylum applicants by citizenship, age and sex Annual aggregated data. Last update: 09-09-2015.

24 Vid. Castles, Stephen: Towards a Sociology of Forced Migration and Social Transformation. Sociology, Vol. 77, no. 1, 2003, pp. 13-34. Disponible en: http://rimd.reduaz.mx/documentos_miembros/18713SC_Sociology_of_FM_2002.pdf (Consulta: 12 de diciembre de 2015) 


\section{CAPÍTULO 1}

de forma parcial y poco desarrollada el fenómeno migratorio. Los derechos de la persona migrante se encuentran escasamente protegidos, siendo especialmente precaria $\mathrm{y}$ vulnerable la situación de los migrantes irregulares ${ }^{25}$. Históricamente, los Estados se han mostrado recelosos de regular en común las cuestiones migratorias y buscar la cooperación multilateral para afrontar estas cuestiones. Las principales razones que se pueden invocar para comprender esta situación tienen que ver con los distintos intereses entre los países de origen, tránsito y destino de las migraciones, así como la resistencia de los Estados a ceder soberanía ${ }^{26}$.

En el DIDH el derecho a la libre circulación y elección de residencia se encuentra circunscrito a aquellas personas que se encuentren en un Estado de forma legal ${ }^{27}$. Dado que la residencia legal en el territorio es un requisito básico para poder acceder a la mayoría de los demás derechos, este se presenta como un "derecho llave". Esta distinción entre migrantes regulares e irregulares ha sido limitada y matizada posteriormente por el Derecho Internacional, estableciendo una serie de derechos para los segundos.

En la práctica esta distinción migrante-refugiado también encuentra sus dificultades. La propia Unión Europea incluye la cuestión del asilo en la temática más amplia de políticas relativas la inmigración, el control de fronteras y la seguridad. En este trabajo iremos saltando entre estas dos esferas, de acuerdo a las características propias de los flujos mixtos que caracterizan estas migraciones. Los refugiados son migrantes, en un sentido demográfico y desprovisto de connotaciones jurídicas y políticas; y son también mayoritariamente migrantes irregulares; a la vista de la legislación nacional y comunitaria, al cruzar la frontera del país europeo y hasta que acceden al procedimiento de asilo. Resulta difícil diferenciar numéricamente entre refugiados y estas otras figuras

\footnotetext{
${ }^{25}$ La AGNU señaló en su resolución sobre la "Protección de los migrantes", que se debe tener presente "la situación de vulnerabilidad en que suelen encontrarse los migrantes debido, entre otras cosas, a que no viven en sus Estados de origen y a las dificultades que afrontan a causa de diferencias de idioma, costumbres y culturas, así como las dificultades económicas y sociales y los obstáculos para regresar a sus Estados de origen a que deben hacer frente los migrantes sin documentación o en situación irregular", apelando a los Estados a que "protejan plenamente los derechos humanos universalmente reconocidos de los migrantes, en particular de las mujeres y los niños, independientemente de su situación jurídica, y que los traten con humanidad, sobre todo en lo relativo a la asistencia y la protección". Doc. A/RES/54/166. Disponible: http://documents-ddsny.un.org/doc/UNDOC/GEN/N00/265/75/pdf/N0026575.pdf?OpenElement (Consulta: 12 de diciembre de 2015)

${ }^{26}$ Vid. Pérez González, Carmen: Migraciones irregulares y Derecho Internacional. Gestión de los flujos migratorios, devolución de extranjeros en situación administrativa irregular y Derecho Internacional de los Derechos Humanos, Valencia, Tirant lo Blanc, 2012.p. 39

${ }^{27}$ El art. 12.1 del PIDCP establece que "Toda persona que se halle legalmente en el territorio de un Estado tendrá derecho a circular libremente por él, y a escoger libremente su residencia". Se incluye una definición similar en el art. 2 del Protocolo $\mathrm{n}^{\circ} 4$ del CEDH.
} 
en los flujos de personas que intentan alcanzar Europa desde el Mediterráneo. ACNUR estimó en más de 900.000 los migrantes que llegaron a Europa por el mar Mediterráneo a lo largo de $2015^{28}$. Gil Arias, antiguo director ejecutivo de Frontex, estimó en más de un $80 \%$ el número de estos migrantes que serían potenciales beneficiarios de protección internacional ${ }^{29}$.

Reducir la complejidad de los movimientos migratorios que se producen en el mundo, y más concretamente los que ocupan este trabajo, a una dicotomía migranterefugiado es de igual forma inexacta. En las últimas décadas tanto a nivel nacional como internacional los estados han venido reconociendo otras figuras legales que no encajan con ninguna de las dos categorías principales pero que precisan de una protección específica y se encuentran protegidos frente a la devolución a su país de origen: menores no acompañados, personas enfermas, víctimas de trata y/o de violencia de género, desplazados temporales, etc...

Los Estados tienen la obligación de distinguir entre refugiados y migrantes, y entre las distintas categorías de éstos, cuando se enfrentan a flujos mixtos, para ofrecer una adecuada protección individual. En la práctica, está distinción es difícil de realizar, especialmente en el caso de la migración marítima. Las medidas que prejuzgan de una forma superficial y sin debida consideración la situación de los posibles refugiados y otras personas susceptibles de merecer algún tipo de protección suponen una protección inadecuada de estas y, por tanto, una vulneración de sus derechos. Si los Estados retienen la discreción para determinar el grado de aplicación de la CG51, entonces la protección de refugiados bajo el derecho internacional está seriamente debilitada.

Un migrante internacional, sea su condición administrativa regular o irregular, realiza un viaje entre países. Los que cruzan las fronteras terrestres a pie, en tren o auto pueden ser detenidos en alguna estación o puesto fronterizo, pero se encuentra cara a cara con las autoridades que decidirán su futuro. Los que llegan al país en un avión comercial y aterrizan en un aeropuerto se encuentran en una situación similar. Incluso si es retenido en "territorio internacional", se encuentra con autoridades migratorias, una cierta seguridad física y una serie de reglas y procedimientos establecidos que decidirán su petición de entrada al territorio o de asilo. Para aquellos que intentan entrar ilegalmente en un territorio por vía marítima, la situación es radicalmente diferente. La

${ }^{28}$ Nota de prensa del 9 de diciembre de 2015: "Refugees and migrants in Europe need protection and respect for their human rights". Disponible en: http://www.unhcr.org/5667f2bd6.html (Consulta: 12 de diciembre de 2015)

29 Entrevista disponible en: euskadi/programas/boulevard/audios/detalle/3148464/inmigracion--el-80-inmigrantes-son-refugiados/ 


\section{CAPÍTULO 1}

posibilidad de que pisen territorio del Estado no está asegurada. Si tienen suerte, pueden desembarcar sin ser detectados, y su presencia solamente será revelada una vez se encuentren a salvo en el territorio. Sin embargo, para aquellos que son interceptados o rescatados, su suerte es insegura. Pueden permanecer en un buque durante días (incluso semanas) hasta que algún estado decida hacerse cargo de ellos. Pueden ser devueltos al país desde el que salieron, o a alguna patrullera de la policía de este país. Para aquellos que son desembarcados en el país de destino y llevados a un centro de detención no debería haber diferencia en su trato con otro inmigrante irregular o solicitante de asilo llegado por tierra y aire. Sin embargo, como veremos, los Estados se muestran más restrictivos en el caso de llegadas masivas de migrantes por mar, y las repatriaciones pueden producirse de forma colectiva y arbitraria.

Los Estados de la UE tienen garantizado en sus legislaciones nacionales el acceso al procedimiento de asilo y la protección contra la devolución (aunque no siempre la cumplen). Sin embargo, la práctica generalizada de estos es que tienden a considerar que estas protecciones se empiezan a cumplir cuando los solicitantes "ponen pie" en el territorio. Los Estados tienden a negarse a asumir responsabilidades de protección de derechos humanos y de los refugiados cuando actúan más allá de sus límites territoriales. De ahí que la mayor parte de las políticas europeas de asilo en los últimos años han buscado impedir el acceso de los potenciales solicitantes de asilo a través del control fronterizo, la externalización del procedimiento y la cooperación con los países de origen y tránsito.

\subsection{El régimen de asilo y el derecho de los refugiados}

Según el artículo 1.A de la Convención de Ginebra de 1951 (de ahora en adelante, CG51) se entiende como refugiada a aquella persona que "debido a fundados temores de ser perseguida por motivos de raza, religión, nacionalidad, pertenencia a determinado grupo social u opiniones politicas, se encuentre fuera del país de su nacionalidad y no pueda o, a causa de dichos temores, no quiera acogerse a la protección de tal país; o que, careciendo de nacionalidad y hallándose fuera del país donde antes tuviera su residencia habitual, no pueda o, a causa de dichos temores, no quiera regresar a él"30

\footnotetext{
${ }^{30}$ Convención de Ginebra sobre el estatuto de los refugiados, de 28 de julio de 1951, art. 1. A. Disponible en: $\quad$ http://www.acnur.org/t3/fileadmin/scripts/doc.php?file=t3/fileadmin/Documentos/BDL/2001/0005 (Consulta: 12 de diciembre de 2015)
} 
El Manual del ACNUR para la determinación del estatuto de refugiado ${ }^{31}$, por su parte, define como emigrante a aquel que, sin cumplir con los motivos del artículo arriba citado, "abandona voluntariamente su país a fin de establecer su residencia en otro lugar. Puede actuar así movido por un deseo de cambio o de aventura, por razones familiares o por otros motivos de carácter persona. Si obedece exclusivamente a consideraciones de tipo económico, es un emigrante y no un refugiado" ${ }^{32}$. El propio Manual reconoce la imprecisión de esta distinción ${ }^{33}$, añadiendo algunos ejemplos de medidas de carácter económico que pueden ser motivos que fuercen a una persona a abandonar su propio país ${ }^{34}$.

Conviene también hacer una aclaración entre los conceptos de solicitante de asilo y refugiado. En el texto de la CG51 aparece únicamente el término "refugiado". Esto es debido a que la figura del solicitante de asilo no existía en el periodo en que se redactó la Convención. Es, de hecho, una consecuencia de la disposición fijada en la convención que obliga a los Estados a crear sistemas de asilo nacionales. Considerar, pues, que las disposiciones contenidas en la CG51 no son aplicables a los solicitantes de asilo es una interpretación simplista, contraria al espíritu de la Convención y del DIDH.

Por una persona refugiada entendemos a aquella que se ajusta en la definición que la CG51 hace de ella, independientemente si algún estado ha determinado su estatus formalmente. Este reconocimiento estatal es, por tanto, un acto declarativo, no constitutivo, que determina un determinado estatus legal en el país ${ }^{35}$. Como ACNUR insiste, un refugiado no se convierte en refugiado debido al reconocimiento que haga un Estado, sino que es reconocido porque es un refugiado. En la práctica esto significa que una persona que pudiera ser un refugiado debe ser tratado provisionalmente como tal y a menos que se determine de forma justa por un procedimiento legal y justo cuál es su estatus jurídico. El propio lenguaje es significativo; el estatuto de refugiado se "reconoce", no se "otorga". En el presente trabajo, emplearé de forma general el

\footnotetext{
${ }^{31}$ ACNUR: Manual de Procedimientos y Criterios para Determinar La Condición de Refugiado en virtud de la Convención de 1951 y el Protocolo de 1967 sobre el Estatuto de los Refugiados, Ginebra, 1979. Disponible en: http://www.acnur.org/t3/fileadmin/Documentos/BDL/2011/7575.pdf?view=1 (Consulta: 12 de diciembre de 2015)

${ }^{32}$ Ibíd., para. 62

${ }^{33}$ Ibíd., para. 63

${ }^{34}$ Cuando nos refiramos en el presente trabajo a "su país" o "país de origen" de los migrantes y refugiados, entendemos no solamente el de nacionalidad sino aquel con el que pueda tener "vínculos especiales o pretensiones en relación" a dicho país, por el que no pueda ser considerado "como un simple extranjero" (Comité de Derechos Humanos. Observación General no 27: Artículo 12 - libertad de circulación. $67^{\circ}$ período de sesiones, 1 de noviembre de 1999, para. 20. Disponible en: http:/tbinternet.ohchr.org/ layouts/treatybodyexternal/Download.aspx?symbolno=CCPR $\% 2 \mathrm{fC} \% 2 \mathrm{f} 21 \% 2 \mathrm{f}$ Rev.1\%2fAdd.9\&Lang=en (Consulta: 12 de diciembre de 2015)

${ }^{35}$ ACNUR: Manual de procedimientos..., op. cit., para. 28
} 


\section{CAPÍTULO 1}

término refugiado, usando el de solicitante de asilo cuando me refiera al estatus de dicha persona ante el procedimiento nacional específico de un determinado país.

\subsection{Objetivo de la investigación}

El objetivo general de este trabajo es examinar la vigilancia del principio de nonrefouelement en las políticas fronterizas de la UE en el mar mediterráneo, en especial los obstáculos que estas plantean para el acceso a los sistemas de asilo, como las interceptaciones marítimas y devoluciones a los países de origen. Atenderé especialmente a la adecuación de estas políticas a los estándares internacionales de derechos humanos. Con el fin de situar la problemática de la investigación, será necesario mapear las principales normas del Derecho Internacional, del Mar y de la UE que son relevantes, así como visualizar sus posibles contradicciones y límites.

Al respecto del objeto de la investigación, la hipótesis que manejaré es que la protección de este principio en las fronteras marítimas del sur de Europa se encuentra debilitada por dos factores: a) una deficiente regulación en el derecho internacional que permite un amplio margen de actuación de los Estados en las operaciones de salvamento e interceptación; y b) una creciente preocupación por el control de las fronteras y los flujos migratorios tanto en la UE como en los EEMM, que orienta la acción política y legislativa hacia enfoque más restrictivo en lo que respecta a las vías de entrada al territorio y al procedimiento de asilo.

El trabajo está estructurado en cuatro capítulos. En el primero, esbozaré una panorámica de la evolución de normas y políticas comunitarias sobre asilo, migración y fronteras. Le dedicaré especial atención a la agencia encargada de la vigilancia de fronteras, Frontex. En el segundo, introduciré de forma no exhaustiva la norma internacional que informa el contenido de este trabajo: la prohibición de expulsar a un individuo a un territorio en el que su vida o seguridad corre peligro. En el tercero, examinaré una de las problemáticas principales que se presenta en las políticas fronterizas que se realizan en el mar, más allá del territorio de un Estado: la cuestión de la jurisdicción y la territorialidad de la soberanía y las obligaciones respecto del derecho internacional. Se trata de uno de los aspectos clave de esta investigación, dado que determina la existencia de responsabilidades y su alcance en relación tanto al salvamento marítimo como a la protección de los derechos humanos. La cuarta parte estará enfocada en las normas y prácticas de salvamento marítimo e interceptación. Analizaré las obligaciones de rescate y desembarco de los Estados ribereños respecto de 
aquellos migrantes y refugiados que cruzan el mediterráneo, así como las prácticas de interceptación marítima en el ámbito de la vigilancia fronteriza, incluyendo las principales operaciones realizadas por los Estados europeos y Frontex. Finalizaré la presente tesis esbozando algunas consideraciones generales sobre el tema, a tenor de los últimos acontecimientos.

Previamente, me es necesario tratar algunas consideraciones iniciales. Como he señalado antes respecto de la distinción entre migrante y refugiado, la situación jurídica de las personas sobre las que trata este trabajo presenta una cierta complejidad. Los límites que existen entre inmigrantes clandestinos y solicitantes de asilo, víctimas de redes de trata, personas que pudieran ser beneficiarios de algún tipo de protección subsidiaria, náufragos que precisan de auxilio y polizones son difusos, quedando muy a menudo su determinación en manos de la arbitrariedad de los Estados. La propia actividad de estos a menudo se produce fuera de los límites clásicos de la soberanía, con agentes nacionales efectuando detenciones en aguas territoriales de otro Estado, personal de agencias europeas coordinando operaciones poco transparentes, y las así llamadas "zonas de tránsito", ficciones jurídicas que emplean los Estados intentando colocar al inmigrante irregular en una situación cercana al "estado de excepción" tal como lo redefine Giorgio Agamben ${ }^{36}$. Teniendo en cuenta esto, a lo largo del presente trabajo se entrecruzarán diferentes ámbitos del derecho, tanto temáticos (derechos humanos, de los refugiados, migratorio, marítimo, entre otros) como territoriales (derechos nacionales, europeo e internacional).

Dicho esto, un abordaje exhaustivo a los citados ordenamientos jurídicos no puede pretender elaborar una simple lista de derechos que un refugiado puede reclamar, y su correspondiente contralista de deberes de los Estados. Un análisis legal y de políticas públicas desde un enfoque de derechos humanos ${ }^{37}$ debe ayudar a clarificar los claroscuros y señalar las grietas por las que se deteriora el Estado de derecho y se vulneran los derechos de los migrantes y refugiados. Ofrecer un análisis más

36 "El principio según el cual la necesidad define una situación singular en la que la ley pierde su ius obligandi (éste es el sentido del adagio necessitas legem non habet) se revierte en aquél según el cual la necesidad constituye, por así decir, el fundamento último y la surgente misma de la ley" (Agamben, Giorgio: Estado de excepción. Homo Sacer II. 1, Valencia, Pre-Textos, 2004, p. 63)

37 El Enfoque Basado en los Derechos Humanos (EBDH) consiste en un marco conceptual y metodológico basado normativamente en estándares internacionales de derechos humanos y operativamente dirigido a promover, proteger y hacer efectivos estos derechos. Es decir, pretende, mediante la integración de la normativa internacional de los derechos humanos en las políticas públicas, promover el cumplimiento y disfrute de estos derechos. Vid. UNDG: El Enfoque basado en los Derechos Humanos para la Cooperación del Desarrollo. Hacia un Entendimiento Común entre las Agencias de la ONU. Nueva York. 2013. Disponible en: http://hrbaportal.org/the-human-rights-based-approach-todevelopment-cooperation-towards-a-common-understanding-among-un-agencies $\quad$ (Consulta: 12 de diciembre de 2015) 


\section{CAPÍTULO 1}

compresivo, si bien más complejo precisa de la incorporación de otras disciplinas y puntos de vista que complementen el análisis jurídico. Este enfoque debe situar a las personas migrantes y refugiadas y sus derechos en el centro del presente trabajo. Por lo que el criterio con el que trataré de ordenar el presente trabajo será el principio pro homine ${ }^{38}$.

\subsection{Delimitación del campo de análisis y metodología}

De entrada, es necesario señalar que a la hora de realizar la investigación me enfrenté a una serie de limitaciones; la primera fue mi imposibilidad de realizar un exhaustivo trabajo de campo, confinando pues los objetivos en una dimensión más descriptiva, y recurriendo al empleo de fuentes secundarias. La consulta de documentos y estadísticas, las entrevistas telefónicas o través de e-mail no proveen de información tan directa como el trabajo sobre el terreno y el contacto personal. Es por eso que el lector debe tener en cuenta que los testimonios aquí provistos y las historias de vida reflejada proceden en su mayoría de fuentes indirectas o se han realizado a través de medios telemáticos. Una dificultad que surge respecto del acceso de la información, muchas de las actuaciones que aquí se analizan (operaciones de patrullaje marítimas en Alta Mar, devoluciones en caliente o masivas, etc...) son de naturaleza ilegal o se mantienen en secreto por parte de los gobiernos, por lo que el acceso a información o estadísticas fiables resulta difícil. Teniendo en cuenta estos condicionamientos, las principales metodologías utilizadas fueron básicamente el despojo de fuentes secundarias (jurídicas, sociológicas o estadísticas), y las técnicas de investigación cualitativas, especialmente las entrevistas en profundidad a migrantes, refugiados y trabajadores de organizaciones que trabajan en este ámbito.

Debido a la delimitación del objeto de análisis y los objetivos propios de esta tesis, muchas cuestiones relacionadas con el tema quedarán fuera de este trabajo o serán tratadas de modo marginal. A pesar de ser actores importantes de este proceso las obligaciones internacionales de los Estados africanos de origen y tránsito no serán tratadas, más allá de la participación de algunos Estados ribereños en las operaciones de

\footnotetext{
${ }^{38}$ Aquí tomo la definición de Mónica Pinto que lo define como "un criterio hermenéutico que informa todo el derecho internacional de los derechos humanos, en virtud del cual se debe acudir a la norma más amplia, o a la interpretación más extensiva, cuando se trata de reconocer derechos protegidos, e inversamente, a la norma o a la interpretación más restringida cuando se trata de establecer restricciones permanentes al ejercicio de los derechos o su suspensión extraordinaria” (p. 163). En: Pinto, Mónica: "El principio pro homine. Criterios de hermenéutica y pautas para la regulación de los derechos humanos"; en: Abregú, Martín y Courtis, Christian (comp.): La aplicación de los tratados de derechos humanos por los tribunales locales. Buenos Aires, Centro de Estudios Legales y Sociales, Editorial Del Puerto, 1997, pp. 163
} 
patrullaje conjuntas. Dejo fuera también los proyectos más "ambiciosos" de la UE de externalización de fronteras, a través del establecimiento de "zonas de asilo" fuera de las fronteras europeas, y la revisión de conceptos como tercer país seguro o país de origen seguro. Diversos aspectos del acceso al procedimiento de asilo y la situación de los derechos humanos de los refugiados y migrantes también se tratarán en diversos capítulos de forma superficial, dado que un examen global de dichas cuestiones sería inabarcable aquí.

El presente trabajo incorpora un análisis de las políticas públicas de asilo, migración y control fronterizo de la Unión Europea y de cuatro países mediterráneos. Se tomará como base el marco legislativo del SECA (Sistema Europeo Común de Asilo), además de otros documentos de trabajo de las instituciones y agencias de la Unión. Así mismo tendré en cuenta la jurisprudencia de los tribunales de Estrasburgo y Luxemburgo y, de manera secundaria, de los órganos de derechos humanos de Naciones Unidas. Dada la poca jurisprudencia existente, mencionaré igualmente casos semejantes ocurridos en el Caribe o el Pacífico. Debido a la inconsistencia entre las normas y, especialmente, los estándares de derechos humanos, tendré en cuenta además los informes relativos a la temática que han publicado organizaciones de derechos humanos como AI, HRW, JSR, el Consejo de Europa o la Agencia de Naciones Unidas para los Refugiados (ACNUR). Estos informes han sido una fuente de material de gran importancia, no en vano son utilizados usualmente por las propias instituciones y tribunales para los asuntos referidos a migrantes y refugiados.

Dada la existencia de numerosa literatura sobre el derecho internacional de refugiados, fronteras y migraciones, el objetivo del presente trabajo no se centra únicamente en un enfoque legal sobre el tema. En general estos tienden a enfocar el problema desde una perspectiva concreta, ya sea el derecho internacional, comunitario o nacional $^{39}$, impidiendo ver las interrelaciones de estos y su influencia sobre la vida y los derechos de los migrantes y refugiados. No obstante, convendrá sistematizar las diferentes aproximaciones al problema hechas bajo el punto de vista del DIDH y el principio pro homine. A lo largo de todo el trabajo he utilizado el enfoque basado en derechos de forma transversal. Una pretensión específica de dicho análisis, y que detallaré en el último capítulo, será un esbozo de recomendaciones para mejorar las garantías de derechos a las personas migrantes y refugiadas que intentan llegar a Europa por la ruta mediterránea. El análisis jurídico presenta además otra limitación. Los casos que llegan ante los tribunales de Luxemburgo o Estrasburgo, o a los diversos comités del sistema de Naciones Unidas, sólo son la punta del iceberg de muchas violaciones de

${ }^{39}$ Vid. Pallis, Mark: Obligations of States towards Asylum Seekers at Sea: Interactions and Conflicts Between Legal Regimes. International Journal of Refugee Law, vol 14, no. 2 \& 3, 2010, pp. 329-364. 


\section{CAPÍTULO 1}

derechos humanos que quedan resueltas en los tribunales locales, o que sólo encuentran eco en los informes de organizaciones de derechos humanos.

Tampoco entro a valorar el "supuesto" éxito o eficacia de las políticas migratorias y de fronteras de la UE en virtud de sus objetivos propios, esencialmente la reducción de la llegada de inmigrantes irregulares a las costas europeas. Según datos de la propia Frontex, la Agencia no ha podido frenar la llegada de migrantes irregulares por el Mediterráneo: en 2014 la Agencia detectó hasta 280.000 entradas ilegales al territorio de la Unión ${ }^{40}$. Uno de los efectos ha sido la modificación de las rutas migratorias. Por ejemplo, desde 2005 el incremento en la vigilancia en el estrecho de Gibraltar provocó que cada vez más migrantes intentaran llegar a España viajando directamente a las Islas Canarias desde Mauritania, Senegal u otros estados del noroeste africano. Similares fenómenos se han observado en las rutas migratorias a las islas Cerdeña, Lampedusa, Malta y Creta. Más recientemente, la construcción de un muro en la frontera greco-turca de Evros ha desplazado la ruta de refugiados sirios hacia las islas del mar Egeo.

Uno de los riesgos en el que he tratado evitar caer es el de presentar una visión excluyente y parcial de la problemática de los derechos de los refugiados, aislándola de la situación de los migrantes irregulares y otras personas que forman parte de estos movimientos migratorios. Al presentar una visión separada e individualizada de los derechos y mecanismos de protección de los refugiados, se podría presuponer que se trata de minimizar las violaciones de derechos humanos a las que se enfrentan los demás migrantes. Cuando desde el poder político de la UE se plantea una división entre migrantes "legítimos" necesitados de protección internacional e "ilegítimos" que deben ser devueltos a sus países en el menor tiempo posible ${ }^{41}$.

\footnotetext{
${ }^{40}$ Frontex, Annual Risk Analysis 2015. Varsovia, abril de 2015, Frontex reference number 4613/2015, p. 5 . Disponible http://frontex.europa.eu/assets/Publications/Risk Analysis/Annual Risk Analysis 2015.pdf (Consulta: 12 de diciembre de 2015)

${ }^{41}$ Valga el ejemplo de la propuesta del plan de acción de 10 puntos dela Comisión del 21 de abril de 2015, que incluía "Establecer un nuevo programa de retorno para el retorno rápido de los inmigrantes irregulares coordinado por Frontex desde los Estados miembros en "primera línea". Disponible en: http://ec.europa.eu/spain/actualidad-y-prensa/noticias/justicia-libertad-y-seguridad/eucoinmigracion es.htm (Consulta: 15 de diciembre de 2015)
} 


\subsection{Estado actual del tema}

Una de las principales dificultades que afronta este trabajo es el carácter reciente de la mayoría de los hechos que aquí tratan. Si bien el mediterráneo siempre ha sido una ruta por la que numerosos migrantes y refugiados intentaban alcanzar Europa, la estabilización de un flujo migratorio de dimensiones importantes únicamente aconteció desde finales de los años ochenta, siendo en los últimos quince cuando se ha convertido en tema de discusión pública. Es desde entonces cuando han aparecido los primeros textos sobre esta problemática, en su inmensa mayoría de las instituciones comunitarias y de organizaciones que luchan por los derechos de refugiados y migrantes.

Las sucesivas crisis marítimas de refugiados que se han venido produciendo desde los años setenta sí que han producido una abundante bibliografía académica sobre el principio de non-refoulement y las obligaciones de los Estados respecto a los refugiados rescatados en el mar $^{42}$. El tema ha sido tratado por algunos de los autores más relevantes del Derecho de los Refugiados, como Guy Goodwin-Gill, Jane McAdam o James Hathaway ${ }^{43}$ Existe también una largo debate jurídico sobre la aplicación extraterritorial del DIDH y de los refugiados, que se remonta a la sentencia de la extinta Corte Permanente de Justicia Internacional en el caso SS Lotus (1927), del que aquí tendré en consideración los trabajos más recientes de Thomas Gammeltoft-Hansen, Marko Milanovic y Maarten den Heijer ${ }^{44}$.

En sus inicios, la ruta mediterránea fue considerada como transitada mayoritariamente por personas migrantes. Los estudios realizados sobre este fenómeno apenas tuvieron en consideración aspectos relacionados con el asilo, estando centrados en las cuestiones fronterizas, de seguridad o de la política de cooperación de la UE. En

\footnotetext{
${ }^{42}$ Lauterpacht, Elihu y Bethlehem, Daniel: "The scope and content of the principle of non-refoulement: Opinion". En: Feller, Türk, y Nicholson (eds.): Refugee Protection in International Law: UNHCR's Global Consultations on International Protection, Cambridge University Press, 2003; Barnes, Richard: Refugee Law at Sea, International and Comparative Law Quarterly vol. 53, $\mathrm{n}^{\circ}$ 1, 2004, pp. 47-77; Van Selm, J. y Cooper, B.: The New..., op. cit.; y Trevisanut, Seline: The Principle of Non-Refoulement at Sea and the Effectiveness of Asylum Protection, Max Planck Yearbook of United Nations Law, vol. 12, 2008, pp. 205-246.

${ }^{43}$ Goodwin-Gill, Guy y McAdam, Jane: The Refugee in International Law, Oxford University Press, $3^{\mathrm{a}}$ ed., 2007; Hathaway, James: The Rights of Refugees under International Law, Cambridge University Press, 2005.

${ }^{44}$ Gammeltoft-Hansen, Thomas: Access to Asylum: International Refugee Law and the Globalization of Migration Control, Cambridge University Press, 2011; y Milanovic, Marko: Extraterritorial Application of Human Rights Treaties: Law, Principles, and Policy. Oxford University Press, 2011; Den Heijer, Maarten y Lawson, Rick: "Extraterritorial Human Rights and the Concept of Jurisdiction", en Langford, M. et. al (eds): Global Justice, State Duties, The Extraterritorial Scope of Economic, Social and Cultural Rights in International Law, Cambridge Unviersity Press, 2013, pp. 153-191.
} 


\section{CAPÍTULO 1}

este campo destacan los trabajos sobre la deriva securitaria de la política migratoria europea, como los efectuados por Sergio Carrera, Elspeth Guild, Didier Bigo o María Teresa Gil-Bazo ${ }^{45}$. La inexistencia hasta hace unos pocos años de una política marítima común europea también han sido la causa de una escasa bibliografía que tenga en cuenta ambos regímenes legales, el DIDH y el del Mar. En este sentido debemos destacar los trabajos de Efthymios Papastavridis, cuyos análisis ocuparan un espacio relevante en el cuarto capítulo ${ }^{46}$.

La presente tesis no es, pues, la primera que trata de indagar sobre estas cuestiones. Los textos que arriba he reseñado no son más que una parte, en mi opinión la más significativa, de una profusa literatura que ha cubierto los distintos aspectos de la problemática aquí tratada: la política migratoria y de asilo europea, la responsabilidad internacional de los Estados cuando actúa más allá de sus fronteras, las operaciones de salvamento e interceptación marítimo, las obligaciones ante el desembarco de personas refugiadas, etc... El enfoque del que han partido la mayor parte de estas investigaciones tratan de aproximarse a la cuestión desde una perspectiva concreta. Tal como he indicado en esta introducción, esto dificulta completar un análisis dada la realidad sumamente compleja, en la que coexisten distintos regímenes jurídicos, actores con intereses enfrentados y situaciones poco definidas normativamente que permiten un amplio margen a la arbitrariedad o incluso propician la comisión actividades ilícitas. En este sentido, la investigación que aquí se presenta trata de emplear las aportaciones de los distintos autores y organizaciones para avanzar en una comprensión integral de la problemática. Todo con el propósito final de que ésta sirva para fortalecer y promover la protección de los derechos humanos de las personas migrantes y refugiadas.

\footnotetext{
${ }^{45}$ Carrera, Sergio: The EU Border Management Strategy. FRONTEX and the Challenges of Irregular Immigration in the Canary Islands, CEPS Working Doc. No. 261, marzo de 2007; Guild, Elspeth y Carrera, Sergio: EU Borders and their Controls. Preventing unwanted movement of people in Europe?, Centre for European Policy Studies, no. 6, 14 de noviembre de 2013; Guild, Elspeth y Bigo, Didier: "The Transformation of European Border Control", en Ryan, Bernard y Mitsilegas, Valsamis (eds.): Extraterritorial Immigration Control. Legal Challenges, Leiden, Koniklijke Brill, 2010; Gil-Bazo, María Teresa: The Practice of Mediterranean States in the context of the European Union's

Justice and Home Affairs External Dimension. The Safe Third Country Concept Revisited, International Journal of Refugee Law, vol. 19, no. 3-4, 2006, pp. 571-600.

${ }^{46}$ Aquí debemos citar en especial los trabajos de Efthymios Papastavridis: Rescuing Migrants at Sea: The Responsibility of States under International Law, Working Paper Series Social Science Research Network, septiembre de 2011. Disponible https://www.researchgate.net/publication/228275123 Rescuing Migrants at Sea The Responsibility of States Under International Law (Consulta: 15 de diciembre de 2015); y The Interception of Vessels on the High Seas: Contemporary Challenges to the Legal Order of the Oceans, Bloomsbury Publishing, n 4, 2014.
} 
$\sum$ Capítulo 2

La política migratoria y de asilo en la Unión Europea 



\section{La política migratoria y de asilo de la Unión Europea}

\subsection{La comunitarización de la política migratoria}

\subsubsection{Los antecedentes de la cooperación intergubernamental}

En su origen, las comunidades europeas que surgieron tras la Segunda Guerra Mundial tenían como objetivo el mantenimiento de la paz y el desarrollo económico. El Tratado de Roma de 1957 no incluyó ninguna referencia sobre políticas de asilo, migración o fronteras. El objetivo original de las comunidades europeas era la creación de un mercado común, lo que implicaba "la supresión, entre los Estados miembros, de los obstáculos a la libre circulación de personas, servicios y capitales" ${ }^{47}$. No obstante, en la parte normativa el tratado solamente constataba la libre circulación de los trabajadores nacionales de los Estados Miembros ${ }^{48}$. Mientras, quedaba bajo competencia nacional "las disposiciones legales, reglamentarias y administrativas que prevean un régimen especial para los extranjeros y que estén justificadas por razones de orden público, seguridad y salud públicas" ${ }^{\prime 9}$. Durante las primeras décadas de su existencia, las comunidades europeas no entraron a valorar las facultades estatales respecto de los extranjeros comunitarios, los refugiados o la gestión de sus fronteras.

En los años ochenta, renace el debate a nivel europeo sobre cómo avanzar en la libre circulación de los ciudadanos europeos y la eliminación de los controles fronterizos internos. Dos posturas se enfrentaban respecto al alcance de este derecho. Para algunos países (Reino Unido, Irlanda, e Italia), esta libertad sólo debía aplicarse a ciudadanos de los Estados Miembros, lo que suponía mantener los controles de frontera para diferenciar entre nacionales de Estados Miembros y de terceros países. La posición del resto de Estados era la de la eliminación total de las fronteras interiores.

Ante la imposibilidad de alcanzar un acuerdo en el seno de las instituciones comunitarias, 5 estados (Francia, Alemania, Bélgica, Holanda y Luxemburgo) aprobaron el Acuerdo de Schengen el 14 de junio 1985. El Acuerdo creaba un territorio sin fronteras en estos 5 países $^{50}$. Un año después, el Acta Única Europea introducía la

\footnotetext{
47 Tratado Constitutivo de la Comunidad Europea, adoptado el 25 de marzo de 1957 en Roma, art. 3.1.c. Disponible en: http://eur-lex.europa.eu/legalcontent/ES/TXT/?qid=1452297035008\&uri=CELEX:11957E/TXT (Consulta: 9 de enero de 2016)

48 Ibíd., art. 48.2, 52 y 53, donde se emplea la fórmula "nacionales de Estados miembros" en las disposiciones donde se reconoce la libre circulación de personas.

49 Ibíd., art. 56.1

${ }^{50}$ En la práctica el Acuerdo reconocía una realidad existente, puesto que dentro del Benelux ya existía libre circulación de personas, y en julio de 1984 Francia y Alemania habían acordado en Saarbrucken eliminar los controles fronterizos, pacto al que se sumaron los tres Estados del Benelux en octubre.
} 


\section{CAPÍTULO 2}

libre circulación de personas como uno de los cuatro elementos constitutivos del mercado único ${ }^{51}$.

Si bien la finalidad del Acuerdo de Schengen ${ }^{52}$ era establecer la libre circulación de movimiento en Europa, eliminando las fronteras entre los Estados Miembros, tuvo una gran importancia para la integración de las políticas de asilo, inmigración y fronteras exteriores. Los gobiernos europeos entendieron que la eliminación de las fronteras interiores hacía necesaria la introducción de las llamadas "medidas compensatorias". Estas incluían un reforzamiento de las fronteras exteriores y un aumento en la cooperación en las políticas de inmigración y asilo, con el objetivo de prevenir posibles "consecuencias no deseadas" de la libre circulación. La introducción de las políticas migratorias y de asilo no estuvo, por tanto, motivada por el interés en desarrollar medidas de protección más eficaces para los refugiados a través de la cooperación interestatal. Los gobiernos estaban pensando, sobre todo, en la seguridad y la lucha contra la delincuencia transnacional que, temían, podía incrementarse con el fin de las fronteras interiores. A partir de entonces las políticas referidas a migración irregular y asilo siempre se han tomado bajo el ámbito de decisión de la seguridad y los asuntos de interior. La implantación del espacio común - o espacio Schengen -, conllevó así mismo un incrementó en la cooperación policial y judicial ${ }^{53}$.

El 19 de junio de 1990 se firmó el Convenio de Schengen, que completaba el acuerdo y definía las condiciones y las garantías de aplicación de está libre circulación. El Convenio introducía las primeras reglas comunes sobre visas, asilo y fronteras. Este Convenio no entró en vigor hasta el 26 de marzo de 1995, ya con la incorporación de Italia, España, Portugal, Grecia y Austria. En el Tratado de Ámsterdam de 1997 el acervo Schengen (entendido como el Acta, el Convenio y todas las normas que lo desarrollaban) se integra en el marco institucional y jurídico de la UE a través de un protocolo anexo.

\footnotetext{
51 Acta Única Europea, firmada en La Haya el 28 de febrero de 1986. DO L 169 de 29 de junio de 1987, pp. 1-29., art. 13, que modifica el art. 8.A del Tratado CEE. Disponible en: http://eur-lex.europa.eu/legalcontent/ES/TXT/PDF/?uri=OJ:L:1987:169:FULL\&from=ES (Consulta: 9 de enero de 2016)

${ }^{52}$ El acuerdo venía acompañado por un Convenio de Aplicación del Acuerdo Schengen (CAAS).

${ }^{53}$ En 1989 se formó el Grupo TREVI '92 a cargo de “las implicaciones del Mercado Único Europeo en el nivel de la seguridad". Los grupos TREVI se habían formado en los años setenta como reuniones informales de los ministros de interior y justicia para incrementar la cooperación intergubernamental en áreas que no eran competencias comunitarias. Originalmente con el propósito de coordinar operaciones contraterroristas (de hecho sus siglas significaban Terrorisme, Radicalisme, Extrémisme et Violence Internationale) con el paso de los años se fueron creando más grupos ad hoc sobre diversas temáticas. Así, al Grupo 3, encargado del crimen organizado internacional, se le encargaron tareas sobre inmigración y control fronterizo hasta que estas pasaron al Grupo TREVI '92. Éste fue el último de estos grupos antes de que se institucionalizaran en el Tratado de Maastricht bajo el área de Justicia y Asuntos de Interior (JAI).
} 


\section{LA POLÍTICA MIGRATORIA Y DE ASILO EN LA UNIÓN EUROPEA}

E1 7 de febrero de 1992 se firma el Tratado de Maastricht ${ }^{54}$, por el que el asilo y la inmigración entraron en el marco competencial de la ahora llamada Unión Europea. Se ubicaron dentro del tercer pilar, de cooperación intergubernamental en los ámbitos de la Justicia y Asuntos de Interior (JAI). La incorporación de estas competencias se justifica dentro de aquellas medidas compensatorias que buscan "la realización de los fines de la Unión, en particular de la libre circulación de personas (...):

1) La política de asilo;

2) Las normas por las que se rigen el cruce de personas por las fronteras exteriores de los Estados miembros y la práctica de controles sobre estas personas.

3) La política de inmigración y la política relativa a los nacionales de terceros Estados acerca de:

a) las condiciones de acceso al territorio de los Estados miembros y de circulación por el mismo de los nacionales de terceros Estados; (...)

c) la lucha contra la inmigración, la estancia y el trabajo irregulares de nacionales de los terceros Estados en el territorio de los Estados miembros" 55

Se establece además la necesidad de adecuar estas cuestiones en el respeto al CEDH y la CG51 ${ }^{56}$. El ámbito político de decisión de estas cuestiones es el Consejo, que precisa de una mayoría de $2 / 3$ en cuestiones de cooperación intergubernamental y de unanimidad en lo relativo a visados y extranjería ${ }^{57}$.

\subsubsection{El derecho originario y la Carta de Derechos Fundamentales}

El Tratado de Ámsterdam ${ }^{58}$, firmado el 2 de octubre de 1997, supuso un gran avance hacia la integración de las políticas sobre control de fronteras, asilo e inmigración. Por

\footnotetext{
${ }^{54}$ Tratado de la Unión Europea, firmado en Maastricht el 7 de febrero de 1992. DO C 191 de 29 de julio de 1992, pp. 1-110. Disponible en: http://eur-lex.europa.eu/legalcontent/ES/TXT/PDF/?uri=OJ:C:1992:191:FULL\&from=ES (Consulta: 9 de enero de 2016)

55 Ibíd., Título VI, Art. K. 1

56 Ibíd., Art. K. 2. 1

${ }^{57}$ Conforme al art. K.9, (la llamada disposición pasarela) los gobiernos contaban con la posibilidad de llevar los temas del JAI al ámbito de la Comunidad, si los miembros del Consejo lo aceptaban unánimemente, pero esta disposición nunca llegó a utilizarse.

58 Tratado de Ámsterdam por el que se modifican el Tratado de la Unión Europea, los Tratados constitutivos de las Comunidades Europeas y determinados actos conexos, firmado el 2 de octubre de 1997. DO C 340 de 10 de noviembre de 1997, pp. 1-144. Disponible en: http://eur-lex.europa.eu/legalcontent/ES/TXT/PDF/?uri=OJ:C:1997:340:FULL\&from=ES (Consulta: 9 de enero de 2016)
} 


\section{CAPÍTULO 2}

primera vez, la Unión Europea se dotaba de competencias para legislar en estas materias, hasta ahora en manos de los Estados Miembros, cuando hasta ahora únicamente podía coordinar políticas nacionales y cooperar en su puesta en práctica. Fija como uno de los objetivos de la Unión "mantener y desarrollar la Unión como un espacio de libertad, seguridad y justicia, en el que esté garantizada la libre circulación de personas conjuntamente con medidas adecuadas respecto al control de las fronteras exteriores, el asilo, la inmigración y la prevención y la lucha contra la delincuencia"59

El título III bis ${ }^{60}$, denominado "Visados, asilo, inmigración y otras políticas relacionadas con la libre circulación de personas" recoge los objetivos de la UE en materia de inmigración y asilo, incluyendo la progresiva armonización de las normativas nacionales, dado que las competencias básicas de extranjería siguen quedando bajo la soberanía de los Estados Miembros. El Tratado otorga al Consejo un plazo de 5 años para adoptar medidas relativas los controles en las fronteras exteriores, el asilo y la inmigración ${ }^{61}$. Entre los objetivos que se debían desarrollar en ese periodo, estaban el establecimiento de normas mínimas para la acogida de los solicitantes de asilo, la protección de personas desplazadas y la repatriación de residentes ilegales ${ }^{62}$, así como la previsión de medidas excepcionales para una situación de emergencia derivada de la llegada repentina de nacionales de terceros países ${ }^{63}$.

De forma paralela, algunas competencias relacionadas con las fronteras y el asilo quedan encuadradas en el tercer pilar, de cooperación policial y judicial en materia penal (Título VI). Este pilar continuará funcionando los próximos años bajo el procedimiento de la cooperación intergubernamental. En 2003 se renombró JAI como Cooperación Policial y Judicial en Materia Criminal. En 2009, con la entrada en vigor del Tratado de Lisboa, el área quedó absorbida dentro de la estructura consolidada de la Unión Europea.

En el año 2000 se firma una revisión del Tratado de la Unión Europea en la Conferencia de Niza, celebrada del 7 al 9 de diciembre de 2000. Si bien no incluye modificaciones sustanciales en las materias pertinentes a este trabajo, durante la

\footnotetext{
${ }^{59}$ Ibíd., art. 1.5

${ }^{60}$ Reino Unido e Irlanda firmaron cláusulas de opt-out a este título, por el que tenían la posibilidad de descolgarse de las decisiones tomadas en base a dicho título, siempre y cuando no fueran medidas relacionadas con el acervo de Schengen. Por su parte Dinamarca no participaba en la adopción de medidas en esta área, excepto nueva mente en las relativas al área Schengen.

${ }^{61}$ Ibíd., art. 73 I.

${ }^{62}$ Art. $73 \mathrm{~K}$

${ }^{63}$ Art. 73 L. 2
} 
Conferencia se aprobó también la Carta de Derechos Fundamentales (CDF) ${ }^{64}$ de la Unión Europea. El ámbito de aplicación de la CDF está dirigido a acciones que provienen o bien de alguna institución europea, o de un Estado parte cuando se encuentra aplicando una norma europea ${ }^{65}$.

La Carta reconoce el derecho de asilo ${ }^{66}$, prohíbe las expulsiones colectivas y garantiza el principio de non-refoulement ${ }^{67}$. Se estipula como criterio de interpretación de los derechos de la CDF que en ningún caso puede rebajarse la protección mínima que establece otros instrumentos nacionales o internacionales, entre los que cita expresamente el $\mathrm{CEDH}^{68}$. Esta disposición consta de una gran importancia, ya que como veremos la jurisprudencia del TEDH en materia de asilo es larga y, en muchos aspectos, con unos estándares de protección de derechos más elevados que el derecho comunitario.

Aunque nacida como una simple declaración de derechos, el Tratado de Lisboa modificó su estatuto otorgándole carácter vinculante. Desde entonces las instituciones de la UE y los EEMM están obligados a respetar la Carta en el proceso de aplicación del derecho comunitario ${ }^{69}$. Si bien Reino Unido y Polonia consiguieron que se añadiera un protocolo de interpretación de la Carta en relación a su normativa interna, el TJUE sostuvo que dicho protocolo no afectaba a sus obligaciones internacionales en materia de asilo $^{70}$.

En 2007 se firma el Tratado de Lisboa ${ }^{71}$, que refunda el derecho derivado de la UE, agrupándolo en dos tratados: el Tratado de la Unión Europea (TUE) ${ }^{72}$ y el Tratado de

\footnotetext{
${ }^{64}$ Carta de los Derechos Fundamentales de la Unión Europea (versión consolidada). DO C 362 de 26 de octubre de 2012, pp. 391-407. Disponible en: http://eur-lex.europa.eu/legalcontent/ES/TXT/PDF/?uri=OJ:C:2012:326:FULL\&from=ES (Consulta: 9 de enero de 2016)

${ }^{65}$ Ibíd., art. 51.1

${ }^{66}$ Ibíd., art. 18

${ }^{67}$ Ibíd., art. 19

${ }^{68}$ Ibíd., art. 52

${ }^{69}$ Tratado de la Unión Europea (versión consolidada). DO C 326 de 26 de octubre de 2012, pp. 13-46, art. 6.1. Disponible en: http://eur-lex.europa.eu/legalcontent/ES/TXT/PDF/?uri=OJ:C:2012:326:FULL\&from=ES (Consulta: 9 de enero de 2016)

${ }^{70}$ TJUE, "M. S. contra Secretary of State for the Home Department" (C-411/10) y "M. E. y otros contra Refugee Applications Commissioner y Minister for Justice, Equality and Law Reform" (C-493/10), sentencia del 21 de diciembre de 2011, § 4. Disponible en: http://curia.europa.eu/juris/document/document.jsf;jsessionid=9ea7d0f130d53bb3aa2f16544603800dbad2 974ed23d.e34KaxiLc3eQc40LaxqMbN4Oc3uPe0?text=\&docid=117187\&pageIndex=0\&doclang=ES\&m ode $=1$ st\&dir $=\&$ occ $=$ first\&part $=1 \&$ cid $=618311$ (Consulta: 9 de enero de 2016)

${ }_{71}$ Tratado de Lisboa, por el que se modifican el Tratado de la Unión Europea y el Tratado constitutivo de la Comunidad Europea, firmado el 13 de diciembre de 2007. DO C 306 de 17 de diciembre de 2007, pp. 1-271. Disponible en: http://eur-lex.europa.eu/legalcontent/ES/TXT/PDF/?uri=OJ:C:2007:306:FULL\&from=ES (Consulta: 9 de enero de 2016)
} 


\section{CAPÍTULO 2}

Funcionamiento de la Unión Europea $(T F U E)^{73}$. Son los últimos tratados "constituyentes" firmados por la UE y por tanto que se encuentran en vigor. Aparecen nuevas disposiciones relativas al asilo y la inmigración ${ }^{74}$.

El ESLJ queda definido como "un espacio de libertad, seguridad y justicia sin fronteras interiores, en el que esté garantizada la libre circulación de personas conjuntamente con medidas adecuadas en materia de control de las fronteras exteriores, asilo, inmigración y de prevención y lucha contra la delincuencia"75 La competencia sigue siendo compartida entre la UE y los EEMM. En el Cap. 2 del Título $\mathrm{V}$ del TFUE se encuentran las disposiciones relativas a las fronteras ${ }^{76}$, asilo $^{77}$, e inmigración ${ }^{78}$. Así mismo, se modifican las bases jurídicas que permite la adopción de normas en este campo, internamente con la adopción del procedimiento legislativo ordinario (PLO) como método de toma de decisiones ${ }^{79}$; y externamente con la habilitación a la UE para celebrar acuerdos de readmisión con terceros Estados ${ }^{80}$.

Resulta de gran importancia también que por primera vez se le otorga al TJUE plena aplicación de la jurisdicción en esta materia. Sin embargo, se excluye de su competencia el examen de la validez o proporcionalidad de las operaciones efectuadas por la policía $\mathrm{u}$ otros servicios con funciones coercitivas de un EM en relación a las políticas migratorias y fronterizas ${ }^{81}$. Como veremos más adelante, el uso desproporcionado de la fuerza contra migrantes irregulares y refugiados en el control fronterizo marítimo ha sido denunciado por ONGs y el Consejo de Europa, especialmente en el caso de Grecia.

\footnotetext{
72 TUE, ibídem.

${ }^{73}$ Tratado de Funcionamiento de la Unión Europea (versión consolidada). DO C 326 de 26 de octubre de 2012, pp. 47-390- Disponible en: http://eur-lex.europa.eu/legalcontent/ES/TXT/PDF/?uri=OJ:C:2012:326:FULL\&from=ES (Consulta: 9 de enero de 2016)

${ }_{74}$ Dinamarca, Irlanda y el Reino Unido solicitaron cláusulas de exclusión en materia de asilo, visas e inmigración (Protocolo 19, art. 3 y 4)

75 TUE, art. 3.2

76 TFUE. art. 77. Definen tres objetivos de la política comunitaria: a) garantizar la ausencia total de controles de las personas, sea cual sea su nacionalidad, cuando crucen las fronteras interiores; b) garantizar los controles de las personas y la vigilancia eficaz en el cruce de las fronteras exteriores; c) instaurar progresivamente un sistema integrado de gestión de las fronteras exteriores.

${ }^{77}$ Ibíd., art. 78. Delimita como objetivos de la `política común de asilo: ofrecer un estatuto apropiado a todo nacional de un tercer país que necesite protección internacional y a garantizar el respeto del principio de no devolución

${ }^{78}$ Ibíd., art. 79. En este caso, los objetivos de la política migratoria son tres: una gestión eficaz de los flujos migratorios, un trato equitativo de los nacionales de terceros países que residan legalmente en los Estados miembros, así como una prevención de la inmigración ilegal y de la trata de seres humanos y una lucha reforzada contra ambas.

${ }^{79}$ En el PLO o codecisión, el Parlamento actúa como colegislador y el Consejo debe adoptar sus acuerdos por mayoría cualificada (doble mayoría) Es previsible que a partir de esta fecha, en un proceso legislativo sin derecho a veto, será más fácil aprobar una legislación de mayor calidad, así como que la armonización entre las legislaciones nacionales sea más alta.

80 TFUE, art. 79.3

${ }^{81}$ Ibíd., Art. 276
} 
Por último, destacar que el Tratado de Lisboa señala que la Unión se adherirá como miembro al $\mathrm{CEDH}^{82}$. Actualmente el proceso de adhesión al Convenio se encuentra encallado, tras un dictamen del TJUE que considera el proyecto de adhesión al Convenio que había impulsado la Comisión incompatible con el acervo comunitario ${ }^{83}$.

\subsubsection{Los programas de Tampere, La Haya y Estocolmo}

Tras la aprobación del Tratado de Ámsterdam, la política migratoria y de asilo se ha venido desarrollando a través de una serie de planes multianuales encargados de implementar a nivel político y legislativo los objetivos del área de ESLJ. En el presente capítulo, me centraré en las políticas implementadas en el área migratoria, deteniendo especialmente en aquellas normas que tengan especial incidencia en el objeto de este trabajo. Dejaré el relato de la construcción del Sistema Europeo Común de Asilo (SECA) en un capítulo específico dada su importancia.

Coincidiendo con la entrada en vigor del Tratado de Ámsterdam, los días 15 y 16 de octubre 1999 se celebró el Consejo Europeo de Tampere, dedicado a establecer las directrices políticas que desarrollarían el ESLJ en los próximos cinco años. El Consejo definió varias líneas estratégicas, entre ellas la creación de un sistema común de asilo y el combate de la inmigración irregular ${ }^{84}$. Estas líneas se plasmarían en la aprobación de las nuevas directivas de asilo y la reforma del reglamento de Dublín, así como la Directiva 2002/90/CE, destinada a definir la ayuda a la entrada, a la circulación y a la estancia irregular.

La Comisión reconoció en su balance del programa de Tampere con claroscuros en lo relativo a los avances del Programa, señalando específicamente que "las obligaciones derivadas del proceso de toma de decisiones y el contexto institucional actual constituyeron un obstáculo para el cumplimiento eficaz, rápido y transparente de

\footnotetext{
${ }^{82}$ TUE, art. 6.2. Por su parte, el Protocolo ${ }^{\circ} 14$ del CEDH ya había introducido las modificaciones necesarias para que esta adhesión pudiera producirse.

${ }^{83}$ TJUE, Comunicado de Prensa $\mathrm{n}^{\circ}$ 180/2014, Luxemburgo, 18 de diciembre de 2014. Disponible en: http://curia.europa.eu/jcms/upload/docs/application/pdf/2014-12/cp140180en.pdf (Consulta: 9 de enero de 2016)

${ }^{84}$ Comunicación de la Comisión al Consejo y al Parlamento Europeo, de 22 de noviembre de 2000, sobre una política comunitaria de migración (COM (2000) 757 final). Disponible en: http://eurlex.europa.eu/LexUriServ/LexUriServ.do?uri=COM:2000:0757:FIN:ES:PDF (Consulta: 9 de enero de 2016)
} 


\section{CAPÍTULO 2}

determinados compromisos políticos" $"$. Las nuevas normas aprobadas contaban con un bajo grado de concreción, permitiendo una amplia libertad de los EEMM en el desarrollo de sus políticas migratorias y de asilo. Dado que durante este periodo, la iniciativa legislativa era compartida por la Comisión y el Consejo, el Parlamento quedaba con un rol puramente consultivo. Además, las decisiones en el Consejo debían de ser tomadas por unanimidad ${ }^{86}$. Esto tuvo como consecuencia que las propuestas que se acabaron aprobando fueran de un alcance limitado, fruto de ser el resultado de acuerdos de mínimos entre gobiernos con pocos incentivos para llegar a entendimientos.

Coincidiendo con el fin del programa de Tampere y el inicio del de La Haya, en mayo de 2004 vence el periodo de transición fijado por el Tratado de Ámsterdam, y se introducen así mismo modificaciones en los procedimientos de voto que se habían establecido en el Tratado de Niza, especialmente en el área del asilo. Así, la Comisión Europea obtuvo de forma exclusiva el derecho de iniciativa, y el Parlamento Europeo aumento su participación en la formulación de las políticas. En cuanto al Consejo, si bien se mantuvo el procedimiento por unanimidad para definir las normas comunes y principios básicos (que en la práctica ya habían sido definidos en Ámsterdam), para el resto de votaciones se adoptó el voto por mayoría cualificada y por decisión compartida con el Parlamento.

En noviembre de 2004 el Consejo Europeo aprobaba el denominado Programa de La Haya (2005-2009), inicialmente conocido también como Tampere II. Entre los objetivos fijados citaba: "proporcionar a quienes la necesiten la protección de acuerdo con la Convención de Ginebra sobre el estatuto de los refugiados y otros tratados internacionales, regular los flujos de migración y controlar las fronteras exteriores de la Unión, luchar contra la delincuencia organizada transfronteriza y reprimir la amenaza del terrorismo" $" 87$. Este programa también introduce una nueva línea de actuación, que pone el énfasis en el carácter global del fenómeno migratorio ${ }^{88}$, incluyendo de forma creciente la cooperación con los países de origen y tránsito en la

${ }^{85}$ Comunicación de la Comisión al Consejo y al Parlamento Europeo, del 2 de junio de 2004, Espacio de Libertad, Seguridad y Justicia: balance del programa de Tampere y futuras orientaciones $(\mathrm{COM} / 2004 / 0401$ final), p. 4. Disponible en: http://eur-lex.europa.eu/legalcontent/ES/TXT/PDF/?uri=CELEX:52004DC0401\&rid=1 (Consulta: 9 de enero de 2016)

86 Tratado de Ámsterdam, art. 73 O.1

${ }^{87}$ Comunicación de la Comisión al Consejo y al Parlamento Europeo, de 10 de mayo de 2005, Programa de La Haya: Diez prioridades para los próximos cinco años. Una asociación para la renovación europea en el ámbito de la libertad, la seguridad y la justicia (COM (2005) 184 final). Disponible en: http://eurlex.europa.eu/legal-content/ES/TXT/PDF/?uri=CELEX:52005DC0184\&from=ES (Consulta: $9 \overline{\text { de enero }}$ de 2016)

${ }^{88} \mathrm{La}$ estrategia desarrollada por la UE se denomina Global Approach to Migration, definida por el Consejo en el documento Enfoque global de la migración: medidas prioritarias centradas en África y el Mediterráneo, Documento del Consejo $\mathrm{n}^{\mathrm{o}}$ 15744/05, 13 de diciembre de 2005. . Disponible en: http://register.consilium.europa.eu/doc/srv?l=ES\&f=ST\%2015744\%202005\%20INIT (Consulta: 9 de enero de 2016) 
gestión de los flujos migratorios, el control de las fronteras marítimas y la migración irregular y la responsabilidad respecto de los solicitantes de asilo.

La reforma de más calado durante este periodo fue "Directiva del retorno" 89 , destinada a fijar unas normas comunes en materia de expulsión de nacionales de terceros países en situación irregular. La más importante fue el periodo máximo de internamiento en un centro, que podía llegar a extenderse bajo unos supuestos a 18 meses $^{90}$. Al determinar su ámbito de aplicación, permite que los EEMM excluyan de sus derechos y garantías a aquellos extracomunitarios que "sean detenidos o interceptados por las autoridades competentes con ocasión del cruce irregular de las fronteras exteriores terrestres, maritimas o aéreas de un Estado miembro y no hayan obtenido ulteriormente una autorización o derecho de estancia en dicho Estado miembro" "91, así como a los solicitantes de asilo $^{92}$. Sin embargo, algunas de las disposiciones reconocidas en la Directiva sí que han sido adoptadas por el TJUE y los tribunales de distintos países cuando tenía un estándar de protección más alto que otras normas aplicables.

En materia de control de fronteras, la creación de la agencia Frontex y las primeras operaciones conjuntas llevadas a cabo situaron la cuestión de las llegadas de embarcaciones en el primer plano de la agenda europea. En los capítulos siguientes profundizaré en estas cuestiones.

A nivel político, reviste gran importancia el Pacto Europeo sobre inmigración y asilo $^{93}$, aprobado en el Consejo Europeo de 15-16 de octubre de 2008. Se fijaron cinco grandes objetivos que debían orientar la acción europea en los siguientes años: organizar la inmigración legal, combatir la inmigración ilegal (garantizando el regreso de los irregulares, y firmando acuerdos de readmisión), reforzar la eficacia de los controles de frontera; erigir una "Europa del asilo" con el fin de instaurar en 2012 un procedimiento de asilo único y potenciar la cooperación con terceros países.

\footnotetext{
${ }^{89}$ Directiva 2008/115/CE del Parlamento Europeo y del Consejo, de 16 de diciembre de 2008, relativa a normas y procedimientos comunes en los Estados miembros para el retorno de los nacionales de terceros países en situación irregular. DO L 348 de 24 de diciembre de 2008, pp. 98-107. Disponible en: http://eurlex.europa.eu/legal-content/ES/TXT/PDF/?uri=CELEX:32008L0115\&rid=1 (Consulta: 9 de enero de 2016)

${ }^{90}$ Ibíd., art. 15.6

${ }^{91}$ Ibíd., art. 2. a)

${ }^{92}$ Ibíd., art. 4.2

${ }^{93}$ Consejo de la Unión Europea: Pacto Europeo sobre inmigración y asilo, Bruselas 24 de septiembre de 2008, $\mathrm{n}^{\mathrm{o}}$ doc. $13189 / 08$ ASIM 68.2 Disponible en: http://register.consilium.europa.eu/doc/srv?l=ES\&f=ST\%2013440\%202008\%20COR\%204 (Consulta: 9 de enero de 2016)
} 


\section{CAPÍTULO 2}

El Programa de Estocolmo fue aprobado en la reunión del Consejo Europeo del 14 y 15 de diciembre de 2009, determinando el curso y la legislación de las políticas de inmigración y asilo en la Unión Europea entre 2010 y 2014 ${ }^{94}$. La principal línea de actuación del Programa de Estocolmo fue el desarrollo del Pacto Europeo sobre Inmigración y Asilo. Para las políticas de asilo, el programa se fijó como meta el establecimiento definitivo del SECA, definiendo su objetivo clave establecer estándares más altos de protección y asegurar que casos similares eran tratados y solventados de forma similar, independientemente del EM en que la solicitud sea presentada.

El Programa de Estocolmo ha sido considerado menos efectivo que sus predecesores $^{95}$. La mayor parte de las medidas adoptadas eran reformas de directivas y otras normas a existentes, así como la implementación definitiva del SECA, ya planteada con anterioridad y puesta en marcha con retraso. Los nuevos desarrollos se limitan a incorporar bases de datos como el SIS (Schengen Information System) y el VIS (Visa Information System).

\subsection{EI Sistema Europeo Común de Asilo}

Durante muchas décadas del siglo $\mathrm{XX}$ el asilo se consideró un fenómeno mayoritariamente europeo, tanto numéricamente como por la influencia histórica y política que tuvo. Sin embargo, hasta fechas muy recientes el asilo se desarrolló estrictamente en cada ámbito nacional. A partir de los años ochenta se produjeron una serie de factores que incentivaron a los estados europeos a negociar unos criterios mínimos compartidos para la regulación del asilo.

Por una parte, como vimos en el apartado anterior, la aprobación del Acuerdo de Schengen incluía el reforzamiento de la cooperación en políticas de asilo como una de las medidas compensatorias a la supresión de las fronteras exteriores. Por otro lado, la caída del muro de Berlín facilitó el acceso desde los países de Europa oriental, lo que

\footnotetext{
94 Comunicación de la Comisión al Parlamento Europeo, al Consejo, al Comité Económico y Social Europeo y al Comité de las Regiones, de 20 de abril de 2010 - Garantizar el espacio de libertad, seguridad y justicia para los ciudadanos europeos - Plan de acción por el que se aplica el Programa de

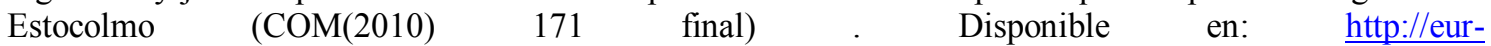
lex.europa.eu/LexUriServ/LexUriServ.do?uri=COM:2010:0171:FIN:es:PDF (Consulta: 9 de enero de 2016)

95 Vid. Collett, Elizabeth: Future EU policy development on immigration and asylum: Understanding the challenge. Migration Policy Institute, Policy Brief Series, no. 4, mayo de 2014. Disponible en: http://www.migrationpolicy.org/research/future-eu-policy-development-immigration-and-asylumunderstanding-challenge (Consulta: 9 de enero de 2016)
} 
hizo temer a los gobiernos occidentales con una avalancha de solicitantes de asilo ${ }^{96}$. Las guerras balcánicas de los años noventa produjeron la primera crisis de refugiados en el continente desde el fin de la II Guerra Mundial. Además, se produjo un cambio en la percepción de los solicitantes de asilo, que pasaron de ser vistos como víctimas de la represión de los regímenes comunistas a ser asimilados con los migrantes económicos. Las preocupaciones que estaban en la base de la discusión política pasaron de tener que ver con cuestiones humanitarias a estar relacionadas con la seguridad nacional y las amenazas al estado del bienestar ${ }^{97}$ Este contexto político tuvo que ver con el establecimiento de una base ideológica restrictiva en la implantación del sistema de asilo europeo. Los principales aspectos en los que los estados europeos querían ponerse de acuerdo eran en el reparto de cargas ("burden-sharing"), la intención de atacar el fraude en las solicitudes de asilo ${ }^{98}$, la agilización de las expulsiones de los solicitantes rechazados o el desarrollo de los sistemas de asilo en terceros países.

Con el fin de ofrecer una mejor explicación al proceso de construcción del SECA, dividiré este apartado en tres fases que se corresponden con los tres grandes periodos de reforma normativa, a los que he nombrado con referencias al principal elemento de estas, el Convenio y Reglamento de Dublín.

\subsubsection{Dublín I.}

El Convenio de Dublín se aprobó el 15 de junio de 1990, entrando en vigor el 1 de septiembre de $1997^{99}$. La disposición más relevante introducida por el Convenio fue el principio de que el Estado de entrada del refugiado era el responsable del examen de su solicitud de asilo ${ }^{100}$. La premisa en la que se basa el sistema es la concepción de los solicitantes de asilo como una carga para el Estado que acepta la entrada. El primer rasgo común del sistema de Dublín es el reconocimiento mutuo de las decisiones

\footnotetext{
${ }^{96}$ Vid. Hattrell, Felicity: Redefining the Limits of Refugee Protection? The Securitised Asylum Policies of the 'Common European Asylum System'. National Centre for Research on Europe, University of Canterbury, diciembre de 2010, pp. 3-8

${ }^{97}$ Vid. Huysmans, Jeff: The European Union and the Securitization of Migration, Journal of Common Market Studies, Vol. 38, No. 5, 2010, pp. 751-777. Disponible en: http://onlinelibrary.wiley.com/doi/10.1111/1468-5965.00263/pdf (Consulta: 10 de enero de 2016)

98 Conocido como "asylum shopping", según el cual algunos solicitantes de asilo realizaban múltiples peticiones de asilo en diferentes países, por regla general tras serles denegadas en su primer intento, con el fin de tener más opciones de conseguir una respuesta positiva.

${ }^{99}$ Los países que se habían incorporado a la Unión en 1995 tuvieron un pequeño retraso para la entrada en vigor: el 1 de octubre de 1997 para Austria y Suecia y el 1 de enero de 1998 para Finlandia. El 1 de abril de 2001 se incorporaron dos Estados europeos no comunitarios, Islandia y Noruega.

${ }^{100}$ Convenio relativo a la determinación del Estado responsable del examen de las solicitudes de asilo presentadas en los Estados miembros de las Comunidades Europeas, firmado en Dublín el 15 de julio de 1990. DO C 254 de 19 de agosto de 1997, pp. 1-12, art. 6. Disponible en: http://eur-lex.europa.eu/legalcontent/ES/TXT/PDF/?uri=CELEX:41997A0819\%2801\%29\&from=ES (Consulta: 10 de enero de 2016)
} 


\section{CAPÍTULO 2}

negativas, incluso cuando los procedimientos de reconocimiento de estatus permanecen a nivel nacional y se permite una amplia disparidad entre sistemas nacionales. A su vez, se reconocía implícitamente que los Estados parte del sistema de Dublín pasaban a ser considerados países seguros.

Este hecho supuso un cambio radical en los países del sur de Europa. Tradicionalmente los refugiados preferían solicitar asilo en países del norte y centro, dado que tenían sistemas de asilo más desarrollados y niveles de vida más alto, que permitían mayores oportunidades de futuro para los recién llegados. Los países de la Europa meridional tenían un número de refugiados reducido, sistemas de revisión de las solicitudes poco desarrollados y políticas de integración casi inexistentes. Con la entrada en vigor del Convenio, tuvieron que mejorar sus sistemas de asilo e integración para hacer frente al creciente número de solicitudes. Este fenómeno también se ha producido, años después, en los países del este de Europa, anteriormente generadores de refugiados que escapaban de las dictaduras comunistas y ahora responsables de los refugiados que, llegan de Asia y antiguas repúblicas soviéticas.

Durante el interregno entre la aprobación del Convenio y su entrada en vigor en 1997, los EEMM llegaron a una serie de acuerdos en el marco de la cooperación intergubernamental. En 1992 se acuerdan en el Consejo Europeo las llamadas "London Resolutions" "101, específicas para los "terceros países seguros"102. Establecía un procedimiento abreviado armonizado para rechazar las peticiones manifiestamente infundadas. Los estados firmantes acordaron unos criterios para designar a un tercer país no comunitario como "seguro" y que por lo tanto debía ser responsable de examinar la solicitud de asilo y, en su caso, ofrecer protección internacional. De la misma forma establecía una conclusión sobre los "países seguros de origen", en los cuales las solicitudes de solicitantes provenientes de estos países debían ser consideradas como "manifiestamente infundadas" a menos que pudiera demostrar que el país de origen no era seguro en su caso particular. Estas resoluciones se complementan con la aprobación de otras dos resoluciones sobre el reparto de cargas ${ }^{103}$, y sobre a las

\footnotetext{
101 Resolución de 30 de noviembre de 1992 sobre las solicitudes de asilo manifiestamente infundadas; Resolución de 30 de noviembre de 1992 sobre un enfoque armonizado de las cuestiones relativas a los terceros países de acogida; Conclusiones de 30 de noviembre de 1992 relativas a los países en que, por regla general, no existen serios riesgos de persecución. Disponibles en: http://eur-lex.europa.eu/legalcontent/ES/TXT/HTML/?uri=URISERV:133102\&from=ES (Consulta: 10 de enero de 2016)

${ }_{102}$ País seguro es definido como aquel en el que "se aprecia, a través de un procedimiento objetivo y verificable, que normalmente no produce refugiados, o que se puede claramente apreciar, por procedimientos objetivos y verificables que las circunstancias que en el pasado justificaban el recurso a la Convención de Ginebra de 1951 han dejado de existir".

${ }^{103}$ Resolución del Consejo de 4 de marzo de 1996 sobre el reparto de cargas en relación con la acogida y la estancia, con carácter temporal, de las personas desplazadas. DO L 63, de 13 de marzo de 1996, pp. 1011. Disponible: en http://eur-lex.europa.eu/legal-
} 
garantías mínimas aplicables al procedimiento de asilo ${ }^{104}$, que significaron unos tímidos precedentes a las Directivas de asilo del siguiente periodo.

\subsubsection{Dublín II}

Con el Tratado de Ámsterdam el asilo pasó del área de cooperación intergubernamental a ser una competencia compartida entre la UE y los EEMM, bajo el área del Espacio de Libertad, Seguridad y Justicia. Uno de los objetivos del Programa de Tampere era la creación de un Sistema Europeo Común de Asilo (SECA) ${ }^{105}$. En 2003 la Comisión fija los tres objetivos del nuevo planteamiento europeo sobre asilo: “1) la llegada ordenada y gestionada de las personas necesitadas de protección internacional a la UE desde la región de origen; 2) el reparto de la carga y las responsabilidades tanto dentro de la UE como con las regiones de origen, que permita proporcionar una protección efectiva, lo más rápidamente posible y teniéndose en cuenta en la mayor medida posible las necesidades de las personas necesitadas de protección internacional y 3) el desarrollo de un planteamiento integrado de procedimientos eficientes y ejecutorios de adopción de decisiones y retorno en materia de asilo" ${ }^{\prime 06}$.

Estos tres objetivos serán los fundamentos del primer paquete legislativo del SECA. Se aprobaron tres directivas (sobre procedimientos de asilo ${ }^{107}$, sobre condiciones de acogida $^{108}$ y sobre requisitos ${ }^{109}$ ) y el Reglamento de Dublín ${ }^{110}$ que se mantendrían en

content/ES/TXT/PDF/?uri=CELEX:31996D0198\&qid=1452382990689\&from=EN （Consulta: 10 de enero de 2016)

${ }^{104}$ Resolución del Consejo de 20 de junio de 1995 relativa a las garantías mínimas aplicables al procedimiento de asilo. DO C 274, de 19 de septiembre de 1996, pp. 13-17. Disponible: en http://eurlex.europa.eu/legal-content/ES/TXT/PDF/?uri=CELEX:31996Y0919\%2805\%29\&from=ES (Consulta: 10 de enero de 2016)

${ }^{105}$ En las conclusiones del Consejo de Tampere se acordaba "trabajar con vistas a la creación de un sistema europeo común de asilo, basado en la plena y total aplicación de la Convención de Ginebra; de ese modo, se logrará que ninguna persona sea repatriada a un país en que sufre persecución, lo que significa que se observará el principio de no devolución." (COM (2000) 757 final, op. cit., para. 13)

${ }^{106}$ Comunicación de la Comisión al Consejo y al Parlamento Europeo, del 3 de junio de 2003, Hacia sistemas de asilo mejor gestionados, más accesibles y equitativos (COM/2003/315 final), p. 14. Disponible en: http://eur-lex.europa.eu/legalcontent/ES/TXT/PDF/?uri=CELEX:52003DC0315\&qid=1452383629649\&from=EN (Consulta: 10 de enero de 2016)

107 Directiva 2005/85/CE, del Consejo, de 1 de diciembre de 2005, sobre normas mínimas para los procedimientos que deben aplicar los Estados miembros para conceder o retirar la condición de refugiado. DO L 326 de 13 de diciembre de 2005, pp. 13-34. Disponible en: http://eur-lex.europa.eu/legalcontent/ES/TXT/PDF/?uri=CELEX:32005L0085\&from=ES (Consulta: 10 de enero de 2016)

${ }_{108}$ Directiva 2003/9/CE, del Consejo, de 27 de enero de 2003, por la que se aprueban normas mínimas para la acogida de los solicitantes de asilo en los Estados miembros. DO L 31 de 6 de febrero de 2003, pp. 


\section{CAPÍTULO 2}

vigor durante una década aproximadamente. Las nuevas normas fijaban una serie de estándares mínimos para los EEMM, pero estaban lejos de crear un verdadero sistema europeo de asilo ${ }^{111}$. La directiva de procedimientos, por ejemplo, estaba más cerca de constituir una colección de diversas prácticas nacionales antes que una serie de reglas comunes. Como aspectos complementarios a las nuevas directivas, se produjeron varias reformas menores, como la base de datos Eurodac ${ }^{112}$ y los primeros pasos hacia la externalización del asilo con los Programas Europeos de Protección Regional (más conocidos por sus siglas en inglés; RPP) $)^{113}$.

Durante esta fase la UE profundiza en la política de externalización del asilo, a través de la asunción de competencias por parte de los Estados de tránsito y de origen. Siguiendo la célebre definición de Gammeltoft-Hansen, el control fronterizo ha sido "offshored and outsourced"114, esto es, externalizado más allá del territorio y privatizado fuera del control del Estado. A medio y largo plazo se buscaba que estos países pudieran desarrollar sistemas de asilo que les permitieran ser considerados "terceros países seguros" y por tanto poder desestimar las solicitudes de aquellas

18-25. Disponible en: http://eur-lex.europa.eu/legal-

content/ES/TXT/PDF/?uri=CELEX:32003L0009\&from=ES (Consulta: 10 de enero de 2016)

${ }^{109}$ Directiva 2004/83/CE del Consejo, de 29 de abril de 2004, por la que se establecen normas mínimas relativas a los requisitos para el reconocimiento y el estatuto de nacionales de terceros países o apátridas como refugiados o personas que necesitan otro tipo de protección internacional y al contenido de la protección concedida. DO L 304 de 30 de noviembre de 2004, pp. 12-23. Disponible en: http://eurlex.europa.eu/legal-content/ES/TXT/PDF/?uri=CELEX:32004L0083\&from=ES (Consulta: 10 de enero de 2016)

${ }^{110}$ Reglamento (CE) $\mathrm{n}^{\circ} 343 / 2003$ del Consejo, de 18 de febrero de 2003, por el que se establecen los criterios y mecanismos de determinación del Estado miembro responsable del examen de una solicitud de asilo presentada en uno de los Estados miembros por un nacional de un tercer país. DO L 50 de 25 de febrero de 2003, p. 1-10. Disponible en: http://eur-lex.europa.eu/legalcontent/ES/TXT/PDF/?uri=CELEX:32003R0343\&from=ES (Consulta: 10 de enero de 2016)

${ }^{111}$ Un análisis detallado de estas directivas en el contexto de la armonización legislativa a nivel europeo puede encontrarse en: Maas, Wies: Fleeing to Europe: Europeanization and the Right to Seek Refugee Status. La Haya, Institute of Social Studies, Working Paper no. 454, enero de 2008. Disponible en: http://repub.eur.nl/pub/18740/wp454.pdf (Consulta: 10 de enero de 2016)

${ }^{112}$ Se trata de una base de datos de impresiones dactilares. Cuando alguien presenta una solicitud de asilo en cualquier punto de la UE, sus impresiones dactilares se transmiten a una base de datos central, disponible para todos los EEMM. Aprobada por el Reglamento (CE) n ${ }^{\circ}$ 2725/2000 del Consejo, de 11 de diciembre de 2000, relativo a la creación del sistema «Eurodac» para la comparación de las impresiones dactilares para la aplicación efectiva del Convenio de Dublín. Disponible en: http://eurlex.europa.eu/legal-content/ES/TXT/PDF/?uri=CELEX:32000R2725\&from=ES (Consulta: 10 de enero de 2016)

${ }^{113}$ Los RPPs son proyectos financiados por la Unión Europea en países de origen y tránsito para que puedan desarrollar sistemas de asilo nacionales a medio-largo plazo. El objetivo final es que pasen a ser considerados países seguros, de forma que puedan hacerse responsables tanto de las solicitudes de asilo que les lleguen como de acuerdos de reasentamiento con la UE. La propuesta orginal se encuentra en la Comunicación de la Comisión "Hacia sistemas de asilo mejor gestionados, más accesibles y equitativos" (COM/2003/315 final), supra n. 106. Para ver una evaluación de los programas hasta la fecha se puede consultar: ECRE: Regional Protection Programmes: an effective policy tool?, Discussion paper, Bruselas, enero de 2015. Disponible en http://ecre.org/component/downloads/downloads/982.html (Consulta: 10 de enero de 2016)

${ }^{114}$ Gammeltoft-Hansen, T.: Access to Asylum ..., op. cit., p. 317 
personas provenientes de éstos ${ }^{115}$. El instrumento más importante han sido los RPPs ${ }^{116}$, destinados a ofrecer asistencia técnica y financiera para la creación de sistemas de asilo en los países de origen y tránsito. Los diversos programas que engloban son específicos y flexibles, adaptándose a las necesidades y características de cada Estado beneficiario $^{117}$. La finalidad principal es que, a medio plazo, los estados africanos se hagan cargo de gestionar los flujos migratorios y las solicitudes de asilo en caso de grandes afluencias de refugiados provocados por conflictos civiles, epidemias o catástrofes naturales. La posibilidad de extraterritorializar los procedimientos de asilo a países con sistemas jurídicos menos "sofisticados" permitiría a los estados europeos exonerarse de unos costes tanto económicos como políticos, especialmente elevados en casos de afluencia masiva. Sin embargo, se ha señalado que la dotación económica de dichos programas no es para nada suficiente si dichos estados deben construir sistemas de asilo adecuados a los estándares de la CG51. El primer RPP fue el Programa AENEAS. Entre 2004-2008, cuando se puso en marcha el programa ${ }^{118}$, se otorgaron a dicho programa 250 millones de euros con el objetivo de luchar contra la inmigración irregular, especialmente mediante el desarrollo de las capacidades nacionales de recepción de solicitantes de asilo y refugiados. En 2005 la Comisión envió una misión técnica a Marruecos ${ }^{119}$ con la finalidad elaborar un análisis de este país (considerado el más estable de la región) con vistas al posible desarrollo de un sistema de asilo nacional propio. En esa época, el ordenamiento jurídico marroquí ni siquiera preveía un procedimiento formal para la determinación del estatuto de refugiado.

\footnotetext{
115 Para profundizar más en las políticas de externalización de asilo durante el Programa de La Haya, se puede ver el informe de Oxfam: "Foreign Territory. The Internationalisation of EU Asylum Policy", Oxford, Oxfam Publishing, $2005 . \quad$ Disponible en http://oxfamilibrary.openrepository.com/oxfam/bitstream/10546/112380/1/foreign-territoryinternationalisation-EU-asylum-policy-010105-en.pdf (Consulta: 10 de enero de 2016)

${ }^{116}$ Comunicación de la Comisión al Consejo y al Parlamento Europeo, de 1 de septiembre de 2005, sobre los programas regionales de protección [COM (2005) 388 final. Disponible en http://eurlex.europa.eu/legal-content/ES/TXT/PDF/?uri=CELEX:52005DC0388\&from=ES (Consulta: 10 de enero de 2016)

${ }^{117}$ La Comunicación de la Comisión "COM (2004) 410 final Mejora del acceso a soluciones durables" incluía una lista de características que podían incluir estos programas: medidas destinadas convertir a estos países en prestadores estables de protección efectiva, creación de un perfil biométrico del sistema de inscripción del ACNUR, mejora de la infraestructura de las comunidades locales, ayuda para la integración local de las personas necesitadas de protección internacional en el país tercero, cooperación en la gestión de los flujos migratorios y la inmigración legal, y políticas de retorno al país de origen u otros terceros países. (para. 51) Disponible en http://eur-lex.europa.eu/legalcontent/ES/TXT/PDF/?uri=CELEX:52004DC0410\&from=ES (Consulta: 10 de enero de 2016)

${ }_{118}$ Reglamento (CE) n ${ }^{\circ}$ 491/2004 del Parlamento Europeo y del Consejo, de 10 de marzo de 2004, por el que se establece un programa de asistencia financiera y técnica a los terceros países en los ámbitos de la migración y el asilo (Aeneas). DO L 80, de 18 de marzo de 2004, p. 1-5. Disponible en: http://eurlex.europa.eu/legal-content/ES/TXT/PDF/?uri=CELEX:32004R0491\&qid=1452385239919\&from=EN (Consulta: 10 de enero de 2016)

${ }_{119}$ Technical Mission to Morocco. Visit to Ceuta and Melilla on Illegal Immigration. 7th October- 11th October 2005. Mission Report MEMO/05/380. Comisión Europea, 18 de octubre de 2005. Disponible en: http://europa.eu/rapid/press-release MEMO-05-380 en.pdf (Consulta: 10 de enero de 2016)
} 


\section{CAPÍTULO 2}

Las negociaciones para la adopción del Reglamento de Dublín mostraron las tensiones entre los países del Norte y Sur de Europa. Los primeros querían reforzar el criterio fijado por la Convención, según el cual el EM responsable de hacerse caso del procedimiento de asilo sería el primero al que accediera el solicitante. Los segundos, especialmente Italia y Grecia se opusieron ya que su localización geográfica les hacía países de tránsito para refugiados que no querían solicitar asilo allí, sino continuar su viaje hacia otros países europeos. Proponían que la responsabilidad fuera compartida. Tras meses de negociaciones se introdujo la "Sangatte clause" que excluía de sus responsabilidades al Estado sobre los refugiados que hubieran entrado de forma irregular en su territorio, permaneciendo sin detectar por un periodo de al menos cinco meses.

Durante el programa de Tampere se aprueba también la Directiva 2001/55/CE, de protección temporal en caso de desplazamiento masivo ${ }^{120}$. El estatus de protección temporal tiene una duración máxima de tres años, y conlleva una serie de derechos como permiso de trabajo, asistencia médica, acceso a la educación y algunas ayudas sociales como la vivienda ${ }^{121}$. Para que la UE implemente esta medida de protección, es necesaria una "decisión política" del Consejo ${ }^{122}$ que determine que existe una situación de afluencia masiva de personas desplazadas. Cuando este la adopte, todos los EEMM están obligados a admitir a las personas desplazadas ${ }^{123}$ bajo una base prima facie: esto es, concederlas automáticamente asilo ${ }^{124}$. El mecanismo de protección temporal no se ha utilizado desde su aprobación, aunque la ACNUR y algunos Estados europeos han reclamado su aplicación para hacer frente a la crisis de refugiados sirios ${ }^{125}$.

\footnotetext{
${ }^{120}$ Directiva 2001/55/CE, de 20 de julio de 2001, relativa a las normas mínimas para la concesión de protección temporal en caso de afluencia masiva de personas desplazadas. DO L 212, de 7 de agosto de 2001, p. 12-24. Disponible en: http://eurlex.europa.eu/LexUriServ/LexUriServ.do?uri=OJ:L:2001:212:0012:0023:ES:PDF (Consulta: 10 de enero de 2016)

${ }^{121}$ Ibíd., art. 8-16

122 Ibíd., art. 5.4

${ }^{123}$ Aunque en la directiva el término utilizado es de personas desplazadas, el procedimiento de garantía es del asilo territorial, por lo que sus beneficiarios solo pueden ser considerados como refugiados, tal como se indica en el artículo 2.c de la directiva

${ }^{124}$ Ibíd., art. 5.3.

${ }^{125}$ Ineli-Ciger, Meltem: 'Has the Temporary Protection Directive Become Obsolete? An Examination of the Directive and its Lack of Implementation in View of the Recent Asylum Crisis in the Mediterranean' en C. Bauloz, M. Ineli-Ciger, S. Singer, V. Stayanova (ed): Seeking Asylum in the European Union: Selected Protection Issues Raised by the Second Phase of the Common Asylum System, Brill/Martinus Nijhoff Publishers, 2015, p. 225.
} 


\subsubsection{Dublín III}

La puesta en marcha definitiva del SECA se produce con la revisión de las tres directivas de las que hemos hablado anteriormente (procedimientos de asilo ${ }^{126}$; condiciones de $\operatorname{acogida}^{127}$ y requisitos ${ }^{128}$ ) así como la reforma del Reglamento de Dublín $^{129}$ y de Eurodac ${ }^{130}$. Este nuevo paquete sobre el asilo fue presentado y publicado de forma integrada en el Diario Oficial de la Unión Europea el 29 de junio de 2013. Los EEMM estaban obligados a incorporar estas directivas en su legislación interna en un plazo de dos años, fecha que finalizó el 20 de julio de $2015^{131}$. Sin embargo, muchos Estados siguen sin transponer el paquete de asilo adecuadamente. En el caso de los estados mediterráneos, las directivas de procedimiento y condiciones de acogida no han sido transpuestas por España, Grecia ni Malta.

126 Directiva 2013/32/UE del Parlamento Europeo y del Consejo, de 26 de junio de 2013, sobre procedimientos comunes para la concesión o la retirada de la protección internacional. DO L 180, de 29 de junio de 2013, pp. 60-95. Disponible en: $\underline{\text { http://eur- }}$ lex.europa.eu/LexUriServ/LexUriServ.do?uri=OJ:L:2013:180:0060:0095:ES:PDF (Consulta: 10 de enero de 2016)

${ }^{127}$ Directiva 2013/33/UE del Parlamento Europeo y del Consejo, de 26 de junio de 2013, por la que se aprueban normas para la acogida de solicitantes de protección internacional. DO L 180 de 29 de junio de 2013, pp. 96-116. Disponible en: lex.europa.eu/LexUriServ/LexUriServ.do?uri=OJ:L:2013:180:0096:0116:ES:PDF (Consulta: 10 de enero de 2016)

${ }^{128}$ Directiva 2011/95/UE del Parlamento Europeo y del Consejo, de 13 de diciembre de 2011, por la que se establecen normas relativas a los requisitos para el reconocimiento de nacionales de terceros países o apátridas como beneficiarios de protección internacional, a un estatuto uniforme para los refugiados o para las personas con derecho a protección subsidiaria y al contenido de la protección concedida. DO L 337 de 20 de diciembre de 2011, pp. 9-26. Disponible en: http://eurlex.europa.eu/LexUriServ/LexUriServ.do?uri=OJ:L:2011:337:0009:0026:ES:PDF (Consulta: 10 de enero de 2016)

${ }^{129}$ Reglamento (UE) n 604/2013 del Parlamento Europeo y del Consejo, de 26 de junio de 2013, por el que se establecen los criterios y mecanismos de determinación del Estado miembro responsable del examen de una solicitud de protección internacional presentada en uno de los Estados miembros por un nacional de un tercer país o un apátrida. DO L 180 de 29 de junio de 2013, p. 31-59. Disponible en: http://eur-lex.europa.eu/legal-content/ES/TXT/PDF/?uri=CELEX:32013R0604\&rid=1 (Consulta: 10 de enero de 2016)

${ }^{130}$ Reglamento (UE) n ${ }^{\circ}$ 603/2013 del Parlamento Europeo y del Consejo de 26 de junio de 2013 relativo a la creación del sistema «Eurodac» para la comparación de las impresiones dactilares para la aplicación efectiva del Reglamento (UE) no 604/2013, por el que se establecen los criterios y mecanismos de determinación del Estado miembro responsable del examen de una solicitud de protección internacional presentada en uno de los Estados miembros por un nacional de un tercer país o un apátrida, y a las solicitudes de comparación con los datos de Eurodac presentadas por los servicios de seguridad de los Estados miembros y Europol a efectos de aplicación de la ley, y por el que se modifica el Reglamento (UE) no 1077/2011, por el que se crea una Agencia europea para la gestión operativa de sistemas informáticos de gran magnitud en el espacio de libertad, seguridad y justicia. DO L 180 de 29 de junio de 2013, pp. 31-59. Disponible en: http://eur-lex.europa.eu/legalcontent/ES/TXT/PDF/?uri=OJ:L:2013:180:FULL\&from=ES (Consulta: 10 de enero de 2016)

131 A esta decisión no se han sumado Reino Unido e Irlanda (que continúan sujetas a las Directivas originales de 2003 y 2005) ni Dinamarca, que se encuentra fuera del SECA. 


\section{CAPÍTULO 2}

Las reformas avanzan en la armonización de los procedimientos de asilo nacionales, y se presta especial atención al procedimiento en frontera y a los sistemas de detención. Varios aspectos incluidos en las reformas eran la respuesta a varias sentencias de los tribunales de Luxemburgo y Estrasburgo ${ }^{132}$. Algunas organizaciones de refugiados consideraron estas reformas como una gran oportunidad perdida ${ }^{133}$, tanto por la insuficiencia de los avances en la protección de derechos humanos como en el bajo nivel de armonización entre los sistemas de asilo nacionales, de forma que los EEMM seguían teniendo un importante margen de maniobra en determinados aspectos como los procedimientos acelerados. A pesar de que con estas medidas la Unión celebró la puesta en marcha definitiva del SECA, para estas organizaciones "the EU is still far from having a CEAS worthy of the appellation 'common""134

Un ejemplo de esta mezcla de elementos positivos y negativos se puede ver en las reformas de los procedimientos de asilo. Por una parte, establece reglas más concretas sobre el acceso ${ }^{135}$, aclarando los diferentes pasos del procedimiento y fijando requisitos adicionales para las actuaciones en las fronteras externas de la $\mathrm{UE}^{136}$. Por otro otorga mayor capacidad a los EEMM frente a las solicitudes abusivas y en los llamados procedimientos acelerados. La Directiva de Procedimientos permite 10 supuestos diferentes en los que un Estado puede aplicar un procedimiento acelerado y en frontera ${ }^{137}$, muchos de los cuales son criterios que permiten una interpretación ambigua $^{138}$. Se concede también bastante flexibilidad a los estados para que apliquen el principio de tercer país seguro ${ }^{139}$. El acceso a la justicia gratuita se restringe, imponiendo una serie de condiciones y dejando fuera a las solicitudes con "pocos visos de prosperar" 140 Respecto a los aquellos solicitantes que precisen de garantías especiales, se introducen mayores garantías y procedimientos específicos ${ }^{141}$. Resulta decepcionante, sin embargo, que no se haya producido una exclusión total del

\footnotetext{
132 Entre otros, revistieron especial importancia los asuntos M.S.S. c. Bélgica y Grecia (2011) y Hirsi Jamaa y otros c. Italia (2012) del TEDH y el caso C-355/10 (2012) del TJUE. En los capítulos siguientes trataré de los principales aspectos de estas y otras sentencias recientes.

133 AIDA: Not there Yet. An NGO Perspective on Challegens to a Fair and Effective Common European Asylum System, Asylum Information Database, Annual Report 2012/2013. Disponible en: http://www.asylumineurope.org/sites/default/files/shadow-reports/not there yet 02102013.pdf

(Consulta: 10 de enero de 2016); y ECRE: Common European Asylum System: The real job still needs to be done, nota de prensa del 11 de junio de 2013. Disponible en: http://www.ecre.org/component/downloads/downloads/753.html (Consulta: 10 de enero de 2016)

${ }^{134}$ Ibíd., p. 9

135 Directiva 2013/32/UE, art. 6

136 Ibíd., art. 8

${ }^{137}$ Ibíd., art. 31.8

${ }^{138}$ Por ejemplo, la no revelación de información, la mala fe en la destrucción de documentos personales o en la presentación de solicitudes para impedir la expulsión.

139 Ibíd., art. 38

140 Ibíd., art. 20.1

${ }^{141}$ Ibíd., art. 24
} 
procedimiento acelerado de víctimas de tortura ${ }^{142} \mathrm{o}$ a los menores no acompañados (en adelante, MENAs) ${ }^{143}$, si bien se introducen una serie de condiciones para que pueda producirse. En general, las reformas parecen incidir en una división entre unos solicitantes de asilo "legítimos" y otros "fraudulentos". Mientras que aumentan las garantías para algunos solicitantes, como los que pertenecen a grupos vulnerables, o se mejora el sistema de reagrupación familiar, se facilita la arbitrariedad de los EEMM en el acceso a los procedimientos de frontera y acelerados.

Balance más positivo presentan las reformas contenidas en la directiva de condiciones de acogida. Se introduce por primera vez normas comunes para asegurar que el internamiento de los solicitantes de asilo solo pueda aplicarse en casos concretos con arreglo a una lista detallada de motivos ${ }^{144}$. Se regula el recurso contra los órdenes de internamiento, con garantías jurídicas de asistencia jurídica e información, y restricciones en el uso del internamiento para personas vulnerables, incluidos los menores $^{145}$. Se refuerza la obligación de realizar una evaluación individual para identificar las necesidades particulares de acogida de las personas vulnerables ${ }^{146}$ y se asegura el acceso al apoyo psicológico.

El sistema de protección se complementa con el régimen de protección subsidiaria, reconocida en la Directiva 2011/95/UE, de requisitos, que permite permanecer en el territorio del Estado a personas que no son reconocidas como refugiados, pero que si fueran devueltos a su país de origen o a otro tercer país correría un riesgo real de sufrir daños graves. La concesión de la protección subsidiaria se produce una vez se ha tomado la decisión de que el solicitante no cumple los requisitos del régimen de asilo ${ }^{147}$.

El SECA nació con un grave problema heredado. Durante años la llegada de refugiados a Grecia había desbordado el sistema nacional de asilo. ACNUR había calificado la situación en 2010 en dicho país como "crisis humanitaria"148. Las violaciones de derechos de los refugiados llegaron a los Tribunal de Estrasburgo y

\footnotetext{
142 Ibíd., art. 24.3

143 Ibíd., art. 25.6 a)

${ }^{144}$ Directiva 2013/33/UE, art. 8.3

145 Ibíd., art. 26

146 Ibíd., art. 22

${ }^{147}$ Directiva 2013/32/UE, art. 10.2

148 UNHCR says asylum situation in Greece is 'a humanitarian crisis, nota de prensa de 21 de septiembre 2010. Disponible en http://www.unhcr.org/4c98a0ac9.html (Consulta: 10 de enero de 2016) De acuerdo con el Alto Comisionado, durante 2009 solo fueron aprobadas en primera instancia un 0,04\% de las solicitudes de asilo (11 de 30.000)
} 


\section{CAPÍTULO 2}

Luxemburgo, cuyas sentencias de 2011 en los casos M.S.S. ${ }^{149}$ y C-411/10 y C-493/10 ${ }^{150}$, respectivamente, tuvieron el efecto práctico de situar al país heleno fuera del sistema europeo de asilo. En los siguientes capítulos profundizaré sobre la importancia de dichas sentencias para elevar los estándares de protección de los solicitantes de asilo en materias de retorno y condiciones de detención. Simplemente constatar que, desde dichas sentencias, los tribunales y las administraciones de los otros países europeos comenzaron a suspender los traslados a Grecia de solicitantes de asilo bajo el sistema de Dublín. A pesar de que la introducción de reformas legislativas en 2013 mejoró la situación de las condiciones de detención y el acceso al procedimiento, el país heleno sigue encontrándose fuera del sistema común.

\subsubsection{EASO}

La Agencia fue creada en $2010^{151}$, con la misión de ofrecer apoyo técnico y operativo a los EEMM en materia de asilo, especialmente aquellos que "se encuentren sujetos a presiones especiales" a través de la coordinación de expertos directamente en campo, las aportaciones a las legislaciones nacionales y el análisis de las políticas desarrolladas $^{152}$. La sede de la agencia se encuentra, precisamente, en Malta. En su breve periodo de vida, la agencia ha llevado actuaciones en algunos a estados meridionales, orientadas al apoyo técnico en la gestión de flujos masivos de refugiados:

- Apoyo urgente a Grecia. Desarrollada en dos fases (febrero 2011-marzo 2013, y ampliada posteriormente hasta diciembre de 2014) la Agencia actuó apoyando al país heleno ante el colapso del sistema de asilo nacional, con 70 expertos de otros países europeos, encargados entre otras funciones de proporcionar formación sobre la determinación de la nacionalidad y el reforzar el acceso al procedimiento de asilo para todos los inmigrantes que se encuentra retenidos en

\footnotetext{
149 TEDH: M.S.S. c. Bélgica y Grecia, sentencia del 21 de enero de 2011, $\mathrm{n}^{\mathrm{o}}$ 30696/09. Disponible en: http://hudoc.echr.coe.int/eng? $\mathrm{i}=001-103050$ (Consulta: 10 de enero de 2016)

${ }_{150}$ TJUE: C-411/10 y C-493/10, donde prohíbe a los EEMM “... trasladar a un solicitante de asilo al «Estado miembro responsable» en el sentido del Reglamento $n^{\circ} 343 / 2003$ cuando no puedan ignorar que las deficiencias sistemáticas del procedimiento de asilo y de las condiciones de acogida de los solicitantes de asilo en ese Estado miembro constituyen motivos serios y acreditados para creer que el solicitante correrá un riesgo real de ser sometido a tratos inhumanos o degradantes" (§ 2)

${ }^{151}$ Reglamento (UE) número 439/2010 del Parlamento Europeo y del Consejo, de 19 de mayo de 2010, por el que se crea una Oficina Europea de Apoyo al Asilo. DO L 132 de 29 de mayo de 2010, pp. 11-28. Disponible en: http://eur-lex.europa.eu/legal-content/ES/TXT/PDF/?uri=CELEX:32010R0439\&from=ES (Consulta: 10 de enero de 2016)

152 En diciembre de 2015 la Agencia presentó una evaluación externa de sus primeros tres años (20112014). Se puede consultar en: https://easo.europa.eu/download/114352/ (Consulta: 10 de enero de 2016)
} 
el país, incluso en las zonas fronterizas ${ }^{153}$. El presupuesto del plan ascendió a 3.601.857€.

- Apoyo especial a Italia. En este caso el periodo se redujo a 18 meses (desde el 4 de junio de 2013 hasta fines de 2014) y estuvo enfocado a mejorar el sistema de acogida y la capacidad de respuesta en situaciones de emergencia, especialmente en periodos de gran afluencia de inmigrantes.

En marzo de 2014 la Agencia publicó un currículo ${ }^{154}$ y un manual de formación destinado a los funcionarios competentes para el examen de las solicitudes y demás profesionales del campo del asilo. En el currículo se incluían módulos sobre DIDH y de los refugiados, legislación comunitaria y metodologías para llevar a cabo entrevistas con niños y personas vulnerables.

El Informe Anual de EASO de 2014, el último publicado, elevó para ese año a más de 660.00 las solicitudes de asilo en la UE, lo que representa la cifra más alta y el mayor aumento anual (en 2013 fueron 435.760, lo que supone un crecimiento del 43\%) desde que comenzaron a recogerse estos datos en 2008. Los solicitantes de asilo procedieron mayoritariamente de Siria, los Balcanes y Eritrea, y los principales países receptores fueron Alemania, Francia, Suecia, el Reino Unido e Italia.

${ }^{153}$ EASO: Informe Anual 2013 sobre la situación del asilo en la Unión Europea, Luxemburgo, Oficina de Publicaciones de la Unión Europea, julio de 2014, p. 60. Disponible en https://easo.europa.eu/wpcontent/uploads/BZAB14001ESC PDF.Web .pdf (Consulta: 10 de enero de 2016)

${ }^{154}$ EASO: Currículo de formación de la EASO, marzo de 2014, Luxemburgo, Oficina de Publicaciones de la Unión Europea, diciembre de 2014. Disponible en: https://easo.europa.eu/wpcontent/uploads/BZ0413152ESC.pdf (Consulta: 10 de enero de 2016) 
Fig. 3. Ciudadanía de origen de los solicitantes de asilo en la UE, 2014

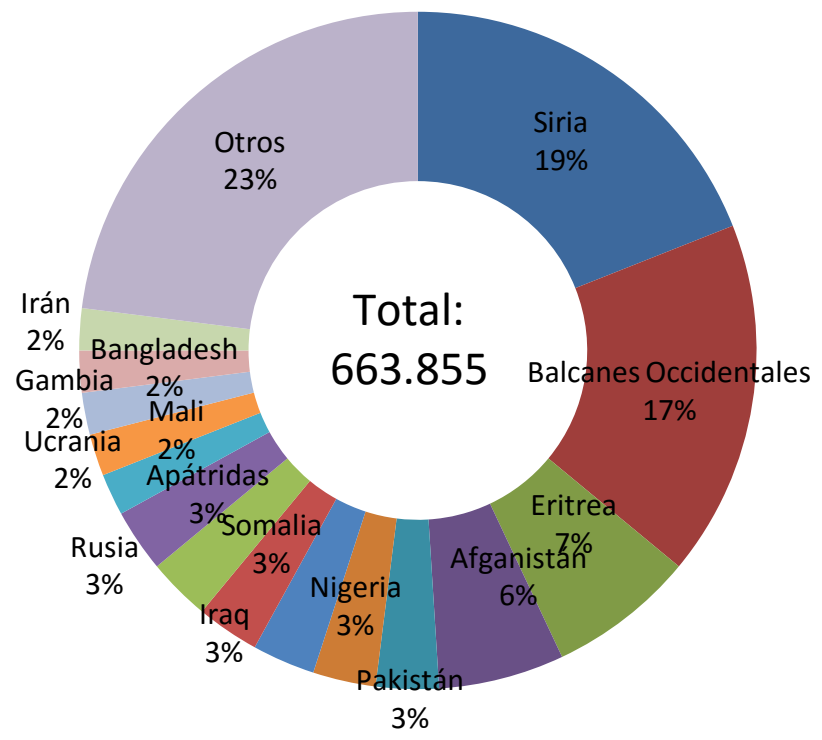

Fuente: Eurostat, datos de 18 de marzo de 2015

En línea con este mayor número de solicitantes, en 2013 se adoptaron más de 390.00 resoluciones en primera instancia. La tasa global de reconocimiento en sus distintas modalidades se situó en el $47 \%$. Se distribuyeron en 99.440 personas a las que se concedió el estatuto de refugiado, 59.565 de protección subsidiaria y 22.315 de protección humanitaria. Los mayores porcentajes de reconocimiento de la protección correspondieron a sirios, eritreos y apátridas.

\subsection{La Agencia Europea FRONTEX}

\subsubsection{La Agencia}

Frontex es la agencia europea encargada de coordinar las políticas de gestión de fronteras exteriores de la UE. Su nombre oficial es Agencia Europea para la Cooperación Operativa en las Fronteras Exteriores de los Estados Miembros de la Unión. El acrónimo proviene del francés "Frontières extérieures". Fue establecida por 
la Reglamento (CE) no 2007/2004 en octubre de $2004^{155}$. Entró en funcionamiento el 3 de octubre de $2005^{156}$. Su sede se encuentra en Varsovia, y actualmente cuenta con alrededor de 300 empleados. El Reglamento fija seis funciones principales para la Agencia ${ }^{157}$ :

a) coordinar la cooperación operativa entre los Estados miembros en material de gestión de las fronteras exteriores;

b) asistir a los Estados miembros en la formación de los agentes de la guardia nacional de fronteras y establecer normas comunes de formación;

c) realizar análisis de riesgos;

d) seguir de cerca la evolución de la investigación en materia de control y vigilancia de las fronteras exteriores;

e) ayudar a los Estados miembros enfrentados a una situación que exija una asistencia operativa y técnica reforzada en sus fronteras exteriores;

f) facilitar a los Estados miembros el apoyo necesario para la organización de operaciones de retorno conjuntas.

De sus funciones encomendadas se puede desprender el carácter técnico y operativo de la Agencia, que debe fundamentar sus acciones en la cooperación de los Estados miembros. No tiene mandato para suplir en su gestión fronteriza a los EEMM, que mantienen sus competencias ${ }^{158}$. En todo caso, conviene recordar que los Estados siguen siendo recelosos de ceder soberanía en esta área, por lo que Frontex sólo puede llevar a cabo operaciones bien bajo petición de uno o varios estados, o con el beneplácito y la cooperación de estos, en los casos donde la iniciativa parte de la propia Agencia ${ }^{159}$. En la práctica, con el paso de los años Frontex ha ido adquiriendo cada vez mayor

\footnotetext{
${ }^{155}$ Reglamento (CE) n 2007/2004 del Consejo, de 26 de octubre de 2004, por el que se crea una Agencia Europea para la gestión de la cooperación operativa en las fronteras exteriores de los Estados miembros de la Unión Europea. DO L 349 de 25 de noviembre de 2004, pp. 1-11. Disponible en: http://eurlex.europa.eu/LexUriServ/LexUriServ.do?uri=CONSLEG:2004R2007:20070820:ES:PDF (Consulta: 10 de enero de 2016)

${ }^{156}$ Para ver todo el proceso de construcción de esta Agencia, véase Jorry, Hélène: Construction of a European Institutional Model for the Management of Operational Cooperation at the EU External Borders: Does the FRONTEX Agency take a decisive step forward?, en CHALLENGE Research Paper $\mathrm{n}^{\circ}$ 6, Centre for European Policy Studies, Bruselas, marzo de 2007. Disponible en: https://www.ceps.eu/system/files/book/1483.pdf (Consulta: 10 de enero de 2016)

${ }^{157}$ Reglamento 2007/2004, art. 2.1. Posteriormente el Reglamento 863/2007 agregó una séptima función: g) "desplegar equipos de intervención rápida en los Estados miembros" (art. 12.3)

${ }^{158}$ En el considerando 4 del reglamento se señala que "El control y la vigilancia de las fronteras exteriores son competencia de los Estados miembros. La Agencia debería facilitar la aplicación de las medidas comunitarias existentes y futuras relativas a la gestión de las fronteras exteriores, garantizando para ello la coordinación de las actuaciones de los Estados miembros destinadas a aplicar dichas medidas."

${ }^{159}$ Ibíd., art. 3
} 


\section{CAPÍTULO 2}

influencia en el diseño y lanzamiento nuevas operaciones conjuntas, sobre todo a partir de los análisis de riesgo que elabora.

El Reglamento apela a dos artículos del Tratado de la Unión como justificación para su creación; son los artículos 62. 2. $\mathrm{a}^{160}$ y $66^{161}$. Sin embargo, más adelante reclama competencias en otras políticas como las de retorno ${ }^{162} \mathrm{o}$ en ámbitos policiales como los sistemas de vigilancia o información y la cooperación con Europol ${ }^{163}$. Frontex ha venido realizando funciones sin una base legal clara, a menudo debido a la presión de los propios gobiernos interesados. Esta arbitrariedad es todavía más preocupante cuando tratamos con grupos de personas en situación de vulnerabilidad como los inmigrantes en situación de irregularidad y los solicitantes de asilo.

El órgano de decisión de Frontex es el Consejo de Administración. Está compuesto por un representante de cada Estado Miembro ${ }^{164}$ y dos representantes de la Comisión, y se reúne cada dos meses. Los miembros de cada estado deben ser los jefes operativos de los servicios nacionales encargados de la gestión de la guardia fronteriza o por sus representantes. Toma sus decisiones por mayoría cualificada de dos tercios. El Consejo elige entre sus miembros a un Presidente y a un Vicepresidente. La duración de sus mandatos es de cuatro años renovable por una única vez. La Agencia también cuenta con un Director Ejecutivo, nombrado por el Consejo de Administración sobre una terna de candidatos propuesta por la Comisión. Le asiste un Director Ejecutivo Adjunto, nombrado por el Consejo a propuesta del Director Ejecutivo. Ambos cargos tienen un mandato de cinco años renovables una única vez.

\footnotetext{
160 “El Consejo, con arreglo al procedimiento previsto en el artículo 67, adoptará, en el plazo de cinco años a partir de la fecha de entrada en vigor del Tratado de Ámsterdam: 1) medidas sobre el cruce de las fronteras exteriores de los Estados Miembros en las que se establezcan: a) las normas y los procedimientos que deben aplicar los Estados miembros para la realización de controles sobre las personas en dichas fronteras"

161 "El Consejo, con arreglo al procedimiento previsto en el artículo 67, tomará las medidas necesarias para garantizar la cooperación entre los servicios pertinentes de las administraciones de los Estados miembros en los ámbitos previstos en el presente título, así como entre dichos servicios y la Comisión." ${ }^{162}$ Ibíd., art. 9.1.: "La Agencia facilitará la asistencia necesaria para la organización de operaciones de retorno conjuntas de los Estados miembros ateniéndose a la politica comunitaria en la materia. Podrá utilizar los recursos financieros de la Comunidad disponibles al efecto"

${ }^{163}$ Reglamento 2007/2004., art. 13

164 Tres estados de la UE decidieron no participar en la Agencia: Irlanda, Reino Unido y Dinamarca, haciendo uso de su cláusula de opt-out en el marco de Schengen. En cambio, dos estados europeos que no forman parte de la Unión (Islandia y Noruega) sí participan.
} 


\section{LA POLÍTICA MIGRATORIA Y DE ASILO EN LA UNIÓN EUROPEA}

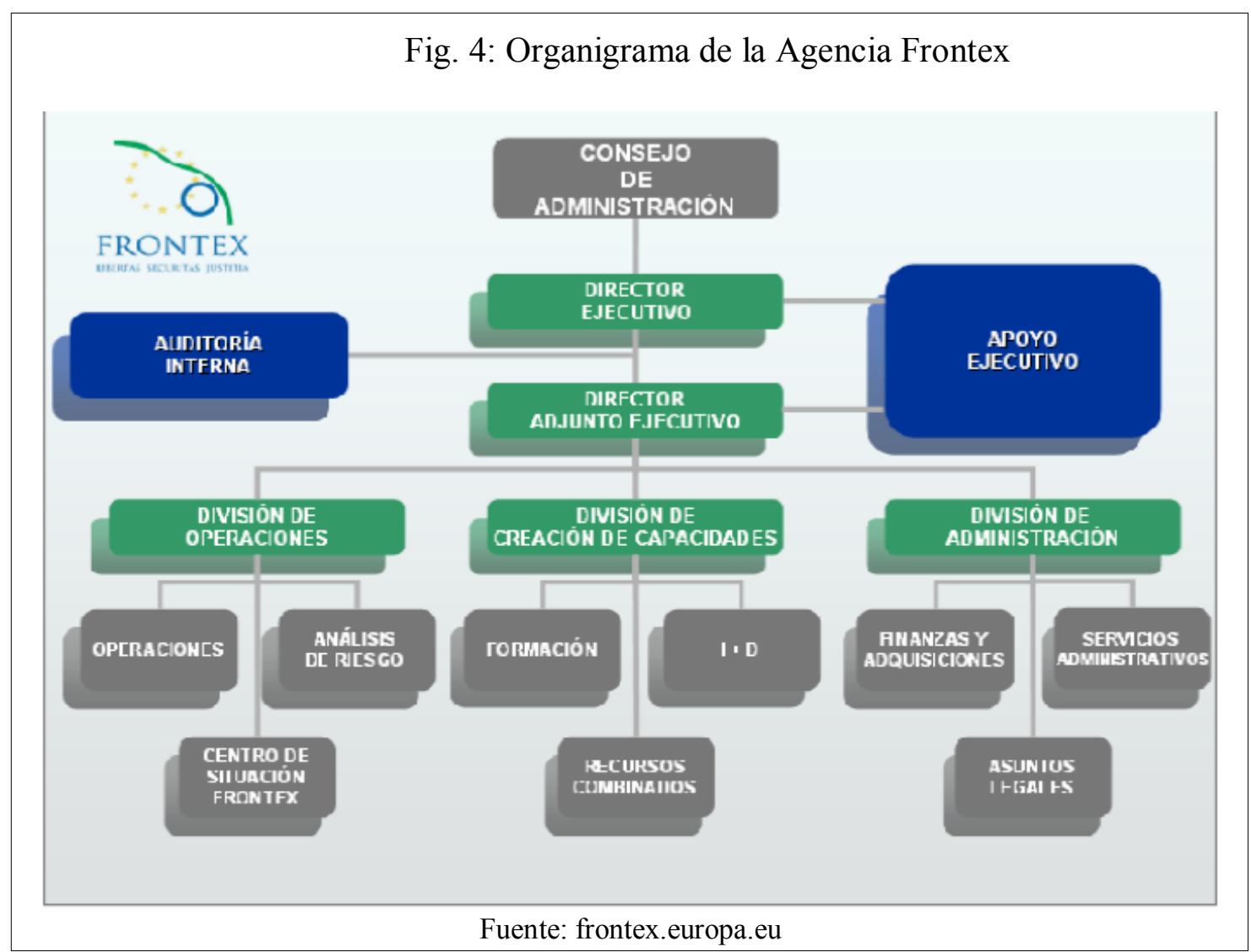

\subsubsection{Evolución y modificaciones}

El mandato original de Frontex incluye todas las fronteras exteriores de la UE, ya sean terrestres, marítimas o aeroportuarias. No obstante, desde su inicio su trabajo se ha centrado casi exclusivamente en las fronteras de Turquía y el Norte de África. Desde el comienzo de su existencia, los gobiernos de los estados mediterráneos han sido quienes más han recurrido a la Agencia, bien ejerciendo presión para la aprobación de operaciones de control de fronteras o para la provisión de recursos técnicos y personales por parte de otros países.

Por otra parte, Frontex ha venido asumiendo cada vez más competencias y asumiendo roles tanto de iniciativa como de diseño en la puesta en marca de operaciones, sobrepasando en la práctica su rol técnico y de coordinación al que le limitaba el Reglamento 2007/2004. En su memoria anual de 2006 se señalaba en la descripción de tareas que "focus will be on fighting irregular migration and trafficking of human beings and on supporting the activities against international terrorism by 


\section{CAPÍTULO 2}

means of border control" ${ }^{165}$. Estos objetivos iban más lejos de las tareas que aparecían en el reglamento de creación - control y vigilancia fronteriza -, y reflejan el enfoque policial y securitario que caracteriza el trabajo realizado por la Agencia y la visión que existe en la UE sobre las migraciones. Con el paso de los años, la colaboración de Frontex con Europol e Interpol se ha incrementado. Por ejemplo, Frontex ha colaborado con la OCTA (Organised Crime Threat Assessment) ${ }^{166}$ de Europol.

En 2006 se adopta el Código de Fronteras Schengen ${ }^{167}$ (en adelante SBC por sus siglas en inglés) que regula y desarrolla las competencias de Frontex en varios $\operatorname{aspectos}^{168}$. El SBC fija como objetivo de la vigilancia de fronteras "impedir el cruce no autorizado de la frontera, luchar contra la delincuencia transfronteriza y adoptar medidas contra las personas que hayan cruzado la frontera ilegalmente". ${ }^{169}$ El SBC reconoce la protección de los derechos de refugiados y solicitantes de asilo, especialmente en lo que concierne al non-refoulement ${ }^{170}$. El reglamento también fija los requisitos con los que se debe contar para entrar en el área Schengen: la posesión de la documentación de viaje e identificativa válida, no estar inscrito como no admisible en las bases de datos nacionales o de la Unión (SIS) y no suponer una amenaza al orden público, la seguridad interior, la salud pública o las relaciones internacionales de los EEMM $^{171}$. Entre las excepciones, se incluyen a los solicitantes de asilo, así como las causas humanitarias ${ }^{172}$, si bien en este caso los EEMM son los que tienen la capacidad última de permitir o denegar la entrada a su territorio. Otra disposición relevante es el derecho a recurrir a una denegación de entrada ${ }^{173}$. El SBC se reformó en 2013 con el Reglamento (UE) 610/2013 ${ }^{174}$.

165 Frontex: Programme of Work 2006, Varsovia, 10 de octubre de 2005, p. 4. Disponible en: http://frontex.europa.eu/assets/About_Frontex/Governance documents/Work_programme/2006/mb_decis ion_013.2005_of_19_oct_2005_-_programme_of_work_2006_-_written_procedure.pdf (Consulta: $10 \mathrm{de}$ enero de 2016)

${ }^{166}$ La OCTA es un documento de análisis estratégico elaborado por Europol, donde se encuentran los análisis y recomendaciones de políticas en materia de lucha contra la delincuencia organizada. Desde su nacimiento, Frontex colabora activamente en la elaboración del documento. Los informes anuales pueden consultarse en: https://www.europol.europa.eu/latest publications/31 (Consulta: 10 de enero de 2016)

${ }^{167}$ Reglamento (CE) n $\mathrm{n}^{\mathrm{0}}$ 562/2006 del Parlamento y del Consejo, de 15 de marzo de 2006, por el que se establece un Código comunitario de normas para el cruce de personas por las fronteras. DO L 105 de 13 de abril de 2006, pp. 1-32. Disponible en: http://eur-lex.europa.eu/legalcontent/ES/TXT/PDF/?uri=CELEX:32006R0562\&from=ES (Consulta: 10 de enero de 2016)

168 Véase el art. 1.2 del Reglamento de 2011, que delimita territorialmente las competencias y funciones de la Agencia.

${ }^{169}$ Reglamento (CE) nº 562/2006., art. 12.1

170 Ibíd., art. 3.b

171 Ibíd., art. 5.1

172 Ibíd., art. 5.4.c

173 Ibíd., art. 13.3

${ }^{174}$ Reglamento (UE) $n^{\circ}$ 610/2013 del Parlamento Europeo y del Consejo, de 26 de junio de 2013 , por el que se modifica el Reglamento (CE) $n{ }^{\circ} 562 / 2006$ del Parlamento Europeo y del Consejo, por el que se establece un Código comunitario de normas para el cruce de personas por las fronteras (Código de fronteras Schengen), el Convenio de aplicación del Acuerdo de Schengen, los Reglamentos del Consejo 


\section{LA POLÍTICA MIGRATORIA Y DE ASILO EN LA UNIÓN EUROPEA}

La Agencia ha estado sometida a la evaluación de otras instituciones comunitarias, particularmente de la Comisión ${ }^{175}$, el Parlamento ${ }^{176}$, y el Ombudsman Europeo ${ }^{177}$. La propia Agencia solicitó en 2009 una evaluación externa ${ }^{178}$, y en 2010 publicó así mismo un informe interno donde evaluaba sus primeros cinco años de vida ${ }^{179}$. Las críticas más recurrentes en dichos informes se centran en la falta de transparencia, falta de control ante el PE y el TJUE y escasa preocupación por el respeto a los derechos humanos, así como el reconocimiento implícito que el mandato de la Agencia no era suficientemente claro y que buena parte de sus objetivos no se habían cumplido.

Finalmente, el Consejo escogió la presentación del Programa de Estocolmo para incluir una petición de reforma del Reglamento 2007/2004. La propuesta incluía como objetivos "clarificar el mandato y reforzar las funciones de Frontex", y "normas claras respecto de la participación en operaciones conjuntas por mar, prestando debida atención a que se garantice la protección de las personas necesitadas que viajan en flujos mixtos, con arreglo al Derecho internacional" ${ }^{\prime 80}$. El Consejo Europeo parece reconocer que tanto el mandato como las operaciones desarrolladas por la Agencia llevaban cinco años desarrollándose sin el apoyo de un marco legal claro. Se han señalado como una de las posibles causas "el apresuramiento que presidió la puesta en marcha de las primeras operaciones de FRONTEX, cuando la preocupación por ofrecer una imagen de coordinación y eficacia en la lucha contra la inmigración

(CE) $n^{\circ} 1683 / 95$ y (CE) $n^{\circ} 539 / 2001$ y los Reglamentos del Parlamento Europeo y del Consejo (CE) $n^{\circ}$ 767/2008 y (CE) $n^{\circ}$ 810/2009. DO L 182 de 29 de junio 2013, pp. 1-18. Disponible en: http://eurlex.europa.eu/LexUriServ/LexUriServ.do?uri=OJ:L:2013:182:0001:0018:ES:PDF (Consulta: 10 de enero de 2016)

${ }^{175}$ Comunicación de la Comisión al Parlamento Europeo, al Consejo, al Comité Económico y Social Europeo y al Comité de las Regiones, de 13 de febrero de 2008, Informe sobre la evaluación y el desarrollo futuro de la Agencia FRONTEX (COM (2008) 67 final). Disponible en: http://eurlex.europa.eu/LexUriServ/LexUriServ.do?uri=COM:2008:0067:FIN:ES:PDF (Consulta: 10 de enero de 2016)

176 Resolución del Parlamento Europeo, de 10 de marzo de 2009, sobre los próximos pasos en la gestión de las fronteras en la Unión Europea y experiencias similares en terceros países (2008/2181(INI)). Disponible en: http://www.europarl.europa.eu/sides/getDoc.do?pubRef=-//EP//NONSGML+TA+P6-TA2009-0085+0+DOC+PDF+V0//ES (Consulta: 10 de enero de 2016)

${ }^{177}$ En septiembre de 2012 el Ombudsman europeo abrió una indagación sobre Frontex ante las quejas por la falta de transparencia y la no publicación de sus documentos de trabajo. Special Report of the European Ombudsman in own-initiative inquiry OI/5/2012/BEH-MHZ concerning Frontex Disponible en: http://www.eowebbot.europarl.europa.eu/en/cases/specialreport.faces/en/52465/html.bookmark

(Consulta: 10 de enero de 2016)

178 COWI: External evaluation of the European Agency for the Management of Operational Cooperation at the External Borders of the Member States of the European Union, Kongens Lyngby, Dinamarca, Doc. P-69209-A, 15 de enero de 2009. Disponible en: http://www.statewatch.org/news/2009/may/frontex-evalreport-2009.pdf (Consulta: 10 de enero de 2016)

179 Frontex: Beyond the Frontiers: The First Five years, Varsovia, 2010. Disponible en: http://frontex.europa.eu/assets/Publications/General/Beyond the Frontiers.pdf (Consulta: 10 de enero de 2016)

${ }^{180} \operatorname{COM}(2010) 171$ final, p. 5.1 


\section{CAPÍTULO 2}

irregular primó sobre la clarificación de las dudas jurídicas que suscitaba, y sigue suscitando, su actuación" $" 181$

El nuevo reglamento 1168/2011 $1^{182}$ se aprueba finalmente el 25 de octubre de 2011, enmendando una serie de artículos del anterior reglamento. La nueva regulación supone un avance, aunque insuficiente, que no soluciona gran parte de los problemas que se señalan en el presente trabajo. Si bien las peores prácticas de la Agencia han desaparecido, las principales cuestiones siguen sin resolverse. Las estrategias y códigos de conducta relativos a la responsabilidad de los agentes y directivos no tienen un carácter vinculante, y las mejores en transparencia y rendición de cuentas son insuficientes. En los próximos apartados entraremos en el detalle de varias modificaciones relevantes, en especial en la llamada "Estrategia de Derechos Fundamentales".

El presupuesto también ha reflejado el incremento de competencias, pasando de 6,2 millones de $€$ en 2005 (primer año de funcionamiento) a más de 114,05 millones de $€$ en 2015, cerca del pico de 118,18 millones en 2011. Como se puede observar en el gráfico, tras un gran incremento durante los primeros años, el crecimiento del presupuesto de la agencia se ha ido moderando, con la excepción de 2011. El pequeño repunte de los últimos años parece deberse a una reacción de la Comisión, principal suministradora de fondos, a la tragedia de Lampedusa ${ }^{183}$

\footnotetext{
181 Pérez, C.: Migraciones irregulares..., op. cit., p. 152

182 Reglamento (UE) no 168/2011 del Parlamento Europeo y del Consejo, de 25 de octubre de 2011 que modifica el Reglamento (CE) no. 2007/2004 del Consejo, por el que se crea una Agencia Europea para la gestión de la cooperación operativa en las fronteras exteriores de los Estados miembros de la Unión Europea. DO L 304 de 22 de noviembre de 2011, pp. 1-17. Disponible en: http://eurlex.europa.eu/LexUriServ/LexUriServ.do?uri=OJ:L:2011:304:0001:0017:ES:PDF (Consulta: 10 de enero de 2016)

${ }^{183}$ Un resumen del presupuesto de 2015 , donde el incremento de fondos de la CE es de casi 20 millones $€$ puede verse aquí: http://frontex.europa.eu/assets/About Frontex/Governance documents/Budget/Budget 2015.pdf (Consulta: 10 de enero de 2016)
} 


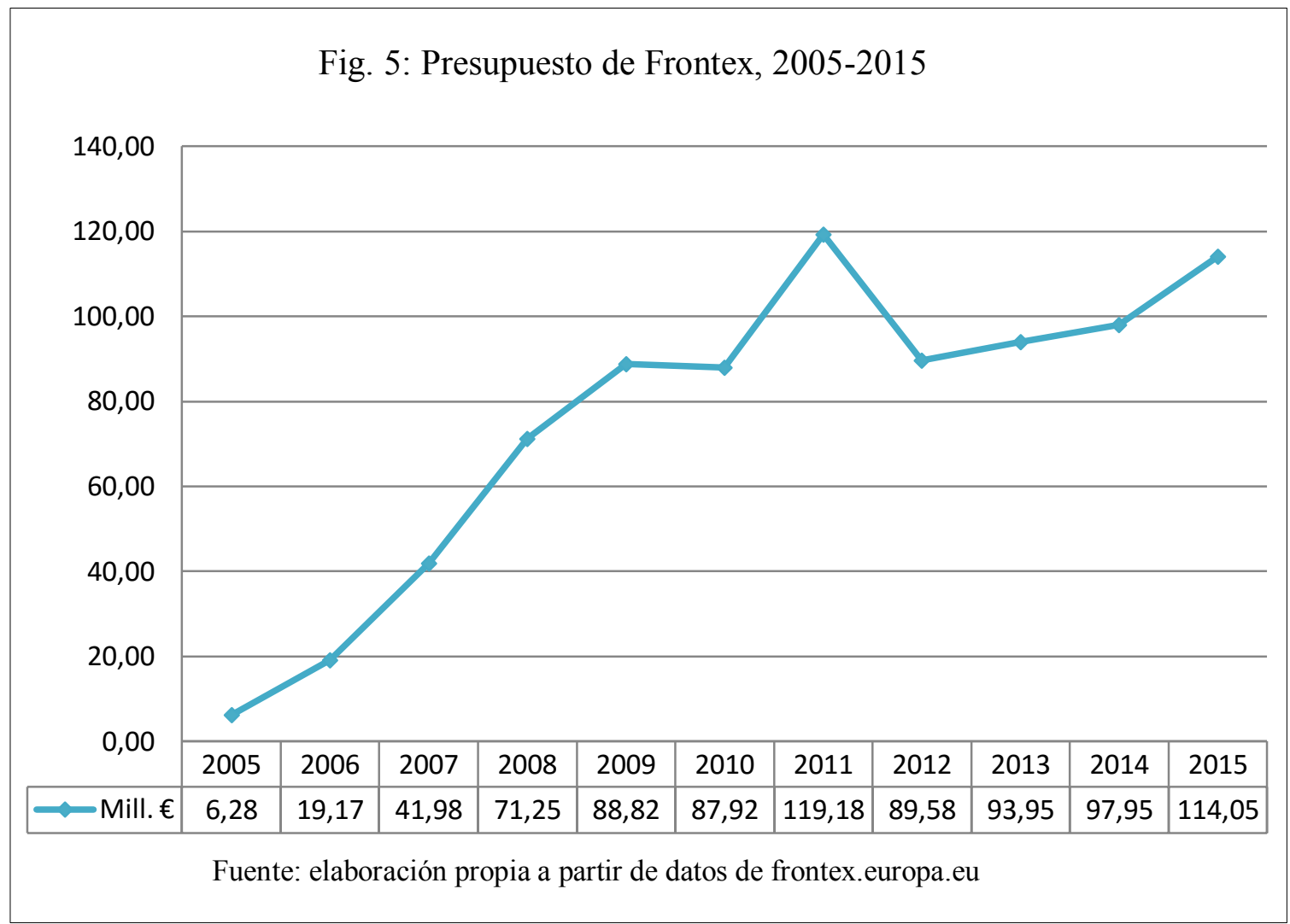

\subsubsection{Rendición de cuentas y protección de los Derechos Humanos}

Ya desde sus primeros pasos, Frontex ha sido una el centro de fuertes polémicas y críticas desde fuera y dentro del ámbito comunitario. Aquí nos centraremos en las cuestiones relativas al respeto a los derechos humanos y la vigilancia de sus actuaciones por parte de otras instituciones europeas.

A pesar de que jurídicamente se trata de una agencia independiente y despolitizada, autores como Sergio Carrera han señalado que en la práctica se encuentra en una situación de dependencia ante los EEMM y otras instituciones europeas como la Comisión. Carrera menciona tres factores: su capacidad es demasiado dependiente de la cooperación entre los distintos gobiernos, que mantienen la competencia sobre el control de sus fronteras y los recursos de las operaciones conjuntas; segundo, las operaciones lanzadas por Frontex suelen ser impulsadas en situaciones de emergencia política y mediática; y tercero, la Comisión sigue ejerciendo una importante influencia sobre la agencia ${ }^{184}$.

${ }^{184}$ Carrera, S.: The EU Border... op. cit., pp. 8-14 


\section{CAPÍTULO 2}

Otra de las críticas proviene de la falta de transparencia. Durante los primeros años de funcionamiento, la mayor parte de los documentos de la Agencia no se hacían públicos. Fue tras las quejas y solicitudes de organizaciones como Statewatch cuando algunos documentos comenzaron a aparecer en la página web de la Agencia. A día de hoy los análisis de riesgo de las operaciones en marcha y los informes sobre violaciones de derechos humanos durante las JO (joint operations) siguen siendo confidenciales, además de otros documentos internos de menor importancia. Los propios planes operativos de las JO censuran buena parte de sus informes. Por ejemplo, en el más reciente Plan Operativo (PO) de la operación Hermes ${ }^{185}$ aparecen tachadas las partes correspondientes a la descripción y valoración de la situación, periodos de implementación, áreas operativas, actores involucrados, comunicaciones e informes de incidentes. La legislación europea sobre transparencia y acceso público ${ }^{186}$ obligaría a Frontex a hacer públicos esos documentos. Sin embargo, la Agencia se escuda en el interés público en materia de seguridad pública y relaciones internacionales para justificar las restricciones en el acceso a dicha información ${ }^{187}$.

La rendición de cuentas ante otras instituciones europeas ha sido otro de los motivos de preocupación, y uno de los aspectos donde el reglamento presenta menos avances. Las capacidades de fiscalización por parte del PE siguen siendo escasas, más allá de las obligaciones de informar por parte de la Agencia. Se mantiene el control intergubernamental en la estructura de decisión de la Agencia, si bien ésta aumenta su capacidad para iniciar operaciones y proyectos pilotos ${ }^{188}$. Se introduce la posibilidad de que órganos de derechos humanos de la UE u otras organizaciones internacionales envíen a observadores a operaciones de la agencia, pero siempre con el consentimiento del estado anfitrión de la operación ${ }^{189}$.

Precisamente el respeto a los derechos humanos ha sido otro aspecto controvertido en las actuaciones de la Agencia. El reglamento de creación apenas incluía una

\footnotetext{
${ }^{185}$ Frontex: Operational Plan Joint Operation EPN Hermes 2014. 2014/SBS/5. Operations Division. Joint Operations Unit. Sea Borders Sector. Disponible en: http://www.asktheeu.org/en/request/1674/response/6081/attach/22/Hermes\%202014\%20OpPlan.pdf (Consulta: 10 de enero de 2016)

186 Reglamento (CE) n ${ }^{\circ}$ 1049/2001, del parlamento Europeo y de la Comisión, del 30 de mayo de 2001 , sobre el acceso público a los documentos del Parlamento Europeo, del Consejo y de la Comisión. DO L 145 de 31 de mayo de 2001, pp. 43-49. Disponible en: http://eurlex.europa.eu/LexUriServ/LexUriServ.do?uri=OJ:L:2001:145:0043:0048:es:PDF (Consulta: 10 de enero de 2016)

${ }^{187}$ Ibíd., art. 4.1 (a)

${ }^{188}$ Ibíd., art. 3.1

${ }^{189}$ Ibíd., art. 13
} 
apelación genérica a los derechos recogidos en el TUE y la $\mathrm{CDF}^{190}$, no aparecía en los primeros análisis de riesgo ni otros documentos de trabajo, y la Agencia no implementó ningún mecanismo para garantizar el respeto a los derechos humanos en sus actuaciones. Desde diversas organizaciones de derechos humanos y derechos de las personas refugiadas se denunció públicamente esta carencia ${ }^{191}$. A partir de 2008, Frontex comenzó a establecer colaboraciones con organismos internacionales de derechos humanos (FRA) y de los refugiados (ACNUR).

El 13 de junio de 2008 se llegó a un acuerdo de trabajo con el ACNUR, que incluía acceso a información, compartir experiencias, y formación a los guardias fronterizos y agentes de la agencia sobre protección internacional ${ }^{192}$. La colaboración no fue del todo satisfactoria, llegando a declarar un oficial de la agencia de los refugiados que "the UNHCR has little information on joint operations, making it difficult to evaluate the impact of training", y proponiendo que "all staff should be trained in fundamental human rights, not just those working on the ground"193.

La cooperación con FRA, por su parte, nace del acuerdo de cooperación celebrado el 26 de mayo de $2010^{194}$. Al igual que la anterior, la colaboración entre ambas agencias europeas estuvo centrada en la formación de los agentes sobre derechos fundamentales e identificación de personas vulnerables. Además, Frontex "facilitará" la tarea de la FRA en la recopilación de datos e información sobre los derechos fundamentales en la gestión de fronteras. Así mismo, la FRA elaboró una lista de buenas prácticas para operaciones de retorno.

La reforma del reglamento de 2011 tenía entre sus novedades más destacadas la inclusión de mayores cláusulas de respeto a los derechos humanos y la adopción de una

\footnotetext{
${ }^{190}$ Reglamento 2007/2004, considerando 22.

191 Vid. el documento conjunto de AI, ECRE y la ICJ: Joint Briefing on the European Commission Proposal for a Regulation of the European Parliament and of the Council establishing rules for the surveillance of the external sea borders in the context of operational cooperation coordinated by the European Agency for the Management of Operational Cooperation at the External Borders of the Member States of the European Union (COM(2013) 197 final). Bruselas, septiembre de 2010. Disponible en: http://www.ecre.org/component/downloads/downloads/790.html (Consulta: 10 de enero de 2016)

192 Se puede consultar el manual de formación en: http://www.unhcr.org/4d948c736.html (Consulta: 10 de enero de 2016)

${ }_{193}$ Calloni, Marina y Hunt-Botting, Eileen (eds.): Borders Sovereignty Rights, The Border Crossing Seminar, Università degli Studi di Milano, 2013, p. 126. Disponible en: https://boa.unimib.it/retrieve/handle/10281/52969/79757/Borders\%2c\%20Sovereignty\%2c\%20Rights\%2 0-\%20BCS\%201.pdf (Consulta: 10 de enero de 2016)

194 Cooperation Arrangement between The European Agency for the Management of Operational Cooperation at the External Borders of the Member States of the European Union, 26 de mayo de 2010. Disponible en: http://fra.europa.eu/fraWebsite/attachments/Cooperation-Agreement-FRA-Frontex en.pdf (Consulta: 10 de enero de 2016)
} 


\section{CAPÍTULO 2}

"Estrategia de Derechos Fundamentales". Se cita explícitamente la CG51 y el principio de non-refoulement en un nuevo artículo:

La Agencia cumplirá sus cometidos dentro del pleno respeto del Derecho de la Unión pertinente, incluida la Carta de los Derechos Fundamentales de la Unión Europea ("Carta de los Derechos Fundamentales"); del Derecho internacional pertinente, incluida la Convención de sobre el Estatuto de los Refugiados hecha en Ginebra el 28 de julio de 1951 ("la Convención de Ginebra"); de las obligaciones relativas al acceso a la protección internacional, en especial el principio de no devolución, y de los derechos fundamentales. ${ }^{195}$

Es destacar también que se refuerzan las garantías contra la devolución:

De conformidad con el Derecho de la Unión y el Derecho internacional, ninguna persona podrá ser desembarcada en un país ni entregada a sus autoridades si ello vulnera el principio de no devolución, o si existe el riesgo de que sea expulsada de tal país o repatriada a otro vulnerando dicho principio. Se atenderá a las necesidades especiales de los niños, de las víctimas de la trata de personas, de las personas que necesitan asistencia médica, de las personas que necesitan protección internacional $y$ de otras personas vulnerables de conformidad con el Derecho de la Unión y el Derecho internacional. ${ }^{196}$

Esta declaración se complementa con la introducción de una estrategia en materia de derechos fundamentales ${ }^{197}$. Se define como objetivo garantizar el respeto de los derechos humanos en todas las actividades llevadas a cabo por la Agencia. Entre las medidas que incluye está la creación de un Foro Consultivo que asistirá a la Agencia en materia de derechos humanos, y del que formaran parte la FRA, el EASO y el ACNUR; y la designación de un agente responsable en materia de derechos fundamentales. Durante la formación de los agentes de fronteras se incluyen materias sobre "los derechos fundamentales y el acceso a la protección internacional, así como a las directrices relativas a la identificación de las personas en busca de protección"198, así como referencias al derecho de la Unión, internacional y marítimo pertinente.

\footnotetext{
${ }^{195}$ Reglamento (UE) n ${ }^{\mathrm{o}} 168 / 2011$, art. 1.2

196 Ibíd., art. 2.1 bis

${ }^{197}$ Ibíd., art. 26 bis

${ }^{198}$ Ibíd., art. 5 (a)
} 
Se establece también la participación del Foro en la elaboración de un "Código de Conducta" que tendrá en cuenta "los principios del Estado de Derecho y el respeto de los derechos fundamentales, prestando especial atención a los menores no acompañados y a las personas vulnerables, así como a las personas que tratan de obtener protección internacional" ${ }^{\prime 199}$. En dicho Código, aprobado en el mismo año que el reglamento, se incluían las obligaciones de los participantes en actividades de Frontex el respecto a los derechos fundamentales ${ }^{200}$ así como al principio de non-refoulement ${ }^{201}$, proveer a sus personas con un adecuado acceso a la atención sanitaria ${ }^{202}$ y otorgar especial consideración a los colectivos vulnerables entre los que incluye mujeres, MENAs, personas discapacitadas, víctimas de la explotación o trata de seres humanos $^{203}$. Por otra parte, se añaden otras disposiciones para los agentes de orden público como los límites al uso de la fuerza ${ }^{204}$.

En lo que respecta a los agentes que participen en las JO, se introducen dos medidas relevantes. Por un lado, establece su responsabilidad individual por las acciones cometidas durante su labor ${ }^{205}$; mientras no establece ninguna responsabilidad de la Agencia como organización. A pesar de esto, conviene recordar que los empleados de Frontex, como los de cualquier otra agencia o institución europea, gozan de inmunidad de jurisdicción respecto a los actos realizados con carácter oficial ${ }^{206}$. Por otro, decreta la obligación de informar a un superior ${ }^{207}$ mediante un procedimiento llamado SIR (Serious Incident Reporting) en caso de violación de derechos humanos (en el caso de ser testigo directo) o sospechas de violaciones (si lo es de forma indirecta). El informe pasa al Frontex Situation Centre (FSC) de Varsovia, que debe reportar a la FRA para que tenga conocimiento del hecho, además de al Director Ejecutivo y a los EEMM envueltos en dicho incidente (ya sea porque se ha producido en su territorio o porque estaba involucrado algún oficial nacional). El departamento legal de la agencia, la Unidad de Operaciones y cualquier EEMM pueden hacer comentarios sobre el caso bajo

\footnotetext{
199 Ibíd., art. 2 bis

${ }^{200}$ Frontex, Code of Conduct for all persons participating in FRONTEX activities, Varsovia, enero de 2013, $\quad$ art. 4.4 Disponible $\quad$ en: http://frontex.europa.eu/assets/Publications/General/Frontex_Code_of_Conduct.pdf_(Consulta: 10 de enero de 2016).

${ }^{201}$ Ibíd., art. 5 (a)

202 Ibíd., art. 5 (b)

${ }^{203}$ Ibíd.. art. 5 (c)

${ }^{204}$ Ibíd., art. 19

205 Ibíd., art. 7

${ }^{206}$ Protocolo ( $\mathrm{n}^{\mathrm{o}}$ 7) sobre los privilegios y las inmunidades de la Unión Europea. DOUE $\mathrm{n}^{\text {o }} 306$, de 17 de diciembre de 2007, art. $12 \quad$ (a). http://www.europarl.europa.eu/transl es/plataforma/pagina/maletin/juri/voll prot privilegios.htm

(Consulta: 10 de enero de 2016). No obstante, dicho artículo circunscribe dicha inmunidad al "territorio de cada uno de los Estados miembros..." por lo que, aventuro, perderían dicha inmunidad en las operaciones realizadas en las aguas territoriales de Estados extracomunitarios.

${ }^{207}$ Frontex, Code of Conduct...., op. cit., art. 22
} 


\section{CAPÍTULO 2}

examen. A pesar de todo, el informe final no se hace público. Si la violación se considera grave o existe posibilidad de que persista, el Director Ejecutivo puede decidir suspender o poner fin a la $\mathrm{JO}^{208}$. Las posibilidades que abre este procedimiento quedan deslucidas ante la falta de transparencia y criterios claros que determinen cuando un incidente es considerado serio ${ }^{209}$. En la práctica, el resultado final de la investigación queda a la libre decisión del Director de la Agencia, fuera del control efectivo de cualquier otro órgano de la Agencia o institución comunitaria ${ }^{210}$.

El Ombudsman de la UE recomendó a Frontex que estableciera un mecanismo interno de denuncias por violaciones de derechos humanos en los que la agencia o sus agentes fueran responsables. Frontex rechazó la propuesta, bajo el argumento de que "human rights infringements are exclusively the responsibility of the Member States concerned"211. La respuesta muestra la falta de voluntad para aplicar en la práctica los mecanismos que proclama en sus documentos, y la intención de evitar su responsabilidad en las actuaciones donde ejerce un rol de coordinador.

Esta cuestión es especialmente relevante y compleja. Discernir las diferentes responsabilidades entre la Agencia y los EEMM que participan en las JO, ya sea como estado anfitrión o participante. Las labores de Frontex en dichas operaciones son de diseño de las operaciones, fijación de objetivos, evaluación de riesgos, gestión del personal y recursos destinados a la operación, coordinación de la puesta en marcha, y toma de decisiones durante éstas. Dado el rol de experto que juega y la experiencia que posee en operaciones de vigilancia marítima, el papel de Frontex suele sobrepasar sus competencias legales, suele actuar desde el liderazgo, siendo el papel de los EEMM más de acompañamiento y seguimiento de las decisiones de la agencia.

A pesar de estos acuerdos y del aumento de referencias a los derechos humanos en las normas y documentos internos de Frontex, los informes anuales de la agencia no incluyen indicadores sobre protección de derechos humanos en sus operaciones de

\footnotetext{
${ }^{208}$ Reglamento (UE) n ${ }^{\text {o }} 168 / 2011$, art. 3.1 bis

209 Actualmente la Agencia señala que dichos criterios están bajo consideración. En: FIDH- EMHRNMigreurop: Frontex, between Greece and Turkey. The Border of Denial, , mayo de 2014, p. 41 Disponible en: http://www.migreurop.org/IMG/pdf/rapport en web.pdf (Consulta: 10 de enero de 2016) 210 La acción de anulación, principal instrumento de control jurisdiccional de las actuaciones comunitarias, deja fuera de su aplicación a las agencias, tal como aparece establecido en el art. 263 TFUE.

211 Nota de prensa No. 17/2013, Ombudsman calls on Frontex to deal with complaints about fundamental rights infringements, 14 de noviembre de 2013. Disponible en: http://www.ombudsman.europa.eu/showResource?resourceId=1384417749904 press release 201317 EN.pdf\&type $=$ pdf\&download=true\&lang=en (Consulta: 10 de enero de 2016)
} 
vigilancia y de retorno. De ahí las dificultades de evaluar las actuaciones de la Agencia desde el enfoque de derechos humanos, más allá del relato de casos individuales de vulneraciones. En una investigación con entrevistas a agentes de frontera noruegos que participaron en operaciones de la agencia, éstos señalaban la significativa presencia de las preocupaciones humanitarias en la formación y diseño de las $\mathrm{JO}$, pero también la dificultad para conciliarlas en la práctica ${ }^{212}$. Así mismo, las experiencias de los agentes confirmaban que los migrantes aparecían más como riesgos y fuentes de información que como sujetos necesitados de protección ${ }^{213}$.

\subsubsection{Joint Operations}

Una de las labores más importantes que desarrolla la Agencia es el diseño y puesta en marcha de operaciones de vigilancia y control fronterizo en las que participan varios EEMM de forma conjunta. En los documentos internos de la Agencia se hace referencia a estas operaciones como JO (Joint Operations). Aunque habitualmente se desarrollan en las fronteras de un único país, en ellas forman parte agentes de otros EEMM y de la propia Agencia. Frontex juega un rol de coordinación entre EEMM, que continúan siendo los responsables de la gestión de sus propias fronteras (en el caso de los países anfitriones de las operaciones) y de las decisiones y acciones realizadas por sus agentes nacionales (de los países participantes).

Las operaciones suelen comenzar con la solicitud de asistencia técnica de algún EM, en virtud del artículo 8 del Reglamento: "cualquier Estado miembro enfrentado a una situación que exija una asistencia operativa y técnica reforzada para cumplir sus obligaciones en materia de control y vigilancia de sus fronteras exteriores podrá solicitar la asistencia de la Agencia. La Agencia podrá organizar la asistencia operativa y técnica necesaria para el Estado o Estados miembros solicitantes"

Una vez aceptada la petición de asistencia por parte del Consejo de Administración, la iniciativa de la operación queda en manos de la Agencia. El funcionamiento de las JO está desarrollado por un reglamento elaborado en marzo de 2006 por el Consejo de Administración ${ }^{214}$. Se establecen cuatro fases:

1) Lanzamiento de una actividad operacional (análisis de riesgos);

\footnotetext{
212 Aas, Katja y Gundhus, Helene: Policing Humanitarian Borderlands: Frontex, Human Rights and the Precariousness of Life, Oxford University Press, vol. 55, $\mathrm{n}^{\circ}$ 1, 2015, p. 5.

${ }^{213}$ Ibíd., p. 9

${ }^{214}$ El documento no es público. Pude encontrarse citado en: Carrera, S.: The EU Border... op cit., p. 10.
} 


\section{CAPÍTULO 2}

2) Preparación de la iniciativa operacional;

3) Preparación del plan operacional e implementación;

4) Evaluación y seguimiento

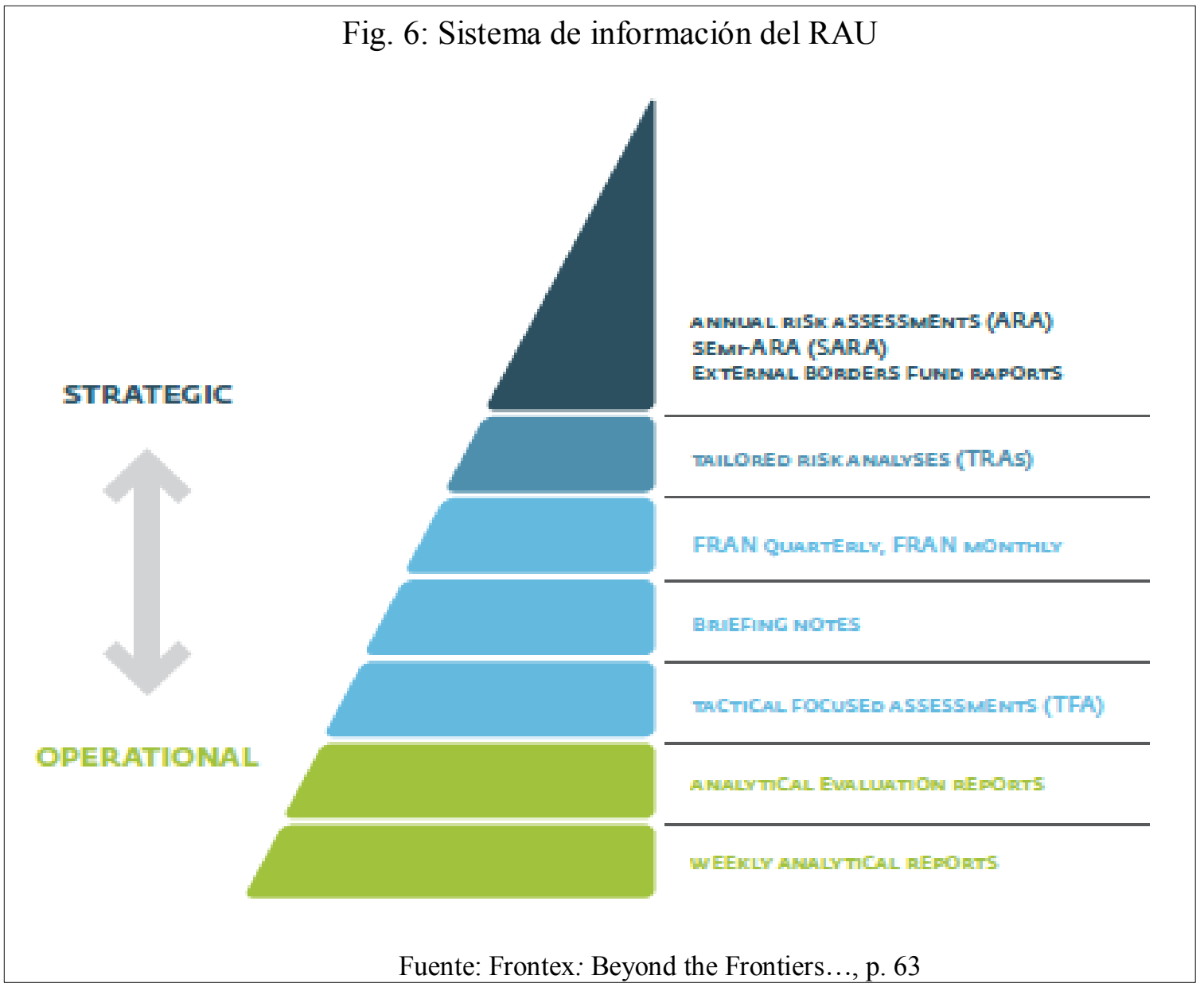

La presentación de un informe de "análisis de riesgo" es una condición indispensable para el lanzamiento de una JO. Un informe tipo contiene, entre otras posibles informaciones, los orígenes, rutas, modus operandi, patrones de los flujos migratorios, situaciones de los países de tránsito, estadísticas de años anteriores, etc... Conviene señalar que estos informes tienen un carácter completamente secreto y son clasificados para otros ciudadanos europeos, investigadores e incluso instituciones comunitarias $^{215}$. La justificación oficial para este secretismo es que los análisis contienen información muy sensible que proveen fuentes de las autoridades de los países de origen y tránsito. A partir de 2010 la Agencia comenzó a publicar en su página web algunos de estos análisis ${ }^{216}$.

${ }^{215}$ El Parlamento solo tiene funciones de control respecto al presupuesto de la Agencia (art. 29.6 y 29.8 del Reg. 2007/2004)

${ }^{216} \mathrm{Se}$ pueden consultar en: http://frontex.europa.eu/publications/?c=risk-analysis (Consulta: 10 de enero de 2016) 
El departamento de la Agencia encargada de realizar estos informes es la RAU (Risk Analysis Unit). Está compuesta por oficiales y guardias fronterizos de EEMM y expertos independientes ${ }^{217}$. La RAU utiliza para la elaboración de sus análisis un modelo conocido como CIRAM (Common Integrated Risk Analysis Model) ${ }^{218}$. E1 modelo CIRAM es una herramienta estratégica, que habilita la recolección, análisis y distribución de información relativa a la seguridad fronteriza. En un informe del Consejo de mayo de 2003, se estableció que CIRAM "dualistically deals with the threats and risks" y "Member States are obliged to undergo a risk assessment of their national border security system" Así mismo la Agencia ha creado redes de cooperación e intercambio de información con algunos países de origen, por ejemplo la Africa Frontex Intelligence Community (AFIC) y la Seahorse Mediterranean Network, un proyecto de Eurosur establecido en 2013 entre los servicios de vigilancia fronteriza de los estados mediterráneos, que busca crear una red euroafricana de vigilancia a través de satélites.

Existen cuatro unidades operacionales (coordinación y operaciones de retorno, fronteras terrestres, fronteras marítimas o aeropuertos), cuyo director es responsable de elaborar el Plan Operacional. De acuerdo al artículo 6 del Reglamento, el Plan Operacional debe incluir "general description of the preparations, schedule, way of action, technical means and manpower available, detailed budget for the operation, implementation costs, risks connected with implementation, etc...". Es en esta fase cuando se produce la mayor parte de la participación de los Estados Miembros en el diseño de las operaciones. Dado que Frontex no cuenta con sus propios recursos técnicos (policías, equipos de vigilancia, medios de transporte, etc...), la decisión sobre la puesta en marcha de las operaciones, así como su alcance depende de la predisposición de los gobiernos, especialmente de los de los países mediterráneos ${ }^{219}$.

La puesta en marcha y ejecución de la JO se realiza desde el Centro de Coordinación Internacional (ICC-International Coordination Centre). Se ubica en el

\footnotetext{
${ }^{217}$ Lu sede del Centro de Análisis de Riesgo (RAC, Risk Analysis Centre) quedó fijada en Helsinki, junto al Frontier Guard Headquarters. Empezó a trabajar el 1 de abril de 2003. Elabora dos informes generales cada año que cubren todas las fronteras exteriores. El de 2014 puede consultarse aquí: http://frontex.europa.eu/assets/Publications/Risk Analysis/Annual Risk Analysis 2014.pdf

(Consulta: 10 de enero de 2016)

${ }^{218} \mathrm{Su}$ elaboración quedo a cargo de SCIFA+ (Strategic Committee on Inmigration, Frontiers and Asylum), que lo adoptó el 28 de enero de 2003

${ }^{219}$ En 2007 FRONTEX creó un "Registro Central de equipo técnico disponible" (CRATE). Este consiste en un inventario de equipo técnico de control y vigilancia fronteriza que los Estados ponen a disposición de la agencia y de otros EEMM para las operaciones conjuntas y los equipos RABIT. Está compuesto por unos 100 barcos, 20 aviones, 25 helicópteros y centenares de equipos de control fronterizo: radares, cámaras térmicas y detectores móviles.
} 


\section{CAPÍTULO 2}

país anfitrión, que dirige sus funciones bajo asesoramiento de Frontex. Dirige la operación siguiendo las directrices del plan operativo, se ocupa de la recogida de información ante cualquier incidente, emite informes y coordina la actuación de los agentes destinados a la operación, así como los de otros EEMM o terceros estados que participen.

En muchas ocasiones el Plan Operativo incluye la participación de agentes expertos de otros países (EU Guest Officers). Se trata de agentes fronterizos que proceden de otros EEMM y trabajan junto a los guardias nacionales y otros agentes de Frontex bajo la dirección del país anfitrión. Están dotados de poderes ejecutivos: pueden realizar controles, revisar documentación y conducir entrevistas, etc... Sin embargo, carecen de capacidad de poder decisión. Por su parte el propio personal de la agencia, se encuentra a cargo de la vigilancia y la coordinación de la operación a nivel local, así como la elaboración de informes y documentos de la operación. Su nombre oficial es Frontex Support Officers (FSE).

Recientemente, con la aprobación del Reglamento $656 / 2014{ }^{220}$ Frontex se ha dotado de un marco de actuación más definido para sus actividades de vigilancia marítima, incluyendo la interceptación marítima, el desembarco y las labores de SAR. Por primera vez, el parlamento introduce una serie de líneas rojas y mecanismos de control a las JO. Los aspectos técnicos del reglamento se tratarán en el capítulo quinto.

Las JO han generado fricciones entre EEMM, llegando a la retira unilateral de Malta en marzo 2010 por desacuerdos con las posiciones respecto a las operaciones de vigilancia y el desembarco de las personas rescatadas ${ }^{221}$. Desde entonces el país insular no ha tomado parte en ninguna de las operaciones, e incluso su posición independiente ha dado lugar a conflictos como el MV Pinar ${ }^{222}$. Tanto la posición del país respecto a las nuevas normas como el citado conflicto serán expuestos más adelante.

\footnotetext{
${ }^{220}$ Reglamento (UE) no 656/2014 del Parlamento Europeo y del Consejo de 15 de mayo de 2014 por el que se establecen normas para la vigilancia de las fronteras marítimas exteriores en el marco de la cooperación operativa coordinada por la Agencia Europea para la Gestión de la Cooperación Operativa en las Fronteras Exteriores de los Estados miembros de la Unión Europea. DO L 189 de 27 de junio de 2014, pp. 93-107. Disponible en: http://eur-lex.europa.eu/legalcontent/ES/TXT/PDF/?uri=OJ:JOL 2014189 R 0005\&from=ES (Consulta: 10 de enero de 2016) 221 "Malta to no longer host Frontex missions, PN, PL MEPs trade blows after EP vote", Malta Independent, 26 marzo de 2010. Disponible en: http://www.independent.com.mt/articles/2010-0326/news/malta-to-no-longer-host-frontex-missions-pn-pl-meps-trade-blows-after-ep-vote-272208/ (Consulta: 10 de enero de 2016)

${ }^{222}$ Tras la retirada de la operación Mare Nostrum, Malta aceptó participar "in very exceptional cases, if security factors require it" en la Operación Tritón. En: Carrera, Sergio y den Hertog, Leonhard: Whose Mare? Rule of law challenges in the field of European border surveillance in the Mediterranean, CEPS
} 


\subsubsection{RABIT}

El Reglamento $863 / 2007^{223}$ que creaba los equipos de intervención rápida (RABIT, de Rapid Borders Intervention Teams) dotó de mayores tareas y responsabilidades a los oficiales que participaran en las operaciones de la Agencia. Se trata de una plantilla de agentes fronterizos y expertos de diversos países europeos, con la función de auxiliar a los EEMM durante llegadas imprevistas a sus fronteras de grupos de inmigrantes en situación irregular y solicitantes de asilo. Empleados en situaciones de carácter excepcional y urgente, para su intervención no se lleva a cabo el modelo de intervención regular de cuatro fases de las JO. Por lo tanto, se trata de operaciones limitadas en el tiempo, que tratan de responder ante situaciones de llegadas masivas de migrantes que sobrepasan las capacidades de gestión fronteriza de los EEMM. Desde su creación, las operaciones donde han intervenido los RABIT han sido escasas. La primera, que transcurrió en la frontera terrestre greco-turca, data de 2010. Los agentes de los RABIT deben llevar un brazalete azul con la insignia de la UE y la agencia durante el desempeño de sus funciones a modo de identificación. Así mismo pueden llevar armas de servicio, munición y equipo autorizados con arreglo a la legislación nacional del Estado miembro de origen, y emplear el uso de la fuerza si es considerado necesario para el cumplimiento de sus funciones ${ }^{224}$. Actualmente el número de personal vinculado a estos equipos está alrededor de 175 personas, encuadrados en "Rapid Pool". Se trata de un grupo diverso, dado que las autoridades encargadas de la vigilancia y control fronterizos varían de país a país ${ }^{225}$.

En octubre 2013 se pone en marcha Eurosur ${ }^{226}$, el sistema europeo de vigilancia de fronteras. El reglamento de creación fija dos objetivos: por un lado "prevenir y combatir

Papers, No. 79, 27 de enero de 2015, p. 9. Disponible: https://www.ceps.eu/system/files/LSE_79.pdf (Consulta: 10 de enero de 2016)

${ }^{223}$ Reglamento (CE) no 863/2007 del Parlamento Europeo y del Consejo, de 11 de julio de 2007, por el que se establece un mecanismo para la creación de equipos de intervención rápida en las fronteras y que modifica el Reglamento (CE) no 2007/2004 del Consejo por lo que respecta a este mecanismo y regula las funciones y competencias de los agentes invitados. DO L 199 de 31 de julio de 2007, pp. 30-39. Disponible en: http://eur-lex.europa.eu/legal-content/ES/TXT/PDF/?uri=CELEX:32007R0863\&from=ES (Consulta: 10 de enero de 2016)

${ }^{224}$ Ibíd., art. 6.5 y 6.6 .

225 Se puede consultar un listado en Carrera, Sergio: Towards a common european border service?, CEPS Working Document No. 331, junio de 2010, Anexo 1. Disponible en: https://www.ceps.eu/publications/towards-common-european-border-service (Consulta: 10 de enero de 2016)

${ }^{226}$ Reglamento (UE) $n^{\circ}$ 1052/2013 del Parlamento Europeo y del Consejo, de 22 de octubre de 2013, por el que se crea un Sistema Europeo de Vigilancia de Fronteras (Eurosur). DO L 295, 6 de noviembre de 2013, pp. 11-26. Disponible h: $\underline{\text { http://eur- }}$ 


\section{CAPÍTULO 2}

la inmigración ilegal y la delincuencia transfronteriza" y por otro "contribuir a garantizar la protección y salvamento de las vidas de los inmigrantes"227. Funciona en coordinación con los sistemas de vigilancia nacionales ${ }^{228}$. El primer programa multianual se extenderá por el periodo de 2014 a 2020 y cuenta con un presupuesto de 244 millones de euros. Una de las características de Eurosur es el empleo de alta tecnología (sensores de movimiento instalados en buques marítimos, sistema de monitoreo por satélite, uso de drones, etc...). De acuerdo a fuentes europeas, esta tecnología contribuirá a salvar vidas de migrantes en el mar, pero autores más escépticos han criticado que el sistema nace enfocado a prevenir la llegada de migrantes irregulares a Europa ${ }^{229}$.

\subsubsection{Operaciones de retorno}

Entre las operaciones llevadas a cabo por Frontex también se incluyen devoluciones de inmigrantes irregulares a su país de origen o a un tercer país. Esta competencia clave, donde la agencia ha venido asumiendo mayores competencias. Si en el reglamento de creación apenas aparecía en labores de apoyo ${ }^{230}$, en su revisión de 2011 se ampliaban las competencias, incluyendo relativas a la coordinación y financiación de operaciones que involucraran a dos o más EEMM, la contratación de aeronaves y la elaboración de un código de conducta sobre las operaciones de retorno, así como la fijación de estándares de criterios en relación a los derechos fundamentales e incluso la elaboración de planes operativos de retorno.

La redacción del nuevo artículo plantea una serie de dudas sobre las garantías legales de estas operaciones. Por un lado, se subordinan los convenios con terceros estados al pleno respeto de la CDF, requisito que supone un débil compromiso en tanto no se establecen mecanismos de control del cumplimiento. De la misma forma rebaja al condicional la obligación de que "El control de las operaciones de retorno conjuntas debería llevarse a cabo sobre la base de criterios objetivos y transparentes y abarcar la

lex.europa.eu/LexUriServ/LexUriServ.do?uri=OJ:L:2013:295:0011:0026:ES:PDF (Consulta: 10 de enero de 2016)

227 Ibíd., art. 2

${ }^{228}$ En España se llama Sistema Integrado de Vigilancia Exterior (SIVE) y está gestionado por la Guardia Civil. En Italia, existen varios sistemas (SIA, SMART...) gestionados por cada autoridad. En Malta (VMS-Vessel Monitoring System) y en Grecia (VTMIS-Vessel Traffic Management Information System) se emplea el mismo dispositivo para la seguridad marítima que para la vigilancia. Se puede encontrar un análisis más detallado de estos dispositivos en: Kenk, V.S., Križaj,, J., Štruc, J. \& Dobrišek S.: Smart Surveillance Technologies in Border Control, European Journal of Law and Technology, Vol 4., No. 2., 2013. Disponible en: http://ejlt.org/article/view/230/378 (Consulta: 10 de enero de 2016)

${ }^{229}$ Guild, E. y Carrera, S.: EU Borders... op. cit., p. 13

${ }^{230}$ Reglamento 2007/2004, art. 9 
totalidad de la operación de retorno conjunta, desde la fase previa a la salida hasta la entrega de los repatriados en el país de retorno" Además, la Agencia facilitará asistencia y la contratación de aeronaves "sin valorar la pertinencia de las decisiones de retorno" 231 .

El reglamento insta a elaborar un Código de Conducta para el retorno de nacionales de terceros países que se encuentren en situación de estancia irregular, donde se garantice "que el retorno discurra de forma humanitaria y con pleno respeto de los derechos fundamentales, y en particular de los principios de la dignidad humana, la prohibición de la tortura y de las penas o los tratos inhumanos o degradantes, el derecho a la libertad y a la seguridad, los derechos a la protección de los datos personales y a la no discriminación" ${ }^{232}$. Finalmente, el Código de Conducta para las operaciones de retorno se aprobó el 7 de octubre de 2013, acompañado por otro documento de Buenas Prácticas. Recoge el respecto a los derechos fundamentales en las operaciones de retorno:

JROs are to be conducted in a humane manner and in compliance with fundamental rights as enshrined in the EU Charter of Fundamental Rights and in other relevant international instruments, in particular the principles of human dignity, the right to life, the principle of non-refoulement, the right to asylum, the prohibition of torture and of inhuman or degrading treatment or punishment, the right to liberty and security, the rights of the child, the rights to the protection of personal data and nondiscrimination, and the right to respect for private and family life. ${ }^{233}$

Así mismo el código introduce otra serie de medidas sobre las operaciones, el uso de la fuerza o el monitoreo de las operaciones ${ }^{234}$ si bien los agentes encargados no tienen capacidad para interferir con la ejecución de una operación ${ }^{235}$.

\footnotetext{
231 Reglamento $1168 / 2011$, art. 9

232 Ibíd., art. 9.1 ter

${ }^{233}$ Frontex: Code of conduct for joint return operations coordinated, Varsovia, noviembre de 2013, art. 4.1 Disponible

en: http://frontex.europa.eu/assets/Publications/Training/Fundamental Rights Training for Border Guardsl. pdf (Consulta: 10 de enero de 2016)

${ }^{234}$ Ibíd., art. 13

${ }^{235}$ Ibíd., art. 14.4
} 


\section{CAPÍTULO 2}

\subsubsection{Acuerdos con terceros países}

Desde su creación, una de las líneas de trabajo de Frontex ha sido la búsqueda de la cooperación fronteriza con terceros países $^{236}$. Se trata de una de los objetivos prioritarios de la política migratoria europea, enunciada ya en el programa de Tampere, y desarrollada a partir de la presentación en 2005 de una estrategia para la dimensión exterior de la $\mathrm{UE}^{237}$. Dicha estrategia se basa en la premisa de que los Estados europeos no se encuentran comprometidos legalmente respecto a las obligaciones de protección internacional mientras que los refugiados no hayan conseguido entrar en el territorio del Estado $^{238}$.

Las actividades incluirían la participación conjunta de funcionares policiales o de otro tipo en las operaciones conjuntas, así como la participación en procesos formativos. Hasta la fecha, Frontex ha concluido acuerdos con 17 países extracomunitarios, la mayoría de los Balcanes y antiguas repúblicas soviéticas. Aunque Frontex ha llevado a cabo negociaciones con la mayoría de los países de origen y tránsito de las migraciones por la ruta mediterránea, solamente ha conseguido firmar acuerdos con Cabo Verde $(2011)^{239}$ y Turquía (2012) ${ }^{240}$. Actualmente se están negociando acuerdos con otros países más, incluidos Libia, Marruecos, Senegal, Mauritania, Egipto y Túnez.

A pesar de que el proceso de negociación y aprobación de un acuerdo entre la UE y terceros países se encuentra profundamente desarrollado ${ }^{241}$, los acuerdos celebrados por

\footnotetext{
${ }^{236}$ El Reglamento de creación ya incluía una disposición tendente a la cooperación con terceros países (art. 14)

${ }^{237}$ Comunicación de la Comisión: Hacia una estrategia sobre la dimensión exterior del Espacio de Libertad, Seguridad y Justicia, de 12 de octubre de 2005. (COM(2005) 491 final). Disponible en: http://eur-lex.europa.eu/legal-content/ES/TXT/PDF/?uri=CELEX:52005DC0491\&from=EN （Consulta: 10 de enero de 2016)

${ }^{238}$ Gil-Bazo, María Teresa: The Practice of ..., op. cit., p. 593

${ }^{239}$ Frontex: Working Arrangement establishing operational cooperation between the European Agency for the Management of Operational Cooperation at the External Borders of the Member States of the European Union (Frontex) and the Policia Nacional de Cabo Verde, enero de 2011. Disponible en: http://frontex.europa.eu/assets/Partners/Third countries/WA with Cape Verde.pdf (Consulta: 10 de enero de 2016)

${ }^{240}$ Frontex: Memorandum of understanding on establishing cooperation between the European Agency for the Management of Operational Cooperation at the External Borders of the Member States of the European Union and the Ministry of Foreign Affairs of the Republic of Turkey, mayo de 2012. Disponible en: http://frontex.europa.eu/assets/Partners/Third countries/WA with Turkey.pdf (Consulta: 10 de enero de 2016)

${ }^{241}$ TFUE, art. 218.6. a) v) donde se establece la necesidad de que los acuerdos sean aprobados por el EP en ámbitos en que se aplique el procedimiento legislativo ordinario, lo que incluye la lucha contra la inmigración irregular y el asilo.
} 
la Agencia se han presentados como de naturaleza técnica ${ }^{242}$, y por tanto fuera del control ejercido por otras instituciones comunitarias, esencialmente el TJUE y el $\mathrm{PE}^{243}$. Por regla general, estos acuerdos se firman entre Frontex y las fuerzas policiales o las autoridades encargadas de la vigilancia de fronteras. En particular, es de especial preocupación la falta de referencias a las obligaciones de derechos humanos y a la responsabilidad ejercida por los agentes de Frontex en el desarrollo de las operaciones. El nuevo reglamento de Frontex obliga a que estos acuerdos incluyan una clausula relativa a los derechos fundamentales ${ }^{244}$. A pesar de este avance, mientras los acuerdos no pasen a ser objeto de revisión y control por otros organismos europeos, estas cláusulas seguirán sin tener carácter imperativo ${ }^{245}$.

La cooperación con otros Estados no les libera de sus obligaciones internacionales de respeto y protección de los derechos humanos. Si durante una operación conjunta con fuerzas policiales de dos o más Estados se produce una interceptación y los pasajeros son entregados a las fuerzas del país de origen o tránsito, eso no elimina sus obligaciones en caso de que las personas retornadas sufran violaciones de sus derechos fundamentales, o sean retornados a un tercer Estado donde las sufran. Sin embargo, el contenido y límites de estas obligaciones se encuentran en discusión, tal como expresa la jurisprudencia del $\mathrm{TEDH}^{246}$. El incumplimiento de una norma del derecho internacional puede, de hecho, conllevar responsabilidades para más de un actor.

Los Estados europeos del mediterráneo también han firmado acuerdos bilaterales de cooperación en la vigilancia fronteriza. Entre las atribuciones que se incluyen suelen hallarse, entre otras, el intercambio de información sobre las salidas de embarcaciones,

\footnotetext{
${ }^{242}$ Los acuerdos suelen incluir una cláusula sobre su estatus legal que la desliga de las obligaciones del derecho internacional. Por ejemplo, en el acuerdo con Cabo Verde (supra n. 237, p. 7): "The present Working Arrangement shall not be considered as an international treaty. Practical implementation of its contents shall not be regarded as fulfilment of international obligations by the European Union and its Institutions and Cape Verde."

${ }^{243}$ De hecho, el propio EP reclamó una mayor control democrático en estos acuerdos; Resolución del Parlamento Europeo, de 18 de diciembre de 2008, sobre la evaluación y el desarrollo futuro de la Agencia Frontex y el sistema europeo de vigilancia de fronteras (Eurosur) (2008/2157(INI)), p. 36. DO C/45 E 199 de 23 de febrero de 2010, pp. 41-48. Disponible en: http://eurlex.europa.eu/LexUriServ/LexUriServ.do?uri=OJ:C:2010:045E:0041:0047:ES:PDF (Consulta: 10 de enero de 2016)

244 Reglamento 1168/2011, art. 15.2

245 Por ejemplo, está clausula se incluye en el acuerdo con Turquía, posterior a la reforma de 2011 (supra n. 238, p. 15). Sin embargo, el mantenimiento de cláusulas que excluyen la vigilancia de las obligaciones internacionales de los Estados firmantes, según los cuales el acuerdo "shall not be considered as a document having legal effect under international law" (Ibíd., p. 17)

246 Vid. TEDH: Bosphorus Hava Yollari c. Irlanda, sentencia de 30 de junio de 2005, n 45036/98, $\S 154$, donde señala que "The State is considered to retain Convention liability in respect of treaty commitments subsequent to the entry into force of the Convention". Disponible en: http://hudoc.echr.coe.int/eng?i=00169564 (Consulta: 10 de enero de 2016)
} 


\section{CAPÍTULO 2}

las operaciones de patrullaje conjuntas, o la formación de agentes y policías de fronteras.

España ha sido uno de los países que más ha desarrollado la cooperación policial con los países de origen y tránsito. Las patrullas mixtas entre gendarmería marroquí y la guardia civil española comenzaron en 2004. Según uno de los guardias, "Una semana al mes nosotros patrullamos allí y una semana al mes ellos patrullan aquí. Nos llevamos bien, hay colaboración plena. Ellos saben cuándo interceptamos aquí y nos comunican también cuando interceptan alli" ${ }^{247}$. En 2012 se ponen en funcionamiento los Centros de Cooperación Policial (CCP) ${ }^{248}$, que cuenta con miembros de las fuerzas policiales de ambos países y tiene como objetivo prevenir y coordinar la lucha contra la inmigración irregular y la trata de seres humanos. De la misma manera existe una colaboración fluida con Mauritania (desde 2009) y Senegal (desde 2006), En ambos casos se trata tanto de barcos y helicópteros españoles patrullando junto a las fuerzas de gendarmería locales.

En Italia, la colaboración entre sus autoridades y libias durante la década previa a la caída de Muamar el Gadafi en 2011 fue motivo de denuncias por la devolución en aguas internacionales o libias de cientos de migrantes y potenciales solicitantes de asilo. ACNUR y el Consejo de Europa señalaron que semejantes operaciones de push backs vulneraban las obligaciones italianas respecto a la CG51 ${ }^{249}$. Las operaciones conjuntas de interceptación entre patrulleras de los dos países comenzaron el 6 de mayo de 2009, y durante la primera semana 500 migrantes fueron devueltos a Libia ${ }^{250}$.

\footnotetext{
${ }^{247}$ Aldalur, M.: Clandestinos, op.cit., p. 164.

${ }^{248}$ En virtud del Acuerdo entre el Gobierno de España y el Gobierno de Marruecos en materia de cooperación transfronteriza, que entró en vigor el 20 de mayo de 2012.

${ }^{249}$ Ver en especial los informes de HRW: Stemming the flow. Abuses Against Migrants, Asylum Seekers and Refugees, Vol. 18, No. 5 (E), septiembre de 2006. Disponible en: https://www.hrw.org/reports/2006/libya0906/libya0906webwcover.pdf (Consulta: 10 de enero de 2016); y Pushed back, pushed around. Italy's Forced Return of Boat Migrants and Asylum Seekers, Libya's Mistreatment of Migrants and Asylum Seekers. No. 1.56432-537, septiembre de 2009. Disponible en: https://www.hrw.org/sites/default/files/reports/italy0909web 0.pdf (Consulta: 10 de enero de 2016)

${ }^{250}$ HRW: Pushed back..., op. cit., p. 23
} 


\subsection{El futuro de las políticas migratorias europeas}

En el año 2011 Frontex encargó la elaboración de un estudio titulado Futures of Borders $^{251}$, en el que se planteaban cuatro posibles escenarios futuros de la política migratoria y fronteriza de la UE: uno continuista, otros dos donde la situación general mejoraba o empeoraba, y el último presentaba un escenario catastrófico.

Lo interesante de las distintas hipótesis era cómo reflejaban de las prioridades y factores de la política actual. La cuestión de los derechos humanos de las personas migrantes y refugiadas sólo se citaba en el escenario optimista, y únicamente como una consecuencia del incremento en la efectividad de las políticas de seguridad y control. La garantía plena de los derechos de migrantes y refugiados sólo sería posible una vez que aumentaran las detenciones, se atacara más eficazmente las redes de tráfico y como consecuencia, se redujera la inmigración irregular ${ }^{252}$.

Merece la pena señalar el carácter profético del escenario titulado 'Back to the Future: A Perfect Storm', en donde un incremento del flujo de refugiados y migrantes irregulares llevaba a la ruptura de la solidaridad entre los EEMM y a la adopción de medidas más duras que penalizaban la entrada ilegal y la colaboración con las redes de tráfico.

Los conflictos de Libia y Siria han producido una grave crisis de refugiados, muchos de los cuales han escapado a Europa y solicitado asilo. En 2015, se produjeron alrededor de 750.000 llegadas a Grecia, principalmente de personas sirias, afganas e iraquíes $^{253}$. Las cifras anuales de solicitantes de asilo se han duplicado en los últimos años. En el verano de 2015 la llegada masiva de refugiados procedentes de estos y otros países ha llevado al comisario de migración, Dimitris Avramopoulos, a calificarla como "la peor crisis de refugiados desde la II Guerra Mundial"254.

\footnotetext{
${ }^{251}$ Frontex: Futures of Borders: A Forward Study of European Border Checks. Frontex Tender/64/2010 Study for RDU. Lot 2. Liron Systems Ltd./University of Southampton/University of Ben Gurion, Eilat., diciembre de 2011. Disponible en: http://frontex.europa.eu/assets/Publications/Research/Futures of Borders.pdf (Consulta: 10 de enero de 2016)

252 Ibíd, p. 75.

253 ACNUR, Greece Data snapshot, 2 de diciembre de 2015. Disponible en: http://data.unhcr.org/mediterranean/download.php?id=232 (Consulta: 10 de enero de 2016)

${ }^{254}$ Nota de prensa de la Comisión del 14 de agosto de 2015. Disponible en: http://europa.eu/rapid/pressrelease_SPEECH-15-5498_en.htm (Consulta: 10 de enero de 2016)
} 
Fig. 7: Evolución de los solicitantes de asilo 2013-2015

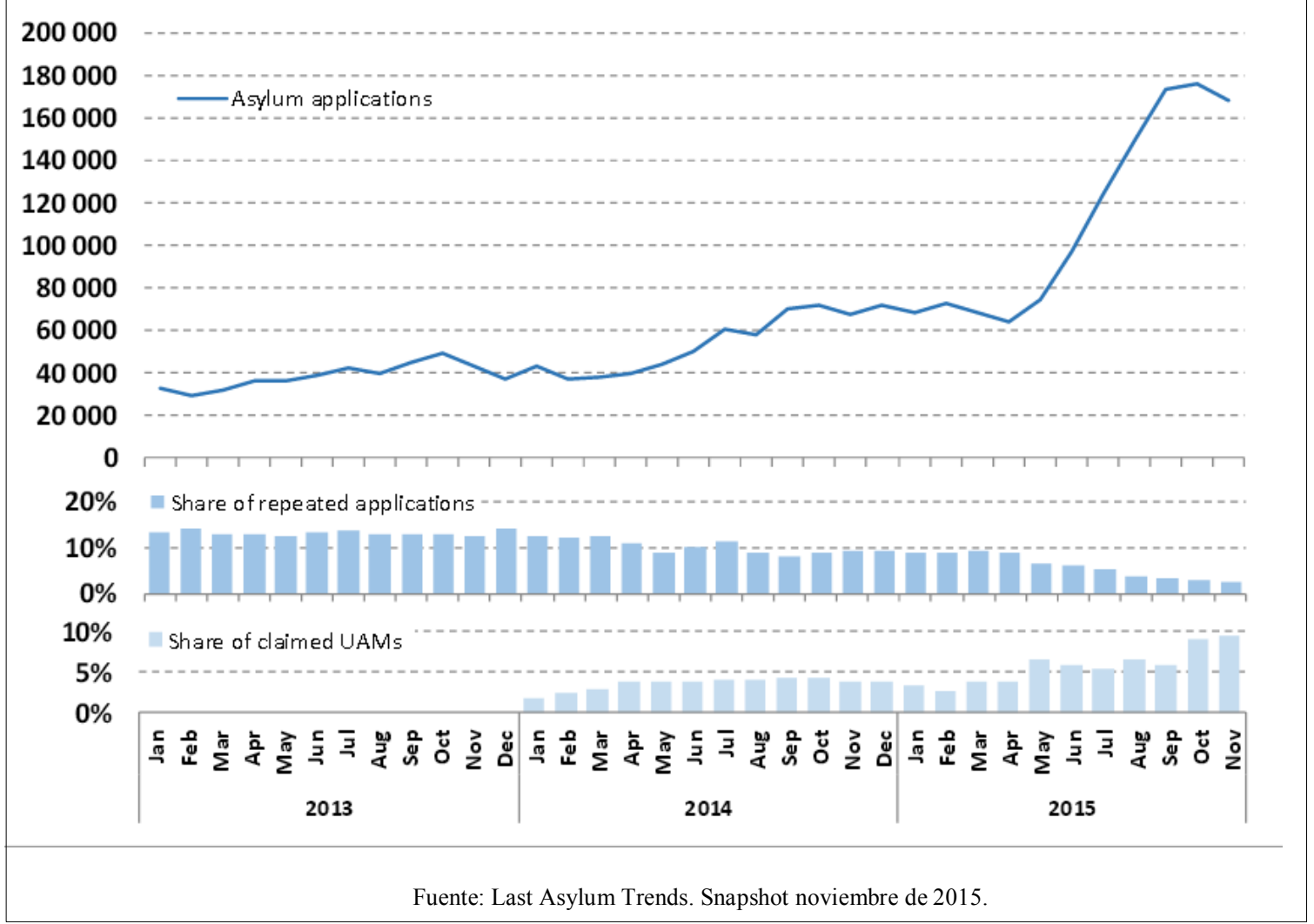

El 13 de mayo de 2015, menos de un mes después de la tragedia del 19 de abril en la que fallecieron alrededor de 700 migrantes en el canal de Sicilia, la Comisión Europea lanzó la nueva Agenda Europea de Migración, con el subtítulo de Gestionando mejor la migración en todos los aspectos ${ }^{255}$. Tras el fin del programa de Estocolmo, que no fue sustituido por otro programa similar, la Agenda fija los objetivos y líneas estratégicas de la UE en los próximos años. El documento plantea dos respuestas a la crisis de la migración marítima: actuaciones a implementar en un corto plazo, y revisión de las líneas de trabajo a medio y largo plazo.

Entre las primeras, se señalan cuatro objetivos para la acción inmediata: prevenir pérdidas de vidas en el mar; asegurar el reasentamiento de estas personas; el desarrollo de los RPPs y apoyar a los países europeos más afectados por la situación debido a su posición geográfica. Si bien varios objetivos han aparecido de forma recurrente en los documentos de trabajo y memorándums del área JAI, hay que valorar positivamente que

255 Comunicación de la Comisión al Parlamento Europeo, al Consejo, al Comité Económico y Social Europeo y al Comité de las Regiones, de 13 de mayo de 2015. Una Agenda Europea de Migración. (COM (2015) 240 final. Disponible en http://eur-lex.europa.eu/legalcontent/ES/TXT/PDF/?uri=CELEX:52015DC0240\&from=E (Consulta: 10 de enero de 2016) 
se cite en primer lugar la tragedia humana de las pérdidas de vida como una de las llamadas a la acción inmediata. Sin embargo, al bajar al nivel de concreción de las medidas propuestas, vemos que no existe ningún cambio de estrategia:

a) El incremento de los fondos para Frontex.

b) El lanzamiento de operaciones contra las redes de trata consistentes en capturar y destruir sus embarcaciones

c) La puesta en marcha del sistema 'Hotspot', que busca agilizar los procedimientos de identificación, registro y devolución de los migrantes llevados a tierra.

En cuanto a la revisión de las líneas generales, se citan cuatro pilares de la política migratoria:

1. La reducción de los incentivos a la migración irregular, abordando las causas en los países de origen, desmantelando las redes de tráfico y trata de personas, y mejorando la aplicación de las políticas de retorno.

2. Salvar vidas y mejorar la seguridad de las fronteras exteriores

3. Fortalecer el SECA y articular un sistema de solidaridad entre los EEMM ${ }^{256}$.

4. Desarrollar una nueva política de migración legal, en vista de las necesidades del continente de trabajadores cualificados.

En resumen, la respuesta de la UE en esta nueva agenda de migración se puede calificar sin lugar a dudas como decepcionante. Las políticas implementadas en la última década no han conseguido sus objetivos de limitar la llegada de migrantes irregulares, acabar con las organizaciones criminales de tráfico y trata de personas, dar una respuesta adecuada a las crisis de refugiados libia o siria, ni evitar las dramáticas muertes de miles de personas en naufragios. A pesar de este visible fracaso, no se plantea una revisión de las políticas ni una búsqueda de alternativas. En todo caso, se profundiza la visión securitaria del problema, y la agilización de los retornos de migrantes irregulares.

\footnotetext{
${ }^{256}$ En abril de 2016, la Comisión presentó una propuesta de reforma del SECA. Entre las medidas más importantes, se incluía la reforma del Reglamento de Dublín con un sistema estable de cuotas de reubicación de solicitantes de asilo, sanciones para los solicitantes que abandonen el país responsable, o la armonización de las listas de "países seguros". Comunicación de la Comisión al Parlamento Europeo y al Consejo, de 6 de abril de 2016. Towards a reform of the Common European Asylum System and enhancing legal avenues to Europe. (COM (2016) 197 final. Disponible en: http://ec.europa.eu/dgs/home-affairs/what-we-do/policies/european-agenda-migration/proposalimplementationpackage/docs/20160406/towards a reform of the common european asylum system and enhancing 1 egal_avenues to europe - 20160406 en.pdf (Consulta: 14 de abril de 2016)
} 

El principio de non-refoulement 



\section{El principio de non-refoulement}

\subsection{Definición}

Uno de los principios básicos de la soberanía es la facultad de los Estados para decidir sobre la entrada, permanencia y salida de los extranjeros en su territorio. Facultad que incluye la posibilidad de devolver a los extranjeros que se encuentren en situación administrativa irregular, y de negar la entrada a su territorio a quienes buscan entrar $^{257}$. Esta potestad no es absoluta, sino que se encuentra límites en una serie de disposiciones presentes en el Derecho Internacional. Estas limitaciones tienen que ver con la condición de aquellos individuos que puedan ser objeto de protección internacional, y con el procedimiento por el que el estado lleva a cabo la expulsión.

El principio de non-refoulement establece que un individuo no debe ser expulsado, extraditado o rechazado en la frontera de un país donde su vida o libertad puedan correr peligro como consecuencia de dicha devolución. La CG51 fue la primera norma del derecho internacional que lo incluyo expresamente, en su artículo 33.1: "Ningún Estado Contratante podrá, por expulsión o devolución, poner en modo alguno a un refugiado en las fronteras de territorios donde su vida o su libertad peligren por causa de su raza, religión, nacionalidad, pertenencia a determinado grupo social o de sus opiniones políticas"

El artículo fija obligaciones negativas a los Estados. Así lo entiende Goodwin-Gill, para el que no constituye una obligación de los Estados de admitir a los refugiados sino simplemente de no devolverles allí donde sus vidas o libertad pudieran estar en peligro $^{258}$. Sin embargo, tal como señaló Noll, su aplicación también conlleva una mínima- consecuencia positiva interna: "Non-refoulement is about being admitted to

\footnotetext{
257 Maurice Kamto, relator especial de la CDI para la expulsión de extranjeros, recogió hasta siete nociones similares que usaban los estados para referirse a la expulsión: deportación, extradición, alejamiento, conducción a la frontera, devolución, no admisión, traslado o transferencia, entrega. Segundo informe sobre la expulsión de los extranjeros. Comité Derecho Internacional, $58^{\circ}$ periodo de sesiones 2006. A/CN.4/573. Disponible en: $\underline{\text { http://daccess-dds- }}$ ny.un.org/doc/UNDOC/GEN/N06/438/14/PDF/N0643814.pdf?OpenElement (Consulta: 12 de enero de 2016)

${ }^{258}$ Goodwin-Gill, G. y McAdam, J.: The Refugee in..., op. cit., p. 132
} 


\section{CAPÍTULO 3}

the State community, although in a minimalist form of non-removal. It could be described as a right to transgress an administrative border" ${ }^{259}$.

La gran aceptación internacional de la CG51 y el reconocimiento que ha adquirido a lo largo de los años, ha llevado a que el principio de non-refoulement sea considerado como una norma del derecho internacional consuetudinario, alcanzando el estatus de ius cogens, esto es, reviste la naturaleza jurídica de una norma perentoria del derecho internacional que no admite su derogación ${ }^{260}$. La Declaración de San Remo, proclamada en 2001 con motivo del 50 aniversario de la CG51, definió el principio de nonrefoulement como "the cornerstone of international refugee law". ${ }^{261}$ Así mismo el TJUE consideró, en un caso relativo a la Directiva sobre requisitos para el reconocimiento, que:

la Convención de Ginebra constituye la piedra angular del régimen jurídico internacional de protección de los refugiados y que las disposiciones de la Directiva relativas a los requisitos para la concesión del estatuto de refugiado y al contenido de éste fueron adoptadas para guiar a las autoridades competentes de los Estados miembros en la aplicación de la citada Convención, sobre la base de conceptos y criterios comunes. ${ }^{262}$

\subsection{Niveles de protección}

El Alto Comisionado de Naciones Unidas para los Derechos Humanos distingue entre tres niveles diferenciados de obligaciones del Estado respecto de la expulsión de extranjeros: "With regard to expulsions, three types of protection are available, namely

\footnotetext{
${ }^{259}$ Noll, Gregor: Seeking Asylum at Embassies: A right to Entry under International Law?, International Journal of Refugee Law, Oxford University Press, vol. 17, nº 3, 2005, p. 542.

${ }^{260}$ Allain, Jean: The jus cogens nature of non-refoulement. International Journal of Refugee Law, Oxford University Press, vol. 13, $\mathrm{n}^{\mathrm{o}}$ 4, 2001, pp. 533-558. Tambien Goodwin-Gill y McAdam le otorgan ese character (Goodwin-Gill, G. y McAdam, J.: The Refugee in..., op. cit., p. 354) Por su parte, Hathaway es el académico más relevante que niega este estatus, basándose especialmente en la práctica llevada a cabo por numerosos Estados. Vid: Hathaway, J.: The Rights of ... op. cit., pp. 363-365

${ }^{261}$ Declaración de San Remo Declaration sobre el principio de Non Refoulement, San Remo, Italia, septiembre de 2001. Disponible en: http://www.iihl.org/iihl/Album/San\%20Remo\%20Declaration\%20\%20on\%20the \%20Principle $\% 20$ of $\% 2$ 0Non-Refoulement.doc (Consulta: 12 de enero de 2016)

262 TJUE: "Aydin Salahadin Abdula y otros contra Bundesrepublik Deutschalnd" (C-175/08), sentencia del 2 de marzo de 2010, $\$$ 52. Disponible en: http://curia.europa.eu/juris/document/document.jsf;jsessionid=9ea7d0f130d56b451e0c8ea64f34b942b8d0 93397648.e34KaxiLc3eQc40LaxqMbN4Oc3yLe0?text=\&docid=75296\&pageIndex=0\&doclang=ES\&mo

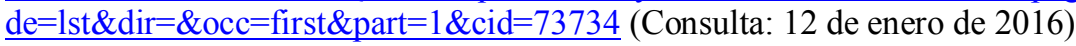


substantive protection against return to face grave violations of human rights, procedural safeguards during deportation procedures, and protection with regard to the methods of expulsions"263. Siguiendo estas categorías, en el presente capítulo identificare el marco legal que regula la discrecionalidad de los Estados para expulsar a los extranjeros de sus territorios, con especial atención a la normativa europea y la jurisprudencia del TEDH.

\subsubsection{No devolución}

En su primera formulación en la CG51, el non-refoulement se circunscribía a las personas refugiadas. En las décadas siguientes el principio ha sido recogido expresamente en otros tratados internacionales de derechos humanos ${ }^{264}$, en la normativa comunitaria $^{265}$ y en los ordenamientos nacionales ${ }^{266}$.

La incorporación de artículos sobre no devolución en todas estas normas ha producido un desarrollo del contenido de dicho principio, ampliando el alcance tanto de los colectivos que protege como de las obligaciones de los Estados. El principio de nonrefoulement no queda ya circunscrito al derecho internacional de los refugiados, sino que ha sido incorporado al DIDH, limitando el derecho de los Estados de devolver a los extranjeros que se encuentren en su territorio, tanto en la cuestión subjetiva (estableciendo categorías de individuos a los que no se prohíbe ser expulsados) como en su contenido (introduciendo salvaguardas legales en el procedimiento de expulsión, y en los métodos para realizarla). Como han señalado algunos autores ${ }^{267}$, de la aplicación

263 OHCHR, Expulsions of aliens in international human rights law. OHCHR Discussion paper. Ginebra, septiembre 2006.

Disponible

en:

http://www2.ohchr.org/english/issues/migration/taskforce/docs/Discussion-paper-expulsions.pdf

(Consulta: 12 de enero de 2016)

${ }^{264}$ Entre otros, la Convención contra la Tortura (art. 3), la Convención contra las desapariciones forzadas (art. 16), la Declaración de 1967 sobre el Asilo Territorial (art. 3), o la CDF (art. 19.1)

${ }^{265}$ Directiva 2011/95/UE, art. 21; Directiva 2013/32/UE, art. 9.3.

${ }^{266}$ La Ley española de asilo señala que "solicitado el asilo por cualquier extranjero, no podrá ser rechazado en frontera o expulsado hasta tanto se haya inadmitido a trámite su petición o resuelto sobre la misma" (art. 5.1) En Italia el art. 19.1 del DLGS 286/98 establece que "In nessun caso pu'o disporsi l'espulsione o il respingimentoverso uno Stato in cui lo straniero possa essere oggetto di persecuzione per motivi di razza, sesso, lingua, cittadinanza, religione, opinioni politiche, condizioni personali o sociali, ovvero possa essere rinviato verso altro Stato in cui non possa essere protetto dalla persecuzione" (http://www.camera.it/parlam/leggi/deleghe/98286dl.htm). En Grecia el art. 24.1 de la ley 3907/2011 (se puede consultar en inglés en: http://www.refworld.org/docid/4da6ee7e2.html) y en Malta en el art. 14.1 del Refugees Act (http://homeaffairs.gov.mt/en/mhasdepartments $/$ the $\% 20$ office $\% 20$ of $\% 20$ the $\% 20$ refugee $\% 20$ commissioner/documents $/$ refugees $\% 20$ act $\% 20$ \%20en.pdf) recogen con fórmulas similares. (Consulta: 12 de enero de 2016)

267 Trevisanut, S.: The Principle of..., op. cit., p. 208 


\section{CAPÍTULO 3}

directa y concreta de la norma han surgido dos preguntas: en qué situaciones el rechazo o devolución de un individuo supone una violación del principio, y quiénes son los individuos protegidos por esta norma.

En contraste con su significado en el Derecho Humanitario, que se encuentra centrado en los solicitantes de asilo, el principio de non-refoulement en el DIDH no está circunscrito a ningún grupo de personas en concreto. Todos los seres humanos se encuentran protegidos frente a la expulsión a un territorio donde existan razones fundadas para creer que pueda existir un riesgo real de ser objeto de la vulneración de ciertos derechos, como la integridad física o el respeto a la vida privada o familiar. Así mismo, para todas las personas que estén sujetas a un procedimiento de expulsión les son reconocidas una serie de garantías y derechos que las protegen de sufrir arbitrariedades, discriminaciones y tratos crueles, inhumanos y degradantes durante dicho proceso.

No cabe reconocer, en todo caso, un derecho individual de carácter universal a no ser devuelto forzosamente al país de origen, ya sea el de nacionalidad o el de residencia habitual. Lo que el DIDH establece es una serie de categorías protegidas frente a la expulsión. De forma necesaria, este "listado" se complementa con un conjunto de derechos, obligaciones y excepciones que dotan de contenido al derecho de nonrefoulement. El contenido de este estándar no se encuentra cerrado, sino que se ha ido modificando de forma progresiva. A partir de los sujetos originales que contaban con la protección (refugiados y solicitantes de asilo), se han ido añadiendo algunos colectivos (mujeres víctimas de violencia de género/por parte de su pareja, MENAs, personas que sufren una enfermedad contra la que no existe tratamiento en su país de nacionalidad o residencia, etc...) y restringiendo en otros casos, si bien no en el derecho sí en la práctica (los sospechosos de ser terroristas islámicos como ejemplo más significativo). De esta lista habría que excluir al grupo más numeroso y significativo de extranjeros susceptibles de la expulsión: los inmigrantes económicos, a los que la protección del principio de non-refoulement no les alcanza.

Una de las principales líneas por las que se ha desarrollado el principio de no devolución ha sido la del riesgo de tortura. Las Convenciones sobre Tortura y Desaparición Forzada incluyeron artículos que prohibían expulsar, devolver, entregar o extraditar a una persona cuando existan razones fundadas para creer que existiera peligro de ser víctima de tales $\operatorname{actos}^{268}$. Si bien la PIDCP no incluía en su articulado

${ }^{268}$ Art. 3 de la Convención contra la Tortura y art. 17 de la Convención Sobre Desaparición Forzada. 
referencia alguna a las expulsiones de extranjeros o refugiados, el $\mathrm{CDH}$ interpretó en su OG sobre el artículo 7 que éste incluía la prohibición de expulsar extranjeros cuando existiera riesgo de tortura. ${ }^{269}$ En el caso Kindler v. Canadá el Comité estableció que si un Estado parte expulsa a una persona de su jurisdicción, y existe una previsible consecuencia de que esto suponga la violación de sus derechos bajo otra jurisdicción, el Estado parte en sí podría estar en violación del Convenio ${ }^{270}$.

Por su parte el Convenio de Roma no contiene un reconocimiento explícito del derecho de asilo ni del non-refoulement, pero la célebre sentencia del caso Soering $c$. Reino Unido el TEDH encontró que la extradición del solicitante (acusado de homicidio en EEUU) constituía una violación del artículo 3 del Convenio -"Nadie podrá ser sometido a tratos inhumanos o degradantes" - porque la situación que sufriría en el corredor de la muerte, incluyendo la tensión psicológica, constituía un trato cruel, inhumano o degradante ${ }^{271}$. Uno de los aspectos más relevantes de la sentencia es la asignación de responsabilidad al Estado:

...hence engage the responsibility of that State under the Convention, where substantial grounds have been shown for believing that the person concerned, if extradited, faces a real risk of being subjected to torture or to inhuman or degrading treatment or punishment in the requesting country. The establishment of such responsibility inevitably involves an assessment of conditions in the requesting country against the standards of Article 3 (art. 3) of the Convention. ${ }^{272}$

\footnotetext{
${ }^{269}$ Vid. Observación General N. 20: Prohibición de la tortura u otros tratos o penas crueles, inhumanos o degradantes (artículo 7), 44 periodo de sesiones, 1992, para. 9. Disponible en: http://tbinternet.ohchr.org/Treaties/CCPR/Shared\%20Documents/1_Global/INT_CCPR_GEC_6621_S.do c (Consulta: 12 de enero de 2016). En su O.G. 31, el CDH amplió esta protección al art. 6, relativo al derecho a la vida: Observación General N. 31: Naturaleza de la obligación jurídica general impuesta a los Estados Partes en el Pacto, $80^{\circ}$ periodo de sesiones, 2004, para. 12. Disponible en: http://docstore.ohchr.org/SelfServices/FilesHandler.ashx?enc=6QkG1d\%2fPPRiCAqhKb7yhsjYoiCfMK oIRv2FVaVzRkMjTnjRO\%2bfud3cPVrcM9YR0iW6Txaxgp3f9kUFpWoq\%2fhW\%2fTpKi2tPhZsbEJW \%2fGeZRATdbWLgyA1RX61E1VC\%2fXrdwzm\%2bNA\%2bPSqz8d7eGbkx8Gng\%3d\%3d (Consulta: 12 de enero de 2016)

270 CDH: Kindler c. Canada, 30 de julio de 1993, $\mathrm{n}^{\circ}$ 470/1991. Disponible en: http://docstore.ohchr.org/SelfServices/FilesHandler.ashx?enc=6QkG1d\%2fPPRiCAqhKb7yhstcNDCvDa n1pXU7dsZDBaDXK6QwAm\%2fLjVm9gFM9MNBR58a0Qm51WUAtMPJ4\%2fv2NOMsdjX7P5LIXJ0 CCvmUBMfYDkc8EE8\%2bKQB51ZJQvDoiM5sUeWwNKpY9rSuPRJHcMQoFIXndkS6uZ5PuEZkam cDHk\%3d (Consulta: 12 de enero de 2016)

271 TEDH: Soering c. Reino Unido, sentencia del 7 de julio de 1989, nº 14038/88, § 111. Disponible en: http://hudoc.echr.coe.int/eng?i=001-57619 (Consulta: 12 de enero de 2016)

${ }^{272}$ Ibíd., § 91
} 


\section{CAPÍTULO 3}

Tras el caso dos aspectos derivados de dicho artículo conocieron un mayor desarrollo conceptual por parte del Tribunal. Por un lado, cuestión de la "valoración de las condiciones" fue desarrollada en el caso Said c. Holanda ${ }^{273}$, y en Hirsi Jamma c. Italia, que trataremos más profundamente, fue uno de los aspectos centrales del razonamiento jurídico ${ }^{274}$. Por otro, el de "riesgo real" incluía una mayor explicación en la misma sentencia del caso Soering ${ }^{275}$. La relevancia de esta disposición fue de tal calibre que algunos autores han pasado a denominar "test Soering" a la evaluación que las autoridades deben realizar ante la expulsión de una persona a otro Estado ${ }^{276}$. El principio fue recogido posteriormente por otros instrumentos como la $\mathrm{CDF}^{277}$ y Directiva de Requisitos ${ }^{278}$.

Desde la Corte de Estrasburgo también han emanado desarrollos del concepto de non-refoulement muy originales, que han ampliado los límites del artículo 3 a través de una interpretación flexible. El Tribunal ha encontrado violaciones en casos donde el riesgo de sufrir tortura provenía de agentes no estatales si las autoridades públicas son incapaces o "no deseosas" de garantizar su protección ${ }^{279}$. El Comité contra la Tortura también ha realizado una interpretación $\operatorname{similar}^{280}$ a pesar de que el artículo 1 de la

273 TEDH: Said c. Países Bajos, sentencia del 5 de julio de 2005, no 2345/02, § 49: "It is nevertheless incumbent on persons who allege that their expulsion would amount to a breach of Article 3 to adduce, to the greatest extent practically possible, material and information allowing the authorities of the Contracting State concerned, as well as the Court, to assess the risk a removal may entail". Disponible en: http://hudoc.echr.coe.int/eng?i=001-69614 (Consulta: 12 de enero de 2016)

274 TEDH: Hirsi Jamaa y otros c. Italia, sentencia del 23 de febrero de 2012, no 27765/09, § 114. Disponible en: http://hudoc.echr.coe.int/eng?i=001-109231 (Consulta: 12 de enero de 2016)

275 TEDH: Soering c. Reino Unido, § 100:” ... ill-treatment, including punishment, must attain a minimum level of severity if it is to fall within the scope of Article 3 (...) it depends on all the circumstances of the case, such as the nature and context of the treatment or punishment, the manner and method of its execution, its duration, its physical or mental effects and, in some instances, the sex, age and state of health of the victim"

${ }^{276}$ Por ejemplo, en Lambert, Hélene: The position of aliens in relation to the European Convention of Human Rights", Council of Europe Publishing, Human Rights files, No. 8, 2007, p. 44 y ss. Disponible en: $\quad$ http://www.echr.coe.int/LibraryDocs/DG2/HRFILES/DG2-EN-HRFILES-08\%282007\%29.pdf (Consulta: 12 de enero de 2016); o Costello, Cathryn: Courting Access to Asylum in Europe: Recent Supranational Jurisprudence Explored. Human Rights Law Review, Vol. 12(2), 2012, pp. 287-339.

${ }^{277}$ CDF, art. 19.2. Aquí se habla de "grave riesgo" en lugar de "riesgo real"

${ }^{278}$ Directiva 2011/95/UE, art. 2 (f)

279 Por citar sólo casos involucrando a refugiados: Vilvarajah y otros c. Reino Unido, sentencia del 30 de octubre de 1991, no 13163/87; 13164/87; 13165/87; 13447/87; 13448/87. Disponible en: http://hudoc.echr.coe.int/eng?i=001-57713 (Consulta: 12 de enero de 2016); Salah Sheekh c. Países Bajos, sentencia del 11 de enero de 2007, $\mathrm{n}^{\circ}$ 1948/04. Disponible en http://hudoc.echr.coe.int/eng?i=00178986 (Consulta: 12 de enero de 2016); Abdolkhani y Karimnia c. Turquía, sentencia del 22 de septiembre de 2009, $\mathrm{n}^{\mathrm{o}}$ 30471/08. Disponible en http://hudoc.echr.coe.int/eng?i=001-94127 (Consulta: 12 de enero de 2016)

280 CAT: Elmi c. Australia, 14 de mayo de 1999, n ${ }^{\circ}$ 120/1998. Disponible en: http://docstore.ohchr.org/SelfServices/FilesHandler.ashx?enc=6QkG1d\%2fPPRiCAqhKb7yhssh2tXWBb yLwahMw00Sn91VM\%2bgAAA4UNIXUBf0QLBxW0hVYcnLPjprbAz4N7qAqQJiJJGtb93pfypAdVa MTHHYa8XG49sb\%2bztcRKIZ1PKNjsgM\%2fquiK\%2fQ9oaeMrLyugircIt3HUj2G1q619CFsUPCqc\%3 d (Consulta: 12 de enero de 2016) 
Convención restringe la definición de tortura a la cometida por o con el consentimiento de las autoridades públicas. En el ilustre caso D. c. Reino Unido $(2001)^{281}$, consideró que la expulsión del solicitante, portador de VIH y nacional de un Estado donde no existía tratamiento adecuado frente a esa enfermedad, suponía una violación del principio de non-refoulement según la interpretación del citado artículo. No obstante, el TEDH ha interpretado posteriormente casos similares de forma más restrictiva, circunscribiendo esta interpretación a casos excepcionales tanto por el precario estado de salud del solicitante como por la situación del país de destino ${ }^{282}$.

En las dos décadas que siguieron a la sentencia Soering, Estrasburgo se pronunció en exclusiva ante devoluciones realizadas a países extracomunitarios, en general considerados no seguros y donde existían razones fundadas de que el demandante podía ser objeto de tortura. En 2011 el TEDH condenó a Bélgica por la devolución bajo Dublín II de un solicitante de asilo a Grecia, en base a las deficiencias de las condiciones de acogida del sistema de acogida y del procedimiento de asilo, interpretando que caían bajo el alcance del artículo 3. A partir del M.S.S., se ha ido creando una incipiente corpus doctrinario en relación a los traslados bajo el Reglamento de Dublín, con sentencias donde la Corte ha establecido criterios en referencia al interés superior del menor y la unidad familiar ${ }^{283}$, la provisión de un tratamiento adecuado en el país al que fuera transferido el solicitante ${ }^{284}$, o la posibilidad de quedar expuestos a la extrema pobreza y a riesgos graves para la salud ${ }^{285}$.

Otros derechos humanos básicos también deben ser tenidos en cuenta ante un procedimiento de expulsión. El que ha conocido mayor desarrollo es el respeto a la vida privada y familiar ${ }^{286}$. Este principio tiene dos dimensiones en su relación con el

281 TEDH: D. c. Reino Unido, sentencia del 2 de mayo de 1997, no 30240/96. Disponible en: http://hudoc.echr.coe.int/eng?i=001-58035 (Consulta: 12 de enero de 2016)

${ }^{282}$ TEDH: Bensaid c. Reino Unido, sentencia del 6 de febrero de 2001, nº 44599/98, § 40. Disponible en: http://hudoc.echr.coe.int/eng?i=001-59206 (Consulta: 12 de enero de 2016). La Corte ha seguido este razonamiento en varios casos como N. c. Reino Unido, sentencia del 27 de mayo de 2008, $\mathrm{n}^{\circ}$ 26565/05. Disponible en: http://hudoc.echr.coe.int/eng?i=001-86490 (Consulta: 12 de enero de 2016)

283 TEDH: Tarakhel c. Suiza, sentencia del 4 de noviembre de 2014, no 29217/12, para. 122. Disponible en: http://hudoc.echr.coe.int/eng?i=001-148070 (Consulta: 13 de enero de 2016)

284 TEDH: A.S. c. Suiza, sentencia del 30 de junio de 2015, no 39350/13, para. 8. Disponible en: http://hudoc.echr.coe.int/eng?i=001-155717 (Consulta: 13 de enero de 2016)

${ }^{285}$ TEDH: V.M. y otros c. Bélgica, sentencia del 7 de julio de 2015, no 60125/11, para. 170. Disponible en: http://hudoc.echr.coe.int/eng?i=001-156243 (Consulta: 13 de enero de 2016)

286 Principio recogido, entre otros, en el art.10 de la CDN, el art. 5.4 de la Declaración sobre los Derechos Humanos de los Individuos que no son nacionales de los países en los que viven, y la OG 15 del CDH. El $\mathrm{CDH}$ ha tratado esta problemática en varias ocasiones, de la que señalamos por tratarse de un solicitante de asilo en la UE el caso Byahuranga c. Dinamarca, 15 de agosto de 2003, $\mathrm{n}^{\mathbf{0}}$ 1222/2003. Disponible en: http://docstore.ohchr.org/SelfServices/FilesHandler.ashx?enc=6QkG1d\%2fPPRiCAqhKb7yhstcNDCvDa n1pXU7dsZDBaDULaUXs\%2fI76DaPntsL4rwiosggS4Sb5dElDOUiwNkcil80SXcOE\%2b4gp\%2fPrsxZ ZJx1Hz2YQI690rKUIOltfuQcqulDiNYwJrGZp\%2brb00c\%2fh3ucYCxwQp1SXOwGg2o16MjGQ\%3d (Consulta: 13 de enero de 2016) 


\section{CAPÍTULO 3}

principio de no devolución: una de obligaciones positivas y otra negativa. En su accionar, los estados deben facilitar, en la medida de lo posible, la reagrupación de los miembros de la familia de un extranjero que se encuentre en su territorio. En términos negativos, implica que no tome decisiones que impidan este reagrupamiento; esto es, que no expulse a un extranjero cuando esta decisión impida su reagrupamiento, bien porque los familiares se encuentran en dicho país o porque la expulsión la impediría. El ACNUR también ha señalado que "en aplicación del principio de unidad de la familia, y por razones humanitarias obvias, es preciso hacer todo lo posible para reunificar a las familias separadas de refugiados", que dicha reunificación se deberá producir "con la menor demora posible". A demás, establece en lo relativo a los requisitos de documentación, que "al decidir sobre la reunificación de la familia, la ausencia de prueba documental de la validez formal del matrimonio o de la filiación de los hijos no debe considerarse impedimento per se"287.

El respeto a la vida privada y familiar también ha conocido un gran desarrollo tanto en el Consejo de Europa ${ }^{288}$, la Unión Europea $^{289}$ y la jurisprudencia del TEDH. El Tribunal ha producido sentencias contradictorias sobre el artículo 8. En una mayoría de pronunciamientos ha interpretado que un individuo, aún en situación administrativa irregular, tendrá derecho a no ser expulsado si esta acción menoscaba su derecho a disfrutar de la vida familiar. En el caso Bensaid c. Reino Unido el Tribunal entendió que la expulsión de una persona podía no alcanzar la severidad del artículo 3 pero sí la del 8 a la vida privada "where there are sufficiently adverse effects on physical and moral integrity" 290 . En el caso Saadi, el TEDH observó que la expulsión de dicho ciudadano tunecino representaba la disolución de su familia, ya que su hija y esposa dependían económicamente del demandante ${ }^{291}$. La expulsión supondría una medida de carácter desproporcionado y vulneraría los derechos de terceras personas. En Rodrigues da Silva and Hoogkamer c. Holanda remarcó la importancia de las responsabilidades de la

\footnotetext{
${ }^{287}$ ACNUR: Conclusión general n ${ }^{\circ} 24$ (XXIV) Reunificación de familias, adoptada en el $32^{\circ}$ periodo de sesiones del Comité Ejecutivo (1981), pp. 82-83. Disponible en: http://www.acnur.org/Pdf/0535.pdf?view=1 (Consulta: 13 de enero de 2016)

${ }^{288}$ Art. 7 CDF y art. 12.1 Convenio Europeo relativo al estatuto jurídico del trabajador migrante. Este último, del que España e Italia forma parte, se encuentra disponible en: http://www.coe.int/t/dg3/migration/archives/Documentation/Legal texts/093 Convention Legal Status Migrant Workers sp.pdf (Consulta: 13 de enero de 2016)

289 Directiva 2003/86/CE del Consejo, de 22 de septiembre de 2003, sobre el derecho a la reagrupación familiar. DO L 251 de 3 de octubre de 2003, pp. 12-19. Disponible en: http://eurlex.europa.eu/LexUriServ/LexUriServ.do?uri=OJ:L:2003:251:0012:0018:ES:PDF (Consulta: 12 de enero de 2016)

290 TEDH: Bensaid c. Reino Unido, § 46

291 TEDH: Saadi c. Italia, sentencia del 28 de febrero de 2008, no. 37201/06, § 165. Disponible en: http://hudoc.echr.coe.int/eng?i=001-85276 (Consulta 13 de enero de 2016)
} 
solicitante con su hija ${ }^{292}$ y el interés superior de esta; y en Mubilanzilia c. Bélgica, las responsabilidades del Estado de facilitar la reunificación familiar, al tratarse de una menor no acompañada ${ }^{293}$. Posteriormente ha limitado esta interpretación en el caso Darren Omoregie y otros c. Noruega (2008), al no encontrar violación en la expulsión de un ciudadano nigeriano de Noruega a pesar de que tanto su mujer e hija eran nacionales de dicho país ${ }^{294}$.

El CDH, por su parte también ha estudiado comunicaciones relativas con otros supuestos de pena de muerte ${ }^{295}$, enfermedades ${ }^{296}$ o mutilación genital ${ }^{297}$. Otros instrumentos internacionales también han recogido limitaciones específicas a la devolución, como el Comité contra la Discriminación Racial ${ }^{298}$ y el Comité de los Derechos del Niño ${ }^{299}$.

292 TEDH: Rodrigues da Silva y Hoogkamer c. Países Bajos, sentencia del 31 de enero de 2006, no. 50435/99, § 44. Disponible en: http://hudoc.echr.coe.int/eng?i=001-72205 (Consulta 13 de enero de 2016)

293 TEDH: Mubilanzila mayeka y Kaniki Mitunga c. Bélgica, sentencia del 12 de octubre de 2006, no. 13178/03, § 85. Disponible en: http://hudoc.echr.coe.int/eng?i=001-77447 (Consulta 13 de enero de 2016)

294 TEDH: Darren Omoregie y otros c. Noruega, sentencia del 31 de julio de 2008, $\mathrm{n}^{\mathrm{o}}$ 265/07, $\S 57$. Disponible en: http://hudoc.echr.coe.int/eng?i=001-88012 (Consulta 13 de enero de 2016)

295 CDH: Judge c. Cánada, 5 de agosto de 2003, no 829/1998. Disponible en: http://docstore.ohchr.org/SelfServices/FilesHandler.ashx?enc=6QkG1d\%2fPPRiCAqhKb7yhstcNDCvDa n1pXU7dsZDBaDVNmMkVCG3Azi\%2bzQxFNvXn4zTR32qgZ3i13auB28wwbws2ybooUbx\%2bFFxt OOWHRSzozkHO8Rc\%2bBTBRmZS0iQ5QkjWS4n3rMi8uB3mxKt3s\%2bBKHukBp6OFAlyiZLeZXG $\% 2 \mathrm{fEU} \% 3 \mathrm{~d}$ (Consulta: 13 de enero de 2016)

296 CDH: C. c. Australia, 28 de octubre de 2002, no 900/1999. Disponible en: http://docstore.ohchr.org/SelfServices/FilesHandler.ashx?enc=6QkG1d\%2fPPRiCAqhKb7yhstcNDCvDa n1pXU7dsZDBaDWvOUuXlmf6Gow5OYFcm4s6GWQXsybl7dlT7zvAgp1U3pBY8MLRaj6BhS37rLm 13eLcusmeOqIJ4JdiLDXPpSaAgVfL1\%2bsc5Uq2y07nrDmvMkmqN\%2bAY6aR44Yh\%2biANZ1jA\%3 d (Consulta: 13 de enero de 2016)

297 CDH: Kaba c.Canadá y Guinea; 25 de marzo de 2010, no 1465/2006. Disponible en: http://docstore.ohchr.org/SelfServices/FilesHandler.ashx?enc=6QkG1d\%2fPPRiCAqhKb7yhstcNDCvDa n1pXU7dsZDBaDU\%2fReKzmedZW15TJ57Wtp\%2fX31j31vM3AK1iXdHMI\%2bpNqF\%2bgcTBYq4Y vfBgYYuszH4MTi44nE1zhj7lvGFfRGgvi4cst5PN4oKIXkXvyGVtZPwG7cks6dsXfr4\%2fcDctqhJs\%3d d (Consulta: 13 de enero de 2016)

298 CEDR: Recomendación General no 30 sobre la discriminación contra los no ciudadanos. $65^{\circ}$ periodo de sesiones, 2005, para. 25-28. http://tbinternet.ohchr.org/Treaties/CERD/Shared\%20Documents/1 Global/INT CERD GEC 7502 S.d oc (Consulta: 13 de enero de 2016)

${ }^{299}$ La Observación General n ${ }^{\circ} 6$ (2005) recoge en sus párrafos 26, 27 y 28 el respeto del principio de no devolución aplicado a menores. En el 28 hay un inciso específico para el riesgo de los menores ante un conflicto armado, ya sea como víctimas o porque puedan ser reclutados. CDN: Observación General n ${ }^{\circ} 6$ : Trato de los menores no acompañados y separados de su familia fuera de su país de origen. $39^{\circ}$ periodo de sesiones, 2005.

Disponible

en: http://docstore.ohchr.org/SelfServices/FilesHandler.ashx?enc=6QkG1d\%2fPPRiCAqhKb7yhsiQq18gX5Z xh0cQqSRzx6ZfXmRo9mdg35\%2bm8BvAjgxjO\%2bIzulGMG7OKG0mWvJJi9e82iOG1uSF\%2b72cH LBLISZNqeK0k5bcWwjaPwfzsZ\%2bbHm (Consulta: 13 de enero de 2016) 


\section{CAPÍTULO 3}

Es preciso también recordar otros casos donde el TEDH ha hecho referencia a la aplicabilidad de los artículos 2 (derecho a la vida) ${ }^{300}$ y 6 (derecho a un juicio justo) ( $^{301}$ en casos de deportación, sin haber encontrado violaciones de dichos derechos. Por último, el TEDH también ha encontrado violaciones en casos donde el solicitante se beneficiaba de la protección subsidiaria ${ }^{302}$.

Hay que recordar también la responsabilidad estatal en los casos del así llamado "refoulement indirecto". Este sucede cuando la devolución se realiza a un tercer país distinto del de origen o de persecución, considerado "seguro" por el estado que ejecuta la deportación. Este tercer Estado realiza a su vez una deportación al país de origen, o a otro país en el que el individuo sea objeto de persecución o vulneración de sus derechos fundamentales. En el caso T.I. c. Reino Unido (2000), el TEDH recordó que "the indirect removal in this case to an intermediary country (...) does not affect the responsibility of the United Kingdom to ensure that the applicant is not, as a result of its decision to expel, exposed to treatment contrary to Article 3 of the Convention" ${ }^{303}$. Estas prácticas han sido denunciadas en países de tránsito de la migración mediterránea. En Marruecos se tienen documentados varios casos donde el gobierno alauita abandonó a migrantes repatriados o rechazados en la frontera española en el desierto del Sahara, cerca de Argelia ${ }^{304}$. En el caso libio, fue una práctica recurrente tras los acuerdos entre el gobierno de Muamar el Gadafi y Berlusconi en $2008^{305}$. En Hirsi Jamaa, el Tribunal

\footnotetext{
${ }^{300}$ Vid. TEDH: D. Reino Unido, §59; Ould Barar c. Suecia, decisión de admisibilidad del 19 de enero de 1999, no. 42367/98. Disponible en: http://hudoc.echr.coe.int/eng?i=001-4507 (Consulta 13 de enero de 2016);

Tomic c. Reino Unido, decisión de admisibilidad del 14 de octubre de 2003, no. 17387/03. Disponible en: http://hudoc.echr.coe.int/eng?i=001-23532 (Consulta 13 de enero de 2016)

301 Vid. TEDH: Soering c. Reino Unido, § 113; F. c. Reino Unido, decisión de admisibilidad del 22 de junio de 2004, no. 17341/03. Disponible en: http://hudoc.echr.coe.int/eng?i=001-24020 (Consulta 13 de enero de 2016); y Mamatkulov y Askarov c. Turquía, sentencia del 4 de febrero de 2005, no. $46827 / 99$ y 46951/99, § 91. Disponible en: http://hudoc.echr.coe.int/eng?i=001-68183 (Consulta 13 de enero de 2016)

302 Entre otros: B.B. c. Francia, sentencia del 7 de septiembre de 1998, no. 30930/96. Disponible en: http://hudoc.echr.coe.int/eng?i=001-58224 (Consulta 13 de enero de 2016); y Tatete c. Suiza, sentencia del 6 de julio de 2000, no. 41874/98. Disponible en: http://hudoc.echr.coe.int/eng?i=001-63309 (Consulta 13 de enero de 2016)

303 TEDH: T.I. c. Reino Unido, sentencia de 7 de marzo de 2000, no. 43844/98, p. 15. Disponible en: http://www.refworld.org/docid/3ae6b6dfc.html (Consulta 13 de enero de 2016)

304 El primer caso documentado se produjo en octubre de 2005, cuando tropas de la MINURSO y el Frente Polisario encontraron a decenas de migrantes hambrientos y sedientos, entre ellos niños y mujeres embarazadas, en la zona de Bou Arfa y Tindouf. La mayor parte habían intentado saltar la valla de Melilla el 29 de septiembre, en un intento masivo que fue duramente reprimido con el resultado de 5 migrantes asesinados por las balas de las fuerzas policiales marroquí y/o española (no se produjo ninguna investigación esclarecedora de los hechos). La posibilidad de que Marruecos llevara a cabo devoluciones indirectas también se encontró en la sentencia del TEDH en el caso A.C. (infra n. 376, §93)

${ }^{305}$ HRW: Pushed back..., op. cit., p. 68-74
} 
tuvo en cuenta la evidencia de las expulsiones en cadena a las que sometía el régimen libio a somalís y eritreos ${ }^{306}$.

En el ámbito europeo, la primera norma en sancionar el principio es el Convenio Europeo de Extradición de 1957 307 , aprobado en el marco del Consejo de Europa. En lo que respecta al sistema comunitario, el artículo 78 del TFUE enmarca la política de asilo de la UE en la garantía del principio de no devolución, estipulando así mismo que deberá ajustarse a la CG51, sus protocolos y los demás tratados pertinentes. La CDF en su artículo 19 también establece que nadie puede ser devuelto, expulsado o extraditado a un Estado en el que corra grave riesgo de ser sometido a la pena de muerte, la tortura o a otras penas o tratos inhumanos o degradantes. La Carta Social Europea también recoge una garantía contra la expulsión para aquellos trabajadores migrantes y sus familias que residan legalmente dentro de su territorio ${ }^{308}$. El principio de non-refoulement se encuentra recogido así mismo en el Código de Fronteras de Schengen $^{309}$ y en el reglamento de Frontex ${ }^{310}$. El desarrollo normativo de la Unión Europea en los últimos años en materia de asilo también ha tenido una consecuencia en la llegada de casos relativos al non-refoulement al TJUE. En algunos casos recientes ha establecido garantías ante personas perseguidas por manifestar públicamente su orientación sexual $^{311}$ o religiosa ${ }^{312}$.

Finalmente, el principio de non-refoulement también se reconoce para los otros dos tipos de protección reconocidos por la UE: la protección subsidiaria, y la protección temporal para casos de desplazamiento masivo. La Directiva 2011/95/UE de protección subsidiaria establece tres supuestos de daños graves en los cuales está prohibida la devolución al país de origen: a) pena de muerte, b) tortura y penas o tratos inhumanos o

306 TEDH: Hirsi Jamaa y otros c. Italia, § 143

307 Convenio Europeo de Extradición, París, 13 de diciembre de 1957, art. 3.2. Disponible en: http://www.coe.int/en/web/conventions/full-list/-/conventions/rms/0900001680064587 (Consulta: 13 de enero de 2016)

308 Carta Social Europea, art. 19.8, Estrasburgo, 3 de mayo de 1996, art. 19.8. Disponible en: http://www.coe.int/en/web/conventions/full-list/-/conventions/rms/090000168007cf93 (Consulta: 13 de enero de 2016)

${ }^{309}$ Reglamento 610/2013, art. 3 bis

${ }^{310}$ Reglamento 1168/2011, art. 1.2

311 TJUE: "X, Y, y Z contra Minister voor Immigratie en Asiel" (asuntos acumulados C-199/12 a C201/12), sentencia del 7 de noviembre de 2013. Disponible en: http://curia.europa.eu/juris/document/document.jsf;jsessionid=9ea7d0f130d5d6a7e2766505499a9227fa8c dcbd9d96.e34KaxiLc3eQc40LaxqMbN4Oc3yLe0?text=\&docid=144215\&pageIndex=0\&doclang=es\&m ode $=1$ st\&dir $=\&$ occ $=$ first\&part $=1 \&$ cid $=583483$ (Consulta: 14 de enero de 2016)

312 TJUE: "Y y Z contra República Federal Alemana" (asuntos acumulados C-71/11 y C-99/11), sentencia del 5 de septiembre de 2012. Disponible en: http://curia.europa.eu/juris/document/document.jsf?text=\&docid=126364\&pageIndex=0\&doclang=es\&m

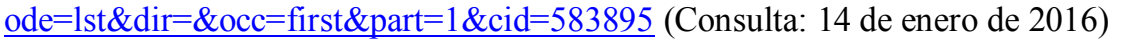




\section{CAPÍTULO 3}

degradantes, y c) amenazas graves contra la vida o la integridad física en situaciones de conflicto armado internacional o interno ${ }^{313}$. El alcance del apartado c) fue desarrollado por la sentencia del TJUE en el caso Elgafaji: "la existencia de amenazas graves $e$ individuales contra la vida o la integridad física del solicitante de protección subsidiaria no está supeditada al requisito de que éste aporte la prueba de que está afectado específicamente debido a elementos propios de su situación personal" ${ }^{114}$. En esa misma sentencia se establece que la protección de la Directiva de requisitos proporciona una protección independiente y complementaria contra la devolución a la del artículo 3 del CEDH. En cuanto a la protección temporal, limita la imposibilidad de regreso en casos de "conflicto armado o violencia permanente" o de "peligro grave de violación sistemática o generalizada de los derechos humanos"315. La observancia del principio de no devolución debe ser absoluta, tal como ha reconocido ACNUR, también en casos de afluencia masiva ${ }^{316}$.

El principio de non-refoulement debe ser considerado un elemento determinante en el diseño de las políticas relativas a la lucha contra la inmigración irregular, el control fronterizo y la expulsión de extranjeros. Cualquier medida que se adopte con ese propósito deberá contar con la existencia de este límite ${ }^{317}$. Junto al principio de nonrefoulement, el DIDH establece también provisiones respecto a la expulsión de extranjeros ${ }^{318}$.

Para finalizar, y volviendo a la CG51, el segundo párrafo del artículo 33 establece dos excepciones al contenido fundamental del principio, al afirmar que alguien reconocido como refugiado puede ser expulsado si se considera, por razones fundadas, que dicho individuo puede ser a) un peligro para la seguridad del país en el que está, o b) habiendo sido condenado por un delito particularmente grave, constituyendo esto una amenaza para la comunidad de ese mismo país. El propio Manual de Procedimientos del

313 Directiva 2011/95/UE, art. 15. La Agencia EASO publicó un análisis más detallado del artículo para facilitar la interpretación de los tribunales nacionales: EASO: Artículo 15, letra c), de la Directiva de reconocimiento (2011/95/UE) Análisis judicial, enero de 2015. Disponible en: https://easo.europa.eu/wpcontent/uploads/Article-15c-QD a-judicial-analysis-ES.pdf (Consulta: 14 de enero de 2016)

314 TJUE: "Meki y Noor Elgafaji contra Staatssecretaris van Justitie" (C-465/07), sentencia del 17 de febrero de 2009, $\quad$ \& $43 . \quad$ Disponible http://curia.europa.eu/juris/document/document.jsf?text=\&docid=76788\&pageIndex=0\&doclang=es\&mo $\mathrm{de}=1$ st\&dir $=\& o c c=$ first\&part $=1 \&$ cid $=584599$ (Consulta: 14 de enero de 2016)

315 Directiva 2001/55/CE, art. 1 y 2.c.

316 ACNUR: Conclusión general $n^{\circ} 22$ (XXII) Protección de las personas que buscan asilo en situaciones de afluencia en gran escala, adoptada en el $32^{\circ}$ periodo de sesiones del Comité Ejecutivo, 1981, p. 2.2. Disponible en: http://www.acnur.org/Pdf/0533.pdf?view=1 (Consulta: 14 de enero de 2016)

317 La Directiva 2008/115/CE (o Directiva del retorno) en su art. 4.4.b reconoce el principio de no devolución como una de las líneas rojas de la política migratoria europea.

318 Se puede encontrar una recopilación de los trabajos de la Comisión de Derecho Internacional (CDI) sobre este tema en: http://legal.un.org/ilc/summaries/9 12.htm (Consulta: 14 de enero de 2016) 
ACNUR $^{319}$ reconoce la dificultad para definir más claramente qué significa un delito 'grave', más allá de circunscribirlos a casos extremos, y que sean delitos castigados con la pena de muerte o con penas muy graves. El Manual también recoge la necesidad de establecer un equilibrio entre la naturaleza del delito y el grado de persecución que éste tema $^{320}$. El Manual es todavía menos concreto en lo que se refiere al primer supuesto.

El posterior desarrollo normativo del principio de non-refoulement ha venido acotando la discrecionalidad para los Estados que incluía la disposición del artículo $33.2^{321}$. De hecho, ninguno de los otros tratados internacionales que contienen disposiciones de non-refoulement incluye excepciones similares a la contenida de la CG51.

En la práctica de los Estados, el conflicto sobre non-refoulement ha estados sobre todo centrado en el campo de la lucha contra el terrorismo. Los Estados se resisten a permitir residir en su territorio a individuos que consideran un peligro para la seguridad o el orden público. En un célebre caso (Chahal c. Reino Unido), el TEDH considero que el principio de non-refoulement (a través de la interpretación del artículo 3 del CEDH que hizo anteriormente en el caso Soering) no puede verse limitado incluso considerando las dificultades a las que debe hacer el Estado en el contexto de la lucha antiterrorista; ninguna persona "however undesirable or dangerous" 322 , puede ser devuelta a un país en el que pueda sufrir tortura. Esto es, la obligación de no devolver a un extranjero a un país donde pueda sufrir tortura es de carácter absoluto, con independencia de la condición de la persona o de una situación de emergencia pública que amenace a la nación ${ }^{323}$. Sin embargo, desde los atentados terroristas del 11 de septiembre de 2001, se ha producido una tendencia que restringe los derechos de aquellos migrantes o refugiados que son considerados por los Estados europeos sospechosos de ser terroristas ${ }^{324}$.

\footnotetext{
${ }^{319}$ ACNUR: Manual de procedimientos..., op. cit., para. 155.

${ }^{320}$ Ibíd., para. 156

${ }^{321}$ En Europa revistió especial importancia la sentencia del TEDH en el ya citado caso Soering. Aunque siempre siguiendo la senda marcada por dicho caso, la jurisprudencia posterior ha oscilado entre pronunciamientos más garantistas como en $D$. c. Reino Unido (1997) hasta más restrictivas como $N$. c. Reino Unido (2008).

${ }^{322}$ TEDH: Chahal c. Reino Unido, sentencia del 15 de noviembre de 1996, $\mathrm{n}^{\circ}$ 22414/93, § 80. Disponible en: http://hudoc.echr.coe.int/eng?i=001-58004 (Consulta: 14 de enero de 2016)

${ }^{323}$ Ibíd., par. 79

${ }^{324}$ Conviene recordar la Resolución del Consejo de Seguridad de Naciones Unidas 1373 aprobada tras los ataques terroristas del 11 de septiembre de 2001, especialmente los apartados f) y g) de su art. $3^{\circ}$, que pedían endurecer los sistemas de asilo en relación con la lucha contra el terrorismo. Consejo de Seguridad: Resolución 1373 (2001) de 28 septiembre de 2001, 4385 sesión. Doc. S/RES/1373. Disponible en: http://www.un.org/es/comun/docs/?symbol=S/RES/1373\%282001\%29 (Consulta: 12 de enero de 2016)
} 


\section{CAPÍTULO 3}

\subsubsection{Garantías jurídicas}

Las garantías procesales no protegen al extranjero frente la expulsión, pero sí garantizan que no está se hará conforme a la ley nacional, que su voz podrá ser oída y que contará con una serie de derechos (asistencia jurídica, intérprete, apelación) que lo protejan de una decisión injusta y/o arbitraria.

En 2014, la CDI elaboró un proyecto de artículos sobre expulsión de extranjeros, con la idea de que sirviera como base a una futura convención ${ }^{325}$. En su estado actual, el DIDH tiende a no considerar aplicables la mayor parte de los derechos y garantías del derecho al juicio justo a los procedimientos de expulsión de extranjeros del territorio de un Estado. Esta negativa de aplicar provisiones generales de juicio justo a los procedimientos de expulsión se puede explicar por dos factores: a) el carácter administrativo que, de forma general, caracteriza a este tipo de procedimientos, y b) la existencia de medidas específicas para los casos de expulsiones en el derecho internacional, nacional y comunitario.

La jurisprudencia del TEDH, por ejemplo, ha excluido las garantías judiciales artículo 6.1 del CEDH de los casos relativos a deportaciones y expulsiones. Desde el caso Maaouia c. Francia en adelante ha venido justificado por la existencia de garantías específicas en el artículo 1 del protocolo 7, así como el carácter administrativo del procedimiento $^{326}$. Para Estrasburgo, "decisions regarding the entry, stay and deportation of aliens do not concern the determination of an applicant's civil rights or obligations or of a criminal charge against him, within the meaning of article 6(1) of the Convention" 327 Es importante señalar que el alcance del artículo 6.1 es más restrictivo que otros artículos relativos a las salvaguardas del debido proceso en otros tratados internacionales, como la Carta Africana $^{328}$ o la Convención Americana ${ }^{329}$. Mientras que el Convenio de Roma restringe los derechos de debido proceso a los

${ }^{325}$ Informe sobre la expulsión de los extranjeros, Comité Derecho Internacional, $66^{\circ}$ periodo de sesiones 2014. A/69/10, pp. 35-45. Disponible en: http://legal.un.org/ilc/reports/2014/spanish/chp4.pdf (Consulta: 29 de enero de 2016)

326 TEDH: Maaouia. c. Francia, sentencia del 5 de octubre de 2000, no 39652/98, § 36 y 37. Disponible en: http://hudoc.echr.coe.int/eng?i=001-58847 (Consulta: 14 de enero de 2016)

327 Ibíd., § 40

${ }^{328}$ Carta Africana sobre los Derechos Humanos y de los Pueblos, aprobada en Banjul el 27 de junio de 1981, durante la XVIII Asamblea de Jefes de Estado y Gobierno de la Organización de la Unidad Africana, OAU Doc. CAB/LEG/67/3, art. 7.1. Disponible en: http://au.int/en/sites/default/files/treaties/7770-file-banjul charter.pdf (Consulta: 14 de enero de 2016) 329 Convención Americana sobre Derechos Humanos, aprobada en San José el 22 de noviembre de 1969, art. 8.1. Disponible en: https://www.oas.org/dil/esp/tratados B32_Convencion_Americana_sobre_Derechos_Humanos.pdf (Consulta: 14 de enero de 2016) 
litigios de carácter civil y penal, la Carta de Banjul y el Convenio de San José lo extienden a todo tipo de proceso.

En lo relativo a solicitantes de asilo, el TEDH también excluyó a los solicitantes de asilo de la protección que ampara el artículo 6.1, en los casos Taheri Kandomabadi c. Países Bajos (2004) $)^{330}$, Mabroki c. Suecia (2006) ${ }^{331}$ y Mollazeinal c. Chipre (2009) ${ }^{332}$. El CDH, por su parte, consideró en un caso sobre la expulsión de un solicitante de asilo que "como el artículo 13 trata directamente la situación del presente caso e incorpora nociones relacionadas con el principio del proceso con las debidas garantías que también se reflejan en el artículo 14 del Pacto, desde el punto de vista del sistema del Pacto sería inapropiado aplicar directamente las disposiciones más amplias y generales del artículo 14."333

Estas medidas específicas se encuentran en una variedad de instrumentos, si bien la mayor parte de ellos restringen los beneficiarios de éstas a aquellos extranjeros que residan legalmente en el territorio ${ }^{334}$. La excepción es la Convención de Trabajadores Migrantes. Dos de sus artículos están relacionados con la expulsión: uno que se aplica a todos los migrantes sin importar su estatus ${ }^{335}$ y otro que sí es únicamente para aquellos en situación regular ${ }^{336}$. Lamentablemente, ningún estado europeo es parte de la Convención. Una de las posibles causas de este rechazo podría ser precisamente esta disposición. De la misma forma, el proyecto presentado por la CDI en 2014 establece

\footnotetext{
${ }^{330}$ Aquí señala que "... Article 6 of the Convention does not apply to proceedings concerning the entry, stay and deportation of aliens, even if the impugned decision incidentally also has major repercussions on a person's private and family life or on his prospects of employment". TEDH: Taheri Kandomabadi c. Países Bajos, decisión de admisibilidad del 29 de junio de 2004, n ${ }^{\circ}$ 6273/03 y 6122/04. Disponible en: http://hudoc.echr.coe.int/eng?i=001-24052 (Consulta: 14 de enero de 2016).

331 TEDH: Mabroki c. Suecia, decisión de admisibilidad del 21 de noviembre de 2006, nº 22556/05. Disponible en http://hudoc.echr.coe.int/eng?i=001-78468 (Consulta: 14 de enero de 2016)

332 TEDH: Mollazeinal c. Chipre, decisión de admisibilidad del 18 de junio de 2009, $\mathrm{n}^{0}$ 20198/05. Disponible en: http://hudoc.echr.coe.int/eng?i=001-93432 (Consulta: 14 de enero de 2016)

333 CDH: Ahani c. Cánada, 15 de junio de 2004, $\mathrm{n}^{\circ}$ 1051/2002, § 10.9. Disponible en: http://docstore.ohchr.org/SelfServices/FilesHandler.ashx?enc=6QkG1d\%2fPPRiCAqhKb7yhstcNDCvDa n1pXU7dsZDBaDWGZIIaTRy0PVBbrs5QCBcAaOeAz8ES7ZxY3FTGjmCnVSDWzMP5I2581VtG2S0i yE\%2bh\%2fRWPlZATfwqg3mwUKXBNCp1r7L88W705iANpTE1f2YnQlUmt5vuJ3s\%2bgfwabWiM\% 3d (Consulta: 14 de enero de 2016)

334 El PIDCP recoge en su art. 13 las garantías al procedimiento, pero no a las bases sustantivas de la expulsión. En su OG ${ }^{\circ} 15$ el Comité especificó que dicho artículo se aplicaba únicamente para aquellos extranjeros que residieran legalmente en el territorio (Observación General n ${ }^{\circ}$ 15: La situación de los extranjeros con arreglo al Pacto. $27^{\circ}$ período de sesiones, 11 de abril de 1986, para. 9-10). Disponible en: http://tbinternet.ohchr.org/ layouts/treatybodyexternal/Download.aspx?symbolno=INT\%2fCCPR\%2fGE C\%2f6625\&Lang=en (Consulta: 12 de diciembre de 2015)

${ }^{335}$ Convención internacional sobre la protección de los derechos de todos los trabajadores migratorios y de sus familiares, aprobada por la AGNU el 18 de diciembre de 1990, resolución 45/158, art. 22. Disponible en: http://www.ohchr.org/SP/ProfessionalInterest/Pages/CMW.aspx (Consulta: 12 de diciembre de 2015) ${ }^{336}$ Ibíd., art. 56
} 


\section{CAPÍTULO 3}

que su ámbito de aplicación personal “... abarca tanto la expulsión de un extranjero legalmente presente en el territorio del Estado expulsor como la del extranjero presente ilegalmente en dicho territorio" 337 .

Debemos hacer mención también a la sentencia de la Corte Internacional de Justicia Ahmadou Sadio Diallo (República de Guinea c. República Democrática del Congo), de 30 de noviembre de 2010. Este fue el primer caso donde la CIJ se pronunció sobre la expulsión de extranjeros, abordando una amplia gama de asuntos: el concepto de conformidad con la ley, la obligación de informar al detenido con miras a su expulsión de las razones de su detención, la obligación de notificar al extranjero objeto de la expulsión los motivos de ésta, la prohibición de infligir malos tratos al extranjero detenido en espera de la expulsión, la obligación de las autoridades competentes del Estado que realiza la detención informen sin retraso alguno, y aunque el extranjero no lo solicite formalmente, a las autoridades consulares del Estado de origen de la detención de su nacional, y el derecho de propiedad del extranjero objeto de expulsión y la constatación de la responsabilidad del Estado autor de la expulsión y su deber de reparación de las consecuencias de la comisión de un hecho internacionalmente ilícito ${ }^{338}$.

El Convenio Europeo no incluyó ninguna disposición en su texto original sobre la expulsión de extranjeros. Hubo que esperar hasta el artículo 1 del Protocolo 7, cuyo texto está basado en el artículo 13 del PIDCP. El TEDH ha reconocido que, cuando en el caso bajo consideración dicho Protocolo no es aplicable, puede entrar en aplicación el artículo $13 \mathrm{CEDH}$ en conjunción con otro artículo de la Convención ${ }^{339}$. Dado que dicho artículo solo presenta garantías a los residentes legales, la práctica común del TEDH ha sido rechazar las demandas a ella dirigida debido a este requisito ${ }^{340}$. El memorando explicativo del protocolo señala además que la revisión del caso corresponde a una "autoridad competente", y que por tanto no tiene por qué ser un órgano judicial ni independiente. Respecto de las garantías previstas en el artículo 6, el TEDH rechazó aplicarlas en casos de entrada, establecimiento y expulsión de extranjeros, así como de

\footnotetext{
${ }^{337}$ Informe sobre expulsión de extranjeros, supra n. 322, comentario sobre el art. 1, para. 3

${ }^{338}$ CIJ: Ahamadou Sadio Dialle (República de Guinea c. República Democrática del Congo), sentencia del 30 de noviembre de 2010. Disponible en: http://www.icj-cij.org/docket/files/103/16244.pdf (Consulta: 14 de enero de 2016)

339 TEDH: Al- Nashif c. Bulgaria, sentencia del 20 de junio de 2002, $\mathrm{n}^{\circ}$ 50963/99, §133. Disponible en: http://hudoc.echr.coe.int/eng?i=001-60522 (Consulta: 10 de enero de 2016)

340 Por ejemplo, en el caso Voulfovitch y Oulianova c. Suecia, la Comisión rechazó la demanda considerando que los demandantes no eran residentes legales, ya que habían sido autorizados a ingresar en Suecia con una visa de un día de duración, y permanecían en el país mientras que su solicitud de asilo era tomada en consideración. CEDH: Voulfovitch y Oulianova c. Suecia, decisión de admisibilidad del 13 de enero de 1993, $\mathrm{n}^{\circ}$ 19373/92. Disponible en: http://hudoc.echr.coe.int/eng?i=001-1480 (Consulta: 14 de enero de 2016)
} 
solicitantes de asilo ${ }^{341}$. Sin embargo, los derechos contenidos en el artículo 1.1 del protocolo 7 sólo protegen aquellos migrantes que residen legalmente en el territorio de dicho Estado ${ }^{342}$, tal como ha refrendado el $\mathrm{TEDH}^{343}$. Por lo tanto, aquellos migrantes sin permiso de residencia, como los que son objeto de la presente investigación, no se encontrarían protegidos bajo dicho artículo, ni podrían demandar a los Estados europeos por su violación ante el $\mathrm{TEDH}^{344}$.

En la normativa comunitaria, destacan dos directivas. La del Retorno, al determinar su ámbito de aplicación, permite que los EEMM excluyan de sus derechos y garantías (que se encuentran en el Cap. III) a aquellos extracomunitarios que "sean detenidos o interceptados por las autoridades competentes con ocasión del cruce irregular de las fronteras exteriores terrestres, marítimas o aéreas de un Estado miembro y no hayan obtenido ulteriormente una autorización o derecho de estancia en dicho Estado miembro"345. Cuando la expulsión involucra a más de un EM, el proceso se encuentra regulado por la Directiva 2001/40/CE, relativa al reconocimiento mutuo de las decisiones de expulsión de nacionales de terceros países. Tiene como objetivo "permitir el reconocimiento de una decisión de expulsión adoptada por una autoridad competente de un Estado miembro, denominado en lo sucesivo "Estado miembro autor», contra un nacional de un tercer país que se encuentre en el territorio de otro Estado miembro, denominado en lo sucesivo "Estado miembro de ejecución"346. Obliga a un EEMM (ejecutor) a llevar a cabo la expulsión de un nacional de un tercer país cuando otro EEMM (autor) haya decidido esta. El Estado ejecutor no puede revocar ni suspender la

\footnotetext{
${ }^{341}$ En un caso de un solicitante de asilo de Sri Lanka en el Reino Unido, la Comisión determinó que: “... procedures followed by public authorities to determine whether an alien should be allowed to stay in a country or should be expelled are of a discretionary, administrative nature, and do not involve the determination of civil rights within the meaning of Article 6 para. 1 (...) political asylum applications fall within this category of procedures which do not determine civil rights within the meaning of Article 6 para. 1". CEDH: V.P. c. Reino Unido, decisión de admisibilidad del 9 de noviembre de 1987, ${ }^{\circ}$ 13162/87. Disponible en: http://hudoc.echr.coe.int/eng?i=001-499 (Consulta: 14 de enero de 2016)

${ }^{342}$ Todo extranjero que resida legalmente en el territorio de un Estado no podrá ser expulsado del mismo más que en ejecución de una decisión adoptada conforme a la ley y debe poder:

a) hacer valer las razones que existan contra su expulsión;

b) hacer que su caso sea revisado;

c) ser representado para estos fines ante la autoridad competente o ante la persona o personas designadas por esta autoridad.

343 TEDH: Lupsa c. Rumanía, sentencia del 8 de junio de 2006, $\mathrm{n}^{\circ} 1$ 0337/04, § 52. Disponible en: http://hudoc.echr.coe.int/eng?i=001-75688 (Consulta: 14 de enero de 2016); y Bolat c. Rusia, sentencia del 5 de octubre de 2006, $\mathrm{n}^{\circ}$ 14139/03, § 76. Disponible en: http://hudoc.echr.coe.int/eng?i=001-77268 (Consulta: 14 de enero de 2016)

${ }^{344}$ Conviene recordar, así mismo, que cuatro estados (Alemania, Holanda, Reino Unido y Turquía) no han ratificado dicho protocolo.

${ }^{345}$ Directiva 2008/115/CE, art. 2.a

${ }^{346}$ Directiva 2001/40/CE del Consejo, de 28 de mayo de 2001, relativa al reconocimiento mutuo de las decisiones en materia de expulsión de nacionales de terceros países, art. 1. DO L 348 de 2 de junio de 2001, pp. 34-36. Disponible en: http://eur-lex.europa.eu/legalcontent/ES/TXT/PDF/?uri=CELEX:32001L0040\&from=ES (Consulta: 14 de enero de 2016)
} 


\section{CAPÍTULO 3}

decisión. La Directiva excluye a los familiares extracomunitarios de los ciudadanos europeos, pero no a los residentes permanentes. Las garantías judiciales de los individuos no están debidamente protegidas en esta directiva. Si bien el interesado puede recurrir contra la medida según la legislación del estado ejecutor (art. 4), éste no tiene capacidad para revocar o suspender la medida (art. 3.1) De hecho, se puede aplicar la medida de expulsión antes de que se lleve a cabo el recurso judicial y ello invalidaría el derecho fundamental ${ }^{347}$. La realidad es que, una vez ejecutada la expulsión y la persona se encuentra fuera del estado, es muy difícil que se inicie un procedimiento de carácter judicial contra la decisión.

En resumen, podemos observar que en su estado actual el DIDH proporciona una protección muy baja a los inmigrantes irregulares en lo relativo a las garantías judiciales frente a su expulsión. En lo que se refiere al objeto de este trabajo, deviene un serio obstáculo para proteger a migrantes y solicitantes de asilo, en tanto otorga una mayor discrecionalidad a los Estados para devolverlos a los países de origen o tránsito. Puede ser preciso acudir a estándares más altos fijados por tribunales nacionales ${ }^{348} \mathrm{u}$ de otros órganos regionales ${ }^{349}$ para asegurar una mayor garantía de las personas migrantes.

De lo contenido en el DIDH podemos extraer varios ejes de obligaciones para los estados en materia de expulsiones de extranjeros:

a) No arbitrariedad. Un fundamento básico del principio de non refoulement es que cada caso individual exige un examen propio, que determine el estatus de cada persona y las medidas que deberá tomar el Estado en consecuencia. Esta regla se encuentra recogida en diversos instrumentos del derecho internacional, como los ya citados PIDCP (art. 13) y CEDH (art. 1 del Protocolo 7). Como veremos más adelante, una consecuencia necesaria de esta norma es la prohibición de realizar expulsiones colectivas. A nivel nacional, los Estados deben prever un prever un procedimiento prefijado por la ley que determine de forma individual que se vaya a producir una medida de devolución forzosa. En la normativa comunitaria, las Directivas sobre

\footnotetext{
${ }^{347}$ El TJUE se declaró incompetente sobre estas cuestiones en el caso "Oxana Dem'Yanenko" (C-45/03), auto del 18 de marzo de 2004. Disponible en: http://curia.europa.eu/juris/document/document.jsf?text=\&docid=51099\&pageIndex=0\&doclang=ES\&m ode=req\&dir $=$ \&occ $=$ first\&part $=1 \&$ cid $=593122$ (Consulta: 14 de enero de 2016)

${ }^{348}$ Vid. entre otras, Tribunal Constitucional, Pleno, sentencia de 22 de mayo (STC 95/2003). Disponible en: http://hj.tribunalconstitucional.es/HJ/es/Resolucion/Show/4870 (Consulta: 14 de enero de 2016) ${ }^{349}$ CIDH: Opinión Consultiva $\mathrm{n}^{\circ}$ 18: Condición jurídica y derechos de los migrantes indocumentados, 17 de septiembre de 2003, par. 121 y 124-126. Disponible en: http://www.corteidh.or.cr/docs/opiniones/seriea_18 esp.pdf (Consulta: 14 de enero de 2016)
} 
procedimientos $^{350}$ y requisitos ${ }^{351}$ obligan a los Estados a realizar el examen de cada solicitud de forma individual, objetiva e imparcial.

Una de las consecuencias de la no arbitrariedad y la necesidad de realizar un examen individual de cada caso es la prohibición de realizar expulsiones colectivas. Esta garantía aparece en el $\mathrm{PIDCP}^{352}$, el $\mathrm{CEDH}^{353}$ y la $\mathrm{CDF}^{354}$, entre otros tratados internacionales $^{355}$ y regionales ${ }^{356}$. Estrasburgo también ha examinado casos de expulsiones desde territorio europeo. En Becker c. Dinamarca (1975), la Comisión definió una expulsión colectiva como "any measure of the competent authority compelling aliens as a group to leave the country, except where such a measure is taken after and on the basis of a reasonable and objective examination of the particular cases

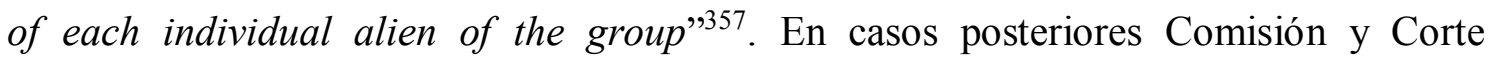
recalcaron que el rechazo de un cierto número de solicitantes de asilo de un mismo país simultáneamente no equivale a una expulsión masiva, en el caso de que cada una de las solicitudes haya sido estudiada y analizada individualmente ${ }^{358}$. El primer caso donde el

${ }^{350}$ Directiva 2013/32/UE, art.10

${ }^{351}$ Directiva 2011/95/UE, art. 4

${ }^{352}$ Si bien el artículo 13 del PIDCP sólo se refiere a los extranjeros que se hallan legalmente en el territorio de un Estado, el Comité de Derechos Humanos ha afirmado que el objetivo del artículo 13 es claramente impedir las expulsiones arbitrarias. Así, los requisitos previstos en el artículo 13 no quedarían satisfechos con leyes o decisiones que dispusiesen expulsiones colectivas o en masa de migrantes irregulares. Vid. OG $\mathrm{n}^{\circ} 15$, p. 10

${ }^{353} \mathrm{CEDH}$, Protocolo 4, art. $\mathrm{n}^{\circ} 4$

${ }^{354} \mathrm{CDF}$, art. 19.1

${ }^{355}$ Entre otros, el art. 22.1 del Convenio de Trabajadores Migrantes. El Comité contra la Discriminación Racial reclamó a los Estados en su OG no 30 "Garantizar que los no ciudadanos no serán objeto de una expulsión colectiva, en particular cuando no haya garantías suficientes de que se han tenido en cuenta las circunstancias personales de cada una de las personas afectadas" (para. 26). La International Law Association (ILA) adoptó en 1986 la Declaración de Principios del Derecho Internacional sobre Expulsión Masiva, donde encuadraba a la expulsión masiva dentro de la categoría de "crímenes internacionales" (p. 9). ILA: Declaración de Principios del Derecho Internacional sobre Expulsión Masiva, Seúl, 62 $2^{\mathrm{a}}$ Conferencia de la ILA, 24 a 30 de agosto de 1986, pp. 13-18 Disponible en: https://www.google.es/url? $\mathrm{sa}=\mathrm{t} \& \mathrm{rct}=\mathrm{j} \& \mathrm{q}=\&$ esrc $=\mathrm{s} \&$ source $=\mathrm{web} \& \mathrm{~cd}=1 \& \mathrm{cad}=\mathrm{rja} \& u a c t=8 \& \mathrm{ved}=0$ ahUKE wj067nF0anKAhUJ8j4KHdl7Bq4QFgggMAA\&url=http\%3A\%2F\%2Fwww.ila-

hq.org\%2Fdownload.cfm\%2Fdocid\%2F52392D73-DED3-435F-

BC0947746E68410A\&usg=AFQjCNELMYjNzHbTjqlk4AZ68GuTPqcBaw\&sig2=mu7HwqjF0x6-

c8mBtCnzNw (Consulta: 14 de enero de 2016)

${ }^{356}$ Véase la Convención de San José (art. 22.9) y la Carta de Banjul (art. 12.5). La Corte Interamericana lo trató más ampliamente en el caso de personas dominicanas y haitianas expulsadas vs. República Dominicana, sentencia de 28 de agosto de 2014, $\S 350-358,361-363$. El parecer de la CIDH es que "el debido proceso debe ser garantizado a toda persona independientemente del estatus migratorio", puesto que "el amplio alcance de la intangibilidad del debido proceso se aplica no solo ratione materiae sino también ratione personae sin discriminación alguna" (§ 350). Disponible en: http://corteidh.or.cr/docs/casos/articulos/seriec 282 esp.pdf (Consulta: 14 de enero de 2016)

357 CEDH: Becker c. Dinamarca, decisión de admisibilidad del 3 de octubre de 1975, n 7011/75, p. 235. Disponible en: http://hudoc.echr.coe.int (Consulta: 14 de enero de 2016)

358 Vid. CEDH: Alibaks y otros c. Países Bajos, decisión de admisibilidad del 16 de diciembre 1988, ${ }^{\circ}$ 14209/88. Disponible en: http:/hudoc.echr.coe.int/eng?i=001-351 (Consulta: 10 de enero de 2016); TEDH: Andric c. Suecia, decisión de admisibilidad del 23 de febrero de 1999, nº 45917/99. Disponible en: http://hudoc.echr.coe.int/eng?i=001-4520 (Consulta: 14 de enero de 2016) 


\section{CAPÍTULO 3}

TEDH halló una violación al artículo 4 del Protocolo 4 fue en Conka c. Bélgica (2002), debido a que el procedimiento de expulsión no proveía de "sufficient guarantees demonstrating that the personal circumstances of each of those concerned had been genuinely and individually taken into account" ${ }^{359}$ Se trataba de un grupo de personas de la comunidad gitana, solicitantes de asilo, cuyas órdenes de expulsión y arrestos se motivaron en términos idénticos. La expulsión venía precedida de una declaración de las autoridades políticas de que dicha expulsión sería llevada a cabo ${ }^{360}$.

Finalmente, Italia ha sido condenada recientemente en varias ocasiones por vulneración del artículo 4 del Protocolo 4: en el ya citado Hirsi Jamaa, donde el traslado de los solicitantes a Libia se había llevado a cabo sin que mediara ningún examen individual $^{361}$; y en Khlaifia y otros, donde sí se había llevado a cabo una identificación de los solicitantes, pero que había sido manifiestamente insuficiente: las entrevistas llevadas a cabo no habían intentado conocer las circunstancias específicas de cada individuo y las órdenes de expulsión eran todas idénticas ${ }^{362}$. Además, en Sharifi y otros, consideró que el alcance de la prohibición incluía el sistema de determinación del país responsable de la solicitud de asilo bajo el Reglamento de Dublín ${ }^{363}$.

Las prácticas de expulsiones arbitrarias han sido muy comunes en el marco de las políticas de retorno en el Mediterráneo ${ }^{364}$. Ya hemos visto un par de sentencias de Estrasburgo que condenaron a Italia por esta cuestión. Desde 2004, el gobierno italiano estableció un puente aéreo entre Lampedusa y Libia mediante el cual se producían devoluciones de forma inmediata de aquellos migrantes que llegaban a la isla, sin proceder a la realización de exámenes individuales de cada caso. En octubre de ese año, dos parlamentarios italianos se encontraban visitando el centro de Lampedusa mientras

Sultani c. Francia, decisión de admisibilidad del 20 de septiembre de 2007, n 45223/05, § 84. Disponible en: http://hudoc.echr.coe.int/eng?i=001-82338 (Consulta: 10 de enero de 2016)

359 TEDH: Conka c. Bélgica, sentencia del 5 de febrero de 2002, $\mathrm{n}^{\circ}$ 51564/99, § 63. Disponible en: http://hudoc.echr.coe.int/eng?i=001-60026 (Consulta: 14 de enero de 2016)

360 Íbíd., § 62

361 TEDH: Hirsi Jamaa y otros c. Italia, § 207

362 TEDH: Khlaifia y otros c. Italia, sentencia del 1 de septiembre de 2015, $\mathrm{n}^{\circ} 16483 / 12, \S 156$. Disponible en: http://hudoc.echr.coe.int/eng?i=001-157277 (Consulta: 29 de enero de 2016)

363 TEDH: Sharifi y otros c. Italia y Grecia, sentencia del 21 de octubre de 2014, n 16643/09, para .223224. Disponible en: http://hudoc.echr.coe.int/eng?i=001-147287 (Consulta: 14 de enero de 2016)

${ }^{364}$ Vid. Oxfam: Foreign Territory... op. cit., p. 24, acerca de las expulsiones de ciudadanos eritreos desde Malta en 2003. Sobre las expulsiones desde España, como las de 4.000 migrantes a Saint-Louis, Senegal desde las Islas Canarias, se puede consultar: Romero, Eduardo: Paremos los vuelos: las deportaciones de inmigrantes y el boicot a Air Europa, Oviedo, Ed. Cambalache, mayo de 2014, p. 18. Disponible en: http://descargas.localcambalache.org/paremos los vuelos.pdf (Consulta: 14 de enero de 2016). En la frontera greco-turca, la propia agencia Frontex también ha sido informada de expulsiones colectivas durante sus operaciones. FIDH- EMHRN-Migreurop: Frontex, between..., op. cit., p. 42) 
se producían las deportaciones. Uno de ellos detalló las condiciones en las que se llevaba a cabo el procedimiento:

While we were in the center of Lampedusa, from some documents that we saw we realized that these people were collectively repatriated under the same name. We saw long lists repeating the same name. Hence, we believe that they were not properly identified. Moreover, these people were not given the possibility to apply for asylum ... We raised this issue during a parliamentary interrogation, asking the Government how it could send back to Libya people that had not been identified. The response was that those people had been identified. Yet, when we asked if we could have the lists [with the names of those repatriated proving that they had been identified], we were told that for privacy reasons this request could not be met. ${ }^{365}$

El 4 de septiembre de 2012 el gobierno español expulsó a 73 personas de origen subsahariano que se encontraban en Isla de Tierra, un islote situado a 50 metros de la costa de Marruecos. Si bien recibieron asistencia humanitaria, y las mujeres embarazadas y menores fueron trasladados a Melilla, no recibieron información legal de su situación ni de la posibilidad de solicitar asilo en España. La expulsión se llevó a cabo con la entrega de este grupo de personas en a las fuerzas de seguridad marroquíes, que posteriormente las trasladaron a Oujda, en la frontera con Argelia ${ }^{366}$.

b) No discriminación. Este principio ${ }^{367}$ imposibilita que los Estados condicionen la devolución en razón de la raza, el sexo, el idioma, la religión, las opiniones políticas, la nacionalidad, la pertenencia a una clase o grupo social o cualquier otra circunstancia personal o social. La discriminación supone adoptar reglas o llevar a cabo actuaciones que impliquen un trato diferenciado sin que dicho trato desigual tenga un fin legítimo

\footnotetext{
${ }^{365}$ Paoletti, Emanuela: "Relations Among Unequals? Readmission between Italy and Libya", p. 63. En: Cassarino, Jean Pierre (ed.): Unbalanced Reciprocities: Cooperation on Readmission in the EuroMediterranean Area, 2010. Disponible en: http://www.statewatch.org/news/2010/sep/eu-unbalancedreciprocities-middle-east-institute.pdf (Consulta: 14 de enero de 2016)

${ }^{366}$ Comunicado de CEAR: El gobierno ha violado la legislación española al entregar a los inmigrantes de la Isla de Tierra a Marruecos, 4 de septiembre de 2012. Disponible en: http://www.cear.es/el-gobierno-haviolado-la-legislacion-espanola-al-entregar-a-los-inmigrantes-de-isla-de-tierra-a-marruecos/ (Consulta: 14 de enero de 2016)

${ }^{367}$ Se encuentra, entre otras, en el art. 2 DUDH, art. 2.1 del PIDCP, el art. 2.3 del PIDESC, el art. 2.1 de la CDN, el art. 1.1 de la CEDR, el art. 1 de la CEDAW y el art. 6 de la CTMF. Además de los art. 1.3, 55 y 56 de la Carta de las N.U. En 2005 entró en vigor el protocolo $\mathrm{n}^{\circ} 12$ del CEDH, ratificado hasta el momento por 18 estados, y que amplía el alcance del art. 14 del Convenio incluyendo parte de la doctrina de Estrasburgo, como la existencia de obligaciones no sólo negativas (no realizar actos discriminatorios) como positivas (tomar medidas que prevengan la discriminación, incluyendo cuando se produzca en el ámbito privado)
} 


\section{CAPÍTULO 3}

que este objetivamente justificado. El TEDH ha señalado que los Estados disfrutan de " a certain margin of appreciation in assessing whether and to what extent differences in otherwise similar situations justify a different treatment in law, but it is for the Court to give the final ruling in this respect ${ }^{\prime 368}$. Lo que determinaría el carácter discriminatorio de una medida sería, especialmente, la falta de justificación para el trato diferente ofrecido por el Estado ${ }^{369}$.

En lo que respecta a las expulsiones de extranjeros, se entiende que no debe existir discriminación entre las distintas categorías de extranjeros, en particular por motivos de raza, sexo, idioma, religión, opinión política o de otra índole, origen nacional o social, posición económica, nacimiento o cualquier otra condición. En un caso pionero de 1981, el CDH consideró ilegal una expulsión porque la normativa protegía frente a ésta a las esposas de nacionalidad mauriciana pero no a los maridos de la misma nacionalidad $^{370}$.

En la práctica, algunos Estados tienden a diferenciar a los migrantes según su nacionalidad, agilizando las expulsiones de migrantes del Magreb y derivando a otros centros de detención a los del África subsahariana, que presentan mayores dificultades de identificación ${ }^{371}$. Una de las consecuencias de estos acuerdos migratorios ha sido la participación de autoridades consulares de los países de origen en la identificación de la nacionalidad de los migrantes. Dichas prácticas suponen una seria amenaza a los derechos de los migrantes y refugiados, dado que agilizan los procedimientos de expulsión, en muchas ocasiones sin tener en cuenta todas las garantías legales. Se han documentado casos en Italia ${ }^{372}$ y España. De este último país, es revelador el testimonio de María Mena, abogada de Cruz Roja en el Centro para refugiados de la isla de Fuerteventura:

Venía el cónsul y señalaba a quienes deportarían. Dado que en este proceso muchas veces mediaba dinero, es decir la policía pagaba por cada persona que se llevaban, al cónsul le interesaba llevarse al máximo posible. He visto casos y me lo ha dicho la propia policía, gente de habla francesa que se la llevaban a

\footnotetext{
368 TEDH: Abdulaziz, Cabales y Balkandali c. Reino Unido, sentencia del 28 de mayo de 1985, $\mathrm{n}^{\circ}$ 9214/80, 9473/81 y 9474/81, § 72. Disponible en: http://hudoc.echr.coe.int/eng?i=001-57416 (Consulta: 10 de enero de 2016)

${ }^{369}$ Por ejemplo, en el caso Darby c. Suecia, se encontró violación al art. 14 por el establecimiento de un impuesto que distinguía entre extranjeros residentes y no residentes sin un fin legítimo. TEDH: Darby c. Suecia, sentencia del 23 de octubre de 1990, $\mathrm{n}^{\mathrm{o}} 11581 / 85, \quad \S 33$. Disponible en: http://hudoc.echr.coe.int/eng?i=001-57642 (Consulta: 14 de enero de 2016)

370 CDH: Aumeeruddy-Cziffra y otras c. Mauricio, 9 de abril de 1981, nº 035/1978. Disponible en: http://tbinternet.ohchr.org/ layouts/treatybodyexternal/Download.aspx?symbolno $=\mathrm{CCPR} \% 2 \mathrm{FC} \% 2 \mathrm{~F} 12 \%$ 2FD\%2F35\%2F1978\&Lang=en (Consulta: 14 de enero de 2016)

${ }^{371}$ HRW: Stemming the Flow..., p. 114

${ }^{372}$ Ibíd., p. 111
} 
Ghana. Casos en los que es imposible que sean de tal país porque son anglófonos o francófonos. Pero es que llega el cónsul y dice, "éste, éste y éste”. Venga, cuarenta para el avión. Con esto quiero decir que en las repatriaciones ha habido vulneraciones de todo tipo. Lo que pasa es que se daba una situación de secretismo, de masificación y de rapidez en la que era imposible luchar por todos. ${ }^{373}$

c) Proporcionalidad. La adopción de medidas de expulsión no debería ser la regla general con la que los Estados hagan frente a la inmigración irregular. Los ordenamientos jurídicos suelen contemplar otro tipo de sanciones alternativas a la expulsión para aquellos casos de incumplimiento de los requisitos de entrada en el territorio $^{374}$. Los estados deberían tener en consideración todas las circunstancias del sujeto antes de concluir que la expulsión es la medida más justa y efectiva. El TJUE, en su caso el-Dridi, por ejemplo, cuestiono que la decisión de expulsión se tramitara por el procedimiento de urgencia previsto en la Directiva de Retorno ${ }^{375}$.

d) Derecho a recurso efectivo. Las dos principales normas de derechos humanos del continente, el CEDH y la $\mathrm{CDF}^{376}$, reconocen el derecho de toda persona cuyos derechos y libertades hayan sido violados a recurrir ante una instancia nacional. Entre las dos existe una diferencia en lo relativo a la instancia de apelación: mientras la CDF exige que el recurso sea ante un tribunal, con la CEDH sólo bastaría que fuese ante una instancia nacional.

La jurisprudencia de Estrasburgo ha reconocido este derecho a todas las personas migrantes, independientemente de su situación administrativa, incluyendo en procedimientos de expulsión ${ }^{377}$. Esta pauta puede suponer una herramienta frente a las

\footnotetext{
373 Aldalur, M.: Clandestinos, op. cit., p. 177.

${ }^{374}$ Un caso sorprendente es el Reglamento 562/2006, que establecía el Código de Fronteras de Schengen. En su versión original en inglés, el art. 11.3 señala que en caso de no cumplirse los requisitos de entrada al país "the third-country national may be expelled by the competent authorities from the territory of the Member States concerned" Sin embargo, en la versión en español, el articulado decía que "el nacional del tercer país será expulsado por las autoridades competentes del territorio del Estado miembro de que se trate"

375 TJUE: "Hassen el-Dridi" (C-61/11 PPU), sentencia del 28 de abril de 2011, §58. Disponible en: http://curia.europa.eu/juris/document/document.jsf;jsessionid=9ea7d0f130d5d51a7102f65649428c728c8c f8540c07.e34KaxiLc3eQc40LaxqMbN4Oc3yLe0?text=\&docid=82038\&pageIndex=0\&doclang=ES\&mo $\mathrm{de}=1$ st\&dir $=\&$ occ $=$ first\&part $=1 \&$ cid $=764905$ (Consulta: 14 de enero de 2016)

$376 \mathrm{CEDH}$, art. 13, y CDF, art. 47.

377 TEDH: Conka c. Bélgica, § 79: "the notion of an effective remedy under Article 13 requires that the remedy may prevent the execution of measures that are contrary to the Convention and whose effects are potentially irreversible"
} 


\section{CAPÍTULO 3}

limitaciones de los artículos 6 del CEDH y 1 del protocolo 7, a través de la incorporación de estándares de juicio justo en los procedimientos de expulsión. Así, en M.S.S. c. Bélgica y Grecia, el TEDH estableció que los solicitantes deben de contar con la posibilidad de recurrir ante una instancia nacional que pueda abordar el fondo de su caso y, de ser necesario, adoptar las medidas adecuadas ${ }^{378}$. Las vulneraciones al artículo 13 han ocasionado numerosas sentencias condenatorias, especialmente en los últimos años $^{379}$. En el caso Hirsi Jamaa y otros, la interceptación de una embarcación con migrantes de origen somalí y eritreo y su devolución a las autoridades libias se consideró también una violación del derecho al recurso efectivo examinado en relación a los artículos 3 (prohibición de la tortura) y 4 del protocolo 4 (prohibición de las expulsiones colectivas) ${ }^{380}$. El contenido del artículo 13 requiere de dos condiciones: a) "un examen independiente y riguroso" de cualquier queja cuando es en relación al artículo 3, y b) la posibilidad de interrumpir la sentencia ${ }^{381}$. El Tribunal identificó además la inexistencia de intérpretes y asesoramiento legal, así como la desinformación de los agentes, que les hicieron creer a los migrantes que estaban siendo trasladados a Italia $^{382}$. Finalmente, en el caso Sharifi, el Tribunal condenó a Italia y Grecia por violación del artículo 13 al encontrar una serie de deficiencias en el procedimiento de asilo, entre ellas la falta de información, la escasez de intérpretes, la insuficiencia de la ayuda legal o el largo plazo de tiempo de la toma de decisión ${ }^{383}$.

Así mismo, las principales normas del acervo comunitario sobre asilo y fronteras recogen el derecho a un recurso efectivo ${ }^{384}$. La Directiva de procedimientos establece como condiciones del recurso la permanencia en el territorio, un completo examen ex nunc, tanto de hechos como de Derecho, así como que los plazos no impidan ni dificultan la presentación de éste. En el marco comunitario, la revisión en el caso de los solicitantes de asilo debe efectuarse por un órgano judicial, mientras que, en los procedimientos de expulsión para migrantes, sólo se requiere si la detención es prolongada. En caso contrario la revisión puede realizarse por un órgano administrativo.

\footnotetext{
378 TEDH: M.S.S. c. Bélgica y Grecia, § 288

379 Vid. TEDH: A.C. y otros c. España, sentencia del 22 de abril de 2014, n ${ }^{\circ}$ 6528/11. Disponible en: http://hudoc.echr.coe.int/eng?i=001-148248 (Consulta: 14 de enero de 2016); B.M. c. Grecia, sentencia del 19 de marzo de 2014, no 53608/11. Disponible en: http://hudoc.echr.coe.int/eng?i=001-139758 (Consulta: 10 de enero de 2016)

380 TEDH: Hirsi Jamaa y otros c. Italia, $\S 206$

${ }^{381}$ Ibíd., $§ 198$

${ }^{382}$ Ibíd., $§ 202$

383 TEDH: Sharifi y otros c. Italia y Grecia, § 175.

${ }^{384}$ Reglamento (CE) 562/2006, art. 13.3; Reglamento (UE) 604/2013, art. 27; Directiva 2013/32/UE, art. 46; y Directiva 2013/33/UE, art. 9
} 


\subsubsection{Métodos de expulsión}

El procedimiento de expulsión suele comenzar con el arresto y detención administrativa del individuo. En ocasiones, la detención se produce en el mismo buque tras una interceptación. La detención puede continuar posteriormente en un centro de recepción de migrantes, de refugiados o incluso una comisaría de policía ubicados cerca del puerto. En relación al procedimiento de expulsión, la principal cuestión que entra en consideración es el del uso de medidas de fuerza por parte de las autoridades cuando realicen una expulsión de forma forzosa, como suele suceder en la mayoría de los casos. El criterio que rige la actuación de las autoridades debe ser el de la proporcionalidad.

La situación de los solicitantes de asilo detenidos en centros a lo largo de la costa mediterránea ha sido motivo de preocupación por organizaciones de migrantes, refugiados y derechos humanos a lo largo de los últimos años ${ }^{385}$. Se ha denunciado las dificultades de las personas detenidas para acceder al procedimiento de asilo, especialmente a la asistencia legal y al derecho a la información. Otras preocupaciones tienen que ver con el impacto en la salud y el impacto psicológico en dichas personas. El Grupo de Trabajo sobre Detención Arbitraria de Naciones Unidas realizó un informe específico sobre la situación de los inmigrantes detenidos en Italia $^{386}$.

No existen, en el marco del derecho internacional de los derechos humanos, normas específicas sobre la detención de extranjeros con vistas a la expulsión ${ }^{387}$. Quiero esto decir que son de aplicación las provisiones generales referidas al derecho a la vida, a la libertad, la prohibición de la tortura y de los tratos crueles, inhumanos y degradantes, entre otras, y así lo han venido interpretando los tribunales y comités de vigilancia de los tratados ${ }^{388}$. La detención debe producirse de acuerdo a un procedimiento establecido por ley, y proveer accesos a recursos contra la acción que lo prevengan de interferencias arbitrarias al derecho de libertad ambulatoria, con salvaguardas como la información al detenido de sus derechos, el acceso a la asistencia jurídica y la presentación ante una autoridad judicial dentro de un periodo razonable de tiempo. Algunos organismos

\footnotetext{
385 Vid. JRS: Becoming Vulnerable in Detention, Civil Society Report on the Detention of Vulnerable Asylum Seekers and Irregular Migrants in the European Union, 2010. Disponible en: http://jrsmalta.jesuit.org.mt/wp-content/uploads/downloads/2011/02/Becoming-Vulnerable-in-DetentionMT.pdf (Consulta: 14 de enero de 2016)

386 Consejo de Derechos Humanos: Report of the WGAD on its Mission to Italy, 26 de enero de 2009, Doc. A/HRC/10/21/Add.5. Disponible en: http://daccess-ddsny.un.org/doc/UNDOC/GEN/G09/105/76/PDF/G0910576.pdf?OpenElement (Consulta: 14 de enero de 2016)

${ }^{387}$ Vid. OHCHR, Expulsions of aliens..., op. cit, p. 17.

${ }^{388}$ En especial las disposiciones contenidas en el art. 5 del CEDH y art. 9 del PIDCP
} 
internacionales sí que han presentado instrumentos del soft law, por ejemplo el ACNUR $^{389}$, el Consejo de Europa ${ }^{390}$ y la FRA ${ }^{391}$.

El CEDH incluye el control fronterizo y los procedimientos de expulsiones como una excepción a la privación de libertad ${ }^{392}$. En su artículo 5.1 f): "Si se trata de la detención preventiva o del internamiento, conforme a derecho, de una persona para impedir que entre ilegalmente en el territorio o contra la que esté en curso un procedimiento de expulsión o extradición". Durante décadas, y de forma creciente en los últimos años, diversas sentencias han conformado una jurisprudencia sobre las causas y los límites en la detención de migrantes irregulares y solicitantes de asilo. E1 TEDH ha examinado los límites de este supuesto en varias sentencias, tanto en lo relativo a la razonabilidad de las detenciones como a la longitud y el lugar de la detención $^{393}$. En dos casos de 1996 se cuestionó sobre la diferencia entre privación y restricción de la libertad ${ }^{394}$ e hizo notar que el artículo no exige que la detención se justifique para impedir la comisión de una infracción o la huida, sino simplemente "with a view to deportation" 395 . La ligereza de este razonamiento jurídico erosiona el derecho a no ser privado de forma arbitraria de su libertad, de forma que la mera existencia de una orden de expulsión o un control fronterizo podrían ser consideradas razones justificables para la detención de los migrantes. Establece, además, un trato desigual no razonable respecto a otros supuestos del artículo 5.1, como el c), donde el tribunal ha exigido estándares más elevados para justificar la detención ${ }^{396}$.

${ }^{389}$ ACNUR: Directrices sobre los criterios y estándares aplicables a la detención de solicitantes de asilo y las alternativas a la detención, 2012. Disponible en: http://www.unhcr.org/cgibin/texis/vtx/refworld/rwmain/opendocpdf.pdf?reldoc=y\&docid=4992fb672 (Consulta: 14 de enero de 2016)

${ }^{390}$ Consejo de Europa: The Detention of Asylum Seekers and Irregular Migrants in Europe, doc. 12105 de la Asamblea Parlamentaria, 11 de enero de 2010. Disponible en: http://assembly.coe.int/nw/xml/XRef/Xref-XML2HTML-EN.asp?fileid=12435\&lang=en (Consulta: 14 de enero de 2016)

${ }^{391}$ Agencia de Derechos Fundamentales: Detention of Third-Country Nationals in Return Procedures, noviembre de 2010. Disponible en: http://fra.europa.eu/sites/default/files/fra uploads/1306-FRA-reportdetention-december-2010_EN.pdf (Consulta: 14 de enero de 2016)

392 Hay que recordar que el art. 5 concierne a la legalidad de la "privación" de libertad, no a las restricciones o limitaciones a la libertad de movimientos, que se encuentra recogida en el art. 2 del protocolo $\mathrm{n}^{\circ}$ 2, o la legalidad de las condiciones de detención, cuestión tratada en el art. 3 y en el Convenio Europeo para la Prevención de la Tortura y los Tratos o penas inhumanos o degradantes.

393 Para un examen más detallado de la jurisprudencia del TEDH sobre detención de migrantes, ver Costello, Cathryn: Human Rights and the Elusive Universal Subject: Immigration Detention Under International Human Rights and EU Law, Indiana Journal of Global Legal Studies Vol. 19, $\mathrm{n}^{\circ} 1,2012$, pp. 257-303. Disponible en: http://www.repository.law.indiana.edu/ijgls/vol19/iss1/10 (Consulta: 16 de enero de 2016)

394 TEDH: Amuur c. Francia, sentencia del 25 de junio de 1996, no 19776/92, § 42. Disponible en: http:/hudoc.echr.coe.int/eng?i=001-57988 (Consulta: 10 de enero de 2016)

395 TEDH: Chahal c. Reino Unido, $§ 112$

${ }^{396}$ La lista sería interminable, remontándose a Lawless c. Irlanda, sentencia del 1 de julio de 1971, ${ }^{\circ}$ 332/57. Disponible en: http://hudoc.echr.coe.int/eng?i=001-57518 (Consulta: 10 de enero de 2016) 
Lo que para el TEDH determina la validez de la detención es que debe realizarse de acuerdo a un procedimiento establecido por ley, y estar dotado de "calidad suficiente", esto es: garantías jurídicas, límites temporales, acceso a asistencia legal, social y humanitaria. En sucesivas sentencias el Tribunal fue fijando dichos estándares de calidad. El confinamiento no debe privar a los solicitantes del acceso efectivo al procedimiento de determinación del estatus de refugiado ${ }^{397}$. En Conka c. Bélgica (2002): el TEDH encontró una violación del artículo 5 (libertad y seguridad de la persona) en un caso donde las autoridades recluyeron a los solicitantes de asilo en una estación de policía con vistas a deportarles: "a conscious decision by the authorities to facilitate or improve the effectiveness of a planned operation for the expulsion of aliens by misleading them about the purpose of a notice so as to make it easier to deprive them of their liberty is not compatible with article 5."398

En Rasu c. Austria ${ }^{399}$, el TEDH reiteró que la detención de un individuo es una medida grave y que en un contexto en que la detención fuera necesaria para alcanzar un objetivo definido, sería arbitraria salvo que estuviese justificada como último recurso después de tomar en consideración otras medidas menos graves y haberlas considerado insuficientes para salvaguardar el interés individual o público. El razonamiento de las autoridades para detener a la solicitante era inadecuado y su detención presentaba un elemento de arbitrariedad. En Saadi c. Reino Unido (2008), la Corte examinó el caso de un ciudadano iraquí que solicitó asilo a su llegada al Reino Unido, siéndole concedido un permiso de residencia temporal hasta que se resolviera su petición. No obstante, 4 días después fue detenido por el periodo de una semana. El TEDH estimó que "Until a potential immigrant had been granted leave to remain in the country, he had not effected a lawful entry, and detention could reasonably be considered to be aimed at preventing unlawful entry" "400 y concedió que "the State had a broader discretion to decide whether to detain potential immigrants than was the case for other interferences with the right to liberty" ${ }^{\prime 01}$ recordando eso sí que ésta no debe ser arbitraria y ser parte de un proceso de determinación del estatus del individuo. El tribunal fijo también un plazo razonable para ser informado de las razones de su detención, al encontrar una violación al artículo 5.2 del Convenio un retraso superior a 72 horas en ser informado ${ }^{402}$.

\footnotetext{
397 TEDH: Chahal c. Reino Unido, § 119; Ammur c. Francia, § 43

398 TEDH: Conka c. Bélgica, $\$ 42$.

399 TEDH: Rusu c. Austria, sentencia del 2 de octubre de 2008, $\mathrm{n}^{\circ}$ 34082/02, § 58. Disponible en: http://hudoc.echr.coe.int/eng?i=001-88669 (Consulta: 14 de enero de 2016)

${ }_{400}$ TEDH: Saadi c. Reino Unido, sentencia del 29 de enero de 2008, $\mathrm{n}^{\circ}$ 13229/03, § 44. Disponible en: http://hudoc.echr.coe.int/eng?i=001-84709 (Consulta: 14 de enero de 2016)

${ }^{401}$ Ibíd., $§ 45$

${ }^{402}$ Ibíd., § 84
} 


\section{CAPÍTULO 3}

Finalmente, en los últimos años el TEDH se ha tenido que encargar de un gran número de casos sobre la detención de extranjeros y solicitantes de asilo en Grecia, haciendo especial hincapié en las pobres condiciones en las que se encuentran los centros de detención en aquel país. Debemos destacar especialmente la sentencia del caso Tatishvili (2015), donde la Corte estableció cuatro condiciones para que la detención no pudiera ser considerada arbitraria, y por tanto, violara el artículo 5.1.f): 1) que sea llevada a cabo de buena fe; 2) que esté estrechamente relacionada con el propósito de prevenir la entrada no autorizada al territorio; 3) que el lugar y las condiciones de la detenciones sean apropiadas, tomando en consideración que el solicitante era un solicitante de asilo y no un supuesto criminal; y 4) que la duración de la detención no exceda razonablemente para el propósito perseguido (en este caso estimado en tres meses) $)^{403}$.

El TJUE también se ha fijado en el internamiento de extranjeros en los procesos de expulsión, especialmente tras la aprobación de la Directiva del retorno. En 2014 examinó conjuntamente dos casos relativos a solicitantes de asilo cuyos casos habían sido resueltos negativamente $\mathrm{y}$, posteriormente, detenidos con el propósito de ser expulsados. En la sentencia, encontrando contraria a la legislación comunitaria la detención en prisiones ordinarias de cara a la expulsión ${ }^{404}$.

Cuando hablamos de los métodos usados para proceder a la expulsión, nos estamos refiriendo al uso de esposas, vendas y otros materiales para sujetar al individuo, la privación de la visión, engañarle sobre el destino del viaje, o el uso de drogas (tranquilizantes) contra su voluntad para "anular su resistencia", medidas todas destinadas a eliminar o reducir la resistencia del extranjero ante su expulsión. Si bien no existen normas de carácter compulsorio, debemos hacer referencia a las 20 directrices sobre el retorno forzoso aprobadas por el Consejo de Ministros del Consejo de Europea en $2005^{405}$. Su directriz 19 indica que "los únicos aceptables son aquellos que constituyen respuestas estrictamente proporcionadas a una resistencia física actual o que quepa anticipar razonablemente de parte de la persona que se pretenda retornar. $\mathrm{Su}$ uso debe ir dirigido a controlar dicha resistencia". Por su parte, el CDH indicó una

403 TEDH: Tatishvili c. Grecia, sentencia del 31 de julio de 2014, no 26452/11, § 54. Disponible en: http://hudoc.echr.coe.int/eng?i=001-145785 (Consulta: 14 de enero de 2016)

404 TJUE: "Bero contra Regierungspräsidium Kassel” (C-473/13) y "Bouzalmate contra Kreisverwaltung Kleve” (C-514/13), sentencia del 17 de julio de 2014. Disponible en: http://curia.europa.eu/juris/document/document.jsf?text=\&docid=155112\&pageIndex $=0 \&$ doclang=es\&m ode $=1$ st\&dir $=\&$ occ $=$ first\&part=1\&cid=769561 (Consulta: 14 de enero de 2016)

405 Consejo de Europa: Veinte directrices sobre el retorno forzoso, Ad hoc Committee of Experts on the Legal Aspects of Territorial Asylum, Refugees and Stateless Persons (CAHAR), Doc. CM(2005) 40. Disponible en: https://wcd.coe.int/ViewDoc.jsp?id=858071\&Site=COE (Consulta: 14 de enero de 2016) 
serie de medidas relativas al empleo de la fuerza en casos de repatriaciones en un informe sobre Bélgica:

b) Sin perjuicio de las disposiciones legales, los medios de empleo de la fuerza deben satisfacer las condiciones siguientes:

i) la toma en consideración de la seguridad del vuelo;

ii) la toma en consideración de la seguridad y de la salud de las personas que son afectadas por esa medida;

iii) la limitación máxima de los inconvenientes para los otros pasajeros;

c) Se prohibe estrictamente el uso de las siguientes medidas coercitivas:

i) técnicas que obstruyan las vías respiratorias;

ii) la administración de calmantes o de otros medicamentos para obligar a la persona;

iii) toda traba a la libertad de movimientos de la persona durante el vuelo que, en una situación de peligro, pudiera hacer más difícil o imposible el salvamento de la persona;

iv) el uso de medios coercitivos cuyo fin es castigar a la persona interesada. $^{406}$

Por último, el TEDH sí que se ha tratado casos de expulsiones cuando estos han implicado el artículo 3 del Convenio (prohibición de tortura o trato cruel inhumano y degradante) o trataban casos de menores ${ }^{407}$. El Comité contra la Tortura ha revisado casos donde los solicitantes estimaban que la deportación supondría un empeoramiento de su salud, no encontrando el Comité violación de sus derechos en estos casos bajo el artículo 16 de la Convención ${ }^{408}$.

${ }^{406}$ CDH: Cuarto Informe Periódico de Bélgica, 16 de mayo de 2003, CCPR/C/BEL/2003/4, para. 2.3.1. Disponible http://docstore.ohchr.org/SelfServices/FilesHandler.ashx?enc=6QkG1d\%2fPPRiCAqhKb7yhsnKB82NyZ V5e4fvxB6eLo8G\%2b9Y61k1zRs\%2bqlJgIrcvWq4boAzW7Vtd7RUYUIR24ZTB0FyHUxvALTi3LRvF hN8niJSjN9GfD9Hhy\%2fZeVTpXS0 (Consulta: 14 de enero de 2016)

${ }^{407}$ Vid. TEDH: Mubilanzila c. Bélgica, op. cit.

408 CAT: G.R.B. c. Suecia, 15 de mayo de 1998, $\mathrm{n}^{\circ}$ 83/1997, § 6.7. Disponible en: http://docstore.ohchr.org/SelfServices/FilesHandler.ashx?enc=6QkG1d\%2fPPRiCAqhKb7yhssh2tXWBb yLwahMw00Sn91UvznuOMGh6DpI8GkXnGo\%2f2loNe5r5VNB26GMyHPDTg2\%2b5v2cfq\%2fTt2ck dZ\%2fWYi8GV5Nagqqx7z67PySHNKaGN8eyJvYXfgc6ENfBzEg616C\%2b4NaivtuO6Dy8R5LnL3Ff8 \%3d (Consulta: 14 de enero de 2016) 


\section{CAPÍTULO 3}

\subsection{Acuerdos de readmisión}

Los acuerdos de readmisión consisten en compromisos recíprocos entre estados para retornar migrantes irregulares a su país de origen o tránsito. En la práctica, como dichos acuerdos se firman entre países receptores y emisores de migrantes, la readmisión funciona de una forma unidireccional. A cambio, el país que acepta la readmisión de nacionales o individuos de terceros países expulsados recibe contrapartidas en otros ámbitos, especialmente el económico (fondos de desarrollo, acuerdos comerciales, etc...) En términos jurídicos los acuerdos de readmisión pueden realizarse por dos vías: a) la existencia de una cláusula de readmisión en un tratado general de cooperación o asociación en materia migratoria, o b) la existencia de un acuerdo específico de readmisión.

Dependiendo de la nacionalidad del migrante irregular, se pueden distinguir dos tipos de figuras legales que pueden figurar en estos acuerdos: la repatriación, que implica el retorno del migrante irregular al país del que es nacional; y la readmisión, en sentido estricto, que consiste en la admisión del nacional de un tercer país o un apátrida por el Estado de tránsito. A diferencia de la repatriación, la readmisión de nacionales de terceros países o apátridas no constituye una regla del derecho internacional ${ }^{409}$.

Técnicamente, la readmisión es un procedimiento administrativo que requiere de la cooperación bilateral con el país al cual las personas expulsadas van a ser retornadas. Para los estados europeos y la UE, los acuerdos de readmisión suponen una ventaja considerable, ya que les permiten llevar a cabo las expulsiones de una forma rápida y expedita, sin formalidades innecesarias y en un plazo corto de tiempo. En dichos acuerdos suelen encontrarse además una cláusula que reconoce el debido respeto a las obligaciones contenidas en el derecho internacional para con a las personas refugiadas o que pudieran ser objeto de alguna forma de protección internacional. Como veremos más adelante, la efectividad de estas cláusulas ha sido puesta en duda por numerosas organizaciones de derechos humanos e instituciones europeas, que han denunciado también la escasa transparencia que rodea estos acuerdos, desde su negociación y contenido a su implementación.

\footnotetext{
${ }^{409}$ Cassarino, Jean-Pierre: Readmission Policy in the European Union, Bruselas, estudio del Parlamento Europeo, septiembre de 2010, p. $13 . \quad$ Disponible en: http://www.europarl.europa.eu/RegData/etudes/etudes/join/2010/425632/IPOLLIBE ET\%282010\%29425632 EN.pdf (Consulta: 17 de enero de 2016)
} 
Si bien se pueden encontrar ciertos antecedentes, la cooperación migratoria euroafricana nace como tal en los años noventa. Los Estados del sur de Europa tratan de reaccionar ante la llegada de pateras y polizones, que había experimentado un fuerte crecimiento desde finales de los años ochenta. Por otra parte, tras el Tratado de Maastricht la recién creada UE empieza a asumir competencias de política exterior, migración y asilo. Competencias todas ellas compartidas, por lo que esta cooperación euroafricana se ha producido a dos niveles. La UE ha intentado llegar a acuerdos macro bien con países bien con grupos de países, mientras que los EEMM han seguido negociando de forma bilateral toda clase de tratados y acuerdos, si bien éstos han tenido que adecuarse al marco comunitario.

\subsubsection{Acuerdos bilaterales}

El objetivo principal de los acuerdos bilaterales de readmisión es facilitar y agilizar el traslado de migrantes irregulares a los países de origen y tránsito. Hay que señalar que, a diferencia de los acuerdos firmados por la UE, la mayor parte de los acuerdos de readmisión firmados entre países europeos y norteafricanos comprenden únicamente la repatriación, siendo menos comunes los que incluyen la readmisión de nacionales de terceros países.

Otra diferencia existente es que los acuerdos firmados por los Estados pueden incluir también toda clase de acuerdos sui generis que quedan fuera del alcance del derecho internacional convencional (memorandos de entendimiento, pactos de cooperación policial, acuerdos de gestión fronteriza, etc...). Esto supone una serie de ventajas para ambos países. Por una parte, no precisan de largos procesos de ratificación, ni tienen que exponer las negociaciones ante el parlamento o la opinión pública. En ciertas ocasiones, los Estados se escudan en razones de seguridad nacional para evitar la publicación de los acuerdos. En el lado más puramente técnico, esta falta de visibilidad permite llevar a cabo acciones más flexibles y adaptadas a la situación específica. Toda esta opacidad redunda en mayores incentivos a las fuerzas policiales y las autoridades políticas de evadir el cumplimiento de aquellas normas que garantizan los derechos de migrantes y refugiados. En un reciente caso concerniente a una expulsión colectiva de ciudadanos tunecinos en Italia, el TEDH señaló el carácter no 


\section{CAPÍTULO 3}

público del acuerdo bilateral entre los dos países como uno de los factores que habían permitido evitar la protección de los solicitantes frente a la expulsión arbitraria ${ }^{410}$.

El ejemplo más revelador de la cooperación entre Estados de ambas orillas del Mediterráneo es la relación libio-italiana ${ }^{411}$. Aunque el primer acuerdo policial data del año $2000^{412}$, la cooperación real comenzó en el año 2004, con la cesión de un par de patrulleras por parte de Italia, con las que Libia estableció su primera guarda costera ${ }^{413}$. La colaboración entre los dos países se profundizó durante el mandato de Silvio Berlusconi (2001-2006). Hay que tener en cuenta que Libia no formaba parte en ese momento de la CG51, ni había creado un sistema de asilo, contando únicamente ACNUR con una pequeña oficina en la capital.

Hasta septiembre de 2004, a pesar de que no existía ningún acuerdo de readmisión entre ambos países, Libia también aceptó readmitir inmigrantes ilegales procedentes de Italia sin realizar inquisiciones sobre su nacionalidad o situación personal. Italia aprovechó para efectuar expulsiones forzosas de forma indiscriminada, incluso a posibles solicitantes de asilo o menores no acompañados, sin proceder a identificaciones ni permitirles presentar una solicitud de asilo. De acuerdo a Frontex, ${ }^{414}$ en 2006 se llevaron a cabo 53.842 expulsiones. El International Center for Migration Policy Development, ${ }^{415}$ elevó las cifras de migrantes deportados a 86.006 en 2006 y 30.940 en 2007. En mayo de 2009, un grupo de eritreos y somalíes presentaron una denuncia contra Italia ante el TEDH tras ser expulsados, lo que daría lugar a la sentencia del caso Hirsi Jamaa. La Comisión Europea también solicitó explicaciones a Italia después de que 70 personas fueran devueltas el 30 de agosto de 2009. La defensa de las autoridades italianas fue que ninguno de ellos había expresado su deseo de solicitar asilo ${ }^{416}$. Tras su devolución a Libia, los migrantes irregulares subsaharianos o bien eran repatriados de

\footnotetext{
${ }^{410}$ TEDH: Khlaifia y otros c. Italia, op. cit., §28-30, 153.

${ }^{411}$ Paoletti, E: "Relations Among...", p. 58 y ss.; HRW: Stemming the flow..., p. 99 y ss.

${ }^{412}$ Consejo de la Unión Europea, Technical Mission to Libya on Illegal Immigration, 27 Nov - 6 Dec 2004, Doc. 7753/05, Bruselas, 4 de abril de 2005, p. 58. Disponible en: http://www.fluechtlingsrathamburg.de/content/libyaEUreport.pdf (Consulta: 17 de enero de 2016)

${ }^{413}$ Van Selm, J. y Cooper, B.: The New..., op. cit, p. 64

${ }^{414}$ Frontex, Frontex-Led EU Illegal Immigration Mission to Libya 28 May - 5 Jun 2007, Varsovia, 2007, p. 10. Disponible en: http://www.statewatch.org/news/2007/oct/eu-libya-frontex-report.pdf (Consulta: 17 de enero de 2016)

${ }^{415}$ International Centre for Migration Policy Development: East Africa Migration Route Initiative: Gaps \& Needs Analysis Project Country Reports: Ethiopia, Kenya, Libya, Viena, 2008, p. 94. Disponible en: http://igad.int/index.php?option=com docman\&task=doc download\&gid=16\&Itemid=144 (Consulta: 17 de enero de 2016)

416 Consejo de Europa, "Report to the Italian Government on the visit to Italy carried out by the European Committee for the Prevention of Torture and Inhuman or Degrading Treatment or Punishment (CPT) from 27 to 31 July 2009", Estrasburgo, 28 de abril de 2010, Doc. CPT/Inf(2010)14. Disponible en: http://www.cpt.coe.int/documents/ita/2010-inf-14-eng.pdf (Consulta: 17 de enero de 2016)
} 
nuevo a sus países de origen ${ }^{417}$, o eran internados en centros de detención para migrantes irregulares ${ }^{418}$.

Las protestas de $\mathrm{ACNUR}^{419}$ y el Parlamento Europeo ${ }^{420}$ arreciaron, llevando a Italia a suspender temporalmente las expulsiones a mediados de $2006^{421} .13$ organizaciones de derechos humanos, entre las que se incluían HRW y ECRE, solicitaron a la Comisión que sancionase a Italia por haber hecho caso omiso a la prohibición de expulsiones colectivas y violar el principio de non-refoulement de la CG551. Así mismo, mostraban su preocupación de que los migrantes retenidos en centros libios pudieran ser víctimas de violaciones de derechos humanos.

En 2008, con la vuelta al poder de Berlusconi, ambas naciones firmaron en Bengazhi el Trattato di Amicizia, por el que Italia se comprometía a pagar 5 mil millones de dólares durante los próximos 20 años, supuestamente para compensar las "profundas heridas" causadas por el pasado colonial. Junto a contratos petroleros y de infraestructuras, en el artículo 19 del tratado las partes se comprometían a reforzar los controles fronterizos para frenar la inmigración clandestina. Como documentaron diversos organismos, las peores prácticas en materia de retorno regresaron ${ }^{422}$. Desde 2011, con la caída del régimen de Gadafi y la falta de una autoridad centralizada en el país han convertido en papel mojado los acuerdos firmado. La situación de los migrantes y refugiados, en el contexto de un país en conflicto militar, no ha hecho sino empeorar $^{423}$.

\footnotetext{
${ }^{417}$ HRW: Stemming the flow..., p. 55

${ }^{418}$ De acuerdo a Frontex, en el año 2007 en estos centros se encontraban presos más de 60.000 migrantes (supra n. 411, p. 10). Algunos de estos centros fueron construidos con financiación italiana proveniente de los acuerdos de colaboración migratoria, como los de Gharyan y Kufra.

${ }^{419}$ ACNUR: Italy: UNHCR Deeply Concerned About Lampedusa Deportations of Libyans, Briefing Notes, 18 de marzo de 2005. Disponible en: http://www.unhcr.org/423ab71a4.html (Consulta: 17 de enero de 2016)

${ }^{420}$ El Parlamento denunciaba que "Italian authorities have failed to meet their international obligations by not ensuring that the lives of the people expelled by them [to Libya] are not threatened in their countries of origin". Resolución del Parlamento Europeo sobre Lampedusa, 4 de abril de 2005, Doc. P6_TA(2005)0138. Disponible en: http://www.europarl.europa.eu/sides/getDoc.do?pubRef=//EP//NONSGML+TA+P6-TA-2005-0138+0+DOC+PDF+V0//ES (Consulta: 17 de enero de 2016)

${ }_{421}$ En ese momento Italia se encontraba inmersa en plena campaña electoral, lo que pudo ser una motivación para el cambio de actitud del gobierno de Berlusconi.

${ }^{422}$ HRW: Pushed back..., p. 37; AI: 'Libya of Tomorrow'. What hope for human rights?, Londres, 2010, AI Doc. MDE 19/007/2010, p. 91 y ss.; Disponible en: https://www.amnesty.org/download/Documents/40000/mde190072010en.pdf (Consulta: 17 de enero de 2016)

${ }^{423}$ JRS: Más allá de lo imaginable. Solicitantes de asilo hablan de su vida en Libia. Servicio Jesuita a Refugiados - Malta, enero de 2014. Disponible en: https://jrseurope.org/assets/Publications/File/jrs-masalla-de-lo-imaginable1.pdf (Consulta: 17 de enero de 2016)
} 


\section{CAPÍTULO 3}

Otro acuerdo significativo es el existente entre España y Marruecos. El convenio se firma en 1992, y recoge que las autoridades de las partes "readmitirán en su territorio, a petición formal de las autoridades fronterizas del Estado requirente, a los nacionales de países terceros que hubieren entrado ilegalmente en el territorio de este último procedentes del Estado requerido" 424 . Por tanto -y en este aspecto resulta básicoestamos ante una norma de readmisión de extranjeros, no de nacionales marroquíes o españoles. El Estado requirente debe probar tres aspectos: la nacionalidad del extranjero (distinta a las partes); la entrada ilegal en el territorio del Estado requirente; y la procedencia del territorio requerido ${ }^{425}$. La aplicación de la norma impediría a las partes devolver a personas cuya nacionalidad no pueda probar o cuya entrada ilegal o cuya procedencia no pueda demostrar. Este punto ha sido vulnerado sistemáticamente por las autoridades españolas durante los últimos años, tal como han venido denunciando organizaciones de derechos humanos ${ }^{426}$. El acuerdo no contenía ninguna referencia expresa a la obligación de respeto a los derechos humanos o la protección de los refugiados. Sí que incorporaba la obligación del Estado requerido de enviar "lo antes posible" a los extranjeros readmitidos a sus países de origen ${ }^{427}$.

En la década siguiente se produjeron una serie de acuerdos entre España países de origen y tránsito del noroeste africano en el marco del llamado Plan África: Argelia, Guinea Bissau, Mauritania, Gambia, Guinea-Conakry y Cabo Verde. Sólo uno, el de Mauritania, fijaba un plazo de tiempo para la presentación de la solicitud de readmisión ${ }^{428}$. A diferencia del acuerdo hispano-marroquí, sí se incluyen en estos acuerdos cláusulas de respeto a los derechos humanos y los acuerdos y convenios internacionales ${ }^{429}$. Eso no ha impedido que se hayan seguido produciendo refoulement indirectos, por ejemplo Mauritania ha tenido la práctica habitual de devolver a los

\footnotetext{
${ }^{424}$ Acuerdo entre el Reino de Marruecos y el Reino de España, relativo a la libre circulación de personas, el tránsito y la readmisión de extranjeros entrados ilegalmente, firmado en Madrid, el 13 de febrero de 1992, art. 1. BOE de 25 de abril de 1992, pp. 13969 a 13970. Disponible en: http://www.boe.es/boe/dias/1992/04/25/pdfs/A13969-13970.pdf (Consulta: 17 de enero de 2016)

${ }^{425}$ Ibíd., art. 2

${ }^{426}$ Vid.: MSF: Violence, Vulnerability and Migration: Trapped at the Gates of Europe. A report on the situation of sub-Saharan migrants in an irregular situation in Morocco, marzo de 2013. Disponible en: https://www.msf.org/sites/msf.org/files/migrants in morocco report.pdf (Consulta: 17 de enero de 2016) 427 Acuerdo entre el Reino de Marruecos y el Reino de España, op. cit., art. 5

${ }^{428}$ Acuerdo entre el Reino de España y la República Islámica de Mauritania en materia de inmigración, hecho, en Madrid el 1 de julio de 2003, art. XI.1. BOE de 4 de agosto de 2003, pp. 30050 a 30053. Disponible en: http://www.boe.es/boe/dias/2003/08/04/pdfs/A30050-30053.pdf (Consulta: 17 de enero de 2016)

429 Por ejemplo, el art. 8 del Protocolo entre el Gobierno del Reino de España y el Gobierno de la República Argelina Democrática y Popular sobre circulación de personas, de 31 de julio de 2002: "El presente Protocolo se celebra en el estricto respeto de los compromisos suscritos en materia de protección de los derechos humanos y no afectará a las obligaciones derivadas de los Acuerdos y Convenciones internacionales concluidos por las Partes". BOE del 12 de febrero de 2004, pp. 6350 a 6352. Disponible en: http://www.boe.es/boe/dias/2004/02/12/pdfs/A06350-06352.pdf (Consulta: 17 de enero de 2016)
} 
nacionales de Mali y Senegal a la frontera de sus respectivos países ${ }^{430}$. Se incluye también la prohibición de recurrir a la fuerza indebida, tortura y tratos crueles, inhumanos o degradantes en la aplicación de los retornos ${ }^{431}$. Como ultima observación relacionada con la protección de los derechos fundamentales, hay que señalar que en ninguno de los acuerdos se contemplan garantías procesales ni posibilidad de recurrir la decisión de expulsión por parte del migrante que va a ser retornado.

\subsubsection{Acuerdos a nivel europeo}

Previamente al Tratado de Ámsterdam, los Estados europeos habían venido concertando este tipo de acuerdos relativos a la readmisión de extranjeros entrados ilegalmente. La Unión, que no tenía competencia en estos ámbitos, apoyó desde sus instituciones estos acuerdos. El Consejo recomendó a los EEMM la celebración de estos acuerdos, y recordando la necesidad de salvaguardar los derechos de los refugiados y asilados, así como el CEDH y los aspectos relacionados con la protección de datos de carácter personal ${ }^{432}$.

Con la comunitarización de las políticas migratorias, la UE empezó a involucrarse en la firma de acuerdos de readmisión con otros países o grupos de países. La base legal de los acuerdos en los artículos 79.3 y 218 del TFUE, este último al regular la negociación y celebración de acuerdos entre la Unión y terceros países. Las conclusiones del Consejo de Tampere llamaron a la UE y los EEMM a firmar acuerdos de cooperación con los países de origen y tránsito para promover el retorno de migrantes ${ }^{433}$. En la década siguiente, se firmaron más de 250 acuerdos con países de todo el mundo ${ }^{434}$. Aunque el contenido de cada documento depende de la negociación entre las partes, la UE suele emplear un modelo tanto para los convenios bilaterales

\footnotetext{
430 CEAR: Acceso a la protección: Un derecho humano, Madrid, 2013, p.15. Disponible en: http://www.cear.es/wp-content/uploads/2013/07/Trip-espa\%C3\%B1ol-EPIM.pdf (Consulta: 17 de enero de 2016)

${ }^{431}$ Véase por ejemplo art. 23 del acuerdo con Mauritania.

${ }^{432}$ Recomendación del Consejo, de 24 de julio de 1995, sobre los principios rectores que deberán seguirse en la elaboración de protocolos sobre la aplicación de acuerdos de readmisión, DOCE, de 19 de septiembre de 1996, C 274, pp. 25-34. Disponible en: http://eur-lex.europa.eu/legalcontent/ES/TXT/PDF/?uri=CELEX:31996Y0919\%2808\%29\&from=ES (Consulta: 17 de enero de 2016)

${ }^{433}$ Consejo Europeo de Tampere, pp. 22, 26, 27.

434 Balzacq, Thierry: The Implications of European Neighbourhood Policy in the context of border controls, Bruselas, estudio del Parlamento Europeo, marzo de 2008, p. 20 Disponible en: http://www.europarl.europa.eu/RegData/etudes/etudes/join/2008/393284/IPOL-

LIBE_ET\%282008\%29393284_EN.pdf (Consulta: 17 de enero de 2016)
} 


\section{CAPÍTULO 3}

como los multilaterales ${ }^{435}$. Entre las principales artículos del modelo se encuentra la obligación de readmitir a los ciudadanos de terceros países "sin ninguna formalidad", un tiempo máximo de respuesta a las peticiones de readmisión de 15 días, y de un mes para hacerse cargo de las personas retornadas, la obligación de cumplir con las obligaciones internacionales contenidas en el CG51 o el CEDH, y la posibilidad de las partes de suspender o finalizar el acuerdo debido a razones de salud pública, seguridad nacional u orden público.

El primer ejemplo son los "acuerdos de Cotonou", firmados el 23 de junio de 2000 con los Estados del $\mathrm{ACP}^{436}$. El acuerdo establece que cada firmante readmitirá y aceptará el retorno de sus nacionales que residan ilegalmente en un segundo estado " $a$ petición de este último y sin mediar más trámites"437. Aunque el artículo establece obligaciones recíprocas, es evidente que la carga es desproporcionada hacia una parte dado que la cantidad de inmigrantes irregulares europeos en estos países es ínfima. La Comisión citó dicho artículo como un modelo para futuros acuerdos ${ }^{438}$.

En los años siguientes se celebraron acuerdos bilaterales con Egipto (2001) y Líbano (2002). En ambos se incluían que cada una de las partes "acuerda readmitir a cualquiera de sus ciudadanos ilegalmente presente en el territorio de un Estado

${ }^{435}$ El modelo originario surge de la reunión del Consejo Europeo de noviembre de 1994, si bien luego ha sufrido modificaciones. Para profundizar más en la política comunitaria de acuerdos de readmisión, vid. Cassarino, J-P: Readmission policies..., op. cit., p. 15

${ }^{436}$ Los ACP (Estados de Asia, Caribe y Pacífico) son 78 países de estas regiones que se encuentran organizados en torno al acuerdo comercial con la UE. Cuba es el único ACP que no firmó los Acuerdos de Cotonou

${ }^{437}$ Art. 13.5. c)

i) Cada Estado miembro de la Unión Europea readmitirá y aceptará el retorno de cualquiera de sus propios nacionales que reside ilegalmente en el territorio de un Estado ACP, a petición de este último y sin mediar más trámites.

Cada uno de los Estados ACP readmitirá y aceptará el retorno de cualquiera de sus propios nacionales que resida ilegalmente en el territorio de un Estado miembro de la Unión Europea, a petición de este último y sin mediar más trámites...

ii) A petición de una Parte, se iniciarán negociaciones con los Estados ACP encaminados a celebrar de buena fe y de acuerdo con los principios correspondientes del Derecho internacional, acuerdos bilaterales que regulen las obligaciones específicas de readmisión y retorno de sus nacionales. Estos acuerdos incluirán también, si una de las Partes lo considerare necesario, disposiciones sobre la readmisión de nacionales de terceros países y apátridas. Los acuerdos precisarán las categorías de personas afectadas por estas disposiciones así como las modalidades de su readmisión y retorno...».

Acuerdo de Asociación entre los Estados de África, del Caribe y del Pacífico, por una parte, y la Comunidad Europea y sus Estados miembros, por otra, firmado en Cotonou el 23 de junio de 2000. DOCE de 15 de diciembre de 2000, L 317, pp. 3-353. Disponible en: http://eur-lex.europa.eu/legalcontent/ES/TXT/?uri=celex:22000A1215\%2801\%29 (Consulta: 17 de enero de 2016)

438 Comunicación de la Comisión al Consejo y al Parlamento Europeo, de 3 de diciembre de 2002: Integración de las cuestiones de migración en las relaciones de la Unión Europea con países terceros $(\operatorname{COM}(2002) 703$ final), p. 25 . Disponible en: http://eur-lex.europa.eu/legalcontent/ES/TXT/PDF/?uri=CELEX:52002DC0703\&from=EN (Consulta: 17 de enero de 2016) 
miembros, a petición por este último y sin otras formalidades, una vez se haya determinado la situación ilegal de dichas personas" ${ }^{339}$. Además, se preveía que esta cláusula se pudiera completar con acuerdos bilaterales entre estados donde, si las partes lo consideran necesarios, incluyan disposiciones sobre readmisión de nacionales de terceros estados ${ }^{440}$.

Desde entonces Comisión Europea ha venido buscando la firma de acuerdos de readmisión con los países norteafricanos, aunque sin mucho éxito. Con Marruecos se firmó una declaración conjunta para la creación de un "partenariado de movilidad" en junio de $2013^{441}$, pero de momento no se han producido mayores avances. Argelia y Egipto comenzaron negociaciones en 2011, pero hasta han rechazado las propuestas de la UE. Libia sigue siendo "el país prioritario" con el que espera iniciar el diálogo "en cuanto las circunstancias lo permitan" ${ }^{442}$. En mayo de 2013 el Consejo autorizó la apertura de negociaciones con Liba para el establecimiento del programa de asistencia fronteriza EUBAM-Libia con un presupuesto de 30,3 millones durante el primer año de su puesta en marcha ${ }^{443}$. El Ejecutivo comunitario admite como uno de los principales desafíos para alentar la cooperación en inmigración irregular "la disponibilidad limitada de incentivos" por parte de los países no comunitarios para negociar y concluir acuerdos de readmisión de inmigrantes irregulares con la UE y apuesta por vincular esta propuesta con otras negociaciones sobre comercio y cooperación económica para garantizar una oferta "equilibrada". Al momento de finalizar la escritura de esta investigación, la UE alcanzó un acuerdo en materia migratoria y de asilo con Turquía, cuya finalidad era detener el flujo de llegadas a Grecia, mayoritariamente compuesto por refugiados de nacionalidad siria. A cambio del desembolso de más de 3.000 millones de euros por parte de la UE, Turquía aceptaba la devolución de "todos" los migrantes irregulares llegados a Grecia, la puesta en marcha de un plan de reasentamiento desde su territorio y la ejecución de "todas las medidas necesarias para evitar que se abran nuevas rutas maritimas o terrestres de migración ilegal desde Turquía a la UE"444.

\footnotetext{
439 Art. 68 de ambos tratados

440 Art. 69 de ambos tratados

441 Consejo de la Unión Europea: Joint declaration establishing a Mobility Partnership between the Kingdom of Morocco and the European Union and its Member States, Bruselas, 3 de junio de 2013, Doc. $6139 / 13$. Disponible en: http://ec.europa.eu/dgs/home-affairs/what-isnew/news/news/2013/docs/20130607 declaration conjointe-maroc eu version 3613 en.pdf (Consulta: 17 de enero de 2016)

442 Consejo de la Unión Europea, Bruselas, 23-24 de mayo de 2011, comunicado de prensa 10440/11, p. 9 Disponible en: http://europa.eu/rapid/press-release PRES-11-143 en.pdf (Consulta: 17 de enero de 2016)

443 Consejo de la Unión Europea, Bruselas, 22 de mayo de 2013, comunicado de prensa 9478/13. Disponible en: http:/www.consilium.europa.eu/uedocs/cms data/docs/pressdata/en/foraff/137189.pdf (Consulta: 17 de enero de 2016)

444 Disponible en: http://www.consilium.europa.eu/es/press/press-releases/2016/03/18-eu-turkeystatement/ (Consulta: 27 de marzo de 2016). Aunque aún es pronto para evaluar la aplicación del acuerdo,
} 


\section{CAPÍTULO 3}

La política comunitaria de celebración de acuerdos, cada vez más extensa en su número y amplia en sus compromisos genera una serie de preocupaciones en materia de derechos humanos. En lo relativo al respeto al principio de non-refoulement, los acuerdos permiten acelerar los procedimientos de expulsión, generando incentivos a los Estados para que eviten las salvaguardas legales. A pesar de la inclusión de cláusulas de respeto a la CG51 y otros tratados internacionales, la falta de transparencia y de mecanismos de control de estos tratados han propiciado numerosos casos donde los EEMM han expulsado a personas que eran potenciales merecedoras de protección internacional. Por otra parte, muchos de los terceros estados con los que se han firmado los acuerdos tienen un pobre historial en materia de respeto de derechos humanos. Además, en ocasiones complementan estos acuerdos con la UE con otros del mismo tipo firmados con los terceros estados de origen de los migrantes. Esta situación parece indicar la predisposición de estos Estados para realizar refoulement indirectos.

numerosas voces han mostrado su preocupación por la posibilidad de que permita expulsiones colectivas o arbitrarias. Existen serias dudas para considerar a Turquía un país seguro. Si bien es un estado parte de la CG51, en su firma del protocolo de 1967 introdujo una reserva de limitación geográfica que excluía a los refugiados no europeos. Se han denunciado también vulneraciones de derechos en la detención de refugiados y devoluciones al país de origen. Vid. AI: Europe's Gatekeeper. Unlawful detention and deportation of refugees from Turkey, Doc. EUR 44/3022/2015, diciembre de 2015. Disponible en: https://www.amnesty.org/en/documents/eur44/3022/2015/en (Consulta: 27 de marzo de 2016) 
\Capítulo 4

Territorialidad y jurisdicción de los derechos humanos 



\section{Territorialidad y jurisdicción de los derechos humanos}

Uno de los aspectos centrales de este trabajo tiene que ver con la aplicación de la CG51 y otras normas de DIDH más allá de su territorio. Los derechos humanos son universales precisamente porque protegen a todos los seres humanos, independientemente de donde se encuentre. La responsabilidad de los Estados no depende únicamente de la nacionalidad o lugar de residencia de una determinada persona, sino que también pueden serlo si dicha persona está bajo la jurisdicción efectiva del Estado o de alguno de sus agentes. En las últimas décadas, operaciones extraterritoriales de los Estados en conflictos armados, operaciones de mantenimiento de la paz, contra la piratería o el tráfico de drogas han impulsado el cuestionamiento y revisión de este concepto ${ }^{445}$.

En sus políticas de vigilancia marítima, los Estados ejercen su soberanía en formas que no se corresponden con acepción tradicional de la jurisdicción. De entrada, actúan en el medio marítimo, más allá de las costas que delimitan físicamente su territorio. Allí sus acciones pueden conllevar consecuencias y obligaciones jurídicas distintas dependiendo de la zona marítima en la que se encuentren sus buques y agentes, demarcadas por la distancia en millas respecto a sus costas. En el caso de las interceptaciones realizadas en el Mediterráneo, en muchas ocasiones se trata de operaciones conjuntas entre varios Estados europeos bajo coordinación de una Agencia independiente de la Unión, Frontex. Algunas de estas operaciones europeas o nacionales de vigilancia se han desarrollado en las aguas territoriales de los países de origen de las embarcaciones, gracias a un acuerdo bilateral que regula, de manera poco clara muchas veces, la presencia de agentes y embarcaciones extranjeros y su colaboración con las autoridades policiales y fronterizas locales. Por otro lado, y atendiendo a los sujetos a quienes se dirigen estas políticas, tampoco aquí estamos hablando de los individuos de los que se ha preocupado la concepción tradicional de la soberanía: ciudadanos nacionales y extranjeros que residen legalmente en un Estado. Los pasajeros de las embarcaciones que tratan de alcanzar las costas europeas refugiados huyen de la persecución o la guerra y buscan solicitar asilo, migrantes que intentan entrar ilegalmente en Europa para buscar mayores oportunidades económicas, víctimas de redes de trata de personas, menores que dejan a su familia o tratan de reunirse con ella en Europa...

445 Vid. Goodwin-Gil, Guy: "The Extra-Territorial Reach of Human Rights Obligations: A Brief Perspectove on the Link to Jurisdiction". En: Boisson, Laurence y Kohen, Marcelo (eds.): International law and the Quest for its Implementation. Leiden, Koniklijke Brill, 2010, pp. 293-308. 


\section{CAPÍTULO 4}

Ambas realidades, la territorial y la personal, se entrecruzan en varios dilemas que interrogan a los Estados sobre sus responsabilidades y límites de su soberanía. En el presente capítulo trataremos de profundizar sobre alguno de estos interrogantes a partir de los diversos instrumentos del Derecho Internacional y europeo.

\subsection{La jurisdicción en el Derecho Internacional}

El término jurisdicción se usa en dos esferas diferentes del Derecho Internacional: el Derecho Internacional Público (DIP) y Derecho el Internacional de los Derechos Humanos (DIDH). En ambos casos se refiere a la "a la capacidad del Estado para ejercer determinados aspectos sustantivos de su soberanía, especialmente sus derechos (o reclamaciones), las libertades y poderes"446. Sin embargo, la definición varía en ciertos aspectos que son de relevancia en lo referente a la aplicación territorial y personal de la jurisdicción.

El sentido tradicional del término jurisdicción procede del DIP, y alude a la capacidad soberana de los estados de actuar en su propio territorio, tal como acabamos de explicar. A su vez, dicha capacidad queda limitada por la soberanía de otros Estados, y también por límites territoriales como los espacios marítimos o aéreos. El anclaje territorial del concepto es aquí evidente; los Estados cuentan con la competencia de ejercer su soberanía en su propio territorio. Cuando actúan fuera de éste, precisan de alguna base legal específica que le autorice de forma excepcional, y comúnmente deben contar además con el visto bueno del otro Estado donde van a actuar, o de las Naciones Unidas. En el caso contrario, se encontrarían cometiendo un acto ilegal según el derecho internacional.

En el DIDH el concepto de jurisdicción parte de la misma premisa, pero tiene unas connotaciones diferentes. La mayor parte de los tratados internacionales de derechos humanos lo incluyen para delimitar su ámbito de aplicación ${ }^{447}$. El aspecto de la soberanía que adquiere más relevancia en este caso son las obligaciones de respeto a los derechos humanos a las que se comprometen los Estados al firmar dicho documento. Dichas obligaciones no proceden de una competencia ratione loci sino ratione personae: los Estados deben garantizar los derechos humanos de todas las personas bajo

\footnotetext{
${ }^{446}$ Brownlie, Ian: Principios del derecho público internacional, Oxford University Press, $6^{\mathrm{a}}$ ed., 2003, p. 106

${ }^{447}$ Entre otras, el PIDCP (art. 2) o el CEDH (art.1). La Convención contra la Tortura (art.2) por su parte, obliga al Estado a tomar medidas "en cualquier territorio bajo su jurisdicción".
} 
su autoridad (bajo su jurisdicción) ${ }^{448}$. Por lo tanto, es posible que un Estado realice una actuación fuera de su territorio que se encuentre dentro del ámbito de su jurisdicción, bajo el DIDH pero no el DIP. Como por ejemplo veremos que ocurre en las operaciones de rescate e interceptación marítima de inmigrantes en el Mediterráneo.

En los casos López Burgos y Celiberti de Casariego (1981), ambos contra Uruguay, el CDH sentó las bases por las cuales los Estados podían ser responsables de violaciones de derechos humanos fuera de su territorio cuando ostentaran el control efectivo sobre las víctimas:

Article 2 (1) of the Covenant places an obligation upon a State party to respect and to ensure rights "to all individuals within its territory and subject to its jurisdiction", but it does not imply that the State party concerned cannot be held accountable for violations of rights under the Covenant which its agents commit upon the territory of another State, whether with the acquiescence of the Government of that State or in opposition to it. ${ }^{449}$

La primacía del criterio personal sobre el territorial se explicita más adelante, en referencia al artículo 1 del protocolo facultativo, por el que los Estados firmantes aceptan la competencia del comité para examinar las denuncias individuales:

....article 1 of the Optional Protocol to "individuals subject to its jurisdiction" does not affect the above conclusion because the reference in that article is not to the place where the violation occurred, but rather to the relationship between the individual and the State in relation to a violation of any of the rights set forth in the Covenant, wherever they occurred. ${ }^{450}$

En 2004 el Comité elaboró una Observación General sobre las obligaciones jurídicas de los Estados Parte, donde reincidía en la responsabilidad de los Estados por sus acciones más allá de sus fronteras: “...un Estado Parte debe respetar y garantizar

${ }^{448}$ Aquí sigo el razonamiento de Den Heijer, M. y Lawson, R.: "Extraterritorial Human Rights...op. cit., p. 153 y ss.

449 CDH: López Burgos c. Uruguay, 29 de julio de 1981, $\mathrm{n}^{\circ}$ 52/1979, § 12.3. Disponible en: http://wwwl.umn.edu/humanrts/undocs/session36/12-52.htm (Consulta: 18 de enero de 2016); Celiberti de Casariego c. Uruguay, 29 de julio de 1981, $\mathrm{n}^{\circ}$ 56/1979, § 10.3. Disponible en: http://wwwl.umn.edu/humanrts/undocs/session36/13-56.htm (Consulta: 18 de enero de 2016)

${ }^{450} \mathrm{CDH}$ : Celiberti de Casariego, $\S 10.2$ 


\section{CAPÍTULO 4}

los derechos establecidos en el Pacto a cualquier persona sometida al poder o al control efectivo de ese Estado Parte, incluso si no se encuentra en el territorio del Estado Parte." 451

La Corte Internacional de Justicia tuvo en cuenta la argumentación del CDH con respecto a la construcción por Israel de un muro en Palestina $(2004)^{452}$ y en el caso Congo-Uganda $(2005)^{453}$.

El Comité Contra la Tortura (CAT), por su parte, ha hecho especial énfasis en la responsabilidad de los agentes perpetradores de la violación de derechos humanos:

... el concepto de "todo territorio que esté bajo su jurisdicción", vinculado al principio de imperatividad, incluye cualquier territorio o instalación y es aplicable para proteger a toda persona, sea o no nacional y sin discriminación, que esté sujeta al control de jure o de facto de un Estado Parte. El Comité subraya que la obligación del Estado de impedir la tortura también se aplica a todas las personas que actúen, de jure o de facto, en nombre del Estado Parte, en colaboración con éste o a instancia de éste. ${ }^{454}$

Al delimitar el ámbito de aplicación de la Convención "se exige que los Estados Partes adopten medidas eficaces para impedir los actos de tortura no sólo en su propio territorio sino también "en todo territorio que esté bajo su jurisdicción”. El Comité ha admitido que "todo territorio" comprende todos los ámbitos en que el Estado Parte ejerce, directa o indirectamente, en todo o en parte, un control efectivo de jure o de facto, de conformidad con el derecho internacional. ${ }^{455}$

${ }^{451} \mathrm{CDH}: \mathrm{OG}^{\circ} 31: \S 10$.

${ }^{452}$ CIJ: Opinión Consultiva de la Corte Internacional de Justicia sobre las consecuencias jurídicas de la construcción de un muro en el territorio palestino ocupado. Decimo periodo de sesiones de emergencia. 13 de julio de 2004 A/ES-10/273, pp. 108-111. Disponible en: http://www.icjcij.org/homepage/sp/advisory/advisory 2004-07-09.pdf (Consulta: 18 de enero de 2016)

453 CIJ: Concerning Armed Activities on the Territory of Congo, Democratic Republic of Congo v. Uganda, sentencia del 19 de diciembre de 2005, pp. 216-220. Disponible en: http://www.icjcij.org/docket/files/116/10455.pdf (Consulta: 18 de enero de 2016)

${ }_{454}$ CAT: Observación General n ${ }^{\circ}$ 2: Aplicación del artículo 2 por los Estados Partes, $39^{\circ}$ periodo de sesiones, 2007, para. $7 . \quad$ Disponible en: http://docstore.ohchr.org/SelfServices/FilesHandler.ashx?enc=6QkG1d\%2fPPRiCAqhKb7yhskvE\%2bTu w1mw\%2fKU18dCyrYrZhDDP8yaSRi\%2fv43pYTgmQ5ha3y9ciYQTndQSRsnHNfl3LsBC9NRMmaE3 LGcm3s41Q\%3d (Consulta: 18 de enero de 2016)

${ }^{455}$ Ibíd., para. 16. 
La interpretación que ha hecho el TEDH ha sido más estrecha que la del CDH y el CAT. Ha reiterado en su jurisprudencia una concepción más territorializada sobre la jurisdicción, en la que se admite que en circunstancias excepcionales esta pueda aplicarse fuera de las fronteras del Estado parte. La jurisprudencia del TEDH sobre su artículo 1 - "Las Altas Partes Contratantes reconocen a toda persona dependiente de su jurisdicción los derechos y libertades definidos en el título I del presente Convenio" ha sido amplia, reconociendo los diversos supuestos en que dichas obligaciones estatales puedan dar lugar a una aplicación extraterritorial e implicar su responsabilidad. A lo largo de las sentencias el Tribunal ha ido perfilando los límites y posibilidades de esta excepcionalidad.

El primer caso en el que tuvo oportunidad de juzgar las acciones extraterritoriales de un Estado parte fue Drozd y Janousek c. Francia y España (1992) el TEDH señaló que "The term "jurisdiction" is not limited to the national territory of the High Contracting Parties; their responsibility can be involved because of acts of their authorities producing effects outside their own territory" ${ }^{\prime 56}$. La Corte amplió esta interpretación en Loizidou c. Turquía (1996). El caso involucraba las acciones de soldados turcos en el norte de Chipre, un territorio reclamado por Turquía pero no reconocido internacionalmente. La Corte mencionó el principio de non-refoulement, haciendo referencia expresa al caso Soering, para recordar que:

El concepto de «jurisdicción» según [el artículo 1 del Convenio Europeo de Derechos Humanos] no está restringido al territorio nacional de las Altas Partes Contratantes. Según su jurisprudencia, por ejemplo, el Tribunal ha opinado que la extradición o la expulsión de una persona por un Estado contratante pueden dar lugar a una violación según el artículo 3, y por lo tanto puede comprometer la responsabilidad de ese Estado en virtud de la Convención [...]. Además, la responsabilidad de las partes contratantes puede verse involucrada por actos de sus autoridades, ya sea que se hayan realizado dentro o fuera de linderos nacionales, que produzcan efectos fuera de su territorio. ${ }^{457}$

Habiendo concluido que las acciones de los Estados fuera de su territorio pueden implicar responsabilidades internacionales, en sentencias posteriores vino a delimitar

\footnotetext{
456 TEDH: Drozd y Janousek c. Francia y España, sentencia del 26 de junio de 1992, no. 12747/87, § 91. Disponible en: http://hudoc.echr.coe.int/eng?i=001-57774 (Consulta: 18 de enero de 2016)

457 TEDH: Loizidou c. Turquía, objeciones preliminares del 23 de marzo de 1995, § 63. Disponible en: http://hudoc.echr.coe.int/eng?i=001-57920 (Consulta: 18 de enero de 2016)
} 


\section{CAPÍTULO 4}

esta posibilidad a circunstancias excepcionales. En la decisión sobre admisibilidad del caso Bankovic c. Bélgica (1999), el Tribunal examinó en profundidad el concepto de jurisdicción y las obligaciones de los Estados según el artículo 1 de la CEDH. Señaló que este articulo reflejaba "this ordinary and essentially territorial notion of jurisdiction, other bases of jurisdiction being exceptional and requiring special justification in the particular circumstances of each case"458. Seguidamente se especificaban las acciones que podían dar lugar al reconocimiento del ejercicio de la jurisdicción por un Estado parte: "acts of the Contracting States performed, or producing effects, outside their territories" ${ }^{259}$; en concreto daba dos ejemplos: cuando, mediante el control efectivo de un territorio y sus habitantes, ejerce todo o alguno de los poderes públicos estatales ${ }^{460}$ y cuando involucran actividades de sus agentes diplomáticos o consulares, y se encuentra a bordo de embarcaciones o buques de su pabellón $^{461}$. El Tribunal desestimó la demanda, que versaba sobre la pérdida de vidas resultantes del bombardeo de la OTAN a Belgrado, justificándose en que las víctimas no se encontraban bajo la jurisdicción de los Estado demandados. Posteriormente, en Al-Skeini y otros c. Reino Unido (2011) determinó que el mero hecho que un individuo hubiera sido afectado por una acción cometida por un Estado parte o sus agentes no era base suficiente para establecer que se encontrara dentro de su jurisdicción ${ }^{462}$ y que " $a$ State would not be held to exercise Article 1 jurisdiction over an overseas territory merely by virtue of exercising effective control there ${ }^{" 463}$ La corte negó el criterio de control efectivo ya que las tropas ocupantes no podían mantener dicho control en el área donde se produjeron los hechos ${ }^{464}$.

Sin embargo, en otras sentencias el TEDH sí que encontró que el caso se hallaba dentro de aquellas "circunstancias excepcionales" que permiten ubicar la actuación extraterritorial del Estado parte dentro del ámbito jurisdiccional del artículo 1. Por ejemplo en el caso D. c. Reino Unido (1997), el TEDH consideró que el solicitante "regardless of whether [the applicant] ever entered the UK in the technical sense it is to be noted that he has been physically present there and thus within the jurisdiction within the meaning of Article 1"465. En Öcalan c. Turquía (2003), examinó el arresto y retorno forzado del líder de la guerrilla kurda desde el aeropuerto de Nairobi, ejecutado por agentes turcos. El Tribunal encontró que el solicitante se encontraba bajo la

458 TEDH: Bankovic y otros c. Bélgica., decisión de admisibilidad del 12 de diciembre de 2001, no. 52207/99, § 61. Disponible en: http://hudoc.echr.coe.int/eng?i=001-22099 (Consulta: 18 de enero de 2016)

459 Ibíd., § 67

460 Ibíd., $\$ 71$

461 Ibíd., $\$ 73$

${ }^{462}$ TEDH: Al-Skeini y otros c. Reino Unido, sentencia del 7 de julio de 2011, no. 55721/07, § 109.

Disponible en: http://hudoc.echr.coe.int/eng?i=001-105606 (Consulta: 18 de enero de 2016)

463 Ibíd., § 111

464 Ibíd., § 112

${ }^{465}$ TEDH: D. c. Reino Unido, $§ 48$. 
autoridad de Turquía, y por lo tanto dentro de su jurisdicción ${ }^{466}$. En el caso Al-Saadoon y Mufdhi c. Reino Unido (2010), que concernía la actuación de las fuerzas de ocupación británicas en Iraq y la detención y entrega a las autoridades locales de dos nacionales iraquíes, resultando en la condena del gobierno británico. Aquí el Tribunal entendió que no se daban las mismas circunstancias que en Al-Skeini, dado "the exceptional nature of the case derived specifically from the fact that the United Kingdom was acting or being required to act outside its own territory" 467

Tres casos son especialmente relevantes para la presente investigación, en cuanto entran a dirimir posibles violaciones de la Convención en intercepciones marítimas. En la decisión de admisibilidad de Xhavara c. Italia $(2001)^{468}$, la Corte consideró que Italia se encontraba dentro del alcance del Convenio cuando uno de sus patrullas costeras colisionó con una patera con el resultado de la muerte de 58 migrantes albaneses. La apelación fue declarada inadmisible debido a que los demandantes no habían agotado los recursos internos. En Medvedyev y otros contra Francia (2010), la Corte consideró que Francia había ejercido su jurisdicción durante la interceptación por parte de un navío militar de un buque con pabellón camboyano y su traslado a un puerto francés. La interceptación se había producido en Alta Mar, fuera del territorio y las aguas soberanas francesas. La Corte señaló como decisivo el control ejercido de forma continua e ininterrumpida del buque y su tripulación por parte de Francia ${ }^{469}$.

Finalmente, la sentencia más relevante para este trabajo es la más reciente Hirsi Jamaa y otros c. Italia (2013). La denuncia atañía a una de las operaciones de 'pushbacks' en la que tres embarcaciones con unas 200 personas de origen eritreo y somalí fueron interceptadas 35 millas al sur de Lampedusa y devueltas a Libia. Dos de los tripulantes murieron en circunstancias desconocidas tras ser entregados a las autoridades libias. El primer problema que el caso planteaba era si los solicitantes se encontraban efectivamente bajo jurisdicción italiana, entendida en los términos del artículo 1 del Convenio. Siguiendo la jurisprudencia que hemos visto arriba, el Tribunal recordó que

... Cuando un Estado, mediante agentes que operan fuera de su territorio, ejerce control y "autoridad, y, por lo tanto, su jurisdicción, sobre un individuo, tal

\footnotetext{
${ }^{466}$ TEDH: Öcalan c. Turquía, sentencia de 12 de mayo de 2005, no. 46221/99, § 91.

Disponible en: http://hudoc.echr.coe.int/eng?i=001-69022 (Consulta: 18 de enero de 2016)

467 TEDH: Al-Saadoon y Mufdhi c. Reino Unido, sentencia del 2 de marzo de 2010, no. 61498/08, § 155. Disponible en: http://hudoc.echr.coe.int/eng?i=001-97575 (Consulta: 18 de enero de 2016)

468 TEDH: Xhavara y otros c. Italia y Albania, decisión de admisibilidad del 11 de enero de 2001, no. 39473/98. Disponible en: http://hudoc.echr.coe.int/eng?i=001-31884 (Consulta: 18 de enero de 2016)

469 TEDH: Medvedyev y otros c. Francia, sentencia del 29 de marzo de 2010, $\mathrm{n}^{\circ}$ 3394/03, § 67. Disponible en: http://hudoc.echr.coe.int/eng?i=001-97979 (Consulta: 18 de enero de 2016)
} 


\section{CAPÍTULO 4}

Estado tiene obligación, en virtud del artículo 1, de garantizar a este individuo todos los derechos y libertades previstos en el Título 1 del Convenio que sean pertinentes en la situación de ese individuo. ${ }^{470}$

El gobierno italiano intentó justificar que el artículo 4 del protocolo 4 no era aplicable, ya que no se trataba de una expulsión del territorio italiano, sino de una negativa a autorizar su entrada ${ }^{471}$. La Corte rechazó las alegaciones italianas basándose en dos argumentos: el primero que existía de jure jurisdicción italiana al encontrarse el patrullero italiano en aguas internacionales; y el segundo que los demandantes se encontraban de facto bajo el control del Estado italiano dado que la tripulación de dicho patrullero estaba formada por personal militar italiano ${ }^{472}$. Según el TEDH, una interpretación de dicho artículo que sólo incluyera a las expulsiones colectivas del territorio de un Estado parte, una parte importante de las tendencias migratorias contemporáneas quedarían fuera de su ámbito de aplicación ${ }^{473}$. Además, ante el argumento del gobierno italiano de que los demandantes no habían solicitado formalmente asilo, el Tribunal señaló que "who faced a situation which involved systematic violations of human rights, to 'find out about the treatment to which the applicants would be exposed after their return,' irrespective of whether the applicants had expressly requested asylum ${ }^{474}$. Fue la primera vez que Estrasburgo dio efecto a la provisión del artículo 4 del protocolo 4 con efectos extraterritoriales ${ }^{475}$.

Merece la pena citar el voto razonado del juez Pinto de Albuquerque. En ella el juez portugués profundiza en el debate sobre jurisdicción y territorialidad. En su opinión, la jurisdicción abarcaría todas las actividades de control fronterizo, sin importar donde se lleven a cabo:

... the full range of conceivable immigration and border policies, including denial of entry to territorial waters, denial of visa, denial of pre-clearance embarkation or provision of funds, equipment or staff to immigration control operations performed by other States or international organisations on behalf of the Contracting Party, remain subject to the Convention standard. They all constitute

\footnotetext{
470 TEDH: Hirsi Jamaa y otros c. Italia, $§ 74$.

${ }^{471}$ Ibíd., $\$ 160$.

472 Ibíd., § 81: "en el periodo de tiempo entre el momento en que embarcaron a bordo de los barcos de las fuerzas armadas italianas y en el que fueron entregados a las autoridades libias, los demandantes estuvieron bajo el control continuo y exclusivo, de jure y de facto, de las autoridades italianas"

${ }^{473}$ Ibíd., § 177

${ }^{474}$ Ibíd., $\$ 133$

${ }^{475}$ Ibíd., § 175
} 
forms of exercise of the State function of border control and a manifestation of State jurisdiction, wherever they take place and whoever carries them out. ${ }^{476}$

De la jurisprudencia del TEDH y los órganos de Naciones Unidas que hemos visto se observa un nexo recurrente entre la jurisdicción estatal y las obligaciones derivadas de los instrumentos del DIDH. Se trata del criterio que determina si las acciones u omisiones de un Estado se encuentran bajo el ámbito de un tratado, y consecuentemente, pueden dar lugar a un 'acto internacionalmente ilícito' Por lo tanto "jurisdicción” y "responsabilidad" son conceptos diferentes, aunque interconectados, que abordan distintas cuestiones jurídicas del Derecho Internacional. El primero se pregunta acerca de la competencia de un tribunal, comité u otro órgano para examinar el cumplimiento de los Estados parte de las obligaciones contenidas en un tratado. Por su parte el segundo es por el que se examina si puede atribuírsele a dicho Estado la responsabilidad por la violación de una norma de dicho tratado ${ }^{477}$. Tal como ha señalado Goodwin-Gill: "human rights obligations are certainly capable of binding the State in its extraterritorial activities. Whether they do, and what are the consequences, depend first on the nature and content of the primary rule establishing the obligation; secondly, on whether the claimant comes within the scope of that rule; and thirdly, on whether the injury, the act, is attributable to the State impugned"478. Un ejemplo de esta separación puede encontrarse en el caso Issa y otros c. Turquía (2005), donde examina unas operaciones militares del ejército turco en el norte de Iraq. El TEDH no consideró atribuibles al Estado turco los asesinatos que se examinaban, pero no excluyó la posibilidad de que, bajo ciertas condiciones, pudieran encontrarse bajo la jurisdicción de Turquía $^{479}$.

Otras dos cuestiones que surgen con el reconocimiento de la jurisdicción estatal por actos cometidos fuera de su territorio es: a) si la responsabilidad está limitada a un determinado grupo de derechos o alcanzaría a todos, y b) si está es contingente dependiendo del grado de control ejercido en cada situación. En el arriba citado caso Bankovic el TEDH interpretaba que la Convención no fue diseñada para ser aplicada en todo del mundo, incluso en lo que respecta a la conducta de los Estados parte ${ }^{480}$ y que aceptar el enfoque de control efectivo que postulaban los demandantes, llevaría a

\footnotetext{
${ }^{476}$ Ibíd., Concurring Opinion of Judge Pinto de Albuquerque, § 79-80

477 Un análisis más pormenorizado de esta cuestión puede encontrarse en Milanovic, Marko: From Compromise to Principle: Clarifying the Concept of State Jurisdiction in Human Rights Treaties, Human Rights Law Review, vol. 8, 2008. Disponible en: http://ssrn.com/abstract=1139174 (Consulta: 18 de enero de 2016)

${ }^{478}$ Goodwin-Gill, Guy: “The Extra-Territorial...”, op. cit., p. 306.

${ }^{479}$ TEDH: Issa y otros c. Turquía, sentencia del 16 de noviembre de 2004, $\mathrm{n}^{\circ} 31821 / 96$, §74. Disponible en: http://hudoc.echr.coe.int/eng?i=001-67460 (Consulta: 18 de enero de 2016)

${ }^{480}$ Ibíd., § 80
} 


\section{CAPÍTULO 4}

aceptar un enfoque causa-efecto que convertiría el propio concepto de jurisdicción en superfluo $^{481}$. Sin embargo, otras sentencias del mismo Tribunal han aceptado la premisa de que "effective control entails responsability" por el que el deber de Estados parte de respetar los derechos y libertades de los individuos más allá de sus fronteras en concordancia con el alcance de su control sobre esos individuos. Así, en el caso AlSkeini, ya citado, el Tribunal argumentaba en clara contradicción con lo que había señalado en Bankovic que:

It is clear that, whenever the State, through its agents, exercises control and authority over an individual, and thus jurisdiction, the State is under an obligation under Article 1 to secure to that individual the rights and freedoms under Section I of the Convention that are relevant to the situation of that individual. In this sense, therefore, the Convention rights can be "divided and tailored. ${ }^{482}$

Este concepto de "extraterritorialidad" también ha sido objeto de debate en torno a cuáles son los derechos que tienen este efecto, y por consiguiente cual es el alcance de las obligaciones de los Estados fuera de sus fronteras. Sí que existe un consenso en que, entre ellos, está incluido el principio de non-refoulement. Sin embargo, parece más improbable que dicha exigibilidad se mantenga en lo relativo a las garantías del debido proceso, derecho a la información o protección de los colectivos más vulnerables.

\subsection{La territorialidad en el Derecho de los Refugiados}

En la CG51 se incluyen referencias en varios artículos al "territorio" para delimitar el ámbito de aplicación de normas contenidas en ella, entre ellas la prohibición de "por expulsión o devolución, poner en modo alguno a un refugiado en las fronteras de los territorios donde su vida o su libertad peligre" ${ }^{483}$ La Convención fue una respuesta histórica a las crisis de refugiados europeos de la primera mitad del siglo XX. En ellas, en su inmensa mayoría las fronteras que cruzaban los refugiados eran terrestres, siendo la mayor preocupación las condiciones de vida que encontrarían al establecerse en el nuevo Estado. En las décadas siguientes, los refugiados han debido optar en numerosos casos por la vía marítima para escapar de los Estados donde sufrían persecución, o para alcanzar sus destinos de refugio. Esta situación ha dado lugar a que deba replantearse la

${ }^{481}$ Ibíd., $§ 75$

482 TEDH: Al-Skeini..., § 137

${ }^{483}$ CG51, art. 33.1 
lectura de la CG51, para adaptarla a las nuevas situaciones ${ }^{484}$. En lo que concierne al presente trabajo, la cuestión en la que nos centraremos es la de si el principio de nonrefoulement es de aplicación extraterritorial.

El ACNUR ha venido interpretando el artículo 33.1 CG51 de forma dinámica, adecuándola a la realidad de los refugiados y al objetivo y fin del tratado. Así, en 1997, en una nota general sobre el principio de non-refoulement, argumentó que dado que el propósito de dicho artículo es asegurar que los refugiados sean protegidos contra el retorno forzoso ante situaciones de peligro, “...it applies both within a State's territory and to rejection at its borders. It also applies outside the territory of States. In essence, it is applicable wherever States act" ${ }^{\prime 485}$. En el año 2000 el Comité Ejecutivo presentó un documento con recomendaciones sobre la interpretación de solicitantes de asilo y refugiados, donde señalaba que el principio "does not imply any geographical limitation (...) the resulting obligations extend to all government agents acting in an oficial capacity, within or outside national territory"486. En 2007 presentó una Opinión Consultiva sobre la aplicación extraterritorial del principio de non-refoulement. Sostenía que la obligación contenida en dicho artículo "aplica siempre que un Estado ejerce jurisdicción, incluyendo en las fronteras, en alta mar o en el territorio de otro Estado" 487 . La inclusión de referencias territoriales en la CG51 tiene base de aplicación "únicamente con respecto al país a donde un refugiado no puede ser devuelto, no al lugar desde el cual esa persona sería enviada"488. Una interpretación contraria sería pues "fundamentalmente incongruente con el objeto y fin humanitario de la Convención de 1951 y su Protocolo de 1967"489. En otro documento sobre interceptaciones marítimas, ACNUR vinculó el concepto de jurisdicción al "control eficaz de jure o de facto sobre un territorio o sobre las personas" ${ }^{490}$, donde incorpora además una base de

${ }^{484}$ Para un análisis más detallado del principio de non-refoulement en el Derecho de los Refugiados, véase Lauterpacht, E. y Bethlehem, D.: The Scope... op. cit.

485 ACNUR: Note on the Principle of Non-Refoulement, noviembre de 1997. Disponible en: http://www.refworld.org/docid/438c6d972.html (Consulta: 18 de enero de 2016)

486 ACNUR: La interceptación de solicitantes de asilo y refugiados: el marco internacional y recomendaciones para un enfoque integral, $18^{\mathrm{a}}$ reunión del Comité Ejecutivo, 9 de junio de 2000, doc. EC/EC/50/SC/CRP.17, p. $23 . \quad$ Disponible http://www.acnur.org/t3/fileadmin/Documentos/BDL/2005/2234.pdf?view=1 (Consulta: 27 de enero de 2016).

487 ACNUR: Opinión Consultiva sobre la aplicación extraterritorial de las obligaciones de no devolución en virtud de la Convención sobre el Estatuto de los Refugiados de 1951 y su Protocolo de 1967, 26 de enero de 2007, $\quad$ d 24.2 Disponible en: http://www.acnur.org/t3/fileadmin/Documentos/BDL/2009/7123.pdf?view=1 (Consulta: 18 de enero de 2016)

${ }^{488}$ Ibíd., $\S 26$

${ }^{489}$ Ibíd., § 29

490 ACNUR: Operaciones de interceptación marítima y tramitación de solicitudes de protección internacional: normas jurídicas y consideraciones de políticas con respecto al procesamiento extraterritorial, Documento de políticas de protección, noviembre de 2010, para. 9. Disponible en: 


\section{CAPÍTULO 4}

fundamentación jurídica del DIDH, en particular a la noción de control efectivo que emplea el CDH en el caso López Burgos c. Uruguay, arriba comentado.

En el debate académico no existe un consenso sobre cuál es la extensión de las obligaciones de los Estados respecto de los refugiados que no han alcanzado el territorio del país. La actividad extraterritorial de los Estados más allá de sus fronteras ha sufrido evoluciones en las últimas décadas: despliegue de policía, agentes costeros y de inmigración en Alta Mar e incluso mares territoriales de terceros países, intercepciones en el mar, creación de "zonas internacionales" donde los estados claman que no se aplican todas las salvaguardas, y las variaciones incrementalmente variadas del concepto de tercer país seguro (STC). Existe una preocupación creciente sobre la falta de regulación, que ha convertido el control migratorio extraterritorial en un 'agujero negro legal ${ }^{391}$.

Algunos autores como Barnes ${ }^{492}$ han señalado las dudas sobre el alcance que da la CG51, dado que en todo su articulado toma referencia el territorio de los Estados parte. Por ejemplo, el artículo 31 que se refiere a aquellos refugiados que "hayan entrado o se encuentre en el territorio de tales Estados sin autorización". A pesar de esta interpretación literal del tratado, el propio Barnes recuerda que la Convención fue firmada después de la Segunda Guerra Mundial con el fin de proteger a los refugiados europeos que ésta había provocado, los cuales atravesaban fronteras terrestres. Otros autores se han situado en posiciones más cercanas al ACNUR. Para Hathaway el desarrollo progresivo del principio ha dejado claro que la responsabilidad estatal se aplica allá donde ejercite su jurisdicción, lo que incluiría el tratamiento de personas que se encuentran bajo agentes estatales en aguas internacionales o de otro estado ${ }^{493}$. De la misma opinión son Goodwin-Gill y McAdam, que parten en su argumentación de lo que consideran el elemento nuclear del principio de non-refoulement: la prohibición de devolver a los refugiados a países en los cuales pudieran sufrir persecución "in any manner whatsoever". Por lo tanto, el ámbito de aplicación de la norma se extendería a cualquier acción estatal, en cualquier lugar donde se ejecute, ya sea en su territorio, en la frontera o mediante sus agentes fuera de su jurisdicción territorial ${ }^{494}$

http://www.acnur.es/PDF/interceptacionmaritima solicitudes pi 20130129165620.pdf (Consulta: 18 de enero de 2016)

${ }^{491}$ Gammeltoft-Hansen, T.: Access to Asylum..., op. cit., p. 13.

492 Barnes, R.: Refugee Law... op. cit., pp. 136-7

493 Hathaway, J.: The Rights of... op. cit., p. 338

${ }^{494}$ Goodwin-Gill, G. y McAdam, J.: The Refugee in ..., op. cit., p. 248 
En jurisprudencia tuvo gran relevancia internacional el caso del Supremo estadounidense Sale v. Haitian Centers Council ${ }^{495}$. En ella examinó si las operaciones de push-backs en Alta Mar que rechazaban embarcaciones procedentes de Haití cargadas de refugiados eran compatibles con la legislación nacional y las obligaciones internacionales. Para el Tribunal Supremo, el artículo 33.1 CG51 no tendría efecto extraterritorial, y por tanto, el uso de la fuerza física para rechazar la entrada de buques en aguas territoriales estadounidenses sería legal. Además, consideraba que la práctica de interceptación del gobierno estadounidense consistía en la "exclusión" y no en la "devolución" de los balseros haitianos. La polémica sentencia se saldó con un voto disidente del juez Harry Blackmun ${ }^{496}$. La Comisión Interamericana de Derechos Humanos también estudió un caso similar al Sale, encontrando que el Estado norteamericano había violado varios derechos contenidos en la Convención Americana de Derechos Humanos ${ }^{497}$. La Comisión, además, se manifestó explícitamente de forma contraria a la decisión del Supremo en el caso Sale, aceptando la interpretación de ACNUR de que el artículo 33 no reconoce limitaciones geográficas ${ }^{498}$.

\subsection{Jurisdicción y territorialidad en la Unión Europea}

Dado que estamos en el presente trabajo estamos tratando de operaciones coordinadas por una agencia de la UE, merece la pena detenerse en el tratamiento de la jurisdicción en el derecho comunitario. La UE presenta un caso especial de jurisdicción, ya que por su carácter supranacional el régimen competencial que presenta se basa en los principios de atribución, subsidiariedad y proporcionalidad ${ }^{499}$.

El concepto de jurisdicción en el derecho comunitario es singular, dada la especial configuración legal de la UE. Por una parte, la Unión no es un Estado ni posee muchas de las características y poderes de la soberanía estatal tradicional. Por otro, sí que es un sujeto del Derecho Internacional Público, cuyas normas la informan y comprometen ${ }^{500}$.

\footnotetext{
495 Corte Suprema de los Estados Unidos: sentencia Sale v. Haitian Ctrs. Council, 509 US 155, 156 (USSC 1993). Disponible en: https://supreme.justia.com/cases/federal/us/509/155/case.html (Consulta: 18 de enero de 2016)

${ }^{496} \mathrm{Su}$ razonamiento se basaba en la aplicación personal y no geográfica del principio: “Article 33.1 is clear not only in what it says, but also in what it does not say: it does not include any geographical limitation. It limits only where a refugee may be sent "to," not where he may be sent from". Ibíd., Dissenting Opinion Blackmun, § 193.

497 Comisión Interamericana de Derechos Humanos: aso 10.675, de 13 de marzo de 1997, Informe $\mathrm{n}^{\circ}$ 51/96 OEA/Ser.L/V/II.95 Doc. $7 . \quad$ Disponible en: https://www.cidh.oas.org/annualrep/96span/EEUU10675.htm (Consulta: 18 de enero de 2016)

${ }_{498}$ Ibíd., $\$ 157$

499 TUE, art. 5

500 TUE, art. 3.5
} 


\section{CAPÍTULO 4}

El derecho comunitario no hace referencia salvo en muy raras ocasiones al "territorio" de la Unión, término que sí se usa comúnmente en relación a los Estados Miembros ${ }^{501}$. Para referirse a aquellos ámbitos donde la UE cuenta con competencias propias o compartidas, se usa más preferentemente el término "espacio", como en el "Espacio de Libertad, Seguridad y Justicia" o, al definir el mercado interior, como "un espacio sin fronteras interiores".

Merece la pena hacer referencia también a la CDF, uno de los instrumentos del derecho originario, y que entró en vigor tras el Tratado de Lisboa. Las nociones de jurisdicción y soberanía de la Carta se centran más en la funcionalidad que en la territorialidad. Al delimitar su ámbito de aplicación, se remite al principio de subsidiariedad al dirigir a las "instituciones, órganos y organismos de la Unión" la obligación de respetar los derechos contenidos en la Carta, "con arreglo a sus respectivas competencias y dentro de los límites de las competencias que los Tratados atribuyen a la Unión" "502. El carácter legal de la UE, por tanto, informa las provisiones de la CDF. El seguimiento de los derechos fundamentales se dirige a todas las actividades que realizan las instituciones, órganos y organismos de la UE, así como los EEMM cuando implementan una norma comunitaria. No existe un criterio territorial que restringa el alcance de estas obligaciones, por lo que es irrelevante si las situaciones tienen o no lugar en el territorio de un $\mathrm{EM}^{503}$. La aplicación extraterritorial de la CDF también ha sido objeto de estudio ${ }^{504}$.

Un documento de especial relevancia para conocer como desarrolla la UE los conceptos de jurisdicción y territorialidad es el Código de Fronteras Schengen (SBC). Al definir "fronteras exteriores" lo hace de un modo territorial, citando simplemente una serie de espacios geográficos. Sin embargo, en el Anexo VI, que trata sobre normas específicas de fronteras y transporte, reemplaza el criterio geográfico por uno de carácter funcional. En el artículo sobre las inspecciones marítimas, estipula que estas

\footnotetext{
${ }^{501}$ Por ejemplo, en los tratados constitucionales sólo existe un caso; el art. 153.g TFUE habla de "las condiciones de empleo de los nacionales de terceros países que residan legalmente en el territorio de la Unión"

${ }^{502}$ Art. 51.1

${ }^{503}$ Compárese este artículo con los correspondientes al PIDCP: "Cada uno de los Estados Partes en el presente Pacto se compromete a respetar y a garantizar a todos los individuos que se encuentren en su territorio y estén sujetos a su jurisdicción los derechos reconocidos en el presente Pacto" (art. 2)

${ }^{504}$ Moreno-Lax, Violeta y Costello, Cathryn: "The Extraterritorial Application of the EU Charter of Fundamental Rights; From Territoriality to Facticity, the Effectiveness Model”. En: Peers, Steve, Hervey, Tamara, et al.: The EU Charter of Fundamental Right. A Commentary, Hart Publishing, Oxford, 2014, pp. 1657-1683. Disponible en: http://oppenheimer.mcgill.ca/IMG/pdf/59 Moreno-Lax Costello 2 .pdf (Consulta: 18 de enero de 2016)
} 
puedan tener lugar "durante el trayecto que realice el buque, o bien a la llegada de este buque al territorio de un tercer país o a la salida del mismo de dicho territorio"505

Posteriormente, el Consejo aprobó la Decisión 2010/252/UE que fijaba una serie de normas aplicables a las operaciones marítimas de interceptación de Frontex, y unas directrices de carácter no vinculante para actuar de cara a las situaciones de búsqueda, salvamento y desembarco. La Decisión daba cobertura legal a ciertas actuaciones que ya se estaban llevando a cabo en operaciones de interceptación alta mar, incluyendo medidas de carácter coercitivo ${ }^{506}$. El PE elevó la modificación al TJUE, criticando que fuera adoptada sin seguir el procedimiento legislativo ordinario, en tanto regulaba cuestiones más allá de la vigilancia fronteriza. El TJUE decidió anular las Decisión, debido a que las cuestiones que afectan a derechos fundamentales debían adoptarse a través del procedimiento legislativo ordinario y un simple acto de ejecución ${ }^{507}$. La Corte también encontró que dichas medidas podían entrar en conflicto con la soberanía de los Estados de pabellón ${ }^{508}$, y dotaban de un grado de autoridad a los guardias de frontera "entre las que figuran el arresto de las personas aprehendidas, el apresamiento del buque y el reenvio de las personas aprehendidas hacia un lugar determinado, afectan de tal manera a los derechos fundamentales de las personas implicadas" ${ }^{\text {509. }}$.

El TEDH tomó la decisión de mantener la vigencia de la Decisión hasta que otra norma, ésta aprobada por el PLO, fuera aprobada. Se trató del Reglamento 610/2013, que reforma el anexo IV del SBC. Regula por ejemplo los "pasos fronterizos conjuntos" 510 , en el que agentes de guardias de fronteras de un EEMM y de un tercer Estado realizan inspecciones sucesivas de entrada y salida en el territorio de cualquiera de los dos Estados, siempre que sea al amparo de un acuerdo bilateral y del derecho interno. Incluye así mismo una cláusula de garantía por las que los EEMM están obligados a actuar en concordancia con los derechos fundamentales, incluyendo la

\footnotetext{
${ }^{505}$ Reglamento (CE) no 562/2006, Anexo VI, art. 3.1.1

506 Decisión del Consejo 2010/252/UE, de 26 de abril de 2010, por la que se completa el Código de fronteras Schengen por lo que se refiere a la vigilancia de las fronteras marítimas exteriores en el marco de la cooperación operativa coordinada por la Agencia Europea para la Gestión de la Cooperación Operativa en las Fronteras Exteriores de los Estados miembros de la Unión Europea, anexo 1, art. 2.5.2. DO L 111 de 4 de mayo de 2010, p. 20-26. Disponible en: http://eurlex.europa.eu/LexUriServ/LexUriServ.do?uri=OJ:L:2010:111:0020:0026:ES:PDF (Consulta: 18 de enero de 2016)

507 TJUE: "Parlamento Europeo contra Consejo de la Unión Europea" (C-355/10), sentencia del 5 de septiembre de 2012, $\quad$ de $\quad 52-56 . \quad$ Disponible http://curia.europa.eu/juris/document/document.jsf?text=\&docid=126363\&pageIndex=0\&doclang=es\&m ode $=1$ st\&dir $=\& o c c=$ first\&part $=1 \&$ cid $=276283$ (Consulta: 18 de enero de 2016)

508 Ibíd., $\$ 76$

${ }^{509}$ Ibíd., § 77

${ }^{510}$ Reglamento (UE) 610/2013 art. 1.8 bis
} 


\section{CAPÍTULO 4}

protección internacional de los refugiados y el principio de non-refoulement ${ }^{511}$. Por otra parte, el Reglamento 656/2014, sobre vigilancia marítima en las fronteras exteriores, legisla no sólo las operaciones de vigilancia e interceptación en las aguas territoriales de los EEMM sino también en Alta Mar ${ }^{512}$.

Por su parte, el reglamento de Frontex también define de un modo funcional el principio de no-devolución: "ninguna persona podrá ser desembarcada en un país ni entregada a sus autoridades si ello vulnera el principio de no devolución, o si existe el riesgo de que sea expulsada de tal país o repatriada a otro vulnerando dicho

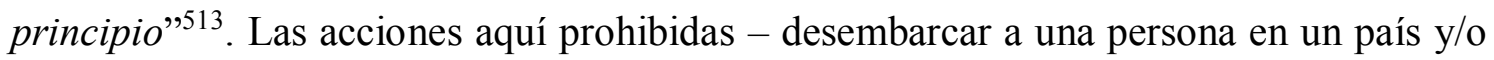
entregarla a sus autoridades - se llevan a cabo por regla general fuera de los territorios de los EEMM. Carece de sentido, por tanto, una interpretación que excluyera de las responsabilidades por incumplimiento a los Estados por haber realizado precisamente esta acción fuera de su territorio.

511 Ibíd., art. 3.bis

${ }^{512}$ Reglamento 656/2014/UE, art. 7

${ }^{513}$ Reglamento (UE) 1168/2011, art. 2. 1.bis. 
Capítulo 5

Salvamento marítimo y derechos humanos 



\section{Salvamento marítimo y derechos humanos.}

\subsection{Introducción al Derecho del Mar}

El marco jurídico internacional marítimo se encuentra organizado en torno a la Organización Marítima Internacional (OMI), el organismo de las Naciones Unidas responsable de la seguridad y protección de la navegación. Todos los Estados miembros de la UE, incluidos los mediterráneos, son miembros. También lo son todos los estados norteafricanos y del África Occidental desde cuyas costas zarpan las embarcaciones que se dirigen a Europa. El instrumento jurídico central es la Convención de las Naciones Unidas sobre Derecho del Mar de 1982, también conocida como Convención de Jamaica o UNCLOS por sus siglas en inglés ${ }^{514}$.

Jurídicamente, los mares se dividen en distintas zonas dependiendo de su cercanía a las costas de un Estado. Hasta las doce millas náuticas se extienden el mar territorial ${ }^{515}$, dentro del cual los Estados ejercen plenamente su soberanía. Doce millas más, hasta las veinticuatro, los Estados pueden extender su soberanía a la zona contigua ${ }^{516}$ donde tienen competencias para ejercer la prevención y sanción de infracciones aduanaras, fiscales, de inmigración o sanitarios que se cometan en su territorio o mar territorial ${ }^{517}$. Por último, los Estados cuentan con la Zona Económica Exclusiva (ZEE), que se extiende hasta las 200 millas náuticas. En la ZEE los Estados ostentan derechos relativos a los recursos naturales, la investigación científica y la protección y preservación del medio marino ${ }^{518}$ su soberanía. No se incluyen competencias relativas a las fronteras, la inmigración u otras cuestiones de carácter civil o penal. Más allá de estas tres zonas, se encuentra el Alta Mar, destinada a fines pacíficos ${ }^{519}$, y a la que los estados no pueden someter su soberanía ${ }^{520}$ Esto no implica un vacío legal, ya que los

\footnotetext{
514 Es en su forma inglesa por como me referiré de ahora en adelante, debido a ser la más comúnmente utilizada a nivel internacional.

515 Convención de las Naciones Unidas sobre el Derecho del Mar, aprobada en Jamaica el 10 de diciembre de $1982,182^{\circ}$ sesión plenaria de la III Conferencia de las Naciones Unidas sobre el Derecho del Mar, art $\quad 2, \quad 3 \quad$ y $\quad 4 . \quad$ Disponible $\quad$ en: http://www.un.org/depts/los/convention agreements/texts/unclos/convemar es.pdf (Consulta: 20 de enero de 2016)

516 Ibíd., art. 33.2

517 Ibíd., art. 33.1

518 Ibíd., art. 56

519 Ibíd., art. 88

${ }^{520}$ Ibíd., art. 89
} 


\section{CAPÍTULO 5}

buques que navegan por alta mar se encuentra sometidos a la jurisdicción del Estado bajo el que enarbolan pabellón ${ }^{521}$.

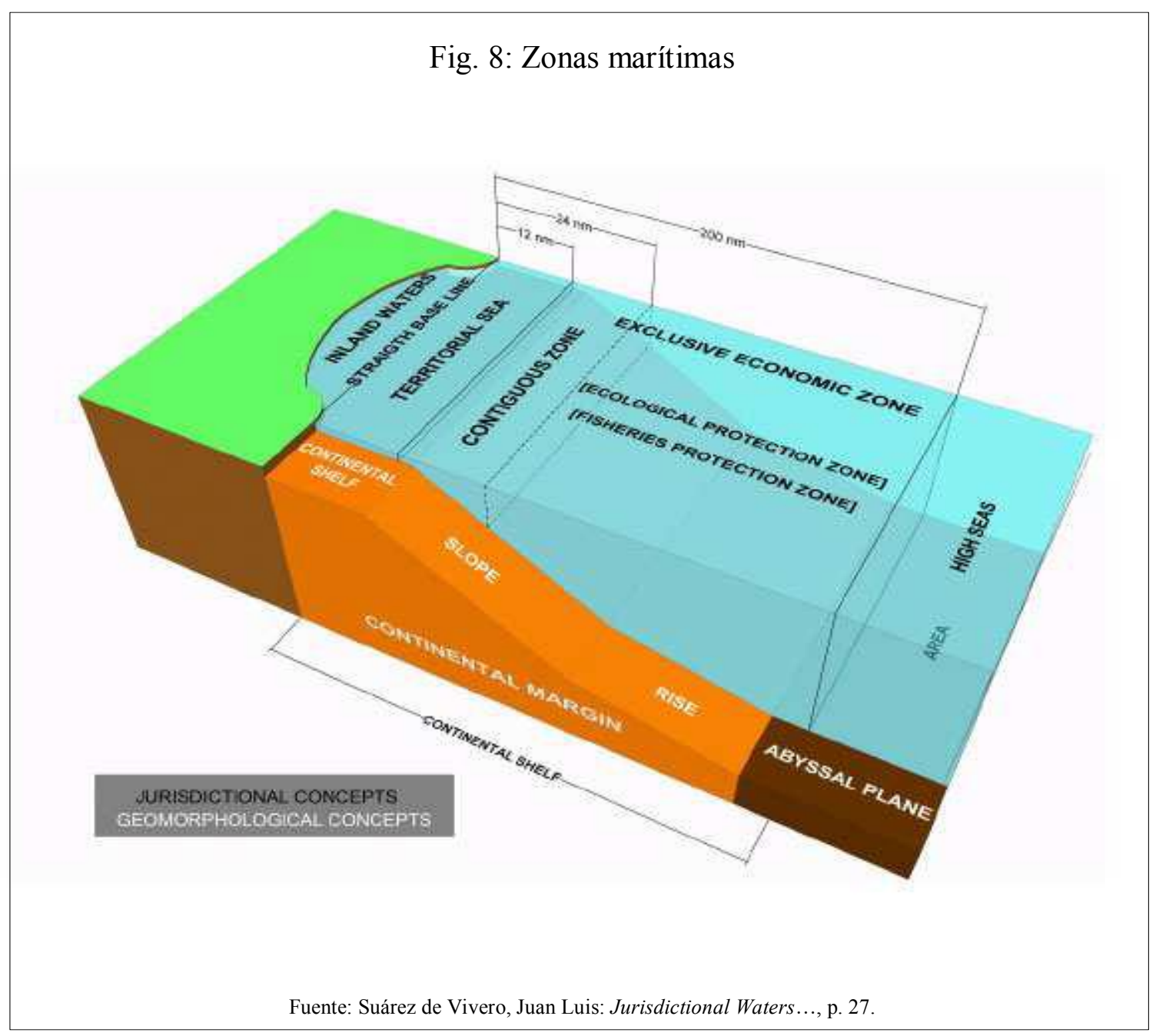

La Convención UNCLOS expone con razonable detalle los estándares relativos a la seguridad y protección de los buques, así como a la tripulación de éstos. No es así en los aspectos relativos a los derechos de los boat people y los polizones, ni con las obligaciones de los Estados en materia de búsqueda, rescate y refugio de transportes precarios y en problemas como en los que suelen viajar los migrantes que intenta alcanzar Europa por la vía marítima. En estos casos, especialmente el primero, nos enfrentamos a obligaciones poco comprometedoras, conceptos pobremente definidos y con escaso desarrollo jurisdiccional de la norma. Además, las escasas disposiciones no son autoejecutables, ni su incumplimiento conlleva unas infracciones lo suficientemente

${ }^{521}$ Ibíd., art. 92.1 
elevadas. UNCLOS instituyó la creación de un Tribunal Internacional del Derecho del Mar, pero el acceso se encuentra restringido a los Estados parte ${ }^{522}$.

Para el presente capítulo, haremos referencia a varios instrumentos internacionales del Derecho del Mar además de la citada Convención sobre Derecho del Mar:

- Convención Internacional sobre Búsqueda y Salvamento Marítimo (o Convenio SAR $)^{523}$

- Convenio Internacional para la Seguridad de la Vida Humana en el Mar $(\mathrm{SOLAS})^{524}$, especialmente su capítulo III (Dispositivos y Medios de Salvamento), así como el V (Seguridad de la Navegación) y XI (Medidas especiales para incrementar la seguridad marítima)

- Convenio Internacional sobre Salvamento Marítimo (SALVAGE) ${ }^{525}$

También tendremos en cuenta algunos documentos emitidos por parte del Comité Marítimo Internacional (CMI) ya que, a pesar de ser una organización privada, sus recomendaciones gozan de gran importancia en la interpretación de las normas de derecho del mar.

En 1957 se firmó en Bruselas la Convención Internacional sobre Polizones ${ }^{526}$, cuyo artículo 2.3 obligaba a los estados a desembarcarlos en sus puertos ${ }^{527}$. Esta fue la razón de que la mayoría de los Estados se negaron a firmarla, y finalmente la Convención

522 Ibíd., anexo VI, art. 20

${ }^{523}$ Convenio internacional sobre búsqueda y salvamento marítimos, aprobado en Hamburgo el 27 de abril de 1979. Disponible

en:

http://www.imo.org/es/About/Conventions/ListOfConventions/Paginas/International-Convention-onMaritime-Search-and-Rescue-\%28SAR\%29.aspx (Consulta: 20 de enero de 2016)

${ }_{524}$ Convenio Internacional para la seguridad de la vida humana en el mar, aprobado el 1 de noviembre de 1974. Disponible

http://www.imo.org/es/About/Conventions/ListOfConventions/Paginas/International-Convention-for-theSafety-of-Life-at-Sea-\%28SOLAS\%29,-1974.aspx (Consulta: 20 de enero de 2016)

525 Convenio Internacional sobre Salvamento Marítimo, aprobado en Londres el 28 de abril de 1989. Disponible en: http://www.imo.org/en/About/Conventions/ListOfConventions/Pages/InternationalConvention-on-Salvage.aspx (Consulta: 20 de enero de 2016)

${ }^{526} \mathrm{El}$ art. 1 de la Convención definía al polizón como "a person who, at any port or place in the vicinity thereof, secretes himself in a ship without the consent of the shipowner or the Master or any other person in charge of the ship and who is on board after the ship has left that port or place"

527 "Unless the stowaway is under a previous individual order of deportation or prohibition from entry, the appropriate authority of a Contracting State shall receive any stowaway delivered to it in accordance with the foregoing provisions of this Article and deal with him in accordance with the provisions of this Convention". Convención Internacional sobre Polizones, firmada en Bruselas el 10 de octubre de 1957. Disponible en: http://www.refworld.org/docid/3ae6b3a80.html (Consulta: 20 de enero de 2016) 


\section{CAPÍTULO 5}

nunca llegó a entrar en vigor. El ACNUR aboga para que, cuando sea posible, se permita a los polizones desembarcar en la primera escala a puerto, donde las autoridades locales determinarán su condición de refugiado. Si algún Estado no permite desembarcar a un polizón, y la siguiente escala del barco es en un Estado donde la vida del polizón peligra, entonces, la acción es sinónimo de denegación. En estos casos, los oficiales del ACNUR están instruidos para tratar de organizar una entrevista a bordo, y si se descubre que el solicitante de asilo puede ser reconocido como refugiado, los oficiales deben ayudar a encontrar una solución duradera -normalmente un tercer país de reasentamiento ${ }^{528}$.

Conviene recordar que, en las situaciones que tratamos en esta investigación, dos campos del derecho internacional se entremezclan. Por un lado, el Derecho del Mar establece obligaciones a los Estados para realizar operaciones de búsqueda y rescate a personas que se encuentren en peligro y, de una manera menos concreta, directrices sobre donde deben ser desembarcados. El Derecho Internacional de los Derechos Humanos y de los Refugiados protegen los derechos de los migrantes y solicitantes de asilo, donde quiera que se encuentre. Además, tendremos en cuenta las competencias comunitarias en esta esfera, actualmente muy reducidas pero que durante la última década han producido unas primeras normas. En este trabajo nos centramos en la protección contra la devolución de aquellas personas migrantes y refugiadas que viajan a Europa por vía marítima. En el capítulo tercero vimos una introducción al principio de non-refoulement, con especial interés en el ámbito europeo. En el cuarto presentamos una serie de debates que surgían en las operaciones de intercepción y salvamento marítimo en torno a las nociones de jurisdicción y territorialidad. En el presente quinto capítulo nos sumergimos en el Derecho del Mar, para conectar las normas sobre salvamento, rescate y desembarco con las obligaciones de derechos humanos.

En noviembre de 2011 el ACNUR convocó en Djibouti una reunión de expertos para discutir propuestas prácticas sobre cooperación internacional en salvamento marítimo cuando se veían involucrados refugiados y solicitantes de asilo ${ }^{529}$. De la reunión se presentaron una serie de principios básicos que debían seguir los Estados:

\footnotetext{
528 Vid. ACNUR: Note on Stowaway Asylum-Seekers, International Protection (SCIP), 22 de julio de 1988, Doc. EC/SCP/51. Disponible en: http://www.unhcr.org/3ae68cbf8.html (Consulta: 20 de enero de 2016)

${ }^{529}$ ACNUR: Refugiados y solicitantes de asilo en peligro en el mar - ¿Cómo responder mejor?, Reunión de expertos en Djibouti, Resumen de las conclusiones, 8-10 de noviembre de 2011. Disponible http://www.acnur.es/PDF/refugiados solicitantesasilo peligro mar comorespondermejor 201304091215 07.pdf (Consulta: 20 de enero de 2016)
} 
$\square$ El deber de prestar auxilio a las personas en peligro en el mar, sin discriminación alguna

$\square$ La obligación de garantizar los acuerdos para la coordinación y la comunicación de socorro

$\square$ El deber de cooperar para asegurar que los capitanes de buques que están prestando la asistencia a las personas en peligro sean liberados de sus obligaciones y que los supervivientes sean desembarcados del buque que presta auxilio y llevados a un lugar seguro tan pronto como sea razonablemente posible.

$\square$ El principio de no devolución, que prohíbe el retorno a los territorios en que una persona puede ser objeto de persecución, tortura, tratos inhumanos y degradantes u otro daño irreparable. El principio de no devolución también se aplica cuando un Estado actúa fuera del territorio.

La obligación de tratar a las personas rescatadas de manera humanitaria de conformidad con el Derecho Internacional de los Derechos Humanos.

$\square$ El deber de respetar la soberanía de otros Estados.

$\square$ El principio subyacente de cooperación internacional en el régimen de los refugiados, derivadas de la Carta de las Naciones Unidas y la Convención sobre el Estatuto de los Refugiados de 1951.

\subsubsection{La política marítima integrada (Integrated Maritime Policy)}

El acervo normativo de la UE en cuestiones marítimas es escaso y reciente, consecuencia de la asunción tardía de competencias en fronteras exteriores a partir del tratado de Ámsterdam. La primera norma relacionada es la Directiva 2002/59/CE, posteriormente enmendada por la Directiva 2009/17/CE, que establece un sistema de seguimiento y de información sobre el tráfico marítimo. Una de la finalidad de la directiva es mejorar la respuesta de las autoridades de los Estados miembros a los accidentes marítimos, incluidas las operaciones de búsqueda y rescate ${ }^{530}$.

\footnotetext{
${ }^{530}$ Directiva 2009/17/CE del Parlamento Europeo y del Consejo, de 23 de abril de 2009 por la que se modifica la Directiva 2002/59/CE relativa al establecimiento de un sistema comunitario de seguimiento y de información sobre el tráfico marítimo, art. 20. DOUE L 131 pp. 101-113. Disponible en: http://eurlex.europa.eu/LexUriServ/LexUriServ.do?uri=OJ:L:2009:131:0101:0113:ES:PDF (Consulta: 20 de enero de 2016)
} 


\section{CAPÍTULO 5}

En 2006 la Comisión publicó el libro verde sobre la política marítima europea ${ }^{531}$, a partir del cual se ha venido desarrollando la "Política Marítima Integrada" (IMP por sus siglas en inglés), que incluye entre otros sectores y desarrollos la vigilancia marítima y el control fronterizo. La inmigración clandestina aparece como uno de los riesgos a los que se enfrenta la Unión. Uno de los conceptos claves de la IMP es el llamado "dominio marítimo de la UE":

The EU maritime domain encompasses the EU Member States' Territorial waters, Exclusive Economic Zones and Continental Platforms as defined by the 1982 United Nations Convention on Law of the Sea as well as all maritime related activities carried out therein, on the seabed, subsurface, surface and above the sea such as installations, cargo, small boats and vessels flagged, owned, managed by or bound to the EU. Beyond the above, it also comprises any Search and Rescue Area and any Area of Operations that has been designated for an EU Maritime Operation under civil or military authority. ${ }^{532}$

En el marco institucional comunitario, las actividades marítimas de vigilancia entrarían dentro de las competencias compartidas. Sin embargo, esta definición del "dominio marítimo" parece invadir competencias estatales, en tanto la UE no forma parte de la OMI y, por tanto, sólo podría actuar como espacio de coordinación de los Estados costeros en sus acciones de salvamento.

En junio de 2014 se lanzó la Estrategia de Seguridad Marítima de la Unión Europea $(\mathrm{MSS})^{533}$, con el objetivo de proporcionar un marco común para las políticas europeas y nacionales de seguridad marítima. Si uno de los puntos que habíamos destacado positivamente de la reforma del reglamento de Frontex era una mayor basculación entre los intereses estratégicos y securitarios y una visión más humanitaria de las personas migrantes y refugiadas, la MSS parece hacernos retroceder al punto de partida. La

${ }^{531}$ Libro Verde de la Comisión: Hacia una futura política marítima de la Unión: perspectiva europea de los océanos y los mares, 7 de junio de 2006 (COM(2006) 275 final). Disponible en: http://eurlex.europa.eu/legal-content/ES/TXT/?uri=celex:52006DC0275 (Consulta: 20 de enero de 2016)

532 Comunicación de la Comisión al Consejo, al Parlamento Europeo, al Comité Económico y Social Europeo y al Comité de las Regiones: Hacia la integración de la vigilancia marítima: Entorno común de intercambio de información sobre las cuestiones marítimas europeas, 15 de octubre de 2009 (COM(2009) 538 final) Disponible en: lex.europa.eu/LexUriServ/LexUriServ.do?uri=COM:2009:0538:FIN:Es:PDF (Consulta: 20 de enero de 2016)

${ }^{533}$ Estrategia de Seguridad Marítima de la Unión Europea, Consejo de la Unión Europea, Bruselas, 24 de junio de 2014, Doc. 11205/14. Disponible en: http://register.consilium.europa.eu/doc/srv?l=ES\&f=ST\%2011205\%202014\%20INIT (Consulta: 20 de enero de 2016) 
migración ilegal vuelve a figurar como uno de los riesgos y amenazas a los que se enfrenta la Unión, junto a la piratería y el tráfico de armas y estupefacientes ${ }^{534}$, y entre los objetivos se encuentra la seguridad de las fronteras marítimas exteriores de la UE ${ }^{535}$ Desaparece cualquier referencia a los derechos humanos y la protección internacional, y se incide entre la cooperación entre actores militares y civiles y en el control y la vigilancia como respuesta ante todas las amenazas, según el propio listado arriba establecido, a las que se enfrenta Europa.

\subsection{Obligaciones de rescate y desembarco}

\subsubsection{El deber de prestar auxilio}

El deber de prestar auxilio a personas en peligro es uno de los principios más significativos del Derecho del Mar. Partiendo de una práctica común entre los marineros, se estableció como una norma consuetudinaria y paso a formar parte de la costumbre internacional ${ }^{536}$, incorporándose al derecho convencional en una serie de tratados durante el siglo XX. El deber de salvar a toda persona que se encuentre en peligro en el mar "constituye una obligación para todos los marineros por razones evidentes de solidaridad" 537 .

El principio aparece por vez primera positivizado en Convenio de Bruselas de 1910 para la Unificación de Ciertas Reglas en Materia de Auxilio y Salvamento Marítimos y en el Convenio Internacional para la Seguridad de la Vida Humana en el Mar de 1914 (más conocido como Convenio SOLAS). Posteriormente forma parte del tratado sobre el que se funda el Derecho del Mar moderno: el ya citado UNCLOS ${ }^{538}$. Las

\footnotetext{
${ }^{534}$ Ibíd., Cap. V (c)

${ }^{535}$ Ibíd., Cap. III (f)

${ }^{536}$ Se suele citar como un caso primigenio el del buque Eleanor en 1809, en el que Lord Stowell razonó que "real and irresistible distress must be at all times a sufficient Passport for human beings under any such application of human laws" (citado en Papastavridis, E.: The Interception ..., op. cit., p. 6)

${ }^{537}$ Gabaldón, José Luis: Curso de Derecho Marítimo Internacional. Derecho marítimo internacional público y privado y contratos marítimos internacionales. Madrid, Marcial Pons, Ediciones Jurídicas y Sociales, 2012, p. 684.

${ }^{538}$ UNCLOS, art. 98 :

1. Todo Estado exigirá al capitán de un buque que enarbole su pabellón que, siempre que pueda hacerlo sin grave peligro para el buque, su tripulación o sus pasajeros:

a) Preste auxilio a toda persona que se encuentre en peligro de desaparecer en el mar;

b) Se dirija a toda la velocidad posible a prestar auxilio a las personas que estén en peligro, en cuanto sepa que necesitan socorro y siempre que tenga una posibilidad razonable de hacerlo;
} 


\section{CAPÍTULO 5}

obligaciones de los Estados se desarrollaron más profundamente tras la reforma del Convenio SOLAS en 1974, la aprobación del Convenio Internacional sobre Salvamento y Rescate Marítimo (más conocido como Convenio SAR) de 1979; y el Convenio Internacional sobre Salvamento Marítimo de 1989, que viene a sustituir al Convenio de Bruselas de 1910.

Conviene comenzar con un apunte terminológico. El derecho continental europeo arrastra una distinción conceptual entre asistencia y salvamento, siendo la primera preventiva e involucrando bienes y personas y la segunda que se aplica únicamente en supuestos de naufragio, tratándose por tanto de una operación reactiva. Con diversos matices, esta distinción se encuentra en el Derecho francés (assistance y sauvetage), italiano (assistenza y salvataggio) o alemán (hilfleistung y bergung). Sin embargo, esta diferencia no ha se ha conocido nunca en el derecho anglosajón, y debido a su influencia, en el internacional. Ya desde el Convenio de Bruselas de 1910 recoge que "no puede distinguirse entre estas dos clases de servicios" 539 .

En todos estos instrumentos se establecen obligaciones para los Estados tanto sobre las zonas marítimas en que ejercen su jurisdicción como sobre los buques que enarbolan su pabellón en relación al rescate de las personas y embarcaciones que se encuentran en peligro. Estas normas son especialmente relevantes si tenemos en cuenta las condiciones en las que suelen encontrarse los migrantes durante su travesía marítima, cuyas vidas en la mayoría de las ocasiones se encuentran en peligro dado la precariedad de las embarcaciones, la falta de agua y comida, el hacinamiento y la fragilidad ante las inclemencias del mar, la lluvia o el viento. Ante situaciones donde la vida y la seguridad de seres humanos se encuentran en riesgo, deben primar la adopción de medidas que presten auxilio de forma inmediata sin distinción de la situación administrativa de estas, el control de fronteras $u$ otras consideraciones. Los migrantes que viajan en pateras o cayucos son, pues, "personas en peligro" conforme al Derecho del Mar y por tanto objeto de especial protección.

c) Caso de abordaje, preste auxilio al otro buque, a su tripulación y a sus pasajeros y, cuando sea posible, comunique al otro buque el nombre del suyo, su puerto de registro y el puerto más próximo en que hará escala.

2. Todo Estado ribereño fomentará la creación, el funcionamiento y el mantenimiento de un servicio de búsqueda y salvamento adecuado y eficaz para garantizar la seguridad marítima y aérea y, cuando las circunstancias lo exijan, cooperará para ello con los Estados vecinos mediante acuerdos mutuos regionales.

539 Convenio Internacional para la unificación de ciertas reglas en materia de abordaje, firmado en Bruselas el 23 de septiembre de 1910, art. 1.1. Disponible en: http://www.admiraltylawguide.com/conven/collisions1910.html (Consulta: 20 de enero de 2016) 
El rescate de personas implica, así mismo, la satisfacción de una serie de necesidades humanitarias que van más allá de las básicas del salvamento de la vida en peligro, alimentación, asistencia sanitaria de emergencia, etc... y que incluyen entre otras el acceso a la protección internacional del asilo para aquellas personas que lo precisen. Si bien un buque puede ser rescatado por navíos privados (buques pesqueros, de recreo, yates) la garantía de estas necesidades humanitarias que hemos hablado solo puede ser efectivamente garantizadas por las autoridades nacionales.

\subsubsection{Los peligros de los viajes migratorios en el Mediterráneo}

En los últimos años, las condiciones de los viajes migratorios en el mar Mediterráneo han sufrido una dramática involución ${ }^{540}$. Controles fronterizos más sistemáticos y una mayor presencia policial en los últimos años ha desviado las rutas hacia alternativas más largas y peligrosas. Las dificultades para cruzar el mar de forma individual e independiente refuerzan el papel de las organizaciones que se dedican al tráfico de migrantes. Sus estrategias se han encaminado en reducir los costes y las medidas de seguridad de los buques, aprovechándose del incremento de personas que buscan cruzar el Mediterráneo por vía marítima. En los últimos años, se ha tenido constancia de los denominados "barcos fantasmas", buques de carga que son abandonados en alta mar con cientos de migrantes a bordo. El primer caso del que se tuvo constancia apareció diciembre de 2014 cerca de la isla griega de Corfú, seguido al mes siguiente por el mercante 'Ezadeen' de pabellón sierraleonés encontrado a $128 \mathrm{~km}$ de la costa italiana de Crotona. Ambos buques fueron rescatados por la Guardia Costera italiana $^{541}$.

Las cifras de migrantes muertos en el mediterráneo son pavorosas. En los últimos veinte años, los números aproximados rondan desde los 30.000 muertos que cita el proyecto Migrants Files ${ }^{542}$ hasta los 21.105 que registró la APDHA en el mismo

\footnotetext{
${ }^{540}$ En una entrevista con Israel Díaz, patrón del buque de Salvamento Marítimo español Salvamar Alkaid: "Antes era con pateras [barcas de madera de desecho y casco plano] que daban una mayor seguridad. Luego vinieron con embarcaciones neumáticas más estables en la mar. Y ahora hemos dado un paso atrás porque vienen en las toys [embarcaciones hinchables de juguete]. Son balsas mucho más difíciles de localizar y con una gran inestabilidad y fragilidad." Entrevista disponible en: http://ccaa.elpais.com/ccaa/2013/10/17/andalucia/1382024787 592579.html (Consulta: 20 de enero de 2016)

541 'ICGV TYR conducts Search and Rescue of 450 migrants', Nota de prensa de Frontex del 1 de marzo de 2015. Disponible en: http://frontex.europa.eu/news/update-icgv-tyr-conducts-search-and-rescue-of450-migrants-9zLoW0 (Consulta: 20 de enero de 2016)

542 www.themigrantsfiles.com (Consulta: 20 de enero de 2016)
} 


\section{CAPÍTULO 5}

periodo $^{543}$. Desde el año 2000, una media anual de 1.500 vidas perdidas en el Mediterráneo, si bien en los últimos años ha ascendido hasta superar los 3.000. Por región de origen de los fallecidos, los principales provienen del norte de África y los países subsaharianos, destacando que el origen de hasta un $29 \%$ de los migrantes muertos permanece desconocido.

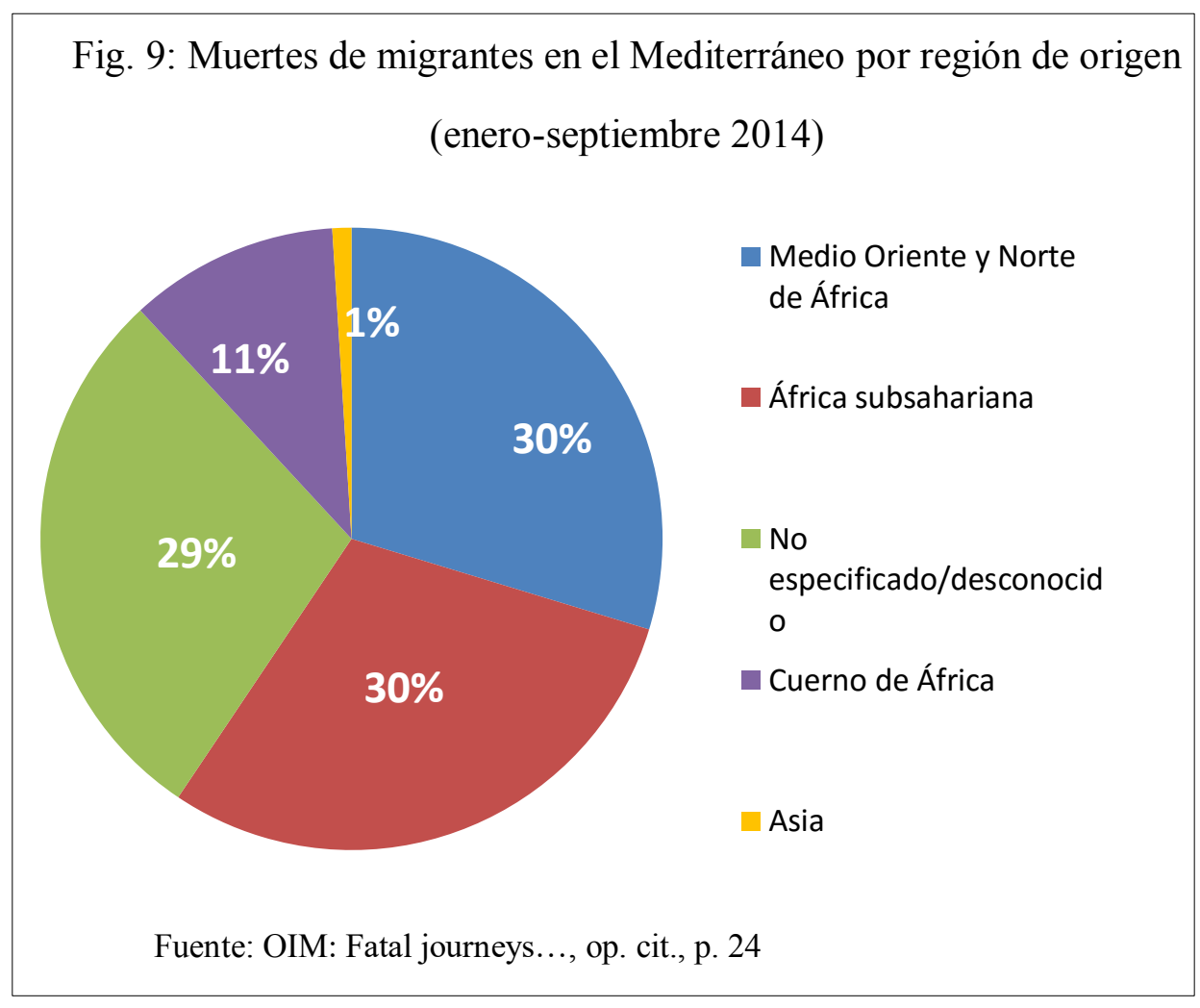

En la última investigación del Migration Policy Centre (MPC) sobre muertes en el mar mediterráneo ${ }^{544}$, se puede constatar el incremento en la proporción de migrantes muertos en el mar durante la última década, elevándose la probabilidad de morir durante el trayecto por encima de un 3\% (30 muertos por cada 1.000 personas cruzando el mar $)^{545}$. Se trata, sin duda alguna, de la ruta migratoria más peligrosa del mundo ${ }^{546}$. El

543 APDHA: Derechos humanos en la frontera sur 2015, p.16. Disponible en: https://www.detective.io/detective/the-migrants-files (Consulta: 20 de enero de 2016)

${ }^{544}$ Fargues, Philippe y Di Bartolomeo, Anna: Drowned Europe, European University Institute, Florence, Migration Policy Centre Policy Brief, doc. 2015/05, abril de 2015. Disponible en: http://cadmus.eui.eu/bitstream/handle/1814/35557/MPC 2015 05 PB.pdf?sequence=1\&isAllowed=y (Consulta: 20 de enero de 2016)

545 Ibíd., n. 5 p. 4. El MPC reconoce la dificultad de obtener fuentes estadísticas fiables para su investigación, y el carácter aproximatorio de los datos que expone. Para el cálculo de la ratio entre personas desaparecidas o encontradas muertas (numerador) y el del total de viajeros (denominador), los investigadores encuentran posible que la mayor presencia de vigilancia marítima haya tanto disminuido (al aumentar el número de personas rescatadas) como aumentado (un mayor número de accidentes detectados) el numerador. 
viaje a través del Mediterráneo sería incluso más peligroso que el que muchos migrantes subsaharianos emprenden previamente al cruzar el desierto del Sahara.

Fig. 10: Personas muertas y desaparecidas en rutas marítimas migratorias irregulares a la UE, 1988-2015 (19/04)

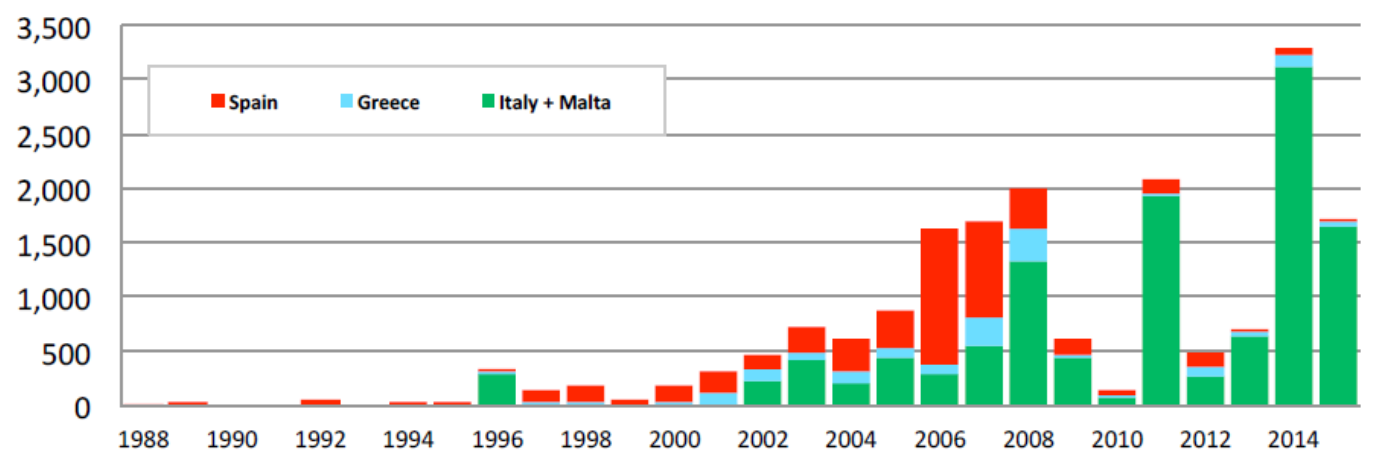

Fuente: Fargues, P. y Di Bartolomeo, A.: Drowned Eruope..., op cit, p. 3

Fig. 11: Probabilidad de morir en rutas marítimas migratorias irregulares a la UE, 1988$2015(19 / 04)$ (tanto por 1.000)

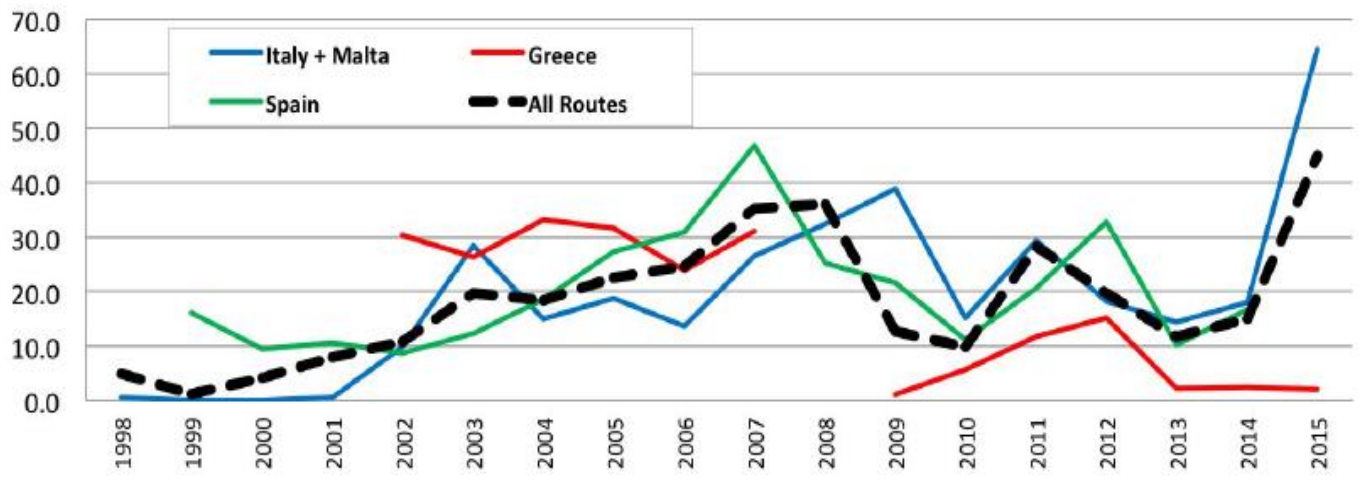

Fuente: Fargues, P. y Di Bartolomeo, A.: Drowned Eruope..., op cit, p. 4

Hay que tener cuenta también la dificultad para disponer de una estadística fiable dado la naturaleza de la tragedia. La OIM cita cinco factores en concreto: la

${ }^{546}$ Entre enero y septiembre de 2014, un $75 \%$ de las muertes de migrantes en el mundo se produjeron en el Mediterráneo. Ver: OIM: Fatal Journeys. Tracking Lives Lost During Migration, Ginebra, OIM Publications, 2014, $\quad$ p. $20 . \quad$ Disponible $\quad$ en: https://publications.iom.int/system/files/pdf/fataljourneys countingtheuncounted.pdf (Consulta: 20 de enero de 2016) 


\section{CAPÍTULO 5}

invisibilidad y carácter clandestino del viaje, la topografía de la ruta, la imposibilidad de verificar la mayoría de los datos, la presencia de actores delictivos, y la disparidad entre las definiciones entre las distintas fuentes. Dichas dificultades provocaban que se tendiera a contabilizar de manera inferior a la realidad. Sugería así mismo que el propio control fronterizo debía añadirse al viaje marítimo a las causas de estas muertes ${ }^{547}$.

\subsubsection{Obligaciones de salvamento}

El Convenio SAR es el principal instrumento internacional que recoge las obligaciones de los estados en materia de salvamento. Define salvamento ${ }^{548}$ como una "operación para rescatar a personas en peligro, prestarles los primeros auxilios médicos o de otro tipo y trasladarlas a un lugar seguro" 549 . Por su parte, de una forma más concisa el Convenio SOLAS define rescate como "la recogida y puesta a salvo de supervivientes" ${ }^{\text {"550. }}$.

De los diversos instrumentos internacionales pueden distinguirse entre dos conjuntos de obligaciones en relación al salvamento: una es la de crear servicios de búsqueda y salvamento por parte de los Estados ribereños; y otra que concierne a los buques que enarbolen el pabellón de un Estado que forme parte de dichos convenios.

\subsubsection{Los Estados ribereños}

La principal obligación que recae en los estados ribereños es la de crear servicios de búsqueda y salvamento adecuados, sea de forma autónoma, en coordinación con otros Estados, o con la OMI. En el Derecho del Mar, estos servicios son conocidos por sus siglas en inglés SAR (Search And Rescue), y los centros nacionales a través de los cuales se realizan RCC (Rescue Coordination Centre).

\footnotetext{
${ }^{547}$ Ibíd., p. 16

${ }^{548}$ A menudo se produce una confusión con la traducción al español del acrónimo SAR: Search and Rescue. Si bien el Convenio lo traduce exclusivamente como "salvamento", tanto en la IMO como en la UE se pueden encontrar documentos donde aparece traducido como "rescate". Así mismo esto ha generado un problema de "false friends" con los términos "salvage", que en la terminología marítima se refiere al rescate de los bienes en casos de naufragio. En este trabajo, emplearé "salvamento" cuando me refiera a las obligaciones contenidas en el Derecho del Mar, ciñéndome a la definición tal como aparece en el convenio SAR, que incluye no sólo el rescate de las personas en peligro, sino la prestación de auxilios médicos y su traslado a un lugar seguro. Cuando me refiera a "rescate", lo haré con la intención de limitarme a la acción de poner en un lugar seguro a los tripulantes de un navío en situación o en peligro de naufragio.

${ }^{549}$ Convenio SAR, art. 1.3.2

${ }^{550}$ SOLAS, Parte A, Regla 3. 20
} 
Esta obligación se encuentra recogida en de forma genérica por el artículo 98.2 UNCLOS $^{551}$. A pesar de que dicho artículo se encuentra incluido dentro del capítulo de Alta Mar, el deber de prestar auxilio es aplicable a todas las zonas marítimas ${ }^{552}$. Así mismo, podemos encontrar una formulación similar en los convenios SOLAS $^{553}$ y SALVAGE ${ }^{55}$, la Convención sobre Alta Mar de $1958^{555}$, y el Convenio SAR ${ }^{556}$. Este último, además, desarrolla de forma más detallada las distintas obligaciones. Recoge el carácter universal del principio, imponiendo la obligación de prestar auxilio " $a$ cualesquiera personas que se hallen en peligro en el mar. Harán esto sean cuales fueren la nacionalidad o la condición jurídica de dichas personas o las circunstancias en que éstas se encuentren" ${ }^{\circ 57 .}$

Estos servicios de búsqueda y rescate se organizan en una serie de regiones o áreas SAR, bajo responsabilidad de cada Estado ribereño. Dichas áreas no se corresponden ni superponen a las distintas zonas marítimas, y el ejercicio de poderes soberanos por parte de los Estados se reduce a las funciones de asistencia arriba señaladas. La extensión de las regiones se delimita conjuntamente por la OIM y la OACI (Organización de la

551 “Todo Estado ribereño fomentará la creación, el funcionamiento y el mantenimiento de un servicio de búsqueda y salvamento adecuado y eficaz para garantizar la seguridad marítima y aérea y, cuando las circunstancias lo exijan, cooperará para ello con los Estados vecinos mediante acuerdos mutuos regionales"

Conviene tener presente que este artículo se encuentre bajo el capítulo VII “Alta Mar”. Los Estados parte no pueden por tanto limitar sus actividades de salvamento a sus aguas territoriales.

552 Durante la negociación del tratado se produjo un debate sobre el artículo, pero la redacción ("a toda persona que se encuentre en peligro de desaparecer en el mar" y no "en alta mar") ha de ser interpretada según el objeto del tratado, que era garantizar la seguridad marítima.

${ }^{553}$ Convenio SOLAS, Cap. V, Regla 7.1: "Todo Gobierno Contratante se obliga a garantizar la adopción de cualquier medida necesaria para mantener las comunicaciones de socorro y la coordinación en su zona de responsabilidad y para salvar a las personas que se hallen en peligro en el mar cerca de sus costas. Dichas medidas comprenderán el establecimiento, la utilización y el mantenimiento de las instalaciones de búsqueda y salvamento que se juzguen factibles y necesarias, habida cuenta de la densidad del tráfico marítimo y los peligros existentes para la navegación, y proporcionarán, en la medida de lo posible, medios para la localización y el salvamento de tales personas".

${ }^{554}$ Convenio SALVAGE, art. 11: "Todo Estado Parte, al dictar reglas o adoptar decisiones acerca de cuestiones relacionadas con operaciones de salvamento, tales como la admisión en puerto de buques necesitados de socorro o la prestación de servicios a los salvadores, tendrá en cuenta la necesidad de que exista cooperación entre los salvadores, las otras partes interesadas y las autoridades públicas con el fin de asegurar la ejecución eficaz y satisfactoria de las operaciones de salvamento encaminadas a salvar vidas humanas o bienes en peligro, así como a evitar daños al medio ambiente en general."

${ }^{555}$ Convención sobre Alta Mar, art. 12.2: "El Estado ribereño fomentará la creación y el mantenimiento de un servicio de búsqueda y salvamento adecuado y eficaz, en relación con la seguridad en el mar ycuando las circunstancias lo exijan-cooperará para ello con los Estados vecinos mediante acuerdos mutuos regionales."

${ }^{556}$ Convenio SAR, art. 2.1.1: "Las Partes harán que se tomen las medidas necesarias para la creación de servicios adecuados de búsqueda y salvamento de personas que se hallen en peligro cerca de sus costas en el mar"

${ }^{557}$ Ibíd., art. 2.1.10 


\section{CAPÍTULO 5}

Aviación Civil Internacional), si bien su demarcación suele ser objeto de polémica. En el mar mediterráneo la división es la siguiente:

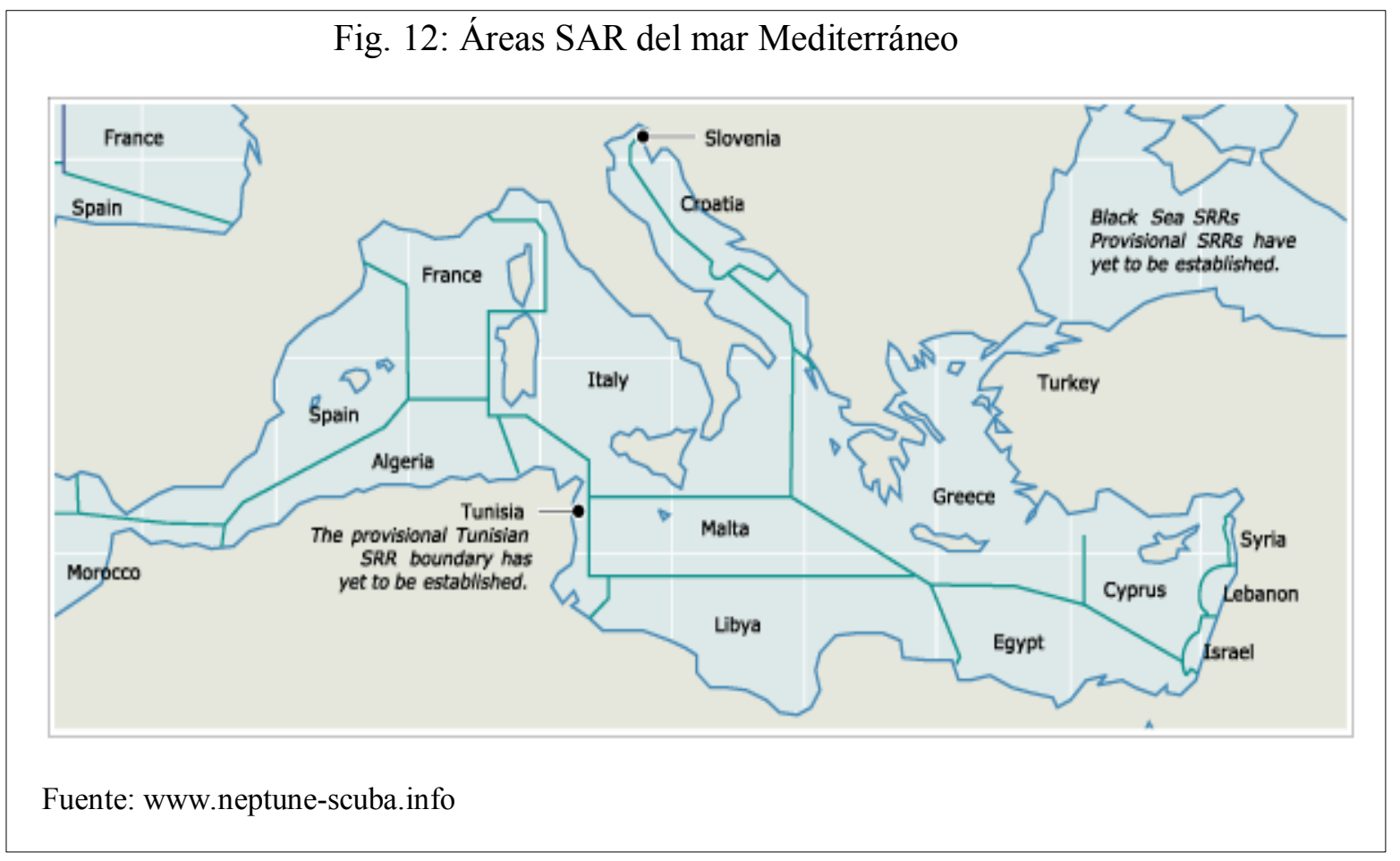

Una disposición de especial relevancia es la que establece obligaciones de actuación inmediata a los RCCs. Entre ellos, que "toda unidad de búsqueda y salvamento que reciba información sobre un suceso que entrañe peligro tomará inicialmente medidas inmediatas si está en condiciones de prestar ayuda"558. Los RCCs tienen además la responsabilidad principal de coordinar las operaciones de rescate, lo que incluye el deber de los capitanes de los buques de obedecer sus órdenes ante una situación de peligro en el mar" 559 . Tal como explica Barnes "where a rescue operation is controlled by a rescue coordination centre (RCC), then such an evaluation should be carried out by the RCC because it is in better possession of all the relevant facts. Where the rescue is prompted by a localised distress call directly from the vessel, then the master would have to make such an evaluation" 560 .

558 Ibíd., art. 4.3

${ }^{559}$ UNCLOS, art. 98.2; SAR, art. 3.19

${ }^{560}$ Barnes, R.: Refugee Law... op. cit., pp. 136-7 
La puesta en marcha de una operación de salvamento precisa que se establezca la existencia de una situación de "peligro" en el mar. UNCLOS no lo define, mientras que en el Convenio SAR distingue entre 3 fases: incertidumbre ${ }^{561}$, alerta $^{562}$ y socorro ${ }^{563}$. Esta última sería la que da lugar a una operación de salvamento. Por su parte, para la ILC una situación de peligro "may at most include a situation of serious danger, but not necessarily one that jeopardizes the very existence of the person concerned (...) The protection of something other than life, particularly where the physical integrity of a person is still involved" 564 . La jurisprudencia al respecto es escasa, destacando la resolución del tribunal de arbitraje en el caso Rainbow Warrior, que aceptó que un riesgo serio para la salud supondría una razón válida para la petición de socorro ${ }^{565}$. En las prácticas de salvamento marítimo se diferencia entre las tres llamadas de urgencia (pan-pan) y emergencia (mayday).

En cualquier caso, cualquier rango de la definición de "en peligro" puede aplicarse a la mayoría de las embarcaciones en las que cruzan el Mediterráneo los migrantes, como las pateras y cayucos ${ }^{566}$. La Decisión 2010/252/UE del Consejo añadía que para la determinación de una situación de peligro no debería ser basarse únicamente en la emisión de una petición de auxilio ${ }^{567}$, debiendo tomarse en cuenta factores como la sobrecarga de pasajeros, la probabilidad de que no alcance su destino final, la presencia de pasajeros que precisen asistencia médica urgente, entre otras ${ }^{568}$.

\footnotetext{
${ }^{561}$ Convenio SAR, art. 1.3.11: "Situación en la cual existe incertidumbre en cuanto a la seguridad de una persona, un buque u otra nave"

562 Ibíd., art. 1.3.12: "Situación en la cual se teme por la seguridad de una persona, un buque u otra nave"

${ }^{563}$ Ibíd., art. 1.3.13: "Situación en la cual existe la convicción justificada de que una persona, un buque u otra nave están amenazados por un peligro grave o inminente y necesitan auxilio inmediato."

${ }^{564}$ CDI: International Law Yearbook, vol. II, 1979, Cap. IV, Implication of a State in the internationally wrongful act of another State, para. 135

${ }^{565}$ CIJ: Case concerning the difference between New Zealand and France concerning the interpretation or application of two agreements concluded on 9 July 1986 between the two States and which related to the problems arising from the Rainbow Warrior affair, UNRIAA, sentencia del 30 de abril de 1990 vol. XX (1990), § 79. Disponible en: http://legal.un.org/riaa/cases/vol_XX/215-284.pdf (Consulta: 25 de enero de 2016)

566 En un informe sobre la operación Tritón, la Comisión Europea señalaba que de las 16.402 personas que fueron detectadas, 15.325 (un 93,43\%) se encontraban en peligro. Questions and Answers: Smuggling of Migrants in Europe and the EU response. Comisión Europea, Bruselas, 13 de enero de 2015. Disponible en: http://europa.eu/rapid/press-release MEMO-15-3261 es.htm (Consulta: 25 de enero de 2016)

${ }^{567}$ Decisión 2010/252/UE, Anexo II, p. 1.4.

${ }^{568}$ Ibíd., p. 1.3
} 


\section{CAPÍTULO 5}

\section{¿Un SAR europeo?}

Como vimos en el capítulo anterior, la Unión Europea carece de competencias marítimas, incluyendo también las relativas a los servicios SAR. En la sentencia C$355 / 10$, citada anteriormente, el TJUE examinó hasta qué punto la competencia comunitaria de vigilancia fronteriza incluye cuestiones de salvamento y desembarco. E1 recurso planteado por el PE se centraba sobre todo en que una regulación de este tipo debía llevarse a cabo a través del procedimiento legislativo ordinario, no de una decisión del Consejo. El TJUE resolvió la cuestión señalando que las normativas sobre vigilancia fronteriza "constitutes a major development in the SBC system" pero "entails political choices falling within the responsabilities of the European Union legislature"569 Así, centra la problemática en una disputa entre instituciones comunitarias mientras acepta implícitamente que el asunto cae bajo los poderes de la Unión $^{570}$. El reciente Reglamento 656/2014, consecuencia directa de la sentencia, incluye algunas disposiciones que entran a regular directamente las operaciones de salvamento y desembarco. En el considerando 1 del reglamento se señala que:

La vigilancia de fronteras no se limita a la detección de los intentos de cruce no autorizado de las fronteras, sino que engloba también medidas positivas como la interceptación de embarcaciones sospechosas de intentar entrar en la Unión sin someterse a controles fronterizos, asi como disposiciones dirigidas a abordar las situaciones de búsqueda y salvamento que pueden surgir durante una operación de vigilancia maritima de fronteras y disposiciones destinadas a finalizar con éxito esas operaciones.

Se establecen normas comunes en materia de salvamento y desembarco, incluyendo la provisión de que el estado responsable del RCC sea el mismo que designe el lugar seguro para desembarcar ${ }^{571}$. Esto sería de aplicación incluso cuando éste fuera un Estado no europeo participando en una JO de Frontex. En esa situación, la responsabilidad de los EEMM participantes en la operación se limita a velar "porque el desembarco de las personas rescatadas se efectúe de manera rápida y efectiva". La escasa infraestructura de los RCC norteafricanos ${ }^{572}$ y la desigualdad de fuerzas en los acuerdos euroafricanos en materia fronteriza hacen temer que los gobiernos europeos empleen esta norma para intentar desentenderse de la acogida de migrantes rescatadas en el mar.

\footnotetext{
${ }^{569}$ TJUE: C-355/10, § 76.

570 Ibíd., § 79

571 Reglamento 656/2014, art. 10.c.

572 El propio reglamento incluye una artículo previendo deficiencias en los RCC de terceros países durante las operaciones de salvamento en el art. 9.2.i
} 
Los seis EEMM mediterráneos (España, Francia, Italia, Malta, Grecia y Chipre) se opusieron durante la negociación, calificando como "inaceptable" y constituye "una línea roja"573 Aunque la norma excluye a las operaciones llevadas a cabo de forma individual por los estados mediterráneos, éstos expresaron sus temores de que "we would effectively be creating an EU regime that runs in parallel with the international regime" 574 . Sin embargo, otras instituciones como el Consejo de Europa, a través de la comisaria Tineke Strik, han solicitado que el deber de coordinación se extienda también a las operaciones nacionales: "This regulation however only applies to these joint operations, therefore I recommend applying the norms in this regulation to all SAR actions by individual member States" ${ }^{\circ 75}$

Este conflicto debe entenderse bajo el sistema y las relaciones de poder dentro de la Unión Europea que definen las políticas fronterizas. La disputa principal entre las instituciones europeas y los EEMM trata sobre quien detenta el control en el diseño y ejecución de las políticas, y las responsabilidades y obligaciones entre los Estados mediterráneos y los del norte de Europa. Así mismo, existen diferencias entre los Estados del Sur al respecto de quien debe asumir la responsabilidad en casos de salvamento, desembarco y acogida.

Un ejemplo de esta discordia fue el caso MV Pinar, donde la falta de cooperación entre las autoridades italiana y maltesa dejó durante semanas en el limbo a un mercante turco que había rescatado a 154 migrantes en abril de 2009. Ambos Estados se negaron a aceptar el acceso a sus puertos del navío, dado que Malta insistía en el criterio del puerto más cercano (Lampedusa) mientras que para Italia éste no era un lugar seguro y el rescate se había producido en el área SAR maltesa. Finalmente, la intervención de la Comisión Europea desbloqueó el conflicto, y los migrantes pudieron desembarcar en Porto Empedocle, Sicilia ${ }^{576}$. Lamentablemente, el conflicto no sirvió para mejorar la cooperación entre estos dos países, ya que en agosto de 2013 se produjo un caso muy similar con el petrolero liberiano Salamis, que había recogido a 102 náufragos. Malta se

\footnotetext{
573 Proposal for a Regulation of the European Parliament and of the Council establishing rules for the surveillance of the external sea borders in the context of operational cooperation coordinated by the European Agency for the Management of Operational Cooperation at the External Borders of the Members States of the European Union - Position on Articles 9 and 10. Doc. 14612/13, Consejo de la Unión Europea, Bruselas, 10 de octubre de 2013. Disponible en: http://www.statewatch.org/news/2013/oct/eu-sea-surveillance-14612-13.pdf (Consulta: 25 de enero de 2016)

${ }^{574}$ Ibíd., p. 2

575 Consejo de Europa: The "left-to-die boat": actions and reactions, doc. 13532 de la Asamblea Parlamentaria, 9 de junio de 2014, p. 61. Disponible en: http://www.assembly.coe.int/nw/xml/XRef/X2HXref-ViewPDF.asp?FileID=20940\&lang=en (Consulta: 25 de enero de 2016)

576 Trevisanut, S.: The Principle of..., op. cit., p. 524.
} 


\section{CAPÍTULO 5}

negó a permitir la entrada en sus aguas territoriales, señalando que debían regresar al puerto libio de origen. Finalmente, tras la intermediación de la Comisión, el Salamis desembarcó en Italia.

La disputa tiene su raíz en la problemática declaración de la zona SAR de Malta. Malta delimitó la extensión de su área de forma unilateral, y no negoció su demarcación con países vecinos, con el resultado de que se superpone parcialmente con el área italiana. Además, la extensión territorial es enorme, equivalente a 750 veces el territorio de la isla. Los servicios costeros malteses no tienen capacidad para cumplir con las responsabilidades derivadas de la proclamación del área SAR, y su negativa a colaborar bilateralmente con otros Estados o en el marco europeo bajo la coordinación de Frontex han sido señalados como una de las causas de fallos en operaciones de rescate en los últimos años ${ }^{577}$.

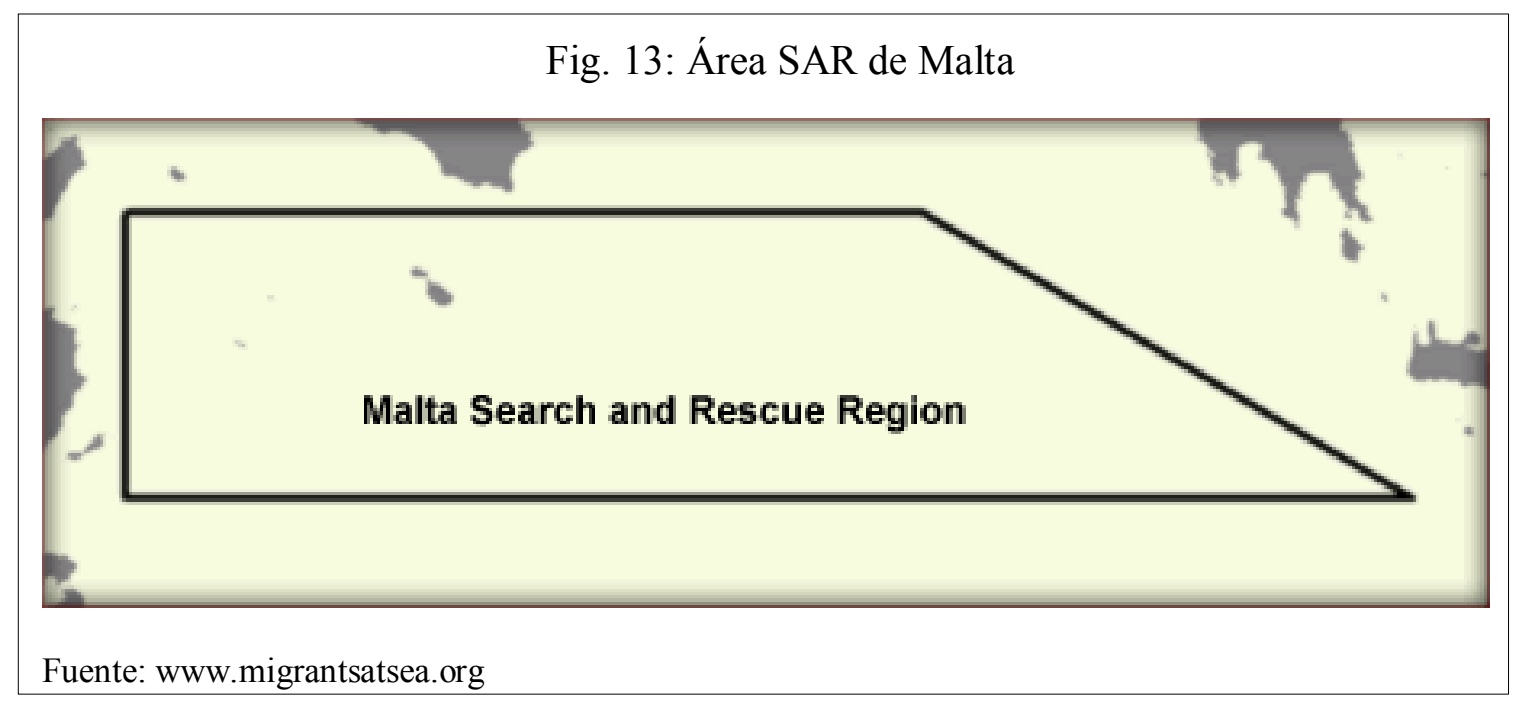

$\underline{\text { La tragedia de } 2011}$

El 26 de marzo de 2011, un pequeño bote neumático zarpó con 72 migrantes (50 hombres, 20 mujeres y 2 bebes, la mayoría de origen eritreo) a bordo de las playas de Trípoli con destino a Italia. 15 días después regresó a las costas de Libia con solo diez supervivientes. Durante esas dos semanas el bote se encontró a la deriva por el Mediterráneo, y a pesar de las continuas llamadas de socorro que emitieron sus tripulantes, terminaron falleciendo debido a la falta de agua y comida. Se trata de una de las mayores tragedias en el salvamento marítimo, no sólo por el número de personas que

577 Vid. HRW: Pushed back..., op. cit., p. 41-46, donde se citan varios incidentes donde el gobierno maltés incumplió las obligaciones básicas de salvamento. 
fallecieron, sino a la inhumana inacción de Estados y buques que se negaron a auxiliar a los migrantes.

El RCC italiano conoció la situación del bote apenas un día después de que zarparan, dado que el capitán realizó una llamada a un sacerdote eritreo que residía en Italia, el cual informó inmediatamente a las autoridades que la embarcación se hallaba en peligro. Explicó también la escasez de agua y alimentos en la que se encontraban, ya que los traficantes habían sacado parte de los suministros del bote para hacer sitio a más pasajeros. Unas horas después de la notificación de peligro, un helicóptero militar alcanzó el bote, lanzándoles botellas de agua y galletas y prometiéndoles que regresaría, pero nunca llegó a hacerlo. Los supervivientes relataron que vieron al menos dos pesqueros, ninguno de los cuales respondió a sus peticiones de auxilio. Al décimo día de viaje, llevando ya varios días sin alimentos y cuando la mitad de los pasajeros habían fallecido, un buque portaviones se situó cerca del bote, pero tampoco acudió a rescatarlo. A las dos semanas, las olas condujeron el bote nuevamente ante las costas libias. Los diez supervivientes fueron detenidos y encarcelados. Uno de ellos, en una grave situación de salud, murió debido a la falta de asistencia médica. Finalmente, los nueve restantes fueron liberados por las autoridades libias.

El Consejo de Europa emprendió una investigación para esclarecer los hechos ${ }^{578}$. En primer lugar, el RCC italiano verificó la posición del bote tras recibir la notificación de la situación y realizó un llamamiento general, pero no cumplió con su tarea de coordinar la operación de rescate. No encomendó a los buques que se encontraban en esa región la misión, ni realizó un seguimiento para asegurarse de que se produjera el rescate. Hay que recordar que en ese momento Libia se encontraba en medio de un conflicto militar.

Finalmente, el informe señaló un vacío legal existente en el Derecho del Mar. El bote se encontraba en el área SAR libio, pero el Estado era incapaz de cumplir sus obligaciones debido al conflicto militar en el que se hallaba envuelto. No existe ninguna disposición en el Derecho del Mar que clarifique como deben responder los Estados vecinos cuando un Estado no puede o no quiere responder con sus obligaciones de salvamento y rescate.

\footnotetext{
${ }^{578}$ Consejo de Europa: Lives lost in the Mediterranean Sea: who is responsible?, Informe de Tineke Strik para la Asamblea Parlamentaria, 29 de marzo de 2012. Disponible en: http://assembly.coe.int/CommitteeDocs/2012/20120329 mig RPT.EN.pdf (Consulta: 25 de enero de 2016)
} 


\section{CAPÍTULO 5}

\subsubsection{Buques y Estados de pabellón}

El Derecho del Mar establece también obligaciones para los estados de los buques que enarbolen su pabellón, ya sean patrulleras de las fuerzas de seguridad o guardas costeras, buques mercantes de pasaje o de carga. Dichas obligaciones se encuentran en el artículo 98.1 de UNCLOS, por el que los Estados deben exigir a todos los buques que llevan su pabellón que presten "auxilio a toda persona que se encuentre en peligro de desaparecer en el mar". La única excepción a este deber es que esta tarea no suponga un grave peligro para el buque, su tripulación o pasajeros. Debemos señalar aquí que la obligación que recae sobre los Estados sobre los buques que lleven su pabellón es de conducta, y no de resultado. Es decir, su obligación se limita a incluir en su ordenamiento interno dicha prescripción, y perseguir a aquellos sujetos (patrones o compañías) que la incumplen.

El resto de tratados internacionales incluyen también el deber de prestar auxilio a aquellas personas que se encuentren en peligro ${ }^{579}$. En el caso de los buques públicos (patrulleras, barcos de salvamento, etc....) la responsabilidad excedería el ámbito personal, extendiéndose hacia lo estatal. Las convenciones SAR y SOLAS, además, recogen explícitamente la prohibición de discriminación en las operaciones de salvamento, así como de tratar a las personas rescatadas con humanidad, conforme a la capacidad y las limitaciones del buque ${ }^{580}$. La Convención de Bruselas de 1910 incluso obligaba al patrón del buque "to render assistance to everybody, even though an enemy, found at sea in danger of being lost"

El deber de prestar auxilio es un principio básico y reconocido por las gentes del mar, antes incluso de su positivización. También se trata de una práctica generalizada y aceptada por la inmensa mayoría de los marinos ${ }^{582}$. Sin embargo, se producen también casos de buques comerciales que se niegan o evitan acudir al rescate de embarcaciones en peligro se producen regularmente. Para el capitán de un buque comercial, embarcarse en una operación de rescate supone hacerse cargo de las consecuencias económicas, los retrasos en la entrega y la búsqueda de un puerto para desembarcarlo. A pesar de que el

\footnotetext{
${ }^{579}$ El art. 12.2 del Convenio de Alta Mar de 1958, la reg. 33.1 del Cap. V del Convenio SOLAS y el art. 10 del Convenio SALVAGE

${ }^{580}$ Cap. V art. 33.1 y 33.6 SOLAS, 2.1.10 Anexo SAR

${ }^{581}$ Convención de Bruselas de 1910, art. 11

${ }^{582}$ La confederación europea de asociaciones de navieros cifró en 57.000 migrantes rescatados en el Mediterráneo entre enero de 2014 y mayo de 2015. Disponible en: http://www.ecsa.eu/news-andmedia/latest-news/9-latest-news/208-meps-support-shipping-industry-s-call-for-stronger-member-stateaction-in-the-mediterranean (Consulta: 25 de enero de 2016)
} 
artículo 16 de SALVAGE recoge el derecho a recibir una indemnización por actos de asistencia y salvamento, no está claro el sujeto encargado de asumir esta compensación económica. El dilema al que se enfrentan los capitanes de los buques se acentúa ante el peligro de ser acusados de ayudar o colaborar con el tráfico de personas o la inmigración irregular.

Los Estados europeos y la Unión han establecido sanciones contra la ayuda a la inmigración irregular. El Convenio de Aplicación de Schengen prevé que los Estados introduzcan sanciones contra las personas que, con fines lucrativos, ayuden a entrar a un inmigrante irregular a entrar o permanecer en un Estado parte ${ }^{583}$, o a los transportistas que introdujeran a extranjeros sin los documentos de viaje válidos ${ }^{584}$. En 2002 se aprobó la Directiva 2002/90/CE, destinada a definir la ayuda a la entrada, a la circulación y a la estancia irregular. De apenas 6 artículos, la Directiva exhorta a los EEMM a introducir sanciones contra "cualquier persona que intencionadamente ayude a una persona que no sea nacional de un Estado miembro a entrar en el territorio de un Estado miembro o a transitar a través de éste" ${ }^{585}$ incluida la incitación participación y tentativa ${ }^{586}$, si bien permite que no se fijen sanciones cuando la situación exija la prestación de ayuda humanitaria $^{587}$ La directiva venía acompañada de la Decisión Marco 2002/946/JAI ${ }^{588}$, que introduce que las sanciones pueden dirigirse tanto a las personas físicas como jurídicas que participen en estas actividades. Sobre las primeras, y cuando se produzcan una serie circunstancias agravantes (ánimo de lucro, organización delictiva, peligro en las vidas de los migrantes) se fijaba un mínimo de 6 años para la duración máxima de la pena de privación de libertad ${ }^{589}$, entre otras posibles sanciones como el decomiso del medio de transporte utilizado, la prohibición de ejercer la actividad profesional motivo de la cual se cometió la infracción, y la expulsión en caso de ser un nacional de otro país ${ }^{590}$. En relación a las personas jurídicas, las sanciones pueden incluir sanciones económicas, la disolución o colocación de la entidad bajo vigilancia judicial, la

${ }^{583}$ Convenio de Aplicación del Acuerdo Schengen, firmado el 19 de junio de 1990, relativo a la supresión gradual de los controles en las fronteras comunes, art. 27.1. DO L 239, de 22 de diciembre de 2000, pp. 19-62. Disponible en: http://eur-lex.europa.eu/legalcontent/ES/TXT/HTML/?uri=CELEX:42000A0922\%2802\%29\&qid=1454313691548\&from=ES

(Consulta: 25 de enero de 2016)

${ }^{584}$ Ibíd., art. 26.2

${ }^{585}$ Directiva 2002/90/CE del Consejo, de 28 de noviembre de 2002, destinada a definir la ayuda a la entrada, a la circulación y a la estancia irregulares, art. 1.1. DO L 238, de 5 de diciembre de 2002, pp. 17 $18 . \quad$ Disponible en: http://eur-lex.europa.eu/legalcontent/ES/TXT/PDF/?uri=CELEX:32002L0090\&from=ES (Consulta: 25 de enero de 2016)

586 Ibíd., art. 2

587 Ibíd., art. 1.2

588 Decisión marco 2002/946/JAI del Consejo, de 28 de noviembre de 2002, destinada a reforzar el marco penal para la represión de la ayuda a la entrada, a la circulación y a la estancia irregulares. DO L 328 de 5 de diciembre 2002, pp. 1-3. Disponible en: http://eur-lex.europa.eu/legalcontent/ES/TXT/PDF/?uri=CELEX:32002F0946\&from=ES (Consulta: 25 de enero de 2016)

${ }^{589}$ Ibíd., art. 1.4

${ }^{590}$ Ibíd., art. 1.2 


\section{CAPÍTULO 5}

exclusión de ayudas públicas o la prohibición de ejercer una actividad comercial. Las personas jurídicas también pueden ser declaradas responsables en el caso de que la persona física imputada en las infracciones ejerza autoridad suficiente $\mathrm{u}$ ostente un poder de representación de la entidad ${ }^{591}$. El TJUE confirmó, en el caso C-83/12, la obligación de los EMM de que "'abra un proceso penal contra cualquier persona que intencionadamente ayude a un nacional de un Estado tercero a entrar en el territorio de un Estado miembro vulnerando la normativa aplicable" 592 .

Los EEMM incorporaron esta directiva a su legislación nacional. Italia ya había tipificado como delito "procurare l'ingresso illegale" meses antes de la Directiva, con la llamada Ley Bossi-Fini ${ }^{593}$. Las sanciones incluían la extradición, penas privativas de libertad de cuatro a doce años y sanciones económicas de hasta 15.000 euros por persona que ingresara en el país ${ }^{594}$. Si citamos aquí la legislación italiana expresamente es porque se trata del país que más ha puesto en práctica la vía de la criminalización de la ayuda a la inmigración ilegal.

El caso más emblemático es sin duda el del navío alemán Cap Anamur. Se trataba de un barco fletado por un comité de acción humanitaria ${ }^{595}$, que lo registró como un buque de rescate y asistencia. Durante años operó en el Mediterráneo, y según sus cálculos rescataron a más de 10.000 personas. El 20 de junio de 2004, en el transcurso de una misión cerca de la costa maltesa, rescató a 37 migrantes, la mayoría sudaneses, que pedían ayuda desde un bote hinchable. En ese momento Sudán se encontraba inmerso en un conflicto armado, y la mayoría de los rescatados solicitaron protección internacional.

Tras semanas de negociaciones entre Italia, Alemania y Malta, y tras la intermediación del ACNUR ${ }^{596}$, el gobierno italiano aceptó que desembarcara en Porto Empedocle, Sicilia. Sin embargo, una vez producido el desembarco y la entrada en un

${ }^{591}$ Ibíd., art. 2.3

${ }^{592}$ TJUE: "Minh Khoa Vo contra Bundesgerichtshof" (C-83/12 PPU), sentencia del 10 de abril de 2012, § 44.

http://curia.europa.eu/juris/document/document.jsf;jsessionid=9ea7d0f130d55c9d38d41bcf4567b5c18028 70dc59ce.e34KaxiLc3eQc40LaxqMbN4Och0Qe0?text $=\&$ docid $=121501$ \&pageIndex $=0$ \&doclang $=$ ES\&m ode $=1$ st\&dir $=$ \&occ $=$ first\&part $=1 \&$ cid $=302859$ (Consulta: 14 de enero de 2016)

593 Legge DDL 795 B in materia di immigrazione e di asilo, de 28 de febrero de 2002

Disponible

en:

http://www.senato.it/japp/bgt/showdoc/frame.jsp?leg=14\&id=00018531\&tipodoc=Ddlpres\&modo

(Consulta: 25 de enero de 2016)

${ }_{594}^{5}$ Ibíd., art. 11.

$595 \mathrm{http} / / /$ www.cap-anamur.org/

${ }^{596}$ UNHCR urges Disembarkation on Humanitarian Grounds, UNHCR Briefing Notes, 9 de julio 2004;

Disponible en: www.unhcr.org/40ee70780.html (Consulta: 25 de enero de 2016) 
centro de acogida de los 37 rescatados, los policías italianos arrestaron al capitán y al primer oficial del Cap Anamur junto al presidente del Comité. La fiscalía acusó a los tres detenidos de haberse asociado para violar la ley migratoria italiana, con el propósito de obtener un beneficio (en forma de publicidad para el Comité) y haber engañado a las autoridades italianas al presentar la existencia de una emergencia médica entre los migrantes rescatados.

Finalmente, el 15 de febrero de 2010 el Tribunal de Agrigento absolvió a los acusados, reconociendo la existencia de un estado de emergencia y que éstos actuaron cumpliendo el deber de rescatar a los náufragos y transportarlos hasta un lugar seguro. Para ser considerado como tal, según el Tribunal, el lugar debería garantizar no solamente la salvación física para los supervivientes, sino también un mínimo respeto a los derechos humanos. Eso excluía tanto a Libia como a Malta, por lo que la decisión de desembarcar a los 37 supervivientes en Italia era la más lógica ${ }^{597}$. El final no fue feliz para los 37 refugiados. La mayoría fueron deportados de Italia en las semanas siguientes, a pesar de que alguno de ellos se encontraba inmerso en el proceso de reconocimiento del estatus de refugiado. Uno de ellos falleció en 2006 en un naufragio cerca de las costas de Sicilia, mientras intentaba regresar a Italia ${ }^{598}$

Mientras transcurría el proceso legal del Cap Anamur se produjo una situación similar en Italia cuando dos pescadores tunecinos, Abdelkarim Bayoudh y Abdelbasset Zenzeri, rescataron a 44 migrantes que habían pedido ayuda al naufragar el buque en el que viajaban ${ }^{599}$. Tras el rescate Zenzeri solicitó a las autoridades italianas cercanas que embarcaran a los rescatados, entre los que se encontraban una mujer embarazada y un menor con discapacidades. Inicialmente Italia rechazó la solicitud, y las unidades navales italiana intentaron bloquear la entrada en sus aguas territoriales al pesquero. Finalmente, el gobierno cambio de postura y accedió al desembarco, tras el cual detuvieron a los dos pescadores. Fueron acusados de ayuda e instigación a la inmigración ilegal, y de resistencia a un agente público. El 17 de noviembre de 2009, el mismo tribunal ante el cual estaba pendiente el caso Cap Anamur absolvió a los pescadores del primer cargo. Tendrían que esperar dos años más hasta que la Corte de Casación de Palermo hiciera lo mismo con la acusación de resistencia. En la sentencia

597 Tribunale di Agrigento, sentencia del 07 de noviembre de 2009, contra Schmidt, S., Dachkevitch, V. y Bierdel, E. Disponible en: http://www.asgi.it/wpcontent/uploads/public/tribunale agrigento 15022010 1.pdf (Consulta: 25 de enero de 2016)

598 Umbriano, Pierluigi: Is it a crime to help people to survive?, Migrants - Outlaws Everywhere, conferencia del 4 de mayo de 2013, p. 5. Disponible en: http://www.eldh.eu/fileadmin/user upload/ejdm/publications/2013/Pierluigi Umbriano Speech.pdf?PHPSESSID=051a86793dbac1a0c80a6885a9a9cf03 (Consulta: 25 de enero de 2016)

${ }^{599}$ Fortress Europe: Escape from Tripoli, Report on the conditions of migrants in transit in Libya, 2008, p. 9. Disponible en: http://www.statewatch.org/news/2007/nov/fortress-europe-libya-report.pdf (Consulta: 25 de enero de 2016) 


\section{CAPÍTULO 5}

2932/2011 afirmó que "the action of the force exerted on the Italian warships by the accused, [...] must be deemed necessary and unavoidable"

\subsubsection{Obligaciones de desembarco}

Si bien se puede afirmar que la obligación de rescatar a aquellas personas que se encuentran en una situación de peligro en el mar está asentada en el derecho internacional, hasta el punto de gozar del estatus de norma de ius cogens, la cuestión de donde desembarcar a las personas rescatadas no ha alcanzado un desarrollo semejante en el derecho del mar.

En este punto nos encontramos en una paradoja similar al derecho existente a salir del propio país, que no encuentra correlato en un derecho a entrar en otro país a la elección de la persona. En el Derecho del Mar, el deber (tanto de los Estados como de los patrones de los buques) de rescatar a las personas que se encuentren en peligro no se complementa con un deber por parte del Estado de pabellón o del de la costa más cercana a aceptar su desembarco.

Cuando se produce una operación de salvamento que da lugar al rescate de un grupo de personas, hay una serie de actores involucrados en el destino de los rescatados: el Gobierno al que le corresponda la responsabilidad por la zona SAR donde se rescata a las personas, otros Estados ribereños en la derrota prevista del buque que realiza el salvamento, el Estado de abanderamiento, los propietarios del buque y sus representantes, los Gobiernos de los países de los que son nacionales o en los que residen las personas rescatadas, el Estado del que partieron las personas rescatadas, si se conoce, y la Unión Europea y el Alto Comisionado de las Naciones Unidas para los Refugiados (ACNUR).

\subsubsection{La evolución de las prácticas de desembarco marítimo}

Las primeras normas sobre salvamento marítimo no regulaban el lugar donde debían ser desembarcadas las personas que fueran rescatadas. Tanto UNCLOS como el Convenio SAR se limitaban a fijar disposiciones de auxilio ante buques y personas en peligro en el mar. Los buques cargados de refugiados, o los pesqueros que recogían a 
náufragos, dependían de la buena voluntad de las autoridades del Estado costero para que aceptara recibir en tierra a los pasajeros ${ }^{600}$.

No fue hasta los años setenta cuando el que el desembarco de migrantes y refugiados se transforma en una problemática de relevancia mundial. Se produjeron diversas crisis de refugiados donde la negativa de los Estados ribereños a aceptar la entrada de buques mercantes o pesqueros que transportaran refugiados puso a los estados de pabellón bajo una presión considerable. Los Estados solamente los aceptaban en sus puertos a condición de que el Estado de bandera del buque, un tercer estado o las Naciones Unidas (ACNUR) se ofrecieran hacerse cargo del reasentamiento de los refugiados y de sus solicitudes de asilo.

En 1975 comienza la crisis de refugiados de Indochina ${ }^{601}$. En 1979 las Naciones Unidas convocan una Conferencia en Ginebra para buscar una solución. La principal medida que se adoptó fue el programa DISERO (Disembarkation Resettlement Offers) por el que varios Estados accedían a aceptar a cualquier refugiado vietnamita que accediera por vía marítima a sus costas. En 1985 comenzó un programa paralelo, RASRO (Rescue at Sea Resettlement Offers) por el que 16 estados aceptaron recibir un cierto número de refugiados rescatados en el mar. En 1989, cuando volvieron a incrementarse flujos de refugiados vietnamitas a países vecinos, se aprobó un Comprehensive Plan of Action (CPA) por el que algunos estados europeos, norteamericanos y Australia aceptaron recibir refugiados. Las medidas destinadas a garantizar una solución para los refugiados pudieron ser consideradas un éxito, en gran medida gracias que la solución se dio a través de la cooperación internacional ${ }^{602}$. El ACNUR, por su parte, ocupó un rol importante en la crisis actuando como mediador entre los gobiernos afectados y aquellos que se ofrecieron a recibir refugiados. Durante este periodo adoptó una serie de resoluciones llamando a los gobiernos de los países costeros a cumplir sus obligaciones humanitarias de recibir en sus puertos a

\footnotetext{
${ }^{600}$ Uno de los casos históricos más infames fue el del MS St. Louis, un buque en el que 915 judíos escaparon de la Alemania nazi y emprendieron el viaje a América, donde fueron rechazados por varios gobiernos latinoamericanos, de EEUU y Canadá. Finalmente tuvieron que regresar a Europa, donde 254 de los pasajeros fallecieron en campos de concentración y uno en un bombardeo en Inglaterra. El suceso fue novelado en 1977 por Gordon Thomas y Max Morgan-Witts en "El viaje de los malditos".

${ }^{601}$ Se puede encontrar un análisis de dicha crisis y de la respuesta a nivel internacional que se produjo en: Robinson, Courtland.: The Comprehensive Plan of Action for Indochinese Refugees, 1989-1997: Sharing the Burden and Passing the Buck, Oxford University Press, Journal of Refugee Studies, Vol. 17, no. 3, 2004. Disponible en: http://www.jhsph.edu/research/centers-and-institutes/center-for-refugee-anddisaster-response/publications tools/publications/additional pdfs/Robinson2004Indochinese refugees.pdf (Consulta: 26 de enero de 2016)

${ }^{602}$ Van Selm, J. y Cooper, B.: The New..., op. cit., p. 20.
} 


\section{CAPÍTULO 5}

embarcaciones en peligro, y promoviendo el desembarco de las personas rescatadas en el siguiente puerto de escala ${ }^{603}$.

En los años noventa se produjeron nuevas crisis de refugiados marítimos. Especial importancia tuvieron los casos de los refugiados haitianos de 1994 y el caso Tampa de Australia. En el primero, los EEUU decidieron recluir en la base de Guantánamo a los miles de boat people haitianos que huían de su país tras un golpe de estado, con la intención de evitar su entrada en territorio norteamericano. A los refugiados se les dio las opciones de ser repatriados a Haití, o de esperar a que otro país se ofreciera a aceptarles. El gobierno posteriormente decidió aplicar la misma política a los refugiados cubanos.

En el caso del $M V$ Tampa, se trataba de un buque noruego que rescató 433 refugiados, en su mayoría afganos, en aguas internacionales entre Indonesia y Australia, en agosto de 2001. Se desencadenó un conflicto político tanto en Australia como a nivel internacional, al negarse las autoridades de este país el desembarco al barco. Finalmente el desembarco se produjo en la isla de Nauru, donde el ACNUR realizó la determinación del status de los solicitantes de asilo. Australia negoció con este y otros estados vecinos la así llamada "Pacific Strategy": mediante la cual estos aceptaban, de forma temporal, los refugiados que trataban de acceder al país por mar a cambio de ayuda financiera ${ }^{604}$. Esta externalización del procedimiento de asilo, negociado con terceros países a cambio de contrapartidas financieras fue tomada como ejemplo por parte de EEMM de la UE para tratar de frenar los flujos migratorios del mediterráneo, en programas como los RPPs, ya citados, y otras propuestas de externalización del asilo $^{605}$.

\footnotetext{
${ }^{603}$ ACNUR: Conclusión general no 23 (XXXII) Problemas relativos al rescate de personas en busca de asilo encontrándose en peligro en el mar, adoptada en el $32^{\circ}$ periodo de sesiones del Comité Ejecutivo, 1981. Disponible en: http://www.acnur.org/Pdf/0534.pdf?view=1 (Consulta: 26 de enero de 2016)

${ }^{604}$ De acuerdo a Amnistía Internacional el monto de ayuda a otros países del Pacífico que formaran parte de este acuerdo era de alrededor de 75 millones USD al año entre 2002 y 2006. En: AI: Australia-Pacific: Offending Human Dignity - the 'Pacific Solution"', Doc. ASA 12/2009/2002, 26 de agosto de 2002. Disponible en: https://www.amnesty.org/download/Documents/116000/asa120092002en.pdf (Consulta: 26 de enero de 2016)

${ }^{605}$ En 2003 el Reino Unido lanzó la propuesta "New International Approaches to Asylum Processing and Protection", basada en la "Pacific Solution" australiana. Pretendía la creación de centros que procesaran las solicitudes de asilo en los países de origen y tránsito. La propuesta fue objeto de un largo debate, incluida la propuesta "three-pronged" del ACNUR, que influyó en la comunicación de la Comisión "Hacia sistemas de asilo mejor gestionados, más accesibles y equitativos" (COM/2003/315 final), supra n. 106.
} 


\subsubsection{La reforma de los Convenios SAR y SOLAS}

En noviembre de 2001, unos meses después del conflicto del MV Tampa, la Asamblea de la OMI aprobó una resolución llamando a identificar "cualquier laguna, inconsistencia, ambigüedad, vaguedad o inadecuación" de la normativa vigente del derecho internacional marítima respecto de las obligaciones de salvamento con el fin de tomar medidas para que los supervivientes de un siniestro reciban auxilio, independientemente de su nacionalidad o situación jurídica, sean transportados a un lugar seguro, y sean tratados con arreglo a los acuerdos internacionales pertinentes, incluyendo a los migrantes indocumentados, los solicitantes de asilo, refugiados y polizones $^{606}$. El Comité de Seguridad Marítima ${ }^{607}$ fue el encargado de redactar una serie de enmiendas a los convenios SAR y SOLAS, que fueron aprobadas por la asamblea de la OMI en 2004 y entraron en vigor el 1 de julio de 2006.

En relación al desembarco, tanto SAR como SOLAS incluyen nuevas normas que obligan tanto a los Estados de pabellón como a los ribereños. Estas disposiciones tienen carácter obligatorio, como evidencia el empleo del verbo en tiempo futuro (en inglés, shall), definido en el apartado de definiciones como indicador de "En el presente anexo, el empleo del futuro de los verbos con un sentido imperativo indica una disposición cuya aplicación uniforme se exige a todas las Partes en pro de la seguridad de la vida humana en el mar" ${ }^{608}$.

En concreto, ambos convenios otorgan al Estado responsable del área SAR la responsabilidad primordial de que los supervivientes sean desembarcados en un lugar seguro $^{609}$. Se reitera el deber de las distintas partes involucradas de cooperar y colaborar en la búsqueda de la solución, por lo que la provisión no implicaría que el desembarco deba producirse necesariamente en el territorio de este Estado. La nueva responsabilidad creada en este artículo implica que los Estados al mando de las operaciones no terminan siendo devueltos a las costas de un país que pudiera cometer violaciones de derechos humanos sobre ellos, incluyendo su devolución al país del que tratan de escapar a través del refoulement indirecto.

\footnotetext{
${ }^{606}$ Resolución A.920 (22) de la Asamblea OMI, Review of Safety Measures and Procedures for the Treatment of Persons Rescued at Sea, aprobada el 29 de noviembre de 2001, 22 periodo de sesiones. Disponible

en: http://www.imo.org/en/OurWork/Facilitation/personsrescued/Documents/Resolution\%20A.920\%2822\%2 9.pdf (Consulta: 26 de enero de 2016)

${ }^{607} \mathrm{El}$ CSM de la OMI es un órgano de carácter técnico encargado de prestar asesoramiento a la OMI en el desempeño de sus funciones y de adoptar las modificaciones a las Convenciones que resulten pertinentes. ${ }^{608}$ Convenio SAR, art. 1.1

${ }^{609}$ SAR, art. 3.1.9, SOLAS regla 33.1-1
} 


\section{CAPÍTULO 5}

Una modificación importante se produjo en relación a la terminación de las operaciones de salvamento ${ }^{610}$. Con anterioridad a la reforma de 2004, el Convenio no recogía ninguna alusión al desembarco de las personas rescatadas, dejando a la consideración de los Estados la forma en que se produzca la finalización de las operaciones de salvamento, sea porque ha tenido éxito o porque ya no exista la situación de emergencia ${ }^{611}$. El Convenio recoge ahora la obligación de los centros coordinadores de salvamento de tener en consideración "el lugar o lugares más idóneos para desembarcar esas personas"612. Dada la vaguedad de la apelación a la "idoneidad", es necesario que los Estados tengan en cuenta con la obligación que nos hemos referido antes a llevar a las personas rescatadas a "un lugar seguro".

Así mismo, el convenio SAR establece la obligación de los Estados parte de proporcionar asistencia a cualquier persona que la necesite en el mar, con independencia de su nacionalidad, su condición jurídica o las circunstancias en las que fue encontrada, a asegurarse de que recibe una primera asistencia médica, o de otra naturaleza si la necesita, y a llevarlos a un lugar seguro ${ }^{613}$. Nótese que, en su apartado de definiciones, el Convenio usa el término "proporcionar asistencia" en lugar de "rescatar"614. El Convenio SOLAS recordaba la obligación de los capitanes de los buques a tratar a los rescatados "con humanidad, conforme a la capacidad y las limitaciones del buque"

Las reformas de 2004 tuvieron una importancia esencial al trasladar la responsabilidad primordial del destino de las personas rescatadas de los patrones de los buques a los Estados responsables de las áreas SAR. Como punto negativo, las obligaciones de los Estados ribereños son exclusivamente de coordinación y colaboración y, por tanto, escasamente comprometedoras. Además, las referencias a "las circunstancias particulares del caso" y al plazo "tan pronto como sea razonablemente posible" para llevar a cabo el desembarco, permiten a los Estados un amplio margen de apreciación y una escasa posibilidad de que su incumplimiento conlleve consecuencias. La necesidad de que los Estados tengan en cuenta a la hora de decidir el lugar del desembarco que éste sea un lugar seguro debe interpretarse no solamente en términos físicos y sanitarios, sino que debe incorporar estándares de derechos humanos y la protección frente a la devolución.

610 SAR, art. 4.8

${ }^{611} \mathrm{El}$ art. 1.3.10 la define de forma genérica, pudiendo significar una situación de incertidumbre, alerta o socorro.

${ }^{612}$ Ibíd., art. 4.8.5

${ }^{613}$ Ibíd., art. 1.3.2.

${ }^{614}$ Ibíd., art. 2.1.10

${ }^{615}$ SOLAS, art. 6, regla 33, cap. V 
Es interesante en este punto observar cuales fueron las posiciones de los países euromediterráneos en los debates internos de la $\mathrm{OMI}^{616}$. En calidad de estados ribereños y receptores de flujos migratorios por vía marítima, los gobiernos de España, Italia y Malta han participado activamente en los debates de los distintos órganos sobre salvamento y desembarco. Los dos primeros enviaron al subcomité sobre los buques de pabellón una nota conjunta ${ }^{617}$ en el que se quejaban de que "in the majority of the operations where Spanish- or Italian-flagged ships have been involved, the Governments responsible for the SAR regions, where persons have been rescued, have failed to provide a safe place for their disembarkation"618 lo que suponía que la responsabilidad de decidir el lugar seguro acababa recayendo en los buques encargados de las operaciones de salvamento o de interceptación, que en el Mediterráneo suelen ser guardias de frontera o pesqueros privados de ambos países. Por su parte, Malta presentó otro documento donde proponía como alternativa priorizar el criterio del puerto más cercano en la definición de lugar seguro, a la vez que rechazaba que los estados responsables de las áreas SAR asuman tareas e cuestión de desembarco. Conviene tener en cuenta que Malta se ha negado a aceptar las enmiendas a los convenios SAR y SOLAS de 2004.

\subsubsection{El desembarco en las fuentes auxiliares}

Las reformas de 2004 introdujeron disposiciones sobre una serie de requisitos que debían producirse en los desembarcos, y la responsabilidad de los Estados encargados de las áreas SAR. Sin embargo, no proporcionan una respuesta clara sobre cuál debe ser el puerto donde se desembarcan a las personas rescatadas en el mar. Tampoco sobre el alcance de las obligaciones de los Estados cuando son sus patrullas costeras las que han llevado a cabo las operaciones de salvamento. Acudamos a otras fuentes del derecho, aquellas no convencionales, para profundizar en la discusión:

a) La costumbre internacional. La práctica internacional dista de ser homogénea en lo que se refiere al desembarco de personas. A lo largo de los años se han producido ejemplos diversos, donde los rescatados son desembarcados en la siguiente escala de

${ }^{616}$ Trevisanut, S.: The Principle of..., op. cit., p. 531 y ss.

617 OMI: Measures to protect the safety of persons rescued at sea, Compulsory guideline for the treatment of persons rescued at sea, Sub-Committee on Flag State Implementation, presentado por España e Italia, sesión $\mathrm{n}^{\mathrm{o}}$ 17, 13 de febrero de 2009, Doc. FSI 17/15/1. Disponible en: http://www.sjofartsverket.se/pages/18709/17-15-1.pdf (Consulta: 26 de enero de 2016)

618 Ibid., p. 3-4. En concreto Italia recriminaba que 13.816 de las 22.754 personas rescatadas se encontraban en el área SAR de Malta, pero que su RCC no había emprendido ninguna acción ante esas emergencias. 


\section{CAPÍTULO 5}

la ruta, en el puerto más próximo, o incluso en puertos de países que no guardan relación con el caso (no son origen de los pasajeros, ni su pretendido destino, ni tenían jurisdicción sobre el territorio marítimo donde fueron rescatados) pero llegaron a algún tipo de acuerdo (por lo general, económico) para recibirles. En estos últimos casos, se ha demostrado que el lugar del desembarco no tiene por qué ser el mismo que provea de una solución a medio o largo plazo a aquellos rescatados que eran refugiados. La falta de una regla clara hace que la actuación de buques y Estados varíe considerablemente. El resultado dependerá en gran medida de cuestiones como la identidad de las personas, la jurisdicción que se aplique a las aguas rescatas, o incluso el clima político y mediático del país en ese momento.

La práctica marítima tradicional era la de desembarcar a las personas rescatadas en el siguiente puerto de escala o, si las circunstancias así lo precisaban, en el puerto más cercano ${ }^{619}$. Resulte difícil creer que esta regla consuetudinaria se mantenga hoy en día. Durante los últimos años hemos visto como los Estados ribereños se niegan a aceptar la entrada de buques en sus puertos cuando en ellos viaja un grupo de migrantes que pudieran solicitar asilo una vez llegado al territorio. En el ámbito geográfico del presente trabajo, el mar Mediterráneo, la mayor parte de los rescates son llevados a cabo por patrulleras de Estados europeos cuya misión consiste, de hecho, en impedir que puedan alcanzar sus costas. Especialmente cuando el rescate o intercepción se produce en aguas internacionales, los Estados son muy reluctantes a hacerse cargo de estas personas.

Desde un enfoque de derechos humanos esta práctica tampoco es defendible. El siguiente puerto de escala o el más próximo podría ser precisamente del país del que tratan de escapar los refugiados ${ }^{620}$, o de un país donde exista peligro de que sufran violaciones graves de derechos humanos o que pudiera entregarles a su país de origen, en caso de ser nacionales de terceros estados. Malta e Italia han tratado de emplear este criterio para devolver buques cargados de inmigrantes a las cosas de Libia.

Respecto de los Estados de pabellón, en ciertas ocasiones se han ofrecido a acoger $u$ ofrecer garantías de reasentamiento a los estados ribereños para que estos aceptaran el desembarco. Resulta dudoso suponer que esta práctica esporádica se

\footnotetext{
${ }^{619}$ Barnes, R.: Refugee Law... op. cit., p. 3

${ }^{620}$ Circunstancia bastante probable dado que la mayoría de los Estados ribereños del norte de África que son origen de las embarcaciones, son también emisores regulares de refugiados. En los últimos años, además, se han producido una serie de acontecimientos que han incrementado el número de personas que huyen de estos países, como el golpe de estado de Mauritania de 2008 o la guerra de Libia en 2011.
} 
haya transformado en costumbre internacional ${ }^{621}$. En el caso MV Tampa, Noruega acogió a varios refugiados debido a que el buque llevaba su pabellón, pero su acción se debió a una decisión política, fruto de las negociaciones con el gobierno australiano para desbloquear el problema. Noruega no justificó su decisión en el cumplimiento de unas normas o la costumbre internacional.

b) El soft law. La OMI ha venido elaborando desde hace décadas una serie de documentos relativos a la seguridad de la vida humana en el mar. Tal como en el derecho convencional, hemos visto un desarrollo positivo, aunque insuficiente, de la preocupación por la suerte de las personas rescatadas. El primer manual, MERSAR (1971) no incluía ninguna referencia al desembarco una vez se produjera el rescate. El Manual IAMSAR (1998) introdujo la responsabilidad del Estado responsable del área SAR de que el desembarco se produzca en un lugar seguro y tan pronto como sea razonablemente posible ${ }^{622}$, lo que significó un precedente a las reformas de 2004. El CSM aprobó el mismo año de las reformas de los convenios SAR y SOLAS las "Directrices respecto de la actuación con las personas rescatadas en el Mar" ${ }^{\prime 23}$, como complemento de éstas. Las Directrices tienen el objetivo de clarificar las modificaciones a los convenios, pero las disposiciones que se encuentran en el documento no tienen carácter preceptivo. Se inciden en la responsabilidad de las autoridades responsables de las regiones SAR añadiendo que "deben realizar todos los esfuerzos posibles a fin de acelerar los acuerdos para el desembarco de los supervivientes del buque"624. En 2007 la OMI de forma conjunta con ACNUR elaboraron una "Guía de referencia sobre los principios y prácticas aplicables a migrantes y refugiados" ${ }^{25}$. Al igual que las Directrices, eran de carácter no vinculante.

Por último, otro organismo de la OMI, el Comité de Facilitación (FAL) ${ }^{626}$, aprobó una circular en enero de $2009^{627}$ en la que se recogían cinco principios que

\footnotetext{
${ }^{621}$ Barnes, R.: Refugee Law... op. cit., n. 75, p. 8.

${ }^{622}$ OMI: Manual Internacional de los Servicios Aeronáuticos y Marítimos de Búsqueda y Salvamento (IAMSAR). Londres/Montreal, edición de 2007, Doc. 9731-AN/958, vol. III, apéndice A, art. 1.1.

${ }^{623}$ CSM: Resolución MSC.167(78), Guidelines on the Treatment of Persons Rescued At Sea, adoptada el 20 de mayo de 2004, en el $78^{\circ}$ periodo de sesiones del Comité, Anexo 34. Disponible en: http://www.refworld.org/docid/432acb464.html (Consulta: 26 de enero de 2016)

${ }^{624}$ Ibíd., art. 6.9

${ }^{625}$ OMI y ACNUR: Salvamento en el mar. Guía de referencia sobre los principios y prácticas aplicables a migrantes y refugiados, septiembre de 2006. Disponible en: http://www.acnur.es/PDF/4495 20120511132013.pdf (Consulta: 26 de enero de 2016)

$\overline{626}$ El Comité de Facilitación es un órgano subsidiario del Consejo de la OMI, encargado de reducir las formalidades y simplificar la documentación que se exige a los buques al entrar o salir de los puertos $\mathrm{u}$ otras terminales.
} 


\section{CAPÍTULO 5}

los Estados deberían incorporar a sus procedimientos administrativos para el desembarco de personas rescatadas en el mar con el fin de armonizar los procedimientos y hacerlos eficientes y predecibles:

1. Coordinar los servicios SAR con otras entidades encargadas de todo lo relacionado con el desembarco de las personas rescatadas.

2. Todas las actuaciones relativas a la identificación del estatus de las personas rescatadas deben llevarse a cabo tras el desembarco en un lugar seguro. El capitán del buque sólo debería solicitar información sobre el nombre, edad, sexo (o género en la versión en inglés), estado de salud y necesidades médicas. Se prestará especial atención a aquellas personas que manifiesten su voluntad de solicitar asilo, información que no se comunicará al país o países donde pudiera estar amenazada.

3. Se citan tres criterios a tener en cuenta para las partes interesadas: la rapidez, las preferencias del capitán y las necesidades básicas de las personas rescatadas. Así mismo, en caso de que el desembarco no pudiera organizarse rápidamente en ninguna otra parte, "el gobierno responsable de la zona SAR debería aceptar que el desembarco de las personas rescatadas tenga lugar (...) en un lugar seguro bajo su control, en el que dichas personas puedan tener pronto acceso a la asistencia posterior al rescate"

4. Se debería facilitar el retorno o repatriación de las personas rescatadas. Los solicitantes de asilo deberían ser transferidos a la autoridad responsable del examen de sus solicitudes.

5. Se recuerda el respeto al principio de non-refoulement.

La intención de esta circular era que estos principios, especialmente el tercero, fueran tomados en cuenta para una nueva reforma de SOLAS y SAR. Sin embargo, dichas enmiendas fueron rechazadas en marzo de 2010, en la $14^{\text {a }}$ sesión del COMSAR (siglas del Sub-Committee on Radiocommunications and Search And Rescue $)^{628}$.

${ }^{627}$ OMI: Principios relacionados con los procedimientos administrativos para el desembarco de personas rescatadas en el mar, Comité de Facilitación, 22 de enero de 2009, Doc. FAL.3/Circ.194. Disponible en: http://www.imo.org/en/OurWork/Facilitation/docs/FAL\%20related\%20nonmandatory\%20instruments/F AL.3-Circ.194.pdf (Consulta: 26 de enero de 2016)

${ }^{628}$ Coppens, Jasmine y Somers, Eduard: Towards New Rules on Disembarkation of Persons Rescued at Sea?, The International Journal of Marine and Coastal Law, $\mathrm{n}^{\circ}$ 25, 2010, pp. 377-403. Disponible en: www.vliz.be/imisdocs/publications/247597.pdf (Consulta: 26 de enero de 2016) 
El ACNUR, por su parte, ha propuesto que sean los Estados ribereños los que acepten el desembarco de las embarcaciones en peligro, y sean ellos mismos quienes se hagan cargo de las personas desembarcadas. En una conclusión de su Comité Ejecutivo reiteró que "es obligación humanitaria de todos los estados costeros permitir que las embarcaciones en peligro busquen refugio en sus aguas, y otorgar asilo, o al menos, refugio provisional, a las personas a bordo en busca de asilo"

d) La academia. Ante la falta de una normativa precise y vinculante, varios autores han analizado las distintas posibilidades para el desembarco y apostado por opciones concretas o propuesto alternativas. De acuerdo a Goodwin-Gill y McAdam $^{630}$, los Estados tienen diversas opciones ante un caso de rescate de inmigrantes irregulares y solicitantes de asilo que naufragan en el mar: a) pueden admitirle y procesar sus solicitudes en concordancia con la legislación doméstica sobre migración y asilo; b) pueden rechazar desembarcarlos y requerir al patrón del buque expulsarlos de su jurisdicción; y c) pueden permitir el desembarco tras obtener una garantía satisfactoria de reasentamiento por parte del estado del pabellón, otros estados u organizaciones internacionales como ACNUR. Para Goodwin Gill, el principio de responsabilidad del estado de pabellón es dudoso, y a pesar de que se trató (y sigue tratando) de una práctica común, no ha emergido a la categoría de costumbre internacional. Especialmente cuando el buque ha alcanzado el mar territorial de un Estado, lo que constituye un factor determinante bajo el derecho internacional para la asunción de responsabilidad del país ribereño.

Van Selm y Cooper también citan varias opciones: "the flag country of the rescuing ship; the closest land to where the rescue takes place; the next port of call on the rescuing ship's established route; the nation from which those rescued originally set out to sea" y señalan que ninguno esta claramente obligado por el Derecho Internacional como lugar de desembarco ${ }^{631}$. Barnes, por su parte, apuesta por que la opción del "next port of call (...) may be regarded as soft law" 632 .

e) Derecho comunitario. Ya hemos visto anteriormente el desarrollo normativo dentro de la Unión Europea que ha llevado a la adopción de normas sobre desembarco, y los conflictos políticos y judiciales debidos a la incorporación de

${ }^{629}$ ACNUR: Conclusión general n. ${ }^{\circ} 53$ (XXXIX) Los pasajeros clandestinos en busca de asilo, adoptada en el $39^{\circ}$ periodo de sesiones del Comité Ejecutivo, 1988, p. 1. Disponible en: http://www.acnur.org/Pdf/0564.pdf?view=1 (Consulta: 26 de enero de 2016)

${ }^{630}$ Goodwin-Gill, G. y McAdam, J.: The Refugee in..., op. cit., p. 278 y ss.

${ }^{631}$ Van Selm, J. y Cooper, B.: The New..., op. cit., p. 7

${ }^{632}$ Barnes, R.: Refugee Law... op. cit., p. 11 


\section{CAPÍTULO 5}

competencias tradicionalmente reservadas a los Estados. Aquí recogeremos otros documentos como guías y recomendaciones, elaboradas principalmente por Frontex y destinadas a sus JO.

La agencia aprobó en 2010 un par de documentos internos: las "Normas aplicables a las operaciones en las fronteras maritimas coordinadas por la agencia" y las "Directrices para las situaciones de búsqueda y salvamento y para el desembarco en el contexto de operaciones en las fronteras maritimas coordinadas por la agencia" ${ }^{\prime 33}$ Se establece allí la preferencia por desembarcar en el país de origen de la embarcación y, en el caso en que no fuera posible, en el estado miembro anfitrión ${ }^{634}$. Se recoge así mismo la norma de non-refoulement a las personas rescatadas, así como su derecho ser informadas, "con el fin de que puedan expresar las razones por las que creen que el desembarco en el lugar propuesto vulneraría el principio de no devolución" ${ }^{635}$ Sin embargo, incluso en esos casos Frontex sigue sin asegurar el desembarco en el país europeo ${ }^{636}$.

\subsubsection{El concepto de lugar seguro}

El Convenio SAR define "salvamento" como la "operación para rescatar a personas en peligro, prestarles los primeros auxilios médicos o de otro tipo y trasladarlas a un lugar seguro"637. La referencia al lugar seguro aparece en las obligaciones contenidas en el artículo 3.1.9 de SAR y la regla 33. 1-1 de SOLAS, si bien no contienen ninguna definición precisa. Las Directrices del CSM, citadas arriba, se encargaron de desarrollar el concepto. Lugar seguro se define como "un lugar en el que la vida de los supervivientes ya no está amenazada y donde pueden satisfacerse sus necesidades humanas básicas (tales como alimentación, abrigo y atención médica)"638. Un buque que presta auxilio no puede ser considerado un lugar seguro ${ }^{639}$ Sin embargo,

\footnotetext{
${ }^{633}$ Incluidas como anexos de la Decisión del Consejo 2010/252/UE.

634 Ibíd., parte II,aArt 2.1: "Sin perjuicio de la responsabilidad del Centro de Coordinación de Salvamento, y a menos que se especifique otra cosa en el plan operativo, convendrá dar prioridad al desembarco en el tercer país del que haya zarpado el buque en el que viajen las personas o en el tercer país por cuyas aguas territoriales o región de búsqueda y salvamento haya transitado dicho buque. Si ello resultara imposible, se dará prioridad al desembarco en el Estado miembro anfitrión, a menos que sea necesario actuar de otro modo para garantizar la seguridad de dichas personas."

635 Ibíd., parte I, art. 1.2

${ }^{636}$ Ibíd., parte II, art. 2.2; "La presencia de personas según lo dispuesto en la parte I, apartado 1.2, debe comunicarse al centro de coordinación, que deberá transmitir esta información a las autoridades competentes del Estado miembro anfitrión. Sobre la base de dicha información, el plan operativo debe determinar qué medidas subsiguientes pueden adoptarse."

${ }^{637}$ Convenio SAR, art. 1.3.2

${ }^{638}$ CSM: Resolución MSC.167(78), art. 6.12

${ }^{639}$ Ibíd., art. 6.13
} 
sí puede serlo una unidad de salvamento u otro buque adecuado "hasta tanto los supervivientes sean desembarcados en su próximo destino" ${ }^{404}$. Sería, por tanto, seguro de forma temporal, siempre que se produzca finalmente un desembarco en un destino que cumpla con las condiciones arriba expuestas y respete el principio de nonrefoulement.

Las directrices también incluyen la necesidad de evitar el desembarco en territorios en los cuales la vida y la libertad de dichas personas estén amenazadas ${ }^{641}$. En un apéndice a estas directrices se desarrolla más este enunciado, relacionándolo tanto con el artículo 33.1 CG51 como con la normativa internacional que prohíbe la devolución allá donde existan razones fundadas para pensar que exista un riesgo de que la persona sea torturada ${ }^{642}$. La sentencia del caso Cap Anamur, arriba citada, incorpora el respeto a los derechos humanos fundamentales dentro del concepto de "lugar seguro" 643

\subsubsection{La entrada a puerto para navíos en peligro}

Una cuestión que surge en el caso de los migrantes rescatados por buques privados, es el acceso al puerto para proceder al desembarco. Reconocido el deber de que este desembarco se produzca en un lugar seguro, desde el otro punto de vista existe la cuestión si el país costero está obligado a aceptar la entrada de dichos buques.

La apertura de los puertos a buques extranjeros entra dentro de las atribuciones soberanas de los Estados ribereños, siempre que este derecho se ejerza de acuerdo a la legislación interna y sin producir una discriminación arbitraria. Ante esto existe una excepción en la costumbre internacional ${ }^{644}$, por la cual los Estados están obligados a permitir la entrada de buques que se encuentren el peligro. La tradición se basa en dos justificaciones: una que emana de consideraciones humanitarias, y otra que reconoce que los marineros pueden encontrarse en ocasiones en situaciones más allá de su control. Este derecho se encuentra bien establecido en la costumbre internacional:

In summary, therefore, I am satisfied that the right of a foreign vessel in serious distress to the benefit of a safe haven in the waters of an adjacent coastal state is

\footnotetext{
${ }^{640}$ Ibíd., art. 6.14

${ }^{641}$ Ibíd., art. 6.17

${ }^{642}$ Ibíd., Apéndice “Algunas observaciones sobre legislación internacional aplicable”, p. 7

643 Tribunal de Agrigento, Sentencia del 7 de octubre de 2009, op. cit., p. 30

${ }^{644}$ Se pueden rastrear casos en la primera mitad del s. XIX, como los buques Enterprize y Creole. Vid. Brugmann, Gero: Access to Maritime Ports, Norderstedt, Book son Demand GMbH, 2003, pp. 114-115.
} 


\section{CAPÍTULO 5}

primarily humanitarian rather than economic. It is not an absolute right. If safety of life is not a factor, then there is a widely recognized practice amongst maritime states to have regard to their own interests and those of their citizens in deciding whether or not to accede to any such request [to enter port] ${ }^{645}$

El alcance exacto de esta garantía no está claramente definido en el Derecho del Mar, ni existe un consenso en el mundo académico sobre la definición de "buques en peligro" de cara a habilitar un derecho a entrada a puerto. La costumbre, por su parte, parece indicar que los Estados aceptan la entrada de estos buques únicamente cuando existe una amenaza apremiante sobre las vidas humanas de uno o varios pasajeros. Este carácter excepcional excluye, por ejemplo, la consideración de peligro por el hecho de que el buque no cuente con los requerimientos de seguridad precisos o esté ocupado por encima de sus capacidades ${ }^{646}$.

Hemos visto en ejemplos arriba mencionados, como los de MV Pinar o Cap Anamur, que la decisión de permitir la entrada de buques con migrantes irregulares y refugiados obedece a una decisión política de las autoridades, no al cumplimiento de una norma concreta. En dichos casos vimos como la aceptación por parte de las autoridades italianas del desembarco fue en gran medida el resultado de medidas de presión, cuestiones políticas o de imagen. Por su parte, el gobierno maltés siempre se ha posicionado más reacio ante la entrada de buques cargados de refugiados en sus puertos.

El rechazo al desembarco en sus puertos puede ser éticamente cuestionable, pero no equivale a la vulneración del principio de non-refoulement. Ante un rechazo a la entrada puerto, el buque puede dirigirse ante un país vecino, o los migrantes rescatados pueden ser trasladados al navío de un Estado que se haga responsable de la acogida de estos. En todo caso, el Estado ribereño debería asegurarse que el nuevo destino de los migrantes no sea un lugar donde estos puedan sufrir persecución, tortura u otros tratos crueles, inhumanos y degradantes.

Bajo una interpretación literal del artículo 33.1 de la Convención, sería ingenuo afirmar que existe una obligación automática a aceptar el desembarco de las personas rescatadas y admitirlas temporalmente con el propósito de examinar sus solicitudes de protección internacional. Para Barnes, "although the consequences of an absolute refusal to allow disembarking may be morally reprehensible (...) it does not of itself

\footnotetext{
${ }^{645}$ Barr J, de la Irish High Court of Admiralty, The MV Toledo [1995] 2 ILRM 30, at 48-9. (citado en Barnes, R.: Refugee Law... op. cit., p. 6)

${ }^{646}$ Esta es la interpretación del CDI, como ya vimos antes: supra n. 560
} 
amount to breach of the principle of non-refoulement or any other specific treaty norm. Refusal of entry does not automatically amount to refoulement" 647 .

Debemos reconocer que, por consiguiente, bajo la provisión del derecho de mar de acceso a puerto y refugio para las personas en peligro en el mar, el desembarco de refugiados no es una razón válida. La situación de los refugiados no puede ser considerada como en peligro de vida en lo que respecta a esta norma del derecho de mar y los Estados ribereños están, por tanto, en su derecho a rechazar su entrada. Un rechazo categórico del desembarco en sus costas de las personas rescatadas, como el llevado a cabo por Malta en los últimos años, no conlleva por tanto una ruptura de la norma de non-refoulement. Al respecto de esto Goodwin-Gill y McAdam han afirmado que el derecho de los refugiados "remains an incomplete legal regime of protection, imperfectly covering what ought to be a situation of exception" "48. Para estos autores, en contraposición a Barnes, la aplicación del principio de no devolución sí conllevaría al menos la admisión temporal con vistas a determinar el estatus de las personas rescatadas $^{649}$.

En 1997 los tribunales franceses juzgaron un caso relativo al rechazo de las autoridades portuarias de Honfleur al desembarco de dos polizones marroquíes, Ben Salem y Taznaret ${ }^{650}$. La acusación la presentó el dueño del barco, que invocó el derecho a la libertad ambulatoria de sus dos pasajeros, y el suyo a la propiedad. El tribunal local señaló que la autoridad competente había actuado dentro de sus atribuciones al negar la entrada, pero condenó el uso de la fuerza para prevenir el desembarco.

Bajo un enfoque integral de los derechos humanos, la opción de rechazar la entrada de un buque en el que viajen refugiados, incluso cuando no existan señales de peligro en la vida de los tripulantes o riesgos en el buque, y dejarlos en alta mar a la espera de encontrar mejor suerte en el siguiente puerto no es admisible. El Estado que ha llevado a cabo la operación de interceptación tiene una responsabilidad en la solución de la situación, ya sea de forma individual o cooperando con otros Estados como el responsable del área SAR, el del pabellón u otros EEMM si se trata de una JO de Frontex. Esta solución no tiene que pasar invariablemente porque sea el Estado ribereño

\footnotetext{
${ }^{647}$ Barnes, R.: Refugee Law... op. cit., p.8

${ }^{648}$ Goodwin-Gill, G. y McAdam, J.: The Refugee in..., op. cit., p. 1

${ }^{649}$ Ibíd., p. 215

650 Tribunal des conflits, sentencia del 12 de mayo de 1997, Préfet de police de Paris c. Tribunal de grande instance de Paris (Ben Salem et Taznaret case). Disponible en: http://www.legifrance.gouv.fr/affichJuriAdmin.do?idTexte=CETATEXT000007607110\&dateTexte= (Consulta: 26 de enero de 2016)
} 


\section{CAPÍTULO 5}

el que asuma las solicitudes de protección internacional, pero sí debe tener en cuenta que sus acciones $\mathrm{u}$ omisiones no lleven a que los tripulantes de la embarcación desembarquen en un territorio en el que puedan sufrir vulneraciones de derechos fundamentales, o desde el que sean deportados a sus países de origen o los que sufrieron persecución.

\subsubsection{Responsabilidades por incumplimiento}

De lo explicado arriba se deduce que los principales instrumentos internacionales de derecho internacional marítimo no fijan criterios que determinen de forma categórica qué Estado es el responsable de hacerse cargo del desembarco de las personas rescatadas. No obstante, si incluyen una serie de indicaciones que se deben tener en cuenta en cada situación:

- que el lugar de desembarco sea "un lugar seguro",

- que se respete "la seguridad y vida" de las personas rescatadas,

- existe una obligación de cooperar para determinar al Estado responsable de hacerse cargo de desembarcar a los supervivientes de una operación de rescate

- para el Estado responsable del área SAR, su deber es coordinar dicha cooperación y, en caso de no encontrar solución en un plazo razonable, desembarcarlos en su propio territorio.

Veamos ahora las responsabilidades en la que incurren los Estados por violaciones de las normas del Derecho del Mar, que como hemos visto comporta obligaciones tanto para los Estados ribereños como para los Estados del pabellón ${ }^{651}$ :

a) Buques y Estados del pabellón. Supongamos un caso donde se produzca el incumplimiento del principio de non-refoulement en un desembarco, mediante el cual un buque privado entrega a los migrantes rescatados ante las autoridades de un Estado en el que pueden sufrir persecución o ver vulnerados sus derechos fundamentales. En primer lugar, debemos distinguir entre las responsabilidades que emergen del Derecho del Mar, y en concreto de los convenios SAR y SOLAS, y de las que suscita el DIDH. Es evidente que en este supuesto se produce una violación de obligaciones internacionales de derechos humanos, y dado el carácter universal de la obligación de non-refoulement, está alcanzaría también a agentes privados. Pero la cuestión si lo es también según el Derecho del Mar resulta más controvertida.

${ }^{651}$ Aquí sigo el razonamiento de Papastavridis, E.: Rescuing..., op. cit., p.17 y ss. 
Un ejemplo de esto lo podemos ver en el caso Marine I. Se trataba de un barco en el que viajaban a bordo 372 inmigrantes, la mayoría de Bangladesh, que debido a una avería se encontraba a la deriva en el área SAR senegalesa. El 30 de enero de 2007 las autoridades de este país solicitaron asistencia que quedó a cargo del remolcador español Luz de Mar, de Salvamento Marítimo español. El Luz de Mar arrastró el Marine hasta el puerto más cercano, Nuadibú, pero las autoridades portuarias mauritanas les denegaron el permiso de entrada. El gobierno del país africano argumentó que era España quien debía hacerse cargo de los pasajeros, ya que era la autoridad que los habían rescatado y se hallaban bajo control efectivo de sus agentes. Tras diez días de negociaciones el gobierno mauritano aceptó su desembarco, siendo retenidos "en una antigua fábrica de pescado, sin poder salir a la calle, sin asistencia letrada, sin que nadie los pudiera asesorar sobre su derecho de asilo"652. A pesar de que había sido un buque de salvamento marítimo español y de que los migrantes se encontraron bajo su jurisdicción por diez días, en ningún caso se les aplico la legislación española, se les informó sobre sus derechos o la posibilidad de solicitar asilo ${ }^{653}$. Sin embargo, como señala Papastavridis ${ }^{654}$, la situación no generó una vulneración de ninguna norma del Derecho del Mar, en tanto en cuanto se produjo una operación de rescate y desembarco en un lugar seguro en el marco de una coordinación interestatal. No habría, por tanto, violación bajo el derecho del mar, pero sí del principio de no devolución.

Posteriormente, las víctimas llevaron el caso ante el Tribunal Supremo Español y ante el Comité contra la Tortura. En el primer caso, la denuncia atañía a la vulneración a la tutela judicial efectiva; en el segundo, tanto a las condiciones de los migrantes en la planta de procesado de pescado de Nuadibú, así como su posible exposición a la tortura y otros tratos crueles a los migrantes retornados a la India, violando la prohibición de refoulement contenida en el artículo 3 de la Convención. A pesar de que el CAT declaró el caso inadmisible, extendió la responsabilidad de España durante toda la operación marítima, reconociendo que había ejercido control sobre el buque y los pasajeros desde el rescate hasta la identificación individual de éstos y el procedimiento de repatriación, por lo que los denunciantes estaban sujetas a la jurisdicción española ${ }^{655}$. En cambio, el Tribunal Supremo realizó en su sentencia una interpretación de la jurisdicción puramente territorial. Negó vulneración alguna de sus derechos al considerar que los denunciantes se encontraban el extranjero, debiendo entrar a valorar únicamente si éstos

\footnotetext{
${ }^{652}$ Aldalur, M.: Clandestinos, op. cit., p. 47

${ }^{653}$ CEAR: Acceso a la protección ..., op. cit., p. 25

${ }^{654}$ Papastavridis, E.: Rescuing..., op.c it., p.20 y ss

655 CAT: J.H.A. c. España, 10 de noviembre de 2008, $\mathrm{n}^{\mathrm{o}}$ 323/2007, §8.2. Disponible en: http://docstore.ohchr.org/SelfServices/FilesHandler.ashx?enc=6QkG1d\%2fPPRiCAqhKb7yhssh2tXWBb yLwahMw00Sn91U0pRetxQ6\%2fdHVH4s16\%2fKIvHR0TYeh7FK7K7dtj9e1iRWh7soiJSy2H228vFHE R1VCsn8w7ea\%2bl1FlnU\%2f35\%2flvDg7jB4hG5ef63MPNv765m3Uv8B1mxa9ydvmQQHn9yPiw\%3d (Consulta: 26 de enero de 2016)
} 


\section{CAPÍTULO 5}

debieron haber sido trasladados a España y no las actuaciones de los agentes españoles en aguas internacionales o en Mauritania ${ }^{656}$.

El CAT estudió otra denuncia similar, el caso Sonko ${ }^{657}$. En la noche del 25 al 2 de septiembre de 2007, cuatro migrantes intentaban entrar a nado en la ciudad autónoma de Ceuta ${ }^{658}$ cuando fueron interceptados por el Servicio Marítimo de la Guardia Civil española. Tras subirlos a la propia embarcación, se acercó a unos metros de la orilla marroquí y arrojó a los cuatro al agua. Uno de ellos, Laucling Sonko, falleció ahogado. Sonko provenía de una Casamance, una región senegalesa donde existe un conflicto bélico desde hace décadas, lo que lo hacía susceptible de necesitar protección internacional ${ }^{659}$. Los guardias civiles no se dirigieron a los cuatro migrantes en ningún momento, realizaron ninguna identificación ni procedimiento administrativo de devolución. Tras intentar llevar la denuncia ante los tribunales españoles, el caso llegó al Comité, que encontró que los migrantes se encontraban bajo jurisdicción española, y los agentes españoles fueron encontrados responsables por los hechos.

Un supuesto diferente sería el de tratarse de un barco privado. ¿En qué supuestos serían atribuibles tales actos al capitán del buque, y en cuáles al Estado del pabellón que enarbola? Aquí la cuestión a dilucidar es si la conducta de los buques privados es atribuible al Estado del pabellón; la respuesta no es tan evidente como con los buques estatales. La Comisión de Derecho Internacional (CDI) adoptó en 2001 un documento sobre la "Responsabilidad del Estado por hechos internacionalmente ilícitos" que fue posteriormente aprobado por la $\mathrm{AGNU}^{660}$. El documento de la CDI establece responsabilidad estatal para "... el comportamiento de una persona o entidad que no sea órgano del Estado según el artículo 4, pero esté facultada por el derecho de ese Estado para ejercer atribuciones del poder público, siempre que, en el caso de que se trate, la persona o entidad actúe en esa capacidad"661. La cuestión de la "facultad para ejercer

\footnotetext{
${ }^{656}$ Tribunal Supremo, Sala de lo Contencioso, Sección $7^{\mathrm{a}}$, sentencia de 17 de febrero de 2010 (STS 833/2010).

Disponible

en: http://www.poderjudicial.es/search/doAction?action $=$ contentpdf\&databasematch $=$ TS\&reference $=507284$ $7 \&$ links $=\% 22548 \% 2 \mathrm{~F} 2008 \% 22$ \&optimize $=20100318$ \&publicinterface=true (Consulta: 26 de enero de 2016)

657 CAT: Sonko c. España, 25 de noviembre de 2011, $\mathrm{n}^{\circ}$ 368/2008. Disponible en: http://docstore.ohchr.org/SelfServices/FilesHandler.ashx?enc=6QkG1d\%2fPPRiCAqhKb7yhssh2tXWBb yLwahMw00Sn91VKy830Pq8xwfIFw3PpFVP3IB0NeM5Xq1DJ7JQju0husnVGrXMCaLsJ5ZFe9GO4A pajqmbN1CMDhci9ruZwPouJKk5zv\%2b8zeamWeo9tsuXeipxy8gsRF8gVODGtv2BjWos\%3d (Consulta: 26 de enero de 2016)

${ }^{658}$ Ceuta es una ciudad autónoma del Estado español situada en el norte de África, lo que la convierte en una entrada recurrente para los migrantes marroquís y subsaharianos.

${ }^{659}$ CEAR: Acceso a la protección..., op. cit., p. 17

${ }^{660}$ Informe de la Sexta Comisión del CDI (A/56/589) Resolución aprobada por la AGNU el 28 de enero de 2002. Disponible en: http://www.uib.cat/depart/dpu/dip/pdf/dip0607/responsabilidad.pdf (Consulta: 26 de enero de 2016)

${ }^{661}$ Ibíd., art. 5
} 
atribuciones del poder público" por parte de los buques que enarbolan el pabellón de un determinado Estado es principalmente una cuestión del derecho interno, sobre la que no existe una regulación internacional. Cada Estado observa y castiga pues, de forma diferente, los incumplimientos llevados a cabo por los buques de su pabellón.

Por otro lado, el documento se refiere a aquellas personas o grupo de personas que, sin ser órganos del Estado, actúan bajo sus instrucciones o dirección ${ }^{662}$. Este es el caso de aquellos barcos privados a los que desde una RCC se les efectúan órdenes para llevar a cabo una operación de salvamento. La respuesta se encontraría en la existencia y cumplimiento de instrucciones para que desembarcara por parte de las autoridades de este Estado al capitán del barco. Parece claro que es en este supuesto cuando es posible achacarle al Estado del pabellón la responsabilidad por actos ilegales según el Derecho del Mar. En el caso contrario, y tratándose de un buque privado, resulta más complejo aseverar un incumplimiento de la norma. Los capitanes y la tripulación de un buque pesquero o mercante no son agentes estatales. Están obligados a proporcionar un trato humanitario a las personas rescatadas, pero está obligación no se extiende a realizar un primer screening para determinar si son susceptibles de gozar de protección internacional, ni discutir sobre su estatus. Sin embargo, no parece razonable suponer que el patrón de un buque pueda decidir devolver las personas rescatadas al puerto más próximo sin tomar en consideración si éste entraña un peligro para su vida y seguridad. Los principios básicos que recoge el Derecho del Mar sobre la obligación de que el desembarco se produzca en un lugar seguro deben aplicarse también a los buques privados.

En cuanto a la responsabilidad de la naviera privada propietaria del buque, el Derecho Internacional no impone obligaciones a las compañías privadas ${ }^{663}$. El único documento existente en la actualidad consiste en guía de recomendaciones presentada por las Naciones Unidas en 2011 y denominada "Principios rectores sobre las empresas y los derechos humanos" $"$. Bajo este documento no vinculante, las navieras tendrían responsabilidades negativas, de "respeto" de los derechos humanos de las personas

\footnotetext{
${ }^{662}$ Ibíd., art. 8

${ }^{663}$ En 2014 el Consejo de Derechos Humanos aprobó una resolución que impulsaba la creación de un instrumento vinculante para las empresas transnacionales. Consejo de Derechos Humanos, Elaboración de un instrumento internacional jurídicamente vinculante sobre las empresas trasnacionales y otras empresas con respecto a los derechos humanos, $26^{\circ}$ periodo de sesiones, 25 de junio de 2014, Doc. A/HRC/26/LL.22/Rev.1. Disponible en: http://daccess-ddsny.un.org/doc/UNDOC/LTD/G14/064/51/PDF/G1406451.pdf?OpenElement (Consulta: 26 de enero de 2016)

${ }^{664}$ Principios rectores sobre las empresas y los derechos humanos. Puesta en práctica del marco de las Naciones Unidas para "proteger, respetar y remediar". Alto Comisionado de Naciones unidas para los Derechos Humanos, Ginebra, doc. HR/PUB/11/04, 2011. Disponible en: http://www.ohchr.org/Documents/Publications/GuidingPrinciplesBusinessHR SP.pdf (Consulta: 26 de enero de 2016)
} 


\section{CAPÍTULO 5}

rescatadas, entre los que se incluiría por tanto la prohibición de desembarcarles donde existiera un riesgo fundado de ser víctimas de persecución o violencia. La guía no incluye sanciones o un mecanismo de supervisión en caso de incumplimiento.

b) Estados costeros. La determinación de la responsabilidad ante violaciones del Derecho Internacional se presenta más clara en este supuesto. En el citado documento de la CDI, se establece la responsabilidad internacional de los órganos estatales, entre los cuales estarían los RCC que, como hemos visto, es la principal obligación en materia de rescate para los estados ribereños. Esto incluye a los buques que pertenecen al Estado_(barcos militares, patrullas fronterizas, de aduanas, etc...), y están comandados por un oficial público ${ }^{665}$. Es un principio arraigado en el Derecho Internacional que la conducta del oficial público actuando bajo sus atribuciones, es atribuible a su Estado incluso si dicha persona está actuando fuera del alcance de la propia ley doméstica o del ejercicio de las competencias que tenga asignadas ${ }^{666}$.

Varias son las circunstancias en las que se puede producir una vulneración de normas del derecho internacional por parte de los Estados costeros. Como vimos arriba, tras las reformas de los convenios SAR y SOLAS, a los Estados en cuyas áreas SAR se encuentra el buque en peligro corresponde la responsabilidad principal de asegurarse que las personas rescatadas sean entregadas en un lugar seguro, ya sea el medio un buque estatal o uno privado que siga las órdenes del RCC. Una decisión de dicho Estado por la que el desembarco se produzca en un país en el que pudieran sufrir persecución, tortura o tratos crueles, inhumanos y degradantes, o fueran expulsados a un tercer país donde sufrieran estas violaciones de sus derechos fundamentales, conllevaría una vulneración tanto de las normas del Derecho del Mar como del principio de nonrefoulement.

La responsabilidad es también atribuible a los Estados costeros donde se produce el desembarco. En el caso del Marine I, España como Estado del pabellón fue considerado responsable de la protección de derechos de los migrantes, al ejercer su jurisdicción sobre ellos desde el salvamento hasta el posterior desembarco. Pero eso no exonera de

\footnotetext{
${ }^{665}$ Entendiendo como tal lo establecido por el art. 4 de los artículos del CDI al que nos hemos referido antes:

1. Se considerará hecho del Estado según el derecho internacional el comportamiento de todo órgano del Estado, ya sea que ejerza funciones legislativas, ejecutivas, judiciales o de otra indole, cualquiera que sea su posición en la organización del Estado y tanto si pertenece al gobierno central como a una división territorial del Estado.

2. Se entenderá que órgano incluye toda persona o entidad que tenga esa condición según el derecho interno del Estado.

${ }^{666}$ Ibíd., art. 7
} 
sus obligaciones internacionales al Estado donde el desembarco se produjo. En este caso, Mauritania no sólo falló en proveerles de asistencia adecuada, sino que los expulsó a la India sin el debido examen individual de cada caso.

\subsection{Las interceptaciones marítimas}

El Derecho del Mar tiende a considerar la cuestión del desembarco como anexa a las operaciones de salvamento y rescate a embarcaciones y personas en peligro. Sin embargo, en muchas ocasiones las embarcaciones en las que viajan los migrantes no son rescatadas sino interceptadas por patrulleras de los Estados durante sus labores de vigilancia fronteriza. Bajo los argumentos de combatir el tráfico y la trata de seres humanos, salvaguardar la vida de las personas en el mar y controlar sus fronteras ${ }^{667}$, los Estados han adoptado la práctica de interceptar a las personas que viajan por vía marítima de forma irregular, ya sea en sus aguas territoriales, en alta mar, o en las propias aguas del país de origen.

La interceptación es una reacción ante los intentos de entrada por vía marítima de migrantes irregulares - una reacción por la que los Estados se oponen a esta práctica y tratan de eliminarla o, al menos, disminuirla. Dado que los Estados suelen contar con acuerdos con los países de origen que permiten la readmisión de sus nacionales, el objetivo de estas prácticas es evitar los costes derivados de la recepción y expulsión de los inmigrantes irregulares y, sobre todo, impedir que aquellas personas susceptibles de obtener protección internacional puedan llegar al territorio del país de destino y solicitar asilo en él. Adicionalmente, sitúan las prácticas de control fronterizo más allá de la vista pública, dificultando el control democrático y la vigilancia de los derechos de los migrantes por parte de otras instituciones y organizaciones de derechos humanos. Algunos autores han denunciado que la vigilancia fronteriza extraterritorial está socavando el sistema de protección internacional ${ }^{668}$. Como vimos antes, una de las consecuencias del incremento de la presencia policial marítima ha sido el desplazamiento de los puntos de partida de las embarcaciones, alejándose progresivamente de las costas europeas, lo que incrementa los riesgos del viaje. El

\footnotetext{
${ }^{667}$ Vid. Reglamento (UE) n ${ }^{\circ}$ 656/2014, en cuyo considerando 1 figura la siguiente definición: "El objetivo de la política de la Unión en el ámbito de las fronteras exteriores de la Unión es garantizar el control eficaz del cruce de las fronteras exteriores, inclusive mediante la vigilancia de fronteras, contribuyendo al mismo tiempo a proteger y a salvar vidas."

${ }_{668}$ Nessel, Lori: Externalized Borders and the Invisible Refugee, Columbia Human Rights Law Review, Vol. 40, No. 625, 2009. Disponible en: http://www3.law.columbia.edu/hrlr/hrlr journal/40.3/Nessel.pdf (Consulta: 27 de enero de 2016)
} 


\section{CAPÍTULO 5}

Consejo de Europa ${ }^{669}$ señaló cinco preocupaciones emergentes sobre las prácticas de interceptaciones que llevaban a cabo los Estados europeos:

1. Las diferentes interpretaciones sobre los derechos y obligaciones de Estados e individuos, especialmente en la aplicación del principio de non-refoulement en alta mar;

2. El concepto de "lugar seguro" tampoco es interpretada de la misma forma por todos los EEMM. El Consejo recalca aquí que no debería ser restringido únicamente a la protección física de las personas, sino que debería incluir el respeto para sus derechos fundamentales;

3. Estas discrepancias tienen un efecto directo que pone en peligro las vidas de migrantes y refugiados en el mar, en particular al retrasar o soslayar actuaciones urgentes de salvamento;

4. En las operaciones de vigilancia bajo el mando de Frontex existen unas inadecuadas garantías por los derechos humanos; y

5. Las llegadas marítimas crean una carga desproporcionada en los Estados mediterráneos, siendo necesaria una mayor solidaridad entre Estados europeos.

Las operaciones de interceptación se producen en un terreno de cierta ambigüedad jurídica. En el Mediterráneo muchas de estas operaciones se realizan de forma conjunta por varios Estados europeos, o por un Estado europeo y otro africano, pudiendo ser además coordinadas por FRONTEX. Territorialmente, la interceptación puede producirse en algunas de las zonas marítimas donde los Estados ejercen su soberanía o en alta mar. Si la operación implica el rescate de estas personas, hay que tener en cuenta el Estado responsable del área SAR también. Respecto a las personas implicadas, en estas embarcaciones puede viajar migrantes irregulares, refugiados y otras personas susceptibles de algún tipo de protección subsidiaria, familias, menores no acompañados, víctimas de redes de trata de personas, así como los propios miembros de las redes de trata de personas o contrabandistas. En todo este complejo escenario, varios estados pueden compartir la jurisdicción y la responsabilidad de los pasajeros. No obstante, en la práctica este laberinto les proporciona una excusa a los Estados para evitar hacerse responsable o tratar de evadir sus responsabilidades, traspasándolas a otros Estados (generalmente, a los africanos) o a la Unión Europea.

${ }^{669}$ Consejo de Europa, "The interception and rescue at sea of asylum seekers, refugees and irregular migrants”, Resolución 1821 (2011) de la Asamblea Parlamentaria, para.5. Disponible en: http://assembly.coe.int/nw/xml/XRef/Xref-XML2HTML-EN.asp?fileid=18006\&lang=en （Consulta: 27 de enero de 2016) 


\subsubsection{Definiciones}

La escasez de normativa internacional relacionada con la interceptación marítima, en tanto se considera una función de control fronterizo derivada de la soberanía estatal, implica la falta de una definición jurídica internacionalmente aceptada de interceptación ${ }^{670}$. Las definiciones ahora explicadas no son más que descripciones más o menos acertadas de las prácticas reales de los Estados.

Una ponencia de ACNUR en el año $2000^{671}$ definió las interceptaciones como "todas aquellas medidas aplicadas por un Estado fuera de su territorio nacional con el fin de prevenir, interrumpir o detener el movimiento de personas sin la documentación requerida a través de fronteras internacionales por tierra, aire o mar, rumbo al potencial país de destino" ${ }^{\text {672 }}$. Parece una definición poco acertada, dado parece presuponer que las autoridades conocen la situación administrativa de los pasajeros de la embarcación antes incluso de que sea interceptada. Además, la expresión "fuera de su territorio nacional" parece excluir de éste sus aguas territoriales, algo incorrecto. La ponencia trata de aclarar algo más al describir el contexto en el que se producen:

La práctica puede ocurrir por medio de la interceptación física o, como a veces se la llama, interdicción de navios que se sospecha transportan migrantes irregulares o solicitantes de asilo. Algunos países tratan de interceptar barcos empleados para el tráfico de migrantes o solicitantes de asilo lo más lejos posible de sus aguas territoriales. Luego de la interceptación, se desembarca a los pasajeros, ya sea en territorios dependientes del país interceptor o en el territorio de un tercer país que acepte su desembarco. En la mayoría de los casos, el objetivo tras la interceptación es la devolución sin demora de todos los pasajeros irregulares a su país de origen. ${ }^{673}$

\footnotetext{
${ }^{670}$ ¿Interceptación o intercepción? Ambos términos son usados con el mismo significado en diferentes documentos legales, académicos o periodísticos. El diccionario de la RAE solamente reconoce "interceptación", pareciendo provenir la segunda de una traducción errónea de la inglesa interception. En el presente trabajo emplearé la primera, aunque mantendré las citas originales.

${ }^{671}$ ACNUR: La interceptación de solicitantes..., op. cit. Esta ponencia generalizaba las interceptaciones a partir del tráfico de migrantes, considerando de entrada que todos los migrantes indocumentados, incluidos los solicitantes de asilo, incidiendo en su criminalización. Por ejemplo, el uso continuo del término "refugiado genuino", o en el para. 15: "Muchos de los solicitantes de asilo indocumentados resultan ser personas con movimientos irregulares, es decir, refugiados que ya han obtenido protección en otro país y para quienes la protección sigue disponible. La percepción se está difundiendo, sobre todo en los paises tradicionales de reasentamiento, de que tales refugiados buscan esquivar los canales establecidos de reasentamiento, recurriendo a los servicios de los traficantes."

${ }^{672}$ Ibíd., para. 10

${ }^{673}$ Ibíd., para. 12
} 


\section{CAPÍTULO 5}

Posteriormente, en la Conclusión $n^{\circ} 97$ (LIV) de 2003 ${ }^{674}$, el ACNUR trato de reformular su definición de interceptaciones como "una de las medidas empleadas por los Estados para:

i) Impedir que las personas inicien un viaje internacional;

ii) Impedir otros desplazamientos internacionales de las personas que han comenzado su viaje;

iii) Controlar los buques respecto de los cuales haya motivos razonables para pensar que transportan personas en contravención del derecho marítimo nacional o internacional.

Por su parte, la Decisión del Consejo que reformaba el SBC incluyó una detallada serie de medidas en las que pueden consistir las interceptaciones llevadas a cabo en operaciones de vigilancia ${ }^{675}$ :

a) solicitar información y documentación sobre la propiedad, la matrícula y la travesía del buque, asi como sobre la identidad, la nacionalidad y otros datos pertinentes de las personas a bordo;

b) detener y abordar el buque, registrar el buque y su carga, y registrar e interrogar a las personas a bordo;

c) informar a las personas a bordo de que carecen de autorización para cruzar la frontera y de que quienes guían el buque pueden ser sancionados por facilitar el viaje;

d) apresar el buque y prender a las personas a bordo;

e) ordenar al buque que altere su rumbo para salir de las aguas territoriales o la zona contigua o evitar entrar en ellas, escoltándolo o navegando junto a él hasta que tome el rumbo correcto;

f) conducir el buque o las personas a bordo a un tercer país o, alternativamente, entregar el buque o las personas a bordo a las autoridades de un tercer país;

g) conducir el buque o las personas a bordo al Estado miembro anfitrión o a otro Estado miembro participante en la operación.

\footnotetext{
674 ACNUR: Conclusión $\mathrm{N}^{\circ} 97$ (LIV) sobre las salvaguardas de protección de las medidas de intercepción, $54^{\circ}$ periodo de sesiones del Comité Ejecutivo, 2003. Disponible en: http://www.acnur.org/t3/fileadmin/Documentos/BDL/2003/2411.pdf?view=1 (Consulta: 27 de enero de 2016)

${ }^{675}$ Decisión 2010/252/UE, Anexo 1, art. 2.4
} 
Para este trabajo preferimos usar la definición de Van Selm y Cooper ${ }^{676}$, más concreta: la interceptación se produce cuando agentes estatales localizan un bote, se anteponen a su trayectoria, y o bien acogen a las personas a bordo en su propia embarcación, los acompañan a otro buque o a un puerto, o fuerzan una modificación de su rumbo. Esta acción puede ocurrir tanto en aguas territoriales de un Estado como en Alta Mar.

\subsubsection{Servicios de salvamento y fronterizas}

Cómo vimos en el punto anterior, el Derecho del Mar impone a los estados una serie de obligaciones relacionadas con la creación de servicios de búsqueda y salvamento para los buques y personas que se encuentran en situaciones de peligro en la mar. Esta obligación implica, así mismo, la de cooperar con otros estados cuando sea necesario.

Los Estados ribereños, a su vez, establecen servicios fronterizos para gestionar la entrada y paso de buques (y de sus pasajeros) por sus zonas marítimas, así como su entrada a puerto. Los derechos de los Estados a controlar los buques y las personas que acceden a sus mares territoriales están claramente estipulados en el Derecho del Mar.

Debido a la similitud de tareas, las labores de salvamento y rescate (SAR) pueden encontrarse integrados en los servicios fronterizos estatales. Los mismos agentes (de frontera, carabinieri, guardias civiles) suelen ocuparse de ambas tareas, sean tanto de rescate como de interceptación. Esta es una de las razones que explica que, en la práctica, interceptación y rescate se confundan y sea difícil establecer una línea de demarcación.

Las interceptaciones, como recuerdan Van Sem y Cooper $^{677}$ se adelantan a los rescates, en tanto que no se precisa una necesidad real de salvaguardar la seguridad de una embarcación y de sus tripulantes. No obstante, en muchas ocasiones, lo que se inició como una operación de interceptación se convierte en una de salvamento cuando las patrullas descubren el estado de peligro de la embarcación o sus tripulantes.

En la práctica, la determinación por las autoridades responsables del tipo de operación que deben lanzar no se encuentra debidamente codificada. Valga el ejemplo de lo sucedido en un par de incidentes en julio de 2012, donde dos embarcaciones con

${ }^{676}$ Van Selm, J. y Cooper, B.: The New..., op. cit., p. 5

${ }^{677}$ Ibíd., p. 31 y ss. 


\section{CAPÍTULO 5}

más de 120 migrantes cada una permanecieron varadas cerca de la costa italiana durante días hasta que fueron interceptados por una patrulla de la JO AENEAS. Las autoridades italianas habían detectado las embarcaciones con anterioridad, pero no consideraron que unas pequeñas pateras atestadas con centenares de personas, incluidos menores, era una situación suficiente para poner en práctica una operación de salvamento ${ }^{678}$.

\subsubsection{El principio de non-refoulement en la interceptación}

El derecho de los Estados de vigilar sus fronteras, y de autorizar y denegar la entrada al país a los extranjeros se encuentra limitado por una serie de circunstancias y normas del DIDH. Entre ellas ocupa especial importancia el principio de nonrefoulement. En el caso de las fronteras marítimas las interceptaciones y operaciones de push back son prácticas concretas donde este principio se encuentra en peligro. En este escenario interseccionan tres ejes normativos que afectan al alcance y los límites del principio de non-refoulement: el contenido de dicho principio según el Derecho de los Refugiados y el DIDH, la soberanía estatal en materia fronteriza y migratoria, y el Derecho del mar.

Partiendo del ámbito territorial que presenta en el CG51, se concluye que los derechos contenidos en dicho tratado, incluidos los del artículo 33.1 son aplicables en el mar territorial y la zona contigua de los Estados ribereños, ya que forman parte del territorio soberano. Eso no implicaría que cualquier práctica de intercepción marítima implique una ruptura del principio de no devolución. Tal como señala Proelss, "it is difficult to see how a "mere" towing back of a ship to the high seas, if viewed individually, could result in a threat of life or freedom on account of "race, religion, nationality, membership of a particular social group or political opinion",679.

Las operaciones de interceptación marítima, en muchas ocasiones, impiden llegar a su destino a refugiados y solicitantes de asilo. Los mayores impedimentos se producen cuando la interceptación se lleva a cabo en alta mar o en las aguas territoriales del Estado de origen. Los migrantes son escoltados a las costas del país de origen o a un

\footnotetext{
${ }^{678}$ Martin, Marie: Violations of the rights of migrants and refugees at sea. Priorising border control over human rights. Copenhague, Euro-Mediterranean Human Rights Network, junio de 2014, p. 9. Disponible en: http://www.statewatch.org/news/2014/jul/eu-migrants-at-sea.pdf (Consulta: 27 de enero de 2016)

${ }^{679}$ Proelss, Alexander: Rescue at sea: What Obligations exist Towards Refugees?, Scandinavian Institute of Maritime Law Yearbook 2008, p. 22. Disponible en: https://www.wsi.unikiel.de/de/lehre/vorlesungen/archiv/ss-

2010/proelss/seerecht/seerecht/materialien/Rescue\%20at\%20Sea\%20\%28Paper\%29.pdf (Consulta: 27 de enero de 2016)
} 
buque patrulla de estos. Lo que nos lleva cuestionar la devolución de los migrantes y refugiados interceptados a los países de donde zarparon. Como hemos visto cuando hemos tratado el tema de la territorialidad y la jurisdicción, el principio de nonrefoulement no se encuentra limitado por barreras geográficas. El ACNUR ha recordado las responsabilidades de los Estados interceptores en relación a la protección y respeto de los derechos humanos de los refugiados y solicitantes de asilo interceptados, incluidos el derecho a la vida y el derecho a no ser sometido a tortura u otros tratos o penas crueles, inhumanos o degradantes, el acceso a la protección internacional, la protección frente a la devolución a territorios donde su vida o libertad se vea amenazada, y la prohibición de ser sancionados por su entrada o ilegal ${ }^{680}$. Argumentar que retornar refugiados interceptados en alta mar o impedir su salida de las aguas territoriales del Estado que pretenden huir no supone ninguna vulneración de derechos humanos y de los refugiados, sería desvirtuar los objetivos y principios en que estos se basa la CG51 y las principales normas del DIDH: la humanidad y la dignidad de todas las personas.

Los migrantes interceptados en el mar pueden ser refugiados que deben tener acceso al procedimiento de asilo. Dado que el destino de las personas interceptadas en el mar es incierto para éstas, los primeros pasos de detección o screening de posibles necesidades de protección debería producirse en el mismo buque, bien mediante la petición formal por parte de un individuo o la expresión de algún temor a ser perseguido o sufrir violaciones de derechos humanos en el país de origen. La misma cuestión debe ser tenida en cuenta cuando se trata de menores de edad, personas enfermas, mujeres embarazadas, u otros grupos vulnerables. Este procedimiento, no obstante, no puede utilizarse como una identificación 'exprés' para distinguir entre personas migrantes y potencias beneficiarias de protección internacional, sobre todo si se realiza a base de la existencia o no de una petición de asilo formal. Las personas que acaban de ser rescatadas en el mar no se encuentran en una condición de la que se pueda esperar que vayan a solicitar de forma inmediata asilo. En ocasiones, puede que no conozcan siquiera que tienen derecho a ello. En cualquier caso, las personas rescatadas o interceptadas deben ser llevadas a un lugar donde puedan producirse un reconocimiento de su situación personal y necesidades, con respeto absoluto a sus derechos humanos. De acuerdo a la Directiva de Procedimientos, los solicitantes de asilo tienen derecho a permanecer en el territorio del Estado que se ocupa de su examen, hasta que las autoridades hayan tomado una decisión definitiva ${ }^{681}$.

${ }^{680}$ ACNUR: Conclusión no 97, supra n. 670

${ }^{681}$ Directiva 2013/32/UE, art. 9 


\section{CAPÍTULO 5}

Las medidas disuasivas de carácter indiscriminado no pueden justificarse bajo la excusa de que los refugiados forman parte flujos mixtos. El principio de nonrefoulement no admite excepciones debido a los costes que los Estados deben asumir por su identificación, incluso en aquellos casos en los que uno de cada diez (o cien) inmigrantes sea realmente un refugiado. Los estados no pueden sortear sus obligaciones de protección simplemente negándose a aceptar las solicitudes de asilo o rechazándolas de forma generalizada. Para Hathaway, "Measures which deter refugee claimants from arriving in an asylum state are therefore no less in breach of refugee law than is the removal of a recognised refugee already present in a state's territory" ${ }^{682}$

La normativa europea sobre interceptaciones fronteras, incluyendo las regulaciones de Frontex, incluyen la obligación de respetar el principio de no-devolución. El Código de fronteras Schengen, establece que las actividades de gestión de fronteras deben respetar el principio de no devolución ${ }^{683}$. A pesar de esta disposición, Frontex se escuda en una visión restrictiva sobre la naturaleza de las funciones para evitar cualquier referencia al asilo dentro del desarrollo de sus operaciones. Las entrevistas que realizan sus oficiales tienen como fin averiguar datos sobre el tráfico de personas o las rutas migratorias, o sirven de apoyo a las autoridades nacionales en la determinación de la identidad y nacionalidad. En una respuesta oficial, la explicación de Frontex era la siguiente:

FRONTEX experts, deployed in the framework of the Joint Operations only interview part of the persons arrived and interviews are carried out for intelligence purposes only...As regards the asylum claims, so far as FRONTEX is not aware of any claims of any claims of asylum which have been submitted to the national authorities during the referred joint operations. Nevertheless, it could be the case, that hosting Member State[s] could receive asylum claims later on, just after the interrogation. $^{684}$

Tampoco se incluyen estadísticas en sus informes o memorias anuales de cuantas personas rescatadas en sus JO solicitaron asilo. Sí que ofrece estadísticas sobre la nacionalidad de las personas entrevistadas. Por ejemplo, en la operación NAUTILUS los países con más representantes eran Somalia (3.578), Eritrea (2.925), Pakistán (182)

\footnotetext{
${ }^{682}$ Hathaway, James: The false panacea of offshore deterrence, Forced Migration Review $n^{\circ} 26,2006$, $p$. 57. Disponible en: http://www.fmreview.org/FMRpdfs/FMR26/FMR2632.pdf (Consulta: 27 de enero de 2016)$$
{ }^{683} \text { Reglamento (UE) 610/2014, art. 12, en relación con el art. } 3 \text { y 3.a) }
$$$$
{ }^{684} \text { Guild, E. y Bigo, D.: The Transformation... op. cit., p. } 16
$$ 
e Iraq (126). Los cuatro países están también entre los primeros en número de solicitantes de asilo en la Unión Europea.

El Código de Conducta para las Operaciones de Retorno de FRONTEX identifica dos supuestos que obligarían a la interrupción o cese de una operación: que la continuación de la operación sea considerada insegura por el capitán de la embarcación, el jefe de operaciones o la propia Agencia, o por violaciones de derechos fundamentales durante la propia operación ${ }^{685}$. Esta cláusula permitiría un medio por el que exigir el respeto al principio de non-refoulement en las operaciones de la Agencia.

\subsubsection{Las interceptaciones según las diferentes zonas marítimas}

\subsubsection{Mar territorial}

El mar territorial, que incluye la zona marítima situada desde la costa hasta las 12 millas náuticas, es un área de soberanía plena estatal ${ }^{686}$. Los buques de terceros estados tienen libertad para navegar por estas aguas, en las que el Estado ribereño no puede obstaculizar el paso de los buques extranjeros ${ }^{687}$. Así mismo, el derecho de paso inocente establece que cualquier buque puede navegar por el mar territorial sin entrar o dirigirse a las aguas interiores, hacer escala en una rada o puerto ${ }^{688}$. El derecho de paso inocente no va acompañado de un derecho absoluto a la entrada a puerto, en caso de que el buque en concreto no se encuentre en una situación de peligro ${ }^{689}$. Conviene tener en cuenta que el artículo 17 se refiere a los buques de todos los Estados, por lo que parecería excluir a los buques que no enarbolen ninguna bandera. Esto incluiría pateras y cayucos, pero no todos los buques en los que viajan los migrantes, ya que en ocasiones suelen utilizar pesqueros adquiridos por los tratantes. Por lo tanto, prácticas como visitar un buque sin pabellón o escoltarlo hasta llevarlo fuera del mar territorial son legales bajo el Derecho del Mar, siempre que la embarcación no se encuentre en peligro y sea pertinente una operación de salvamento.

La base legal para realizar una acción de interceptación está en el artículo 19.2 UNCLOS, cuyo apartado (g) excluye del pase inocente al "embarco o desembarco de

\footnotetext{
${ }^{685}$ Frontex: Código de Conducta para las Operaciones de Retorno, art. 4.3

686 UNCLOS, art. 2.1

687 Ibíd., art. 24

688 Ibíd., art. 18

689 Ibíd., art. 18.2
} 


\section{CAPÍTULO 5}

cualquier producto, moneda o persona, en contravención de las leyes y reglamentos aduaneros, fiscales, de inmigración o sanitarios del Estado ribereño" Así mismo, se regula el paso inocente en lo relativo a "la prevención de las infracciones de sus leyes y reglamentos aduaneros fiscales, de inmigración y sanitarios" ${ }^{960}$. En tales supuestos de paso no inocente, la circulación de la embarcación puede ser obstaculizada o suspender completamente el paso inocente si fuera necesario por motivos de seguridad nacional ${ }^{691}$. En un caso extremo, puede ejercer su jurisdicción penal en casos excepcionales, si el delito tiene consecuencias en el Estado ribereño o puede perturbar la paz del país o el buen orden del mar territorial ${ }^{692}$. No parece razonable que la entrada de una embarcación con una decena de migrantes que llevan días a la deriva en el mar pueda suponer una amenaza de este tipo.

En la práctica, la entrada de un buque sin pabellón cuyos tripulantes son migrantes irregulares puede dar lugar a dos situaciones dependiendo de dónde se realice la operación de intercepción. En el primer caso, el buque ya ha cruzado indudablemente las 12 millas que delimitan las aguas territoriales y se dirige a las costas con el fin de desembarcar. Las autoridades estatales consideran la acción como una infracción a las leyes migratorias y un cruce ilegal de la frontera a través de su mar territorial. Entre las medidas destinadas a interrumpir el paso inocente, se incluye la expulsión del buque de su territorio. Sin embargo, al reconocer el acto ilícito, el Estado reconoce implícitamente que el buque se encuentra dentro de su territorio y, por lo tanto, se halla bajo su jurisdicción. Los pasajeros del mismo tendrían, por consiguiente, garantizados por los derechos fundamentales y las obligaciones internacionales que corresponden a los Estados respecto de todas las personas que se hallen bajo su jurisdicción. Entre ellas, por supuesto, la prohibición de expulsarles a países en los que pudieran ser objeto de persecución, torturas o tratos crueles, inhumanos y degradantes. En su análisis del caso MV Tampa, Barnes argumentó que "unless it can be shown that the passage was not innocent, or that the right of innocent passage had been suspended, then the Tampa are entitled to exercise the right, and Australia refusal to allow the vessel entry into Australian waters is clearly unlawful" ${ }^{693}$. Para este autor, si el Estado interpreta que el paso de un buque es no inocente, esto es, perjudicial para la paz, el buen orden o la seguridad del Estado, en base a la presunción del estatus ilegal de las personas embarcadas sin efectuar un debido proceso legal de identificación, sería una acción que contravendría la CG51.

El otro supuesto ubicaría la situación en las mismas fronteras del mar territorial. Allí el Estado podría optar por rechazar la entrada mediante una opción de bloquear la ruta

\footnotetext{
${ }^{690}$ Ibíd., art. 21.1.h

691 Ibíd., art. 25

692 Ibíd., art.27.1

${ }^{693}$ Barnes, R.: Refugee Law... op. cit., p. 5
} 
de la embarcación con uno o más de sus buques. En este supuesto, los pasajeros del buque no han entrado en el territorio del Estado ribereño, ni se haya bajo la jurisdicción de éste. Sin embargo, esto no elimina totalmente las obligaciones de los Estados, como veremos a continuación.

\subsubsection{Zona contigua}

La zona contigua se extiende hasta las 24 millas, y en ella el Estado ejerce una soberanía limitada, y goza de una naturaleza puramente funcional. Las competencias de los Estados se limitan a aquellas medidas de fiscalización necesarias para "a) Prevenir las infracciones de sus leyes y reglamentos aduaneros, fiscales, de inmigración o sanitarios que se cometan en su territorio o en su mar territorial; b) Sancionar las infracciones de esas leyes y reglamentos cometidas en su territorio o en su mar territorial" ${ }^{\prime 694}$.

Tanto las funciones de prevención y sanción que permite el texto del artículo se refieren a infracciones cometidas en el territorio o el mar territorial del Estado. Parece razonable suponer que la entrada de una embarcación de la cual existan razones fundadas que transporta inmigrantes irregulares entraría dentro del alcance del artículo. Sin embargo, la presencia de migrantes irregulares e incluso tratantes no excluye la presencia de personas que pudieran ser refugiadas o pertenecientes a otros grupos vulnerables, como MENAs, embarazadas o enfermos.

El ejercicio de la función preventiva incluida en el apartado a) da lugar a una serie de preguntas. Una acción que viole la legislación migratoria nacional solo puede producirse cuando ya se han traspasado las fronteras territoriales del Estado. Cuando se trata de migración por vía marítima, se trataría entonces de la frontera de las 12 millas que marca el mar territorial.

Como han señalado Goodwin-Gill y McAdam, "the special jurisdictional rights which a State can exercise in the adjacent area of the contiguous zone do not clearly include the interception of vessels believed to be carrying asylum seekers" ${ }^{\prime 695}$. No obstante, tampoco lo deja fuera explícitamente. Las funciones de prevención no necesitan ser interpretadas de forma amplía para que puedan incluir la interceptación de buques sin bandera de pabellón.

\footnotetext{
${ }^{694}$ UNCLOS, art. 33

${ }^{695}$ Goodwin-Gill, G. y McAdam, J.: The Refugee in..., op. cit., p. 276
} 


\section{CAPÍTULO 5}

El elemento clave en el artículo es el de "medidas necesarias", que introduce el principio de proporcionalidad en las actuaciones. Así, el empleo de la fuerza o el rechazo de una embarcación donde se sospeche que puedan viajar refugiados $u$ otras personas vulnerables, no estaría justificada de forma alguna. Así mismo, la protección de los intereses del país está más justificada cuando la operación marítima tiene que ver con el tráfico de personas o estupefacientes que con la entrada ilegal en el territorio, considerada en todos los países como una infracción de carácter administrativo, y no un delito penal.

Más allá de la zona contigua se halla Zona Económica Exclusiva (ZEE), para la que no existe competencia policial o fronteriza ${ }^{696}$.

\subsubsection{Alta Mar}

UNCLOS define el alta mar como "todas las partes del mar no incluidas en la zona económica exclusiva, en el mar territorial o en las aguas interiores de un Estado, ni en las aguas archipelágicas de un Estado archipelágico" ${ }^{\circ 97}$. El alta mar es un espacio al cual los Estados no pueden someter su soberanía ${ }^{698}$. Una de las consecuencias de esta norma es que los Estados no pueden ejercer control sobre buques de otros Estados ${ }^{699}$. Sin embargo, la limitación no se extiende hasta los buques que navegan sin pabellón, ante los que existe el que se conoce como "derecho de visita", por el que los buques sin nacionalidad pueden ser detenidos y examinados por buques al servicio de un Estado, incluyendo los militares ${ }^{700}$.

El derecho de visita es la principal fundamentación legal a la que acuden los Estados para detener embarcaciones que transportan migrantes y refugiados en alta mar. Sobre este respecto existe un debate jurídico que se cuestiona si los Estados someten a los buques abordados a su jurisdicción ${ }^{701}$. La postura que responde positivamente fundamenta que todo buque que navegue en Alta Mar debe portar el pabellón de algún Estado $^{702}$. Se trataría de un requisito necesario para disfrutar de la libertad de navegación el Alta Mar. De hecho, tanto el artículo 87 (Libertad de Alta mar) como el

${ }^{696}$ UNCLOS, art. 56

697 Ibíd., art. 86

698 Ibíd., art. 89

699 Ibíd., art. 92.1

700 Ibíd., art. 110

${ }^{701}$ Para profundizar en dicho debate, se puede consultar Proelss, A.: Rescue at Sea..., op. cit., pp. 17 y ss.

${ }^{702}$ UNCLOS, art. 91 
90 (Derecho de navegación) otorgan a los Estados y no a los buques la titularidad de ese derecho. Dado que los buques en alta mar se encuentran bajo la jurisdicción de los Estados de su pabellón ${ }^{703}$, en caso de no contar con nacionalidad caerían bajo la jurisdicción del Estado que ejerciera su derecho de visita. Durante muchos años este fue el consenso predominante en el Derecho del Mar en lo concerniente a embarcaciones sin nacionalidad ${ }^{704}$. Un tribunal italiano también coincidió con este punto de vista, al considerar que la falta de nacionalidad del buque es justificación suficiente para la detención y procesamiento de migrantes irregulares en Alta Mar cercanos a la costa de Italia $^{705}$. Más recientemente, el Protocolo contra el tráfico ilícito de migrantes por tierra, mar y aire (conocido como Protocolo de Palermo), incluía la posibilidad de que los Estados parte visiten y registren un buque sin nacionalidad cuando existan "motivos razonables para sospechar" que esté involucrado en el tráfico ilícito de migrantes por mar. En caso de confirmarse las sospechas, el Estado "adoptará medidas apropiadas de conformidad con el derecho interno e internacional, según proceda"706. Aunque el texto en sí no concreta en qué consisten dichas medidas, la apelación a su conformidad legal debe ser interpretada como la inclusión de una serie de líneas rojas en su actuación; entre otras el trato digno, la asistencia médica y sanitaria, la identificación individual y por supuesto el principio de non-refoulement.

Una visión opuesta argumenta que el derecho de visita no debería confundirse con las operaciones de intercepción, ya que el artículo 110 no autoriza a apresar el buque y transportarlo a su puerto de origen $u$ otro lugar en tierra o mar, ni tampoco a ejercer otras medidas de oposición física. Más cuando este tipo de medidas sí que se reconocen como posibilidad en relación a los actos de piratería ${ }^{707}$ Pretender extender las medidas antipiratería a embarcaciones que transportan migrantes y refugiados se encuentra fuera de todo lugar. Otra premisa problemática de la primera posición tiene que ver con la asunción de la jurisdicción sobre el buque, en sustitución del Estado de pabellón. La premisa desde la que parte es que permitir navegar por Alta Mar a buques sin nacionalidad pone el peligro el orden y la seguridad marítima internacional. Al abordar a estos buques, el Estado estaría ejerciendo funciones del Estado del pabellón con la

\footnotetext{
${ }^{703}$ Ibíd., art. 92.1

${ }^{704}$ Véase por ejemplo el célebre caso Asya, donde el Consejo Privado del Reino Unido no encontró una violación de la ley internacional cuando un navío inglés interceptó un buque en alta mar cargado de inmigrantes ilegales y lo escoltó a Palestina. Naim Molvan v. Attorney General for Palestine (The "Asya"), 81 Ll L Rep 277, United Kingdom: Privy Council, 20 de abril 1948. Disponible en: http://www.refworld.org/docid/3ae6b6544.html (Consulta: 27 de enero de 2016)

${ }_{705}$ Tribunale di Crotone, Pamuk y otros, sentencia del 27 de septiembre de 2001. Citado en Papastavridis, E.: Interception ..., op. cit., p. 6.

${ }^{706}$ Convención de las Naciones Unidas contra la delincuencia organizada transnacional. Protocolo contra el tráfico ilícito de migrantes por tierra, mar y aire, firmado el 12 de diciembre de 2000 en Palermo. Anexo II, art. $\quad 8.7 . \quad$ Disponible http://www.unodc.org/documents/peruandecuador/Publicaciones/tocebook.pdf (Consulta: 27 de enero de 2016)

${ }^{707}$ UNCLOS, art. 105
} 


\section{CAPÍTULO 5}

finalidad vigilar el cumplimiento de las normas internacionales. Pero estas funciones se deberían limitar a los límites fijados por el artículo 110 (la investigación sobre el estatus del navío y los pasajeros) y no podrían ejercer una jurisdicción plena como la del Estado de pabellón. En esta interpretación, el derecho de visita no supondría ipso facto el ejercicio total de la jurisdicción por parte del Estado al abordar el buque. En el ya citado caso Hirsi Jamaa, el TEDH condenó al Estado italiano por las expulsiones de eritreos y somalís, al entender que las intercepciones en alta mar con el efecto de impedir llegar a las fronteras de un Estado e incluso empujarlos hacia otros, se encuadraban dentro de la jurisdicción de los Estados según el artículo 1 del Convenio ${ }^{708}$. La situación libia no podía ser desconocida por el gobierno italiano ${ }^{709}$. Por lo tanto, éste sabía, o debería haber sabido, que tras la devolución los migrantes podían quedar expuestos a un trato contrario al artículo 3 del CEDH, incluyendo malos tratos o una segunda devolución a Somalia o Eritrea.

Conviene tener en cuenta tres principios relevantes que UNCLOS fija para el Alta Mar: el estatus de espacio abierto y común, donde la prima la libertad de navegación ${ }^{710}$; la imposibilidad de los Estados de ejercer su soberanía, salvo excepciones, y que se deriva del principio anterior; y la finalidad pacífica de las actividades que allí se realicen ${ }^{711}$. Una interpretación que diera carta blanca para ejercer controles policiales en alta mar, ejerciendo su jurisdicción sobre otros buques con fines migratorios, sería contraria al sentido y los fines del espacio de Alta Mar según la convención. En este sentido no se puede dejar de criticar la inclusión de esta posibilidad en la Decisión 2010/252/UE del Consejo, que da cobertura legal a las operaciones de vigilancia marítima $^{712}$. Caso distinto es, como ya vimos, las obligaciones de prestar asistencia ante buques en peligro de naufragio.

Un asunto relevante tiene que ver con la detención de migrantes irregulares o potenciales solicitantes de asilo durante estas operaciones "de visita" en Alta Mar. Un ejemplo es el citado caso Pamuk. Otorgar a los Estados una jurisdicción plena sobre los buques que abordan llevaría consecuentemente a la capacidad de arrestar a los pasajeros de la embarcación. Aquí es preciso recordar que ni transportar migrantes ni viajar de forma indocumentada constituye un delito internacional, excepto en los supuestos contenidos en el Protocolo de Palermo. Por lo tanto, los Estados no estarían capacitados para arrestar a los pasajeros de las embarcaciones que abordan en principio de este "derecho de visita", al menos hasta que estos se encontraran en sus aguas territoriales y

\footnotetext{
708 TEDH: Hirsi Jamaa y otros c. Italia., $§ 180$

${ }^{709}$ Ibíd., § 89

${ }^{710}$ UNCLOS, art. 87

${ }^{711}$ Ibíd., art. 88

${ }^{712}$ Decisión 2010/252/UE, Anexo 1, art. 2.4 (d)
} 
por tanto hubieran violado su legislación migratoria. En 2015, el Consejo de Seguridad de Naciones Unidas autorizó durante un año la inspección y apresamiento de los buques que transportaban migrantes desde Libia mientras cuando son interceptados en Alta $\operatorname{Mar}^{713}$. El carácter excepcional de la medida, por su motivación y restricción temporal y geográfica, refuerzan la posición de que éstas no pueden ser incluidas en las potestades soberanas que, regularmente, tienen los Estados para actuar en Alta Mar.

Excluida el arresto y procesamiento de los migrantes, queda pendiente cual debe ser el procedimiento a seguir con respecto a dichas personas. En casos donde la vida de los pasajeros se encuentre en peligro, ya sea por el mal estado de la embarcación o por el deterioro de la salud de estos, la actuación del Estado debería ser prestar la asistencia inmediata necesaria en el marco de una operación de salvamento. Si uno o varios de los pasajeros solicitan protección internacional, o los agentes estatales tienen razones fundadas de que podrían necesitarla, deberían producirse los primeros pasos destinados a la determinación del estatus como el screening. El Manual para guardias de fronteras del área Schengen establece las condiciones para que un nacional de un tercer país sea considerado como solicitante de asilo:

...si de cualquier modo expresa miedo a sufrir algún daño grave si regresase a su país de origen o de su anterior residencia habitual.

El deseo de acogerse a la protección no necesita expresarse de forma particular ni es necesario emplear expresamente la palabra "asilo"; el elemento definitorio es la expresión de miedo por lo que pueda suceder en el momento del retorno. En caso de duda sobre si determinada declaración puede interpretarse como deseo de solicitar asilo u otra forma de protección internacional, los guardias de fronteras deberán consultar a las autoridades nacionales responsables de examinar las solicitudes de protección internacional. ${ }^{714}$

En caso de que no concurra ninguno de los supuestos arriba mencionados, el buque debería ser dirigido a las costas del Estado ribereño más cercano o del anfitrión de la operación de interceptación con el propósito de determinar la nacionalidad e intenciones de las personas que viajaban a bordo. En cualquier caso, las personas deben ser tratadas

713 Consejo de seguridad: Resolución 2240 (2015) de 9 de octubre de 2015, $7531^{\circ}$ sesión. Doc. S/RES/2240 (2015), para. 7-8. Disponible http://www.un.org/es/comun/docs/?symbol=S/RES/2240\%282015\%29 (Consulta: 29 de enero de 2016) ${ }_{714}$ Manual práctico para guardias de fronteras (Manual Schengen), documento del consejo 15010/06, 9 de noviembre de 2006, para 10.1 Disponible en: http://register.consilium.europa.eu/doc/srv?1=ES\&f=ST\%2015010\%202006\%20INIT (Consulta: 28 de enero de 2016) 


\section{CAPÍTULO 5}

de forma humanitaria, incluyendo la asistencia ante cualquier necesidad básica, y con especial preocupación ante posibles colectivos vulnerables.

\subsubsection{Zona marítima de un tercer estado}

En ocasiones las operaciones de interceptación se producen en las aguas territoriales del país de origen. En la mayor parte de las ocasiones, los gobiernos africanos comenzaron a realizar estas actuaciones solamente después de su requerimiento por parte de los Estados europeos tras la firma de un convenio bilateral con la UE o con dichos estados. Ya tratamos dichos acuerdos en el capítulo segundo.

Esta forma de control fronterizo en los países de salida ha ido incrementándose en los últimos años, constituyéndose como uno de las realizaciones más concretas de la política de externalización de las fronteras de la $\mathrm{UE}^{715}$. Al realizarse en el territorio del país de origen, estas acciones conllevan una situación legal diferente. En este caso, las interceptaciones se pueden producir en el desarrollo de operaciones conjuntas entre el país de origen y de destino de las embarcaciones, bajo el marco de uno de estos convenios o acuerdos migratorios, a menudo con la participación de agentes estatales de ambos países. Desde una interpretación tradicional del derecho internacional, se asume que acciones realizadas en el territorio de un Estado y dirigidas por sus autoridades son responsabilidad exclusiva de éste. Sin embargo, los Estados europeos y la UE no pueden quedar libres de responsabilidad ante posibles violaciones de derechos humanos cuando efectúan poderes públicos fuera de su territorio. Ya vimos en el cuarto capítulo que este es precisamente uno de los criterios que tenía en cuenta el TEDH para reconocer el ejercicio de la jurisdicción extraterritorial.

En sentido estricto, la CG51 identifica como necesario para la determinación del carácter de refugiado que éste se encuentre fuera de su país ${ }^{716}$. En principio, la protección contra la devolución quedaría excluida los ciudadanos norteafricanos que son interceptados y devueltos en las aguas territoriales de su propio país, bien sea en el marco de una operación conjunta de patrullaje con participación europea. Sin embargo, el Manual de procedimientos de ACNUR establece una excepción en el caso de que el

715 Hathaway, James y Gammeltoft-Hansen, Thomas: Non-refoulement in a World of Cooperative Deterrance, University of Michigan Law School, Law \& Economics Working Papers, n 106, 2014. Disponible

en: http://repository.law.umich.edu/cgi/viewcontent.cgi?article=1216\&context=law econ current (Consulta: 27 de enero de 2016)

${ }^{716}$ CG51, art. 1.A.2) 
intento de salir del país puede conllevar sanciones severas, en cuyo caso el reconocimiento como refugiado está justificado ${ }^{717}$. Además, ya vimos en el capítulo III que el principio de non-refoulement se expande más allá del Derecho Internacional Humanitario. La UE también incluye dicha protección a personas que no reúnen los requisitos para ser refugiadas, pero del cual pueden existir riesgo real de sufrir daños graves, bajo la figura de la protección subsidiaria ${ }^{718}$.

Las prácticas de interceptación en el mar territorial del país de origen de la embarcación plantean, pues, una cuestión relevante que tiene que ver con el derecho a salir del territorio de un Estado, incluido el propio. Tal derecho se encuentra contenido en la DUDH ${ }^{719}$ y en otros tratados internacionales ${ }^{720}$. En varios de estos instrumentos se incluye una serie de excepciones: la protección de la seguridad nacional, el orden y la salud pública y los derechos y libertades de otros. No parecen razones que puedan justificarse para restringir las salidas de migrantes, al menos que se produzcan en forma de afluencia masiva. La Convención sobre la Eliminación de todas las Formas de Discriminación Racial recoge este derecho, vinculándolo a la prohibición de la discriminación y la igualdad ante la ley ${ }^{721}$. En Xhavara c. Italia, ya citado, el TEDH consideró que el Estado italiano ejercía su jurisdicción durante una operación de interceptación en las aguas de otro Estado, Albania. El caso podría haber implicado responsabilidad por la violación del artículo 2 si no hubiera sido declarado inadmisible por no haber agotado los recursos internos. En Bankovic c. Bélgica, el Tribunal había incluido como uno de los requisitos por el que se admitía el ejercicio extraterritorial de la jurisdicción "through the consent, invitation or acquiescence of the Government of that territory, exercises all or some of the public powers normally to be exercised by that Government" ${ }^{\prime 722}$. El Comité Europeo de Prevención contra la Tortura (CPT) lo señalo así mismo en una de sus visitas llevadas a cabo en Italia para investigar el control

\footnotetext{
717 ACNUR: Manual de procedimientos..., op. cit., para. 61

718 Directiva 2011/95/UE, art. 2.f)

${ }^{719}$ DUDH, art. 13.2: "Toda persona tiene derecho a salir de cualquier país, incluso del propio, y regresar a su país".

${ }^{720}$ El art. 12.2 y 12.4 del PIDCP, el art. 10.2 de la CDN y el art. 8.1 del CTMF, que señala también que "Este derecho no estará sometido a restricción alguna salvo las que sean establecidas por ley, sean necesarias para proteger la seguridad nacional, el orden público, la salud o la moral públicas o los derechos y libertades ajenos y sean compatibles con otros derechos reconocidos en la presente parte dela Convención" En el ámbito regional, se encuentra en el art. 3 del protocolo $4^{\circ}$ del CEDH, el art. 22.5 de la CADH, el art. 12.2 de la CADHP, y el art. 27 de la Carta Arabe de los Derechos Humanos de 2004. El Consejo de Europa publicó un informelaborado por E. Guild, con especial énfasis en las políticas migratorias y fronterizas europeas. Guild, Elspeth: The Right to Leave a Country, Informe para el Comisario de Derechos Humanos del Consejo de Europa, octubre de 2013. Disponible en: http://www.coe.int/t/commissioner/source/prems/prems150813 GBR 1700 TheRightToLeaveACountry web.pdf (Consulta: 27 de enero de 2016)

${ }^{721}$ CEFDR, art. 5. C) ii)

${ }^{722}$ TEDH: Bankovic c. Francia, $\S 71$
} 


\section{CAPÍTULO 5}

de la inmigración irregular, donde identifica aquellos supuestos que dan lugar a la jurisdicción extraterritorial:

(a) the activities of the State's diplomatic or consular agents abroad and on board craft and vessels registered in, or flying the flag of, that State; (b) the State's effective control of an area outside its national territory; or (c) the State's exercise of authority over persons or property through its agents operating on the territory of another State or in international territory/waters ${ }^{723}$

Debemos considerar que aquellas medidas que buscan impedir la salida de los inmigrantes de las costas o del mar territorial del país de origen suponen una violación del principio de non-refoulement. En tanto que norma con categoría ius cogens, los Estados no pueden acogerse a excepciones, ni siquiera geográficas, para incumplir las obligaciones que esta norma les impone para todas las personas bajo su jurisdicción. Las operaciones de patrullaje marítimo en las aguas marítimas de los países norteafricanos, al forzar el regreso de los inmigrantes a sus costas de partida, impiden a aquellos refugiados y otras personas que pudieran tener derecho a algún tipo de protección en el país de destino el acceso al procedimiento de asilo y a las garantías jurídicas que les protegerían en dicho país contra la expulsión.

Debemos recordar que los países de salida de las embarcaciones son países de origen de refugiados, y durante los últimos años han sido constantes las denuncias sobre violaciones de derechos humanos a aquellos migrantes de terceros países que viajaban por estos estados como países de tránsito hacia Europa. Entre estas preocupaciones se encontraban la violación del principio de non-refoulement, mediante la expulsión de miles de migrantes y refugiados (muchos de ellos venían de ser devueltos por las autoridades europeas) a sus países de origen. Ninguno de estos países forma parte de la lista de "terceros países seguros" que elabora la UE, y uno de ellos (Libia) tampoco ha ratificado la CG51. Por todo esto se podría estimar que "dichas devoluciones colectivas tienen (...) las mismas consecuencias que las expulsiones colectivas y en esa misma medida deben considerarse prohibidas por el Derecho internacional" ${ }^{\text {724 }}$. Varios de los Estados del Norte y Noroeste de África persiguen y castigan la salida de nacionales o extranjeros desde sus costas a Europa. Si bien en los últimos años se ha producido una importante disminución de la represión en algunos países como Libia, Túnez o Egipto debido a la inestabilidad política.

${ }^{723}$ Consejo de Europa, "Report to the Italian Government..., op. cit., para. 29

${ }^{724}$ Pérez, C.: Migraciones irregulares..., op. cit., pp. 166-167 
Dentro del marco operacional de Frontex, este tipo de actuaciones de intercepción extraterritoriales son conocidas como de "pre-frontera" ("pre-border operations") 725 . Una de las primeras operaciones de la Agencia, HERA, tenía como uno de los puntos esenciales el patrullaje conjunto con las fuerzas costeras senegalesas para impedir que los cayucos que salían de sus costas llegasen a Canarias. Durante el diseño de la operación y posteriormente en su evaluación se señaló como uno de sus objetivos la disminución de salidas desde las costas de Mauritania y Senegal. En su memoria anual de 2006, las patrullas que intervinieron en las operaciones de HERA II y III realizaron bloqueos e interceptaciones de cayucos a su salida de las costas de Mauritania y Senegal, forzando su retorno al puerto de origen. Los datos que presenta la memoria son de 3.887 migrantes irregulares en 57 cayucos interceptados cerca de las costas africanas y devueltas al puerto de origen (que tampoco se especifica). El informe señalaba que "Mediante la información recopilada durante los interrogatorios fue posible detectar varios pasadores de fronteras, principalmente en Senegal, y evitar la salida de más de mil personas" ${ }^{\text {726 }}$. Solamente cuando conseguían zafarse de los controles y alcanzar Alta Mar o el mar territorial español eran desembarcados en las Islas Canarias. Las operaciones contaban como base legal dos acuerdos bilaterales entre esos países con España en materia de migración. Sin embargo, la legalidad de la presencia en aguas territoriales de agentes de otros Estados europeos y de Frontex parece estar menos clara. En el momento de la operación, no existía ningún acuerdo entre la agencia estos estados africanos.

Amnistía Internacional criticó la imprecisión de la estadística presentada, así como los obstáculos que suponía la operación para salir del propio país ${ }^{727}$. Resulta chocante que Frontex califique a dichas personas como "migrantes irregulares" cuando ni siquiera han dejado el territorio de su país de origen. Tampoco incluye ninguna información referente a que se haya llevado a cabo procesos de screening para determinar si pudieran ser beneficiarios de protección internacional. Cabe cuestionarse cuantos de esas mil personas de la que se previno su salida eran refugiados y podrían haberse acogido a la protección internacional a su llegada a España. Acciones como éstas violan este derecho, al interceptar las embarcaciones en las aguas territoriales del

\footnotetext{
${ }^{725}$ Dichas operaciones se encuentran reguladas en el art. 3 del Reglamento 2007/2004

${ }^{726}$ Frontex: Informe Anual 2006, Coordinación de la cooperación basada en la inteligencia a escala de la UE para reforzar la seguridad en las fronteras exteriores, p. 12. Disponible en: http://frontex.europa.eu/assets/About Frontex/Governance documents/Annual report/2006/microsoft w ord - frontex-2008-0001-00-00-enes.pdf (Consulta: 27 de enero de 2016)

${ }^{727}$ AI: Mauritania: "Nadie quiere tener nada que ver con nosotros". Arrestos y expulsiones colectivas de migrantes a quienes se ha negado la entrada en Europa, Londres, 1 de julio de 2008, AFR 38/001/2008. Disponible en: https://www.amnesty.org/download/Documents/52000/afr380012008spa.pdf (Consulta: 27 de enero de 2016)
} 


\section{CAPÍTULO 5}

propio estado de origen y devolverlas a tierra, reteniendo a los migrantes dentro del país que pretende abandonar.

El despliegue por parte de Frontex de operaciones en las aguas territoriales de terceros estados, especialmente cuando gracias a un acuerdo bilateral permite operaciones de patrullaje por parte de Estados europeos representa una serie amenaza al derecho humano a salir de cualquier país. El propio carácter de las operaciones dificulta la rendición de cuentas y la identificación de responsabilidades. En HERA, por ejemplo, participaban agentes tanto españoles como de los países de origen (Mauritania y Senegal), además de agentes de otros EEMM actuando como asesores y de Frontex con labores de coordinación. En caso de violación de derechos, la determinación del sujeto responsable se presenta diluida, y ninguna de las partes cuenta ni con la obligación ni con los incentivos para plantear una investigación independiente.

La última norma que regula las operaciones de Frontex, el Reglamento 656/2014, deja fuera de su regulación este tipo de operaciones ${ }^{728}$. Por lo tanto, las infracciones, prácticas irregulares o vulneraciones de derechos ocurridos durante este tipo de operaciones permanecen sin tener una regulación específica. No obstante, el Reglamento reitera la cláusula contenida en el Reglamento 1168/2011, por la que la Agencia y los EEMM deben fijar criterios al menos equivalentes a los del derecho comunitario cuando las actuaciones se desarrollen en el territorio de terceros estados, así como promover los derechos fundamentales y la dignidad humana ${ }^{729}$.

\subsection{Las operaciones de interceptación de Frontex y los EEMM}

De las decenas de JO en las que la Agencia y los países euro-mediterráneos han desarrollado en los últimos años, analizaremos cuatro casos especialmente significativos en su extensión e importancia para los fines del presente trabajo. Los tres primeros son JO de Frontex; siendo el cuarto la operación italiana Mare Nostrum que, si bien no se trata formalmente de una operación de la agencia, reviste una gran importancia debido al perfil y alcance de sus objetivos. Corresponde también con tres de las principales rutas migratorias hacia Europa por vía marítima: la que va del noroeste africano a las Islas Canarias; la greco-turca a través del mar Egeo; y la del Mediterráneo Central, especialmente la que conecta Libia y Túnez con Italia y Malta.

\footnotetext{
${ }^{728}$ Las operaciones en el mar territorial y en alta mar se recogen en los art. 6 y 7 del Reglamento

${ }^{729}$ Ibíd., considerando 5 y art. 14.1
} 


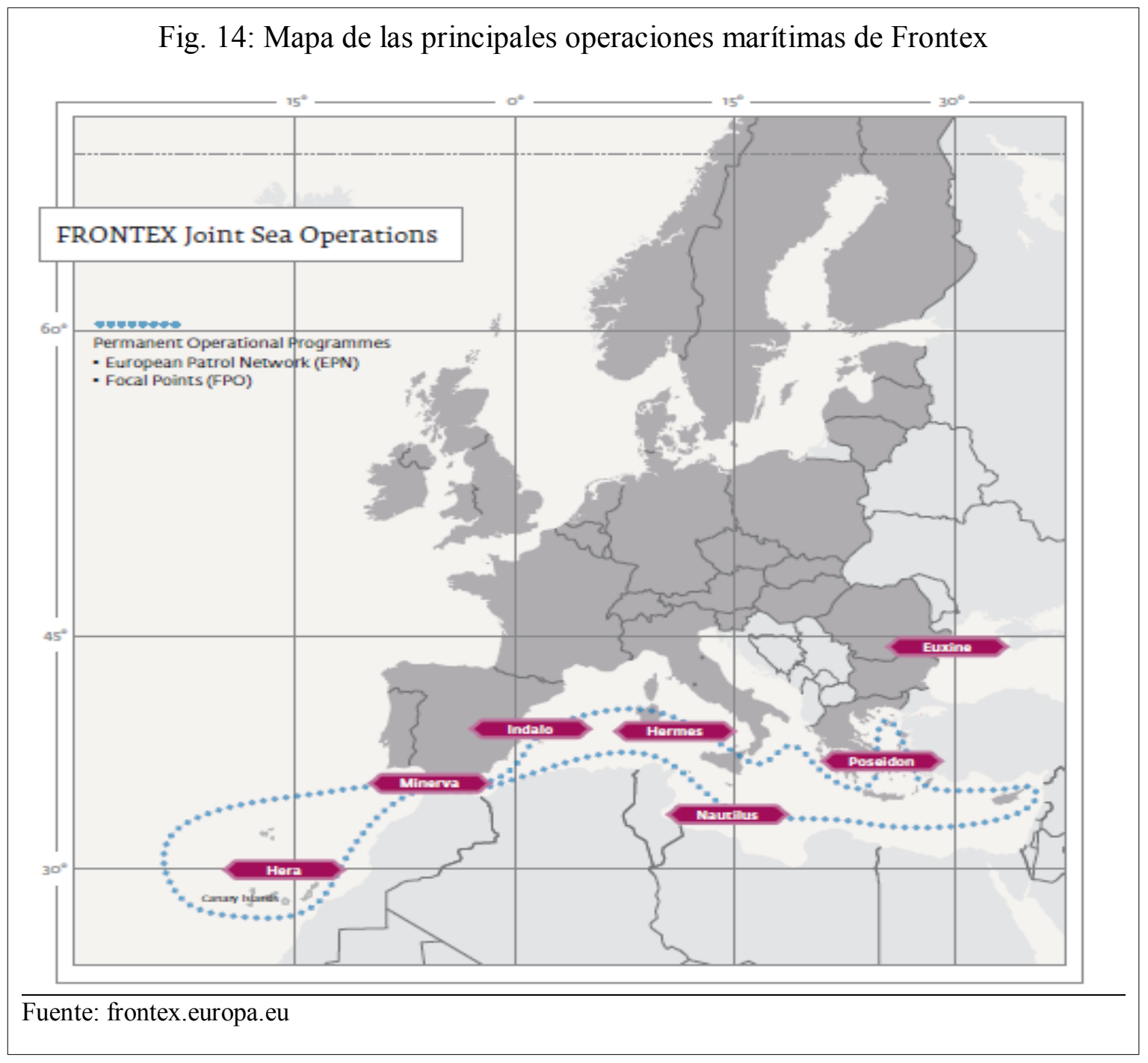

\subsubsection{HERA}

En 2006, menos de dos años después de la creación de FRONTEX, tuvo lugar la primera gran operación coordinada por la Agencia. Se trató de la operación HERA. Sería la primera de una serie de operaciones destinada a impedir la salida de embarcaciones desde países africanos a Europa, mediante su interceptación marítima y devolución a los lugares de partida. HERA fue no sólo la primera operación coordinada por FRONTEX, sino que en sus diferentes fases (denominadas HERA I, II y III) puso en marcha una serie de actividades que cubren buena parte de los campos del presente estudio, por la que la examinaremos más detenidamente. 


\section{CAPÍTULO 5}

Desde verano de 2005 se había constatado un aumento generalizado de pequeñas embarcaciones pesqueras abiertas, generalmente de madera (conocidas como 'cayucos ${ }^{730}$ ) desde el África Occidental hasta las islas Canarias ${ }^{731}$. A partir de ese verano, en los meses siguientes se produjo un importante incremento del flujo migratorio, con la llegada casi diaria de cayucos a las costas canarias. En 2006, 31.700 migrantes irregulares alcanzaron las Islas Canarias ${ }^{732}$. España no tenía en ese momento un sistema de control fronterizo marítimo muy desarrollado. De hecho, el Sistema Integrado de Vigilancia Exterior en el Estrecho y Alta Mar (SIVE) sólo había sido aprobado en 1999, entrando en funcionamiento en las Islas Canarias en 2002. Durante los primeros años sólo contaba con unidades móviles, que tenían que ir rotando por diversos puntos de las islas, y tenía un funcionamiento reducido los fines de semana ${ }^{733}$.

El gobierno español realizó dos solicitudes de asistencia técnica a Frontex en virtud del artículo 8 del Reglamento de la Agencia, el 24 de mayo y el 28 de junio de 2006. Los dos primeros módulos se desarrollaron de forma simultánea a lo largo del segundo semestre del año: HERA I entre el 17 de julio y el 31 de octubre, y HERA II del 11 de agosto al 15 de diciembre.

HERA I implicó la participación inicial de un grupo de nueve expertos de otros tantos países europeos, además de un agente FRONTEX, así como representantes de Senegal, Mauritania y Gambia. Un segundo y tercer grupo de expertos se unirían en los meses siguientes. Las principales tareas de estos expertos eran la identificación de inmigrantes, especialmente de su nacionalidad, con la finalidad proceder a devolverles a sus países de origen. Según FRONTEX, durante esta fase llegaron a las Islas Canarias un total de 18.987 inmigrantes irregulares, de los cuáles a solamente el 100\% pudieron ser determinados sus países de origen. Un total de 6.076 personas fueron repatriadas ${ }^{734}$. El costo de esta primera fase fue de 3,5 millones de euros.

\footnotetext{
${ }^{730}$ Son embarcaciones de unos 22 metros de eslora por 2,5 de altura, con una capacidad máxima de alrededor 100 pasajeros. El precio en Senegal ronda los 7.000 euros

${ }^{731}$ Los puntos de salida más utilizados en las rutas atlánticas para pateras y cayucos se sitúan en el Cabo Bojador, El Aaiun, Tarfaya, Dahkla y la Güera en territorio de Marruecos y del Sahara Occidental; Cabo Blanco, Nouadibou y Nouakchott en Mauritania; Mbour, Dakar, Kayar, Joal, San Luis y la zona sur de Casamance en Senegal; y Gunjur, Tanji y Barra en Gambia.

${ }^{732}$ Frontex: Beyond the Frontiers..., op. cit., p. 34

733 AI: Frontera Sur, El Estado da la espalda a los derechos humanos de los refugiados e inmigrante, 2005, Doc. AI 41/008/2005, p. 51. Disponible en: http://www.amnesty.eu/static/documents/Spain detention report Spanish final.pdf (Consulta: $27 \mathrm{de}$ enero de 2016)

${ }^{734}$ Frontex: "Longest FRONTEX Coordinated Operation - HERA, the Canary Islands", Nota de prensa, 19 de diciembre de 2006. Disponible en: http://frontex.europa.eu/news/longest-frontex-coordinatedoperation-hera-the-canary-islands-WpQlsc (Consulta: 27 de enero de 2016)
} 
El segundo módulo, HERA II, tenía por objeto un incremento de la presencia en la zona marítima, por el que se pretendía "reforzar la presencia y el control" de la zona marítima entre las Islas Canarias y la costa africana y disuadir a otros migrantes que se encontraban en territorio africano de emprender el viaje. Contó con la cesión al gobierno español de equipamiento de técnico para la vigilancia fronteriza. En caso de que los cayucos fueran avistados en el mar, el objetivo pasaba a ser su interceptación en las aguas territoriales del país africano. Los migrantes apresados serían devueltos a las autoridades de dicho país, que se ocuparían del retorno de estos al territorio. Un comunicado de prensa de la Comisión indicaba el procedimiento: "When a target is seen, they get in touch with the other FRONTEX means deployed and FRONTEX local coordination centre in Santa Cruz de Tenerife and prepare the interception. Normally the Senegalese boats escort the migrants inshore, start the legal procedure and try to arrest the people that were paid for organising the journey"735. Al menos un oficial senegalés debía ir a bordo de la patrullera, dado que solamente ellos tenían autoridad para parar y devolver los cayucos a las aguas territoriales senegalesas. El coronel de la Guardia Civil Eduardo Lobo, explicaba el reparto de funciones entre los agentes locales y los de Frontex: "The FRONTEX members provide the platform and support them but they are the authority for intercepting and returning the boats" ${ }^{\text {736 }}$. El mismo coronel explicaba el carácter de la operación: "It is a preventative operation. If we locate and identify any illegal boat within 24 miles of the coast they are immediately returned." $" 737$ Solamente las embarcaciones que superaban ese umbral y eran interceptados en Alta Mar o en el mar territorial español eran desembarcadas en las Islas Canarias, y contaban con la posibilidad de realizar una solicitud de asilo. La falta de transparencia e información sobre la operación levantó dudas sobre si se había respetado el principio de non-refoulement, al no establecerse ningún procedimiento de screening para los migrantes interceptados, ni incluirse en la evaluación ninguna consideración sobre el asilo. Además, organizaciones como ECRE mostraron preocupación ante la posibilidad de que cayucos interceptados en Alta Mar fueron retornados al país de origen arbitrariamente: "since it is not known whether any of the thousands of individuals that have come into contact with Frontex coordinated border guards wanted or attempted to seek asylum, we cannot be satisfied that adequate safeguards are in place to ensure that access to asylum is guaranteed." 738

735 Comisión Europea: Operation of the European Agency for the Management of the External Border Frontex, nota de prensa del 14 de septiembre de 2006. Disponible en: http://ec.europa.eu/avservices/video/shotlist.cfm?format=pdf\&ref=48133\&sitelang=en (Consulta: $27 \mathrm{de}$ enero de 2016)

${ }^{736}$ Frontex: Beyond the Frontiers..., op. cit., p. 34

737 BBC News: Stemming the immigration wave. 10 de diciembre de 2006. Disponible en: http://news.bbc.co.uk/go/pr/fr/-/2/hi/europe/5331896.stm (Consulta: 27 de enero de 2016)

${ }^{738}$ ECRE y Refugee Council: Refugee Council and the European Council on Refugees and Exiles (ECRE) Joint Response to Select Committee on the European Union Sub-Committee F (Home Affairs): Frontex Inquiry, 24 de septiembre de 2007, para. 6.1. Disponible en: http://www.ecre.org/component/downloads/downloads/61.html (Consulta: 27 de enero de 2016) 


\section{CAPÍTULO 5}

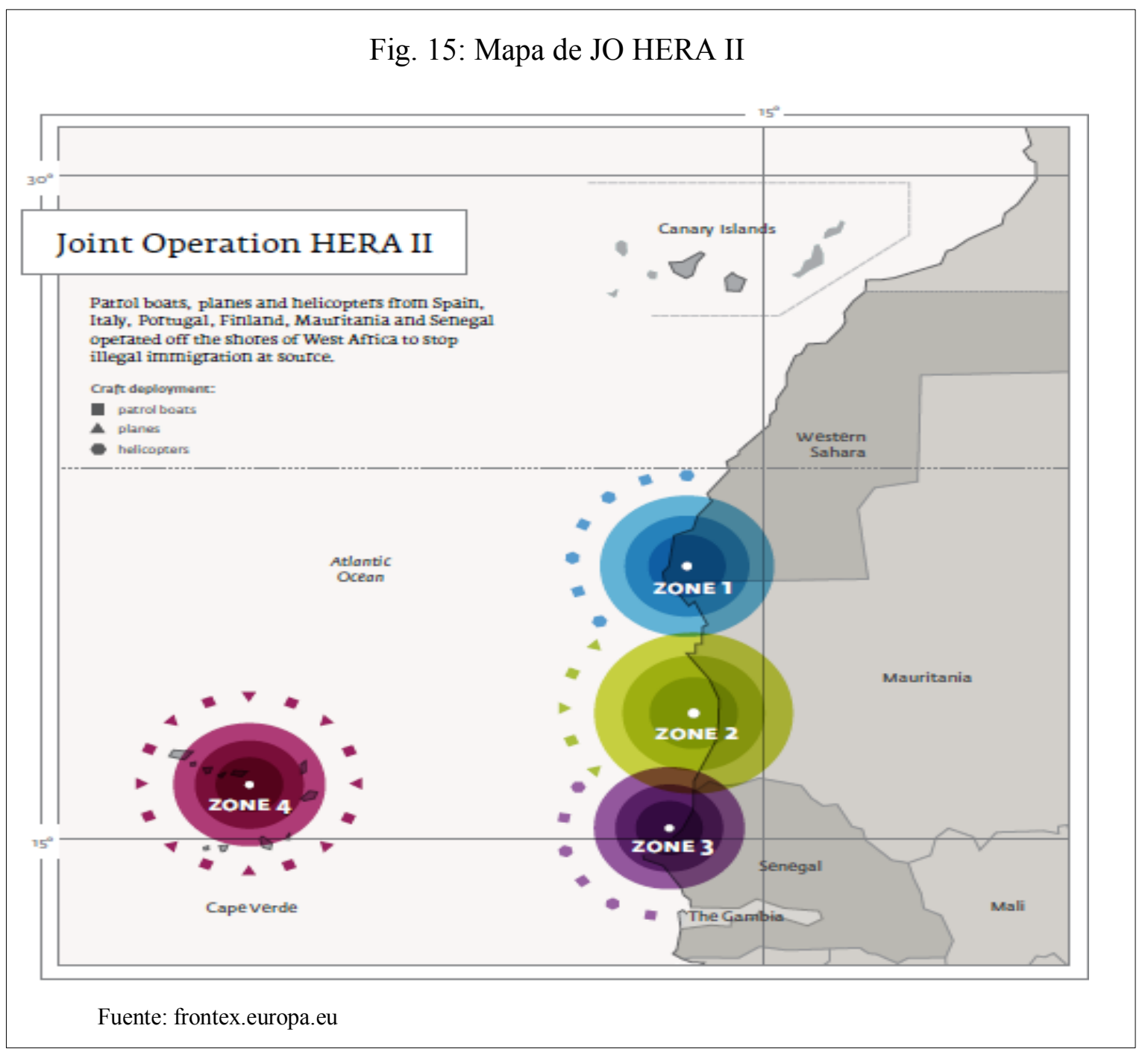

Tres gobiernos africanos aceptaron colaborar con España y FRONTEX en las operaciones de patrullaje conjunto y la aceptación de los migrantes aprehendidos: Mauritania, Senegal y Cabo Verde ${ }^{739}$. Esta colaboración tenía su base legal en los acuerdos bilaterales firmados entre España y estos países. Como vimos en el capítulo dedicado a estos acuerdos, el contenido de estos acuerdos permaneció secreto durante las operaciones.

En su evaluación de HERA II, FRONTEX cuantificó en 3.500 el número de migrantes detenidos, reconociendo que "the flow of irregular migration has decreased drastically". Sin embargo, el número total de cayucos que llegaron a costas canarias en

Vid. Crosbie, Judith: Frontier agency keeps migrants in its sights, European Voice 13 (13), 2007, donde cita a un trabajador del ACNUR: "Difficult situations may arise out on the high seas and it is difficult to tell what is going on in interception operations". Disponible en: http://www.politico.eu/article/frontieragency-keeps-migrants-in-its-sights (Consulta: 27 de enero de 2016)

${ }^{739}$ Carrera, S.: The EU Border... op. cit., p. 22. 
los meses de agosto y septiembre se mantuvo similar al de los meses anteriores y siguientes, e incluso se produjo un ligero aumento ${ }^{740}$. HERA II era un reflejo concreto de las orientaciones a la externalización del control de fronteras y la prevención contra la inmigración irregular que se estaban desarrollando a nivel político en la UE. Otras críticas procedieron del mal diseño de la operación. Debido a las presiones políticas del gobierno español para llevar a cabo acciones con carácter urgente, ni los objetivos de la operación ni la coordinación entre Frontex y el gobierno español estuvieron claramente definidos $^{741}$.

HERA III fue anunciado en febrero de 2007. Continuaba y ampliaba las operaciones navales y aéreas de control fronterizo de cayucos, en mares de Senegal y Mauritania con la cooperación de estos estados, que aceptaban el patrullaje de guardias españoles o de la Agencia. En cuanto a los resultados globales de la operación, según los datos del Ministerio de Interior español la llegada de inmigrantes irregulares a las Islas Canarias disminuyó en un 60'6 \% entre 2006 y 2007, en un 26,6 \% entre 2007 y 2008 y en un 75,5\% entre 2008 y $2009^{742}$. Por su parte, FRONTEX en su evaluación de la operación incluyó que "en el transcurso de las operaciones HERA I y II fue posible evitar que casi 5.000 inmigrantes ilegales emprendieran un peligroso viaje que podría haberles costado la vida". Las estadísticas hablan así mismo de 1.243 (HERA I), 1.167 (II) y 5.969 (III) migrantes irregulares retornados al país de origen ${ }^{743}$. No se incluyó ninguna estadística sobre la nacionalidad de estos, lo que podría darnos información acerca de la posibilidad de que fueran potenciales solicitantes de asilo.

La JO se ha ido renovando anualmente hasta la fecha. A partir de 2008, la ruta comenzó a perder afluencia, cifrándose en apenas 200 personas anuales durante el último quinquenio. En 2014, Frontex declaró que ninguna de las personas interceptadas o rescatadas en el área de la operación podía ser susceptible de merecer protección internacional $^{744}$.

\footnotetext{
${ }^{740}$ Ibíd., p. 23: "August and September were the two months with a higher "mobility" of irregular immigrants during the whole year: 6,000 arrivals in August and 7,700 in September"

${ }^{741}$ Ibíd.., pág. 13.

742 Cebrián, Juan A. y Charef, Mohammed : La inmigración irregular Española procedente de Marruecos, San Diego, Instituto Trans-Fronterizo, Borders/Fronteras n ${ }^{\circ} 2,2012$, p. 14. Disponible en: http://digital.csic.es/bitstream/10261/62432/1/2012-Funciva..pdf (Consulta: 27 de enero de 2016)

743 Frontex: HERA III Operation, nota de prensa de 13 de abril de 2007. Disponible en: http://frontex.europa.eu/news/hera-iii-operation-It9SH3 (Consulta: 27 de enero de 2016)

${ }_{744}$ Frontex: Annual Report on the implementation on the EU Regulation 656/2014 of the European Parliament and of the Council of 15 May 2014 establishing rules for the surveillance of the external sea borders, Varsovia, 9 de julio de 2015, p. 14. Disponible en: http://frontex.europa.eu/assets/About Frontex/Governance documents/Sea Surveillance/Sea Surveillanc e_report_2014.pdf (Consulta: 27 de enero de 2016)
} 


\section{CAPÍTULO 5}

\subsubsection{Nautilus}

La JO Nautilus se desarrolló en el Mediterráneo Central entre 2006 y 2009. Al igual que HERA, la operación buscaba interceptar barcos clandestinos procedentes del norte de África para devolver a los inmigrantes a sus países de origen. La base legal de la operación era confusa: por una parte Malta no aplicaba en ese momento el SBC, por otro la JO contaba con la cooperación de Libia que solamente había firmado un acuerdo con Italia, no con Frontex o la UE. Geográficamente, las actividades superaron el área operativa designada. Por ejemplo, durante la primera fase de la operación, llevada a cabo entre el 25 de junio y el 27 de julio de 2007, se "detectaron" 63 migrantes fuera del área en que se desarrollaba la operación ${ }^{745}$.

La Agencia dio un paso adelante en sus competencias de control fronterizo. Mientras que en HERA se trataba de operaciones de patrullaje conjunto y buscaba impedir la salida de los cayucos de las costas africanas, en Nautilus implicaba la entrega de los migrantes rescatados en áreas SAR italiana y maltesa a las autoridades libias. En 2007 el Ministro del interior del país insular informaron de que 700 migrantes irregulares habían sido devueltos a Libia ${ }^{746}$. El 28 de junio de 2009, un equipo fronterizo formado un helicóptero Puma alemán y una patrullera italiana interceptó un buque en el que viajaban 75 migrantes 29 millas al sur de Lampedusa. La Guardia Costera italiana entregó a los migrantes a unos agentes libios, que los llevaron de vuelta a Trípoli ${ }^{747}$. En un informe de HRW, se citaba al entonces Vicedirector de la Agencia, Gil-Arias Fernández, en el que valoraba la operación en los siguientes términos: "On the humanitarian level, fewer lives have been put at risk, due to fewer departures. But our agency does not have the ability to confirm if the right to request asylum as well as other human rights are being respected in Libya"748.

El rechazo de Malta a compartir las responsabilidades de acogida y procesamiento de asilo de las personas rescatadas en el transcurso de la operación fue la principal causa del fin de la operación. Frontex reorganizó un nuevo programa en la JO Chronos.

\footnotetext{
745 Frontex: Informe general 2007, p. 24. Disponible en: http://frontex.europa.eu/assets/About Frontex/Governance documents/Annual report/2007/frontex2008-0011-00-00-enes.pdf (Consulta: 27 de enero de 2016)

${ }^{746}$ Klepp, Silka: A Contested Asylum System: the European Union between Refugee Protection and Border Control in the Mediterranean Sea, European Journal of Migration and Law, vol. 12, $\mathrm{n}^{\circ}$ 1, 2012, $\mathrm{p}$. 16. Disponible en: http://booksandjournals.brillonline.com/content/journals/15718166 (Consulta: 27 de enero de 2016)

${ }^{747}$ HRW: Pushed back..., op. cit., p. 98

${ }^{748}$ Ibíd., p. 37
} 


\subsubsection{Poseidón}

En los últimos años, especialmente tras el conflicto sirio, la frontera greco-turca se ha convertido en uno de los puntos calientes de la actividad de Frontex.

En 2009 Frontex había llevado a cabo un proyecto piloto, Attica, con la intención de ofrecer apoyo a las autoridades griegas en la identificación y repatriación de migrantes. Un grupo de expertos europeos y personal de la Agencia realizó talleres formativos sobre screening (procedimiento de identificación del país de origen de los migrantes) y detección de falsos documentos. Tras un año inicial de testeo, el proyecto se ha ido renovando anualmente desde entonces.

Desde mediados 2010 se había producido una desviación de las rutas migratorias que habían convertido la frontera greco-turca por la provincia de Evros y el mar Egeo en la principal entrada a Europa. En noviembre de ese año, Frontex informó que el 90\% de las entradas ilegales a la UE se producían en esta área ${ }^{749}$. El gobierno griego realizó una petición de ayuda urgente a la agencia ${ }^{750}$, solicitando la intervención de los RABITs para asistir al gobierno griego ante la situación de excepcionalidad que se había producido $^{751}$. La petición fue concedida, y un grupo de 175 expertos en vigilancia fronteriza se desplegaron en la región durante cuatro meses (de noviembre 2010 a marzo 2011). Los objetivos de esta operación era asistir a los agentes fronterizos helenos en el screening y las entrevistas a migrantes detenidos.

Con la finalización del despliegue del equipo RABIT, y ante la constatación de que el flujo migratorio no había menguado, el gobierno griego y Frontex decidieron poner en marcha planes más duraderos para contener la entrada irregular de migrantes y refugiados. Por una parte, Grecia inició dos operaciones nacionales, Aspida y Xenios

\footnotetext{
${ }^{749}$ HRW: The EU's Dirty Hands. Frontex Involvement in Ill-Treatment of Migrant Detainees in Greece, septiembre de 2011, p. 20.2 Disponible en: https://www.hrw.org/sites/default/files/reports/greece0911webwcover 0.pdf (Consulta: 27 de enero de 2016)

${ }^{750}$ Frontex: "Frontex to Deploy 175 Specialist Border-Control Personnel to Greece," nota de prensa, 29 de octubre de 2010. Disponible en: http://frontex.europa.eu/news/frontex-to-deploy-175-specialist-borderpersonnel-to-greece-9neidF (Consulta: 27 de enero de 2016)

${ }^{751}$ Vid. Carrera, Sergio y Guild, Elspeth: Joint Operation RABIT 2010: Frontex Assistance to Greece's Border with Turkey. Revealing the Deficiencies of Europe's Dublin Asylum System, CEPS Paper in Liberty and Security in Europe, noviembre de 2010. Disponible en: http://aei.pitt.edu/15186/1/No 34 Carrera \%26 Guild on RABIT 2010.pdf (Consulta: 27 de enero de 2016)
} 


\section{CAPÍTULO 5}

Zeus, a la vez que comenzaba con la construcción de un muro en la frontera con Turquía.

Frontex, por su parte, respondió a la finalización de los RABIT con la aprobación de una operación más profunda y estable, la JO Poseidón. Estaba dividida en dos suboperaciones, una terrestre y que continuaba la labor de los RABIT, y otra marítima y que se extendía alrededor de las islas griegas del Mar Egeo ${ }^{752}$. La JO Poseidón ha sido renovada hasta el día de hoy, siguiendo en funcionamiento.

La intervención marítima de Frontex estaba articulada en torno a tres objetivos: detección temprana, disuasión e intercepción. El Plan Operativo de 2012 permitía ordenar la intervención de una embarcación para cambiar su curso y desviarla de su ruta hacia territorio europeo ${ }^{753}$. Los Planes Operativos de los 2 primeros años de Poseidón Mar no contenían información sobre el espacio geográfico de intervención marítima. Información provista posteriormente mostraba que cubre prácticamente todo el mar Egeo y otras áreas del Mediterráneo. El Plan Operativo de 2012 establece como objetivo controlar los flujos de migración irregular desde Turquía Occidental y Egipto que se dirigen a Grecia e Italia.

\footnotetext{
752 Frontex: "Update to Joint Operation Poseidon 2011", nota de prensa de 26 de marzo 2011. Disponible en: http://frontex.europa.eu/news/update-to-joint-operation-poseidon-2011-jzZfWV (Consulta: 27 de enero de 2016)

${ }^{753}$ FIDH- EMHRN-Migreurop: Frontex, between Greece..., op. cit., p. 34
} 


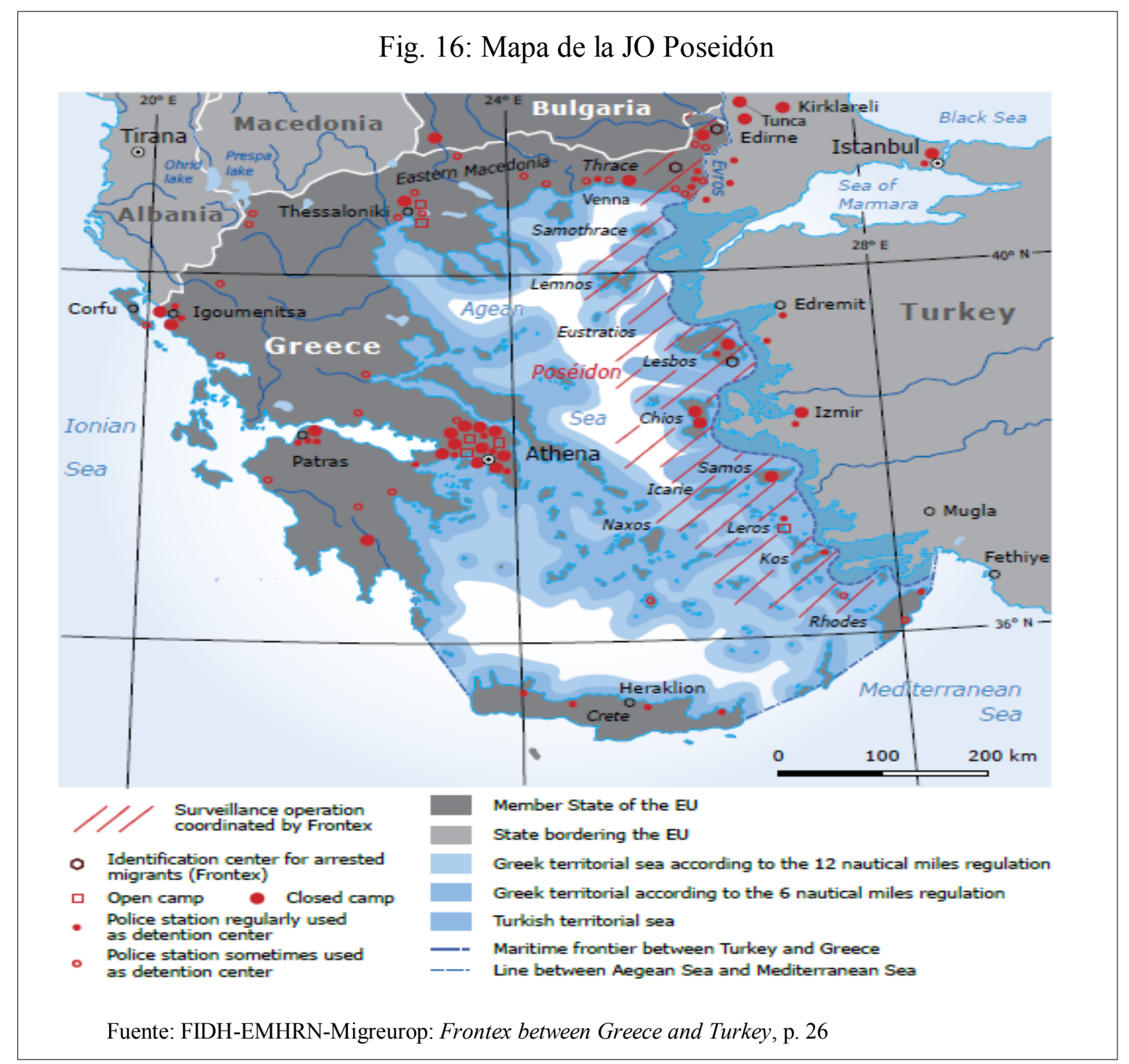

Por otro lado, la UE incrementó sus negociaciones con Turquía para mejorar la cooperación migratoria. El 28 de mayo de 2012 se firmó un memorándum de entendimiento $^{754}$ que incluía cláusulas de intercambio de información, entrenamiento conjunto de guardias fronterizos y la posibilidad de que éstos participaran en operaciones de retorno.

La evolución que se observa en la frontera greco-turca es un claro ejemplo de los posibles resultados de una mayor restricción de las políticas greco-turcas. El incremento en la vigilancia en la frontera terrestre y la construcción de un muro redujo significativamente las entradas por esta vía. Los datos indican que la llegada de migrantes a la región de Evros se redujo de 2.000 a 10 por semana entre agosto y

${ }^{754}$ Supra n. 238 


\section{CAPÍTULO 5}

octubre de $2012^{755}$. La consecuencia directa fue el desplazamiento de la ruta migratoria a la vía marítima que se dirige a las islas egeas. Un informe de la Asamblea Parlamentaria del Consejo de Europa mostraba que el número personas interceptadas en la frontera marítima griega habían pasado de 102 en el primer semestre de 2012 a 3.280 en el siguiente ${ }^{756}$. Otro aspecto del fenómeno es la inseguridad del viaje marítimo. Entre septiembre de 2012 y mayo de 2014 se contabilizaron en el mar Egeo 191 muertes y 33 desapariciones en 18 naufragios ${ }^{757}$. En otra estadística ofrecida por Frontex ${ }^{758}$, aunque ofrecía un número de interceptaciones marítimas en 2012 ligeramente menor (3.007) mostraba que se habían triplicado en el año siguiente, llegando hasta las 10.427. Siguiendo su política de no incluir estadísticas de protección internacional, el informe no contenía información directa sobre solicitantes de asilo. Sin embargo, del listado de nacionalidades observamos que la mayoría provenían de países emisores de refugiados. Con datos acumulados de 2012 y 2013 los grupos más numerosos eran los provenientes de Siria (6.022), Afganistán (4.820) y Somalia (470).

A pesar de que Turquía no ha participado oficialmente en ninguna operación conjunta con Grecia, la cooperación entre los agentes de ambos países es constante. De acuerdo con el Ministro de la Marina Varyutsiotsis "if [the boats] are on the Turkish side, first we inform the Turkish authorities so that they collect them. If they are on the

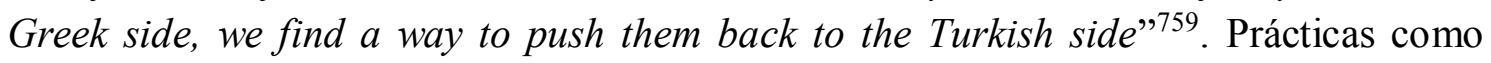
estas evidencian tanto una vulneración del derecho a salir de un Estado cometida por Turquía como del principio de no devolución llevado a cabo por Grecia. La alta probabilidad de que los migrantes rechazados puedan ser merecedores de protección internacional añaden a su vez una ruptura clara del derecho a solicitar asilo.

Las actuaciones corroboradas por el ministro han sido expuestas y denunciadas por distintas organizaciones internacionales, que han documentado cientos de casos de refugiados en los que denuncian los rechazos y devoluciones realizadas por Grecia

\footnotetext{
${ }^{755}$ FIDH- EMHRN-Migreurop: Frontex, between Greece ..., op. cit., p. 3

756 Consejo de Europa: Migration and asylum: mounting tensions in the Eastern Mediterranean, Resolución 1918 (2013) de la Asamblea Parlamentaria, 24 de enero de 2013. Disponible en: http://assembly.coe.int/nw/xml/XRef/Xref-XML2HTML-en.asp?fileid=19467\&lang=en (Consulta: 27 de enero de 2016)

${ }^{757}$ Pro Asyl: Pushed back. Systematic human right violations against refugees in the Aegean sea and at the Greek-Turkish land border, noviembre de 2013, p. 33. Disponible en: http://www.proasyl.de/fileadmin/fmdam/1 EU Fluechtlingspolitik/proasyl pushed back 24.01.14 a4.pdf (Consulta: 27 de enero de 2016) 758 Frontex, Annual Risk Analysis 2013, Varsovia, abril de 2013. Disponible en: http://frontex.europa.eu/assets/Publications/Risk Analysis/Annual Risk Analysis 2013.pdf (Consulta: 27 de enero de 2016)

${ }^{759}$ FIDH- EMHRN-Migreurop: Frontex, between Greece ..., op. cit., p.27
} 
desde el comienzo de la operación Poseidón ${ }^{760}$. El relator especial para los derechos de los migrantes también expresó su preocupación por las violaciones de derechos humanos cometidas en esta frontera ${ }^{761}$. Y es que además de las vulneraciones al Derecho de los refugiados, dichos informes denuncian otras violaciones a los derechos humanos, incluyendo la detención arbitraria, la violencia contra los refugiados ${ }^{762}$ y las degradantes condiciones de detención ${ }^{763}$.

La propia Agencia Frontex ha reconocido que en los dos primeros años de la operación se recibieron 27 denuncias sobre violaciones de derechos humanos, de las cuales 19 tenían que ver con expulsiones colectivas (lo que Frontex denomina "unprocessed returns"), 10 de ellas habiéndose producido en las fronteras marítimas. Otras denuncias tenían que ver con la violencia y el trato inhumano y degradante de los guardias a los migrantes. 3 de los incidentes fueron denunciados por agentes involucrados en la operación que fueron testigos directos, como intérpretes o asesores de otros estados. Uno agente de Frontex también fue acusado de golpear a un migrante. La investigación fue llevada a cabo por el país de origen, que retiró al agente implicado de la operación ${ }^{764}$.

En un informe realizado por Migreurop ${ }^{765}$, se recoge el testimonio de varios refugiados que fueron arrestados en operaciones en el marco de la JO Poseidón. Entre las denuncias realizadas se encuentran haber sido devueltos a Turquía de forma ilegal, detenciones arbitrarias durante días, robos de sus posesiones personales y dinero durante los registros, o registros realizados a mujeres por oficiales masculinos delante del resto del grupo. Además denunciaron que habían oído a los agentes hablar en alemán e italiano, lo que podría indicar la presencia de agentes de Frontex durante estos episodios. El caso más grave es de una mujer somalí, embarazada de seis meses, que fue

\footnotetext{
760 Vid. entre otras: ACNUR: Syrians in Greece: Protection Considerations and UNHCR Recommendations, 17 de abril de 2013 Disponible en: https://www.unhcr.gr/fileadmin/Greece/News/2012/Syria/pc/Greece_Syria_Note_for_Pressconference_E nglish.pdf (Consulta: 27 de enero de 2016); AI: Frontier Europe: Human Rights Abuses on Greece's border with Turkey, 2013, AI Doc. 25/008/2013. Disponible en: https://www.amnesty.org/download/Documents/12000/eur250082013en.pdf (Consulta: 27 de enero de 2016); y Pro Asyl: Pushed back..., op. cit.;

${ }^{761}$ Informe de 24 de abril de 2013, supra n. 11

${ }^{762}$ El TEDH condenó en 2012 al país heleno por violar el artículo 3 del CEDH en el caso Zontul c. Grecia. Un guardacostas heleno violó al solicitante, un refugiado turco, con una porra extensible en la isla de Creta. Zontul c. Grecia, sentencia del 17 de enero de 2012, n ${ }^{\circ}$ 12294/07. Disponible en: http://hudoc.echr.coe.int/eng?i=001-108587 (Consulta: 18 de enero de 2016)

${ }^{763}$ Vid. HRW : The EU's Dirty..., op. cit.; MSF: Invisible suffering. Prolonged and systematic detention of migrants and asylum seekers in substandard conditions in Greece, abril de 2014. Disponible en: http://www.msf.org/sites/msf.org/files/invisible suffering.pdf (Consulta: 27 de enero de 2016)

${ }^{764}$ FIDH- EMHRN-Migreurop: Frontex, between Greece..., op . cit., p. 42

${ }^{765}$ Ibíd., p. 29
} 


\section{CAPÍTULO 5}

golpeada por un agente de frontera durante una operación marítima en la que la embarcación fue retornada a Turquía.

En enero de 2014, cerca del islote de Farmakónisi, un naufragio costó la vida de 8 niños y 3 mujeres mientras su barca estaba siendo remolcada por los guardias griegos en dirección a Turquía en medio de un fuerte oleaje. El naufragio se produjo cuando la cuerda que tiraba de la pequeña barca pesquera se rompió. El buque costero no subió a borda a los migrantes, y ni siquiera les lanzó chalecos salvavidas. Los tribunales griegos condenaron a 145 años a un sirio de 21 años, que fue identificado como miembro de la red de tráfico de personas, pero a día de hoy no están esclarecidas las responsabilidades de los agentes locales. A pesar de que el incidente se produjo en el marco de la misión de JO Poseidón, Frontex se desvinculó del incidente ${ }^{766}$.

Desde que se puso en marcha el JO Poseidon hasta el momento de escribir estas líneas, el flujo de entrada de migrantes que cruzan las fronteras greco-turcas con destino a países de Unión Europea se ha mantenido en unas cantidades elevadas, llegando a su punto álgido en el verano de 2015. Los conflictos bélicos en Siria e Iraq son las principales causas que explican este movimiento migratorio; la inmensa mayoría de los que viajan por esta ruta lo hacen huyendo de la guerra y la persecución.

\subsubsection{Mare Nostrum}

La operación Mare Nostrum tiene como origen la tragedia del 18 de octubre de 2013, en la que murieron 366 migrantes ahogados cerca de la isla italiana de Lampedusa. E1 gobierno italiano lanzó la propuesta de hacer uso de un volumen considerable de navíos militares para patrullar la zona entre Italia y Libia. En un principio, tanto Frontex como la Comisión Europea se opusieron a la puesta en marcha de un operativo de este tipo. A pesar de las reticencias, el gobierno italiano siguió hacia delante de forma unilateral, lo que provocó malestar en otros gobiernos europeos. La UE se desmarcó argumentando que Frontex no contaba con ninguna base legal aplicable al tipo de actividades que desarrollaría Mare Nostrum, al integrar operaciones de $\mathrm{SAR}^{767}$. Unos meses después del

766 Pro Asyl: Analysis regarding the death of eleven refugees near the island of Farmakonisi, enero de 2015. Disponible

en: http://www.proasyl.de/en/press/press/news/analysis by pro asyl regarding the death of eleven refuge es near the island of farmakonisi-1/ (Consulta: 27 de enero de 2016)

${ }^{767}$ Comisión Europea: "Frontex Joint Operation 'Triton' - Concerted efforts to manage migration in the Central Mediterranean", nota de prensa de 7 de octubre de 2014. Disponible en: http://europa.eu/rapid/press-release_MEMO-14-566_en.htm (Consulta: 27 de enero de 2016) 
lanzamiento de la operación, la UE aprobaba el Reglamento 656/2014, que facultaba a emprender acciones de este tipo en el marco de las $\mathrm{JO}^{768}$.

Los objetivos y las funciones de la operación expresados por las autoridades italianas tampoco estaban totalmente claras. Lanzada de forma prematura como respuesta a la tragedia, presentaba unas intenciones ambiguas, donde se mezclaban propósitos humanitarios y securitarios ${ }^{769}$. Así, entre las actividades incluidas y citadas por las autoridades italianas se encontraba la vigilancia, el SAR, los procedimientos sobre el destino de los migrantes rescatados, la detención de facilitadores y el desembarco en los puertos italianos. Un rango de actividades tan amplio, la participación de cuerpos militares y unos objetivos algo difusos presenta también una amenaza ante el Estado de derecho, especialmente en lo referente al control judicial de las acciones que pudieran suponer vulneraciones de la legislación italiana o internacional. La inclusión de actividades SAR, y la presencia como actor principal a la Armada Italiana dificultaron el anclaje de la operación con el modus operandi de Frontex.

Desde 2011 Frontex venía desarrollando en la zona las JO Hermes y Aeneas, como una respuesta a los movimientos migratorios generados por la primavera árabe. El gobierno italiano fue el que formuló la petición de asistencia ${ }^{770}$, siendo el Estado anfitrión de ambas operaciones, que se mantuvieron en vigor hasta 2014. La entrada en vigor de Mare Nostrum implicó una reducción del rol de la Agencia en el área ${ }^{771}$ y una disminución de las personas interceptadas.

\footnotetext{
${ }^{768}$ Reglamento 656/2014, art. 9

${ }^{769} \mathrm{Se}$ puede consultar el comunicado emitido por la Marina italiana en: http://www.marina.difesa.it/EN/operations/Pagine/MareNostrum.aspx (Consulta: 27 de enero de 2016)

770 Frontex: "Hermes 2011 starts tomorrow in Lampedusa", nota de Prensa de 19 de febrero de 2011. Disponible en: http://frontex.europa.eu/news/hermes-2011-starts-tomorrow-in-lampedusa-X4XZcr (Consulta: 27 de enero de 2016)

${ }^{771}$ La Comisión Europea intento reposicionar su posición de autoridad central en la zona, solicitando que las operaciones lanzadas por los Estados fueran de forma coordinada con la Agencia: Staff working document - Implementation of the Commission on the work of the Task Force Mediterranean, Doc. SWD(2014) 173 final, 22 de mayo de 2014. Disponible en: http://ec.europa.eu/dgs/home-affairs/elibrary/documents/policies/legalmigration/general/docs/sdw implementation of the communication on the work of the task force $\mathrm{m}$ editerranean_part_2_en.pdf (Consulta: 27 de enero de 2016)
} 
Fig. 17. Personas interceptadas, rescatadas y facilitadores arrestados en la JO Hermes, 2013-14

\begin{tabular}{|l|c|c|c|}
\hline $\begin{array}{l}\text { Nombre de la } \\
\text { operación }\end{array}$ & $\begin{array}{c}\text { Total de personas } \\
\text { interceptadas }\end{array}$ & $\begin{array}{c}\text { Total de personas } \\
\text { rescatadas }\end{array}$ & $\begin{array}{c}\text { Facilitadores } \\
\text { arrestados }\end{array}$ \\
\hline EPN 2013 Hermes & 64.647 & 57.677 & 204 \\
\hline EPN 2014 Hermes & 28.953 & 26.877 & 76 \\
\hline
\end{tabular}

Fuente: Frontex Liaison Office, agosto de 2014

El coste de la operación para Italia se estimó en 9 millones de euros al mes ${ }^{772}$, elevándose a 114 millones durante el año que estuvo en marcha. La operación movilizó una gran cantidad de recursos bajo la coordinación del Ministerio de Defensa italiano, siendo la Armada la principal fuerza involucrada. Frontex también aportó recursos y personal de la Agencia, aunque al no tratarse de una JO propia, su rol estuvo centrado en el apoyo técnico ${ }^{773}$. El número de personas trabajado en labores de rescate y salvamento era de aproximadamente 900. En cuanto a medios, Italia puso a disposición 1 buque anfibio, 2 fragatas, 4 buques patrulla de Alta Mar y 6 costeros, 3 aviones, y 6 helicópteros ${ }^{774}$. Hasta el momento, se ha tratado de la operación más amplia y ambiciosa de salvamento y vigilancia fronteriza marítima en el mar Mediterráneo.

El siguiente mapa muestra el despliegue geográfico de Mare Nostrum. Su radio de acción se extiende hasta 75 millas $(120 \mathrm{~km})$ al sur de Sicilia, ocupando la mayor parte del Mediterráneo Central, incluyendo zonas que pertenecían a las áreas SAR de Malta y Libia:

${ }^{772}$ Carrera, S. y den Hertog, L.: Whose Mare? ..., op. cit., p. 3

${ }^{773}$ Entre otras ayudas, el gobierno italiano recibió fondos por 23 millones en concepto de prestaciones de urgencia tras la tragedia de Lampedusa. Comunicación de la Comisión al Parlamento Europeo y al Consejo, V Informe Anual de Migración y Asilo, $\operatorname{COM(2014)~} 288$ final, de 22 de mayo de 2014, p. 6. Disponible en: http://ec.europa.eu/transparency/regdoc/rep/1/2014/ES/1-2014-288-ES-F1-1.Pdf (Consulta 27 de enero de 2016)

774 AI: La vergüenza de Europa, a pique. Omisión de socorro a refugiados y migrantes en el mar, Doc. EUR 03/1434/2015, abril de 2015, p. 13. Disponible en: https://www.amnesty.org/es/documents/eur03/1434/2015/es/ (Consulta: 27 de enero de 2016) 


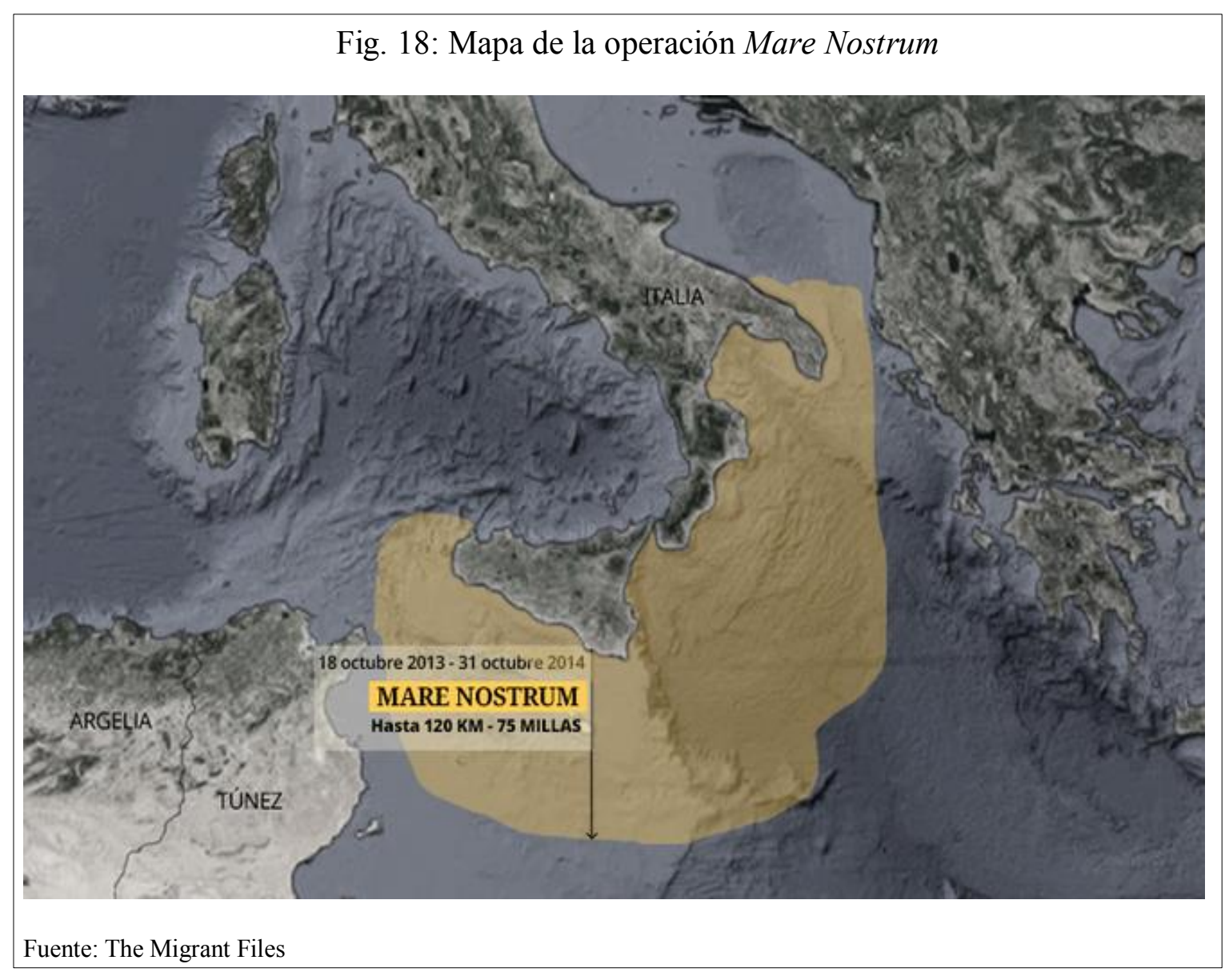

Durante el periodo de la operación Mare Nostrum, las autoridades italianas rescataron a más de 166.000 personas. De ellas, casi 83.000 fueron rescatadas por naves de Mare Nostrum o la Marina italiana; más de 38.000 por los guardacostas italianos; más de 42.000 por buques mercantes, coordinados por el Centro de Coordinación de Salvamento Marítimo (RCC) de Roma; y 1.700 por la policía de aduanas italiana, individuos particulares y agentes de Frontex. Durante esos dos años 499 personas murieron ahogadas y 1.446 desaparecieron en el mar. También fueron arrestados 728 traficantes. Gil Arias, director ejecutivo de Frontex en ese momento, ofreció datos sobre la ruta migratoria del Mediterráneo Central, que cubría Mare Nostrum. En 2014, Libia fue el punto de partida del $86 \%$ de los viajes por mar a Europa, siendo eritreos (23\%) y sirios (17\%) las nacionalidades de los migrantes más numerosas. Estos datos muestran que, aunque el sistema ordinario de búsqueda y salvamento, basado en los servicios de guardacostas y buques mercantes, puede salvar a decenas de miles de personas con procedimientos adecuados y seguros.

El carácter unilateral con el que se lanzó Mare Nostrum generó otra polémica en lo relativo a la gestión de las solicitudes de asilo de las personas rescatadas. Las autoridades italianas no tuvieron en cuenta los requisitos establecidos por el Reglamento 


\section{CAPÍTULO 5}

de Dublín para la gestión de las solicitudes, como la impresión de huellas digitales ${ }^{775}$. En consecuencia, no se respetó el principio de que dichas personas realizaran la solicitud de asilo en el primer país por el que ingresaran a Europa, desplazándose en su mayoría a países del norte de Europa y realizándola la solicitud allí. El sistema de asilo italiano no estaba preparado para recibir tal cantidad de refugiados, ni en términos de capacidad para gestionar todas las solicitudes en un tiempo adecuado ni para posibilitar unas condiciones de acogida dignas para tal cantidad de personas ${ }^{776}$. Es evidente que, teniendo esto en mente cuando se lanzó la operación, el gobierno italiano contaba con no hacerse cargo de sus responsabilidades respecto a los potenciales solicitantes de asilo que fueran rescatados por sus buques en las operaciones de rescate.

Debemos reconocer y felicitarnos por los esfuerzos emprendidos por Italia en la operación Mare Nostrum, que contribuyeron al salvamento de miles de vidas en peligro en el mar. Las autoridades italianas movilizaron una gran cantidad de recursos personales y materiales, y colocaron sus deberes de salvamento marítimo como un objetivo prioritario de su actuación como no había hecho ningún país europeo antes. Sin embargo, esto no le exime de sus responsabilidades respecto a las personas rescatas, especialmente respecto a las que pudieran ser beneficiarias de protección internacional, MENAs y otros colectivos en situación de vulnerabilidad. Dichas personas se encontraban sin ningún género de dudas bajo la jurisdicción italiana durante todo el proceso: fueron rescatadas o interceptadas por sus navíos militares o de salvamento y desembarcados en sus puertos. Las operaciones estuvieron coordinadas bajo el mando del ministerio de Defensa en conjunción con el RCC nacional. Italia evitó hacerse cargo de todas las tareas que le correspondían según el derecho internacional y comunitario. Posiblemente una solución deseable habría sido que el reparto de las cargas de recepción y gestión de las solicitudes se hubieran gestionada a través de la cooperación con otros Estados europeos. El carácter unilateral de la operación impidió cualquier posible solución conjunta, ya que muchos EEMM, Frontex y la Comisión Europea se mantuvieron desinformados tanto del diseño como de la ejecución de la operación. La decisión italiana de desentenderse supuso un abandono de sus responsabilidades contenidas en la CG51 y el Reglamento de Dublín.

Por su parte, otros gobiernos europeos centraron sus críticas en el posible 'efecto llamada' que podía generar una operación de esta envergadura centrada en el SAR. E1

\footnotetext{
${ }^{775}$ Fargues, Philippe y Bonfanti, Sara: "When the best option is a leaky boat: why migrants risk their lives crossing the Mediterranean and what Europe is doing about it". European University Institute, Florence, Migration Policy Centre Policy Brief, No. 5, octubre de 2014, p. 13. Disponible en: http://cadmus.eui.eu/bitstream/handle/1814/33271/MPC PB 2014-05.pdf?sequence=1\&isAllowed=y (Consulta: 27 de enero de 2016)

${ }^{776}$ Carrera, S. y den Hertog, L.: Whose Mare? ..., op. cit., p. 5
} 
gobierno británico y el director de Frontex afirmaron que su existencia suponía un incentivo para los inmigrantes. Este último declaró que:

... the number of trips and of persons has drastically increased with the launching of Mare Nostrum. I am afraid of saying it is a pull factor, but the smugglers have abused the proximity of this operation near to the Libyan coast to put more people in the sea with the assumption that they would be rescued very soon. This made it cheaper for them, they put less fuel, less food and less water on the boats which at the same time increases the risks of the migrants. ${ }^{777}$

La polémica sobre Mare Nostrum se reprodujo durante 2014 en el seno del propio gobierno italiano, con diferencias sobre la renovación de la operación ${ }^{778}$. En octubre de 2014, ante la falta de acuerdo, se declaró el término de la operación con un periodo de transición de dos meses ${ }^{779}$. El final de Mare Nostrum ha incrementado la presión sobre los buques mercantes para rescatar a refugiados y migrantes. El 31 de marzo de 2015, los representantes de la principal asociación del sector naval y de los sindicatos de marinos expresaron de manera inequívoca su preocupación:

Es inaceptable que la comunidad internacional dependa cada vez más de los buques mercantes y los marinos para llevar a cabo cada vez más salvamentos y a mayor escala, en una situación en la que un solo buque tiene que rescatar a hasta 500 personas de una sola vez. Los buques mercantes no están equipados para llevar a cabo operaciones de salvamento en tan gran escala, y eso genera además graves riesgos para la seguridad, la salud y el bienestar de los tripulantes, de quienes no debería esperarse que tuvieran que hacer frente a tales situaciones. ${ }^{780}$

En agosto de 2014, ante la cercanía a la fecha de finalización de Mare Nostrum, la comisaria de interior Cecilia Malmström planteó sustituirla progresivamente por la

\footnotetext{
777 Director Ejecutivo de Frontex Gil Arias durante la presentación ante el Comité de Libertades Civiles, Justicia y Asuntos de Interior del Parlamento Europeo, el 4 de septiembre de 2014. Citado en: Carrera, S. y den Hertog, L.: Whose Mare? ..., op. cit., p. 4

778 The Guardian: "Italian navy says it will continue refugee rescue mission despite plan to scrap it", The Guardian, 28 de octubre de 2014. Disponible en: http://www.theguardian.com/world/2014/oct/28/italiannavy-refugee-rescue-mission-mare-nostrum (Consulta: 27 de enero de 2016)

779 Consejo de Justicia y Asuntos de Interior: "Conclusions on "Taking action to better manage migratory flows", Luxemburgo, 10 de octubre de 2014. Disponible en: http://www.consilium.europa.eu/uedocs/cms data/docs/pressdata/en/jha/145053.pdf (Consulta: 27 de enero de 2016)

${ }^{780}$ AI: La vergüenza ..., op. cit., p.21
} 


\section{CAPÍTULO 5}

operación "Frontex Plus"781. Esta preveía fusionar las dos JOs de Frontex que se estaban desarrollando en el Mediterráneo central, Hermes y Aeneas. Finalmente fue sustituido por el programa Tritón, que convergía las dos JO de Frontex. Aunque inicialmente la idea era cubrir la misma área que Mare Nostrum, el alcance de la vigilancia de esta operación se redujo a 30 millas de las costas italianas. El programa se puso en marcha el 1 de noviembre de 2014, justo el día siguiente de la finalización de Mare Nostrum. Gil Arias Fernández, presidente de Frontex, reconoció los límites impuestos por los objetivos de la agencia: "Tritón nace para vigilar las fronteras, no para operaciones de búsqueda y socorro". Tritón, que es una operación de gestión de fronteras encomendada a patrullas fronterizas, y no una operación de búsqueda y salvamento, cuenta con barcos más pequeños, menos aviones y menos personal que Mare Nostrum. Hasta el momento contaba con un personal de 65 agentes, 4 aviones, 7 barcos y un helicóptero. El mandato de la misión finaliza en diciembre de 2015. E1 presupuesto también era menor: 2,9 millones $€$ por mes. Según Frontex el programa ha salvado 22.300 vidas $^{782}$.

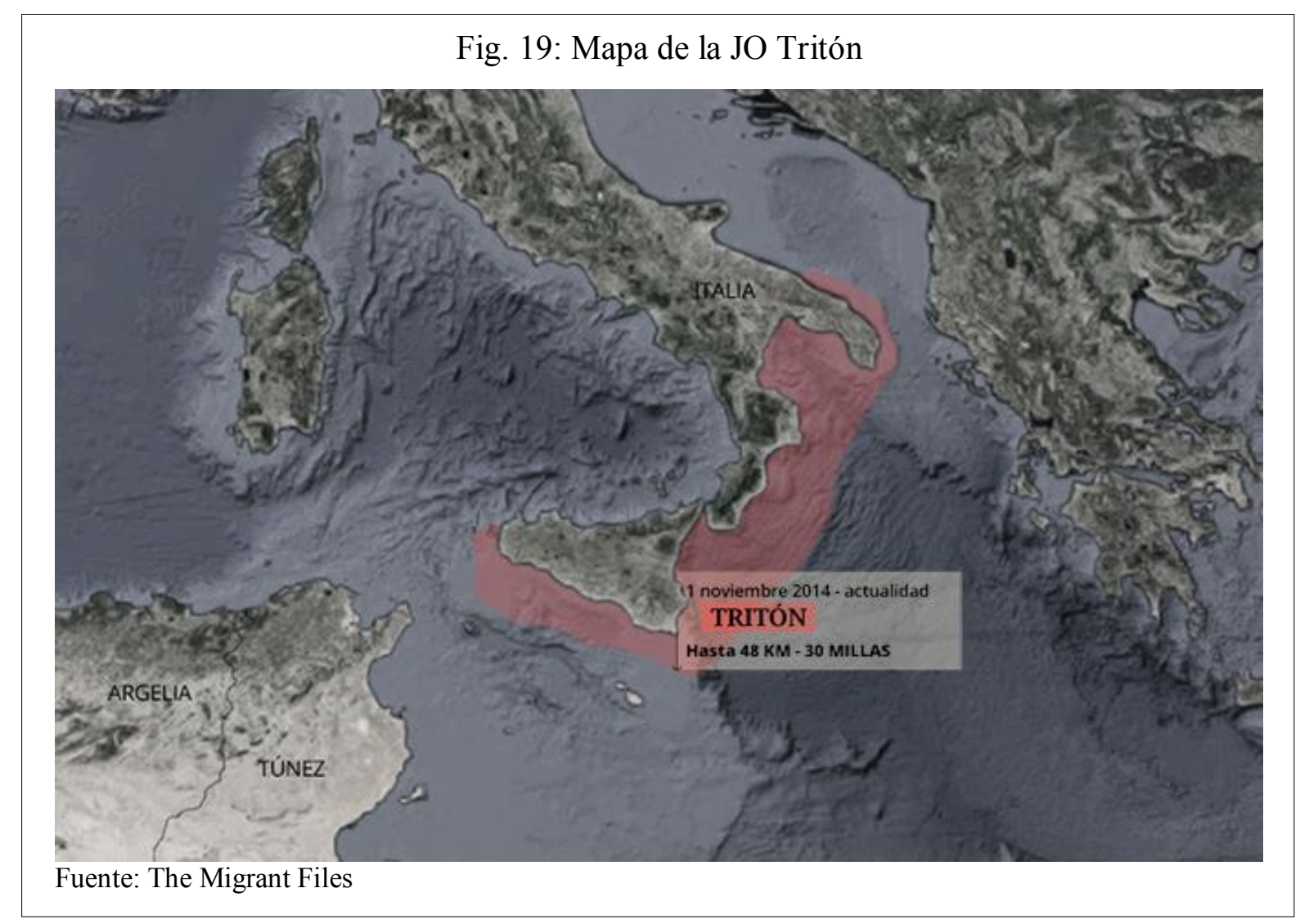

781 Frontex: Concept of reinforced joint operation tackling the migratory flows towards Italy: JO EPN Triton - to better control irregular migration and contribute to SAR in the Mediterranean Sea, Varsovia, 28 de agosto de 2014, p. 10. Disponible en: http://www.proasyl.de/fileadmin/fmdam/q PUBLIKATIONEN/2014/JOU Concept on EPN-TRITON 2 .pdf (Consulta: 27 de enero de 2016)

782 Frontex: "Joint Operation Triton extended to the end of 2015 ", nota de prensa de 21 de febrero de 2015. Disponible en: http://frontex.europa.eu/news/joint-operation-triton-extended-to-the-end-of-2015NXCwpk (Consulta: 27 de enero de 2016) 
$\sum$ Capítulo 6

\section{Conclusiones}





\section{Conclusiones}

El 12 de abril de 2015, la guardia costera italiana rescató a 142 supervivientes de un naufragio a unas 80 millas náuticas de a las costas de libia. La investigación llevada a cabo por la OIM indicó que murieron hasta 400 personas ${ }^{783}$. Apenas una semana después otro barco naufragó en la misma zona con más de 850 migrantes a bordo. E1 número de supervivientes fue de apenas $28^{784}$. La inmensa mayoría de los cuerpos de estas tragedias no pudieron ser rescatados. Dichos siniestros han marcado hasta el día de hoy el punto más elevado de la siniestra cuenta de migrantes fallecidos en el mediterráneo mientras intentaban alcanzar las costas europeas. Las principales instituciones europeas presentaron documentos y declaraciones sobre la tragedia instando a la toma de medidas ${ }^{785}$. En mayo la Comisión Europea presentó la "Agenda Europa de Migración"786, con la intención de sentar las bases para las reformas en política migratoria y de asilo en los próximos años. Las principales líneas de la Agenda eran la lucha contra las redes de traficantes, el control de la entrada y las solicitudes de asilo mediante huellas dactilares y refuerzos de las agencias Frontex y EASO, las políticas de retorno y colaboración con los países de origen y tránsito. Como novedades, la promesa para 2016 de una norma que consolide y abarque todos los aspectos de la gestión de las fronteras exteriores de la Unión ${ }^{787}$. Dentro de este ámbito, se apela a mejorar en la coordinación fronteriza y aumentar los recursos de las operaciones marítimas de Frontex.

En los meses siguientes a la tragedia, la UE tuvo que afrontar el incremento en la llegada de cientos de miles de refugiados procedentes de Siria y otros países de la región que huyen de la guerra de su país y buscan un futuro estable y seguro en el continente europeo. La mayoría de ellos lo hicieron cruzando el mar Egeo de Turquía a Grecia. Según datos de la OIM, las cifras de migrantes irregulares y refugiados que llegaron a Europa en 2015 alcanzaron el millón de personas, el número más alto desde

\footnotetext{
${ }^{783}$ AI: La vergüenza de Europa..., op. cit., p. 4.

${ }^{784}$ ACNUR: Mediterranean boat capsizing: deadliest incident on record, nota de prensa del 21 de abril de 2015. Disponible en: www.unhcr.org/553652699.html (Consulta: 28 de enero de 2016)

785 El 20 de abril la Comisión Europea presentó un plan de 10 puntos sobre migraciones (http://ec.europa.eu/spain/actualidad-y-prensa/noticias/justicia-libertad-y-seguridad/euco-

inmigracion es.htm). El 23 el Consejo Europeo celebró una reunión extraordinaria, donde establecía como prioridad "evitar que más personas mueran en el mar" (http://www.consilium.europa.eu/es/press/press-releases/2015/04/23-special-euco-statement/) y el 29 el Parlamento aprobaba una resolución sobre la tragedia en el mediterráneo y las políticas migratorias y de asilo (http://www.europarl.europa.eu/sides/getDoc.do?type=TA\&language=EN\&reference=P8-TA-20150176)

${ }_{786}^{78}$ Agenda Europa de Migración, supra n. 249

${ }^{787}$ Ibíd., p. 13
} 


\section{CAPÍTULO 6}

la II Guerra Mundial. Según los mismos datos, el número de migrantes que perdieron la vida durante el trayecto fue de $3.724^{788}$.

Fig. 20: Llegadas de migrantes irregulares y refugiados por vía marítima y terrestre, y fallecidos durante el trayecto a Europa, 2015

\begin{tabular}{|c|c|c|c|c|}
\hline Grecia & 821.008 & 816.752 & 4.256 & 731 \\
\hline Italia & 150.317 & 150.317 & - & 2.889 \\
\hline Bulgaria & 29.959 & - & 29.959 & - \\
\hline España & 3.845 & 3.845 & - & 104 \\
\hline Chipre & 269 & 269 & - & - \\
\hline Malta & 106 & 106 & - & - \\
\hline Total & $\mathbf{1 . 0 0 5 . 5 0 4}$ & $\mathbf{9 7 1 . 2 8 9}$ & $\mathbf{3 4 . 2 1 5}$ & $\mathbf{3 . 7 2 4}$ \\
\hline
\end{tabular}

Fuente: OMI: Irregular Migrant, Refugee...op. cit.

Aunque en principio los gobiernos europeos no parecieron darse por enterados, la presión social y mediática tras la fotografía que mostraba la muerte del niño sirio Alan Kurdi en septiembre de 2015 provocó una catarata de reuniones, declaraciones y propuestas de revisión de Schengen, el SECA y la misión de Frontex. En noviembre se celebró una cumbre extraordinaria sobre migración el La Valeta (Malta), donde se presentó un plan de acción con cinco puntos. El documento seguía la senda de la "Agenda" presentada en abril, enfatizando en la cooperación en los países de origen y tránsito para evitar la emigración y facilitar el retorno y readmisión ${ }^{789}$. En esta línea se enmarca el reciente acuerdo con Turquía, del que hemos hablado en el capítulo 3.

La más reciente propuesta de la Comisión Europea, del 15 de diciembre, es la creación de una agencia de "Guardia Europea de Fronteras y Costas", con la finalidad de "proteger las fronteras exteriores"790. La propuesta incluye la posibilidad de que los agentes europeos actúen incluso aunque los EEMM no hayan realizado una solicitud, si

\footnotetext{
788 Irregular Migrant, Refugee Arrivals Top One Million in Europe, nota de prensa del 22 de diciembre de 2015. Disponible en: https://www.iom.int/news/irregular-migrant-refugee-arrivals-europe-top-onemillion-2015-iom (Consulta: 28 de enero de 2016)

${ }^{789}$ Plan de actuación del Consejo Europeo, aprobado en la Cumbre de La Valeta sobre migración, 11 y 12 de noviembre de 2015. Disponible en: http://www.consilium.europa.eu/en/meetings/internationalsummit/2015/11/ACTION PLAN EN pdf/ (Consulta: 28 de enero de 2016)

${ }^{790}$ Proposal for a Regulation of the European Parliament and of the Council on the European Border and Coast Guard and repealing Regulation (EC) No 2007/2004, Regulation (EC) No 863/2007 and Council Decision 2005/267/EC, COM (2015) 671 final, Comisión Europea, Estrasburgo, 15 de diciembre de 2015. Disponible en: http://ec.europa.eu/dgs/home-affairs/what-we-do/policies/securing-eu-borders/legaldocuments/docs/regulation on the european border and coast guard en.pdf (Consulta: 28 de enero de 2016)
} 
la Comisión considera que existe una "presión migratoria desesperada" y el gobierno concreto no ha aplicado las medias coercitivas decididas por la agencia ${ }^{791}$. Más preocupante sería otra medida incluida, que incluye la creación de equipos dependientes de la agencia encargados de la devolución de migrantes irregulares en situaciones de emergencia ${ }^{792}$.

La respuesta de la Unión Europea ahonda en las mismas líneas que han vertebrado sus políticas sobre migración y gestión fronteriza en los últimos años: represión de la migración clandestina, agilización del retorno de irregulares, externalización de las fronteras y enfoque securitario. La evolución de los flujos migratorios en los últimos años, hasta llegar a la actual crisis nos muestra que dichas políticas no son eficaces para los objetivos que se plantean. Lo que es más grave, las crecientes dificultades que se les plantean a los migrantes y refugiados durante su viaje a Europa favorecen las vías irregulares, las redes de tráfico y las rutas más peligrosas, y como resultado de ello, ponen en riesgo su vida, seguridad y otros derechos básicos. Hasta que la UE no abandone una mirada centrada en la seguridad, que ve los flujos migratorios como una amenaza, el respeto absoluto a los derechos humanos de los migrantes y refugiados no será posible. En el caso de aquellas personas que escapan de la guerra o la persecución en sus países, estas medidas obstaculizan el acceso a la protección internacional de la que podrían ser beneficiarias en caso de alcanzar el territorio del país de destino.

En el presente trabajo hemos visto las consecuencias prácticas de dichas políticas en la frontera marítima del sur de Europa. La interceptación y devolución de embarcaciones en alta mar, la cooperación con los países de origen para impedir que salgan desde sus costas o las devoluciones "en caliente" vulneran las obligaciones internacionales de los Estados europeos al negar el acceso al proceso de asilo mediante la imposibilidad de acceder al territorio del Estado o, incluso habiéndolo hecho, sitiándoles en un limbo jurídico donde sus derechos no gozan del debido reconocimiento, con la finalidad de expulsarles de dicho país. Estos sucesos ilustran el carácter violento de la soberanía, tal como denunciaba Agamben, capaz de infringir la muerte y excluir la vida de la esfera de la protección legal.

El argumento usado por los Estados de que estas personas no se encuentran dentro del territorio europeo constituye el principal argumento para negar su responsabilidad respecto de los refugiados que interceptan o rescatan en el mar

\footnotetext{
791 Ibíd., art. 18

${ }^{792}$ Ibíd., art. 31
} 


\section{CAPÍTULO 6}

Mediterráneo. Al reducir la complejidad de los flujos mixtos que compone esta ruta, la UE convierte su política migratoria en una mera cuestión de gestión fronteriza cuyo único objetivo es reducir los números de entradas irregulares al área Schengen. Con ese fin se legitima cualquier acción que pueda alejar el problema de la 'Fortaleza Europea': aceleración de los plazos y arbitrariedad en los procedimientos de frontera, cooperación con los Estados vecinos para el control de la migración, push backs de las embarcaciones que se aproximan a nuestras aguas territoriales, externalización del procedimiento de asilo a oficinas ubicadas en terceros países, restricciones en la concesión de visados y reagrupamiento familiar, etc...

Como vimos en el cuarto capítulo, este argumento esconde una trampa. Al llevar fuera de su territorio la gestión fronteriza y los primeros pasos del procedimiento de asilo, los Estados pretenden de este modo quedar fuera del control del Derecho Internacional sobre sus obligaciones de respeto y protección de los derechos humanos. El DIDH ha puesto el foco reiteradamente en la noción de jurisdicción, definida como la relación que se da entre un individuo y el Estado, antes que en la territorialidad para fijar la existencia de obligaciones estatales de derechos humanos. Los estados no pueden argumentar que los refugiados no han llegado a su territorio y que, por tanto, no tienen ninguna responsabilidad respecto de ellos. El propio ejercicio de su soberanía les faculta para efectuar controles fronterizos hasta los mismos límites de su mar territorial, el Derecho del Mar les otorga ciertas facultades de actuación el Alta Mar y mediante la cooperación con los países de origen ejercen funciones policiales en territorio de terceros Estados. Es profundamente incoherente otorgarse la capacidad de ejercer su poder en estos escenarios mientras se rehúye de las responsabilidades internacionales que lleva aparejadas.

Los Estados, en resumen, tienen obligaciones respecto de los refugiados fuera de su territorio, pero dentro de su jurisdicción. Las personas se encuentran sujetas a la jurisdicción de un Estado cuando se hallan bajo su control efectivo o se ven afectadas por su autoridad o la de sus agentes, independientemente del lugar donde este poder se ejerza. Se deduce pues que la prohibición de expulsar a personas a países donde pudiera estar en peligro su vida o seguridad, será imperativa para cualquier persona que actúe bajo la autoridad de un Estado, sea en su territorio, en Alta Mar o en las aguas territoriales de un tercer Estado.

Debido al escenario donde toma lugar, la situación derivada de la aplicación del principio de non-refoulement según el DIDH se entrecruza con las disposiciones que el Derecho del Mar establece sobre el viaje y las embarcaciones irregulares en las que 
migrantes y refugiados suelen viajar, así como sobre las operaciones de salvamento marítimo y la situación de peligro en la que se encuentran. En el capítulo quinto hemos constatado la inadecuación de las normas internacionales para proteger las vidas de las personas en peligro, debido a las ambiguas definiciones respecto qué Estado tiene el deber de dirigir la operación de salvamento y donde desembarcar a dichas personas, y la inexistencia de mecanismos de control y vigilancia ante el incumplimiento o la pobre implementación de las obligaciones contenidas en los principales instrumentos del Derecho del Mar. En su análisis del caso MV Tampa en 2004, Richard Barnes señaló tres lagunas legales que dificultaron una solución plausible a la crisis: la decisión sobre si un buque disfruta del derecho de paso inocente en las aguas territoriales de un Estado; sobre si un buque se encuentra en peligro y puede dirigirse a un puerto a desembarcar pasajeros; y el derecho de un Estado a permitir o no la entrada de solicitantes de asilo en dicho desembarco ${ }^{793}$. A pesar de las reformas de los tratados SAR y SOLAS y numerosos nuevos casos durante la última década, ninguna de las tres cuestiones ha sido resuelta. Continua, como en aquel momento, sin resolverse el abismo legal que obliga a los Estados a rescatar y proporcionar asistencia a las personas en peligro en el mar mientras no establece ninguna regla sobre donde tienen que ser desembarcadas esas mismas personas.

El enfoque que hemos mantenido en el presente trabajo es aquella que pretende ubicar en el centro del problema la vida y derechos de las personas involucradas, tanto si son consideradas como migrantes irregulares, refugiadas o en una situación de peligro en el mar. Desde una perspectiva de derechos humanos, ante una situación donde se entrecruzan diferentes ámbitos jurídicos e intereses contrapuestos de los actores implicados, cualquier opción que no sea la preeminencia del respeto y protección de los derechos de dichas personas supone un claro retroceso para la construcción de una sociedad más justa. El control y gestión de los flujos migratorios, el coste de la acogida de los solicitantes de asilo o los intereses políticos nacionales nunca deberían tener preferencia ante el menoscabo de los derechos humanos más esenciales.

Con este principio de actuación en mente, y partiendo de lo analizado a lo largo del presente trabajo, me permito formular una serie de propuestas para mejorar la protección de las personas migrantes y refugiadas que viajan a Europa por la vía marítima. Muchas de estas ya han sido recogidas por organizaciones como ACNUR, la OIM u organizaciones no gubernamentales, entre las que debemos hacer especial mención a dos de ellas por la diversidad y profundidad de sus propuestas, que ponen el énfasis en las necesidades de los refugiados, por encima de los intereses de los Estados: la resolución del Consejo de Europa sobre interceptación y salvamento de solicitantes

${ }^{793}$ Barnes, R.: Refugee Law... op. cit., p. 13 


\section{CAPÍTULO 6}

de asilo, refugiados y migrantes irregulares de $2011^{794}$, y la iniciativa del ACNUR sobre protección en el mar $^{795}$.

Antes de comenzar, creo necesario hacer una precisión. La enunciación de un listado de recomendaciones en tesis y otros textos es una parte necesaria y consecuente del análisis realizado, especialmente cuando tratan como la presente de temas jurídicos y políticos. Permiten identificar las fallas o injusticias que provocaron el interés del investigador, y proponer modificaciones que podrían eliminarlas o al menos paliarlas. Sin embargo, en muchas ocasiones éstas se presentan como aportaciones "técnicas" que permiten alumbrar una solución a un enigma irresuelto, pareciendo pues que las causas de dicho problema hubieran surgido del desconocimiento o la incompetencia. Si algo podemos colegir de todo lo visto hasta ahora es que no es el enfoque adecuado. Las motivaciones e intereses que orientan las normativas y las políticas públicas pueden no ser las mismas que persigue el investigador. La definición de cuál es el problema es, por tanto, esencial. En las últimas décadas la Unión Europea ha señalado como sus principales preocupaciones en ésta área la entrada de migrantes de forma irregular, los costes derivados de la acogida de solicitantes de asilo o la agilización de los retornos. No son, obviamente, los que han orientado este trabajo. Las propuestas aquí formuladas están enfocadas a mejorar la protección de los derechos de las personas migrantes y refugiadas, garantizando un tránsito seguro, un trato digno y la imposibilidad de ser devueltos a países donde no se respeten los derechos humanos básicos.

- Las diversas declaraciones y agendas europeas obvian una de las respuestas más importantes para garantizar la vida y seguridad de las personas refugiadas: proporcionarles vías seguras y legales de acceder a Europa, ya sea a través de la posibilidad de solicitar asilo en las embajadas y consulados, otorgar visados humanitarios o aumentando los números de los planes de reasentamiento. Ambas posibilidades disminuirían los incentivos para viajar de forma clandestina, disminuiría el poder de las organizaciones que trafican con migrantes e impediría que estos tuvieran que embarcarse en viajes peligrosos que pondrían en peligro su vida. Los planes de reubicación aprobados por la UE en 2015 no forman parte de esta solución, en tanto que solo pueden beneficiarse de ellos quienes ya han alcanzado territorio europeo. En el caso de la crisis que producen un gran número de refugiados, los procedimientos de reagrupación o extensión familiar son largos e inciertos. Muchas personas inician viajes peligrosos a pesar de que tienen en Europa familiares que son beneficiarios de protección internacional.

\footnotetext{
${ }^{794}$ Consejo de Europa: Resolución 1821 (2011), supra n. 665

795 ACNUR: Global Iniciative on Protection at Sea, High Commissioner's Dialogue on Protection Challenges mayo de 2014. Disponible en: http://www.unhcr.org/5375db0d9.html (Consulta: 29 de enero de 2016)
} 
- Las políticas represivas ante la migración clandestina tienen el efecto paradójico de beneficiar a las redes de tráfico. Las penalizaciones por entrada ilegal al territorio deben ser removidas, especialmente para aquellas personas susceptibles de ser merecedoras de protección internacional. Otra medida relativa al control de fronteras y que implica un obstáculo para el acceso de refugiados a la UE es la exigencia previa de un visado, práctica que repercute directa $-\mathrm{y}$ negativamente- en su búsqueda de asilo. Desde esta perspectiva no parece favorable la última modificación del régimen de visados para entrar en la $\mathrm{UE}^{796}$. La nueva norma establece que si un Estado miembro detecta aumentos repentinos y sustanciales durante 6 meses del número de solicitudes de asilo presentadas por nacionales de un país exento de visado (y cuyas tasas de reconocimiento de refugiados son bajas), podrá notificarlo a la Comisión Europa siempre que este aumento represente una presión específica sobre su sistema de asilo. Se trata de una "situación de emergencia" que dicho Estado miembro no podrá resolver por sí solo y se suspenderá entonces la exención de visado para nacionales de este tercer país ${ }^{797}$. Se considera que una tasa de reconocimiento de solicitudes de asilo es baja cuando se encuentra en torno al 3 o $4 \%{ }^{798}$. No obstante, este porcentaje puede ser superior si la Comisión lo considera aplicable al caso concreto notificado por el Estado miembro de que se trate. La lucha contra las redes de tráfico debe incluir un análisis de sus causas; las crecientes dificultades para la entrada legal a Europa fomentan la creación y fortalecen estas redes. Ante una migración forzosa pocas barreras se pueden poner eliminando las personas y organizaciones que intermedian el trayecto. Así mismo, las víctimas de redes de trata y tránsito de personas deben ver mejoradas su protección y asistencia.

- Los Estados europeos deben cumplir de forma tajante terminal inmediata con sus obligaciones internacionales en materia de salvamento marítimo. El deber de salvar vidas no puede verse menoscabado por los intereses nacionales, el coste financiero o cualquier otra excusa. Frontex debe incorporar funciones SAR en sus operaciones, o a través de la coordinación con los RCCs nacionales poner a disposición sus recursos ante cualquier necesidad de salvamento. Debería, además, estar capacitada para llevar a cabo operaciones más extensas en regiones como la frontera greco-turca, donde existe actualmente una necesidad

\footnotetext{
${ }^{796}$ Reglamento (UE) n ${ }^{\circ}$ 1289/2013 del Parlamento Europeo y del Consejo, de 11 de diciembre de 2013, por el que se modifica el Reglamento (CE) n ${ }^{\circ} 539 / 2001$ del Consejo por el que se establece la lista de terceros países cuyos nacionales están sometidos a la obligación de visado para cruzar las fronteras exteriores y la lista de terceros países cuyos nacionales están exentos de esa obligación. DO L 347 de 20 de diciembre de 2014, pp. 74-80. Disponible en: http://eur-lex.europa.eu/legalcontent/ES/TXT/PDF/?uri=CELEX:32013R1289\&from=ES (Consulta: 28 de enero de 2016)

797 Ibíd., art. 1 bis (2)

798 Ibíd., considerando 6
} 
imperiosa de salvar vidas. La vergonzosa pasividad está provocando que el rescate de personas esté quedando en manos de organizaciones privadas ${ }^{799}$.

- Con respecto al desembarco, la normativa marítima internacional, en concreto los Convenios SAR y SOLAS, deben incorporar en su próxima modificación criterios relacionados con la seguridad física y jurídica de las personas rescatadas, especialmente en relación al respeto de sus derechos fundamentales. Por ejemplo, en la regla 33.1-1 del convenio SAR, donde específica la extensión de la obligación de llevar a las personas rescatadas a un lugar seguro, o la definición de situación de peligro. Es necesario además que la definición sea de mayor precisión, con el fin de no dar espacio a interpretaciones arbitrarias de los Estados involucrados. Así mismo, se debe clarificar la forma de compensar a los buques privados que se ven involucran en operaciones de salvamento. Las últimas reformas de los Convenios SAR y SOLAS parecen marcar una evolución hacia otorgar mayores responsabilidades en los Estados responsables del área SAR donde se produce el incidente. Por otro lado, el enfoque defendido por ACNUR sigue siendo el del "next port of call" 800 . La normativización de esta postura tendría una serie de ventajas, como el establecimiento de una obligación internacional clara para los Estados, o reduciría la carga e incertidumbre de los buques privados involucrados en las operaciones de salvamento. Sin embargo, y en el caso específico del Mediterráneo, no sería un cambio positivo. Primero, no resolvería la cuestión en el caso de las interceptaciones realizadas en operaciones de vigilancia marítima. Segundo, facilitaría que los Estados europeos desembarcaran a los migrantes y refugiados en los países de origen del viaje como Libia o Turquía, sobre todo en el caso de los naufragios que se producen cerca de sus costas. Ya vimos como esto provocaría una violación del principio de non-refoulement en numerosos casos. Tercero, otorgaría a los patrones de los buques privados una responsabilidad excesiva en la decisión sobre el destino de las personas rescatadas. Finalmente, parece además una opción poco viable en cuanto para su aprobación necesitaría el acuerdo de los Estados costeros y de destino, que no en el momento actual no parecen proclives de aceptar una obligación de este tipo.

- Tanto en las JO de Frontex como en las operaciones de interceptación de los Estados del sur de Europa, se deben introducir protocolos y salvaguardas para garantizar que cualquier medida respete el principio de non-refoulement de las personas que viajan en las embarcaciones. Deben ser provistos de información

\footnotetext{
799 Algunas de las iniciativas más visibles han sido las de MSF (mediterraneo.msf.es) o la organización maltesa MOAS (www.moas.eu/) que han fletado barcos para efectuar operaciones de salvamento en el Mediterráneo. También se han producido iniciativas ciudadanas de voluntarios compuestas por bomberos (proemaid.org) o socorristas (www.proactivaopenarms.org/) para rescatar a náufragos en las costas griegas.

${ }^{800}$ Vid. Conclusión general n. ${ }^{\circ} 53$ (XXXIX), op. cit.
} 
sobre sus derechos, tener la posibilidad de ser escuchados y atenderse sus necesidades más urgentes. Además, se debe continuar en la formación a los oficiales de inmigración y frontera con contenido en derechos humanos y de los refugiados, continuando con el positivo avance reflejado en el Código de Conducta de Frontex.

- Estas salvaguardas deben extenderse a la cooperación con los países de origen y tránsito, especialmente en los acuerdos de readmisión y las operaciones de vigilancia marítima conjunta. En el primer caso los últimos acuerdos firmados por la UE incluyen una cláusula de protección de derechos humanos, aunque en caso de incumplimiento no parece claro cuáles son las consecuencias. Debe incluir, de forma primordial, fórmulas que impidan los refoulements indirectos.

- Dado el escenario político, y la presencia de diferentes actores e intereses, aquellas soluciones que promuevan una mayor cooperación entre las partes tiene más visos de ser exitosa. Desligar las labores de salvamento, el puerto de desembarco y el país encargado del procedimiento de asilo puede facilitar la puesta a disposición de mayores medios en las operaciones de salvamento. Si países mediterráneos como Italia y Malta tuvieran la certeza de que, en caso de que entre las personas rescatadas existan refugiados, no tendrá que hacerse cargo de todas las solicitudes puede permitir que sea más fácil movilizar recursos (técnicos, materiales y políticos) para salvar vidas. Tanto ACNUR como la EASO pueden y deben jugar un rol más importante en la determinación de su destino. Es interesante recordar, tal como ha hecho Van Selm y Cooper ${ }^{801}$, que la solución que se dio a la crisis de refugiados vietnamitas en los años ochenta tuvo como principio la cooperación, con los programas DISERO y RASRO ${ }^{802}$. Es menos entendible entonces que ante el incremento en la llegada de refugiados a Europa en los últimos años, y siendo la UE un espacio de mayor integración política que Naciones Unidas, los Estados hayan optado por privilegiar sus intereses nacionales y reducir la cooperación hasta el mínimo. El proyecto de apoyo a la asistencia, identificación e información de migrantes y solicitantes de asilo en el sur de Italia Praesidium ${ }^{803}$, en el que participan ACNUR, la IOM, Cruz Roja y Save the Children puede suponer un buen ejemplo de cooperación entre distintos actores para desarrollar en otras regiones del Mediterráneo.

- La Unión debe considerar la posibilidad de poner en marcha la Directiva 2001/55/CE de protección temporal en caso de afluencia masiva de personas

\footnotetext{
${ }^{801}$ Van Selm, J. y Cooper, B.: The New..., op. cit, p. 50

${ }^{802}$ Comenté el desarrollo de dichos programas en el apartado 5.2.4.1

${ }^{803}$ ACNUR: Refugee protection and international migration: a review of UNHCR ${ }^{e c}$ s operational role in southern Italy, septiembre de 2009, doc. PDES/2009/05. Disponible en: http://www.unhcr.org/4ac35c600.pdf (Consulta: 28 de enero de 2016)
} 
desplazadas. Lastimosamente, esta directiva exige un acuerdo por unanimidad en el Consejo, lo que en el contexto político actual la convierte en letra mojada.

- El acceso a la información: las operaciones de interceptación y retorno se siguen produciendo en un contexto de oscurantismo. El acceso a la información resulta dificultoso, muchos documentos no se publican, lo hacen tardíamente o con datos censurados. Es especialmente grave cuando tiene que ver con "incidentes" sucedidos en el transcurso de JO, o con el destino final de solicitantes de asilo. En el caso de las personas fallecidas o desaparecidas, se une además el derecho de las familias de conocer la suerte que han corrido.

- Así como externamente, es necesario disponer de mejores datos sobre la situación de los viajes, el perfil de los migrantes (recordemos que Frontex no incluye por ejemplo en sus informes si las personas interceptadas en una JO han solicitado asilo), incidentes trágicos en el mar.... Esta información puede ayudarnos a entender mejor las causas y diseñar mejores políticas tanto a nivel nacional como europeo. Actualmente no existe un sistema homologado de información, siendo iniciativas privadas (como el ya citado proyecto The Migrant Files) las que están cumpliendo mejor la función de dar cuenta de esta tragedia.

- Para finalizar, es preciso incorporar la voz de las personas refugiadas y migrantes que han recorrido estas rutas en el diseño de las soluciones. Las propuestas institucionales tienden a silenciar y minusvalorar la experiencia y conocimiento de las propias personas migrantes y refugiadas. Habitualmente son interrogados por los agentes fronterizos que investigan las rutas $y$ organizaciones de inmigración clandestina, pero sus conocimientos no son tenidos en cuenta a la hora de diseñar las políticas públicas. Debemos destacar en este sentido la positiva aportación del proyecto DRIVE, que ha realizado encuestas a migrantes en los cuatro países que son objeto de esta investigación con la finalidad de conocer sus experiencias durante el trayecto migratorio ${ }^{804}$. En dicha encuesta se identificaban cinco grandes problemas: falta de coordinación eficaz; falta de planificación, predominando las respuestas ad hoc, violación de derechos humanos en las fronteras y durante la detención; falta de mecanismos claros y consistentes de identificación, diferenciación y derivación; y asistencia humanitaria insuficiente para las personas más vulnerables en la llegada ${ }^{805}$.

\footnotetext{
${ }^{804}$ ICMC Europe: MAYDAY! Strengthening responses of assistance and protection to boat people and other migrants arriving in Southern Europe, septiembre de 2011, pp. 62 y ss. Disponible en: http://www.accem.es/ficheros/documentos/pdf drive/MAYDAY ICMC Europe.pdf (Consulta: 29 de enero de 2016)

${ }^{805}$ Ibíd., pp. $72-78$
} 
Las propuestas arriba esbozadas buscan formar parte de una solución a un problema complejo, pero a la vez concreto y localizado geográficamente. No podemos soslayar que la cuestión que hemos tratado en el trabajo aquí expuesto se inscribe en un marco migratorio más amplio, es necesario analizar las políticas de asilo de forma transversal junto a las políticas migratorias.

En los últimos años, se ha venido configurando un emergente Derecho Internacional de las Migraciones, cuyo eje es la protección del migrante y de sus derechos ${ }^{806}$. Uno de los aspectos claves, tal como hemos visto a lo largo del presente trabajo, es la determinación de los límites, salvaguardas y excepciones que el DIDH impone a los Estados en su competencia soberana de denegar la entrada de extranjeros en su territorio y expulsar a aquellos que se encuentren en situación irregular.

Hay que señalar que no existe actualmente en el Derecho Internacional un derecho humano a inmigrar, entendiendo esto como un derecho individual a elegir como lugar de residencia un país distinto al de la propia nacionalidad. Uno de los axiomas universalmente aceptados en el Derecho Internacional Público es la capacidad de los estados, en el ejercicio de su soberanía, para definir los términos de admisión y presencia de nacionales de otros países dentro de su territorio ${ }^{807}$. Esta disposición está necesariamente restringida por las obligaciones de respeto a otros derechos humanos de los migrantes. Los Estados no pueden refugiarse en "la defensa de su soberanía" para vulnerar derechos o cometer actos ilícitos del derecho internacional.

\footnotetext{
${ }^{806}$ Referencia obligada merece la Convención internacional sobre la protección de los derechos de todos los trabajadores migratorios y de sus familiares, que ya hemos comentado. Lamentablemente ninguno de los Estados europeos que forman parte del objeto de investigación de este trabajo la ha ratificado. En el ámbito americano, ha sido de gran importancia la $\mathrm{OC} \mathrm{n}^{\mathrm{o}} 18$ de la Comisión Interamericana sobre migrantes indocumentados.

${ }^{807}$ El Comité de Derechos Humanos también señaló que "El Pacto no reconoce a los extranjeros el derecho a entrar en el territorio de un Estado Parte ni de residir en él. En principio, corresponde al Estado decidir a quién ha de admitir en su territorio" (OG no 15, para. 5). Así mismo, la Declaración sobre los derechos humanos de los individuos que no son nacionales del país en que viven (Resolución 40/144 de la AGNU, del 13 de diciembre de 1985) recordó que "Ninguna disposición de la presente Declaración se interpretará en el sentido de legitimar la entrada ni la presencia ilegales de un extranjero en cualquier Estado. Tampoco se interpretará ninguna disposición de la presente Declaración en el sentido de limitar el derecho de cualquier Estado a promulgar leyes y reglamentaciones relativas a la entrada de extranjeros y al plazo y las condiciones de su estancia en él o a establecer diferencias entre nacionales y extranjeros" (art. 2.1) La última resolución relativa a la protección de los migrantes (65/212, de 1 de abril de 2011), vuelve a reafirmar el "derecho soberano de promulgar y aplicar disposiciones relativas a la migración y la seguridad de sus fronteras", aún con vista a "las obligaciones que les incumben en virtud del derecho internacional, incluidas las normas internacionales de derechos humanos, a fin de que se respeten plenamente los derechos humanos de los migrantes"
} 


\section{CAPÍTULO 6}

No obstante, algunos autores vienen reclamando el establecimiento de un Derecho a migrar, utilizando la expresión latina ius migrandi ${ }^{808}$. Derecho que debería comprender cuatro elementos: el derecho a no migrar de tu propio país; el derecho de cada persona a migrar; el derecho a establecerse pacíficamente; y el derecho a retornar ${ }^{809}$. La investigación que he llevado a cabo en el presente trabajo me conduce a las mismas conclusiones. Las salvaguardas de los derechos humanos deben incorporarse y acompañar a cada fase de la ruta migratoria, desde partida hasta el establecimiento en el nuevo país o la decisión de retornar. La elemental protección de la vida y el principio de non-refoulement, dos aspectos fundamentales sin los que no puede garantizarse la dignidad básica de las personas refugiadas, son vulnerados de forma continua en el mar Mediterráneo. Esta situación, que no es nueva ni única en el planeta, debe obligarnos a replantear las bases ideológicas que regulan los regímenes migratorios y fronterizos, sustituyendo en su núcleo la razón de los Estados por la razón de las personas.

\footnotetext{
${ }^{808}$ Vid. Vitale, Ermanno: Ius migrandi. Barcelona, Ed. Melusina, 2006.

${ }^{809}$ Vid. Chueca Sancho, Ángel y Aguelo Navarro, Pascual: Contenido y límites del "ius migrandi". Revista Electrónica Iberoamericana. Vol. 7, $\mathrm{n}^{\circ}$ 2, 2012. Disponible en: http://www.urjc.es/ceib/investigacion/publicaciones/REIB_07_02_Pascual\%20Aguelo.pdf (Consulta: 12 de diciembre de 2015)
} 
Bibliografía y documentación 



\section{Bibliografía y documentación}

\subsection{Monografías e informes}

\subsubsection{Académica}

Acosta Estévez, José B.: "La internacionalización de los derechos humanos y los mecanismos de protección de los refugiados". En: Camps Mirabet, Nuria (ed.): El Derecho Internacional ante las migraciones forzadas: refugiados, desplazados y otros migrantes involuntarios, Universitat de Lleida, 2005, pp. 15-58.

Agamben, Giorgio: Estado de excepción. Homo Sacer II. 1, Valencia, Pre-Textos, 2004.

Aldalur, Martín: Clandestinos. Barcelona, Ediciones B, 2010.

Allain, Jean: The jus cogens nature of non-refoulement. International Journal of Refugee Law, Oxford University Press, vol. 13, n 4, 2001, pp. 533-558.

Aas, Katja y Gundhus, Helene: Policing Humanitarian Borderlands: Frontex, Human Rights and the Precariousness of Life, Oxford University Press, vol. 55, $\mathrm{n}^{\mathrm{o}}$ 1, 2015, pp. $1-18$.

Balzacq, Thierry: The Implications of European Neighbourhood Policy in the context of border controls, Bruselas, estudio del Parlamento Europeo, marzo de 2008. Disponible en: http://www.europarl.europa.eu/RegData/etudes/etudes/join/2008/393284/IPOLLIBE_ET\%282008\%29393284_EN.pdf (Consulta: 17 de enero de 2016)

Barnes, Richard: Refugee Law at Sea, Cambridge University, International and Comparative Law Quarterly, vol. 53, nº 1, 2004, pp. 47-77.

Boubakri, Hassan: Revolution and International Migration in Tunisia, Florencia, European University Institute, Robert Schuman Centre for Advanced Studies. Migration Policy Center Research Report, RR2013/14, 2013. Disponible en:

http://www.migrationpolicycentre.eu/docs/MPC-RR-2013-04.pdf (Consulta: 12 de diciembre de 2015)

Brugmann, Gero: Access to Maritime Ports, Norderstedt, Book son Demand GMbH, 2003, pp. 114-115.

Brownlie, Ian: Principios del derecho público internacional, Oxford University Press, $6^{\mathrm{a}}$ ed., 2003. 


\section{CAPÍTULO 7}

Carrera, Sergio: The EU Border Management Strategy. FRONTEX and the Challenges of Irregular Immigration in the Canary Islands, CEPS Working Doc. No. 261, marzo de 2007.

- Towards a common european border service?, CEPS Working Doc. No. 331, junio de 2010. Disponible en: https://www.ceps.eu/publications/towards-common-europeanborder-service (Consulta: 10 de enero de 2016)

Carrera, Sergio y den Hertog, Leonhard: Whose Mare? Rule of law challenges in the field of European border surveillance in the Mediterranean, CEPS Papers, No 79, 27 de enero de 2015. Disponible: https://www.ceps.eu/system/files/LSE 79.pdf (Consulta: 10 de enero de 2016)

Carrera, Sergio y Guild, Elspeth: Joint Operation RABIT 2010: Frontex Assistance to Greece's Border with Turkey. Revealing the Deficiencies of Europe's Dublin Asylum System, CEPS Paper in Liberty and Security in Europe, noviembre de 2010. Disponible en: http://aei.pitt.edu/15186/1/No_34_Carrera_\%26_Guild_on_RABIT_2010.pdf (Consulta: 27 de enero de 2016)

Cassarino, Jean-Pierre: Readmission Policy in the European Union, Bruselas, estudio del Parlamento Europeo, septiembre de 2010. Disponible en: http:/www.europarl.europa.eu/RegData/etudes/etudes/join/2010/425632/IPOLLIBE_ET\%282010\%29425632_EN.pdf (Consulta: 17 de enero de 2016)

Castles, Stephen: Towards a Sociology of Forced Migration and Social Transformation. Sociology, Vol. 77, no. 1, 2003, pp. 13-34. Disponible en: http://rimd.reduaz.mx/documentos_miembros/18713SC_Sociology_of_FM_2002.pdf (Consulta: 12 de diciembre de 2015)

Cebrián, Juan A. y Charef, Mohammed: La inmigración irregular española procedente de Marruecos, San Diego, Instituto Trans-Fronterizo, Borders/Fronteras no 2, 2012. Disponible en: http://digital.csic.es/bitstream/10261/62432/1/2012-Funciva..pdf (Consulta: 27 de enero de 2016)

Chueca Sancho, Ángel y Aguelo Navarro, Pascual: Contenido y límites del "ius migrandi”. Revista Electrónica Iberoamericana. Vol. 7, nº 2, 2012. Disponible en: http://www.urjc.es/ceib/investigacion/publicaciones/REIB $07 \quad 02$ Pascual\%20Aguelo.p df (Consulta: 12 de diciembre de 2015)

Collett, Elizabeth: Future EU policy development on immigration and asylum: Understanding the challenge. Migration Policy Institute, Policy Brief Series, no. 4, 
mayo de 2014. Disponible en: http://www.migrationpolicy.org/research/future-eupolicy-development-immigration-and-asylum-understanding-challenge (Consulta: 9 de enero de 2016)

Coppens, Jasmine y Somers, Eduard: Towards New Rules on Disembarkation of Persons Rescued at Sea?, The International Journal of Marine and Coastal Law, $\mathrm{n}^{\mathrm{o}} 25$, 2010, pp. 377-403. Disponible en: www.vliz.be/imisdocs/publications/247597.pdf (Consulta: 26 de enero de 2016)

Costello, Cathryn: Courting Access to Asylum in Europe: Recent Supranational Jurisprudence Explored. Human Rights Law Review, Vol. 12(2), 2012, pp. 287-339.

- Human Rights and the Elusive Universal Subject: Immigration Detention Under International Human Rights and EU Law, Indiana Journal of Global Legal Studies Vol. 19, no 1, 2012, pp. 257-303. Disponible en:

http://www.repository.law.indiana.edu/ijgls/vol19/iss1/10 (Consulta: 16 de enero de 2016)

Crosbie, Judith: Frontier agency keeps migrants in its sights, European Voice 13 (13), 2007. Disponible en: http://www.politico.eu/article/frontier-agency-keeps-migrants-inits-sights (Consulta: 27 de enero de 2016)

De Bruycker, Philippe, Di Bartolomeo, Anna y Fargues, Philippe: Migrants smuggled by sea: facts, laws and policy options. Florencia, European University Institute, Robert Schuman Centre for Advanced Studies, Migration Policy Centre Research Report RR2013/09, 2013. Disponible en: http://www.migrationpolicycentre.eu/docs/MPC-RR2013-009.pdf (Consulta: 12 de diciembre de 2015)

De la Rica, Sara; Glitz, Albrecht y Ortega, Francesc: Immigraton in Europe: Trends, Policies and Empirical Evidence, Bonn, Forschungsinstitut zur Zikunft der Arbeit (IZA), Discussion Paper no. 7778, noviembre de 2013. Disponible en: http://ftp.iza.org/dp7778.pdf (Consulta: 12 de diciembre de 2015)

De Lucas, Javier: "El marco jurídico internacional de las migraciones. Algunas consideraciones sobre la protección de los derechos humanos de los inmigrantes. Acerca del derecho a ser inmigrante.” En: Mariño Menéndez, Fernando (coord.): Un Mundo sin desarraigo: el derecho internacional de las migraciones. Madrid, Los Libros de la Catarata, 2006.

Den Heijer, Maarten y Lawson, Rick: "Extraterritorial Human Rights and the Concept of Jurisdiction", en Langford, M. et. al (eds): Global Justice, State Duties, The 


\section{CAPÍTULO 7}

Extraterritorial Scope of Economic, Social and Cultural Rights in International Law, Cambridge University Press, 2013, pp. 153-191.

Fargues, Philippe: 2015: The year we mistook refugees for invaders. Florencia, European University Institute, Robert Schuman Centre for Advanced Studies, Migration Policy Centre, doc. 10.2870/093089, diciembre de 2015. Disponible en: http://cadmus.eui.eu/bitstream/handle/1814/38307/Policy_Brief_2015_12.pdf?sequence =1\&isAllowed $=y$ (Consulta: 29 de enero de 2016)

Fargues, Philippe y Bonfanti, Sara: "When the best option is a leaky boat: why migrants risk their lives crossing the Mediterranean and what Europe is doing about it". European University Institute, Florence, Migration Policy Centre Policy Brief, No. 5, octubre de 2014. Disponible en:

http://cadmus.eui.eu/bitstream/handle/1814/33271/MPC PB 2014-

05.pdf?sequence $=1 \&$ is Allowed $=\mathrm{y}$ (Consulta: 27 de enero de 2016)

Fargues, Philippe y Di Bartolomeo, Anna: Drowned Europe, European University Institute, Florence, Migration Policy Centre Policy Brief, doc. 2015/05, abril de 2015. Disponible en:

http://cadmus.eui.eu/bitstream/handle/1814/35557/MPC_2015_05_PB.pdf?sequence=1 \&isAllowed=y (Consulta: 20 de enero de 2016)

Gabaldón, José Luis: Curso de Derecho Marítimo Internacional. Derecho marítimo internacional público y privado y contratos marítimos internacionales. Madrid, Marcial Pons, Ediciones Jurídicas y Sociales, 2012.

Gammeltoft-Hansen, Thomas: Access to Asylum: International Refugee Law and the Globalization of Migration Control, Cambridge University Press, 2011.

Gil-Bazo, María Teresa: The Practice of Mediterranean States in the context of the European Union's Justice and Home Affairs External Dimension. The Safe Third Country Concept Revisited, International Journal of Refugee Law, vol. 19, no. 3-4, 2006, pp. 571-600.

Goodwin-Gil, Guy: "The Extra-Territorial Reach of Human Rights Obligations: A Brief Perspectove on the Link to Jurisdiction". En: Boisson, Laurence y Kohen, Marcelo (eds.): International law and the Quest for its Implementation. Leiden, Koniklijke Brill, 2010, pp. 293-308.

Goodwin-Gill, Guy y McAdam, Jane: The Refugee in International Law, Oxford University Press, $3^{\text {a }}$ ed., 2007. 
Guild, Elspeth: The Right to Leave a Country, Informe para el Comisario de Derechos Humanos del Consejo de Europa, octubre de 2013. Disponible en:

http://www.coe.int/t/commissioner/source/prems/prems150813_GBR 1700_TheRightT oLeaveACountry_web.pdf (Consulta: 27 de enero de 2016)

Guild, Elspeth y Bigo, Didier: "The Transformation of European Border Control", en Ryan, Bernard y Mitsilegas, Valsamis (eds.): Extraterritorial Immigration Control. Legal Challenges, Leiden, Koniklijke Brill, 2010.

Guild, Elspeth y Carrera, Sergio: EU Borders and their Controls. Preventing unwanted movement of people in Europe?, Centre for European Policy Studies, no. 6, 14 de noviembre de 2013.

Hathaway, James: The Rights of Refugees under International Law, Cambridge University Press, 2005.

- The false panacea of offshore deterrence, Forced Migration Review no 26, 2006. Disponible en: http://www.fmreview.org/FMRpdfs/FMR26/FMR2632.pdf (Consulta: 27 de enero de 2016)

Hathaway, James y Gammeltoft-Hansen, Thomas: Non-refoulement in a World of Cooperative Deterrance, University of Michigan Law School, Law \& Economics Working Papers, $n^{\circ} 106,2014$. Disponible en:

http://repository.law.umich.edu/cgi/viewcontent.cgi?article=1216\&context=law_econ_c urrent (Consulta: 27 de enero de 2016)

Hattrell, Felicity: Redefining the Limits of Refugee Protection? The Securitised Asylum Policies of the 'Common European Asylum System'. National Centre for Research on Europe, University of Canterbury, diciembre de 2010.

Huysmans, Jeff: The European Union and the Securitization of Migration, Journal of Common Market Studies, Vol. 38, No. 5, 2000, pp. 751-777. Disponible en:

http://onlinelibrary.wiley.com/doi/10.1111/1468-5965.00263/pdf (Consulta: 10 de enero de 2016)

Ineli-Ciger, Meltem: 'Has the Temporary Protection Directive Become Obsolete? An Examination of the Directive and its Lack of Implementation in View of the Recent Asylum Crisis in the Mediterranean' en C. Bauloz, M. Ineli-Ciger, S. Singer, V. Stayanova (ed.): Seeking Asylum in the European Union: Selected Protection Issues Raised by the Second Phase of the Common Asylum System, Brill/Martinus Nijhoff Publishers, 2015. 


\section{CAPÍTULO 7}

Jorry, Hélène: Construction of a European Institutional Model for the Management of Operational Cooperation at the EU External Borders: Does the FRONTEX Agency take a decisive step forward?, en CHALLENGE Research Paper n. ${ }^{\circ}$ 6, Centre for European Policy Studies, Bruselas, marzo de 2007. Disponible en:

https://www.ceps.eu/system/files/book/1483.pdf (Consulta: 10 de enero de 2016)

Kenk, V.S., Križaj, J., Štruc, J. \& Dobrišek S.: Smart Surveillance Technologies in Border Control, European Journal of Law and Technology, Vol 4., No. 2., 2013. Disponible en: http://ejlt.org/article/view/230/378 (Consulta: 10 de enero de 2016)

Klepp, Silka: A Contested Asylum System: the European Union between Refugee Protection and Border Control in the Mediterranean Sea, European Journal of Migration and Law, vol. 12, n 1, 2012. Disponible en: http://booksandjournals.brillonline.com/content/journals/15718166 (Consulta: 27 de enero de 2016)

Lambert, Hélene: The position of aliens in relation to the European Convention of Human Rights", Council of Europe Publishing, Human Rights files, No. 8, 2007. Disponible en: http://www.echr.coe.int/LibraryDocs/DG2/HRFILES/DG2-ENHRFILES-08\%282007\%29.pdf (Consulta: 12 de enero de 2016)

Lauterpacht, Elihu y Bethlehem, Daniel: "The scope and content of the principle of nonrefoulement: Opinion". En: Feller, Türk, y Nicholson (eds.): Refugee Protection in International Law: UNHCR's Global Consultations on International Protection, Cambridge University Press, 2003

Lutterbeck, Derek: Policing Migration in the Mediterranean. Mediterranean Politics Vol. 11, No. 1, 2006, pp. 59-82.

Maas, Wies: Fleeing to Europe: Europeanization and the Right to Seek Refugee Status. La Haya, Institute of Social Studies, Working Paper no. 454, enero de 2008. Disponible en: http://repub.eur.nl/pub/18740/wp454.pdf (Consulta: 10 de enero de 2016)

Majcher, Izabella: "Crimmigration" in the European Union through the Lens of Immigration Detention. Global Detention Project Working Paper, no. 6, septiembre de 2013. Disponible en:

http://www.globaldetentionproject.org/fileadmin/publications/Crimmigration_EU final. pdf (Consulta: 12 de diciembre de 2015)

Martin, Marie: Violations of the rights of migrants and refugees at sea. Priorising border control over human rights. Copenhague, Euro-Mediterranean Human Rights 
Network, junio de 2014. Disponible en: http://www.statewatch.org/news/2014/jul/eumigrants-at-sea.pdf (Consulta: 27 de enero de 2016)

Milanovic, Marko: From Compromise to Principle: Clarifying the Concept of State Jurisdiction in Human Rights Treaties, Human Rights Law Review, vol. 8, 2008. Disponible en: http://ssrn.com/abstract=1139174 (Consulta: 18 de enero de 2016)

- Extraterritorial Application of Human Rights Treaties: Law, Principles, and Policy. Oxford University Press, 2011

Moreno-Lax, Violeta y Costello, Cathryn: "The Extraterritorial Application of the EU Charter of Fundamental Rights; From Territoriality to Facticity, the Effectiveness Model". En: Peers, Steve, Hervey, Tamara, et al: The EU Charter of Fundamental Right. A Commentary, Hart Publishing, Oxford, 2014, pp. 1657-1683. Disponible en: http://oppenheimer.mcgill.ca/IMG/pdf/59_Moreno-Lax_Costello_2_.pdf(Consulta: 18 de enero de 2016)

Nessel, Lori: Externalized Borders and the Invisible Refugee, Columbia Human Rights Law Review, Vol. 40, No. 625, 2009. Disponible en:

http://www3.law.columbia.edu/hrlr/hrlr_journal/40.3/Nessel.pdf (Consulta: 27 de enero de 2016)

Noll, Gregor: Seeking Asylum at Embassies: A right to Entry under International Law?, International Journal of Refugee Law, Oxford University Press, vol. 17, n 3, 2005, pp. 542-573.

Pallis, Mark: Obligations of States towards Asylum Seekers at Sea: Interactions and Conflicts Between Legal Regimes. International Journal of Refugee Law, vol.14, no. 2 \& 3, 2002, pp. 329-364.

Paoletti, Emanuela: "Relations Among Unequals? Readmission between Italy and Libya”. En: Cassarino, Jean Pierre (ed.): Unbalanced Reciprocities: Cooperation on Readmission in the Euro-Mediterranean Area, 2010. Disponible en: http://www.statewatch.org/news/2010/sep/eu-unbalanced-reciprocities-middle-eastinstitute.pdf (Consulta: 14 de enero de 2016)

Papastavridis, Efthymios: Rescuing Migrants at Sea: The Responsibility of States under International Law, Working Paper Series Social Science Research Network, septiembre de 2011. Disponible en:

https://www.researchgate.net/publication/228275123_Rescuing_Migrants_at_Sea_The Responsibility_of States_Under_International_Law (Consulta: 15 de diciembre de 2015) 


\section{CAPÍTULO 7}

- The Interception of Vessels on the High Seas: Contemporary Challenges to the Legal Order of the Oceans, Bloomsbury Publishing, n 4, 2014.

Pérez González, Carmen: Migraciones irregulares y Derecho Internacional. Gestión de los flujos migratorios, devolución de extranjeros en situación administrativa irregular y Derecho Internacional de los Derechos Humanos, Valencia, Tirant lo Blanc, 2012.

Pinto, Mónica: "El principio pro homine. Criterios de hermenéutica y pautas para la regulación de los derechos humanos"; en: Abregú, Martín y Courtis, Christian (comp.) La aplicación de los tratados de derechos humanos por los tribunales locales. Buenos Aires, Centro de Estudios Legales y Sociales, Editorial Del Puerto, 1997, pp. 163-171, 1997.

Proelss, Alexander: Rescue at sea: What Obligations exist Towards Refugees?, Scandinavian Institute of Maritime Law Yearbook 2008. Disponible en: https://www.wsi.uni-kiel.de/de/lehre/vorlesungen/archiv/ss2010/proelss/seerecht/seerecht/materialien/Rescue $\% 20$ at $\% 20$ Sea $\% 20 \% 28$ Paper $\% 29$.pdf (Consulta: 27 de enero de 2016)

Robinson, Courtland.: The Comprehensive Plan of Action for Indochinese Refugees, 1989-1997: Sharing the Burden and Passing the Buck, Oxford University Press, Journal of Refugee Studies, Vol. 17, no. 3, 2004. Disponible en:

http://www.jhsph.edu/research/centers-and-institutes/center-for-refugee-and-disasterresponse/publications tools/publications/additional_pdfs/Robinson2004Indochinese refugees.pdf (Consulta: 26 de enero de 2016)

Romero, Eduardo: Paremos los vuelos: las deportaciones de inmigrantes y el boicot a Air Europa, Oviedo, Ed. Cambalache, mayo de 2014. Disponible en:

http://descargas.localcambalache.org/paremos los_vuelos.pdf (Consulta: 14 de enero de 2016)

Suárez de Vivero, Juan Luis: Jurisdictional Waters in The Mediterranean and Black Seas, estudio del Parlamento Europeo, diciembre de 2010. Disponible en:

http://www.eurocean.org/np4/file/2063/download.do.pdf (Consulta: 20 de enero de 2016)

Umbriano, Pierluigi: Is it a crime to help people to survive?, Migrants - Outlaws Everywhere, conferencia del 4 de mayo de 2013. Disponible en: http://www.eldh.eu/fileadmin/user_upload/ejdm/publications/2013/Pierluigi_Umbriano - Speech.pdf?PHPSESSID=051a86793dbac1a0c80a6885a9a9cf03 (Consulta: 25 de enero de 2016) 
Van Selm, Joanne y Cooper, Betsy: The new "Boat People”: Ensuring Safety and Determining Status. Migration Policy Institute Working Paper, enero de 2006.

Disponible en: http://www.migrationpolicy.org/research/new-boat-people-ensuringsafety-and-determining-status (Consulta: 12 de diciembre de 2015)

Vitale, Ermanno: Ius migrandi. Barcelona, Ed. Melusina, 2006.

\subsubsection{Informes de ONGs}

AI: Australia-Pacific: Offending Human Dignity - the 'Pacific Solution"', Doc. ASA 12/2009/2002, 26 de agosto de 2002. Disponible en:

https://www.amnesty.org/download/Documents/116000/asa120092002en.pdf

(Consulta: 26 de enero de 2016)

- Frontera Sur, El Estado da la espalda a los derechos humanos de los refugiados e inmigrante, Doc. AI 41/008/2005, 2005. Disponible en:

http://www.amnesty.eu/static/documents/Spain_detention_report_Spanish_final.pdf (Consulta: 27 de enero de 2016)

- Vivir en las sombras. Una introducción a los derechos humanos de las personas migrantes. Londres, septiembre de 2006. Doc. POL 22/006/2006. Disponible en: http://web.amnesty.org/library/Index/ESLPOL330062006 (Consulta: 12 de diciembre de 2015)

- Mauritania: "Nadie quiere tener nada que ver con nosotros". Arrestos y expulsiones colectivas de migrantes a quienes se ha negado la entrada en Europa, Londres, 1 de julio de 2008, AFR 38/001/2008. Disponible en:

https://www.amnesty.org/download/Documents/52000/afr380012008spa.pdf (Consulta: 27 de enero de 2016)

- 'Libya of Tomorrow'. What hope for human rights?, Londres, 2010, Doc. MDE 19/007/2010. Disponible en:

https://www.amnesty.org/download/Documents/40000/mde190072010en.pdf (Consulta: 17 de enero de 2016)

- Frontier Europe: Human Rights Abuses on Greece's border with Turkey, 2013, Doc. 25/008/2013. Disponible en:

https://www.amnesty.org/download/Documents/12000/eur250082013en.pdf (Consulta: 27 de enero de 2016)

- La vergüenza de Europa, a pique. Omisión de socorro a refugiados y migrantes en el mar, Doc. EUR 03/1434/2015, abril de 2015. Disponible en: 


\section{CAPÍTULO 7}

https://www.amnesty.org/es/documents/eur03/1434/2015/es/ (Consulta: 27 de enero de 2016)

- Europe's Gatekeeper. Unlawful detention and deportation of refugees from Turkey, Doc. EUR 44/3022/2015, diciembre de 2015. Disponible en:

https://www.amnesty.org/en/documents/eur44/3022/2015/en/ (Consulta: 27 de marzo de 2016)

AI, ECRE e ICJ: Joint Briefing on the European Commission Proposal for a Regulation of the European Parliament and of the Council establishing rules for the surveillance of the external sea borders in the context of operational cooperation coordinated by the European Agency for the Management of Operational Cooperation at the External Borders of the Member States of the European Union (COM(2013) 197 final). Bruselas, septiembre de 2010. Disponible en:

http://www.ecre.org/component/downloads/downloads/790.html (Consulta: 10 de enero de 2016)

AIDA: Not there Yet. An NGO Perspective on Challenges to a Fair and Effective Common European Asylum System, Asylum Information Database, Annual Report 2012/2013. Disponible en: http:/www.asylumineurope.org/sites/default/files/shadowreports/not there yet 02102013.pdf (Consulta: 10 de enero de 2016)

APDHA: Derechos humanos en la frontera sur 2015. Disponible en: https://www.detective.io/detective/the-migrants-files (Consulta: 20 de enero de 2016)

CEAR: Acceso a la protección: Un derecho humano, Madrid, 2013. Disponible en: http://www.cear.es/wp-content/uploads/2013/07/Trip-espa\%C3\%B1ol-EPIM.pdf (Consulta: 17 de enero de 2016)

COWI: External evaluation of the European Agency for the Management of Operational Cooperation at the External Borders of the Member States of the European Union, Kongens Lyngby, Dinamarca, Doc. P-69209-A, 15 de enero de 2009. Disponible en: http://www.statewatch.org/news/2009/may/frontex-eval-report-2009.pdf (Consulta: 10 de enero de 2016)

ECRE: Common European Asylum System: The real job still needs to be done, nota de prensa del 11 de junio de 2013. Disponible en:

http://www.ecre.org/component/downloads/downloads/753.html (Consulta: 10 de enero de 2016)

-Regional Protection Programmes: an effective policy tool?, Discussion paper, Bruselas, enero de 2015. Disponible en 
http://ecre.org/component/downloads/downloads/982.html (Consulta: 10 de enero de 2016)

ECRE y Refugee Council: Refugee Council and the European Council on Refugees and Exiles (ECRE) Joint Response to Select Committee on the European Union SubCommittee F (Home Affairs): Frontex Inquiry, 24 de septiembre de 2007. Disponible en: http://www.ecre.org/component/downloads/downloads/61.html (Consulta: 27 de enero de 2016)

FIDH- EMHRN-Migreurop: Frontex, between Greece and Turkey. The Border of Denial, mayo de 2014. Disponible en:

http://www.migreurop.org/IMG/pdf/rapport_en_web.pdf (Consulta: 10 de enero de 2016)

Fortress Europe: Escape from Tripoli, Report on the conditions of migrants in transit in Libya, 2008. Disponible en: http://www.statewatch.org/news/2007/nov/fortress-europelibya-report.pdf (Consulta: 25 de enero de 2016)

International Centre for Migration Policy Development: East Africa Migration Route Initiative: Gaps \& Needs Analysis Project Country Reports: Ethiopia, Kenya, Libya, Viena, 2008. Disponible en:

http://igad.int/index.php?option $=$ com_docman\&task $=$ doc download\&gid $=16 \&$ Itemid $=$ 144 (Consulta: 17 de enero de 2016)

HRW: Stemming the flow. Abuses Against Migrants, Asylum Seekers and Refugees, Vol. 18, No. 5 (E), septiembre de 2006. Disponible en:

https://www.hrw.org/reports/2006/libya0906/libya0906webwcover.pdf (Consulta: 10 de enero de 2016)

- Pushed back, pushed around. Italy's Forced Return of Boat Migrants and Asylum Seekers, Libya's Mistreatment of Migrants and Asylum Seekers. No. 1.56432-537, septiembre de 2009. Disponible en:

https://www.hrw.org/sites/default/files/reports/italy0909web_0.pdf (Consulta: $10 \mathrm{de}$ enero de 2016)

- The EU's Dirty Hands. Frontex Involvement in Ill-Treatment of Migrant Detainees in Greece, septiembre de 2011. Disponible en:

https://www.hrw.org/sites/default/files/reports/greece0911webwcover 0.pdf (Consulta: 27 de enero de 2016)

ICMC Europe: MAYDAY! Strengthening responses of assistance and protection to boat people and other migrants arriving in Southern Europe, septiembre de 2011. Disponible 


\section{CAPÍTULO 7}

en:

http://www.accem.es/ficheros/documentos/pdf_drive/MAYDAY_ICMC_Europe.pdf (Consulta: 29 de enero de 2016)

JRS: Becoming Vulnerable in Detention, Civil Society Report on the Detention of Vulnerable Asylum Seekers and Irregular Migrants in the European Union, 2010. Disponible en: http://jrsmalta.jesuit.org.mt/wpcontent/uploads/downloads/2011/02/Becoming-Vulnerable-in-Detention-MT.pdf (Consulta: 14 de enero de 2016)

- Más allá de lo imaginable. Solicitantes de asilo hablan de su vida en Libia. Servicio Jesuita a Refugiados - Malta, enero de 2014. Disponible en: https://jrseurope.org/assets/Publications/File/jrs-mas-alla-de-lo-imaginable1.pdf (Consulta: 17 de enero de 2016)

MSF: Violence, Vulnerability and Migration: Trapped at the Gates of Europe. A report on the situation of sub-Saharan migrants in an irregular situation in Morocco, marzo de 2013. Disponible en:

https://www.msf.org/sites/msf.org/files/migrants_in_morocco_report.pdf (Consulta: 17 de enero de 2016)

- Invisible suffering. Prolonged and systematic detention of migrants and asylum seekers in substandard conditions in Greece, abril de 2014. Disponible en: http://www.msf.org/sites/msf.org/files/invisible_suffering.pdf (Consulta: 27 de enero de 2016)

OXFAM: "Foreign Territory. The Internationalisation of EU Asylum Policy", Oxford, Oxfam Publishing, 2005. Disponible en http://oxfamilibrary.openrepository.com/oxfam/bitstream/10546/112380/1/foreignterritory-internationalisation-EU-asylum-policy-010105-en.pdf (Consulta: 10 de enero de 2016)

Pro Asyl: Pushed back. Systematic human right violations against refugees in the Aegean sea and at the Greek-Turkish land border, noviembre de 2013. Disponible en: http://www.proasyl.de/fileadmin/fmdam/1_EU_Fluechtlingspolitik/proasyl_pushed_back_24.01.14_a4.pdf (Consulta: 27 de enero de 2016)

- Analysis regarding the death of eleven refugees near the island of Farmakonisi, enero de 2015. Disponible en:

http://www.proasyl.de/en/press/press/news/analysis_by pro asyl_regarding the death 
of_eleven_refugees_near_the_island_of_farmakonisi-1/ (Consulta: 27 de enero de 2016)

\subsection{Normativa, jurisprudencia y otra documentación institucional}

\subsubsection{Derecho Internacional}

\section{a) Tratados internacionales}

Convenio Internacional para la unificación de ciertas reglas en materia de abordaje, firmado en Bruselas el 23 de septiembre de 1910. Disponible en:

http://www.admiraltylawguide.com/conven/collisions1910.html (Consulta: 20 de enero de 2016)

Convención de Ginebra sobre el estatuto de los refugiados, de 28 de julio de 1951. Disponible en:

http://www.acnur.org/t3/fileadmin/scripts/doc.php?file=t3/fileadmin/Documentos/BDL/ 2001/0005 (Consulta: 12 de diciembre de 2015)

Convención Internacional sobre Polizones, firmada en Bruselas el 10 de octubre de 1957. Disponible en: http://www.refworld.org/docid/3ae6b3a80.html (Consulta: 20 de enero de 2016)

Convención Internacional sobre la Eliminación de Todas las Formas de Discriminación Racial, aprobada por la AGNU el 21 de diciembre de 1965, resolución 2106 A (XX). Disponible en: http://www.ohchr.org/SP/ProfessionalInterest/Pages/CERD.aspx (Consulta: 12 de diciembre de 2015)

Pacto Internacional de Derechos Civiles y Políticos, aprobada por la AGNU el 16 de diciembre de 1966, resolución 2200 A (XXI). Disponible en:

http://www.ohchr.org/SP/ProfessionalInterest/Pages/CCPR.aspx (Consulta: 12 de diciembre de 2015)

Convención Americana sobre Derechos Humanos, aprobada en San José el 22 de noviembre de 1969. Disponible en: https://www.oas.org/dil/esp/tratados_B-

32 Convencion_Americana_sobre_Derechos_Humanos.pdf (Consulta: 14 de enero de 2016)

Convenio Internacional para la seguridad de la vida humana en el mar, aprobado el 1 de noviembre de 1974. Disponible en:

http://www.imo.org/es/About/Conventions/ListOfConventions/Paginas/International- 


\section{CAPÍTULO 7}

Convention-for-the-Safety-of-Life-at-Sea-\%28SOLAS\%29,-1974.aspx (Consulta: 20 de enero de 2016)

Convenio internacional sobre búsqueda y salvamento marítimos, aprobado en Hamburgo el 27 de abril de 1979. Disponible en:

http://www.imo.org/es/About/Conventions/ListOfConventions/Paginas/InternationalConvention-on-Maritime-Search-and-Rescue-\%28SAR\%29.aspx (Consulta: 20 de enero de 2016)

Convención sobre la eliminación de todas las formas de discriminación contra la mujer, aprobada por la AGNU el 18 de diciembre de 1979, resolución 34/180. Disponible en: http://www.ohchr.org/SP/ProfessionalInterest/Pages/CEDAW.aspx (Consulta: $12 \mathrm{de}$ diciembre de 2015)

Carta Africana sobre los Derechos Humanos y de los Pueblos, aprobada en Banjul el 27 de junio de 1981, durante la XVIII Asamblea de Jefes de Estado y Gobierno de la Organización de la Unidad Africana, OAU Doc. CAB/LEG/67/3. Disponible en: http://au.int/en/sites/default/files/treaties/7770-file-banjul_charter.pdf (Consulta: 14 de enero de 2016)

Convención de las Naciones Unidas sobre el Derecho del Mar, aprobada en Jamaica el 10 de diciembre de $1982,182^{\circ}$ sesión plenaria de la III Conferencia de las Naciones Unidas sobre el Derecho del Mar. Disponible en:

http://www.un.org/depts/los/convention_agreements/texts/unclos/convemar_es.pdf (Consulta: 20 de enero de 2016)

Convención contra la Tortura y Otros Tratos o Penas Crueles, Inhumanos o Degradantes, aprobada por la AGNU el 10 de diciembre de 1984, resolución 39/46. Disponible en: http://www.ohchr.org/SP/ProfessionalInterest/Pages/CAT.aspx (Consulta: 12 de diciembre de 2015)

Convenio Internacional sobre Salvamento Marítimo, aprobado en Londres el 28 de abril de 1989. Disponible en:

http://www.imo.org/en/About/Conventions/ListOfConventions/Pages/InternationalConvention-on-Salvage.aspx (Consulta: 20 de enero de 2016)

Convención de Derechos del Niño, aprobada por la AGNU el 20 de noviembre de 1989, resolución 44/25. Disponible en:

http://www.ohchr.org/SP/ProfessionalInterest/Pages/CRC.aspx (Consulta: 12 de diciembre de 2015) 
Convención internacional sobre la protección de los derechos de todos los trabajadores migratorios y de sus familiares, aprobada por la AGNU el 18 de diciembre de 1990, resolución 45/158. Disponible en:

http://www.ohchr.org/SP/ProfessionalInterest/Pages/CMW.aspx (Consulta: 12 de diciembre de 2015)

Convención de las Naciones Unidas contra la delincuencia organizada transnacional. Protocolo contra el tráfico ilícito de migrantes por tierra, mar y aire, firmado el $12 \mathrm{de}$ diciembre de 2000 en Palermo. Disponible en: http://www.unodc.org/documents/peruandecuador/Publicaciones/tocebook.pdf (Consulta: 27 de enero de 2016)

Convención Internacional para la protección de todas las personas contra las desapariciones forzadas, aprobada por la AGNU el 21 de diciembre de 2010, resolución 61/177. Disponible en: http://www.ohchr.org/SP/ProfessionalInterest/Pages/CAT.aspx (Consulta: 12 de diciembre de 2015)

\section{b) Alto Comisionado de las Naciones Unidas para los Refugiados}

Manual de Procedimientos y Criterios para Determinar La Condición de Refugiado en virtud de la Convención de 1951 y el Protocolo de 1967 sobre el Estatuto de los Refugiados, Ginebra, 1979. Disponible en:

http://www.acnur.org/t3/fileadmin/Documentos/BDL/2011/7575.pdf?view=1 (Consulta: 12 de diciembre de 2015)

Conclusión general n 22 (XXII) Protección de las personas que buscan asilo en situaciones de afluencia en gran escala, adoptada en el $32^{\circ}$ periodo de sesiones del Comité Ejecutivo, 1981. Disponible en: http://www.acnur.org/Pdf/0533.pdf?view=1 (Consulta: 14 de enero de 2016)

Conclusión general n 23 (XXXII) Problemas relativos al rescate de personas en busca de asilo encontrándose en peligro en el mar, adoptada en el $32^{\circ}$ periodo de sesiones del Comité Ejecutivo, 1981. Disponible en: http://www.acnur.org/Pdf/0534.pdf?view=1 (Consulta: 26 de enero de 2016)

Conclusión general $\mathrm{n}^{\mathrm{o}} 24$ (XXIV) Reunificación de familias, adoptada en el $32^{\circ}$ periodo de sesiones del Comité Ejecutivo (1981). Disponible en:

http://www.acnur.org/Pdf/0535.pdf?view=1 (Consulta: 13 de enero de 2016)

Note on Stowaway Asylum-Seekers, International Protection (SCIP), 22 de julio de 1988, Doc. EC/SCP/51. Disponible en: http://www.unhcr.org/3ae68cbf8.html (Consulta: 20 de enero de 2016) 


\section{CAPÍTULO 7}

Conclusión general n. 53 (XXXIX) Los pasajeros clandestinos en busca de asilo, adoptada en el $39^{\circ}$ periodo de sesiones del Comité Ejecutivo, 1988. Disponible en: http://www.acnur.org/Pdf/0564.pdf?view=1 (Consulta: 26 de enero de 2016)

Note on the Principle of Non-Refoulement, noviembre de 1997. Disponible en: http://www.refworld.org/docid/438c6d972.html (Consulta: 18 de enero de 2016)

La interceptación de solicitantes de asilo y refugiados: el marco internacional y recomendaciones para un enfoque integral, $18^{\mathrm{a}}$ reunión del Comité Ejecutivo, 9 de junio de 2000, doc. EC/EC/50/SC/CRP.17. Disponible en:

http://www.acnur.org/t3/fileadmin/Documentos/BDL/2005/2234.pdf?view=1 (Consulta: 27 de enero de 2016)

Conclusión n 97 (LIV) sobre las salvaguardas de protección de las medidas de intercepción, $54^{\circ}$ periodo de sesiones del Comité Ejecutivo, 2003. Disponible en: http://www.acnur.org/t3/fileadmin/Documentos/BDL/2003/2411.pdf?view=1 (Consulta: 27 de enero de 2016)

Opinión Consultiva sobre la aplicación extraterritorial de las obligaciones de no devolución en virtud de la Convención sobre el Estatuto de los Refugiados de 1951 y su Protocolo de 1967, 26 de enero de 2007. Disponible en:

http://www.acnur.org/t3/fileadmin/Documentos/BDL/2009/7123.pdf?view=1 (Consulta: 18 de enero de 2016)

Refugee protection and international migration: a review of UNHCR ${ }^{\text {ee }}$ s operational role in southern Italy, septiembre de 2009, doc. PDES/2009/05. Disponible en:

http://www.unhcr.org/4ac35c600.pdf (Consulta: 28 de enero de 2016)

Operaciones de interceptación marítima y tramitación de solicitudes de protección internacional: normas jurídicas y consideraciones de políticas con respecto al procesamiento extraterritorial, Documento de políticas de protección, noviembre de 2010. Disponible en:

http://www.acnur.es/PDF/interceptacionmaritima_solicitudes_pi_20130129165620.pdf (Consulta: 18 de enero de 2016)

La protección de los refugiados y la migración mixta: El Plan de los 10 puntos en acción, febrero de 2011. Disponible en: http://www.acnur.es/PDF/7526_20120511131557.pdf (Consulta: 12 de diciembre de 2015) 
UNHCR Protection Training Manual for European Border and Entry Officials Protection Manuals, abril de 2011. Disponible en:

http://www.unhcr.org/4d948c736.html (Consulta: 10 de enero de 2016)

Refugiados y solicitantes de asilo en peligro en el mar - ¿Cómo responder mejor?, Reunión de expertos en Djibouti, Resumen de las conclusiones, 8-10 de noviembre de 2011. Disponible en:

http://www.acnur.es/PDF/refugiados_solicitantesasilo_peligro_mar_comorespondermej or_20130409121507.pdf (Consulta: 20 de enero de 2016)

Directrices sobre los criterios y estándares aplicables a la detención de solicitantes de asilo y las alternativas a la detención, 2012. Disponible en: http://www.unher.org/cgibin/texis/vtx/refworld/rwmain/opendocpdf.pdf?reldoc=y\&docid=4992fb672 (Consulta: 14 de enero de 2016)

Global Iniciative on Protection at Sea, High Commissioner's Dialogue on Protection Challenges, mayo de 2014. Disponible en: http://www.unhcr.org/5375db0d9.html (Consulta: 29 de enero de 2016)

\section{c) Asamblea General de las Naciones Unidas}

Declaración de 1967 sobre el Asilo Territorial, aprobada por la AGNU el 14 de diciembre de 1967, resolución 2312 (XXII). Disponible en:

http://www.acnur.org/t3/fileadmin/scripts/doc.php?file=t3/fileadmin/Documentos/BDL/

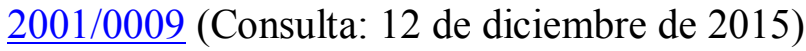

Declaración sobre los Derechos Humanos de los Individuos que no son nacionales de los países en los que viven aprobada por la AGNU el 13 de diciembre de 1985, resolución 40/144. Disponible en:

http://www.ohchr.org/SP/ProfessionalInterest/Pages/HumanRightsOfIndividuals.aspx (Consulta: 12 de diciembre de 2015)

Resolución "54/166 Protección de los migrantes" de 24 febrero de $2000.54^{\circ}$ periodo de sesiones. Doc. A/RES/54/166. Disponible: http://documents-ddsny.un.org/doc/UNDOC/GEN/N00/265/75/pdf/N0026575.pdf?OpenElement (Consulta: 12 de diciembre de 2015)

Resolución "40/144 Declaración sobre los derechos human os de los individuos que no son nacionales del país en que viven" de 13 de diciembre de $1985.40^{\circ}$ periodo de sesiones. Doc. A/RES/40/144. Disponible:

http://www.un.org/en/ga/search/view_doc.asp?symbol=A/RES/40/144\&referer=http://w 


\section{CAPÍTULO 7}

ww.un.org/depts/dhl/resguide/r40_resolutions_table_eng.htm\&Lang=S (Consulta: $12 \mathrm{de}$ diciembre de 2015)

\section{d) Comité de Derechos Humanos}

López Burgos c. Uruguay, 29 de julio de 1981, n 52/1979. Disponible en: http://www1.umn.edu/humanrts/undocs/session36/12-52.htm (Consulta: 18 de enero de 2016)

Celiberti de Casariego c. Uruguay, 29 de julio de 1981, no 56/1979. Disponible en: http://www1.umn.edu/humanrts/undocs/session36/13-56.ht (Consulta: 18 de enero de 2016)

Aumeeruddy-Cziffra y otras c. Mauricio, 9 de abril de 1981, no 035/1978. Disponible en:

http://tbinternet.ohchr.org/_layouts/treatybodyexternal/Download.aspx?symbolno=CCP R\%2FC\%2F12\%2FD\%2F35\%2F1978\&Lang=en (Consulta: 14 de enero de 2016)

Observación General n ${ }^{\circ}$ 15: La situación de los extranjeros con arreglo al Pacto. $27^{\circ}$ período de sesiones, 11 de abril de 1986. Disponible en: http://tbinternet.ohchr.org/_layouts/treatybodyexternal/Download.aspx?symbolno=INT \%2fCCPR\%2fGEC\%2f6625\&Lang=en (Consulta: 12 de diciembre de 2015)

Observación General N. 20: Prohibición de la tortura u otros tratos o penas crueles, inhumanos o degradantes (artículo 7), 44 periodo de sesiones, 1992. Disponible en: http://tbinternet.ohchr.org/Treaties/CCPR/Shared\%20Documents/1_Global/INT_CCPR GEC_6621_S.doc (Consulta: 12 de enero de 2016)

Kindler c. Canadá, 30 de julio de 1993, no 470/1991. Disponible en: http://docstore.ohchr.org/SelfServices/FilesHandler.ashx?enc $=6 \mathrm{QkG1d} \% 2 \mathrm{fPPRiCAqhK}$ b7yhstcNDCvDan1pXU7dsZDBaDXK6QwAm\%2fLjVm9gFM9MNBR58a0Qm51WU AtMPJ4\%2fv2NOMsdjX7P5L1XJ0CCvmUBMfYDkc8EE8\%2bKQB51ZJQvDoiM5sU eWwNKpY9rSuPRJHcMQoFIXndkS6uZ5PuEZkamcDHk\%3d (Consulta: 12 de enero de 2016)

Observación General n ${ }^{\circ}$ 27: Artículo 12 - libertad de circulación. $67^{\circ}$ período de sesiones, 1 de noviembre de 1999. Disponible en:

http://tbinternet.ohchr.org/ layouts/treatybodyexternal/Download.aspx?symbolno $=\mathrm{CCP}$

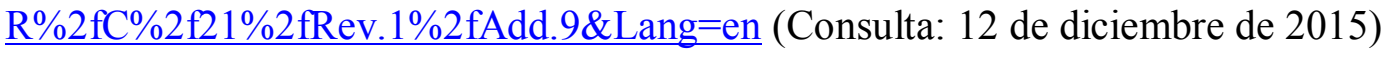

C. c. Australia, 28 de octubre de 2002, no 900/1999. Disponible en: http://docstore.ohchr.org/SelfServices/FilesHandler.ashx?enc=6QkG1d\%2fPPRiCAqhK 
b7yhstcNDCvDan1pXU7dsZDBaDWvOUuXlmf6Gow5OYFcm4s6GWQXsybl7dlT7z vAgp1U3pBY8MLRaj6BhS37rLm13eLcusmeOqIJ4JdiLDXPpSaAgVfL1\%2bsc5Uq2y 07nrDmvMkmqN\%2bAY6aR44Yh\%2biANZ1jA\%3d (Consulta: 13 de enero de 2016)

Judge c. Canadá, 5 de agosto de 2003, nº 829/1998. Disponible en:

http://docstore.ohchr.org/SelfServices/FilesHandler.ashx?enc $=6 \mathrm{QkG1d} \% 2 \mathrm{fPPRiCAqhK}$ b7yhstcNDCvDan1pXU7dsZDBaDVNmMkVCG3Azi\%2bzQxFNvXn4zTR32qgZ3i13 auB28wwbws2ybooUbx\%2bFFxtOOWHRSzozkHO8Rc\%2bBTBRmZS0iQ5QkjWS4n 3rMi8uB3mxKt3s\%2bBKHukBp6OFAlyiZLeZXG\%2fEU\%3d (Consulta: 13 de enero de 2016)

Cuarto Informe Periódico de Bélgica, 16 de mayo de 2003, CCPR/C/BEL/2003/4.

Disponible en:

http://docstore.ohchr.org/SelfServices/FilesHandler.ashx?enc=6QkG1d\%2fPPRiCAqhK b7yhsnKB82NyZV5e4fvxB6eLo8G\%2b9Y61k1zRs\%2bq1JgIrcvWq4boAzW7Vtd7RU YUIR24ZTB0FyHUxvALTi3LRvFhN8niJSjN9GfD9Hhy\%2fZeVTpXS0 (Consulta: 14 de enero de 2016)

Byahuranga c. Dinamarca, 15 de agosto de 2003, no 1222/2003. Disponible en: http://docstore.ohchr.org/SelfServices/FilesHandler.ashx?enc=6QkG1d\%2fPPRiCAqhK b7yhstcNDCvDan1pXU7dsZDBaDULaUXs\%2fl76DaPntsL4rwiosggS4Sb5dEIDOUiw Nkcil80SXcOE\%2b4gp\%2fPrsxZZJxlHz2YQI690rKUIOltfuQcqulDiNYwJrGZp\%2br b00c\%2fh3ucYCxwQp1SXOwGg2o16MjGQ\%3d (Consulta: 13 de enero de 2016)

Ahani c. Canadá, 15 de junio de 2004, no 1051/2002. Disponible en:

http://docstore.ohchr.org/SelfServices/FilesHandler.ashx?enc $=6 \mathrm{QkG1d} \% 2 \mathrm{fPPRiCAqhK}$ b7yhstcNDCvDan1pXU7dsZDBaDWGZIIaTRy0PVBbrs5QCBcAaOeAz8ES7ZxY3FT GjmCnVSDWzMP5I2581VtG2S0iyE\%2bh\%2fRWP1ZATfwqg3mwUKXBNCp1r7L88 W705iANpTE1f2YnQ1Umt5vuJ3s\%2bgfwabWiM\%3d (Consulta: 14 de enero de 2016)

Observación General N. 31: Naturaleza de la obligación jurídica general impuesta a los Estados Partes en el Pacto, $80^{\circ}$ periodo de sesiones, 2004. Disponible en:

http://docstore.ohchr.org/SelfServices/FilesHandler.ashx?enc $=6 \mathrm{QkG1d} \% 2 \mathrm{fPPRiCAqhK}$ b7yhsjYoiCfMKoIRv2FVaVzRkMjTnjRO\%2bfud3cPVrcM9YR0iW6Txaxgp3f9kUFp Woq\%2fhW\%2fTpKi2tPhZsbEJw\%2fGeZRATdbWLgyA1RX61E1VC\%2fXrdwzm\%2 bNA\%2bPSqz8d7eGbkx8Gng\%3d\%3d (Consulta: 12 de enero de 2016)

Kaba Canadá y Guinea; 25 de marzo de 2010, nº 1465/2006. Disponible en:

http://docstore.ohchr.org/SelfServices/FilesHandler.ashx?enc $=6 \mathrm{QkG1d} \% 2 \mathrm{fPPRiCAqhK}$ b7yhstcNDCvDan1pXU7dsZDBaDU\%2fReKzmedZW15TJ57Wtp\%2fX31j31vM3AK1 iXdHMI\%2bpNqF\%2bgcTBYq4YvfBgYYuszH4MTi44nE1zhj7lvGFfRGgvi4cst5PN4 oKIXkXvyGVtZPwG7cks6dsXfr4\%2fcDctqhJs\%3dd (Consulta: 13 de enero de 2016) 


\section{e) Comité contra la Tortura}

G.R.B. c. Suecia, 15 de mayo de 1998, $\mathrm{n}^{\circ}$ 83/1997. Disponible en:

http://docstore.ohchr.org/SelfServices/FilesHandler.ashx?enc $=6 \mathrm{QkG1d} \% 2 \mathrm{fPPRiCAqhK}$ b7yhssh2tXWBbyLwahMw00Sn91UvznuOMGh6DpI8GkXnGo\%2f2loNe5r5VNB26G MyHPDTg2\%2b5v2cfq\%2fTt2ckdZ\%2fWYi8GV5Nagqqx7z67PySHNKaGN8eyJvYX fgc6ENfBzEg616C\%2b4NaivtuO6Dy8R5LnL3Ff8\%3d (Consulta: 14 de enero de 2016)

Elmi c. Australia, 14 de mayo de 1999, no 120/1998. Disponible en:

http://docstore.ohchr.org/SelfServices/FilesHandler.ashx?enc=6QkG1d\%2fPPRiCAqhK b7yhssh2tXWBbyLwahMw00Sn91VM\%2bgAAA4UNIXUBf0QLBxW0hVYcnLPjprb Az4N7qAqQJiJJGtb93pfypAdVaMTHHYa8XG49sb\%2bztcRKIZ1PKNjsgM\%2fquiK \%2fQ9oaeMrLyugircIt3HUj2G1q619CFsUPCqc\%3d (Consulta: 12 de enero de 2016)

Observación General n 2: Aplicación del artículo 2 por los Estados Partes, $39^{\circ}$ periodo de sesiones, 2007. Disponible en:

http://docstore.ohchr.org/SelfServices/FilesHandler.ashx?enc=6QkG1d\%2fPPRiCAqhK b7yhskvE\%2bTuw1mw\%2fKU18dCyrYrZhDDP8yaSRi\%2fv43pYTgmQ5ha3y9ciYQ TndQSRsnHNf13LsBC9NRMmaE3LGcm3s41Q\%3d (Consulta: 18 de enero de 2016)

J.H.A. c. España, 10 de noviembre de 2008, no 323/2007. Disponible en:

http://docstore.ohchr.org/SelfServices/FilesHandler.ashx?enc $=6 \mathrm{QkG1d} \% 2 \mathrm{fPPRiCAqhK}$ b7yhssh2tXWBbyLwahMw00Sn91U0pRetxQ6\%2fdHVH4s16\%2fKIvHR0TYeh7FK7 K7dtj9e1 iRWh7soiJSy2H228vFHER1VCsn8w7ea\%2bl1FlnU\%2f35\%2flvDg7jB4hG5 ef63MPNv765m3Uv8B1mxa9ydvmQQHn9yPiw\%3d (Consulta: 26 de enero de 2016)

Sonko c. España, 25 de noviembre de 2011, no 368/2008. Disponible en: http://docstore.ohchr.org/SelfServices/FilesHandler.ashx?enc $=6 \mathrm{QkG1d} \% 2 \mathrm{fPPRiCAqhK}$ b7yhssh2tXWBbyLwahMw00Sn91VKy830Pq8xwflFw3PpFVP3IB0NeM5Xq1DJ7JQj u0husnVGrXMCaLsJ5ZFe9GO4ApajqmbN1CMDhci9ruZwPouJKk5zv\%2b8zeamWeo 9tsuXeipxy8gsRF8gVODGtv2BjWos\%3d (Consulta: 26 de enero de 2016)

\section{f) Corte Internacional de Justicia}

Case concerning the difference between New Zealand and France concerning the interpretation or application of two agreements concluded on 9 July 1986 between the two States and which related to the problems arising from the Rainbow Warrior affair, UNRIAA, sentencia del 30 de abril de 1990, vol. XX (1990). Disponible en: http://legal.un.org/riaa/cases/vol_XX/215-284.pdf (Consulta: 25 de enero de 2016) 
Opinión Consultiva de la Corte Internacional de Justicia sobre las consecuencias jurídicas de la construcción de un muro en el territorio palestino ocupado. Decimo periodo de sesiones de emergencia. 13 de julio de 2004 A/ES-10/273. Disponible en: http://www.icj-cij.org/homepage/sp/advisory/advisory_2004-07-09.pdf (Consulta: $18 \mathrm{de}$ enero de 2016)

Concerning Armed Activities on the Territory of Congo, Democratic Republic of Congo v. Uganda, sentencia del 19 de diciembre de 2005. Disponible en:

http://www.icj-cij.org/docket/files/116/10455.pdf (Consulta: 18 de enero de 2016)

Ahamadou Sadio Dialle (República de Guinea c. República Democrática del Congo), sentencia del 30 de noviembre de 2010. Disponible en: http://www.icjcij.org/docket/files/103/16244.pdf (Consulta: 14 de enero de 2016)

\section{f) Organización de Estados Americanos}

Comisión Interamericana de Derechos Humanos: aso 10.675, de 13 de marzo de 1997, Informe $\mathrm{n}^{\mathrm{o}}$ 51/96 OEA/Ser.L/V/II.95 Doc. 7. Disponible en:

https://www.cidh.oas.org/annualrep/96span/EEUU10675.htm (Consulta: 18 de enero de 2016)

Corte Interamericana de Derechos Humanos: Opinión Consultiva $\mathrm{n}^{\mathrm{o}}$ 18: Condición jurídica y derechos de los migrantes indocumentados, 17 de septiembre de 2003. Disponible en: http://www.corteidh.or.cr/docs/opiniones/seriea_18_esp.pdf (Consulta: 14 de enero de 2016)

-: caso de personas dominicanas y haitianas expulsadas vs. República Dominicana, sentencia de 28 de agosto de 2014. Disponible en:

http://corteidh.or.cr/docs/casos/articulos/seriec_282 esp.pdf (Consulta: 14 de enero de 2016)

\section{h) Organización Marítima Internacional}

Resolución A.920 (22) de la Asamblea OMI, Review of Safety Measures and Procedures for the Treatment of Persons Rescued at Sea, aprobada el 29 de noviembre de 2001, 22 periodo de sesiones. Disponible en: http://www.imo.org/en/OurWork/Facilitation/personsrescued/Documents/Resolution\%2 0A.920\%2822\%29.pdf (Consulta: 26 de enero de 2016)

CSM: Resolución MSC.167(78), Guidelines on the Treatment of Persons Rescued At Sea, adoptada el 20 de mayo de 2004, en el $78^{\circ}$ periodo de sesiones del Comité. 


\section{CAPÍTULO 7}

Disponible en: http://www.refworld.org/docid/432acb464.html (Consulta: 26 de enero de 2016)

OMI y ACNUR: Salvamento en el mar. Guía de referencia sobre los principios y prácticas aplicables a migrantes y refugiados, septiembre de 2006. Disponible en: http://www.acnur.es/PDF/4495_20120511132013.pdf(Consulta: 26 de enero de 2016)

Manual Internacional de los Servicios Aeronáuticos y Marítimos de Búsqueda y Salvamento (IAMSAR). Londres/Montreal, edición de 2007, Doc. 9731-AN/958, vol. III.

Principios relacionados con los procedimientos administrativos para el desembarco de personas rescatadas en el mar, Comité de Facilitación, 22 de enero de 2009, Doc.

FAL.3/Circ.194. Disponible en:

http://www.imo.org/en/OurWork/Facilitation/docs/FAL\%20related\%20nonmandatory\% 20instruments/FAL.3-Circ.194.pdf (Consulta: 26 de enero de 2016)

Measures to protect the safety of persons rescued at sea, Compulsory guideline for the treatment of persons rescued at sea, Sub-Committee on Flag State Implementation, presentado por España e Italia, sesión n ${ }^{\circ}$ 17, 13 de febrero de 2009, Doc. FSI 17/15/1. Disponible en: http://www.sjofartsverket.se/pages/18709/17-15-1.pdf (Consulta: 26 de enero de 2016)

\section{i) Otras}

Alto Comisionado para los Derechos Humanos, Expulsions of aliens in international human rights law. OHCHR Discussion paper. Ginebra, septiembre 2006. Disponible en: http://www2.ohchr.org/english/issues/migration/taskforce/docs/Discussion-paperexpulsions.pdf (Consulta: 12 de enero de 2016)

- Principios rectores sobre las empresas y los derechos humanos. Puesta en práctica del marco de las Naciones Unidas para "proteger, respetar y remediar". Ginebra, doc.

HR/PUB/11/04, 2011. Disponible en:

http://www.ohchr.org/Documents/Publications/GuidingPrinciplesBusinessHR_SP.pdf (Consulta: 26 de enero de 2016)

Comisión de Derecho Internacional: International Law Yearbook, vol. II, 1979, Cap. IV, Implication of a State in the internationally wrongful act of another State.

-: Informe de la Sexta Comisión del CDI (A/56/589) Resolución aprobada por la AGNU el 28 de enero de 2002. Disponible en: 
http://www.uib.cat/depart/dpu/dip/pdf/dip0607/responsabilidad.pdf (Consulta: 26 de enero de 2016)

- Segundo informe sobre la expulsión de los extranjeros, $58^{\circ}$ periodo de sesiones 2006. A/CN.4/573. Disponible en: http://daccess-ddsny.un.org/doc/UNDOC/GEN/N06/438/14/PDF/N0643814.pdf?OpenElement (Consulta: 12 de enero de 2016)

- Informe sobre la expulsión de los extranjeros, $66^{\circ}$ periodo de sesiones 2014. A/69/10, pp. 35-45. Disponible en: http://legal.un.org/ilc/reports/2014/spanish/chp4.pdf (Consulta: 29 de enero de 2016)

Comité por los Derechos del Niño: Observación General n ${ }^{\circ}$ 6: Trato de los menores no acompañados y separados de su familia fuera de su país de origen. $39^{\circ}$ periodo de sesiones, 2005. Disponible en:

http://docstore.ohchr.org/SelfServices/FilesHandler.ashx?enc=6QkG1d\%2fPPRiCAqhK b7yhsiQq18gX5Zxh0cQqSRzx6ZfXmRo9mdg35\%2bm8BvAjgxjO\%2bIzulGMG7OKG 0mWvJJi9e82iOG1uSF\%2b72cHLBLISZNqeK0k5bcWwjaPwfzsZ\%2bbHm

(Consulta: 13 de enero de 2016)

Comité por la Eliminación de la Discriminación Racial: Recomendación General no 30 sobre la discriminación contra los no ciudadanos. $65^{\circ}$ periodo de sesiones, 2005.

Disponible en:

http://tbinternet.ohchr.org/Treaties/CERD/Shared\%20Documents/1_Global/INT_CERD GEC 7502 S.doc (Consulta: 13 de enero de 2016)

Consejo de Derechos Humanos: Report of the WGAD on its Mission to Italy, 26 de enero de 2009, Doc. A/HRC/10/21/Add.5. Disponible en: http://daccess-ddsny.un.org/doc/UNDOC/GEN/G09/105/76/PDF/G0910576.pdf?OpenElement (Consulta: 14 de enero de 2016)

- Informe del Relator Especial sobre los derechos humanos de los migrantes, François Crépeau, $29^{\circ}$ periodo de sesiones, 24 de abril de 2013, Doc. A/HRC/23/46. Disponible en: http://daccess-dds-

ny.un.org/doc/UNDOC/GEN/G13/133/94/PDF/G1313394.pdf?OpenElement (Consulta: 12 de diciembre de 2015)

- Elaboración de un instrumento internacional jurídicamente vinculante sobre las empresas transnacionales y otras empresas con respecto a los derechos humanos, $26^{\circ}$ periodo de sesiones, 25 de junio de 2014, Doc. A/HRC/26/IL.22/Rev.1. Disponible en: http://daccess-dds- 


\section{CAPÍTULO 7}

ny.un.org/doc/UNDOC/LTD/G14/064/51/PDF/G1406451.pdf?OpenElement (Consulta: 26 de enero de 2016)

- Consejo de Seguridad: Resolución 1373 (2001) de 28 septiembre de 2001, 4385 sesión. Doc. S/RES/1373. Disponible en:

http://www.un.org/es/comun/docs/?symbol=S/RES/1373\%282001\%29 (Consulta: 12 de enero de 2016)

- Resolución 2240 (2015) de 9 de octubre de 2015, 7531º sesión. Doc. S/RES/2240 (2015). Disponible en:

http://www.un.org/es/comun/docs/?symbol=S/RES/2240\%282015\%29 (Consulta: 29 de enero de 2016)

ILA: Declaración de Principios del Derecho Internacional sobre Expulsión Masiva, Seúl, 62 ${ }^{\text {a }}$ Conferencia de la ILA, 24 a 30 de agosto de 1986, pp. 13-18. Disponible en: https://www.google.es/url?sa $=$ t\&rct $=\mathrm{j} \& q=\&$ esrc $=$ s\&source $=$ web\&cd $=1 \&$ cad $=$ rja\&uact $=8 \&$ ved $=0$ ahUKEwj067nF0anKAhUJ8j4KHdl7Bq4QFgggMAA\&url $=$ http $\% 3 \mathrm{~A} \% 2 \mathrm{~F} \%$ 2Fwww.ila-hq.org\%2Fdownload.cfm\%2Fdocid\%2F52392D73-DED3-435FBC0947746E68410A\&usg=AFQjCNELMYjNzHbTjqlk4AZ68GuTPqcBaw\&sig2=mu 7HwqjF0x6-c8mBtCnzNw (Consulta: 14 de enero de 2016)

OIM: Glossary on Migration, International Migration Law, $n^{0}$ 1, Doc. 71/04, Ginebra 2004. Disponible en: http://unobserver.iom.int/sites/default/files/IML_1_EN.pdf (Consulta: 12 de diciembre de 2015)

-Fatal Journeys. Tracking Lives Lost During Migration, Ginebra, OIM Publications, 2014. Disponible en:

https://publications.iom.int/system/files/pdf/fataljourneys_countingtheuncounted.pdf (Consulta: 20 de enero de 2016)

OIT: En busca de un compromiso equitativo para los trabajadores migrantes en la economía globalizada. Ginebra, Conferencia Internacional del Trabajo, 92ª reunión, Informe VI, 2004.

UNDG: El Enfoque basado en los Derechos Humanos para la Cooperación del Desarrollo. Hacia un Entendimiento Común entre las Agencias de la ONU. Grupo de Desarrollo de Naciones Unidas, Nueva York, 2013. Disponible en:

http://hrbaportal.org/the-human-rights-based-approach-to-development-cooperation- 
towards-a-common-understanding-among-un-agencies (Consulta: 12 de diciembre de 2015)

\subsubsection{Derecho de la UE}

\section{a) Derecho primario}

Tratado Constitutivo de la Comunidad Europea, adoptado el 25 de marzo de 1957 en Roma. Disponible en: http://eur-lex.europa.eu/legalcontent/ES/TXT/?qid=1452297035008\&uri=CELEX:11957E/TXT (Consulta: 9 de diciembre de 2015)

Acta Única Europea, firmada en La Haya el 28 de febrero de 1986. DO L 169 de 29 de junio de 1987, pp. 1-29. Disponible en: http://eur-lex.europa.eu/legalcontent/ES/TXT/PDF/?uri=OJ:L:1987:169:FULL\&from=ES (Consulta: 9 de enero de 2016)

Tratado de la Unión Europea, firmado en Maastricht el 7 de febrero de 1992. DO C 191 de 29 de julio de 1992, pp. 1-110. Disponible en: http://eur-lex.europa.eu/legalcontent/ES/TXT/PDF/?uri=OJ:C:1992:191:FULL\&from=ES (Consulta: 9 de enero de 2016)

Tratado de Ámsterdam por el que se modifican el Tratado de la Unión Europea, los Tratados constitutivos de las Comunidades Europeas y determinados actos conexos, firmado el 2 de octubre de 1997. DO C 340 de 10 de noviembre de 1997, pp. 1-144. Disponible en: http://eur-lex.europa.eu/legalcontent/ES/TXT/PDF/?uri=OJ:C:1997:340:FULL\&from=ES (Consulta: 9 de enero de 2016)

Tratado de Lisboa, por el que se modifican el Tratado de la Unión Europea y el Tratado constitutivo de la Comunidad Europea, firmado el 13 de diciembre de 2007. DO C 306 de 17 de diciembre de 2007, pp. 1-271. Disponible en: http://eur-lex.europa.eu/legalcontent/ES/TXT/PDF/?uri=OJ:C:2007:306:FULL\&from=ES (Consulta: 9 de enero de 2016)

Tratado de la Unión Europea (versión consolidada). DO C 326 de 26 de octubre de 2012, pp. 13-46. Disponible en: http://eur-lex.europa.eu/legalcontent/ES/TXT/PDF/?uri=OJ:C:2012:326:FULL\&from=ES (Consulta: 9 de enero de 2016) 


\section{CAPÍTULO 7}

Tratado de Funcionamiento de la Unión Europea (versión consolidada). DO C 326 de 26 de octubre de 2012, pp. 47-390. Disponible en: http://eur-lex.europa.eu/legalcontent/ES/TXT/PDF/?uri=OJ:C:2012:326:FULL\&from=ES (Consulta: 9 de enero de 2016)

Carta de los Derechos Fundamentales de la Unión Europea (versión consolidada). DO C 362 de 26 de octubre de 2012, pp. 391-407. Disponible en: http://eurlex.europa.eu/legal-content/ES/TXT/PDF/?uri=OJ:C:2012:326:FULL\&from=ES (Consulta: 9 de enero de 2016)

\section{b) Derecho derivado}

Convenio de Aplicación del Acuerdo Schengen, firmado el 19 de junio de 1990, relativo a la supresión gradual de los controles en las fronteras comunes. DO L 239, de 22 de diciembre de 2000, pp. 19-62. Disponible en: http://eur-lex.europa.eu/legalcontent/ES/TXT/HTML/?uri=CELEX:42000A0922\%2802\%29\&qid=1454313691548\& from=ES (Consulta: 25 de enero de 2016)

Convenio relativo a la determinación del Estado responsable del examen de las solicitudes de asilo presentadas en los Estados miembros de las Comunidades Europeas, firmado en Dublín el 15 de julio de 1990. DO C 254 de 19 de agosto de 1997, pp. 1-12. Disponible en: http://eur-lex.europa.eu/legalcontent/ES/TXT/PDF/?uri=CELEX:41997A0819\%2801\%29\&from=ES (Consulta: 10 de enero de 2016)

Reglamento (CE) n $n^{\circ} 2725 / 2000$ del Consejo, de 11 de diciembre de 2000, relativo a la creación del sistema «Eurodac» para la comparación de las impresiones dactilares para la aplicación efectiva del Convenio de Dublín. Disponible en: http://eurlex.europa.eu/legal-content/ES/TXT/PDF/?uri=CELEX:32000R2725\&from=ES (Consulta: 10 de enero de 2016)

Directiva 2001/40/CE del Consejo, de 28 de mayo de 2001, relativa al reconocimiento mutuo de las decisiones en materia de expulsión de nacionales de terceros países. DO L 348 de 2 de junio de 2001, pp. 34-36. Disponible en: http://eur-lex.europa.eu/legalcontent/ES/TXT/PDF/?uri=CELEX:32001L0040\&from=ES (Consulta: 14 de enero de 2016)

Reglamento (CE) no 1049/2001, del Parlamento Europeo y de la Comisión, del 30 de mayo de 2001, sobre el acceso público a los documentos del Parlamento Europeo, del Consejo y de la Comisión. DO L 145 de 31 de mayo de 2001, pp. 43-49. Disponible en: http://eur- 
lex.europa.eu/LexUriServ/LexUriServ.do?uri=OJ:L:2001:145:0043:0048:es:PDF

(Consulta: 10 de enero de 2016)

Directiva 2001/55/CE, de 20 de julio de 2001, relativa a las normas mínimas para la concesión de protección temporal en caso de afluencia masiva de personas desplazadas. DO L 212, de 7 de agosto de 2001, p. 12-24. Disponible en: http://eurlex.europa.eu/LexUriServ/LexUriServ.do?uri=OJ:L:2001:212:0012:0023:ES:PDF (Consulta: 10 de enero de 2016)

Directiva 2002/90/CE del Consejo, de 28 de noviembre de 2002, destinada a definir la ayuda a la entrada, a la circulación y a la estancia irregulares. DO L 238, de 5 de diciembre de 2002, pp. 17-18. Disponible en: http://eur-lex.europa.eu/legalcontent/ES/TXT/PDF/?uri=CELEX:32002L0090\&from=ES (Consulta: 25 de enero de 2016)

Decisión marco 2002/946/JAI del Consejo, de 28 de noviembre de 2002, destinada a reforzar el marco penal para la represión de la ayuda a la entrada, a la circulación y a la estancia irregulares. DO L 328 de 5 de diciembre 2002, pp. 1-3. Disponible en:

http://eur-lex.europa.eu/legalcontent/ES/TXT/PDF/?uri=CELEX:32002F0946\&from=ES (Consulta: 25 de enero de 2016)

Directiva 2003/9/CE, del Consejo, de 27 de enero de 2003, por la que se aprueban normas mínimas para la acogida de los solicitantes de asilo en los Estados miembros. DO L 31 de 6 de febrero de 2003, pp. 18-25. Disponible en: http://eurlex.europa.eu/legal-content/ES/TXT/PDF/?uri=CELEX:32003L0009\&from=ES (Consulta: 10 de enero de 2016)

Reglamento (CE) n $\mathrm{n}^{\circ}$ 343/2003 del Consejo, de 18 de febrero de 2003, por el que se establecen los criterios y mecanismos de determinación del Estado miembro responsable del examen de una solicitud de asilo presentada en uno de los Estados miembros por un nacional de un tercer país. DO L 50 de 25 de febrero de 2003, p. 1-10. Disponible en: http://eur-lex.europa.eu/legalcontent/ES/TXT/PDF/?uri=CELEX:32003R0343\&from=ES (Consulta: 10 de enero de 2016)

Directiva 2003/86/CE del Consejo, de 22 de septiembre de 2003, sobre el derecho a la reagrupación familiar. DO L 251 de 3 de octubre de 2003, pp. 12-19. Disponible en: http://eurlex.europa.eu/LexUriServ/LexUriServ.do?uri=OJ:L:2003:251:0012:0018:ES:PDF (Consulta: 12 de enero de 2016) 


\section{CAPÍTULO 7}

Reglamento (CE) n 491/2004 del Parlamento Europeo y del Consejo, de 10 de marzo de 2004, por el que se establece un programa de asistencia financiera y técnica a los terceros países en los ámbitos de la migración y el asilo (Aeneas). DO L 80, de 18 de marzo de 2004, p. 1-5. Disponible en: http://eur-lex.europa.eu/legalcontent/ES/TXT/PDF/?uri=CELEX:32004R0491\&qid=1452385239919\&from=EN (Consulta: 10 de enero de 2016)

Directiva 2004/83/CE del Consejo, de 29 de abril de 2004, por la que se establecen normas mínimas relativas a los requisitos para el reconocimiento y el estatuto de nacionales de terceros países o apátridas como refugiados o personas que necesitan otro tipo de protección internacional y al contenido de la protección concedida. DO L 304 de 30 de noviembre de 2004, pp. 12-23. Disponible en: http://eur-lex.europa.eu/legalcontent/ES/TXT/PDF/?uri=CELEX:32004L0083\&from=ES (Consulta: 10 de enero de 2016)

Reglamento (CE) n 2007/2004 del Consejo, de 26 de octubre de 2004, por el que se crea una Agencia Europea para la gestión de la cooperación operativa en las fronteras exteriores de los Estados miembros de la Unión Europea. DO L 349 de 25 de noviembre de 2004, pp. 1-11. Disponible en: http://eur-

lex.europa.eu/LexUriServ/LexUriServ.do?uri=CONSLEG:2004R2007:20070820:ES:P DF (Consulta: 10 de enero de 2016)

Directiva 2005/85/CE, del Consejo, de 1 de diciembre de 2005, sobre normas mínimas para los procedimientos que deben aplicar los Estados miembros para conceder o retirar la condición de refugiado. DO L 326 de 13 de diciembre de 2005, pp. 13-34. Disponible en: http://eur-lex.europa.eu/legal-

content/ES/TXT/PDF/?uri=CELEX:32005L0085\&from=ES (Consulta: 10 de enero de 2016)

Reglamento (CE) no 562/2006 del Parlamento y del Consejo, de 15 de marzo de 2006, por el que se establece un Código comunitario de normas para el cruce de personas por las fronteras. DO L 105 de 13 de abril de 2006, pp. 1-32. Disponible en: http://eurlex.europa.eu/legal-content/ES/TXT/PDF/?uri=CELEX:32006R0562\&from=ES (Consulta: 10 de enero de 2016)

Reglamento (CE) no 863/2007 del Parlamento Europeo y del Consejo, de 11 de julio de 2007, por el que se establece un mecanismo para la creación de equipos de intervención rápida en las fronteras y que modifica el Reglamento (CE) no 2007/2004 del Consejo por lo que respecta a este mecanismo y regula las funciones y competencias de los agentes invitados. DO L 199 de 31 de julio de 2007, pp. 30-39. Disponible en: http://eur-lex.europa.eu/legal- 
content/ES/TXT/PDF/?uri=CELEX:32007R0863\&from=ES (Consulta: 10 de enero de 2016)

Directiva 2008/115/CE del Parlamento Europeo y del Consejo, de 16 de diciembre de 2008 , relativa a normas y procedimientos comunes en los Estados miembros para el retorno de los nacionales de terceros países en situación irregular. DO L 348 de 24 de diciembre de 2008, pp. 98-107. Disponible en: http://eur-lex.europa.eu/legalcontent/ES/TXT/PDF/?uri=CELEX:32008L0115\&rid=1 (Consulta: 9 de enero de 2016)

Directiva 2009/17/CE del Parlamento Europeo y del Consejo, de 23 de abril de 2009 por la que se modifica la Directiva 2002/59/CE relativa al establecimiento de un sistema comunitario de seguimiento y de información sobre el tráfico marítimo, art. 20. DOUE L 131, pp. 101-113. Disponible en: http://eurlex.europa.eu/LexUriServ/LexUriServ.do?uri=OJ:L:2009:131:0101:0113:ES:PDF (Consulta: 20 de enero de 2016)

Decisión del Consejo 2010/252/UE, de 26 de abril de 2010, por la que se completa el Código de fronteras Schengen por lo que se refiere a la vigilancia de las fronteras marítimas exteriores en el marco de la cooperación operativa coordinada por la Agencia Europea para la Gestión de la Cooperación Operativa en las Fronteras Exteriores de los Estados miembros de la Unión Europea. DO L 111 de 4 de mayo de 2010, p. 20-26. Disponible en: http://eurlex.europa.eu/LexUriServ/LexUriServ.do?uri=OJ:L:2010:111:0020:0026:ES:PDF (Consulta: 18 de enero de 2016)

Reglamento (UE) número 439/2010 del Parlamento Europeo y del Consejo, de 19 de mayo de 2010, por el que se crea una Oficina Europea de Apoyo al Asilo. DO L 132 de 29 de mayo de 2010, pp. 11-28. Disponible en: http://eur-lex.europa.eu/legalcontent/ES/TXT/PDF/?uri=CELEX:32010R0439\&from=ES (Consulta: 10 de enero de 2016)

Reglamento (UE) no 168/2011 del Parlamento Europeo y del Consejo, de 25 de octubre de 2011 que modifica el Reglamento (CE) no. 2007/2004 del Consejo, por el que se crea una Agencia Europea para la gestión de la cooperación operativa en las fronteras exteriores de los Estados miembros de la Unión Europea. DO L 304 de 22 de noviembre de 2011, pp. 1-17. Disponible en: http://eur-

lex.europa.eu/LexUriServ/LexUriServ.do?uri=OJ:L:2011:304:0001:0017:ES:PDF (Consulta: 10 de enero de 2016)

Directiva 2011/95/UE del Parlamento Europeo y del Consejo, de 13 de diciembre de 2011, por la que se establecen normas relativas a los requisitos para el reconocimiento de nacionales de terceros países o apátridas como beneficiarios de protección 


\section{CAPÍTULO 7}

internacional, a un estatuto uniforme para los refugiados o para las personas con derecho a protección subsidiaria y al contenido de la protección concedida. DO L 337 de 20 de diciembre de 2011, pp. 9-26. Disponible en: http://eurlex.europa.eu/LexUriServ/LexUriServ.do?uri=OJ:L:2011:337:0009:0026:ES:PDF (Consulta: 10 de enero de 2016)

Directiva 2013/32/UE del Parlamento Europeo y del Consejo, de 26 de junio de 2013, sobre procedimientos comunes para la concesión o la retirada de la protección internacional. DO L 180, de 29 de junio de 2013, pp. 60-95. Disponible en: http://eurlex.europa.eu/LexUriServ/LexUriServ.do?uri=OJ:L:2013:180:0060:0095:ES:PDF (Consulta: 10 de enero de 2016)

Directiva 2013/33/UE del Parlamento Europeo y del Consejo, de 26 de junio de 2013, por la que se aprueban normas para la acogida de solicitantes de protección internacional. DO L 180 de 29 de junio de 2013, pp. 96-116. Disponible en: http://eurlex.europa.eu/LexUriServ/LexUriServ.do?uri=OJ:L:2013:180:0096:0116:ES:PDF (Consulta: 10 de enero de 2016)

Reglamento (UE) no 603/2013 del Parlamento Europeo y del Consejo de 26 de junio de 2013 relativo a la creación del sistema «Eurodac» para la comparación de las impresiones dactilares para la aplicación efectiva del Reglamento (UE) no 604/2013, por el que se establecen los criterios y mecanismos de determinación del Estado miembro responsable del examen de una solicitud de protección internacional presentada en uno de los Estados miembros por un nacional de un tercer país o un apátrida, y a las solicitudes de comparación con los datos de Eurodac presentadas por los servicios de seguridad de los Estados miembros y Europol a efectos de aplicación de la ley, y por el que se modifica el Reglamento (UE) no 1077/2011, por el que se crea una Agencia europea para la gestión operativa de sistemas informáticos de gran magnitud en el espacio de libertad, seguridad y justicia. DO L 180 de 29 de junio de 2013, pp. 31-59. Disponible en: http://eur-lex.europa.eu/legalcontent/ES/TXT/PDF/?uri=OJ:L:2013:180:FULL\&from=ES (Consulta: 10 de enero de 2016)

Reglamento (UE) n ${ }^{\circ}$ 604/2013 del Parlamento Europeo y del Consejo, de 26 de junio de 2013, por el que se establecen los criterios y mecanismos de determinación del Estado miembro responsable del examen de una solicitud de protección internacional presentada en uno de los Estados miembros por un nacional de un tercer país o un apátrida. DO L 180 de 29 de junio de 2013, p. 31-59. Disponible en: http://eurlex.europa.eu/legal-content/ES/TXT/PDF/?uri=CELEX:32013R0604\&rid=1 (Consulta: 10 de enero de 2016) 
Reglamento (UE) $n{ }^{\circ}$ 610/2013 del Parlamento Europeo y del Consejo, de 26 de junio de 2013 , por el que se modifica el Reglamento (CE) n ${ }^{\circ}$ 562/2006 del Parlamento Europeo y del Consejo, por el que se establece un Código comunitario de normas para el cruce de personas por las fronteras (Código de fronteras Schengen), el Convenio de aplicación del Acuerdo de Schengen, los Reglamentos del Consejo (CE) n ${ }^{\circ}$ 1683/95 y (CE) $\mathrm{n}^{\circ} 539 / 2001$ y los Reglamentos del Parlamento Europeo y del Consejo (CE) $\mathrm{n}^{\circ}$ 767/2008 y (CE) n ${ }^{\circ}$ 810/2009. DO L 182 de 29 de junio 2013, pp. 1-18. Disponible en: http://eurlex.europa.eu/LexUriServ/LexUriServ.do?uri=OJ:L:2013:182:0001:0018:ES:PDF (Consulta: 10 de enero de 2016)

Reglamento (UE) $n^{\circ}$ 1052/2013 del Parlamento Europeo y del Consejo, de 22 de octubre de 2013, por el que se crea un Sistema Europeo de Vigilancia de Fronteras (Eurosur). DO L 295, 6 de noviembre de 2013, pp. 11-26. Disponible en: http://eurlex.europa.eu/LexUriServ/LexUriServ.do?uri=OJ:L:2013:295:0011:0026:ES:PDF (Consulta: 10 de enero de 2016)

Reglamento (UE) n ${ }^{\circ}$ 1289/2013 del Parlamento Europeo y del Consejo, de 11 de diciembre de 2013, por el que se modifica el Reglamento (CE) ${ }^{\circ}{ }^{\circ} 539 / 2001$ del Consejo por el que se establece la lista de terceros países cuyos nacionales están sometidos a la obligación de visado para cruzar las fronteras exteriores y la lista de terceros países cuyos nacionales están exentos de esa obligación. DO L 347 de 20 de diciembre de 2014, pp. 74-80. Disponible en: http://eur-lex.europa.eu/legalcontent/ES/TXT/PDF/?uri=CELEX:32013R1289\&from=ES (Consulta: 28 de enero de 2016)

Reglamento (UE) nº 656/2014 del Parlamento Europeo y del Consejo de 15 de mayo de 2014 por el que se establecen normas para la vigilancia de las fronteras marítimas exteriores en el marco de la cooperación operativa coordinada por la Agencia Europea para la Gestión de la Cooperación Operativa en las Fronteras Exteriores de los Estados miembros de la Unión Europea. DO L 189 de 27 de junio de 2014, pp. 93-107.

Disponible en: http://eur-lex.europa.eu/legalcontent/ES/TXT/PDF/?uri=OJ:JOL 2014_189_R 0005\&from=ES (Consulta: 10 de enero de 2016)

\section{c) Tribunal de Justicia de la Unión Europea}

“Oxana Dem'Yanenko" (C-45/03), auto del 18 de marzo de 2004. Disponible en: http://curia.europa.eu/juris/document/document.jsf?text $=\&$ docid $=51099 \&$ pageIndex $=0$

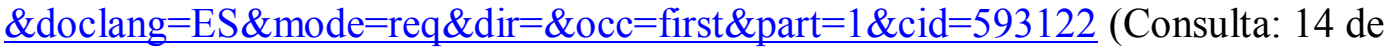
enero de 2016) 


\section{CAPÍTULO 7}

"Meki y Noor Elgafaji contra Staatssecretaris van Justitie" (C-465/07), sentencia del 17 de febrero de 2009. Disponible en:

http://curia.europa.eu/juris/document/document.jsf?text $=\&$ docid $=76788 \&$ pageIndex $=0$ $\underline{\& \text { doclang }=\text { es } \& \text { mode }=1 \text { st\&dir }=\& o c c=\text { first\&part }=1 \& c i d=584599}$ (Consulta: 14 de enero de 2016)

"Aydin Salahadin Abdula y otros contra Bundesrepublik Deutschalnd" (C-175/08), sentencia del 2 de marzo de 2010. Disponible en:

http://curia.europa.eu/juris/document/document.jsf;jsessionid=9ea7d0f130d56b451e0c8 ea64f34b942b8d093397648.e34KaxiLc3eQc40LaxqMbN4Oc3yLe0?text=\&docid=752 96\&pageIndex $=0 \&$ doclang $=\mathrm{ES} \& \operatorname{mode}=1$ st \&dir $=\& o c c=$ first $\&$ part $=1 \& \mathrm{cid}=73734$ (Consulta: 12 de enero de 2016)

“Hassen el-Dridi” (C-61/11 PPU), sentencia del 28 de abril de 2011. Disponible en: http://curia.europa.eu/juris/document/document.jsf;jsessionid=9ea7d0f130d5d51a7102f 65649428c728c8cf8540c07.e34KaxiLc3eQc40LaxqMbN4Oc3yLe0?text=\&docid=8203

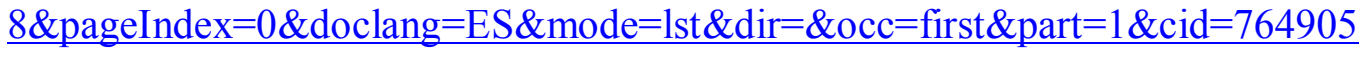
(Consulta: 14 de enero de 2016)

"M. S. contra Secretary of State for the Home Department" (C-411/10) y "M. E. y otros contra Refugee Applications Commissioner y Minister for Justice, Equality and Law Reform" (C-493/10), sentencia del 21 de diciembre de 2011. Disponible en: http://curia.europa.eu/juris/document/document.jsf;jsessionid=9ea7d0f130d53bb3aa2f1 6544603800dbad2974ed23d.e34KaxiLc3eQc40LaxqMbN4Oc3uPe0?text $=$ \&docid $=117$ $187 \&$ pageIndex $=0 \&$ doclang $=E S \&$ mode $=1$ st\&dir $=\& o c c=$ first \&part $=1 \& c i d=618311$ (Consulta: 9 de enero de 2016)

"Minh Khoa Vo contra Bundesgerichtshof" (C-83/12 PPU), sentencia del 10 de abril de 2012. Disponible en:

http://curia.europa.eu/juris/document/document.jsf;jsessionid=9ea7d0f130d55c9d38d41 bcf4567b5c1802870dc59ce.e34KaxiLc3eQc40LaxqMbN4Och0Qe0?text=\&docid=1215 01\&pageIndex $=0$ \&doclang $=\mathrm{ES} \&$ mode $=1$ st \&dir $=\&$ occ $=$ first \&part $=1 \& \operatorname{cid}=302859$

(Consulta: 14 de enero de 2016)

"Y y Z contra República Federal Alemana" (asuntos acumulados C-71/11 y C-99/11), sentencia del 5 de septiembre de 2012. Disponible en:

http://curia.europa.eu/juris/document/document.jsf?text $=\&$ docid $=126364 \&$ pageIndex $=0$ $\underline{\& d o c l a n g=e s \& m o d e=1 s t \& d i r=\& o c c=\text { first\&part }=1 \& c i d=583895}$ (Consulta: 14 de enero de 2016)

"Parlamento Europeo contra Consejo de la Unión Europea" (C-355/10), sentencia del 5 de septiembre de 2012. Disponible en:

http://curia.europa.eu/juris/document/document.jsf?text $=\&$ docid $=126363 \&$ pageIndex $=0$ 
$\&$ doclang $=$ es $\&$ mode $=1$ st $\&$ dir $=\& o c c=$ first $\&$ part $=1 \& c i d=276283$ (Consulta: 18 de enero de 2016)

"X, Y, y Z contra Minister voor Immigratie en Asiel" (asuntos acumulados C-199/12 a C-201/12), sentencia del 7 de noviembre de 2013. Disponible en:

http://curia.europa.eu/juris/document/document.jsf;jsessionid=9ea7d0f130d5d6a7e2766 505499a9227fa8cdcbd9d96.e34KaxiLc3eQc40LaxqMbN4Oc3yLe0?text=\&docid=1442 $15 \&$ pageIndex $=0 \&$ doclang $=$ es $\&$ mode $=1$ st \&dir $=\&$ occ $=$ first \&part $=1 \&$ cid $=583483$ (Consulta: 14 de enero de 2016)

"Bero contra Regierungspräsidium Kassel” (C-473/13) y "Bouzalmate contra Kreisverwaltung Kleve” (C-514/13), sentencia del 17 de julio de 2014. Disponible en: http://curia.europa.eu/juris/document/document.jsf?text=\&docid $=155112 \&$ pageIndex $=0$ $\&$ doclang $=$ es $\&$ mode $=1$ st \& dir $=\&$ occ $=$ first $\&$ part $=1 \&$ cid $=769561$ (Consulta: 14 de enero de 2016)

\section{d) Frontex}

Programme of Work 2006, Varsovia, 10 de octubre de 2005. Disponible en: http://frontex.europa.eu/assets/About_Frontex/Governance_documents/Work_program me/2006/mb_decision_013.2005 of_19 oct_2005 - programme_of_work_2006 _written_procedure.pdf (Consulta: 10 de enero de 2016)

Informe Anual 2006, Coordinación de la cooperación basada en la inteligencia a escala de la UE para reforzar la seguridad en las fronteras exteriores. Disponible en: http://frontex.europa.eu/assets/About_Frontex/Governance_documents/Annual_report/2 006/microsoft_word_-_frontex-2008-0001-00-00-enes.pdf (Consulta: 27 de enero de 2016)

Informe general 2007. Disponible en:

http://frontex.europa.eu/assets/About_Frontex/Governance_documents/Annual_report/2 007/frontex-2008-0011-00-00-enes.pdf (Consulta: 27 de enero de 2016)

Cooperation Arrangement between The European Agency for the Management of Operational Cooperation at the External Borders of the Member States of the European Union, 26 de mayo de 2010. Disponible en: http://fra.europa.eu/fraWebsite/attachments/Cooperation-Agreement-FRAFrontex_en.pdf (Consulta: 10 de enero de 2016)

Beyond the Frontiers: The First Five years. Varsovia, 2010. Disponible en: http://frontex.europa.eu/assets/Publications/General/Beyond the_Frontiers.pdf (Consulta: 10 de enero de 2016) 


\section{CAPÍTULO 7}

Working Arrangement establishing operational cooperation between the European Agency for the Management of Operational Cooperation at the External Borders of the Member States of the European Union (Frontex) and the Policia Nacional de Cabo Verde, enero de 2011. Disponible en:

http://frontex.europa.eu/assets/Partners/Third_countries/WA_with_Cape_Verde.pdf (Consulta: 10 de enero de 2016)

Futures of Borders: A Forward Study of European Border Checks. Frontex Tender/64/2010 Study for RDU. Lot 2. Liron Systems Ltd./University of Southampton/University of Ben Gurion, Eilat, diciembre de 2011. Disponible en: http://frontex.europa.eu/assets/Publications/Research/Futures_of_Borders.pdf (Consulta: 10 de enero de 2016)

Memorandum of understanding on establishing cooperation between the European Agency for the Management of Operational Cooperation at the External Borders of the Member States of the European Union and the Ministry of Foreign Affairs of the Republic of Turkey, mayo de 2012. Disponible en:

http://frontex.europa.eu/assets/Partners/Third_countries/WA_with_Turkey.pdf (Consulta: 10 de enero de 2016)

Code of Conduct for all persons participating in FRONTEX activities, Varsovia, enero de 2013. Disponible en:

http://frontex.europa.eu/assets/Publications/General/Frontex_Code_of_Conduct.pdf (Consulta: 10 de enero de 2016)

Operational Plan Joint Operation EPN Hermes 2014. 2014/SBS/5. Operations Division. Joint Operations Unit. Sea Borders Sector. Disponible en:

http://www.asktheeu.org/en/request/1674/response/6081/attach/22/Hermes $\% 202014 \% 2$ 0OpPlan.pdf (Consulta: 10 de enero de 2016)

Annual Risk Analysis 2013, Varsovia, abril de 2013. Disponible en: http://frontex.europa.eu/assets/Publications/Risk_Analysis/Annual_Risk_Analysis_201 3.pdf (Consulta: 27 de enero de 2016)

Code of conduct for joint return operations coordinated, Varsovia, noviembre de 2013. Disponible en:

http://frontex.europa.eu/assets/Publications/Training/Fundamental_Rights_Training_for Border Guardsl.pdf (Consulta: 10 de enero de 2016)

Concept of reinforced joint operation tackling the migratory flows towards Italy: JO EPN Triton - to better control irregular migration and contribute to SAR in the 
Mediterranean Sea, Varsovia, 28 de agosto de 2014. Disponible en: http://www.proasyl.de/fileadmin/fm-

dam/q_PUBLIKATIONEN/2014/JOU_Concept_on_EPN-TRITON_2_.pdf (Consulta: 27 de enero de 2016)

Annual Risk Analysis 2015. Varsovia, abril de 2015, Frontex reference number 4613/2015. Disponible en:

http://frontex.europa.eu/assets/Publications/Risk_Analysis/Annual_Risk_Analysis_201 5.pdf (Consulta: 12 de diciembre de 2015)

Annual Report on the implementation on the EU Regulation 656/2014 of the European Parliament and of the Council of 15 May 2014 establishing rules for the surveillance of the external sea borders, Varsovia, 9 de julio de 2015. Disponible en:

http://frontex.europa.eu/assets/About_Frontex/Governance_documents/Sea_Surveillanc e/Sea_Surveillance_report_2014.pdf(Consulta: 27 de enero de 2016)

\section{e) EASO}

Currículo de formación de la EASO, marzo de 2014, Luxemburgo, Oficina de Publicaciones de la Unión Europea, diciembre de 2014. Disponible en: https://easo.europa.eu/wp-content/uploads/BZ0413152ESC.pdf (Consulta: 10 de enero de 2016)

Informe Anual 2013 sobre la situación del asilo en la Unión Europea, Luxemburgo, Oficina de Publicaciones de la Unión Europea, julio de 2014. Disponible en https://easo.europa.eu/wp-content/uploads/BZAB14001ESC_PDF.Web_pdf (Consulta: 10 de enero de 2016)

Artículo 15, letra c), de la Directiva de reconocimiento (2011/95/UE) Análisis judicial, enero de 2015. Disponible en: https://easo.europa.eu/wp-content/uploads/Article-15cQD_a-judicial-analysis-ES.pdf (Consulta: 14 de enero de 2016)

Independent External Evaluation of EASO's activities covering the period from February 2011 to June 2014, final report, diciembre de 2015. Disponible en: https://easo.europa.eu/download/114352/ (Consulta: 10 de enero de 2016)

\section{f) Otros documentos}

Resolución de 30 de noviembre de 1992 sobre las solicitudes de asilo manifiestamente infundadas; Resolución de 30 de noviembre de 1992 sobre un enfoque armonizado de las cuestiones relativas a los terceros países de acogida; Conclusiones de 30 de 


\section{CAPÍTULO 7}

noviembre de 1992 relativas a los países en que, por regla general, no existen serios riesgos de persecución. Disponibles en: http://eur-lex.europa.eu/legal-

content/ES/TXT/HTML/?uri=URISERV:133102\&from=ES (Consulta: 10 de enero de 2016)

Resolución del Consejo de 20 de junio de 1995 relativa a las garantías mínimas aplicables al procedimiento de asilo. DO C 274, de 19 de septiembre de 1996, pp. 1317. Disponible: en http://eur-lex.europa.eu/legalcontent/ES/TXT/PDF/?uri=CELEX:31996Y0919\%2805\%29\&from=ES (Consulta: 10 de enero de 2016)

Recomendación del Consejo, de 24 de julio de 1995, sobre los principios rectores que deberán seguirse en la elaboración de protocolos sobre la aplicación de acuerdos de readmisión, DOCE, de 19 de septiembre de 1996, C 274, pp. 25-34. Disponible en: http://eur-lex.europa.eu/legalcontent/ES/TXT/PDF/?uri=CELEX:31996Y0919\%2808\%29\&from=ES (Consulta: 17 de enero de 2016)

Resolución del Consejo de 4 de marzo de 1996 sobre el reparto de cargas en relación con la acogida y la estancia, con carácter temporal, de las personas desplazadas. DO L 63, de 13 de marzo de 1996, pp. 10-11. Disponible: en http://eur-lex.europa.eu/legalcontent/ES/TXT/PDF/?uri=CELEX:31996D0198\&qid=1452382990689\&from=EN (Consulta: 10 de enero de 2016)

Comunicación de la Comisión al Consejo y al Parlamento Europeo, de 22 de noviembre de 2000, sobre una política comunitaria de migración (COM (2000) 757 final).

Disponible en: http://eurlex.europa.eu/LexUriServ/LexUriServ.do?uri=COM:2000:0757:FIN:ES:PDF (Consulta: 9 de enero de 2016)

Comunicación de la Comisión al Consejo y al Parlamento Europeo, de 3 de diciembre de 2002: Integración de las cuestiones de migración en las relaciones de la Unión Europea con países terceros (COM(2002) 703 final). Disponible en: http://eurlex.europa.eu/legal-content/ES/TXT/PDF/?uri=CELEX:52002DC0703\&from=EN (Consulta: 17 de enero de 2016)

Comunicación de la Comisión al Consejo y al Parlamento Europeo, del 3 de junio de 2003, Hacia sistemas de asilo mejor gestionados, más accesibles y equitativos (COM/2003/315 final). Disponible en: http://eur-lex.europa.eu/legalcontent/ES/TXT/PDF/?uri=CELEX:52003DC0315\&qid=1452383629649\&from=EN (Consulta: 10 de enero de 2016) 
Comunicación de la Comisión al Consejo y al Parlamento Europeo, del 2 de junio de 2004, Espacio de Libertad, Seguridad y Justicia: balance del programa de Tampere y futuras orientaciones (COM/2004/0401 final). Disponible en: http://eurlex.europa.eu/legal-content/ES/TXT/PDF/?uri=CELEX:52004DC0401\&rid=1 (Consulta: 9 de enero de 2016)

Comunicación de la Comisión al Consejo y al Parlamento Europeo, de 4 de junio de 2004, sobre la entrada organizada en la UE de personas necesitadas de protección internacional y el incremento de la capacidad de protección de las regiones de origen Mejora del acceso a soluciones durables (COM (2004) 410 final. Disponible en http://eur-lex.europa.eu/legal-

content/ES/TXT/PDF/?uri=CELEX:52004DC0410\&from=ES (Consulta: 10 de enero de 2016)

Resolución del Parlamento Europeo sobre Lampedusa, 4 de abril de 2005, Doc. P6_TA(2005)0138. Disponible en: http://www.europarl.europa.eu/sides/getDoc.do?pubRef=-//EP//NONSGML+TA+P6TA-2005-0138+0+DOC+PDF+V0//ES (Consulta: 17 de enero de 2016)

Comunicación de la Comisión al Consejo y al Parlamento Europeo, de 10 de mayo de 2005, Programa de La Haya: Diez prioridades para los próximos cinco años. Una asociación para la renovación europea en el ámbito de la libertad, la seguridad y la justicia (COM (2005) 184 final). Disponible en: http://eur-lex.europa.eu/legalcontent/ES/TXT/PDF/?uri=CELEX:52005DC0184\&from=ES (Consulta: 9 de enero de 2016)

Comunicación de la Comisión al Consejo y al Parlamento Europeo, de 1 de septiembre de 2005, sobre los programas regionales de protección [COM (2005) 388 final.

Disponible en http://eur-lex.europa.eu/legalcontent/ES/TXT/PDF/?uri=CELEX:52005DC0388\&from=ES (Consulta: 10 de enero de 2016)

Comunicación de la Comisión: Hacia una estrategia sobre la dimensión exterior del Espacio de Libertad, Seguridad y Justicia, de 12 de octubre de 2005. (COM(2005) 491 final). Disponible en: http://eur-lex.europa.eu/legalcontent/ES/TXT/PDF/?uri=CELEX:52005DC0491\&from=EN (Consulta: 10 de enero de 2016)

Technical Mission to Morocco. Visit to Ceuta and Melilla on Illegal Immigration. 7th October- 11th October 2005. Mission Report MEMO/05/380. Comisión Europea, 18 de octubre de 2005. Disponible en: http://europa.eu/rapid/press-release MEMO-05380 en.pdf (Consulta: 10 de enero de 2016) 


\section{CAPÍTULO 7}

Enfoque global de la migración: medidas prioritarias centradas en África y el

Mediterráneo, Documento del Consejo nº 15744/05, 13 de diciembre de 2005.

Disponible en:

http://register.consilium.europa.eu/doc/srv?l=ES\&f=ST\%2015744\%202005\%20INIT

(Consulta: 9 de enero de 2016)

Libro Verde de la Comisión: Hacia una futura política marítima de la Unión:

perspectiva europea de los océanos y los mares, 7 de junio de 2006 (COM(2006) 275

final). Disponible en: http://eur-lex.europa.eu/legal-

content/ES/TXT/?uri=celex:52006DC0275 (Consulta: 20 de enero de 2016)

Manual práctico para guardias de fronteras (Manual Schengen), documento del consejo 15010/06, 9 de noviembre de 2006. Disponible en:

http://register.consilium.europa.eu/doc/srv?l=ES\&f=ST\%2015010\%202006\%20INIT

(Consulta: 28 de enero de 2016)

Protocolo $\left(\mathrm{n}^{\mathrm{o}} 7\right)$ sobre los privilegios y las inmunidades de la Unión Europea. DOUE $\mathrm{n}^{\mathrm{o}}$ 306, de 17 de diciembre de 2007, art. 12 (a). Disponible en:

http://www.europarl.europa.eu/transl_es/plataforma/pagina/maletin/juri/voll_prot_privi legios.htm (Consulta: 10 de enero de 2016).

Comunicación de la Comisión al Parlamento Europeo, al Consejo, al Comité Económico y Social Europeo y al Comité de las Regiones, de 13 de febrero de 2008, Informe sobre la evaluación y el desarrollo futuro de la Agencia FRONTEX (COM (2008) 67 final). Disponible en: http://eurlex.europa.eu/LexUriServ/LexUriServ.do?uri=COM:2008:0067:FIN:ES:PDF (Consulta: 10 de enero de 2016)

Pacto Europeo sobre inmigración y asilo, Consejo de la Unión Europea, Bruselas 24 de septiembre de 2008, $\mathrm{n}^{\mathrm{o}}$ doc. 13189/08 ASIM 68. Disponible en:

http://register.consilium.europa.eu/doc/srv?l=ES\&f=ST $\% 2013440 \% 202008 \% 20 \mathrm{COR} \%$ 204 (Consulta: 9 de enero de 2016)

Resolución del Parlamento Europeo, de 18 de diciembre de 2008, sobre la evaluación y el desarrollo futuro de la Agencia Frontex y el sistema europeo de vigilancia de fronteras (Eurosur) (2008/2157(INI)). DO C/45 E 199 de 23 de febrero de 2010, pp. 4148. Disponible en: http://eurlex.europa.eu/LexUriServ/LexUriServ.do?uri=OJ:C:2010:045E:0041:0047:ES:PDF (Consulta: 10 de enero de 2016) 
Resolución del Parlamento Europeo, de 10 de marzo de 2009, sobre los próximos pasos en la gestión de las fronteras en la Unión Europea y experiencias similares en terceros países (2008/2181(INI)). Disponible en:

http://www.europarl.europa.eu/sides/getDoc.do?pubRef=-//EP//NONSGML+TA+P6TA-2009-0085+0+DOC+PDF+V0//ES (Consulta: 10 de enero de 2016)

Comunicación de la Comisión al Consejo, al Parlamento Europeo, al Comité Económico y Social Europeo y al Comité de las Regiones: Hacia la integración de la vigilancia marítima: Entorno común de intercambio de información sobre las cuestiones marítimas europeas, 15 de octubre de 2009 (COM(2009) 538 final) Disponible en: http://eur-lex.europa.eu/LexUriServ/LexUriServ.do?uri=COM:2009:0538:FIN:Es:PDF (Consulta: 20 de enero de 2016)

Comunicación de la Comisión al Parlamento Europeo, al Consejo, al Comité Económico y Social Europeo y al Comité de las Regiones, de 20 de abril de 2010 Garantizar el espacio de libertad, seguridad y justicia para los ciudadanos europeos Plan de acción por el que se aplica el Programa de Estocolmo (COM(2010) 171 final) . Disponible en: http://eurlex.europa.eu/LexUriServ/LexUriServ.do?uri=COM:2010:0171:FIN:es:PDF (Consulta: 9 de enero de 2016)

Detention of Third-Country Nationals in Return Procedures, Agencia de Derechos Fundamentales, Viena, noviembre de 2010. Disponible en: http://fra.europa.eu/sites/default/files/fra uploads/1306-FRA-report-detentiondecember-2010_EN.pdf (Consulta: 14 de enero de 2016)

Derechos Fundamentales en las fronteras marítimas del sur de Europa, Agencia de Derechos Fundamentales, Viena, marzo de 2013. Disponible en:

https://fra.europa.eu/sites/default/files/summary-fundamental-rights-southern-seaborders es.pdf (consulta: 14 de enero de 2016)

Proposal for a Regulation of the European Parliament and of the Council establishing rules for the surveillance of the external sea borders in the context of operational cooperation coordinated by the European Agency for the Management of Operational Cooperation at the External Borders of the Members States of the European Union Position on Articles 9 and 10. Doc. 14612/13, Consejo de la Unión Europea, Bruselas, 10 de octubre de 2013. Disponible en: http://www.statewatch.org/news/2013/oct/eu-seasurveillance-14612-13.pdf (Consulta: 25 de enero de 2016)

Staff working document - Implementation of the Commission on the work of the Task Force Mediterranean, Doc. SWD(2014) 173 final, 22 de mayo de 2014. Disponible en: http://ec.europa.eu/dgs/home-affairs/e-library/documents/policies/legal- 


\section{CAPÍTULO 7}

migration/general/docs/sdw_implementation_of the_communication_on the_work_of the task_force_mediterranean_part_2 en.pdf (Consulta: 27 de enero de 2016)

Comunicación de la Comisión al Parlamento Europeo y al Consejo, V Informe Anual de Migración y Asilo, COM(2014) 288 final, de 22 de mayo de 2014. Disponible en: http://ec.europa.eu/transparency/regdoc/rep/1/2014/ES/1-2014-288-ES-F1-1.Pdf (Consulta 27 de enero de 2016)

Estrategia de Seguridad Marítima de la Unión Europea, Consejo de la Unión Europea, Bruselas, 24 de junio de 2014, Doc. 11205/14. Disponible en:

http://register.consilium.europa.eu/doc/srv?l=ES\&f=ST\%2011205\%202014\%20INIT (Consulta: 20 de enero de 2016)

Conclusions on "Taking action to better manage migratory flows', Consejo de Justicia y Asuntos de Interior, Luxemburgo, 10 de octubre de 2014. Disponible en: http://www.consilium.europa.eu/uedocs/cms_data/docs/pressdata/en/jha/145053.pdf (Consulta: 27 de enero de 2016)

Resolución del Parlamento Europeo, de 23 de abril de 2015, sobre la tragedia en el mediterráneo y las políticas migratorias y de asilo, Doc. 015/2660(RSP). Disponible en: (http://www.europarl.europa.eu/sides/getDoc.do?type $=$ TA\&language $=$ EN\&reference $=\mathrm{P}$ 8-TA-2015-0176 (Consulta: 28 de enero de 2016)

Comunicación de la Comisión al Parlamento Europeo, al Consejo, al Comité Económico y Social Europeo y al Comité de las Regiones, de 13 de mayo de 2015. Una Agenda Europea de Migración. (COM (2015) 240 final. Disponible en http://eurlex.europa.eu/legal-content/ES/TXT/PDF/?uri=CELEX:52015DC0240\&from=E (Consulta: 10 de enero de 2016)

Plan de actuación del Consejo Europeo, aprobado en la Cumbre de La Valeta sobre migración, 11 y 12 de noviembre de 2015. Disponible en:

http://www.consilium.europa.eu/en/meetings/internationalsummit/2015/11/ACTION_PLAN_EN_pdf/ (Consulta: 28 de enero de 2016)

Proposal for a Regulation of the European Parliament and of the Council on the European Border and Coast Guard and repealing Regulation (EC) No 2007/2004, Regulation (EC) No 863/2007 and Council Decision 2005/267/EC, COM (2015) 671 final, Comisión Europea, Estrasburgo, 15 de diciembre de 2015. Disponible en: http://ec.europa.eu/dgs/home-affairs/what-we-do/policies/securing-eu-borders/legaldocuments/docs/regulation on the european border_and coast_guard en.pdf (Consulta: 28 de enero de 2016) 
Comunicación de la Comisión al Parlamento Europeo y al Consejo, de 6 de abril de 2016. Towards a reform of the Common European Asylum System and enhancing legal avenues to Europe. (COM (2016) 197 final. Disponible en:

http://ec.europa.eu/dgs/home-affairs/what-we-do/policies/european-agendamigration/proposal-implementation-

package/docs/20160406/towards_a_reform_of the_common_european_asylum_system and_enhancing_legal_avenues_to_europe_-_20160406_en.pdf(Consulta: 14 de abril de 2016)

\subsubsection{Consejo de Europa}

Convenio Europeo de Derechos Humanos. Aprobado en Roma el 4 de noviembre de 1950. Disponible en: http://www.echr.coe.int/Documents/Convention_SPA.pdf

(Consulta: 12 de diciembre de 2015)

Convenio Europeo de Extradición, París, 13 de diciembre de 1957. Disponible en: http://www.coe.int/en/web/conventions/full-list/-/conventions/rms/0900001680064587 (Consulta: 13 de enero de 2016)

Protocolo número 4 al Convenio Para la Protección de los Derechos Humanos y de las Libertades Fundamentales reconociendo ciertos derechos y libertades además de los que ya figuran en el Convenio y en el Protocolo Adicional al Convenio. Estrasburgo, 16 de septiembre de 1963. Disponible en: http://www.coe.int/es/web/conventions/search-ontreaties/-/conventions/rms/090000168006b65c (Consulta: 12 de diciembre de 2015)

Convenio Europeo relativo al estatuto jurídico del trabajador migrante, Estrasburgo, 24 de noviembre de 1977. Disponible en:

http://www.coe.int/t/dg3/migration/archives/Documentation/Legal texts/093 Conventi on_Legal_Status_Migrant_Workers_sp.pdf (Consulta: 13 de enero de 2016)

Carta Social Europea, Estrasburgo, 3 de mayo de 1996. Disponible en:

http://www.coe.int/en/web/conventions/full-list/-/conventions/rms/090000168007cf93 (Consulta: 13 de enero de 2016)

Veinte directrices sobre el retorno forzoso, Ad hoc Committee of Experts on the Legal Aspects of Territorial Asylum, Refugees and Stateless Persons (CAHAR), Doc. $\mathrm{CM}(2005)$ 40. Disponible en: https://wcd.coe.int/ViewDoc.jsp?id=858071\&Site $=\mathrm{COE}$ (Consulta: 14 de enero de 2016)

Report to the Italian Government on the visit to Italy carried out by the European Committee for the Prevention of Torture and Inhuman or Degrading Treatment or 


\section{CAPÍTULO 7}

Punishment (CPT) from 27 to 31 July 2009, Estrasburgo, 28 de abril de 2010, Doc. CPT/Inf(2010)14. Disponible en: http://www.cpt.coe.int/documents/ita/2010-inf-14eng.pdf (Consulta: 17 de enero de 2016)

The Detention of Asylum Seekers and Irregular Migrants in Europe, Asamblea Parlamentaria del Consejo de Europa 11 de enero de 2010, doc. 12105. Disponible en: http://assembly.coe.int/nw/xml/XRef/Xref-XML2HTML-

EN.asp?fileid=12435\&lang=en (Consulta: 14 de enero de 2016)

The interception and rescue at sea of asylum seekers, refugees and irregular migrants, Resolución 1821 (2011) de la Asamblea Parlamentaria. Disponible en: http://assembly.coe.int/nw/xml/XRef/Xref-XML2HTMLEN.asp?fileid=18006\&lang=en (Consulta: 27 de enero de 2016)

Lives lost in the Mediterranean Sea: who is responsible?, Informe de Tineke Strik para la Asamblea Parlamentaria, 29 de marzo de 2012. Disponible en: http://assembly.coe.int/CommitteeDocs/2012/20120329_mig_RPT.EN.pdf (Consulta: 25 de enero de 2016)

Migration and asylum: mounting tensions in the Eastern Mediterranean, Resolución 1918 (2013) de la Asamblea Parlamentaria, 24 de enero de 2013. Disponible en: http://assembly.coe.int/nw/xml/XRef/Xref-XML2HTML-en.asp?fileid=19467\&lang=en (Consulta: 27 de enero de 2016)

The "left-to-die boat": actions and reactions, doc. 13532 de la Asamblea Parlamentaria, 9 de junio de 2014. Disponible en: http://www.assembly.coe.int/nw/xml/XRef/X2HXref-ViewPDF.asp?FileID=20940\&lang=en (Consulta: 25 de enero de 2016)

\subsubsection{Comisión Europea de Derechos Humanos}

Becker c. Dinamarca, decisión de admisibilidad del 3 de octubre de 1975, nº 7011/75. Disponible en: http://hudoc.echr.coe.int (Consulta: 14 de enero de 2016)

V.P. c. Reino Unido, decisión de admisibilidad del 9 de noviembre de 1987, $\mathrm{n}^{\mathrm{o}}$ 13162/87. Disponible en: http://hudoc.echr.coe.int/eng?i=001-499 (Consulta: 14 de enero de 2016)

Alibaks y otros c. Países Bajos, decisión de admisibilidad del 16 de diciembre 1988, $\mathrm{n}^{\mathrm{o}}$ 14209/88. Disponible en: http://hudoc.echr.coe.int/eng?i=001-351 (Consulta: 10 de enero de 2016) 
Voulfovitch y Oulianova c. Suecia, decisión de admisibilidad del 13 de enero de 1993, no 19373/92. Disponible en: http://hudoc.echr.coe.int/eng?i=001-1480 (Consulta: 14 de enero de 2016)

\subsubsection{Tribunal Europeo de Derechos Humanos}

Lawless c. Irlanda, sentencia del 1 de julio de 1971, n 332/57. Disponible en: http://hudoc.echr.coe.int/eng?i=001-57518 (Consulta: 10 de enero de 2016)

Abdulaziz, Cabales y Balkandali c. Reino Unido, sentencia del 28 de mayo de 1985, $\mathrm{n}^{\circ}$ 9214/80, 9473/81 y 9474/81. Disponible en: http://hudoc.echr.coe.int/eng?i=001-57416 (Consulta: 10 de enero de 2016)

Soering c. Reino Unido, sentencia del 7 de julio de 1989, n 14038/88. Disponible en: http://hudoc.echr.coe.int/eng?i=001-57619 (Consulta: 12 de enero de 2016)

Darby c. Suecia, sentencia del 23 de octubre de 1990, $\mathrm{n}^{\mathrm{o}}$ 11581/85. Disponible en: http://hudoc.echr.coe.int/eng?i=001-57642 (Consulta: 14 de enero de 2016)

Vilvarajah y otros c. Reino Unido, sentencia del 30 de octubre de 1991, no 13163/87; 13164/87; 13165/87; 13447/87; 13448/87. Disponible en: http://hudoc.echr.coe.int/eng?i=001-57713 (Consulta: 12 de enero de 2016)

Drozd y Janousek c. Francia y España, sentencia del 26 de junio de 1992, no. 12747/87. Disponible en: http://hudoc.echr.coe.int/eng?i=001-57774 (Consulta: 18 de enero de 2016)

Loizidou c. Turquía, objeciones preliminares del 23 de marzo de 1995. Disponible en: http://hudoc.echr.coe.int/eng?i=001-57920 (Consulta: 18 de enero de 2016)

Amuur c. Francia, sentencia del 25 de junio de 1996, n 19776/92. Disponible en: http://hudoc.echr.coe.int/eng?i=001-57988 (Consulta: 10 de enero de 2016)

Chahal c. Reino Unido, sentencia del 15 de noviembre de 1996, n 22414/93. Disponible en: http://hudoc.echr.coe.int/eng?i=001-58004 (Consulta: 14 de enero de 2016)

D. c. Reino Unido, sentencia del 2 de mayo de 1997, $\mathrm{n}^{\circ}$ 30240/96. Disponible en: http://hudoc.echr.coe.int/eng?i=001-58035 (Consulta: 12 de enero de 2016)

B.B. c. Francia, sentencia del 7 de septiembre de 1998, no. 30930/96. Disponible en: http://hudoc.echr.coe.int/eng?i=001-58224 (Consulta 13 de enero de 2016) 


\section{CAPÍTULO 7}

Ould Barar c. Suecia, decisión de admisibilidad del 19 de enero de 1999, no. 42367/98. Disponible en: http://hudoc.echr.coe.int/eng?i=001-4507 (Consulta 13 de enero de 2016)

Andric c. Suecia, decisión de admisibilidad del 23 de febrero de 1999, nº 45917/99. Disponible en: http://hudoc.echr.coe.int/eng?i=001-4520 (Consulta: 14 de enero de 2016)

T.I. c. Reino Unido, sentencia de 7 de marzo de 2000, no. 43844/98. Disponible en: http://www.refworld.org/docid/3ae6b6dfc.html (Consulta 13 de enero de 2016)

Tatete c. Suiza, sentencia del 6 de julio de 2000, no. 41874/98. Disponible en: http://hudoc.echr.coe.int/eng?i=001-63309 (Consulta 13 de enero de 2016)

Maaouia. c. Francia, sentencia del 5 de octubre de 2000, n 39652/98. Disponible en: http://hudoc.echr.coe.int/eng?i=001-58847 (Consulta: 14 de enero de 2016)

Xhavara y otros c. Italia y Albania, decisión de admisibilidad del 11 de enero de 2001, no. 39473/98. Disponible en: http://hudoc.echr.coe.int/eng?i=001-31884 (Consulta: 18 de enero de 2016)

Bensaid c. Reino Unido, sentencia del 6 de febrero de 2001, n 44599/98. Disponible en: http://hudoc.echr.coe.int/eng?i=001-59206 (Consulta: 12 de enero de 2016)

Bankovic y otros c. Bélgica., decisión de admisibilidad del 12 de diciembre de 2001, no. 52207/99. Disponible en: http://hudoc.echr.coe.int/eng?i=001-22099 (Consulta: 18 de enero de 2016)

Conka c. Bélgica, sentencia del 5 de febrero de 2002, no 51564/99. Disponible en: http://hudoc.echr.coe.int/eng?i=001-60026 (Consulta: 14 de enero de 2016)

Al- Nashif c. Bulgaria, sentencia del 20 de junio de 2002, no 50963/99. Disponible en: http://hudoc.echr.coe.int/eng?i=001-60522 (Consulta: 10 de enero de 2016)

Tomic c. Reino Unido, decisión de admisibilidad del 14 de octubre de 2003, no. 17387/03. Disponible en: http://hudoc.echr.coe.int/eng?i=001-23532 (Consulta 13 de enero de 2016)

F. c. Reino Unido, decisión de admisibilidad del 22 de junio de 2004, no. 17341/03. Disponible en: http://hudoc.echr.coe.int/eng?i=001-24020 (Consulta 13 de enero de 2016) 
Taheri Kandomabadi c. Países Bajos, decisión de admisibilidad del 29 de junio de 2004, nº 6273/03 y 6122/04. Disponible en: http://hudoc.echr.coe.int/eng?i=001-24052 (Consulta: 14 de enero de 2016)

Issa y otros c. Turquía, sentencia del 16 de noviembre de 2004, $\mathrm{n}^{\circ} 31821 / 96$. Disponible en: http://hudoc.echr.coe.int/eng?i=001-67460 (Consulta: 18 de enero de 2016)

Mamatkulov y Askarov c. Turquía, sentencia del 4 de febrero de 2005, no. 46827/99 y 46951/99. Disponible en: http://hudoc.echr.coe.int/eng?i=001-68183 (Consulta 13 de enero de 2016)

Öcalan c. Turquía, sentencia de 12 de mayo de 2005, no. 46221/99. Disponible en: http://hudoc.echr.coe.int/eng?i=001-69022 (Consulta: 18 de enero de 2016)

Bosphorus Hava Yollari c. Irlanda, sentencia de 30 de junio de 2005, n 45036/98. Disponible en: http://hudoc.echr.coe.int/eng?i=001-69564 (Consulta: 10 de enero de 2016)

Said c. Países Bajos, sentencia del 5 de julio de 2005, n 2345/02. Disponible en: http://hudoc.echr.coe.int/eng?i=001-69614 (Consulta: 12 de enero de 2016)

Rodrigues da Silva y Hoogkamer c. Países Bajos, sentencia del 31 de enero de 2006, no. 50435/99. Disponible en: http://hudoc.echr.coe.int/eng?i=001-72205 (Consulta 13 de enero de 2016)

Lupsa c. Rumanía, sentencia del 8 de junio de 2006, $\mathrm{n}^{\circ} 1$ 0337/04. Disponible en: http://hudoc.echr.coe.int/eng?i=001-75688 (Consulta: 14 de enero de 2016)

Bolat c. Rusia, sentencia del 5 de octubre de 2006, $\mathrm{n}^{\circ}$ 14139/03. Disponible en: http://hudoc.echr.coe.int/eng?i=001-77268 (Consulta: 14 de enero de 2016)

Mubilanzila Mayeka y Kaniki Mitunga c. Bélgica, sentencia del 12 de octubre de 2006, no. 13178/03. Disponible en: http://hudoc.echr.coe.int/eng?i=001-77447 (Consulta 13 de enero de 2016)

Mabroki c. Suecia, decisión de admisibilidad del 21 de noviembre de 2006, n 22556/05. Disponible en http://hudoc.echr.coe.int/eng?i=001-78468 (Consulta: 14 de enero de 2016) 


\section{CAPÍTULO 7}

Salah Sheekh c. Países Bajos, sentencia del 11 de enero de 2007, no 1948/04. Disponible en http://hudoc.echr.coe.int/eng? $\mathrm{i}=001-78986$ (Consulta: 12 de enero de 2016)

Sultani c. Francia, decisión de admisibilidad del 20 de septiembre de 2007, ${ }^{\circ}$ 45223/05. Disponible en: http://hudoc.echr.coe.int/eng? $\mathrm{i}=001-82338$ (Consulta: $10 \mathrm{de}$ enero de 2016)

Saadi c. Reino Unido, sentencia del 29 de enero de 2008, n 13229/03. Disponible en: http://hudoc.echr.coe.int/eng?i=001-84709 (Consulta: 14 de enero de 2016)

Saadi c. Italia, sentencia del 28 de febrero de 2008, no. 37201/06. Disponible en: http://hudoc.echr.coe.int/eng?i=001-85276 (Consulta 13 de enero de 2016)

N. c. Reino Unido, sentencia del 27 de mayo de 2008, $\mathrm{n}^{\circ}$ 26565/05. Disponible en: http://hudoc.echr.coe.int/eng?i=001-86490 (Consulta: 12 de enero de 2016)

Darren Omoregie y otros c. Noruega, sentencia del 31 de julio de 2008, nº 265/07. Disponible en: http://hudoc.echr.coe.int/eng?i=001-88012 (Consulta 13 de enero de 2016)

Rusu c. Austria, sentencia del 2 de octubre de 2008, no 34082/02. Disponible en: http://hudoc.echr.coe.int/eng?i=001-88669 (Consulta: 14 de enero de 2016)

Abdolkhani y Karimnia c. Turquía, sentencia del 22 de septiembre de 2009, $\mathrm{n}^{\mathrm{o}}$ 30471/08. Disponible en http://hudoc.echr.coe.int/eng?i=001-94127 (Consulta: 12 de enero de 2016)

Mollazeinal c. Chipre, decisión de admisibilidad del 18 de junio de 2009, nº 20198/05. Disponible en: http://hudoc.echr.coe.int/eng?i=001-93432 (Consulta: 14 de enero de 2016)

Al-Saadoon y Mufdhi c. Reino Unido, sentencia del 2 de marzo de 2010, no. 61498/08. Disponible en: http://hudoc.echr.coe.int/eng?i=001-97575 (Consulta: 18 de enero de 2016)

Medvedyev y otros c. Francia, sentencia del 29 de marzo de 2010, no 3394/03. Disponible en: http://hudoc.echr.coe.int/eng?i=001-97979 (Consulta: 18 de enero de 2016)

M.S.S. c. Bélgica y Grecia, sentencia del 21 de enero de 2011, no 30696/09. Disponible en: http://hudoc.echr.coe.int/eng?i=001-103050 (Consulta: 10 de enero de 2016) 
Al-Skeini y otros c. Reino Unido, sentencia del 7 de julio de 2011, no. 55721/07. Disponible en: http://hudoc.echr.coe.int/eng?i=001-105606 (Consulta: 18 de enero de 2016)

Zontul c. Grecia, sentencia del 17 de enero de 2012, n 12294/07. Disponible en: http://hudoc.echr.coe.int/eng?i=001-108587 (Consulta: 18 de enero de 2016)

Hirsi Jamaa y otros c. Italia, sentencia del 23 de febrero de 2012, n ${ }^{\circ}$ 27765/09. Disponible en: http://hudoc.echr.coe.int/eng?i=001-109231 (Consulta: 12 de enero de 2016)

B.M. c. Grecia, sentencia del 19 de marzo de 2014, no 53608/11. Disponible en: http://hudoc.echr.coe.int/eng?i=001-139758 (Consulta: 10 de enero de 2016)

M.G. c. Bulgaria, sentencia del 25 de marzo de 2014, no 59297/12. Disponible en: http://hudoc.echr.coe.int/eng?i=001-142125 (Consulta: 12 de diciembre de 2015)

A.C. y otros c. España, sentencia del 22 de abril de 2014, no 6528/11. Disponible en: http://hudoc.echr.coe.int/eng?i=001-148248 (Consulta: 14 de enero de 2016)

Tatishvili c. Grecia, sentencia del 31 de julio de 2014, no 26452/11. Disponible en: http://hudoc.echr.coe.int/eng?i=001-145785 (Consulta: 14 de enero de 2016)

Sharifi y otros c. Italia y Grecia, sentencia del 21 de octubre de 2014, n 16643/09. Disponible en: http://hudoc.echr.coe.int/eng?i=001-147287 (Consulta: 14 de enero de 2016)

Tarakhel c. Suiza, sentencia del 4 de noviembre de 2014, nº 29217/12. Disponible en: http://hudoc.echr.coe.int/eng?i=001-148070 (Consulta: 13 de enero de 2016)

A.S. c. Suiza, sentencia del 30 de junio de 2015, no 39350/13. Disponible en: http://hudoc.echr.coe.int/eng?i=001-155717 (Consulta: 13 de enero de 2016)

V.M. y otros c. Bélgica, sentencia del 7 de julio de 2015, nº 60125/11. Disponible en: http://hudoc.echr.coe.int/eng?i=001-156243 (Consulta: 13 de enero de 2016)

Khlaifia y otros c. Italia, sentencia del 1 de septiembre de 2015, $\mathrm{n}^{\mathrm{o}}$ 16483/12. Disponible en: http://hudoc.echr.coe.int/eng?i=001-157277 (Consulta: 29 de enero de 2016)

\subsubsection{Otros instrumentos jurídicos nacionales e internacionales}




\section{CAPÍTULO 7}

\section{a) Legislación}

Malta Refugees Act, to make provisions relating to and establishing procedures with regard to refugees and asylum seekers. 1st October, 2001 ACT XX of 2000, as amended by Act VIII of 2004; Legal Notices 40 of 2005 and 426 of 2007; and Act VII of 2008. Disponible en: http://homeaffairs.gov.mt/en/mhasdepartments/the $\% 20$ office $\% 20$ of $\% 20$ the $\% 20$ refugee $\% 20$ commissioner/documents $/$ refu gees $\% 20$ act $\% 20-\% 20$ en.pdf (Consulta: 25 de enero de 2016)

Legge DDL 795 B in materia di immigrazione e di asilo, de 28 de febrero de 2002. Disponible en: http://www.senato.it/japp/bgt/showdoc/frame.jsp?leg=14\&id=00018531\&tipodoc=Ddlp res\&modo (Consulta: 25 de enero de 2016)

Ley $12 / 2009$, de 30 de octubre, reguladora del derecho de asilo y de la protección subsidiaria. BOE núm. 263, de 31 de octubre de 2009, pp. 90860-90884. Disponible en: https://www.boe.es/boe/dias/2009/10/31/pdfs/BOE-A-2009-17242.pdf (Consulta: 25 de enero de 2016)

Law No. 3907 of 2011 on the establishment of an Asylum Service and a First Reception Service, transposition into Greek legislation of Directive 2008/115/EC "on common standards and procedures in Member States for returning illegally staying third country nationals" and other provisions. Disponible en:

http://www.refworld.org/docid/4da6ee7e2.html (Consulta: 25 de enero de 2016)

\section{b) Jurisprudencia}

Corte Suprema de los Estados Unidos: sentencia Sale v. Haitian Ctrs. Council, 509 US 155, 156 (USSC 1993). Disponible en:

https://supreme.justia.com/cases/federal/us/509/155/case.html (Consulta: 18 de enero de 2016)

Tribunale di Agrigento, sentencia del 07 de noviembre de 2009, contra Schmidt, S., Dachkevitch, V. y Bierdel, E. Disponible en: http://www.asgi.it/wpcontent/uploads/public/tribunale_agrigento_15022010_1.pdf (Consulta: 25 de enero de 2016)

Tribunal des conflits, sentencia del 12 de mayo de 1997, Préfet de police de Paris c. Tribunal de grande instance de Paris (Ben Salem et Taznaret case). Disponible en: http://www.legifrance.gouv.fr/affichJuriAdmin.do?idTexte=CETATEXT000007607110 $\underline{\text { \&dateTexte}}=($ Consulta: 26 de enero de 2016) 
Tribunal Constitucional, Pleno, sentencia de 22 de mayo (STC 95/2003). Disponible en: http://hj.tribunalconstitucional.es/HJ/es/Resolucion/Show/4870 (Consulta: 14 de enero de 2016)

Tribunal Supremo, Sala de lo Contencioso, Sección $7^{\mathrm{a}}$, sentencia de 17 de febrero de 2010 (STS 833/2010). Disponible en:

http://www.poderjudicial.es/search/doAction?action=contentpdf\&databasematch=TS\&r eference $=5072847 \&$ links $=\% 22548 \% 2 \mathrm{~F} 2008 \% 22 \&$ optimize $=20100318 \&$ publicinterface =true (Consulta: 26 de enero de 2016)

Tribunal Supremo, Sala de lo Contencioso, Sección $7^{\text {a }}$, sentencia de 17 de febrero de 2010 (STS 833/2010). Disponible en:

http://www.poderjudicial.es/search/doAction?action=contentpdf\&databasematch=TS\&r eference $=5072847 \&$ links $=\% 22548 \% 2 F 2008 \% 22 \&$ optimize $=20100318 \&$ publicinterface =true (Consulta: 26 de enero de 2016)

UK Privy Council: Naim Molvan v. Attorney General for Palestine (The "Asya"), $81 \mathrm{Ll}$ L Rep 277, United Kingdom: Privy Council, 20 de abril 1948. Disponible en: http://www.refworld.org/docid/3ae6b6544.html (Consulta: 27 de enero de 2016)

\section{c) Tratados bilaterales}

Acuerdo entre el Reino de Marruecos y el Reino de España, relativo a la libre circulación de personas, el tránsito y la readmisión de extranjeros entrados ilegalmente, firmado en Madrid, el 13 de febrero de 1992. BOE de 25 de abril de 1992, pp. 13969 a 13970. Disponible en: http://www.boe.es/boe/dias/1992/04/25/pdfs/A13969-13970.pdf (Consulta: 17 de enero de 2016)

Acuerdo entre el Reino de España y la República Islámica de Mauritania en materia de inmigración, hecho, en Madrid el 1 de julio de 2003. BOE de 4 de agosto de 2003, pp. 30050 a 30053. Disponible en: http://www.boe.es/boe/dias/2003/08/04/pdfs/A3005030053.pdf (Consulta: 17 de enero de 2016)

Protocolo entre el Gobierno del Reino de España y el Gobierno de la República Argelina Democrática y Popular sobre circulación de personas, de 31 de julio de 2002. BOE del 12 de febrero de 2004, pp. 6350 a 6352. Disponible en:

http://www.boe.es/boe/dias/2004/02/12/pdfs/A06350-06352.pdf (Consulta: 17 de enero de 2016) 


\section{CAPÍTULO 7}

Acuerdo de Asociación entre los Estados de África, del Caribe y del Pacífico, por una parte, y la Comunidad Europea y sus Estados miembros, por otra, firmado en Cotonou el 23 de junio de 2000. DOCE de 15 de diciembre de 2000, L 317, pp. 3-353.

Disponible en: http://eur-lex.europa.eu/legal-

content/ES/TXT/?uri=celex:22000A1215\%2801\%29 (Consulta: 17 de enero de 2016) 


\section{Índice de Gráficos}

Fig. 1: Principales rutas migratorias desde África y Oriente Próximo a Europa 3

Fig. 2: Llegadas de migrantes irregulares por vía marítima a la UE, 1998-2015 (13/11) ___ 6

Fig. 3. Ciudadanía de origen de los solicitantes de asilo en la UE, 2014 _ 45

Fig. 4: Organigrama de la Agencia Frontex___ 48

Fig. 5: Presupuesto de Frontex, 2005-2015 _

Fig. 6: Sistema de información del RAU__ 59

Fig. 7: Evolución de los solicitantes de asilo 2013-2015 ___ 69

Fig. 8: Zonas marítimas _ 133

Fig. 9: Muertes de migrantes en el Mediterráneo por región de origen ___ 141

Fig. 10: Personas muertas y desaparecidas en rutas marítimas migratorias irregulares a la UE, 1988-2015 (19/04) 142

Fig. 11: Probabilidad de morir en rutas marítimas migratorias irregulares a la UE, 1988-2015 (19/04) (tanto por 1.000) 142

Fig. 12: Áreas SAR del mar Mediterráneo __ 145

Fig. 13: Área SAR de Malta __ 149

Fig. 14: Mapa de las principales operaciones marítimas de Frontex__ 194

Fig. 15: Mapa de JO HERA II ___ 197

Fig. 16: Mapa de la JO Poseidón ___ 202

Fig. 17. Personas interceptadas, rescatadas y facilitadores arrestados en la JO Hermes, 2013-14__207

Fig. 18: Mapa de la operación Mare Nostrum __ 208

Fig. 19: Mapa de la JO Tritón___ 211

Fig. 20: Llegadas de migrantes irregulares y refugiados por vía marítima y terrestre, y fallecidos durante

el trayecto a Europa, 2015 __15 


